Residential Energy Conservation

July 1979

NTIS order \#PB-298410

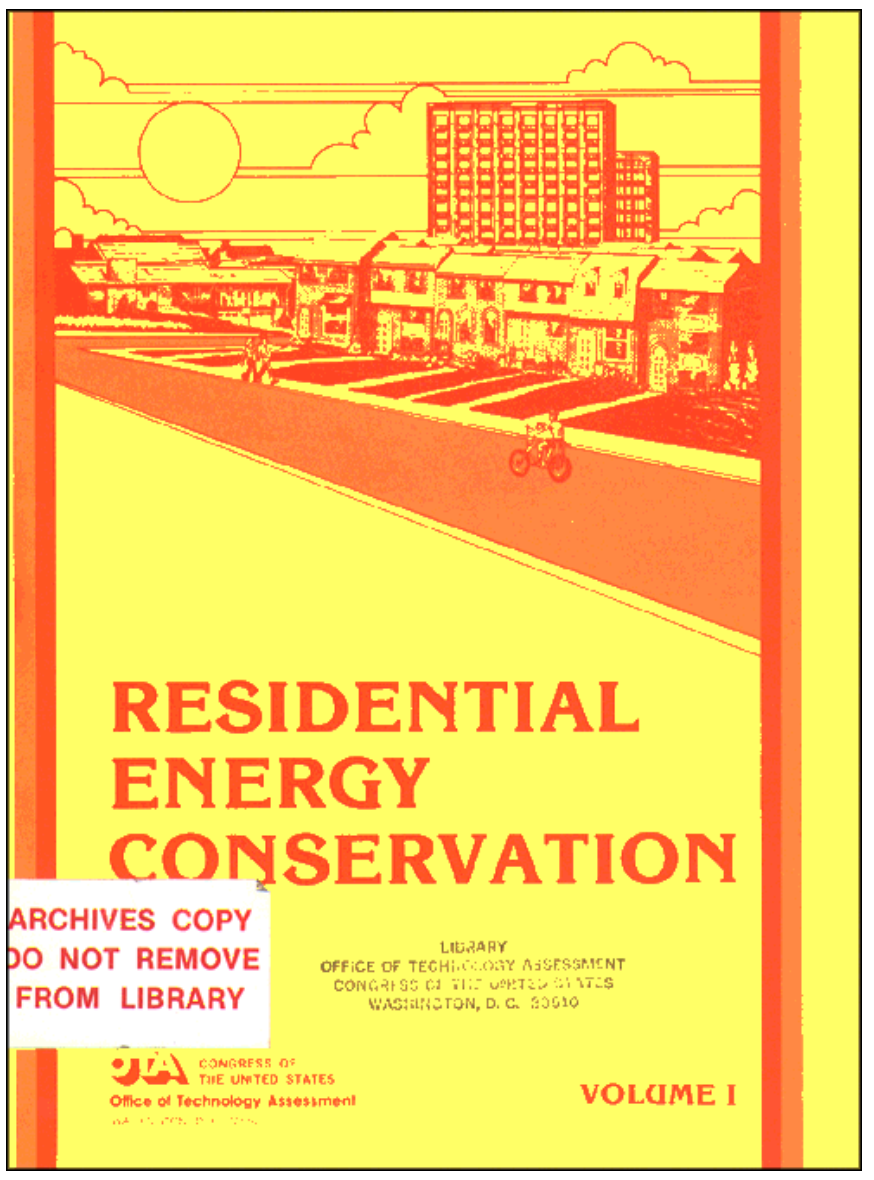




\section{Library of Congress Catalog Card Number 79-600103}

For sale by the Superintendent of Documents, U.S. Government Printing Office Washington, D.C. 20402 Stock No. 052-003 -00691-0 
This report is the result of a request from the Technology Assessment Board that the Office of Technology Assessment (OTA) analyze the potential for conserving energy in homes in terms of energy and costs. The report reviews existing and promising technologies, and a broad set of issues affecting why these technologies are or are not used, how their level of use and effectiveness can be improved, and related Federal programs and policies.

The choices Congress makes in framing energy conservation policy reflect society's views of the present and the future, its concept of the appropriate role of Government, and its sense of urgency about the changing energy picture. The diverse nature of residential housing in this country, the many decisions involved in planning, building, buying, and operating a home, and the basic desire of consumers to be allowed the maximum freedom of choice- all of these factors make policy decisions in this area difficult.

This study focuses on the demand aspect of residential energy use, specifically those functions that consume most of a home energy budget- fuel to heat and cool space and to heat water. A number of related issues are relevant to this topic but go beyond the scope of the study: land use patterns, transportation habits, protection of residential customers as purchasers of certain types of energy, centralized versus decentralized power sources, and cogeneration. While these issues are important, this study deals only with ways to improve energy efficiency within the 80 million existing housing units and in housing to be constructed over the next two decades. Active solar systems are not included, because of the recent publication of OTA's Application of Solar Technology to Today's Energy Needs.

Conservation as discussed in this analysis is the substitution of capital, labor, and ingenuity for energy, in the form of products that make a home more energy efficient. This definition relies on making productive investments that provide the same level of comfort and convenience with less energy. Homeowners and renters who also choose to change their styles of living could achieve savings beyond those resulting from conservation technologies alone. This is a conservative definition of conservation that does not treat ethical arguments or other areas of debate. Although based on the technology of energy conservation, the report also addresses human factors that play such a major role in shaping energy consumption. Choices open to builders, designers, suppliers, local and State officials, lenders, utilities, owners, renters, and others are examined Thus, this work attempts to address comprehensively a problem that at first appears simple, but proves to contain many economic, behavioral, and motivational variables, many technical and human unknowns, and many possible policy paths.

As this report goes to the 96th Congress, the problems generated by an altered energy supply situation are clear and dramatic. I $\mathrm{n}$ addition to broad policy questions such as the contribution that conservation can make and the choice between types of policy approaches, very specific questions-such as standards for new housing-face the Nation. I believe this report can assist Congress in dealing with these vital issues.

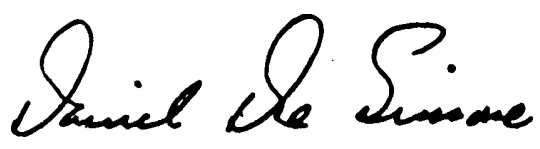

DANIEL DE SIMONE

Acting Director 


\title{
Residential Energy Conservation Staff
}

\author{
Lionel S. Johns, Assistant Director \\ Energy, Materials, and Global Security Division \\ Richard E. Rowberg, Energy Group Manager \\ Nancy Carson Naismith, Project Director \\ David Claridge Steve Plotkin Joanne Seder \\ Pamela Baldwin Doreen McGirr \\ Richard Thoreson John Furber Rosaleen Sutton \\ Lisa Jacobson Lillian Quigg
}

Contractors and Consultants

Booz, Allen \& Hamilton

Consumer Federation of America

Design Alternatives

Malcolm Lewis Associates

NAHB Research Foundation

Oak Ridge National Laboratory

Technology \& Economics
John Bell

Richard Bourbon

Robert D. Brenner

Robert Dubinsky

Dennis Eisen

Frederick Goldstein

C. Alexander Hewes, J r
John Murray McCombs

Joseph Mohbat

Lee Stephenson

Robert Theobald

\section{OTA Publishing Staff}

John C. Holmes, Publishing Officer

Kathie S. Boss Joanne Heming 


\title{
Residential Energy Conservation Advisory Panel
}

\author{
John H. Gibbons, Chairman \\ Director, Environment Center, University of Tennessee
}

\author{
John Richards Andrews \\ Architect \\ Robert E. Ashburn \\ Manager, Economic Research Department \\ Long Island Lighting Company

\section{Edward Berlin} \\ Leva, Hawes, Symington \& Oppenheimer

\section{Ellen Berman \\ Executive Director \\ Consumer Energy Council of America}
Joel Darmstadter
Senior Fellow
Resources for the Future
Sherman B. Given
President
Morley Construction Company
Donald Holtzman
President
Holtzman Petroleum Company

\author{
William Konyha \\ First General Vice President \\ United Brotherhood of Joiners \& \\ Carpenters
W. B. Moore Gulf Reston, Inc.
Donald Navarre
Vice president, Marketing
Washington Natural Gas Company
Harold Olin
Director of Construction Research
U.S. League of Savings Association
David Rickelton
Consulting Engineer
Andy Sansom
Energy Institute
University of Houston
Samuel Stewart
Car/son Companies, Inc. \\ Vice President Operations/Marketing
}

Grant P. Thompson

Senior Associate

The Conservation Foundation 
OTA thanks these people who took time to provide information or review part or all of the study.

\author{
Robert Naismith \\ Atlantic Research Corporation
}

\author{
Lee Schipper \\ Lawrence Berkeley Laboratory
}

Alan Ackerman, Energyworks, Massachusetts

George Amaroli, Public Utility Commission, State of California

Carl Bernstein, Lawrence Berkeley Laboratory

Ed Bistany, Office of Energy Resources, State of Georgia

Ken Bossong, Center for Science in the Public Interest

Mary Love Cooper, Legislative Counsel Bureau, State of Nevada

Alan S. Davis, National Consumer Law Center

Gary DeLoss, Environmental Policy Center

Bruce Hannon, University of Illinois

Craig Hollowell, Lawrence Berkeley Laboratory

Betsy Krieg, Lawrence Berkeley Laboratory

Sally Cook Lopreato, University of Texas

Ed Meyer, Office of Energy Resources, State of Georgia

Harvey Michaels, Energy Office, State of Massachusetts

David Norris, Energy Task Force, New York City

Elliott Wardlaw, Energy Management Office, State of South Carolina

Edith Woodbury, Woodward East, Detroit 
1. Trends . . . . . . . . . . . . . . . . . . . . . 17

II. Residential Energy Use and Efficiency Strategies . . . . . . . . . . 29

III. The Consumer . . . . . . . . . . . . . . . . . 65

Iv. Low-Income Consumers . . . . . . . . . . . . . . . 77

v. Housing Decisionmakers . . . . . . . . . . . . . . 91

VI. Utilities and Fuel Oil Distributors . . . . . . . . . . . . . 119

VII. States and Localities. . . . . . . . . . . . . . . . 153

VIII. Federal Government and Energy Conservation . . . . . . . . . 167

Ix. Economic Impacts.. . . . . . . . . . . . . . . . . 211

x. Indoor Air Quality. . . . . . . . . . . . . . . . . 219

xl. Technical Options. . . . . . . . . . . . . . . . . . 227

Appendix A-Insulation . . . . . . . . . . . . . . . . . . . 277

Appendix B-Thermal Characteristics of Single-Family Detached, SingleFamilyAttached, Low-Rise Multifamily, and Mobile Homes-1975-76. . . . . . . . . . . . . . . . . . . . 292

Appendix C- Thermal Characteristics of Homes Built in 1974, 1973, and 1961 . 322

\section{Volume II-Working Papers}

(These working papers will be available from the National Technical Information Service. Please contact the OTA Public Affairs Office for details)

1. Low-Income Consumers' Energy Problems and the Federal Government's Response: A Discussion Paper-prepared by Consumer Federation of America

II. Description and Evaluation of New Residential Energy Efficient Technologies-prepared by Technology \& Economics 
EXECUTIVE SUMMARY 


\section{EXECUTIVE SUMMARY}

Trends in Residential Energy Consumption , . . . . . . . . . . . ${ }^{\text {Page }} 4$

-Residential Energy Prices. . . . . . . . . . . . . . . . . . 6

Consumer Attitudes . . . . . . . . . . . . . . . . . . 7

Low-Income Consumers. . . . . . . . . . . . . . . . . . . . 7

Existing Housing . . . . . . . . . . . . . . . . 8

Building Industry Response $\ldots \ldots \ldots \ldots \ldots \ldots \ldots \ldots \ldots \ldots$

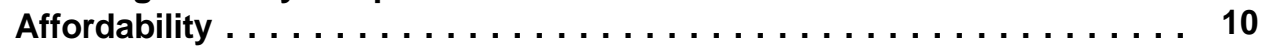

Design Opportunities. . . . . . . . . . . . . . . . . 10

States and Localities.. . . . . . . . . . . . . . . . . . . . 11

Utilities . . . . . . . . . . . . . . . . . . . . . . . . . . . 11

Indoor Air Quality . . . . . . . . . . . . . . . . . . . . . . 12

Federal Conservation Programs $\ldots \ldots \ldots \ldots \ldots \ldots \ldots \ldots \ldots \ldots \ldots$

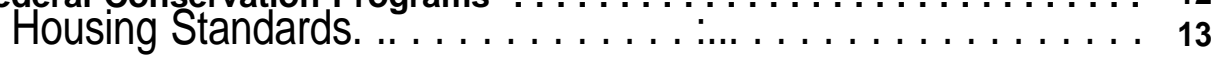

Research and Development . . . . . . . . . . . . . 13

Tax Policy . . . . . . . . . . . . . . . . . . . . . 13

Federal Housing Programs . . . . . . . . . . . . . 14

FIGURES

I. Comparative Energy Use Projections 
Americans are responding to a changed energy situation by rapidly curtailing the direct use of energy in their homes. The patterns of energy use established by households in the 1960's have changed dramatically, Residential energy use, which grew at a rate of 4.6 percent per year during the 1960's, has grown at an average annual rate of 2.6 percent since 1970 . In 1977, Americans used 17 quadrillion Btu* (Quads) of energy in their homes, 22 percent of the total national energy use. Had the growth rate of the 1960's continued, the Nation would have used an additional 2.5 Quads-equivalent to $\mathbf{4 3 0}$ million barrels of oil - in 1977 .

As impressive as these figures are, they can be better. Savings of more than $\mathbf{5 0}$ percent in average use by households, compared to the early 1970's, are already being achieved in some new homes, and experiments with existing homes indicate that similar reductions in heating requirements can be realized through retrofit. These savings can be achieved with existing technology, with no change in lifestyle or comfort- and with substantial dollar savings to homeowners. However, more sophisticated design, quality construction, and careful home operation and maintenance will be required.

For the residential sector as a whole, the potential energy savings can be seen in another way. If the trend of the 1970's were to continue for the balance of the century, the residential sector would use about 31 Quads of energy in 2000. But if investments were made in home energy conservation technologies up to the point where each investor received the highest possible dollar savings (in fuel costs) over the investment's life, energy use in the year 2000 would be reduced to between 15 and 22 Quads, depending on the price of energy. The cumulative savings between now and 2000 compared to the 1970's trend would be equivalent to between 19 billion and 29 billion barrels of oil. Despite the sound economic reasons for achieving these savings, there are reasons why they may not be reached. This report ex-

${ }^{*} \mathrm{~A}$ Quad $=1$ quadrillion Btu $=1.055$ exajoule (E J). amines the underlying problems and what to do about them.

Following this section, the study's major findings are presented. They lead to these conclusions, among others:

. Analysis of data on price and consumption, combined with research on consumer motivation, indicates that the desire to save money is the principal motivation for changes in energy habits (turning down the thermostat at night) and investment in conservation (purchasing insulation or having the furnace improved). This report outlines the approximate level of energy savings that might result from investments up to the point where dollar savings over the life of the investment are greatest. If it is national policy to encourage energy savings beyond this point-for example, to the point where investments in energy savings provide smaller economic return but greater energy savings- additional incentives would be required. The difference between these two points is substantial in energy terms, because once a dwelling is efficient, costs of operation are relatively insensitive to energy prices. Such a shift would be analogous to the standards set in 1975 to improve energy performance of new cars. In addition to price or economic incentives, regulation could also increase energy savings.

2. One of the principal ways to improve energy use lies in the area of information and technology transfer. Those who actually implement policy need more training. Policy may be made in Washington, but is carried out by tradespersons, builders, local code inspectors, loan officers, appraisers, energy auditors, heating technicians, State and local officials, do-ityourselfers - literally thousands of individuals. The essentially human nature of the effort is both a strength and a weakness - many are willing to take some action, but there are many obstacles to perfect performance. 
3. The diversity of the housing stock, number of persons involved, requirements for technology transfer, and product availability all argue for careful pacing of Federal policy, based on setting goals over at least a decade. For example, short-term programs, aimed at one particular solution, appear to constrain the market and may not encourage optimal solutions. This is particularly true of programs aimed at the existing housing stock. Anticipation of the tax credit for insulation caused increased prices and spot shortages and may not have produced substantial insulation beyond what would have occurred in any event. Another reason for deliberate policymaking is that knowledge of the nature of a house as an energy system is imperfect. Although a good deal is already known about saving energy, more remains to be learned. Because choices will vary with climate, local resources need to be developed; these resources will include both trained personnel and improved data.

Policy choices will reflect the goals for savings and costs. If the current trajectory is appropriate, present programs appear to be adequate in number and range. A lower growth rate can probably be accomplished by vigorous congressional oversight, some administrative adjustments, review and fine-tuning of program operation, and improved information efforts. If the sector is already moving fast enough, less emphasis could be placed on residential energy use. In order to move much more rapidly, stronger measures will be required. A great deal of energy could be saved in homes above present levels; these savings would still be cost-effective to the consumer. A stronger program approach might reflect national security goals and a high return on the housing dollar.

The following sections consider the trends illustrated by this volume and the major factors affecting residential energy use and conservation: price, consumer attitudes, the poor, existing housing stock, building industry response, design opportunities, the role of States and localities, the utilities, and Government programs.

\section{Trends in Residential Energy Consumption}

The decade of the 1970's has brought significant changes in the historical patterns of growth in energy consumption in the residential sector. Earlier, Americans as a group were increasing their use of energy in the home at an average rate of 4.7 percent per year; in the 1970's, the annual growth rate has averaged 2.6 percent. Moreover, the remaining growth is attributable primarily to a growth in the number of households; the amount of energy used in each household has remained almost constant between 1970 and 1977. In 1970, 63.5 million households collectively used 14 quadrillion Btu of energy (Quads) or about $\mathbf{2 3 0}$ million Btu apiece. (A Quad is equivalent to 500,000 barrels of oil per day for 1 year-or the annual energy required for the operation of eighteen 1,000 -MW powerplants-or 50 million tons of coal. )

In 1977, residential use of energy accounted for 22 percent of total energy consumption, totaling 17 Quads. By comparison, the commercial sector in 1977 used 11 Quads (1 4.5 percent of total), transportation accounted for 20 Quads (26 percent), and industry used 28 Quads (37 percent). Total 1977 U.S. energy use was 76 Quads.

Many factors have contributed to the slowed growth in residential energy use in this decade. Among them are energy price increases, economic fluctuations, demographic trends, the OPEC embargo, and consumers' responses to rising awareness of energy. Demonstrating a precise cause-and-effect relationship between any one of these factors and the lower growth rate is statistically impossible. Fortunately, isolating and quantifying the contribution of each factor is probably of limited utility to policymaking.

The rapidity of the slowdown suggests that actions taken to reduce consumption so far are primarily changes in the ways people use their 
existing energy equipment - e.g., turning down thermostats and insulating. A longer time frame is normally required to bring about widespread replacement or improvement of capital stock, including heating equipment and housing units.

No one can say with certainty whether the residential energy growth rate will stabilize at today's rate, drop still further, or creep back up toward earlier trends. Countervailing forces could work in either direction. The current demographic trend toward slower population growth is expected to continue for the near term, but household formation rates are likely to exceed population growth rates. Energy use in the residential sector can be expected to grow faster than population as long as new households are forming at a higher rate, although construction of highly efficient new housing would alter that presumption.

On the other hand, if energy prices continue to rise, greater investments in conservation (energy productivity) measures will become cost-effective for consumers. Moreover, while there will be more households, each is likely to be smaller; having fewer people at home generally means smaller dwelling units and lower levels of energy consumption in each home. Very few experts believe that residential energy growth rates will ever again approach the very high pre-1970 rates.

If residential energy use were to continue growing by 2.6 percent annually until the year 2000 , total residential consumption in that year would approximate 31 Quads. This is considerably lower than the 48 Quads American homes would consume in 2000 if growth patterns of the 1960's had continued. Yet actual consumption in $\mathbf{2 0 0 0}$ might be even lower than 31 Quads, driven down by rising prices and a number of other factors, including improved design and technology as well as evolving consumer awareness of the economic benefits of conservation.

If residential energy growth were to match the rate of household formation - that is, if the energy consumption per household were to remain constant between now and 2000-total residential sector consumption in that year would be 24 Quads. This trend would represent an annual growth rate of $\mathbf{1 . 6}$ percent, which is the household formation rate projected by the Oak Ridge National Laboratory housing model. This modest decline from 1970-77 trends would appear to be relatively easy to achieve under current laws and programs (with improvements in their implementation in some cases) and without sacrificing personal comfort, freedom, or social goals that require increases in energy consumption for those at the low end of the economic spectrum. Much of the decline could be accomplished through replacement of capital stock and construction of smaller, more efficient housing units to accommodate new households.

An even lower consumption level in 2000 could be achieved through an optimal economic response - one in which all residential consumers made the maximum investment in conservation technologies that they could justify through paybacks in reduced energy costs over the remaining lives of their dwelling units. Such responses would depend on the levels of energy prices over the next two decades. Using a range of plausible energy prices, possible residential energy consumption levels were projected to be between 15 and 22 Quads in 2000, based on optimal economic response. Few observers expect the lower end of the range to be achieved even using the highest price assumptions, because of imperfections in the marketplace. Circumstances requiring especially vigorous public policies could create additional incentives to consumers to approach this level of savings.

The middle ground between the 1970's trend and the optimal economic response trend is seen by many as a reasonable public policy target. Measuring our progress toward this conservative goal would be relatively easy; each year, the goal would be to maintain constant national average energy consumption per household by keeping the growth in residential energy use to a rate determined by the household formation rate. This target appears to be manageable within our current social, political, and economic situation. This option would not involve sacrifice, because it would allow for a constantly improved level of residential 
amenities that can be achieved by means of improved energy productivity (less energy per unit of amenity provided). Some critics will view this goal as too easy, too modest; considering depletion of nonrenewable resources, maximum return on housing dollars, environmental quality, and the national security implications of our oil imports. (Comparative energy use projections showing these Quad levels appear graphically in figure 1.)

Figure 1.-Comparative Energy Use Projections (Residential sector)

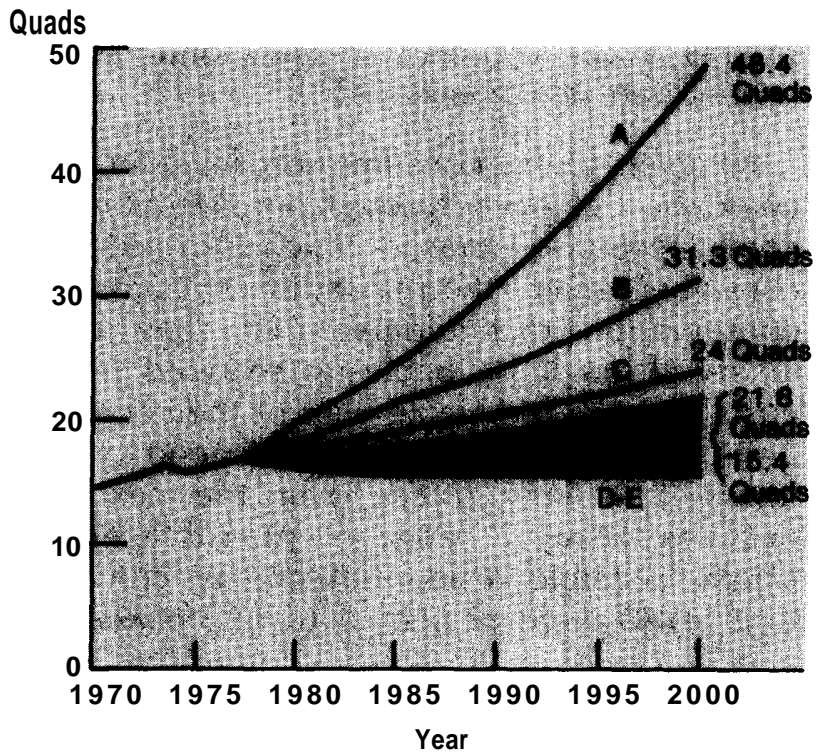

A- Residential consumption based on simple extrapolation of 1970-77 trend.

B- Residential consumption based on simple extrapolation of 1960-70 trend.

C - Residential consumption based on constant level of energy use per household; growth results from increase in number of households.

D-E - Range of "optimal economic response" based on assumption that energy saving devices are installed as they become cost-effective. Range is formed by price; upper boundary represents response to lowest projected price, lower boundary represents response to highest projected price.

NOTES: These curves are not given as predictions of the future, but as points of comparison for discussion See chapter I for detailed information.

For SI users. Quads can be substituted using exajoule (EJ) on this figure within the accuracy of the calculations. One Quad $\cong 1$ EJ.

\section{Residential Energy Prices}

Rising energy prices appear primarily responsible for reduced residential consumption in recent years. Rapid growth in the 1960's accompanied a decline in real energy prices, while the growth slowdown of the 1970's has concurred with a rise in real prices. The increase in energy prices has been especially marked since 1974, when the embargo reached its peak and the Arab oil cartel began a quintupling of oil prices. The OPEC nations' recent decision to raise oil prices in 1979 and other Middle East developments can be expected to affect U.S. energy consumption patterns further

For the residential consumer, the 1970's have already brought a 65-percent rise in home oil-heating bills, a 37-percent increase in the natural gas bill, and a 25-percent rise in the electricity bill (in constant 1976 dollars). I $\mathbf{n}$ current dollars, the increases have been far more dramatic Even so, price controls on oil, average costing of electricity, and Government regulation of natural gas prices at the wellhead have resulted in subsidized retail prices that fail to reflect the full replacement cost of oil, gas, and electricity generated from either nuclear or fossil fuels.

It is important that energy prices represent true replacement costs whether this is higher or lower than current energy prices. It is only under this circumstance that consumers have a correct signal to use in determining how much to invest in conservation if they are to achieve maximum dollar savings. Furthermore, if society decides that information on items such as environmental damage, resource depletion, and reliance on foreign oil would not be accurately given by normal market forces, than it is possible to adjust the replacement cost accordingly or to provide equivalent financial incentives. In any case, since dollar savings are the principal motivation for energy conservation, it is important that conservation policy be concerned with energy prices.

Price increases clearly mean less disposable income for consumers. Stretching the available resources through higher productivity of energy use is a less costly approach than developing new supplies. Improving energy productivity in household use helps to counter the inflationary impact of rising costs. A number of policy responses are possible between holding prices steady or allowing them to rise directly in response to costs; these include matching 
price increases with income subsidies for all or some portion of the population, using taxes to protect against windfall profits, and other strategies. Price-based policy will be unacceptable to those who believe that consumers cannot withstand higher costs, or who believe that price increases do not reflect true scarcity or rising marginal costs.

\section{Consumer Attitudes}

The level of energy use in a given home is greatly influenced by the attitudes, choices, and behavior of its occupants, within a range circumscribed by the limitations of the structure itself. Energy consumption in identical houses may vary by as much as a factor of two depending solely on these variables.

Available research data indicate that consumer motivation to invest in conservation measures stems largely from a basic desire to save money and resist rising prices. This is the prime concern of homeowners. Energy costs are now about 15 percent of the average annual cost of homeownership, and in the heating and cooling season monthly payments may approach the level of the mortgage payment. The dramatic increase in fuel costs, over the very low costs of the 1960's and early 1970's, has graphically demonstrated to residents that reducing direct energy use is a wise investment. Early experiments in helping consumers to change their energy use patterns suggest that providing feedback, or quick response information on how much energy a home is using, helps people conserve. Experiments with special meters, report card billing by utilities (bills that compare use for a month compared to the same month last year), and similar techniques are now underway.

Consumers are frequently unsure about what changes are most effective. Knowledge about effective communication argues for improving local resources. Consumers have more trust in information from their locality or State than from remote institutions. The information provided by the Federal Government and by large oil companies is not well received.
It is unreasonable to expect that consumers will make major housing or behavioral choices based on energy alone. Having adequate space for a growing family, being near schools and shops, feeling certain that a home is warm enough to ensure health and comfort-these, too, are important consumer values.

Data on attitudes and behavior indicate that information programs that emphasize the positive economic benefits of conservation are more likely to show results than those based on ethical urgency. Moreover, public statements or campaigns that link conservation and sacrifice, such as suggestions that conservation means residents should be cold in their homes, may be ineffective, if not counterproductive.

More research on actual household energy use patterns, as well as attitudes and behavior, would improve the policy makers' ability to select successful motivational strategies.

\section{Low-Income Consumers}

Although rising energy prices provide a strong incentive for widespread conservation, they present special hardships for low-income consumers who cannot absorb higher utility and fuel bills, and have little access to investment capital. For the 37 million persons (17 percent of the U.S. population) with household incomes at 125 percent of the poverty level or below, utility costs typically consume between 15 and 30 percent of the family budget.

Some low-income families spend as much as half their budgets on energy in the heating season, yet a significant portion of this heat is lost because of substandard housing. Poor and near-poor households in rented housing are handicapped with regard to energy, as they usually do not control their heating systems or their dwelling's maintenance and improvement.

Efforts to relieve the energy-based economic problems of the poor have taken two ap- 
preaches: first, providing home improvements intended to reduce energy needs, and second, providing financial assistance to meet energy bills. Neither approach has been totally satisfactory or adequately deployed. Although direct aid by "weatherization" appears highly cost-effective in the long run, it is impossible under current funding to reach more than 3 percent of all eligible homes each year. Labor shortages and other programmatic problems have also hampered the Federal weatherization efforts, although the basic concept is both sound and popular. Because the poor frequently cannot reduce consumption and have no access to capital to improve their housing, Federal funds can cause energy savings that would not be achieved without such assistance, as well as improved living conditions.

Financial assistance for payment of utility bills is more controversial. Questions about this approach reflect a larger issue, which may be described as the "right to energy" doctrine. As energy is as necessary as decent housing, adequate nutrition, and medical care- al I of which the Government subsidizes to some extent- consumer advocates have argued that a basic minimum quantity of energy should also be subsidized for low-income persons. Socalled "lifeline" utility rates are one means of subsidizing energy; early experiences with such rates suggest, however, that they may provide neither conservation incentives nor adequate financial relief for many of the poor.

Other proposals include energy stamps and large programs of emergency financial aid, legal aid for poor persons dealing with utilities and fuel providers, and procedures to prevent shutoff of heat and power because of nonpayment during winter months. These programs meet social needs but do not provide resiliency to the problem. Because of a growing concern among elected officials and the wider public about the inability of financial aid programs to address basic causes of poverty, weatherization and broader housing programs designed to put all persons in decent homes may offer a better approach. Such a policy subsidizes energy efficiency rather than price.

\section{Existing Housing}

Improving energy efficiency in existing housing will be a principal area of policy emphasis in the next decade, as most of the population will continue to be housed in the 80 million existing units. Both the largest savings of energy and the largest amount of protection against the impact of rising prices will come from "retrofitting" existing homes. owner-residents, rather than builders, are the principal audience for this effort.

Making homes use less energy without lowering the level of comfort is not technically difficult, but it requires careful attention to the specific needs of the structure, quality workmanship in improvements, and continuing attention to the energy use patterns of the residence. An audit by someone trained in home energy use is necessary to identify the optimal package of changes for a specific home. Data on the energy characteristics of the existing stock are inadequate, and this complicates policy formulation. While Federal level efforts at data collection may be the most effective, States and localities are in a better position to stimulate local conservation efforts and to provide accurate technical information and guidance to occupants. States and localities, along with trade and professional groups, will bear major responsibility for training and for improving the quality control of retrofit projects. Dissemination of technical information by the Federal Government and Federal work on appliance labeling and standards will underpin local efforts.

I $\mathbf{n}$ addition to the savings available through tightening the thermal shell of the building, substantial energy savings can be obtained through retrofit of the heating and cooling equipment, and through replacing the heating and cooling devices with more efficient systems.

Present tax credits will encourage retrofit, although such credits may represent a substantial revenue loss while not adding a large increment of investment. (The Congressional Budg- 
et Office estimates that many persons who install insulation, for example, would have done so without the credit. ) Grants and direct assistance, such as weatherization, are most responsive to the needs of low-income persons. Home improvement loans have not been attractive to those making changes to their homes costing less than $\$ 1,000$, but this could change if fuel prices continue to rise and pressure to retrofit is increased.

As in the case of new housing, lending institutions that finance mortgage lending could play a critical role. If lending institutions reviewed energy costs of a home when considering a mortgage application, a total cost picture would be made available to the prospective purchaser. Funds available to the buyer to finance conservation investments through the mortgage would be amortized over a long period and would bring down monthly operating costs. A more vigorous policy initiative would require that existing housing be brought to a specified standard of energy efficiency prior to sale, or prior to utility connection.

\section{Building Industry Response}

The homebuilding industry appears to be responding to consumer demand, information, and price and taking advantage of opportunities to improve energy efficiency. Typical new construction already matches the preliminary energy standards recently adopted by many States (ASH RAE 90-75 or Model Code levels). New building reflecting these standards is still considerably below the level of energy efficiency indicated as cost-effective by OTA analysis. Tighter code requirements, combined with information targeted at builders and buyers, will help sustain and intensify the trend to better homes.

Although the design and construction industry is fragmented and generally cautious toward major change, it can respond quickly and readily re-adapt its designs and methods once the economic and technical feasibility of new housing features or construction techniques are proven and accepted in the marketplace. For example, many builders are now altering frame construction to utilize 6-inch studs instead of the standard 4-inch studs. This technique makes it easy to increase the amount of insulation in the walls, and the distance between the studs allows the change without economic penalty. Encouraging change in the industry requires making economic and technical determinations, judging what will work and what will save money, and providing that information to the key actors at the right time. Principal actors for the residential sector are:

100,000 builders, who make the basic decisions to build in response to what they perceive market demand to be, within the requirements of specific building codes and available materials;

2. 21,000 lending institutions, which approve financing for both builders and buyers; and

3. homebuyers, who by their purchasing decisions determine the demand for housing of varying types and prices, and thus influence the perceptions and decisions of builders and lenders.

Building standards and codes directly affect new construction. The stringency of codes will reflect the policymaker's views of the abilities of the industry and the urgency of the energy situation. Performance standards, now being drafted by the Federal Government, are needed to allow for flexibility and experimentation in construction. Application of performance standards in housing may be particularly delicate, because of problems of methodology and the resources of builders. The average U.S. homebuilder constructs less than 20 homes a year, does not use sophisticated architects or engineers, and works in a highly leveraged market. These builders may prefer a simple code that can be easily followed by carpenters and laborers.

I $\mathbf{n}$ addition to standards and codes, changes in the economics of the market can encourage energy conservation. Broad interpretation of tax credits and use of tax incentives, particularly tax incentives provided directly to the builder, will stimulate greater change in new housing. 


\section{Affordability}

Properly selected conservation choices will lower utility' costs and thus reduce the total costs of homeownership and operation. The possible effect of eliminating marginal buyers from the housing market must be weighed against the consequences of encouraging these buyers to acquire homes that are likely to have substantial and rapidly increasing monthly energy bills. As fuel costs continue to rise, a broader view of "affordability" is necessary. Better dissemination of information on costeffective opportunities and lifecycle costs to builders, equipment suppliers, lenders, and buyers may be a promising approach for increasing conservation investments.

Energy conservation features often add to the initial cost of homes. Builders and lenders are cautious about decisions to increase purchase costs, especially in light of dramatic increases in the price of housing in recent years. Slightly increased first costs mean that marginal buyers may have to scale down their expectations. First-time homebuyers who have limited savings for downpayments are more affected by increased downpayments than are previous owners who have an equity to invest.

On the other hand, a substantial amount of energy can be saved without great expensetypically $\$ 1,500$ to $\$ 2,000$--and without complicated or untried devices. Some of the most effective actions involve reducing air infiltration through caulking and weatherstripping, investments in storm windows and insulation, and improving the energy efficiency of heating and cooling systems. The energy efficiency of many new homes can be substantially increased by adding enough thermal protection to allow a reduction in the size of heating and ventilating equipment; in some instances this choice has actual [y meant lower first costs.

Lending institutions can improve the flow of information on total costs of homeownership and operation by including energy costs when calculating monthly payments on mortgage applications. The mortgage transaction is a critical intervention point, as buyers are focused on the home and money is being borrowed to be repaid over a long time period. A calculation that includes likely energy costs would give buyers, and lenders, a more complete estimate of total costs and could encourage cost-cutting investments. Federal leverage could be used to provide additional funding for conservation improvements at the time of sale, subsidize downpayments or interest rates for energy-efficient homes, or deny mortgage funding to homes not meeting an energy standard. Federal and State energy agencies could help lending institutions determine standards appropriate to local conditions.

\section{Design Opportunities}

Energy-conscious design is a paradox: once the most ancient of the builders' skills, it is being rediscovered as a modern trend. Proper orientation of the home on the lot, thoughtful placing and sizing of the windows, and planned-in natural ventilation combined with shading by eaves and trees produce houses that use astonishingly little energy. Even though the ideas are as old as shelter itself, modern materials and design techniques can adapt and improve the concepts for urban America. Such homes are neither expensive nor outlandishly designed, and need to be encouraged by Government action. However, policy actions are difficult to develop because energy-conscious design is part of the fabric of the building itself. Unlike discrete, technological add-ens, energy-conscious design features cannot easily be listed in a tax regulation or building code. Special policy focus by Government on such designs may be particularly appropriate because there are few natural market forces to promote such building choice.

Even if the full advantages of energy-conscious design are not explored, quite conventional, off-the-shelf technologies now exist to reduce heating and cooling loads at least $\mathbf{5 0}$ percent below those of homes built in the early 1970's. Houses built using these technologies will reduce energy use through greater efficiency with no change in living habits or level of comfort. In fact, comfort may be increased through reduction of drafts and cold spots. The real bonus results from the low purchasedenergy costs of operating such homes. These 
technological solutions to energy consumption - such as heat exchangers, "smart" thermostats, and draft-excluding devices - can be easily encouraged by Government action assisting the market.

Improved data collection is needed on homes that use little purchased energy. Construction of such homes on a demonstration basis, perhaps one in every county, could provide the type of direct learning experience most valuable and influential for builders and buyers.

Technologies now in the development or commercialization stage will offer opportunities for energy savings well beyond the options now available. More efficient furnaces, new approaches for the design and construction of walls and windows, and electronic systems to monitor and control the operation of homes are now being tested and used experimentally. As these devices become more reliable and lower in cost, the options for reducing home energy use will increase dramatically.

\section{States and Localities}

States and localities bear the major responsibility for implementation of federally authorized residential conservation programs. Building code revision and enforcement, information and education efforts, quality control, and regulation of utilities all come within the jurisdiction of States, counties, and towns. The priority assigned to conservation goals by these levels of government will directly influence the level of effort and thus the resources available to consumers and builders.

Current Federal policies both help and hinder State and local efforts. Central difficulties include rapid pacing of Federal initiatives that may not match the capabilities of the locality; failing to involve States and localities in preparing guidelines and regulations; placing responsibility for administering a large number of complicated programs on State energy offices that are frequently small, understaffed, and underfunded; and imposing Federal priorities that may not match local needs. Programs designed with the needs and capabil- ities of the States in mind are most likely to take root and remain effective as Federal priorities change and Federal funding fluctuates.

Localities work most closely with new construction through the building permit process. Local code inspection offices may require special help, both technical and financial, to improve their level of activity. This will certainly be the case if Federal actions to mandate energy changes in building codes continue. While the needs of localities may press a State energy office beyond its capabilities, these off ices must recognize the importance of providing resources to localities.

Transfer of information and technology from the Federal 'Government can be improved. Trained personnel, either from Washington offices or regional offices, could greatly assist States in working out technical problems and establishing ground rules for program operation.

\section{Utilities}

The ways in which gas and electric utilities can most effectively stimulate energy conservation in the residential sector are just beginning to be understood and exercised. As experience with utility-based conservation activities is gained, early concerns about utility involvement in nontraditional activities (such as insulation financing) and uncertainty about the impacts of innovative pricing and service delivery options (particularly time-of-use pricing and load management) are being replaced with encouraging empirical data.

Utilities can encourage residential energy conservation through information programs and home energy audits; financing and/or marketing insulation and other conservation devices; altering the rate structures to reflect costs that vary with time of use; and instituting programs of load management in the residential sector. Relatively few utilities have carried out aggressive conservation programs to date, although most electric and gas companies have undergone some adjustments in their management and planning functions as a result of changing circumstances. While eco- 
nomic and social criteria encouraged rapid energy growth in the years before 1973, more recent phenomena - including rising fuel costs, massive increases in capital requirements for new capacity, uncertainty about future demand, and changing regulatory requirements - have all caused utilities to expect and even encourage diminished growth.

Activities authorized by the National Energy Conservation Policy Act of 1978 should yield useful data over the next few years. The effects of audit programs, cost-based rates, load management, and time-of-use pricing should be carefully analyzed and the information widely shared. Following evaluation, Congress may wish to consider removal of the prohibition against utility involvement in sale or installation of residential conservation measures.

\section{Indoor Air Quality}

Potential health effects of changes in the quality of indoor air caused by energy conservation must be carefully monitored, and attention should be given to preventing negative effects as houses become tighter. As new standards lower the amount of "fresh" air moving through homes to reduce heat (and cooling) losses, concentrations of undesirable substances already present in indoor air will be intensified. Technological control measures are available to prevent the buildup of concentrations of pollutants indoors.

There is strong evidence that concentrations of several air pollutants tend to be high indoors. Existing houses with gas heating and cooking appliances have been shown to experience levels of carbon monoxide (CO) and nitrogen dioxide $\left(\mathrm{NO}_{2}\right)$ that approach or exceed ambient air quality standards. Other pollutants that may be significant in the indoor environment include respirable particulate, particulate sulfur and nitrogen compounds, nitric oxide (NO), sulfur dioxide $\left(\mathrm{SO}_{2}\right)$, radon, and various organics. Aside from heating and cooking appliances, the sources of these pollutants include building construction materials, cigarettes, aerosol sprays, cleaning products, and other sources. If air exchange rates of new and existing houses are significantly decreased from present rates, indoor concentrations of these pollutants will increase.

Control measures currently available to reduce the concentrations include filters and electrostatic precipitators to reduce particulate levels; kitchen ventilation to reduce cooking-generated pollutants such as $\mathrm{CO}, \mathrm{NO}, \mathrm{NO}_{2}$, and $\mathrm{SO}_{2}$; spray washing, activated carbon filters, and oxidizing chemicals to reduce airborne chemicals and odors; and forced ventilation with heat recovery (to minimize heat loss) to reduce concentrations of all indoor-generated pollutants. A comprehensive approach should include reduction of emissions by improved maintenance and design of stoves and furnaces, reduction in household use of polluting chemicals, and similar measures.

Evaluation of these control measures requires an understanding of health effects of ambient levels of indoor pollutants and the concentrations of such pollutants with and without controls in different housing situations. Thus far, the Federal Government does not appear to have recognized the significance of indoor air quality as a potential health problem. The Department of Energy (DOE) and the Environmental Protection Agency (EPA) have sponsored some early work in this area, but the level of support has been very small. As might be expected from the scarcity of research conducted, the level of understanding of the effects and causes of indoor air quality is insufficient to allow the definition of an optimum strategy for linking energy saving construction requirements and air treatment requirements.

\section{Federal Conservation Programs}

Federal programs support housing production and the maintenance of existing housing by providing subsidies to certain classes of occupants, as well as mortgage loans, insurance, and guarantees to lenders and property owners. Federal programs affect housing through standards for construction and rehabilitation of housing, regulation of the lending industry, maintenance of a secondary market for mortgage lending, research and development (R\&D), financial assistance for community development, tax credits and incentives, and 
programs specifically designed to provide information or technical assistance to encourage conservation. Direct Federal construction, such as housing provided by the Department of Defense, affects the market for housing technology and appliances through the procurement process and the use of standards.

Because of the wide variety of programs influencing both housing and conservation, many mechanisms exist to affect energy consumption in homes. Recent legislative and administrative changes will help to save energy. Energy conservation has not been a major priority for most Federal programs, and there has not been strong coordination of the various departmental efforts. A stronger commitment to energy conservation, combined with improved technical work and more sophisticated cost analysis, could mean a much stronger response to conservation goals from both the public and the private sector.

Some of the most important Federal actions are listed here.

\section{HOUSING STANDARDS}

As a result of postembargo legislation, the Federal Government is now more deeply involved than ever in defining energy-based housing standards, which will eventually influence local building codes. Codes are an effective mechanism for altering construction practices, but they are implemented at the local level, and great care is needed to ensure that adequate time and resources for training accompany this new Federal-State-local approach.

States have been encouraged through Federal funding and training to adopt codes based on an engineering approach. Existing legislation calls for the adoption of performancebased standards by 1980 . Performance standards offer a unique and valuable way to encourage energy efficiency while allowing innovation and providing equal market access to all types of construction. This type of standard is also a totally new method, and there is no agreement on the correct methods for calculation and review, particularly for residential buildings. Despite a sincere desire by DOE to solicit comments on draft standards, time pressures generated by the current schedule do not allow for adequate review and thoughtful analysis. As a result, commitment to the current schedule will almost assuredly result in litigation and dissatisfaction by both supporters and opponents of the standards.

A substantial period may be needed for review and field testing of the new standards in certain areas and markets. Transition to performance standards closely tied to existing methods of analysis and review will increase the likelihood of compliance.

\section{RESEARCH AND DEVELOPMENT}

The short-term focus of current DOE conservation $R \& D$ ignores some longer term options that also have high returns. The attention to commercialization strategies that characterize the program is questionable, as rising prices should enable the private market to absorb commercialization costs. Research on attitudes, energy use patterns, institutional and legal barriers to conservation, and similar important areas have not received adequate emphasis. Research and policy decisions on energy technology do not adequately consider the conservation applications of new technologies; the potential of conservation to reduce demand and provide time for shifting to new energy systems is not fully appreciated. The policy appears to reflect an attitude by DOE and the Office of Management and Budget that conservation should be viewed as a stop gap that merits little Federal research funding, in sharp contrast to new production approaches.

\section{TAX POLICY}

Federal tax policy is probably the major element in decisions by owners of rental property on construction and rehabilitation. Historically, the tax code has encouraged low first-cost (and therefore energy inefficient) housing, and has protected owners to the extent that most program efforts to improve tenant energy use have been futile. Broader use of tax incentives should increase the conservation response. At least, policies should be examined to ensure 
that they do not continue to encourage energywasteful construction.

Similarly, the tax system can be used to reward homeowners for investing in conservation. Critics of this policy believe that homeowners are sufficiently rewarded by the savings in fuel bills, and that the number of people who invest because of the credit is small, while the number who claim the credit is large. This policy does not allow for the fact that many conservation investments can save much energy but are only a breakeven choice without additional incentives. Early Internal Revenue Service decisions on the eligibility of items under the recently authorized conservation tax credits show a reluctance to interpret the law broadly, and raise special problems for energyconscious design approaches.

FEDERAL HOUSING PROGRAMS

Federally owned and subsidized housing represents both a special responsibility and a special opportunity for saving energy and lowering total costs. Energy conservation has had very low priority in most of this housing. Funds and authorizations recently approved by Congress will help to improve the efficiency of these dwellings. Improved levels of conservation would demonstrate real Federal commitment, improve the comfort level of the housing, and save money as utility costs, which are frequently subsidized, continue to rise. 
Chapter I

TRENDS 


\section{Chapter I.-TRENDS}

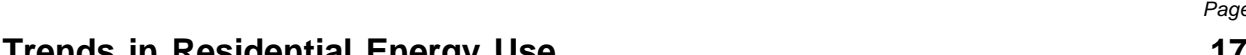

Energy, Demographics, and Prices . . . . . . . . . . . . . . . . 17

Analysis of Electricity and Natural Gas Use as Functions of Weather

and Price . . . . . . . . . . . . . . . . . . . . . 20

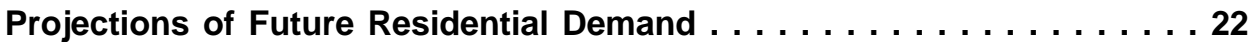

Discussion of Projections. . . . . . . . . . . . . . . . . 24

Technical Note-Residential Energy Consumption Analysis. . . . . . 26

\section{TABLES}

I. Residential Energy Use by Fuel . . .

2. National Average Annual Heating Billsiby Fuel $\ldots \ldots \ldots \ldots 19$

FIGURES

2. Fuel Prices 1960-77.

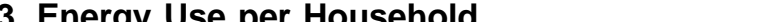

4. Comparative Energy Use Projections . . . . . . . . . . . . 22

5. Comparative Price Projections. . . . . . . . . . . . . 23 


\section{TRENDS IN RESIDENTIAL ENERGY USE}

This chapter analyzes residential energy use since 1960, gives energy use projections to the year 2000, and discusses the potential for energy savings in the residential sector. Aided by computer analysis of residential electricity and natural gas use since 1968, consumer response to changing prices is examined. Finally, computer projections are made of energy demand over a range of possible future energy prices assuming ideal economic behavior.

\section{ENERGY, DEMOGRAPHICS, AND PRICES}

Table 1 shows aggregate energy use for the residential sector, adjusted for annual weather differences and broken down by fuel use and by function, for 1960, 1970, and 1977. From 1960 to 1970, adjusted residential energy use increased at an average rate of 4.7 percent, while from 1970 to 1977 it grew by only 2.6 percent. This substantial reduction has not been spread evenly through the 1970's, however. Between 1970 and 1972, the average annual growth rate for weather-adjusted residential energy use was 3.4 percent; from 1972 to 1975 consumption declined by 1.8 percent; and from 1975 to 1977 it leapt back up to a 3.7-percent average annual growth rate.

Electricity use is growing fastest. From 1960 to 1970 electricity use grew at an average annual rate of 8.3 percent; from 1970 to 1977 the increase was about 5.5 percent. In 1977, electricity represented 45 percent of all the energy used in the residential sector. Unlike total energy use, however, the growth rate in electricity use since the embargo has not departed from that over the entire $1970-77$ period.

Even though growth rates have declined for both electricity and total energy use for 1970-77 compared with 1960-70, the ratio of electricity growth to total energy growth has

'Data for total residential energy use are corrected for weather differences by assuming that 50 percent of the total is for heating, and is therefore weather-sensitive, and by adjusting that portion using a ratio of the average number of annual degree days between 1960 and 1970 $(4,869)$ to the actual number in each year.
Table 1 .-Residential Energy Use by Fuel (Quads)

\begin{tabular}{|c|c|c|c|}
\hline & 1960 & 1970 & 1977 \\
\hline 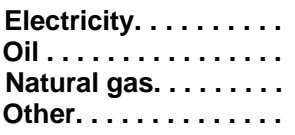 & $\begin{array}{l}2.41 \\
2.37 \\
3.34 \\
1.00\end{array}$ & $\begin{array}{l}5.36 \\
2.81 \\
5.31 \\
0.90\end{array}$ & $\begin{array}{l}7.80 \\
2.98 \\
5.83 \\
0.60\end{array}$ \\
\hline Total . . . . . . . . . & 9.12 & 14.38 & 17.21 \\
\hline
\end{tabular}

NOTE: The 1960 and 1970 figures are from "Residential Energy Use to the Yea 2000: Conservation and Economics," ORNUCON-13, September 1977. The 1977 figures are from the Energy Information Administration, Department of Energy.

1977 Components of Residential Energy Use (Quads)

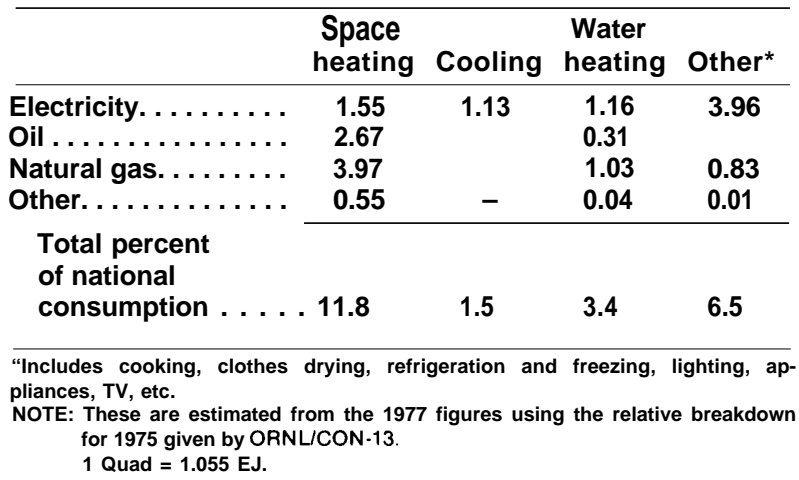

increased. This is a result of rapid expansion in electric heating over the period; about 50 percent of new homes have been constructed with electric heat since 1974, compared with less than 30 percent in 1970 . The proportion of new electrically heated homes using heat pumps is rising rapidly. This trend toward electric heating may be slowing, however, as there appears to be a resurgence of gas space-heating in new homes. 
Many variables have contributed to the gradual reduction in residential energy growth in this decade, but it is difficult to demonstrate a cause-and-effect relationship between demographic trends, prices, and other economic fluctuations on the one hand, and energy consumption statistics on the other. The sharp dip to an absolute decline in weather-adjusted residential energy use between 1972 and 1975 can probably be attributed to the dominant events of that period -the Arab oil embargo and the 1974-75 national bout with "stagflation," or combined recession and double-digit inflation. Beyond that, however, it becomes more difficult to isolate causes of reduced consumption.

Demographic contributions to reduced home energy use can be glimpsed by reducing the consumption statistics to the individual household level. Between 1960 and 1970, energy consumption grew rapidly in each household-that is, total residential energy use grew considerably faster than either the population or household formation growth rates. While total weather-adjusted residential energy use grew by 4.7 percent annually, population increased at an annual rate of only $\mathbf{1 . 3}$ percent and the number of households rose by only 1.9 percent annually. The rapid increase in each household's energy consumption can be attributed to the trend toward saturation in major energy-consuming home appliances such as air-conditioners, dishwashers, and clothes dryers, and to increased energy-intensiveness in such appliances as frost-free refrigerators.

The trend toward higher per-household energy consumption has been halted in the 1970's. A recent study by the General Accounting Office reports that total energy use per household has remained essentially constant in this decade. ${ }^{2}$ Demographic trends help to explain this reversal: as population growth has slowed to an annual increase of 0.6 percent, the rate of household formation has picked up to 2.4

'The Federal Government Should Establish and Meet Energy Conservation Goals, Comptroller General of the United States, June 30,1978, Washington D.C. percent. At the same time, the average number of persons in each household has declined. One- and two-person households increased their share of total households from 45.8 to 51.2 percent between 1970 and 1976, while households with four or more persons dropped from 21.1 to 15.9 percent. The high rate of household formation and smaller household size result from the "coming-of-age" of babyboom children and, to a lesser extent, higher divorce rates, greater longevity, and the increasing tendency of older persons to live alone.

Smaller households, typically occupying smaller homes, use less energy. But each additional household adds more energy consumption to the total than the same number of persons would use in a combined larger household, as each new household normally means an additional furnace and water heater and additional appliances. Therefore, while energy use per household does not grow, total household energy use does increase faster than population.

Projections of future population growth and household formation suggest that the demographic trends of the 1970's are likely to continue. The Bureau of the Census mediumgrowth projection (Series 11) for population in 2000 is 260 million, or an average annual growth of 0.8 percent between 1976 and 2000 . A housing model developed by the Oak Ridge National Laboratory (ORNL) ${ }^{3}$ predicts a household formation rate that continues to outstrip population growth; ORNL projects an average growth of 1.6 percent in the housing stock between 1975 and 2000. The highest growth (2.1 percent annually) will occur in the 1975-85 period, with a drop to 1.3 percent per year between 1985 and 2000. Households in 2000 are expected to total approximately 106.5 million. Combined with the Series I I population projection, this would mean an average household size of 2.40 persons, compared to 2.95 persons in 1976.

\footnotetext{
"An Improved Engineering- Economic Model of Residential Energy Use," Oak Ridge National Laboratory, Oak Ridge, Tennessee.
} 
Most observers agree that the price of energy, and particularly dramatic changes in price, affect residential (and other) energy use. Again, however, documenting the exact relationship between price changes and reduced household energy consumption is virtually impossible, given the scanty data collected during the short period of time when price increases have occurred. Figure 2 shows prices for electricity, natural gas, and heating oil from 1960 to 1977 in constant 1976 dollars (to remove the effects of inflation). The figure shows that all energy prices, in real terms, have increased dramatically in the last few years.

Figure 2.-Fuel Prices 1960.77 (in constant 1976 dollars)
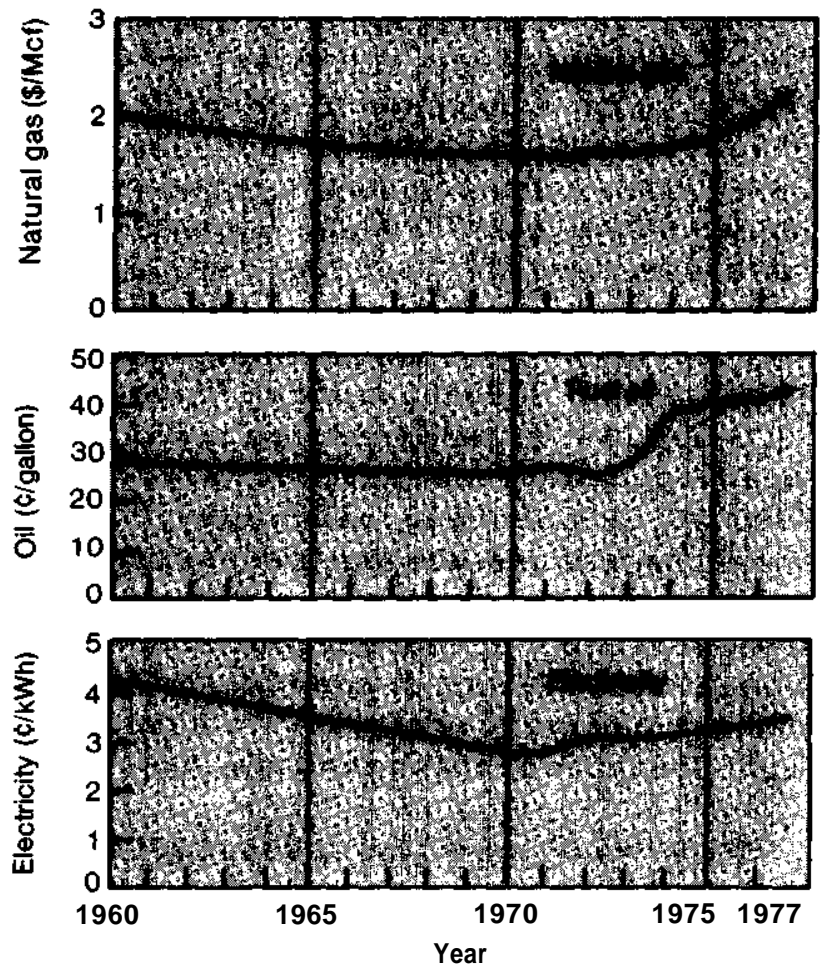

SOURCE: U.S. Energy Demand: Some Low Energy Futures, Science, vol. 200, Apr. 14, 1978, p. 144.
Since 1970, real oil prices have increased an average of 7.6 percent per year (with a 35-percent increase from 1973 to 1974); real natural gas prices increased 4.9 percent annually; and electricity prices rose 3.4 percent per year. Between 1960 and 1970, by contrast, all these prices decreased in real terms.

Viewing these price changes in another way, table 2 presents national average annual heating bills (in 1976 dollars) for electricity, fuel oil, and natural gas, for the years 1960, 1970, 1975, and 1977. These figures show that the real cost of heating dropped substantially from 1960 to 1970 for all three fuels before beginning to grow. The greatest increase has occurred in the oil heating bill, which has increased 65 percent since 1970. Natural gas and electric heating bills have increased 37 percent and 27 percent respectively since 1970 .

Table 2.-National Average Annual Heating Bills by Fuel (1976 dollars)

\begin{tabular}{cccc}
\hline Year & Electricity & Oil & Natural gas \\
\hline $1960 \ldots \ldots \ldots \ldots \ldots$ & $\$ 690$ & $\$ 280$ & $\$ 220$ \\
$1970 \ldots \ldots \ldots \ldots \ldots$ & 450 & 260 & 175 \\
$1975 \ldots \ldots \ldots \ldots \ldots$ & 510 & 400 & 200 \\
$1977 \ldots \ldots \ldots \ldots \ldots$ & 570 & 430 & 240
\end{tabular}

NOTE These estimates of electricity and natural gas were obtained by using the heating energy requirements for 1970, 1975, and 1977 shown in figure 3 and prices for all years from figure 2. The 1960 estimate of use per household is assumed equal to 1970 and the heating energy requirement for oil is assumed to be equal to that for natural gas. Keep in mind that oil heat is used largely in the coldest parts of the country.

The relative costs of the three fuels are also instructive. As expected, electricity is the most expensive, about 2.3 times that of gas in 1977 and about 32 percent higher than oil. In 1970, however, electric heat was about 73 percent more expensive than oil and 2.6 times higher than gas. If electricity prices continue to grow at a slower rate than oil and gas, and heat pumps capture a greater share of the electric heat market, these price differentials should continue to narrow substantially and could contribute to increased electrification of the residential heating market. 


\section{ANALYSIS OF ELECTRICITY AND NATURAL GAS USE AS FUNCTIONS OF WEATHER AND PRICE}

In an effort to isolate the impact of price increases on residential use of electricity and natural gas, OTA employed regression analyses that separated weather-related and nonweather-related use of each energy source on a per-household basis. The analysis covered 1967-77 for natural gas and 1970-77 for electricity. The results of these analyses are shown graphically in figure 3. Major conclusions from the analyses are:

1. The per-household use of natural gas for heating, measured in $1,000 \mathrm{ft}^{3}$ per degree day, declined by about 10 to 15 percent between 1967 and 1977. (Similar results were obtained in a study by the American Gas Association.)

2. Similar changes have occurred in nonweather-related household use of natural gas (such as cooking) over the decade examined. Interesting shorter term trends are also evident: consumption in this category rose about 10 percent through 1973, and dropped by about 25 percent between 1973 and 1977.

3. Per-household weather-related use of electricity, measured as kilowatthours consumed per heating and/or cooling degree day, dropped sharply from 1971 to 1974, but has been rising over the last 3 years.

4. Conversely, non-weather-related uses of electricity per household increased steadily from 1970 to 1974 and then dropped sharply from 1974 to 1977 .

The linear model used in OTA's analysis was not able to indicate a quantitative relationship between those consumption changes and price changes over the same periods. This does not mean that the price effect can be dismissed, however, as the above results do track with increasing prices in most cases. In the case of natural gas, real prices have increased by 35 percent since 1973 (see figure 2). The drop in gas use per degree day that occurred in 1974 was probably caused largely by the embargo, but the continued downward trend since then has likely been a result of price. The nonheating use of gas shows an even greater correlation to price in that the decline has accelerated in the last 2 years, when price increases have been the greatest. The principal conclusion here is that some price response is evident but it is complex and extremely difficult to demonstrate conclusively or quantitatively.

Electricity use shows a much weaker correlation to price. It must be noted that real electricity prices have increased the least among the residential energy sources-only 14 percent since 1973. In fact, the real price of electricity in 1977 was just equal to that in 1965. Therefore, one would not expect to see as much change in electricity use as in other energy sources. There has been a substantial increase in weather-related electricity use per household since 1974 while non-weather-related uses have declined about 25 percent. While these trends are correct, it is possible that the size of the changes which have occurred is smaller than shown in figure 3. Effects due to changed thermostat settings and weatherproofing could cause the linear model used to overstate the actual changes. Perhaps these changes indicate that the modest electricity price increases that have occurred have motivated users to conserve where conservation involves the least discomfort- in lighting, cooking, and use of appliances - but not in the basic amenities of heating and cooling.

The ability of any model to document a relationship between price and consumption in a decade or less-and particularly in the postembargo period of sharp changes in both variables - is limited. Analysis over a longer period should shed further light on the price effects, especially since a longer period is required to test for, the most significant response to price, a replacement of energy-consuming durable goods such as furnaces, refrigerators, water heaters, and other appliances. While shortterm behavioral changes such as setting back 
Figure 3.-Energy Use per Household

Non-weather-related uses
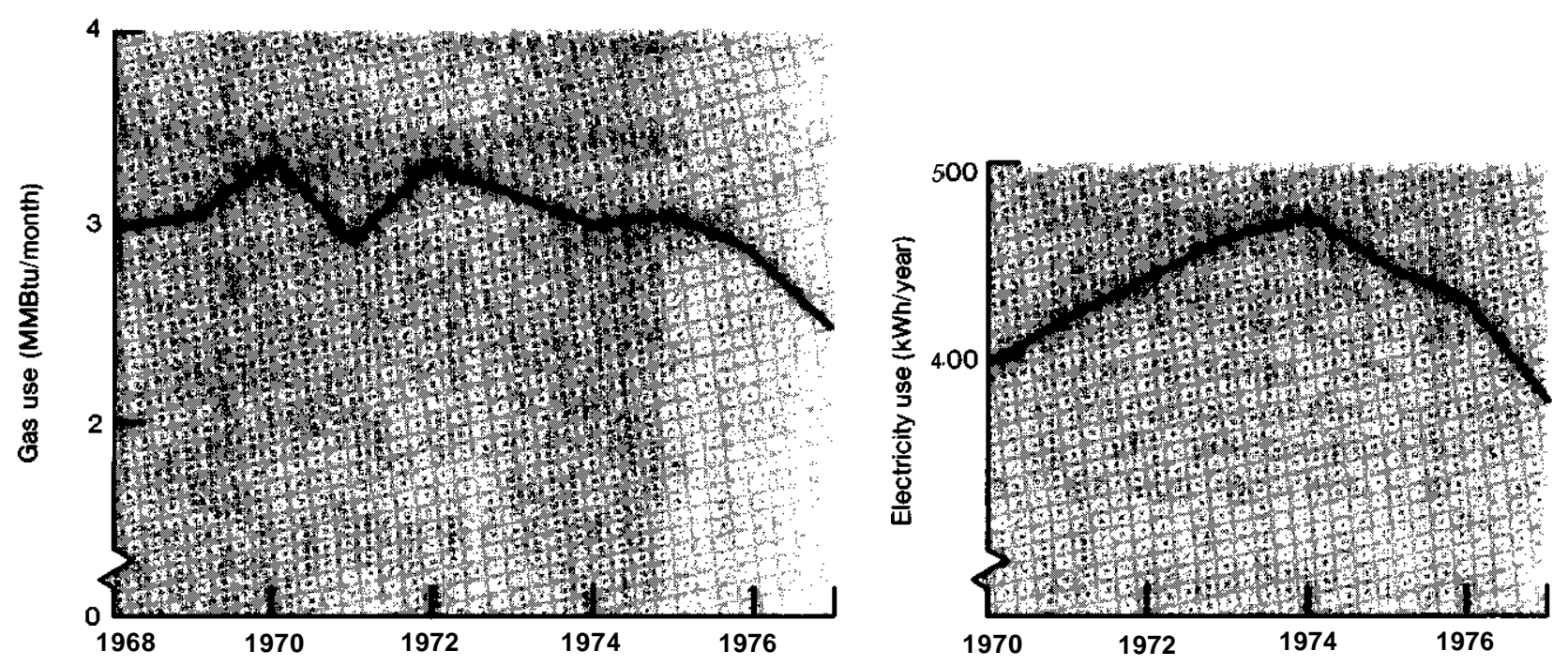

Weather-related uses
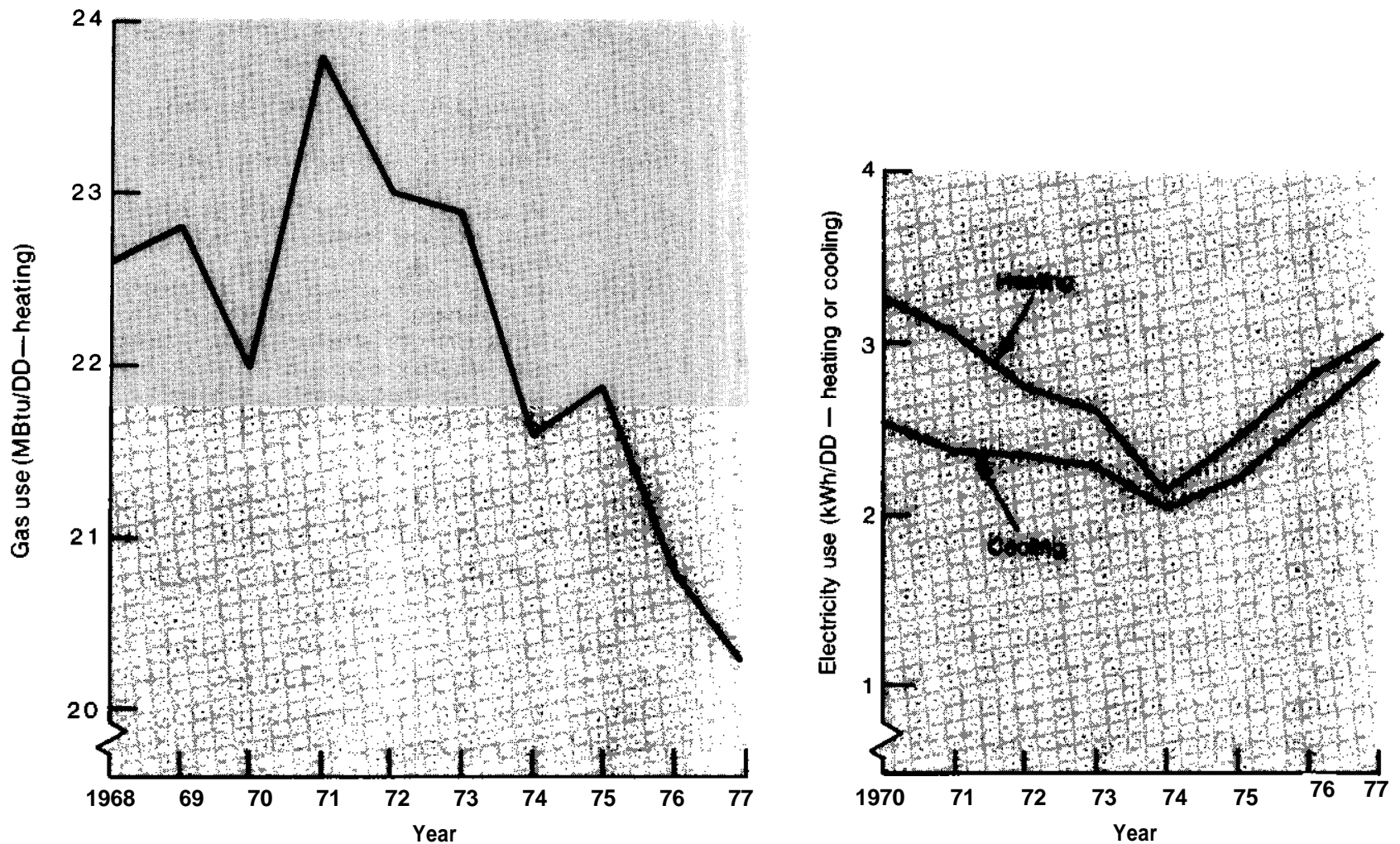

SOURCE: Office of Technology Assessment. See Technical Note-Residential Energy Consumption Analysis, at the end of this chapter. 
the thermostat and lowering the water heater temperature have some effect on total consumption, this effect is small compared with the potential of a new and more efficient furnace or water heater.

\section{PROJECTIONS OF FUTURE RESIDENTIAL DEMAND}

This section presents a series of projections of residential energy demand - not to indicate what is likely to happen, but to establish the potential for residential energy conservation. Demand is projected to 2000 along two curves as if 1960-70 and 1970-77 trends were to continue. Another projection shows potential demand if all consumers behave in an economically optimum manner. The latter case is applied to a range of possible future energy prices.

The results of these projections are shown in figure 4. The upper curve, showing residential use reaching 48.4 quadrillion Btu* (Quads) by 2000 if the growth rate resumes its 1960-70 value, is for illustrative purposes only and is not considered likely to occur. Although the growth rate has picked up over the last 3 years, it still does not approach the 1960-70 levels, and it is unlikely to do so because energy prices are unlikely to fall and saturation is being reached in a number of energy-intensive appliances in the residential sector.

The second trend curve, reaching 31.3 Quads in 2000, is more realistic because it represents continuation of the 1970-77 growth rate of 2.6 percent per year. This projection implies that future response to increased prices and supply uncertainty would follow 1970-77 patterns, and energy prices would not increase relative to income for the remainder of the century. Because the last 3 years have shown a marked increase in the growth rate, a continuation of the 1975-77 trend until 2000 would result in substantially more actual energy use. It is important to remember, however, that the trends of the last few years do not yield enough information, especially in light of the enormous price changes that have occurred, to be considered accurate forecasts of the future. Because energy prices are, in fact, expected to

\footnotetext{
${ }^{*} \mathrm{~A}$ Quad $=1$ quadrillion Btu $=105$ exajoule (EJ)
}

Figure 4.-Comparative Energy Use Projections (Residential sector)

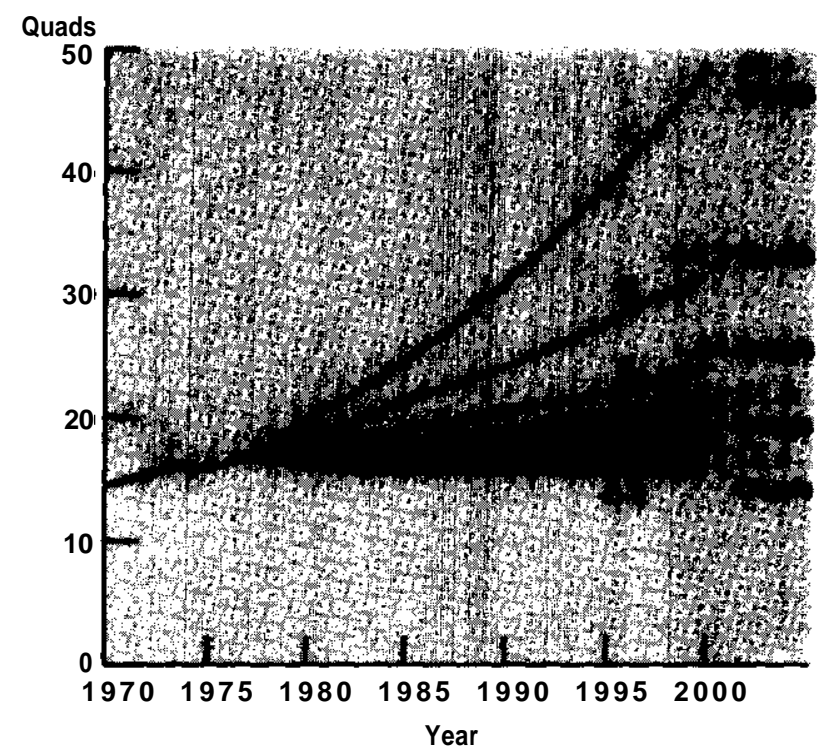

A - Residential consumption based on simple extrapolation of 1960-70 trend.

B - Residential consumption based on simple extrapolation of 1970-77 trend.

C - Residential consumption based on constant level of energy use per household; growth results from increase in number of households.

D-E - Range of "optimal economic response" based on assumption that energy saving devices are installed as they become cost-effective. Range is formed by price; upper boundary represents response to lowest projected price, lower boundary represents response to highest projected price. (See figure 5-Price)

1 Quad= $1.055 \mathrm{EJ}$.

increase, it is probable that actual residential energy demand will fall below 31.3 Quads.

How far below is the key question, To test the conservation potential of hypothetical consumer behavior based on maximum economic self-interest, projections were calculated from the residential energy demand model developed by ORNL. The projections assume that consumers make selected investments designed to increase residential energy efficiency to a point where their marginal cost equals marginal savings - that is, 
the point where an additional dollar invested would return less than a dollar over the life of the investment- and then no more is invested. The resulting consumption levels range from $\mathbf{1 5 . 4}$ to 21.8 Quads in 2000.

Certain assumptions about future energy prices, available equipment, and financial variables are inherent in the projections; the range of future energy prices used is displayed in figure 5. The low price projections correspond to the 1977 Department of Energy price projections. These curves from 1975 to 2000 show a growth rate for prices in 1975 constant dollars of 4.0 percent per year for natural gas, 1.0 percent per year for electricity, and 1.7 percent per year for fuel oil. The Department of Energy is currently revising its price projections upward. The high price projections are placed somewhat above the high Government projections prepared by the Brookhaven National Laboratory (BNL). The rationale for doing this is explained in the OTA report Application of Solar Technology to Today's Energy Needs, Volume II, September 1978. According to this price range calculation, between 1975 and 2000 the average annual rate of increase in constant dollars is $\mathbf{5 . 0}$ percent for natural gas, 4.7 percent for electricity, and 4.8 percent for fuel oil. The 1978 prices (in 1975 dollars) are shown for each of these three fuels for easier comparison.

This analysis assumes that a residential customer would decide to invest his money in a manner calculated to realize a maximum return while meeting his future energy needs. The customer would divide his available funds between energy conservation technologies and fuel purchases to minimize the amount of money spent over the useful life of his investment. Therefore the amount spent on the conservation technologies would be less than the cost of energy saved.

Another way of seeing this tradeoff is to consider the equivalent cost of a barrel of oil saved by an investment in residential conservation and compare it to the cost of the energy purchased in the absence of the investment. This computation may be made using the ORNL model, which considers investments in technologies that reduce the heating and cool-
Figure 5.-Comparative Price Projections (All prices in 1975 dollars)
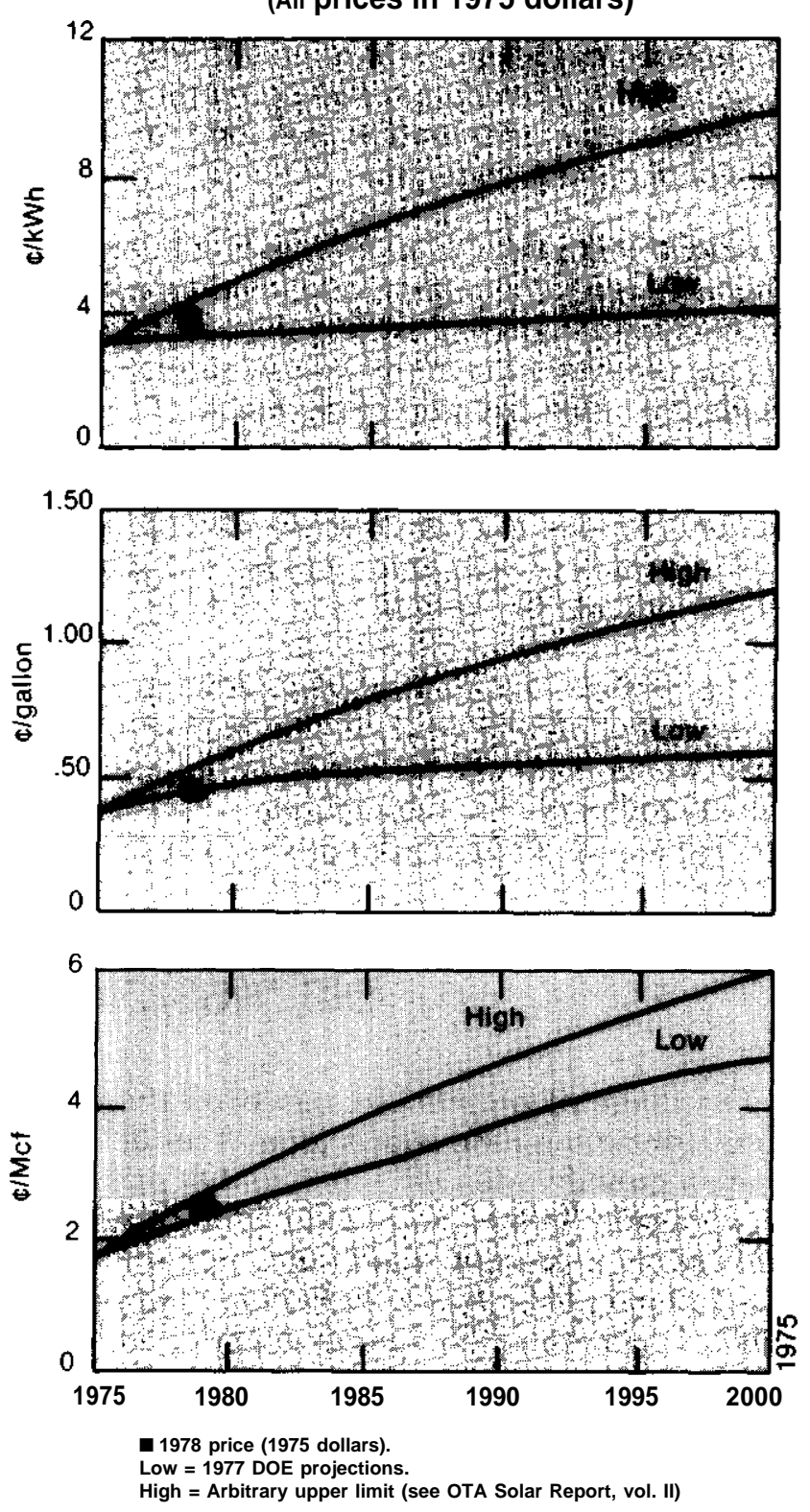

ing load by improving thermal integrity of new single-family homes (e. g., insulation, storm windows). This calculation shows that an initial investment of $\$ 550$ in selected measures would reduce the combined heating and cooling load for a new home by about 52 million Btu per year in an average climate. Over a 20year period (the life of the technologies purchased with the investment) the total energy savings would amount to 1.04 million Btu or the equivalent of 180 barrels of oil. Therefore 
the investment is equivalent to paying a little over $\$ 3.00$ per barrel in 1977 dollars - a price far lower than retail consumers actually pay for oil. Thus, a clear advantage exists for investments in conservation as long as fuel prices stay above this value.

Even though the dollar savings in the above example would be substantial, investments in improvements to the building shell alone may not be the best way to maximize return from residential conservation investments. By putting some money into more efficient equipment (e. g., appliances, air-conditioners, space heaters) an even greater return may be realized. Other calculations using the ORNL model indicate this result.

The model also assumes that only technologies now available will be purchased for increasing efficiency of buildings and equipment for the remainder of the century. In this sense the model is quite conservative. The model also assumes that investors will discount future investments and savings using a discount rate of 10 percent, after inflation. This, too, is a conservative choice and tends to understate the potential for conservation. Finally, the model accounts for the effect of legislation enacted prior to 1978 in carrying out the computations. It has not, however, accounted for the tax credits granted in the National Energy Act of 1978. The effect of these measures in this calculation would be to change the rules governing computation of the optimal investment level. With the credit, the investor will realize a greater return for a given investment than without the credit. Therefore he can go to a higher level of thermal protection before the marginal costs and savings become equal. In essence, Congress decided by enacting the tax credit that our national energy situation requires energy savings greater than those that could be achieved through market price considerations without Government intervention.

\section{DISCUSSION OF PROJECTIONS}

The range of projections based on the economic optimum case shows annual residential energy growth rates of -0.5 to 1.0 percent, considerably below any value that could be verified as a present trend, and probably too low to be realistic future projections. Residential consumers often fail to make economically optimum investments in energy conservation for many reasons, which are discussed elsewhere in this report. Also, the model uses as a payback period for each investment the entire life of the technology being purchased, while most residential conservation "investors" have a time horizon considerably shorter, typically no more than 5 years. Finally, these projections assume continued energy price increases at higher rates than inflation; if this should not occur, energy use in $\mathbf{2 0 0 0}$ would fall between the economic optimum path and the 1970-77 trend curve. (A thorough discussion of the plausibility of future energy price increases is given in the OTA solar report previously cited.)
The economically optimal projections do show, however, what one could expect if consumers had access to all necessary information and no other constraints existed. A residential consumer would then presumably make the investment decisions assumed in the model, as doing so would maximize economic return. Although these projections should not be considered as predictions of what will happen, they are a valid target, and a valid basis for policy measures to reinforce private decisions.

It is worthwhile putting these projections in another perspective. If one assumes that national average household energy use in 1977 does not change for the remainder of the century, then the residential sector would use 24.7 Quads in 2000. This is based on the ORNL projection of about 106 million residences in 2000. Therefore the 31.1 Quad projection from the 1970-77 trend line implies an increase in the average amount of energy used per household. From another point of view, energy use can be 
estimated in 2000 if space-heating and cooling requirements were cut in half from the value projected by the 1970-77 trends. A reduction of this size is reasonable as shown in the section on current technology, chapter II. In 1977 about 57 percent of residential energy went for space heating and cooling. Continuation of that percentage, coupled with the 1970-77 trends projection, would mean that about 18 Quads would be needed for heating and cooling in 2000. Reducing heating and cooling by 50 percent to 9 Quads would give a total residential consumption of 22.3 Quads. Therefore, the projections made under the optimal investment assumption are not as far from reach as they may at first seem.

Going back to these latter projections, one can see a substantial potential for savings in residential energy use. in the highest price projection, a 50-percent reduction in energy use from the 1970-77 trend is possible. For the lower price projection, the savings potential is still more than 30 percent compared with the extrapolation of 1970-77 experience. This savings represents 9.2 to 15.6 Quads in 2000 , or the equivalent of about 4.6 million to 7.8 million barrels of oil per day. The cumulative savings that could be achieved from now until the end of the century, compared to the 1970-77 trends extrapolation, range from 96.7 to 167.8 Quads for the equivalent of about 16.7 billion to 28.9 billion barrels of oil - roughly comparable to two to three Alaskan oilfields of the size discovered in 1967.

It is apparent that large savings are possible in the residential sector, and that they can contribute substantially to reducing imported energy needs. Although the potential savings may be too optimistic, because consumers are not now likely to behave in a strict economically optimum manner, they are not impossible and are worth reaching for. This study discusses many reasons why a gap between actual and optimum savings exists and what might be done to narrow the gap. 


\section{TECHNICAL NOTE-RESIDENTIAL ENERGY CONSUMPTION ANALYSIS}

Regression analyses was applied to total residential consumption of gas and electricity to obtain figure 3.

Residential electric usage was separated into weather-related and non-weather-related consumption by regressing consumption against heating and cooling degree days in the form:

$$
\mathrm{S}=\mathrm{C}+\mathrm{Bh} \text { Ceh } \mathrm{Dh} / \mathrm{Ce}+\mathrm{Bb} \mathrm{Cec} \mathrm{Dc} / \mathrm{Ce}
$$

where $S$ is total electric sales per residential customer; $\mathbf{C}$ is the non-weather-related use per residential customer; Dh and Dc are heatingand cooling-degree-days respectively; $\mathrm{Ce}, \mathrm{Ceh}$, and $\mathrm{Cec}$ are total residential electric, electric heating, and electric cooling customers, respectively; $\mathrm{Bh}$ is the electric heating use per residential electric heating customer per heating degree day; and $\mathrm{BC}$ is the electric cooling use per residential electric cooling customer per cooling degree day. Monthly data was used to determine $\mathrm{C}, \mathrm{Bh}$, and $\mathrm{Bc}$ for each year. Annual customer data was interpolated to estimate customers on a monthly basis.
Gas usage was treated similarlyl except cooling was not included in the regression. Data used was obtained from the followings $\mathrm{ou} \mathrm{r}$ c e $\mathrm{s}$ :

Monthly electric sales: Edison Electric Institute, “Annual Report, "1970-77

Electric customers: Edison Electric Institute,

Electric heating customers: Bureau of the Census, "Characteristics of New One-Family Homes: 1973" and a "Characteristics of New Housing: 1977."

Electrlc cooling customers: Bureau of the Census.

Monthly gas sales: American Gas Association, "Monthly Bulletin of Utility Gas Sales," 1967-77.

Gas Customers: American Gas Association, "Gas Facts "

Gas heating customers: American Gas Association, "Gas Facts."

Monthly heating degree-days: "Monthly State, Regional, and National Heating Degree Days Weighted by Population, "U.S. Department of Commerce, NOAA Environmental Data Service, National Climatic Center, Asheville, N.C.

Monthly cooling degree-days: Monthly State, Regional, and National Cooling Degree Days Weighted by Population," National Climatic Center, Asheville, N C 


\section{Chapter H RESIDENTIAL ENERGY USE AND EFFICIENCY STRATEGIES}

\section{Chapter II.-- RESIDENTIAL ENERGY USE AND EFFICIENCY STRATEGIES}

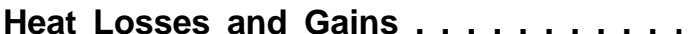

Thermal Envelop

$$
\text { insulation Effectiveness }
$$

insulation Efectiveness . . . . . . . 37

Heating, Ventilation, and Air-Condition-

ing Systems. . . . . . . . 39

Furnaces . . . . . . . . . . . . . . 39

Furnace Retrofits . ., . . . . . . . . . 39

Heat Pumps. . . . . . . . . . . . 41

Air-Conditioners . . . . . . . . . . 41

Appliance Efficiency and Integrated Appliances . . . . . . . . . . 42

\section{,}

39

Page

The ACES System . . . . . . . . . . . . . . . . 44

Energy Savings in Existing Homes -

Experiments ............. . . . 46

Integrating Improved Thermal Envelope,

Appliances, and Heating and Cooling

Equipment . . . . . . . . . . . . . . . . . 50

Lifecycle Costing . . . . . . . . . . . . . . . . . . 52

Technical Note on Definitions of Performance

Efficiency ............... . . . . 54 


\section{TABLES}

3. Disaggregate! Cooling Loads for a Typical 1,200 $\mathrm{ft}^{2}$ "1 1973 " House in Three Different Climates. . . . . . . . . 34

4. Sources and Amounts of Internal Heat Gain During the Cooling Season for Chicago and Houston .......... 34

5. R-Value of Typical Building Sections and Materials . . . . . . . . . . 35

6. Performance Comparison for Three Thermal Envelopes in Three Different Climates . . . . . . . . . . . . . . . . 36

7. Effective R-Values for Different Walls in a Range of New Mexico Climates . 38

8. The Impact of a $\mathbf{1 0 0} \mathrm{kWh} /$ Year Reduction in Appliance Energy Usage on Total Energy Consumption . . . . . 44

9. Energy Consumption of Improved Appliances for the Prototypical Home 44

10. Full-Load Performance of the ACES System. . . . . . . . . . . . . . . 44

11. Actual Space- and Water-Heating Energy Requirements of the ACES Demonstration House. . . . . . . . . . . 46

12. Comparison of Reductions in HeatLoss Rate to Reductions in Annual bleating Load. . . . . . . . . . . . . . . . 49

13. Preretrofit Steady-State Winter HeatLoss Calculations . . . . . . . . 49

14. Postretrofit Steady-State Winter HeatLoss Calculations . . . . . . . . . . 49

15. Primary Energy Consumption for Different House/Equipment Combinations ............ 50

16. Equipment Used in Prototypical Baltimore Houses . . . . . . . . 51

17. Levelized Monthly Energy Cost in Dollars for Energy Price Ranges Shown (All electric houses) . . . . . . . 53

18. Levelized Monthly Energy Cost in Dollars for Energy Price Ranges Shown (Gas heated houses). . . . . . . . 53

19, Structural and Energy Consumption Parameters for the Base 1973 SingleFamily Detached Residence . . . . 56
20. Specifications and Disaggregate Loads for "1973" Single-Family Detached Residence . . . . . . . . . . 57

21. Specifications and Disaggregate Loads for "1976" Single-Family

Detached Residence . . . . . . . . . . 58

22. Specifications and Disaggregate Loads for Low-Energy Single-Family Detached Residence . . . . . . . . . . 59

23. Disaggregated Energy Consumption for Different Combinations of Thermal Envelope and HVAC Equipment for Houses in Houston, Tex. . . . . . . . 60

24. Disaggregated Energy Consumption for Different Combinations of Thermal Envelope and HVAC Equipment for Houses in Baltimore, Md. . . . . . . 61

25. Disaggregated Energy Consumption for Different Combinations of Thermal Envelope and HVAC Equipment for Houses in Chicago, III.. . . . . . . . 62

\section{FIGURES}

6. Residential Energy Use in the United Page States . . . . . . . . . . . . . . 29

7. Disaggregate Energy Usage in the "Typical 1973" House Located in Baltimore, Md., for Three Different Heating and Hot Water Systems . . . . 32

8. Heat Losses and Gains for the Typical 1973 House in Chicago and Houston Heating Season . . . . . . . . . . 33

9. Heating Load/Cost RelationshipKansas City . . ..., . . . . . . . 36

10. Residential Heating Systems. . . , . . 40

11 Performance of Installed Heat Pumps . 42

12, Handbook Estimates of Loss Rates Before and After Retrofit . . . . . . . 48

13. Disaggregated Point of Use Energy Consumption for the Low-Energy House With Heat Pump in Baltimore, Md. . . . 51

14. Lifecycle Cost Savings vs. Conservation Investment for a Gas-Heated and Electrically Air-Conditioned House in Kansas City . . . . . . . . . . 54 


\section{Chapter II \\ RESIDENTIAL ENERGY USE \\ AND EFFICIENCY STRATEGIES}

Technologies available now can substantially reduce home energy use with no loss in comfort. This chapter demonstrates that total energy use in new and existing homes can typically be reduced by 30 to 60 percent and that these energy savings produce a large dollar saving over the life of the home. The review focuses on the "thermal envelope" - the insulation, storm windows, and other aspects of the building shell -the equipment used to heat and cool the home, and energy uses of the principal home appliances.

This chapter presents calculations showing how new homes can be built that use substantially less energy than those built just prior to the embargo. It then discusses experiments on existing houses which indicate that similar savings are possible through retrofit measures. Cost analyses are given that show these energy saving packages significantly reduce the cost of owning and operating these homes.

There is little measured data on energy use in a "typical" home. Experiments are difficult to perform because of individual variations in construct ion, equipment, and appliances; moreover, the living and working patterns of the occupants can change energy use by a factor of two.

Most of the data on residential energy use is based on the interpretation of aggregate consumption data. Monthly gas sales are analyzed to determine the weather-dependent portion that is used for heating; information on light bulb sales is combined with the average bulb lifetime to determine the average household use of energy for lighting; and similar determinations are made for other appliances and uses. The average residential use pattern as determined by Dole' after reviewing previous studies and performing additional analysis is shown in figure 6 . This figure shows "primary" energy usage, which accounts for distribution losses for all fuel types and for electric generation losses.

Calculations based on aggregate consumption do not show the interactions that occur between appliance usage and heating and cooling needs, nor do they show the sources of heat loss that greatly influence total energy usage. It is necessary to consider a particular

\footnotetext{
'Stephen H. Dole, "Energy Use and Conservation in the Residential Sector: A Regional Analysis," (RAND Corporation, June 1975),R-1641 -NSF
}

house for these purposes. Since no single experiment documents all of the interactions that occur, they will be illustrated with computer analysis performed by Hittman Associates. $^{2}$

Additional data is based on analysis performed by Oak Ridge National Laboratory (ORNL), and experiments by the National Bureau of Standards (NBS) and Princeton University on real homes.

Figure 6.-Residential Energy Use in the United States

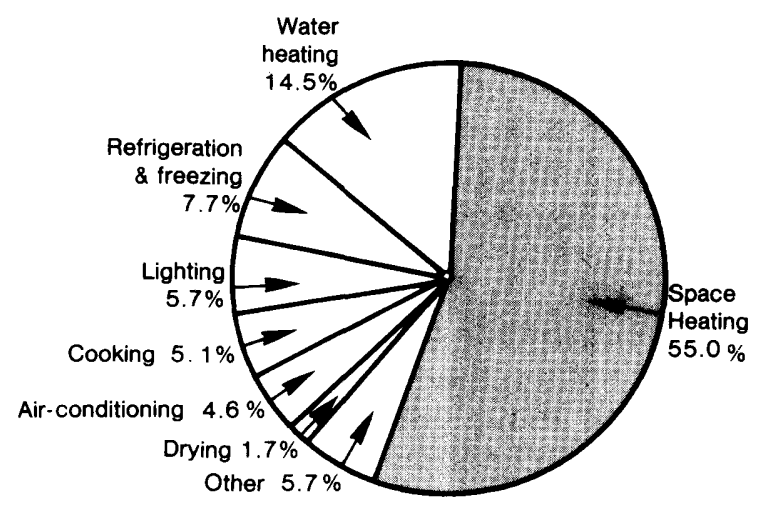

Residential primary energy consumption, 1970-13 quadrillion Btu

SOURCE: Stephen H. Dole, "Energy Use and Conservation in the Residential Sector: a Regional Analysis," RAND Corporation, R-1641-NSF, June 1975, p. vi.

${ }^{2}$ Hittman Associates, Inc. , "Development of Residential Buildings Energy Conservation Research, Development, and Demonstration Strategies, "H IT-681, performed under ERDA Contract No EX-76-C-01-2113, August 1977 
The first calculation is based on a singlestory, three-bedroom, 1,200 $\mathrm{ft}^{2}$ home in Baltimore, Chicago, or Houston. Identified as the "1973 house," it has a full, unheated basement and is constructed of wood frame with brick veneer. Insulation levels and other characteristics are shown in tables 19 through 25 at the end of this chapter. It is sufficiently characteristic of the existing housing stock to illustrate typical energy use patterns.

The energy use patterns of the 1973 house are shown in figure $\mathbf{7}$ for a variety of fuel systems. Figures $7(a)$, (c), and (d) show the energy used at the home and do not include losses in generation or production and transmission of energy. If these are included so that primary energy is shown instead, the percentage distribution is changed dramatically. This is illustrated in figure $7(b)$ for the fuel case corresponding to figure 7 (a).

Heat loss or gain through the building shell results primarily from heat conduction through the walls, windows, ceiling, and floors, and by infiltration through cracks around windows, doors, and other places where construction material is joined. Figures 8 (a) and (b) show, for the typical house in two climates (Chicago and Houston) that heat losses are well distributed across the various parts of the thermal envelope (as are infiltration losses). Thus, major reduction in heat loss will require that more than one part of the shell be improved. Houses will vary widely in this regard. For example, if the house used in figure 8 had been built without any attic insulation, roof losses would have accounted for about $\mathbf{4 0}$ percent of total heat loss rather than the 12 to 14 percent shown. Even though substantial reduction in heat loss would occur if the attic were insulated, there would still be room for substantial improvement in other parts of the shell as well.

Mechanical or electrical heating systems are generally the principal source of heat to make up for these losses to keep a home at a comfortable temperature. Other sources of heat, however, are also significant. Figures 8 (c) and (d) show the distribution of heat gain for the
Chicago and Houston cases. Internal heat gain comes from cooking, lighting, water heating, refrigerator and freezer operation, other appliances, and the occupants themselves. Although none of these internal gains is large, they combine to provide nearly one-fifth of the heat in the colder climates. Heat available from sunlight depends primarily on the window area and orientation and can be considerably Increased if desired.

Everything (except the floor) that contributes to the heating load also contributes to the cooling load. (The floor helps cool the house in summer. ) Internal gains and solar gain from windows that reduce the heating load requirements add to the cooling load, but in very different proportions. As shown in table 3 internal heat gains constitute about half the cooling load There is less infiltration in summer than in winter, because of lower wind speed and smaller indoor-outdoor temperature differences, but humidity removal requirements increase. Thus, infiltration contributes about as much fractionally to the cooling effort as it does to heating. Additions to cooling load from windows are much larger than to heating because their conductive heat gain adds to the solar radiation gain when cooling is considered Other parts of the building shell contribute only 9 to 13 percent of the cooling load in the three simulated locations. The floor, however, does reduce cooling requirements significantly.

Table 4 shows internal gains for the prototypical house in Chicago and Houston. Major sources are the occupants, hot water, cooking, lighting, and the refrigerator/freezer. All other appliances together contribute about as much as any one of the major sources.

\section{The Thermal Envelope}

Current practice in residential energy conservation often begins with attempts to reduce the normal tendency of a house to lose heat through the structure. The rate at which a particular component of a building loses heat 


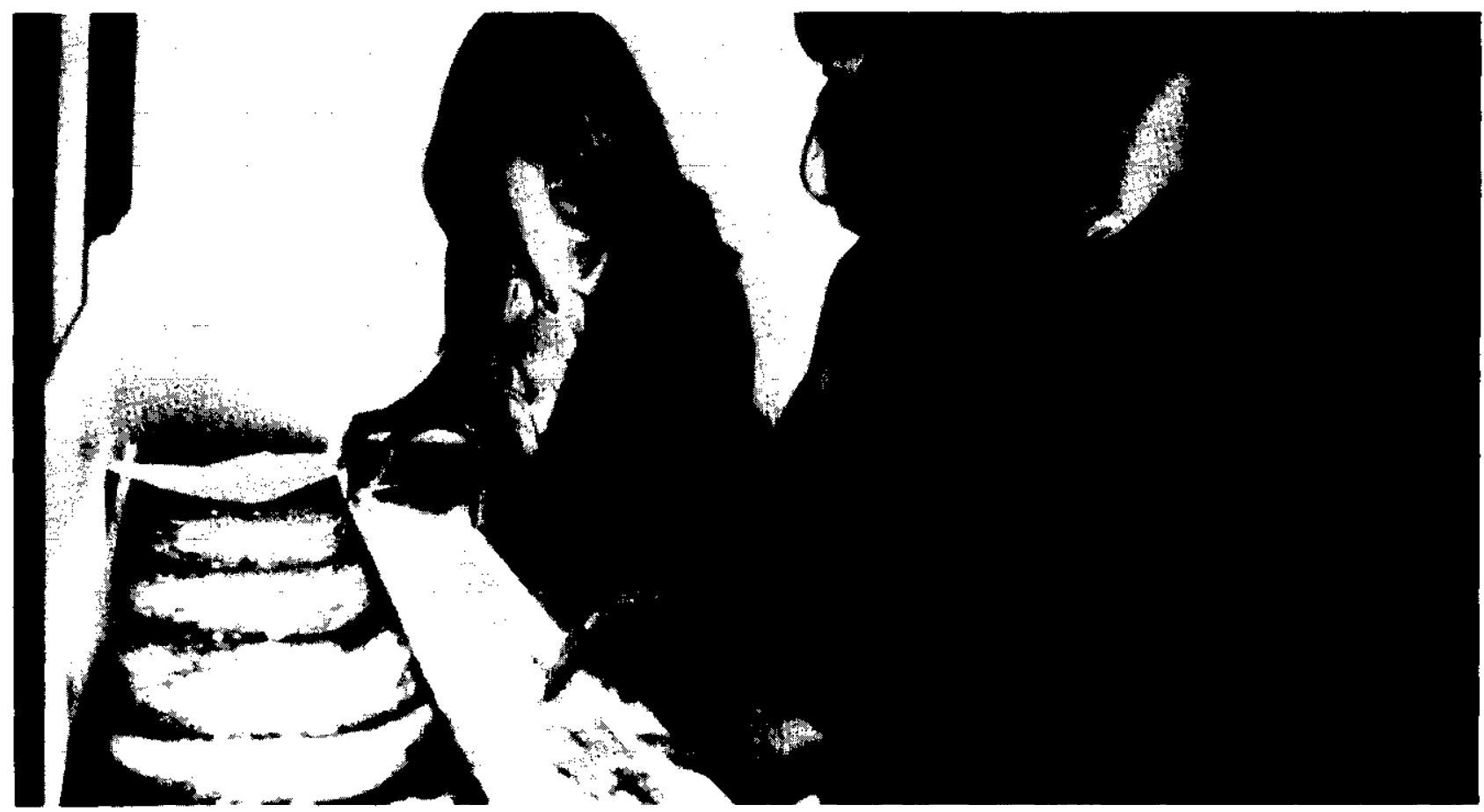

Information dissemination centers were set up in each city. The trained specialist would utilize the conventional daytime photography to locate a particular family's home on the IR pictures; would interpret the prints, pinpointing areas of needed roof insulation, and discussed many effective energy conservation options that would help the consumer. The cost was estimated to be approximately $30 \mathrm{c}$ per home. Thousands of Minnesota homeowners were reached through this program and informed on what they can best do to save energy and dollars.

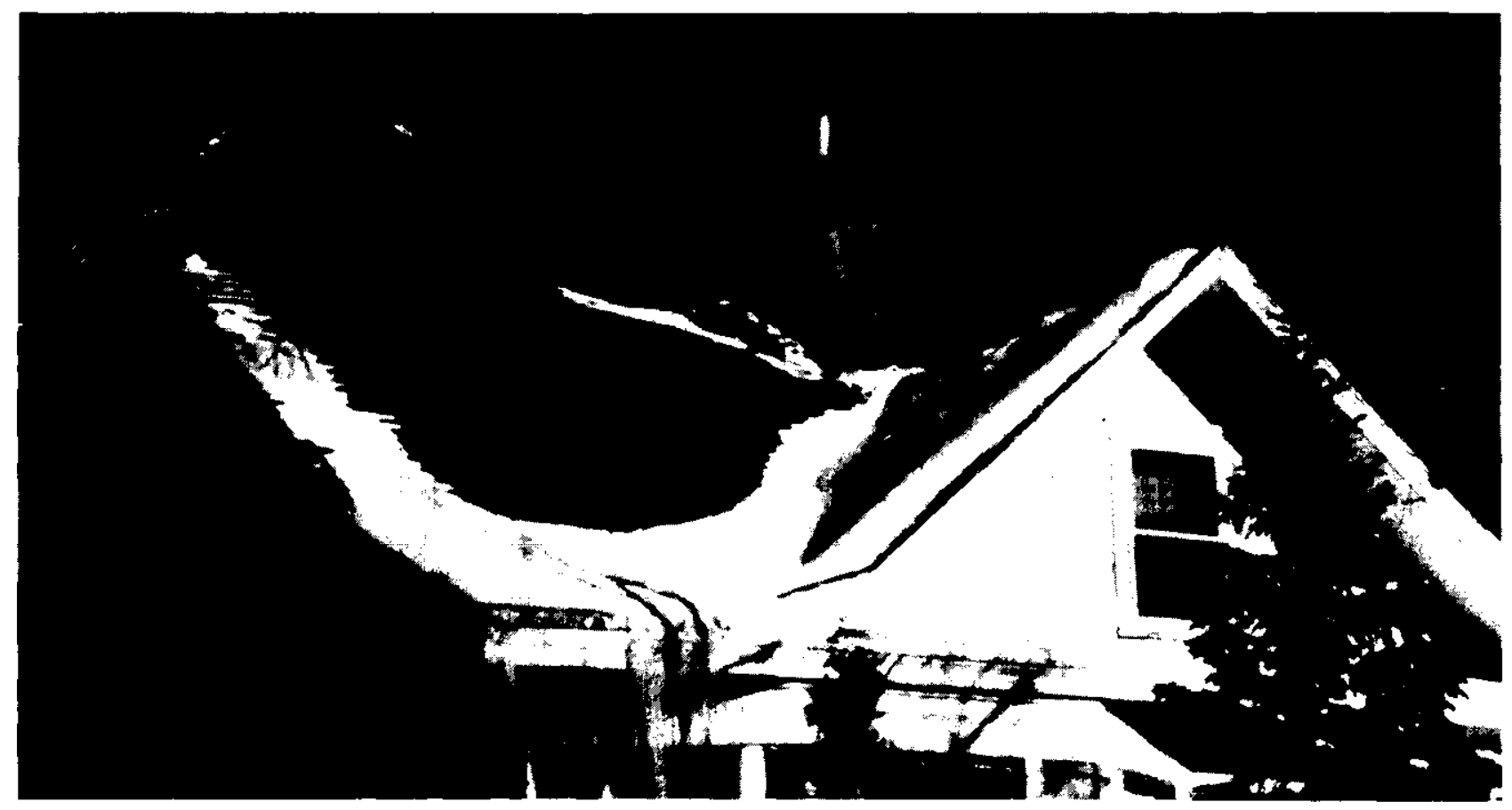

Photo credits: U.S. Department of Energy

Since heat rises, poorly insulated attics usually result in situations like the one shown above 
Figure 7.-Disaggregated Energy Usage in the "Typical 1973" House Located in Baltimore, Md., for Three Different Heating and Hot Water Systems

a Gas hea \& ho wa e

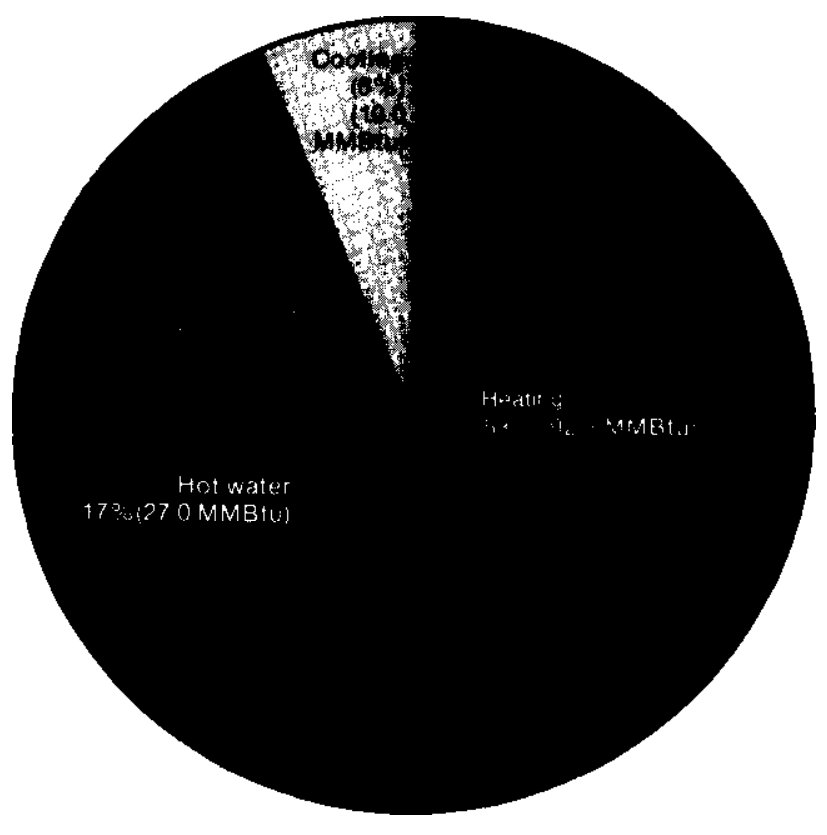

c E ec c u nace \& ho wa e

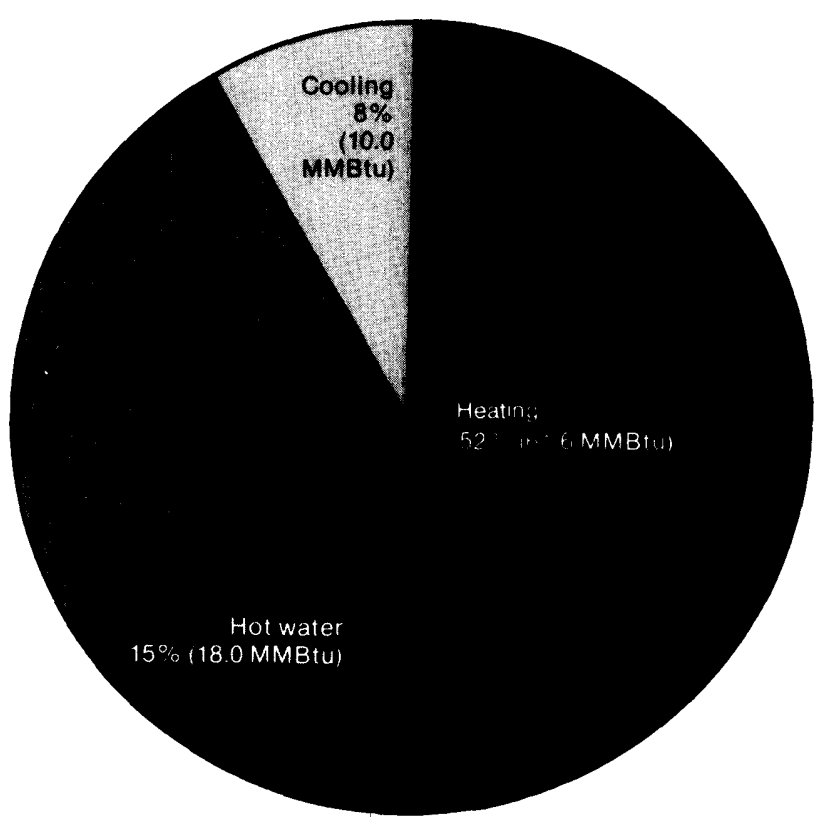

b Gashea \&ho wa e p ma y

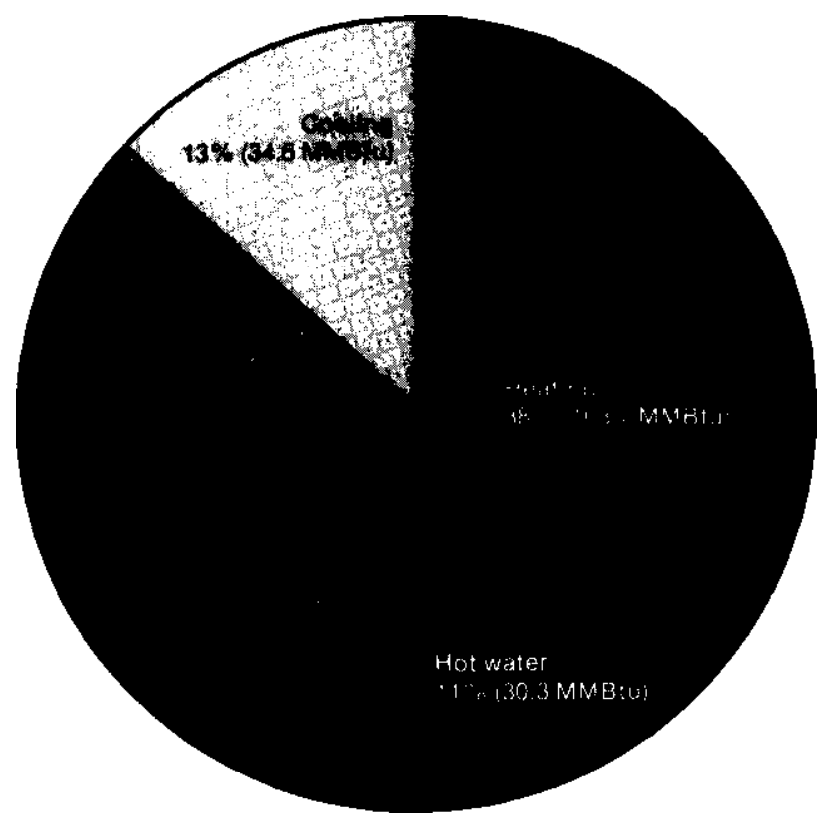

d Hea pump \& e ec cho wa e

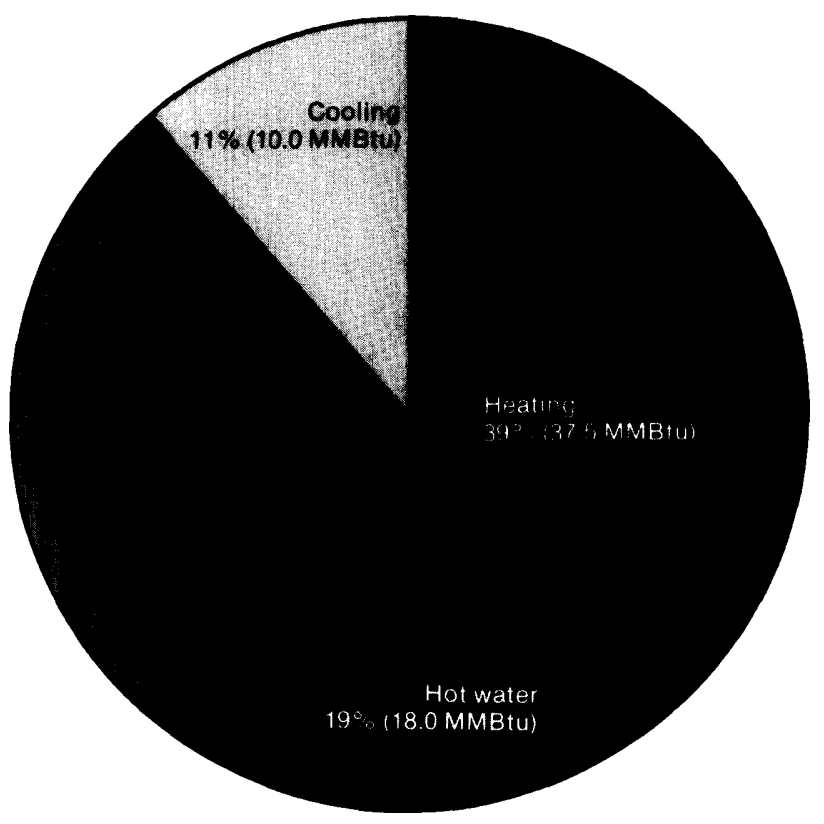


Figure 8.- Heat Losses and Gains for the Typical 1973 House in Chicago and Houston-Heating Season

\section{Heat losses}

(a) Chicago

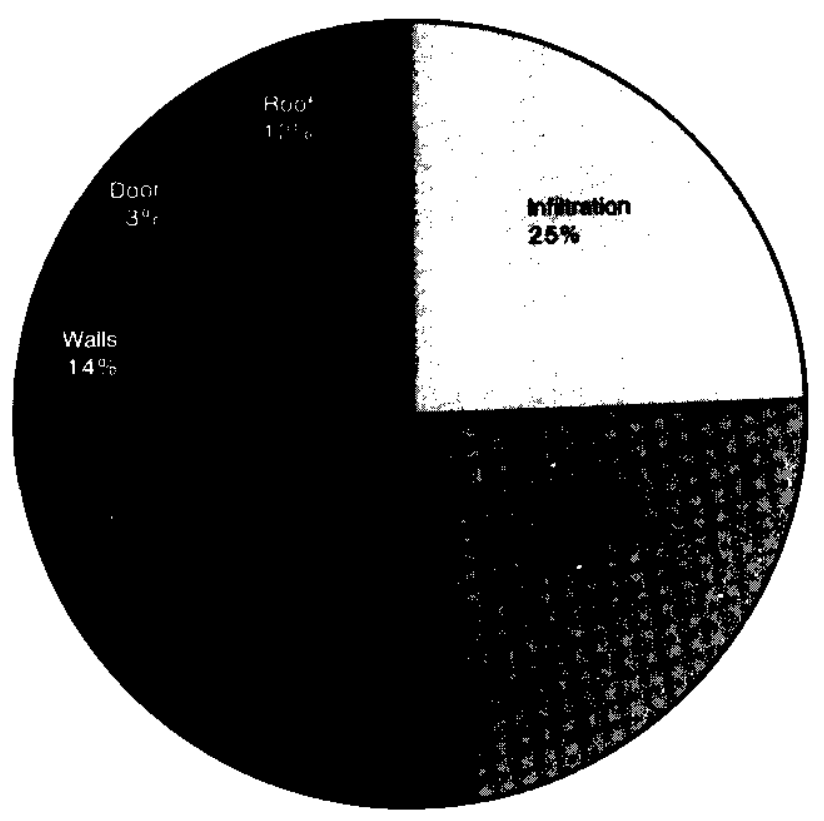

Heat gains

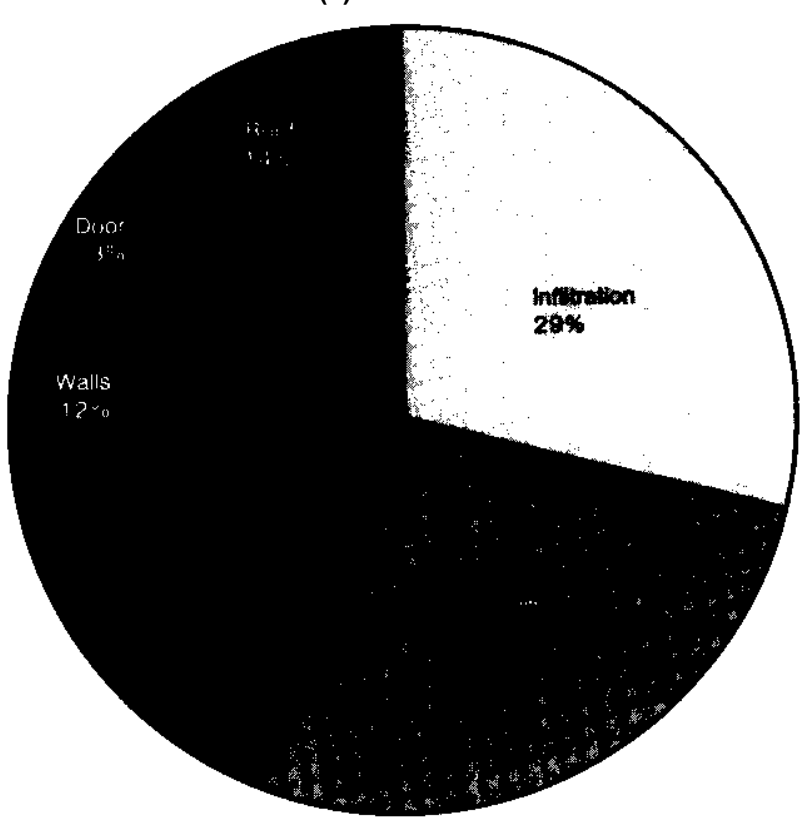

(b) Houston 
Table 3.-Disaggregated Cooling Loads for a Typical 1,200 $\mathrm{ft}^{2}$ "1973" House in Three Different Climates

\begin{tabular}{|c|c|c|c|}
\hline & Baltimore & Chicago & Houston \\
\hline Structural heat gains & percent & percent & percent \\
\hline Roof ................ & 4 & 4 & 5 \\
\hline Doors. . . . . . . . . . . . . & 1 & 1 & 1 \\
\hline Floor. . . . . . . . . &.... & -- & 2 \\
\hline $\begin{array}{l}\text { Walls } \ldots \ldots \ldots \ldots \ldots . . . . . . \\
\text { Window conduction and }\end{array}$ & 4 & 4 & 5 \\
\hline radiation . . . . . . . . . . & 18 & 17 & 19 \\
\hline Infiltration . . . . . . . & $\ldots 22$ & 19 & 24 \\
\hline Total structural gains . . . &. .49 & 45 & 56 \\
\hline Internal heat gains . . . . . & $\ldots 51$ & 55 & 44 \\
\hline Total heat gains . . . . . . . . & 100 & 100 & 100 \\
\hline $\begin{array}{l}\text { Heat losses } \\
\text { Floor } \ldots \ldots \ldots \ldots \ldots \\
\text { Cooling system . . . . . . }\end{array}$ & $\begin{array}{l}\ldots 33 \\
.67\end{array}$ & $\begin{array}{l}40 \\
60\end{array}$ & $\overline{100}$ \\
\hline $\begin{array}{l}\text { Heat removed by cooling } \\
\text { system (MMBtu) . . . . . . . }\end{array}$ & 18.0 & 14.0 & 56.9 \\
\hline
\end{tabular}

Table 4.-Sources and Amounts of Internal Heat Gain During the Cooling Season for Chicago and Houston (1973 House)

\begin{tabular}{cr}
\hline Chicago & Houston \\
\hline $\begin{array}{l}\text { Percent } \\
\text { of total }\end{array}$ & $\begin{array}{r}\text { Percent } \\
\text { of total }\end{array}$
\end{tabular}

MMBtu heat gain MMBtu heat gain

\begin{tabular}{|c|c|c|c|}
\hline Hot water $^{a} \ldots \ldots . . .2 .5$ & 10 & 4.6 & 8 \\
\hline Occupants . . . . . . 2.8 & 12 & 5.2 & 9 \\
\hline Cooking . . . . . . . 1.3 & $\begin{array}{r}5 \\
10\end{array}$ & 2.4 & $\begin{array}{l}4 \\
7\end{array}$ \\
\hline $\begin{array}{lll}\text { Lighting . . . . . } & 2.3 \\
\text { Refrigerator/freezer } & 2.0\end{array}$ & $\begin{array}{r}10 \\
8\end{array}$ & $\begin{array}{l}4.3 \\
3.6\end{array}$ & $\begin{array}{l}7 \\
6\end{array}$ \\
\hline Miscellaneous . . . . 2.3 & 10 & 4.2 & 7 \\
\hline
\end{tabular}

$1 \mathrm{MMBtu}=1.05 \mathrm{GJ}$

aHot water gains were assumed to be jacket losses pIus 25 percent of the heat

added to the water.
b Occupant heat gains were assumed to be 1,020 Btu Per hour for 3.75 months and 7 months respectively based on an average of 3 people in the house.

cThe remaining categories are based on usage levels shown in table 18 for 3.75 and 7 months for Chicago and Houston, respectively.

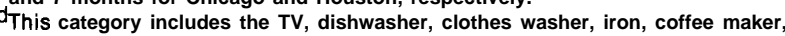
and miscellaneous uses of table 17. The clothes dryer input is neglected since it is vented outdoors.

SOURCE: OTA.

through conduction (and conversely, gains heat in hot weather) is governed by the resistance to heat flow (denoted by the R-value) and the indoor/outdoor temperature difference. Engineers and designers commonly express the R-value of various components in Btu per hour per $\mathrm{ft}^{2}$ per ${ }^{\circ} \mathrm{F}$, which means the number of Btu of heat that would flow through $1 \mathrm{ft}^{2}$ of the component in an hour when a temperature difference of $10 \mathrm{~F}$ is maintained across the component. Different parts of a house have R-values differing by a factor of $\mathbf{1 0}$ or more, as shown in table $5(a)$. Tables $5(b)$ and 5(c) show the R-values of a variety of common building materials and how they are added to obtain the R-value of a specific wall.

Infiltration is described in terms of air changes per hour (ACPH) - and 1 ACPH corresponds to a volume of outside air, equal to the volume of the house, entering in 1 hour. The rate of infiltration is affected by both the wind and the difference between indoor and outdoor temperatures; it increases when the wind rises or the temperature difference increases.

Less is understood about how to measure and describe infiltration than about heat flow. It is clear that specific actions can help lower infiltration such as using good-quality windows and proper caulking and sealing. It is also clear that the general quality of craftsmanship throughout construction is important, and that there may be factors at work that are not yet well understood. Half an air change per hour is considered very tight in this country, although rates below 0.2 have been achieved in buildings in the United States and Sweden. Many U.S. houses have winter air change rates of two or more. Tightening houses must be combined with attention to possible increases in the indoor moisture level and quality of the indoor air (see chapter $\mathrm{X}$ ).

What can be done to reduce the heating and cooling energy use? As an example, the 1973 home has been subjected to a number of changes in the building shell by computer simulation. ${ }^{3}$ Two levels of change have been made, one improves the thermal envelope so it is typical of houses built in 1976 and another uses triple glazing and more insulation - it is described as the "low-energy" house. Each modification was done in the three climate zones represented by Baltimore, Chicago, and Houston.

The 1973 house uses R-1 1 wall insulation and R-1 3 ceiling insulation and has no storm windows or insulating glass. The 1976 house increases ceiling insulation to R-19 and features weather-stripped double-glazing and insulated

\footnotetext{
slbid
} 
Table 5.-R-Value of Typical Building Sections and Materials

a) R-value of typical building sections

\begin{tabular}{|c|c|c|c|}
\hline Building section & R-value & Building section & R-value \\
\hline Exterior frame wail. . . . . . . . . . . . . & .4 .5 & Attic with 6" blown fiberglass $\ldots \ldots \ldots \ldots \ldots$ & 15.0 \\
\hline Exterior wall with $31 / 2$ " fiberglass batts. . . . . . . . . & 13.0 & Attic with 12 " fiberglass batts . . . . . . . . . . . . & 40.0 \\
\hline Exterior wall with $51 / 2$ " blown cellulose. . . . . . . . . & 22.0 & Single-glazed window (excl. frame) . . . . . . . . . . . & .9 \\
\hline \multirow{2}{*}{\multicolumn{2}{|c|}{ 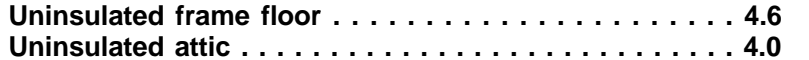 }} & Double-glazed window (excl. frame) . . . . . . . . & 1.6 \\
\hline & & & \\
\hline
\end{tabular}

b) Calculation of the R-value for an exterior wall

\begin{tabular}{|c|c|c|c|}
\hline Construction & $\begin{array}{l}\text { Resist- } \\
\text { ance }\end{array}$ & Construction & $\begin{array}{l}\text { Resist- } \\
\text { ance }\end{array}$ \\
\hline $\begin{array}{l}\text { 1. Outside surface }(15 \mathrm{mph} \text { wind) } \ldots \ldots \ldots \ldots \ldots \ldots \\
\text { 2. Brick veneer }(4 \text { in. face brick) } \ldots \ldots \ldots \ldots \ldots \ldots \\
\text { 3. } 1 / 2 \text { " insulation board sheathing } \ldots \ldots \ldots \ldots \ldots \ldots\end{array}$ & $\begin{array}{l}0.17 \\
0.44 \\
1.32\end{array}$ & $\begin{array}{l}5.1 / 2 " \text { gypsum board } \ldots \ldots \ldots \ldots \ldots \ldots \ldots \ldots \ldots \\
6 . \text { Inside surface }(\text { still air) } \ldots \ldots \ldots \ldots \ldots \ldots\end{array}$ & $\begin{array}{l}0.45 \\
0.68\end{array}$ \\
\hline $\begin{array}{l}\text { A.S1/2" fiberglass batt }- \text { R-1 } 1,2 \times 4 \text { stud }- \text { R-4.53 } \\
\quad \text { (insulation w/studs on } 16 \text { " centers) }{ }^{\star} \ldots \ldots \ldots\end{array}$ & 10.34 & R-value of complete wall. . . . . . . . . . . . & 13.40 \\
\hline
\end{tabular}

'The R-value of the stud/insulation wall section is the weighted average (1 5/8" width, 14 3/8" Insulation width) of the two component R-values.

c) R-values of other common building materials

\begin{tabular}{|c|c|c|c|}
\hline Component & R-value & Component & R-value \\
\hline $1 / 2 "$ Plywood . . . . . . . & 0.62 & $51 \frac{1}{2} "$ fiberglass batt $\ldots \ldots \ldots \ldots \ldots \ldots$ & 19.0 \\
\hline $1 \times 8$ wood siding. . . . & 0.79 & 31/2" blown cellulose. . . . . . . . . . . . . . . . . . & 13.0 \\
\hline 4" common brick .... & 0.80 & 31/2" expanded polystyrene foam . . . . . . . . . . & 17.5 \\
\hline Single-glazed window . . . . . . . . . . . . . & 0.94 & 3/4" still air space (nonreflecting surfaces) . . . . . . . & 1.01 \\
\hline Double-glazed window (1/4" air space). . . . . . . . . . & 1.54 & 4" still air space (nonreflecting surfaces) . . . . . . . . & 1.01 \\
\hline Single-glazed window plus storm window . . . . . . . & 1.85 & & \\
\hline
\end{tabular}

NOTE: The R-values given here are based on the values and methodology given in the ASHRAE Handbook of Fundamentals, Carl MacPhee, cd., American Society of Heating, Refrigerating, and Air-Conditioning Engineers, Inc., New York, N Y., 1972, chs. 20,22.

doors. The low-energy house is very heavily insulated, with $R-38$ ceilings, $R-31$ walls, and $R-30$ floors. It is carefully caulked and weatherstripped to reduce infiltration and has tripleglazing and storm doors. Results of the computer simulation of these houses are shown in table 6. Detailed thermal properties and energy flows are given in tables 19 through 25. (The computer program did not provide hourly simulation; if it had, it is likely that the lowenergy house in Houston would have required a small amount of heating. )

Heat losses in winter are about 16 percent less for the 1976 house than the 1973 house in Chicago and Baltimore, but the calculations show that the heat that must be supplied here by the furnace is reduced by more than 20 percent. This is because the newer house receives a higher proportion of its heat gain from sunlight, appliances, and other internal gains. (Extra glazing slightly reduces heat gain from sunlight, but other internal gains are un- changed. ) Fractional savings for the 1976 house are even larger in Houston, for the same reason. The "1976" summer heat gains are 8 to 10 percent lower than the 1973 house, and cooling system loads are reduced by about 10 to 12 percent. Reduction in the cooling load between the two houses is less than the reduction in heating load, because the thermal improvements do not affect the internal heat gains.

Modifications in the low-energy house cut the heating requirements dramatically. Thermal losses are cut by more than $\mathbf{5 0}$ percent. When this is done, the low-energy Houston house no longer needs a heating system (one burner of an electric range at high heat would keep this house warm in the coldest Houston weather), and the heating requirements for Chicago and Baltimore are reduced by 75 and 82 percent from the 1973 levels. Cooling requirements in Baltimore and Chicago increase, as the heavily insulated floor no longer loses as much heat to the relatively cool ground. In 
Table 6.-Performance Comparison for Three Thermal Envelopes in Three Different Climates

\begin{tabular}{|c|c|c|c|c|c|c|c|c|}
\hline \multirow[b]{2}{*}{ City } & \multicolumn{2}{|c|}{ Winter heat losses } & \multicolumn{2}{|c|}{ Heat system load } & \multicolumn{2}{|c|}{ Summer heat gains } & \multicolumn{2}{|c|}{ Cooling system load } \\
\hline & MMBtu & $\begin{array}{l}\text { Percent of } \\
1973 \text { losses }\end{array}$ & MMBtu & $\begin{array}{c}\text { Percent of } \\
1973 \text { losses }\end{array}$ & MMBtu & $\begin{array}{c}\text { Percent of } \\
1973 \text { losses }\end{array}$ & MMBtu & $\begin{array}{l}\text { Percent of } \\
1973 \text { losses }\end{array}$ \\
\hline \multicolumn{9}{|l|}{ Baltimore } \\
\hline $\begin{array}{l}\text { "1973" house . . . . . . } \\
\text { "1976" house . . . . . . } \\
\text { Low-energy house . . }\end{array}$ & $\begin{array}{l}794 \\
661 \\
287\end{array}$ & $\begin{array}{l}\overline{83} \\
36\end{array}$ & $\begin{array}{r}554 \\
437 \\
99\end{array}$ & $\begin{array}{l}- \\
79 \\
18\end{array}$ & $\begin{array}{l}269 \\
247 \\
219\end{array}$ & $\begin{array}{l}\overline{92} \\
81\end{array}$ & $\begin{array}{l}180 \\
158 \\
204\end{array}$ & $\begin{array}{r}\overline{88} \\
113\end{array}$ \\
\hline \multicolumn{9}{|l|}{ Chicago } \\
\hline $\begin{array}{l}\text { "1973" house } \ldots \ldots \ldots \\
\text { "1976" house . . . . . . } \\
\text { Low-energy house . . }\end{array}$ & $\begin{array}{r}1,057 \\
887 \\
405\end{array}$ & $\begin{array}{l}- \\
84 \\
38\end{array}$ & $\begin{array}{l}811 \\
647 \\
202\end{array}$ & $\begin{array}{l}- \\
80 \\
25\end{array}$ & $\begin{array}{l}236 \\
218 \\
195\end{array}$ & $\begin{array}{l}- \\
93 \\
83\end{array}$ & $\begin{array}{l}140 \\
123 \\
179\end{array}$ & $\begin{array}{r}- \\
88 \\
128\end{array}$ \\
\hline Houston & & & & & & & & \\
\hline $\begin{array}{l}\text { "1973" house } \ldots \ldots \ldots \\
\text { "1976" house } \ldots \ldots \ldots \\
\text { Low-energy house . . . }\end{array}$ & $\begin{array}{r}211 \\
153 \\
-\end{array}$ & $\frac{-}{73}$ & $\begin{array}{r}84 \\
52 \\
0\end{array}$ & $\begin{array}{r}- \\
62 \\
0\end{array}$ & $\begin{array}{l}569 \\
513 \\
434\end{array}$ & $\begin{array}{l}- \\
90 \\
76\end{array}$ & $\begin{array}{l}569 \\
513 \\
434\end{array}$ & $\begin{array}{l}- \\
90 \\
76\end{array}$ \\
\hline
\end{tabular}

1 MMBtu $=1.05$ GJ.

SOURCE: Summarized from tables 19-21.

Houston, however, the cooling load is still lower for the low-energy home, as floor heat losses do not aid cooling in this climate.

A similar analysis was performed by Hutchins and Hirst of ORNL. ${ }^{4}$ This study used the NBS heating and cooling load program to calculate changes in these loads for "typical" new construction of a $1,200 \mathrm{ft}^{2}$ home in 11 cities of differing climates. The results of that analysis are in substantial agreement with those discussed here. Figure 9 shows the heating load reduction for a home in Kansas City, Kans. as more and more improvements are made to the building shell. The cost scale refers to the additional investment needed to install these improvements in a new home. It is a net investment in that it accounts for the added cost of the additional materials (insulation, storm windows, etc. ) as well as the reduced heating equipment cost that occurs because the heating system size is reduced as the heating load decreases. It is important to remember that these costs are for new homes; similar changes for existing homes will be more expensive in some cases (e. g., adding wall insulation).

'Paul F. Hutchins, J r., and Eric Hirst, "Engineering-Economic Analysis of Single-Family Dwelling Thermal Performance" (Oak Ridge National Laboratory, November 1978), ORNL/CON-35.
Figure 9.- Heating Load/Cost RelationshipKansas City

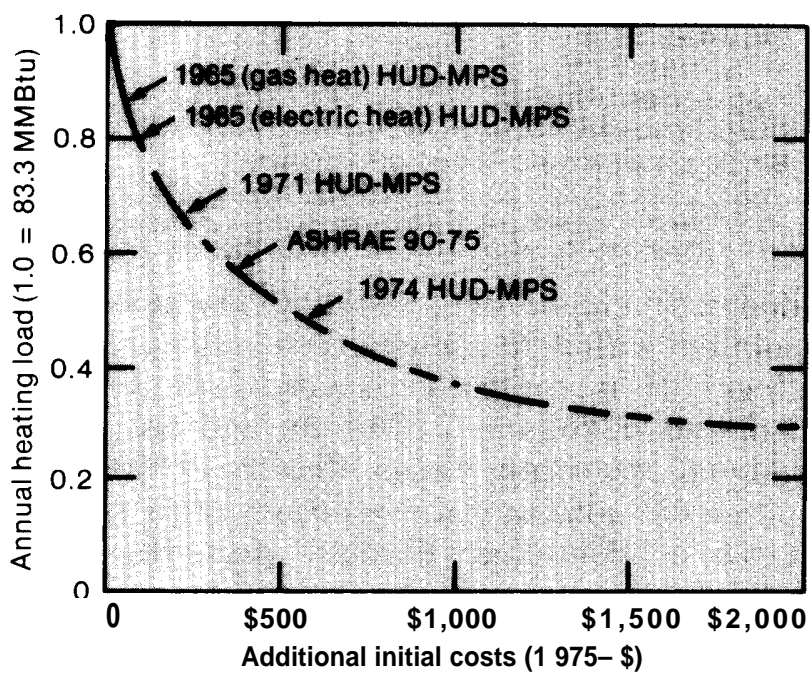

SOURCE Paul F. Hutchins, Jr., and Eric Hirst, "Engineering-Economic Analysis of Single-Family Dwelling Thermal Performance, " Oak Ridge National Laboratory, ORNL/CON-35, November 1978, p. 16.

The Kansas City results show a possible heat load reduction of up to 70 percent with an investment of less than $\$ 2,000$. (The baseline house for the case had no insulation.) These dollar levels compare well with those calculated for the two houses discussed above. In this case it was estimated that the low-energy house would cost about $\$ 3,200$ more than the 1973 house while the 1976 house would be about $\$ 600$ more expensive. I $n$ nearly all cases, 
however, this added cost would be more than recovered in reduced fuel bills over the life of the home.

The results from these two models show that, within the limits of computer simulation, a substantial reduction in heating load is possible from homes built in the early 1970's. When cooling is considered, additional energy is saved in most cases.

\section{Insulation Effectiveness}

What is possible for new homes based on computer simulation and the stated characteristics of materials used to increase the efficiency of the building shell has been shown. A key assumption is that the materials perform at their specifications. For most of the items used in improving the shell -weather-stripping, storm doors, and windows - the assumption is a safe one. With insulation, however, problems, may arise.

Researchers have only recently begun to try determining the actual field effectiveness and durability of insulating materials. (For information on health and safety questions about insulation, see appendix A). Van der Meer ${ }^{5}$ and McGrew $^{6}$ contend that insulation is often less effective than commonly believed, owing to degradation over time, and to the effect of solar heat gain on the net heat loss through a wall or attic over a heating season. It appears from their work that uninsulated south walls or attics, in particular, tend to collect significant amounts of solar heat in the climates of Colorado and New Mexico. The absorbed sunshine can offset a larger fraction of the heat lost through a wall if the entire winter season is considered.

Sunshine striking the roof or walls of a building can significantly change the energy flows. This is the basis for the use of "Solair" temperatures to calculate summer heat gains. However, similar concepts have not received

\footnotetext{
${ }^{5}$ Wybe van der Meer, Jr., "Energy Conservation Housing for New Mexico, " Report No. 76-163, prepared for the New Mexico Energy Resources Board, Nov. 14,1977.

'George Yeagle, Jay McGrew, and John Volkman, "Field Survey of Energy Use in Homes, Denver, Colo." (Applied Science and Engineering, Inc., July 1977).
}

much attention when dealing with winter heat loss. When sunlight strikes a wall or roof, particularly a dark-colored one, it will be heated. If the wind is blowing hard, the solar heat will be removed so rapidly that it will have a very small effect on the surface temperature of the wall and hence on the heat flowing from inside to outside. If the wind is relatively calm, the surface can be heated considerably, and if the outdoor temperatures are mild enough, the flow will be greatly reduced and can even be reversed so that heat is flowing into the house when the outdoor temperature is below the house temperature.

The heat loss through building components and the economic value of insulation are generally calculated from the $R$-values discussed earlier and the winter temperatures as expressed in degree-days. (A measurement of the relative coldness of a location. ) [f the effect of the Sun on a roof or wall as just described is accounted for over the entire winter, the total heat loss can be much smaller than a calculation based only on temperature. This led van der Meer and Bickle to propose the use of an effective R-value (reference discusses an effective U-value, which is the inverse of R-value; Rvalue is used here for consistency with the earlier discussion). If a wall had an R-value of 5 but lost only half as much heat as expected over the course of the winter because of solar effects, it would have an effective R-value of 10.

Van der Meer and Bickle calculated effective R-values for a variety of different types of wall construction for 11 different climatic regions of New Mexico, which ranged from 2,800 to 9,300 degree-days and received different amounts of sunshine. Their results are summarized for three wall types in table 7. Results are shown for north- and south-facing walls and for light and dark colors. (Results for other colors and orientations will be intermediate among those shown.) Clearly color is very important. The effective $R$-value of a light-colored south wall is very close to the lab-

\footnotetext{
${ }^{7}$ Wybe van der Meer, Jr., and Larry W. Bickle, "Effective "U" Factors- A New Method for Determining Average Energy Consumption for Heating Buildings," prepared for the New Mexico Energy Resources Board, Contract Nos. 76-161 and 76-164, Nov. 10, 1977.
} 
Table 7.-Effective R-Values for Different Walls in a Range of New Mexico Climates

\begin{tabular}{|c|c|c|c|c|}
\hline & \multicolumn{4}{|c|}{ Wall orientation } \\
\hline & \multicolumn{2}{|c|}{ North } & \multicolumn{2}{|c|}{ South } \\
\hline & Light & Dark & Light & Dark \\
\hline $\begin{array}{l}\text { Brick veneer wall with } 3 \% \text { " insulation }(R=13.3) \\
\text { Uninsulated frame wall }(R=3.7) \ldots \ldots \ldots \ldots \ldots \\
\text { Brick veneer wall with } 6 \text { " insulation }(R=19.2) \ldots\end{array}$ & $\begin{array}{r}11.6-13.0 \\
3.7-4.0 \\
16.4-18.5\end{array}$ & $\begin{array}{r}14.5-17.2 \\
4.5-5.3 \\
20.8-23.8\end{array}$ & $\begin{array}{r}12.8-14.1 \\
3.9-4.4 \\
17.9-20.0\end{array}$ & $\begin{array}{r}20.8-90.9 \\
6.3-41.7 \\
29.4-111\end{array}$ \\
\hline
\end{tabular}

oratory value for all three walls shown. However, the dark north walls all have an effective R-value slightly higher than the laboratory value. The effective R-values of dark southfacing walls show dramatic increases above the theoretical values. The extremely high effective values for uninsulated walls occur only in the warmer parts of New Mexico.

Several caveats must be applied to the interpretation of this work. Effective R-values in most parts of the country will be closer to the steady state values than for the sunny New Mexico climate. These results consider only the winter heating season, and unless overhangs or other shading measures are employed, increased heat gain in summer could offset much of the benefits of the winter gain.

This is another illustration of the need to make standards responsive to the site. Although increased amounts of insulation almost always reduce the total heat loss of a house, it will not have as large an effect as anticipated in some cases, and hence will be less cost effective than calculated using standard values.

Insulation can also degrade in several ways as it ages. Loose-fill insulation in attics can settle, foam insulation can shrink and crack, and moisture buildup can reduce the effectiveness of different types of insulation. The Minnesota Energy Agency recently measured the properties of retrofitted insulation in 70 homes where the insulation ranged in age from a few months to 18 years (with an average age of $2 \frac{1}{2}$ years). ${ }^{8}$ The R-values of the cellulose and urea-formaldehyde insulation were 4 percent lower on average than expected based on the density of

'Minnesota Energy Agency, "Minnesota Retrofit Insulation In-Site Test Program," HCP/W 2843-01 for U.S. Department of Energy under Contract No. EY76-C-0202843, June 1978. the insulation. The R-values of the mineral fiber (fiberglass and rock wool) insulation varied from 2.35 to $4.25 \mathrm{Btu}^{-1} \mathrm{hr} \mathrm{ft}^{20} \mathrm{~F}$; but the wide variation was due to differences in the material itself rather than to differences in age or thickness. McGrew measured the R-values of insulation installed in several houses and found that while thin layers of insulation had R-values corresponding to their laboratory values, thicker layers fell below their laboratory values. Three inches of rock wool with a lab value of $R-11$ had a measured value of 9.9, and 6 inches of fiberglass with a lab value of R-1 9 had a measured value of 13.4. These are consistent with the general trend of his other field measurements.

Neither of these studies can be regarded as definitive since both sample sizes were small and limited to particular geographic areas. It is also possible that the moisture content and Rvalue will vary throughout the year in a significant manner. More work is needed to establish the long-term performance of different types of insulation in various climates.

A related problem, which seems to have received very little attention, is provision of vapor barriers for insulation retrofits, particularly walls. With the exception of foamed plastics, the insulations used to retrofit wall cavities are degraded by the absorption of water vapor. Exterior walls that were built without insulation seldom include a vapor barrier. This problem is now being investigated. One solution may be the development and use of paints and wallpapers that are impervious

\footnotetext{
'Jay L. McGrew and George P. Yeagle, "Determination of Heat Flow and the Cost Effectiveness of Insulation in Walls and Ceilings of Residential and Commercial Buildings" (Applied Science and Engineering, Inc., October
} 1977) 
to water vapor. While some paints are marketed with vapor barrier properties, most of the work on coatings impervious to water vapor appears to have been done by the paper industry for use in food packaging. Application of this work to products for the housing industry appears desirable.

\section{Heating, Ventilation, and Air-Conditioning Systems}

The efficiency of heating and air-conditioning systems varies widely depending on the quality of the equipment and its installation and maintenance, but the average installation is less efficient than generally realized. This is partially due to the fact that efficiencies listed by the manufacturer are those of the furnace or air-conditioner operating under optimum conditions. These estimates do not include the losses from the duct system that distributes conditioned air to the house. The confusion between potential and actual efficiency is increased by the fact that the performance of different equipment is defined in different terms - the "efficiency" of a furnace, the "coefficient of performance" (COP) for heat pumps, and the "energy efficiency ratio" (EER) for air-conditioners. These different approaches are explained in a note at the end of this chapter. For purposes of comparison, this discussion will emphasize the seasonal system performance, which attempts to measure the actual performance of the system in a real home situation.

\section{Furnaces}

The average seasonal efficiency of oil furnace installations is about 50 percent (including duct losses) as shown in figure 10. However, the Department of Energy (DOE) has determined that the seasonal efficiency of a properly sized and installed new oil furnace of 1975 vintage is 74 percent, "' which suggests that inadequate maintenance, duct losses, and oversizing may be increasing the amount of oil

\footnotetext{
“"Department of Energy, "Final Energy Efficiency Improvement Targets for Water Heaters, Home Heating Equipment (Not Including Furnaces), Kitchen Ranges and Ovens, Clothes Washers, and Furnaces," Federal Register, vol. 43, no. 198 (Oct. 12, 1978), 47118-47127.
}

burned in home heating systems by 50 percent. DOE also determined that it would be possible to achieve an industry-wide productionweighted average seasonal efficiency of 81.4 percent by 1980 . "These improved furnaces would incorporate stack dampers and improved heat exchangers. While the efficiencies cited by DOE do not include duct losses, these losses can be eliminated by placing the furnace and the distribution ducts within the heated space.

The average seasonal efficiency of gas furnace installations is $\mathbf{6 1 . 4}$ percent. This is much closer to the seasonal efficiencies that DOE found for 1975 gas furnaces -61.5 percentthan would be expected. While gas furnaces do not require as much maintenance as oil furnaces and can be made more easily in small sizes, duct losses would be expected to introduce a larger discrepancy than observed. DOE estimates that use of stack dampers, power burners, improved heat exchangers, and the replacement of pilot lights with electric ignition systems can improve the average seasonal efficiency of new furnaces to $\mathbf{7 5 . 0}$ percent.

Steady-state and seasonal efficiencies above 90 percent have been measured for furnaces and boilers employing the "pulse combustion" principle, A gas-fired pulse combustion boiler will be marketed in limited quantities during the latter part of 1979 and an oil-fired unit has been developed by a European manufacturer who has expressed interest in marketing it in the United States. Research on a number of fossil fuel-fired heat pumps is underway and is sufficiently advanced that gas-fired heat pumps with coefficients of performance of $\mathbf{1 . 2}$ to $\mathbf{1 . 5}$ may be on the market in as little as 5 years. These furnaces and heat pumps are discussed in chapter XI.

\section{Furnace Retrofits}

A number of different organizations are conducting tests of the improvements in furnace efficiency that can be achieved by retrofits, including the American Gas Association (AGA),

\footnotetext{
I lbid.

12 lbid.
} 
Figure 10.- Residential Heating Systems

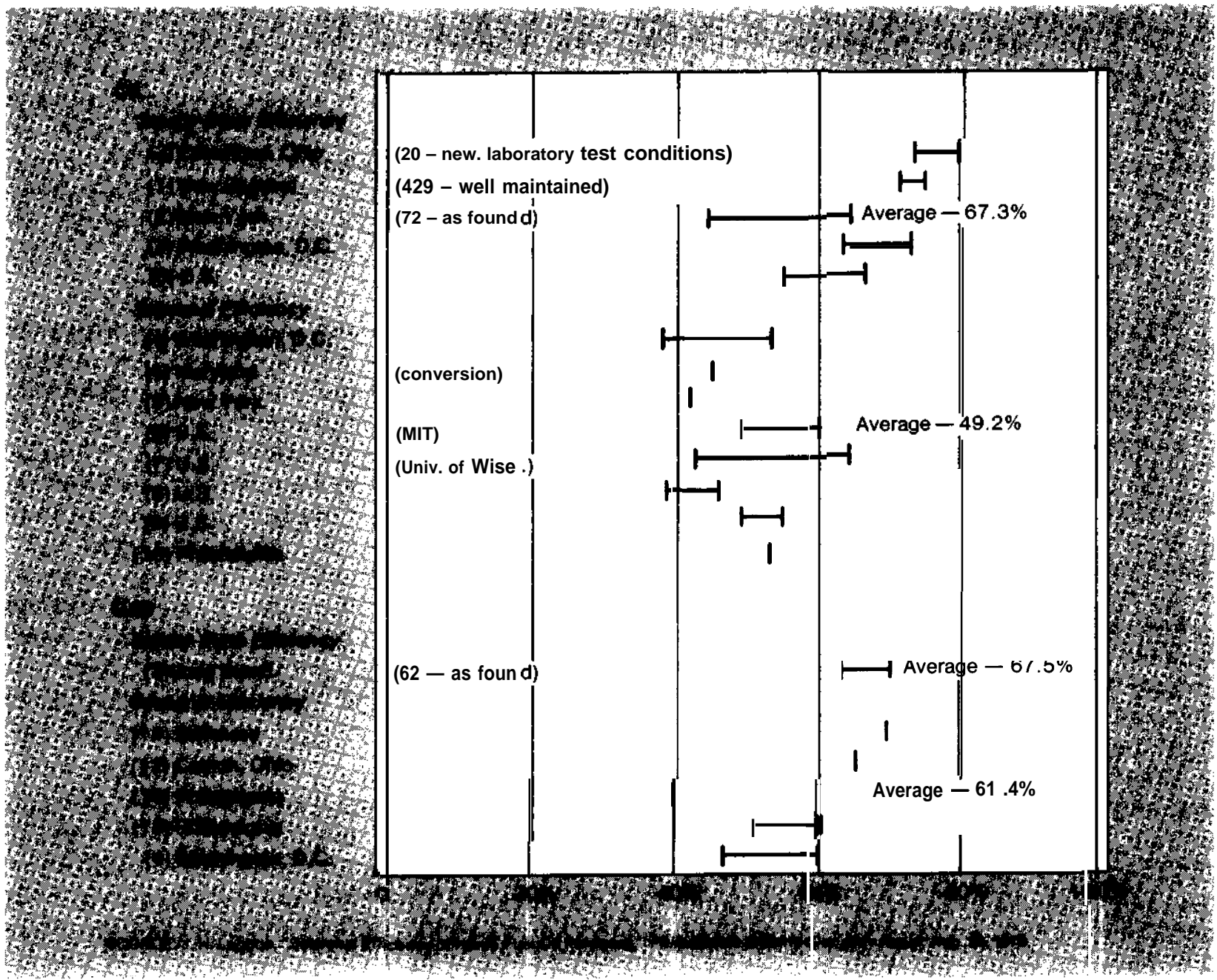

Brook haven National Laboratory (BNL), NBS, and the National Oil Jobbers Council. Only a few results are available now, but these indicate that meaningful savings can be achieved by retrofits.

The AGA program, which is known as the Space Heating System Efficiency improvement Program (SHEIP), involves tests in about 5,000 homes in all parts of the country. Preliminary findings based on the installations that were retrofitted prior to the 1976-77 winter found that adding vent dampers, making the furnace a more appropriate size, and other combinations all saved energy. ${ }^{13}$ The size of

' 'American C-as Association, "The Gas Industry's Space Heating System Efficiency Improvement Program - 1976/77 Heating Season Status Report." the data sample is small and not adequate for generalizations. The savings provided by the adjusted system apparently depended on the initial condition of the heating system, the degree of oversizing, the location, and the vent system design.

Northern States Power Company (Minneapolis, Minn. ) is participating in SHEIP and has monitored 51 homes that had been retrofit prior to the winter of $1977-78 .{ }^{14} \mathrm{~A}$ variety of different retrofits were installed ranging from simply derating the furnace and putting in a vent restrictor to replacement of the furnace. While the sample is too small to draw conclu-

\footnotetext{
${ }^{14}$ Northern States Power Company, "1977-78 Season SHE I P Report “
} 
sions about most of the individual retrofits, it is interesting to note that the retrofits resulted in an average reduction in fuel use (adjusted for weather) of 14. I percent for a cost savings of $\$ 42$. The average installation cost of the retrofits was $\$ 163$, but did not include the markup on the materials, which would have added $\$ 20$ to $\$ 25$ per installation on average. These results were achieved on furnaces that were all in good enough condition that they were expected to last for at least 5 years, so it is likely that their annual efficiencies were slightly higher than average. Thus, it seems probable that seasonal efficiencies of 70 percent can be achieved in gas furnaces that are in condition adequate for retrofitting. These retrofits did not include duct system insulation, which is clearly effective if the exposed ducts are in unconditioned space.

\section{Heat Pumps}

The seasonal performance factor for 39 different heat pump installations was recently measured in a study conducted by Westinghouse." The heat pumps studied were made by several different manufacturers and were installed in 8 different cities. Figure 11 shows the actual performance of the installations ( 0 and $\triangle$ ) measured over two winters and the solid line represents the average measured seasonal performance factor as a function of the heating degree-days. Manufacturers performance specifications were used together with the measured heating demands of each house to calculate the theoretical seasonal performance factor for each installation, and the results were averaged to obtain the broken line shown in the figure. The horizontal dotted line represents the performance of an electric furnace. The figure shows that the average installation achieves 88 percent of the expected electricity savings in a 2,000 degree-day climate, but only 22 percent of the expected savings in an 8,000 degree-day climate.

The study also found that of the 39 installations, only three exceeded the theoretical

\footnotetext{
"Paul J. Blake and William C. Gernert, "Load and Use Characteristics of Electric Heat Pumps in Single-Family Residences," prepared by Westinghouse Electric Corporation for EPRI, EPRI EA-793, Project 432-1 Final Report, vol. 1, June 1978, pp. 2,1-12,13,
}

seasonal performance factor ${ }^{16}$ and four others had a seasonal performance factor at least 90 percent of the theoretical value. Six of the systems that performed near or above specification were located in climates with less than 3,000 heating degree-days, including all three that exceeded the theoretical value. (Duct losses were not included in either measuremerit. )

The deviation between the measured and the theoretical performance did not correlate with the age or size of heat pump model, but there was some indication that the theoretical performance underestimated the defrost requirements. Measurements made by $\mathrm{NBS}^{17}$ on a single heat pump installation found a difference between measured and calculated seasonal performance factors virtually identical to that given by the equations on figure 11 for Washington, D.C. Much of this difference was due to inadequate consideration of defrost requirements in the calculated seasonal performance factor. While it was not possible to place a quantitative measure on installation quality, there seemed to be a qualitative correlation between the experience of the installer and the performance of the installation. ${ }^{18}$ Inadequate duct sizing and improper control settings appeared to degrade the performance. Thus, it seems plausible that a combination of improved installer training and experience and modest technical improvements in heat pumps can result in more installations that achieve the theoretical performance levels.

\section{Air-Conditioners}

The average COP of air-conditioners on the market in 1976 was 2.0 under standard test

\footnotetext{
"Insufficient data was available to calculate the theoretical performance factor for one of these cases, but the measured performance exceeded the theoretical performance of any other installation in that location.

' 'George E. Kelley and John Bean, "Dynamic Performance of a Residential Air-to-Air Heat Pump," National Bureau of Standards, NBS Building Science Series 93, March 1977.

${ }^{18}$ Paul Blake, Westinghouse Electric Corporation, personal communication, December 1978.
} 
Figure 11.-Performance of Installed Heating Systems

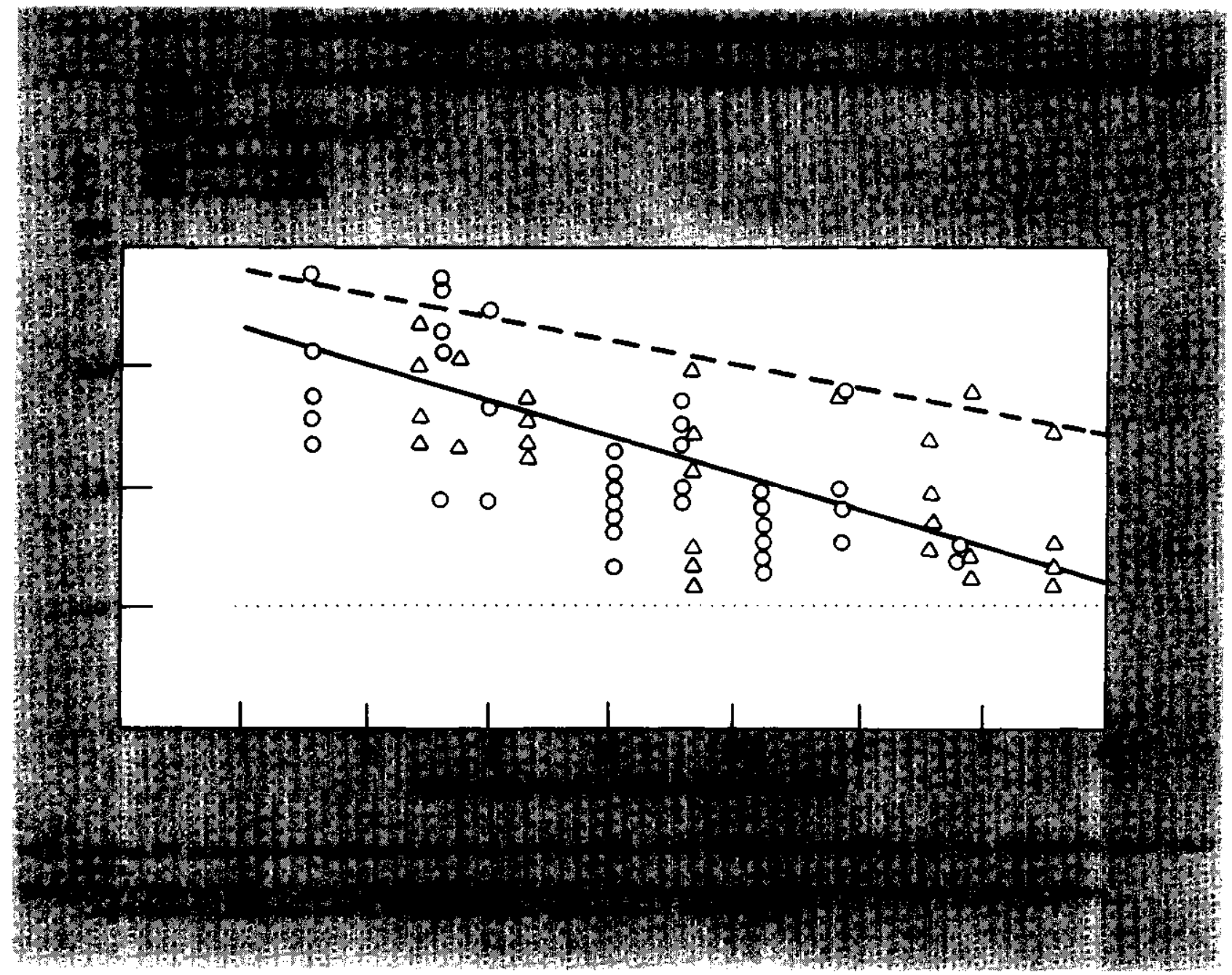

conditions. ${ }^{9}$ However, some units were on the market that had COPS of 2.6. California will not allow the sale of central air-conditioners with a COP below 2.34 after November 3, 1979, and 11 5-volt room air-conditioners must have a COP of at least 2.55 after that date. It is estimated that the cost of increasing the COP of air-conditioners from 2.0 to 26 is about $\$ 10$ per MBtu of hourly cooling capacity. ${ }^{20} \mathrm{To}$ meet these standards and the Federal standards to be developed as directed by the $\mathrm{Na}$ -

\footnotetext{
"George D Hudelson, (Vice President-Engineering, Carrier Corporation), testimony before the California State Energy Resources Conservation and Development Commission, Aug. 10,1976 (Docket No 75; Con-3).

${ }^{20} \mathrm{l}$ bid.
}

tional Energy Act, air-conditioners with larger condensers and evaporators, more efficient compressors, two-speed compressors, multiple compressors, etc., are coming into the market.

\section{Appliance Efficiency and Integrated Appliances}

Although the discussion so far has concentrated on the building shell and heating and cooling equipment, large savings can be achieved in other parts of residential use. I $\mathbf{n}$ figure 7, it was seen that appliances, lighting, and hot water account for 36 percent of the energy for the 1973 house. Therefore the 
potential is great, particularly for retrofit, because of the accessibility of appliances compared to some components of the building shell, such as the walls.

The effect of appliances includes the energy used to operate them and changes in the house's internal heat gains that change the heating and cooling load. As most appliances are used in conditioned space, they exhaust some heat into that space. As with any other change in the house, a careful examination of the system interaction must be made to determine the overall effect of an apparently simple change.

The overall effect of an improved appliance that consumes $100 \mathrm{kWh}$ per year less than the unimproved version is illustrated in table 8. This figure shows the effect of such a change on two electric homes, one with resistance heating and one with a heat pump, in two climates. I n Chicago, where heating is the largest need, the improved appliance reduces total consumption only by half of the appliance savings when resistance heat is in use, but by 79 percent when a heat pump is used. This results from a drop in the appliance contribution to heat gain, due to greater appliance efficiency. I $\mathrm{n}$ Houston, where cooling is more important, total savings are greater than the savings of the appliances alone, since internal heat gain is reduced.

The Department of Energy has published what it has determined to be the maximum feasible improvements, technically and economically, for major appliances by 1980.2' 22 If appliances in the prototypical home were improved according to these estimates, the consumption of the improved appliance would be that shown in table 9. These target figures do not represent final technological limits, but only limits the Department believes can soon be achieved industry-wide. Some appliances now on the market equal or exceed these per-

\footnotetext{
${ }^{21}$ Department of Energy, "Energy Efficiency Improvement Targets for Nine Types of Appliances, "Federal Register, vol. 43, p. 15138 (Apr. 11, 1978).

"Department of Energy, "Energy Efficiency Improvement Targets for Five Types of Appliances," Federal Register, vol. 43, p. 47118 (Oct. 12, 1978),
}

formance levels. A British study has estimated that the average energy use of the appliances shown in table 9 (other than water heaters) could be reduced to 41 percent of present consumption. ${ }^{23}$

As water heating is the second largest use of home energy (after heating) in most locations, a number of methods are under study to reduce this demand below the incremental improvements reflected in table 9. Heat pumps designed to provide hot water are in the works, and proponents expect they may be able to operate with an annual water heating COP of 2 to $3 .{ }^{24}$ Because a heat pump removes heat from the air around it, a typical heat pump water heater will also provide space cooling about equal to that of a typical small window air-conditioner (one-half ton) in summer. Such a heater is expected to cost about $\$ 250$ more than a conventional water heater.

Other approaches to the problem of heating water include use of heat rejected from the condenser of an air-conditioner, refrigerator, or freezer, or the recovery of heat from drain water. Air-conditioner heat pump recovery units now on the market cost $\$ 300$ to $\$ 500$ installed. Estimated hot water production ranges from 1,000 to 4,600 Btu per hour per ton of airconditioning capacity. ${ }^{25}$ The air-conditioner heat recovery unit is identical in concept to the heat pump water heater, but is fitted to existing air-conditioners or heat pumps. A unit installed on a 3-ton air-conditioner in the Baltimore area would reduce the electricity used for heating hot water in a typical home by about 26 percent. ${ }^{26}$

\footnotetext{
"Gerald Leach, et al., A Low Energy Strategy for the United Kingdom (London: Science Reviews, Ltd., 1979), pp. 104,105 .

"R. L. Dunning, "The Time for a Heat Pump Water Heater," proceedings of the conference on Major Home Appliance Technology for Energy Conservation, Purdue University, Feb. 27- Mar. 1,1978 (available from NTIS).

*'David W. Lee, W. Thompson Lawrence, and Robert P. Wilson, "Design, Development, and Demonstration of a Promising Integrated Appliance," Arthur D. Little, Inc., prepared for ERDA under Contract No. EY-76-C-03-1209, September 1977.

"Estimate by the Carrier Corporation for a family using $\mathbf{8 0}$ gal lons of hot water per day.
} 
Table 8.-The Impact of a $100 \mathrm{kWh} /$ Year Reduction in Appliance Energy Usage on Total Energy Consumption

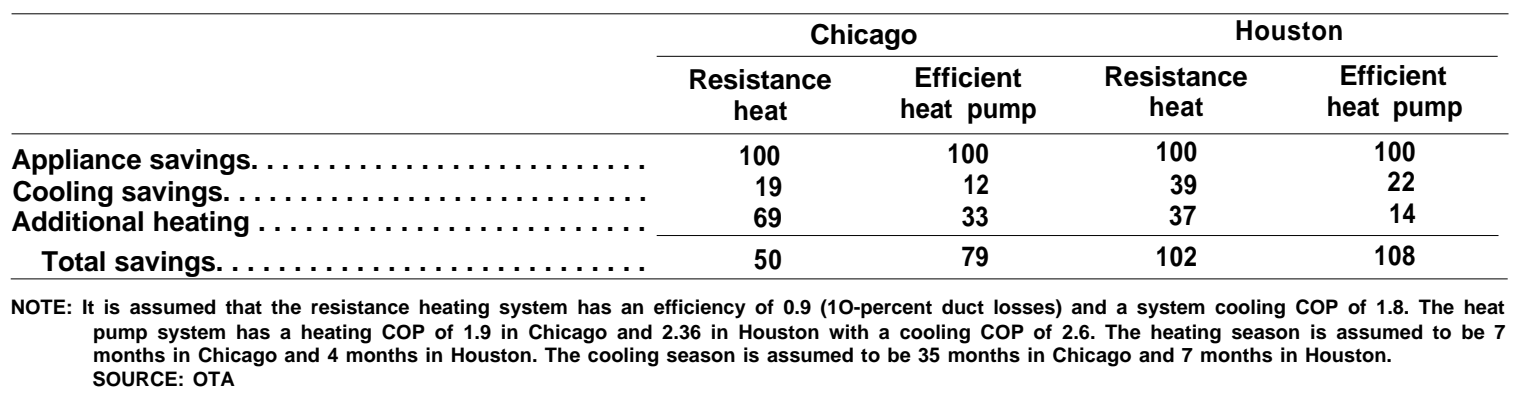

Table 9.-Energy Consumption of Improved Appliances for the Prototypical Home

\begin{tabular}{|c|c|}
\hline Appliance & Energy consumption \\
\hline $\begin{array}{l}\text { Hot water heater }- \text { Gas. } \ldots \ldots \ldots \ldots \ldots \\
\text {-Electric. } \ldots \ldots \ldots \ldots \ldots \\
\text { Cooking range/oven } \ldots \ldots \ldots \ldots \ldots \ldots \\
\text { Clothes dryer. } \ldots \ldots \ldots \ldots \ldots \ldots \ldots \ldots \\
\text { Refrigerator/freezer. } \ldots \ldots \ldots \ldots \ldots \ldots \ldots \\
\text { Dishwasher } \ldots \ldots \ldots \ldots \ldots\end{array}$ & $\begin{array}{r}216 \text { therms } \\
3,703 \mathrm{kWh} \\
1,164 \mathrm{kWh} \\
950 \mathrm{kWh} \\
1,318 \mathrm{kWh} \\
290 \mathrm{kWh}\end{array}$ \\
\hline
\end{tabular}
NOTE: One therm $=29.3 \mathrm{kWh}$ SOURCE: OTA.

As knowledge of home energy use increases and prices of purchased energy rise, the use of appliance heat now wasted should become more common. Some building code provisions may have to be adjusted to encourage these uses.

\section{The ACES System}

The Annual Cycle Energy System (ACES) is an innovative heat pump system that uses substantially less energy than conventional heat pump systems. "A demonstration house incorporating the ACES system has been built near Knoxville, Term., and uses only 30 percent as much energy for heating, cooling, and hot water as an identical control house with an electric furnace, air-conditioner, and hot water heater.

The ACES concept, which was originated by Harry Fischer of ORNL, uses an "ice-maker"

\footnotetext{
${ }^{27}$ A.S.Holmanand V. R. Brantley, "ACES Demonstration: Construction, Startup, and Performance Report," Oak Ridge National Laboratory report ORNL/CON-26, October 1978.
}

heat pump in conjunction with a large ice bin that provides thermal storage. During the winter, the heat pump provides heating and hot water for the house by cooling and freezing other water. The ice is stored in a large insulated bin in the basement and used to cool the house during the next summer. After the heating season, the heat pump is normally operated only to provide domestic hot water. However, if the ice supply is exhausted before the end of the summer, additional ice is made by operating the heat pump at night when offpeak electricity can be used.

The efficiency of the system is higher in all modes of operation than the average efficiency of conventional systems. The "heat source" for the heat pump is always near $320 \mathrm{~F}$ so it is never necessary to provide supplemental resistance heating and the ACES operates with a measured COP of 2.77 as shown in table 10 . When providing hot water, the system has a COP slightly greater than 3 , which is com-

\section{Table 10.-Full-Load Performance of the ACES System}

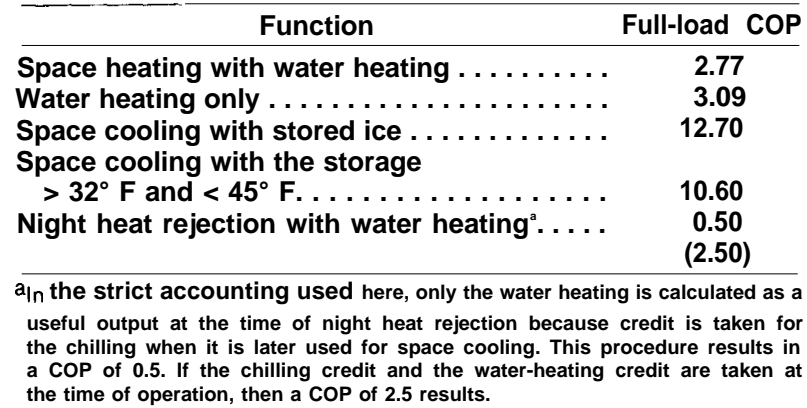




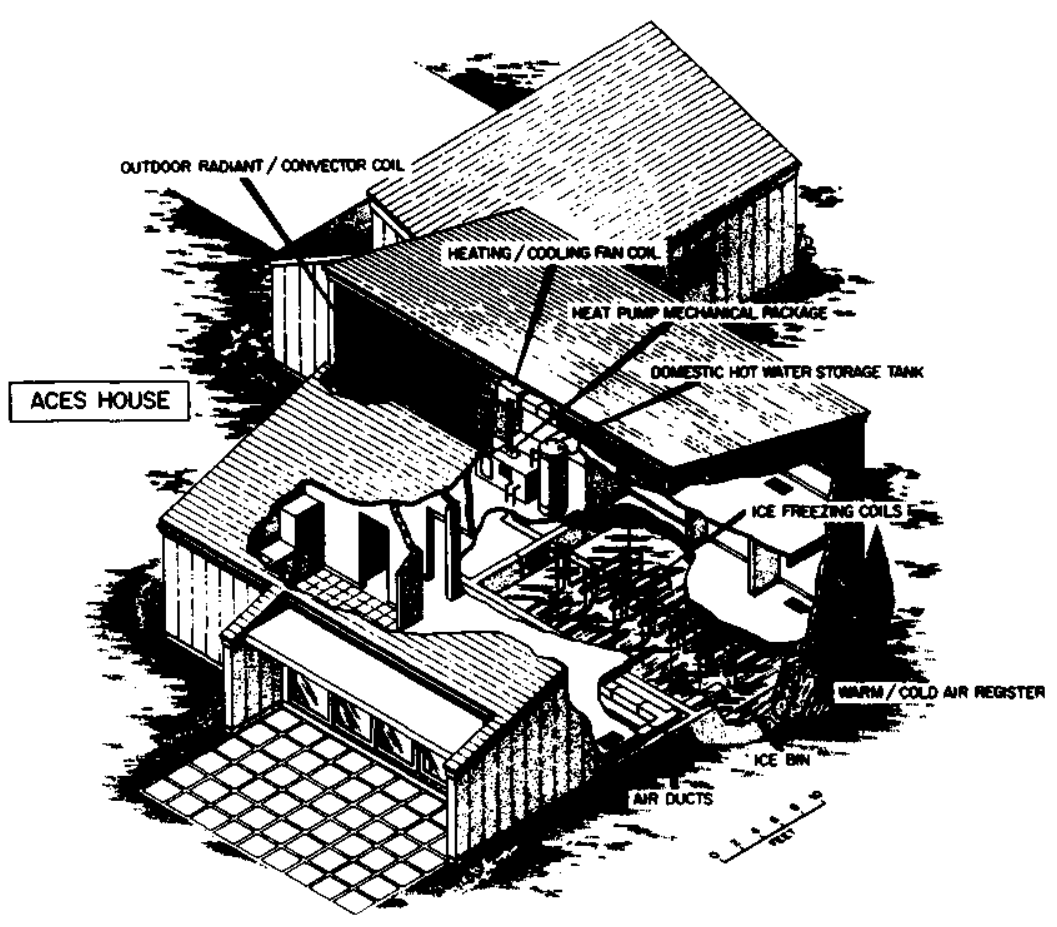

Photo credit: Oak Ridge National Laboratory

The Annual Cycle Energy System (ACES) design is passive energy design utilizing, as its principal component, an insulated tank of water that serves as an energy storage bin

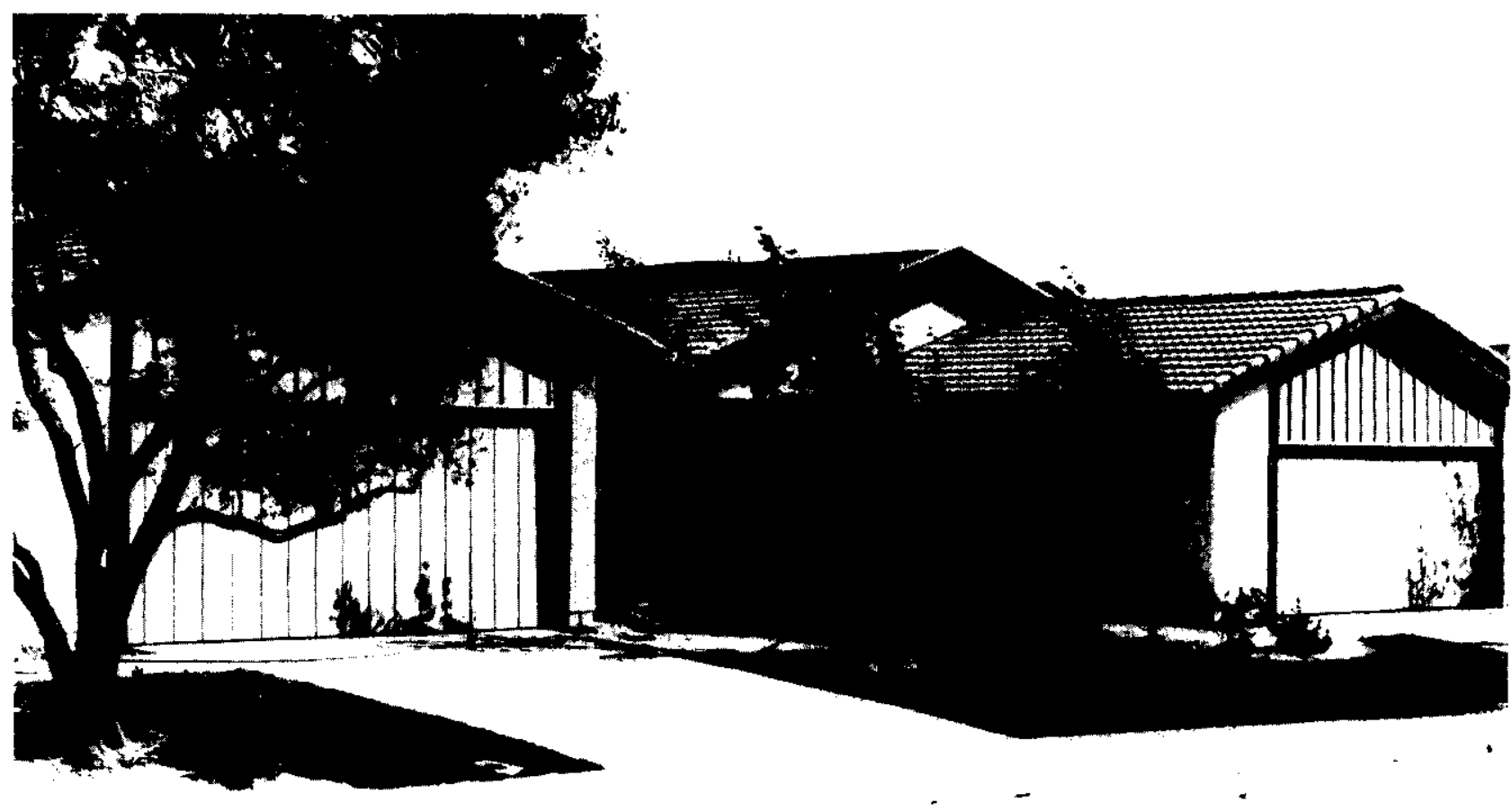


parable to the heat pump water heaters under development and much better than the conventional electric hot water heater COP of 1. The system provides cooling from storage with a COP of more than 10.

The ACES demonstration house is a 2,000$\mathrm{ft}^{2}$, single-family house. It is built next to the control house that has a similar thermal envelope so both houses have nearly identical heating and cooling loads. Both houses are well insulated although not as highly insulated as the "low energy house" of this chapter. The thermal shell improvements reduce the annual heating requirements (20.3 MMBtu) to less than half those of a house insulated according to the Department of Housing and Urban Development (HUD) minimum property standards (43.8 MMBtu) but increase the seasonal cooling requirement from 22.7 to 24.1 MMBtu. The use of natural ventilation for cooling when practical lowers the cooling requirements of the ACES house to 17.1 MMBtu.

The actual space- and water-heating energy requirements for the ACES house are shown in table 11 for a 5-month period during the 1977-78 winter. The ACES system used 62 percent less energy than would have been required if the house had used an electric fur- nace with no duct losses and an electric hot water heater. It used 35 percent less energy than the theoretical requirements of a conventional heat pump/electric hot water heater system. These measurements combined with estimates of the summer cooling requirements show that the ACES system will use only 30 percent of the energy for heating, cooling, and hot water that would be used by the control house with a conventional all-electric system. This is only 21 percent of the energy that would be used for these purposes by this house if constructed to HUD minimum property standards (This is nearly identical to the reduction shown for the low-energy house. )

Table 11.-Actual Space- and Water-Heating Energy Requirements of the ACES Demonstration House ${ }^{a}$

\begin{tabular}{|c|c|c|c|c|}
\hline & $\begin{array}{l}\text { Load } \\
\text { (kWh) }\end{array}$ & $\begin{array}{c}\text { ACES } \\
\text { consumption } \\
(\mathrm{kWh})\end{array}$ & $\begin{array}{l}\text { Elec. furnace, } \\
\text { elec. water } \\
\text { heater } \\
\text { consumption } \\
\text { (kWh) }\end{array}$ & $\begin{array}{l}\text { Heat pump, } \\
\text { elec. water } \\
\text { heater } \\
\text { consumption } \\
\text { (kWh) }\end{array}$ \\
\hline $\begin{array}{l}\text { Heating } \\
\text { Hot water }\end{array}$ & $\begin{array}{r}10,546 \\
2,657\end{array}$ & 4,960 & $\begin{array}{c}10,546 \\
2,657\end{array}$ & $\begin{array}{c}5,021 \\
2,657\end{array}$ \\
\hline Total. . & 13,203 & 4,960 & 13,203 & 7,678 \\
\hline
\end{tabular}

aCovers period from Oct. 31, 1977 through Mar. 26, 1978.

SOURCE: A. S. Holman and V. R. Brantley, "ACES Demonstration: Construction, Startup, and Performance Report," Oak Ridge National Laboratory, Report ORNLCON-26, October 1978, pp. 43,47.

\section{ENERGY SAVINGS IN EXISTING HOMES-EXPERIMENTS}

Although the calculations of heating and cooling loads discussed above were given for new homes, they hold as well for retrofit of existing homes to the extent retrofit is feasible. As the majority of the housing stock between now and the year 2000 is already built, however, it is important to examine the potential for savings by retrofit in more detail. To improve the thermal qualities of the shell, consumers are urged to weatherstrip, caulk, insulate the attic, and add storm windows, often in that order. This is correct for most homes, but resulting savings will vary. Princeton University and NBS have conducted extensive and thoroughly monitored "retrofits" of houses, and Princeton has undertaken an extensive project involving retrofit and monitoring of $\mathbf{3 0}$ townhouses in an area known as Twin Rivers, N.J. The results of this work suggest that large savings are possible on real houses through careful work but that much field work is needed before the full impact of changes is understood.

Thirty townhouses near Princeton, N. J., were improved with different combinations of four options thought to be cost-effective. The houses were constructed with R-11 insulation in the walls and attic, and some units had double glazing. Thus, they were more energy efficient than the average existing house built up to that time. Improvements used by the Princeton researchers were: 1 ) increasing the attic insulation from $R-11$ to $R-30 ; 2$ ) sealing a shaft 
around the furnace flue, which ran from the basement to the attic and released warm air past the attic insulation; 3) weatherstripping windows and doors, caulking where needed, and sealing some openings between the basement and fire walls that separate the houses; and 4) insulating the furnace and its warm air distribution system and adding insulation to the hot water heater. ${ }^{28}$

These retrofits showed winter heating savings averaging about 20 percent for the two attic retrofits and up to 30 percent for the total package. ${ }^{29}{ }^{30}$ Savings varied considerably; this was due to changes in temperature and sunlight combined with changing living patterns of the occupants (al I houses were occupied).

The savings measured are consistent with the reduction in heating required in 600 houses that received attic insulation retrofit through the Washington Natural Gas Company (Seattle) in autumn 1973. These houses indicated an average reduction of gas consumption of 23 percent. ${ }^{31}$

While the Twin Rivers retrofits were conventional, there were some choices the average homeowner would have missed. These choices were important. Plugging the space around the flue and the spaces along the firewall stopped heated air from bypassing the insulation. (Closing openings in the basement also contributed. ) Engineering analysis indicated that up to 35 percent of the heat escaping from the townhouses as built occurred via the insulation bypass-heated air was flowing up and out of the house by direct escape routes! 32

\footnotetext{
${ }^{28}$ David T, Harrje, "Details of the First Round Retrofits at Twin Rivers," Energy and Buildings 1 (1977/78), p. 271.

*'Robert H. Socolow, "The Twin Rivers Program on Energy Conservation in Housing: Highlights and Conclusions," Energy and Buildings 1 (1977/78), p. 207.

${ }^{30}$ Thomas H. Woteki, "The Princeton omnibus Experiment: Some Effects of Retrofits on Space Heating Requirements" (Princeton University Center for Environmental Studies, 1976), Report No. 43, 1976.

${ }^{31}$ Donald C. Navarre, "Profitable Marketing of EnergySaving Services," Utility Ad Views, July/August 1976, p. 26.

"Jan Beyea,Bautam Dutt, and Thomas Woteki, "Critical Significance of Attics and Basements in the Energy Balance of Twin Rivers Townhouses, "Energy and Buildings 1 (1977/78), p. 261.
}

This experience suggests that retrofit will be most effective when based on an energy audit by someone who can identify specific characteristics of the structure, and it further suggests the need for more carefully monitored experiments to identify other common design defects.

Princeton researchers also conducted an intensive retrofit on a single townhouse with careful before-and-after measurements. Attic insulation was increased to R-30 as in the group retrofit, and the hole around the flue and gaps along the firewall were plugged as before. For this experiment, however, the old insulation was lifted and additional holes around pipes and wires entering the attic were plugged. More holes along the partition walls at the attic were filled; the joint between the masonry and the wood at the top of the foundation was sealed, and basement walls were insulated. Careful caulking and weather-stripping was used, and a tracer test to locate small air leaks identified tiny holes. Total labor involved in reducing infiltration was 6 workerdays, and the final infiltration rate was less than 0.4 air changes per hour, even with winds higher than $20 \mathrm{mph}$.

Different treatments were used for windows. Sliding glass doors were improved through adding a storm door. Windows not used for visibility were covered with plastic bubble material placed between two sheets of glass. This type of window covering created an Rvalue of 3.8 , compared with 1.8 for single glass plus a storm window. The living room windows were equipped with insulating shutters, to be closed at night.

Figure 12 shows engineering estimates of the losses through various parts of the house, before and after retrofit. Largest reductions came from lowered infiltration, but it is clear that total reduction in thermal losses was produced by many small adjustments. Thermal losses were reduced to $\mathbf{4 5 . 5}$ percent of their preretrofit value, and annual heating requirements (calculated considering internal heat gain and sunlight) showed the heating system would have only one-third the load of the original system. These impressive numbers are especially significant because the house 


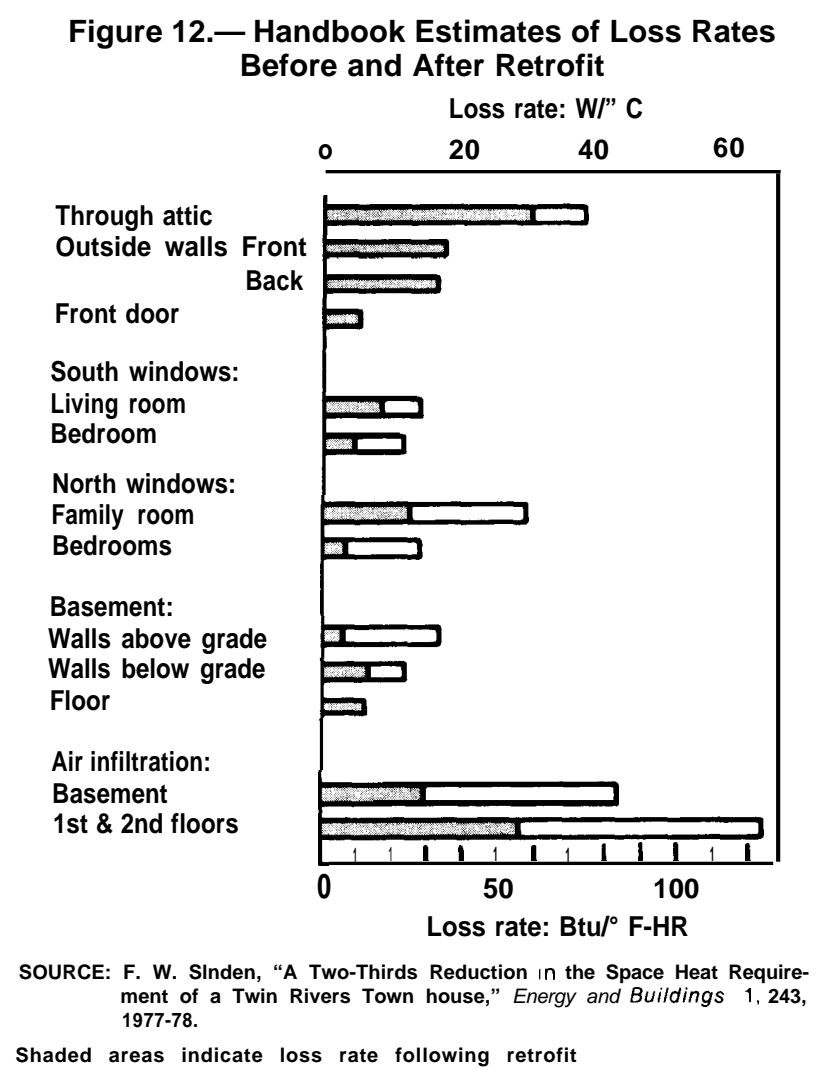

was built in 1972, and thus had lower thermal losses as built than most existing stock.

The materials cost $\$ 425$ and required some 20 worker days for installation. Some items were hand built, so labor requirements were high. Since this work, additional loss mechanisms have been discovered in the party walls of adjoining townhouses, ${ }^{33}$ and correction of these flaws should reduce the heating requirement to 25 percent of the original value.

The National Bureau of Standards monitored the heating requirements of a $2,054 \mathrm{ft}^{2}$ house (commonly called the Bowman house) in the winter of 1973-74, and continued to monitor during a three-stage retrofit the following winter. ${ }^{34} \mathrm{~A}$ single-story wood-frame house with unheated half basement and crawl space, the house was built with R-11 attic in-

"Robert H Socolow, "1 ntroduction," Energy and Buildings 1 (1977/78), p. 203.

${ }^{34} \mathrm{D}$. M Burch and $\mathbf{C} \mathbf{M}$ Hunt, "Retrofitting an Existing Wood-Frame Residence for Energy Conservation - An Experimental Study," NBS Building Science Series 105, July 1978. sulation, and uninsulated walls and floors. Windows were single-glazed except for a living room picture window. The house is surrounded by trees on all sides and has dense shrubbery along the north wall. It showed evidence of above-average craftsmanship in construction. All these factors combined to produce air infiltration rates ranging from one-quarter to two-thirds air change per hour in extreme conditions; this is unusually low.

First retrofits were planned to reduce infiltration - careful caulking, weather-stripping, replacement, or reglazing of window panes. The fireplace damper was repaired, a springloaded damper was installed on the kitchen vent-fan, and the house was painted inside and out. There was no measurable difference in infiltration after the retrofits.

The next step was to install wooden-sash storm windows, which cut the heat loss of the house by 20.3 percent.

Finally, blown cellulose insulation was added to increase the attic to R-21, al I exterior 
walls were insulated (with blown fiberglass, blown cellulose, and urea-formaldehyde foam in different walls), R-11 insulation was placed under the floor over the basement, and R-1 9 over the crawl space. The addition of this insulation cut the heat loss from the house by another 23 percent, but actually resulted in a slight increase in the infiltration rate, a result not fully understood.

Table 12 shows the resulting reduction in thermal losses of the house, based on an assumed occupancy pattern. Thermal losses went down 43.3 percent, and the annual heating system load was reduced by $\mathbf{5 8 . 5}$ percent. Tables 13 and 14 show calculated steady-state heat losses before and after retrofit.

Table 12.-Comparison of Reductions in Heat-Loss Rate to Reductions in Annual Heating Load

\begin{tabular}{|c|c|c|}
\hline Retrofit stage & $\begin{array}{c}\text { Reduction in } \\
\text { heat-loss rate } \\
\%\end{array}$ & $\begin{array}{l}\text { Reductions in } \\
\text { annual heating } \\
\text { load, \%. }\end{array}$ \\
\hline $\begin{array}{l}\text { Preretrofit (and Stage } 1 \\
\text { Stage } 2 \ldots \ldots \ldots \ldots \ldots \ldots \\
\text { Stage } 3 \ldots \ldots \ldots \ldots \ldots \\
\text { Combination } \ldots \ldots \ldots \ldots\end{array}$ & $\begin{array}{ll}\text {. . } & 0 \\
. \quad 20.3 \\
. \quad 23.3 \\
. \quad 43.3\end{array}$ & $\begin{array}{c}0 \\
25.2 \\
33.3 \\
58.5\end{array}$ \\
\hline
\end{tabular}

SOURCE: D. M. Burch and C. M. Hunt, "Retrofitting an Existing Wood-Frame Residence for Energy Conservation-an Experimental Study," NBS Building Science Series 105, July 1978.

Table 13.-Preretrofit Steady-State Winter Heat-Loss Calculations

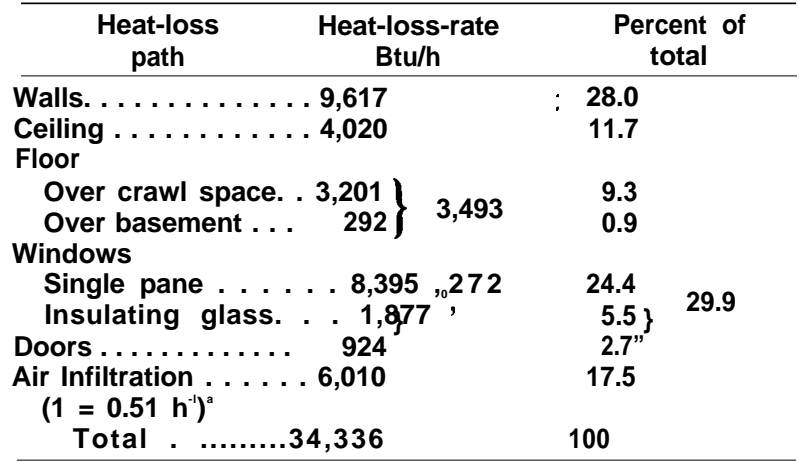

aBased on preretrofit air-infiltration correlation, indoor temperature of $68^{\circ} \mathrm{F}$ and outdoor temperature of 32 " $F$.

SOURCE: D. M. Burch and C. M. Hunt, "Retrofitting an Existing Wood-Frame Residence for Energy Conservation-an Experimental Study," NBS Building Science Series 105, July 1978.
Table 14.-Postretrofit Steady. State Winter Heat-Loss Calculations

\begin{tabular}{|c|c|c|}
\hline $\begin{array}{l}\text { Heat-loss } \\
\text { path }\end{array}$ & $\begin{array}{l}\text { Heat-loss-rate } \\
\text { Btu/h }\end{array}$ & $\begin{array}{l}\text { Percent of } \\
\text { total }\end{array}$ \\
\hline \multicolumn{3}{|l|}{ Walls } \\
\hline Cellulose. . & 2,845 & \\
\hline Glass fiber ........... & \begin{tabular}{l|l}
210 & 3,284
\end{tabular} & 15.6 \\
\hline Ceiling. . . . . . . . . & 2,057 & 9.8 \\
\hline Floor & & \\
\hline $\begin{array}{l}\text { Crawl space } \ldots \ldots \ldots \ldots \\
\text { Basement } \ldots \ldots \ldots \ldots\end{array}$ & $\left.\begin{array}{l}844 \\
233\end{array}\right\} 1,077$ & $\begin{array}{l}4.0 \\
1.1\end{array}$ \\
\hline Windows & & \\
\hline $\begin{array}{l}\text { Double pane ..... } \\
\text { Insulating glass .. }\end{array}$ & $\left.\begin{array}{l}4,115 \\
1,877\end{array}\right\} 5,992$ & 28.5 \\
\hline Doors............ & 924 & 4.4 \\
\hline $\begin{array}{l}\text { Air Infiltration............ } \\
\quad\left(1=0.51 \mathrm{~h}^{-1}\right)^{\mathrm{a}}\end{array}$ & 7,659 & 36.5 \\
\hline Total $\ldots \ldots \ldots \ldots$ & 20,993 & 100 \\
\hline
\end{tabular}

The summer cooling load was slightly increased. Insulation added to the walls and attic reduced heat gain and a polyethylene sheet placed in the crawl space reduced the moisture entering the house, but these reductions were offset by the reduction in cooling resulting from the passage of air through the floor to the basement space.

The experiments at NBS and Princeton suggest possible heating savings of at least 50 percent through straightforward improvements, even in well-constructed houses. They also show that these levels will be reached only through careful examination of the structure, and that our general knowledge of the dynamics of retrofit is not very sophisticated. Additional careful monitoring of actual houses is needed. Such data will help us to obtain better values for public and private investments. 


\section{INTEGRATING IMPROVED THERMAL ENVELOPE, APPLIANCES, AND HEATING AND COOLING EQUIPMENT}

The overall reduction in household energy use is not determined solely by the thermal envelope improvements; it is also influenced by the type and efficiency of heating, cooling, and water heating equipment used as well as the other appliances. This can be seen in table 15 , which shows the total primary energy consumption for five different sets of equipment in the three different simulation houses discussed earlier.

The equipment packages assumed range in performance from that typical of many existing installations to systems with above average but still below many existing commercial facilities. Gas and electric heating equipment is used to illustrate around the country. Price, availability or other considerations lead to the choice of oil, wood, or solar in many new homes.

The effect of the thermal envelope or equipment improvements is rather similar in Chicago and Baltimore. The extra attic insulation, storm windows, and insulated doors of the 1976 house reduce consumption by 12 to 14 percent. Replacing the electric furnace with a heat pump cuts consumption to 72 percent of the baseline 1973 performance. The lowenergy, all-electric house starts with a well-insulated and tight thermal shell, uses a heat pump installed to meet predicted performance, and improved appliances. The only equipment not now commercially available in residential sizes is the heat pump providing the hot water. This house uses 36 to 39 percent of the energy of the 1973 house. The low-energy gas-heated house is comparably equipped, except that it uses an improved furnace, air-conditioner, and hot water heater as shown in table 16. It uses about 55 percent of the energy of the baseline gas-heated house. The reduction is smaller than for the all-electric house, as heating represented a much larger fraction of the primary energy consumption in the baseline all-electric house than in the gasheated house.

In Houston, the qualitative changes observed are similar, but the absolute and fractional reductions observed are generally considerably smaller since heating and cooling are initially a smaller fraction of the total consumption. For the 1976 house, the heating load is already small enough that the heat pump cuts only 3 percent from total consumption. It

Table 15.-Primary Energy Consumption for Different House/Equipment Combinations (in MMBtu)

\begin{tabular}{|c|c|c|c|c|c|c|}
\hline & \multicolumn{2}{|c|}{ Chicago } & \multicolumn{2}{|c|}{ Bait i more } & \multicolumn{2}{|c|}{ Houston } \\
\hline & Consumption & $\begin{array}{l}\text { Percent of } \\
1973 \text { use }\end{array}$ & Consumption & $\begin{array}{l}\text { Percent of } \\
1973 \text { use }\end{array}$ & Consumption & $\begin{array}{l}\text { Percent of } \\
1973 \text { use }\end{array}$ \\
\hline \multicolumn{7}{|l|}{$\begin{array}{l}\text { All-electric houses } \\
\text { "1973" house with }\end{array}$} \\
\hline $\begin{array}{l}\text { electric furnace. } \ldots \ldots \ldots \\
\text { "1976" house with }\end{array}$ & 491 & 100 & 400 & 100 & 294 & 100 \\
\hline $\begin{array}{l}\text { electric furnace. } \ldots \ldots \ldots \\
\text { "1976" house with }\end{array}$ & 424 & 86 & 351 & 88 & 271 & 92 \\
\hline $\begin{array}{l}\text { heat pump } \ldots \ldots \ldots \ldots \ldots \\
\text { Low-energy house }\end{array}$ & 353 & 72 & 286 & 72 & 261 & 89 \\
\hline with heat pump. . . . . . . & 176 & 36 & 154 & 39 & 161 & 55 \\
\hline \multicolumn{7}{|l|}{ Gas-heated houses } \\
\hline "1973" house $\ldots \ldots \ldots \ldots$ & 311 & 100 & 271 & 100 & 252 & 100 \\
\hline "1976" house $\ldots \ldots$. . . . . . & 277 & 89 & 244 & 90 & 240 & 95 \\
\hline Low-energy house . . . . . . . . & 168 & 54 & 150 & 55 & 160 & 63 \\
\hline
\end{tabular}


Table 16.-Equipment Used in Prototypical Baltimore Houses

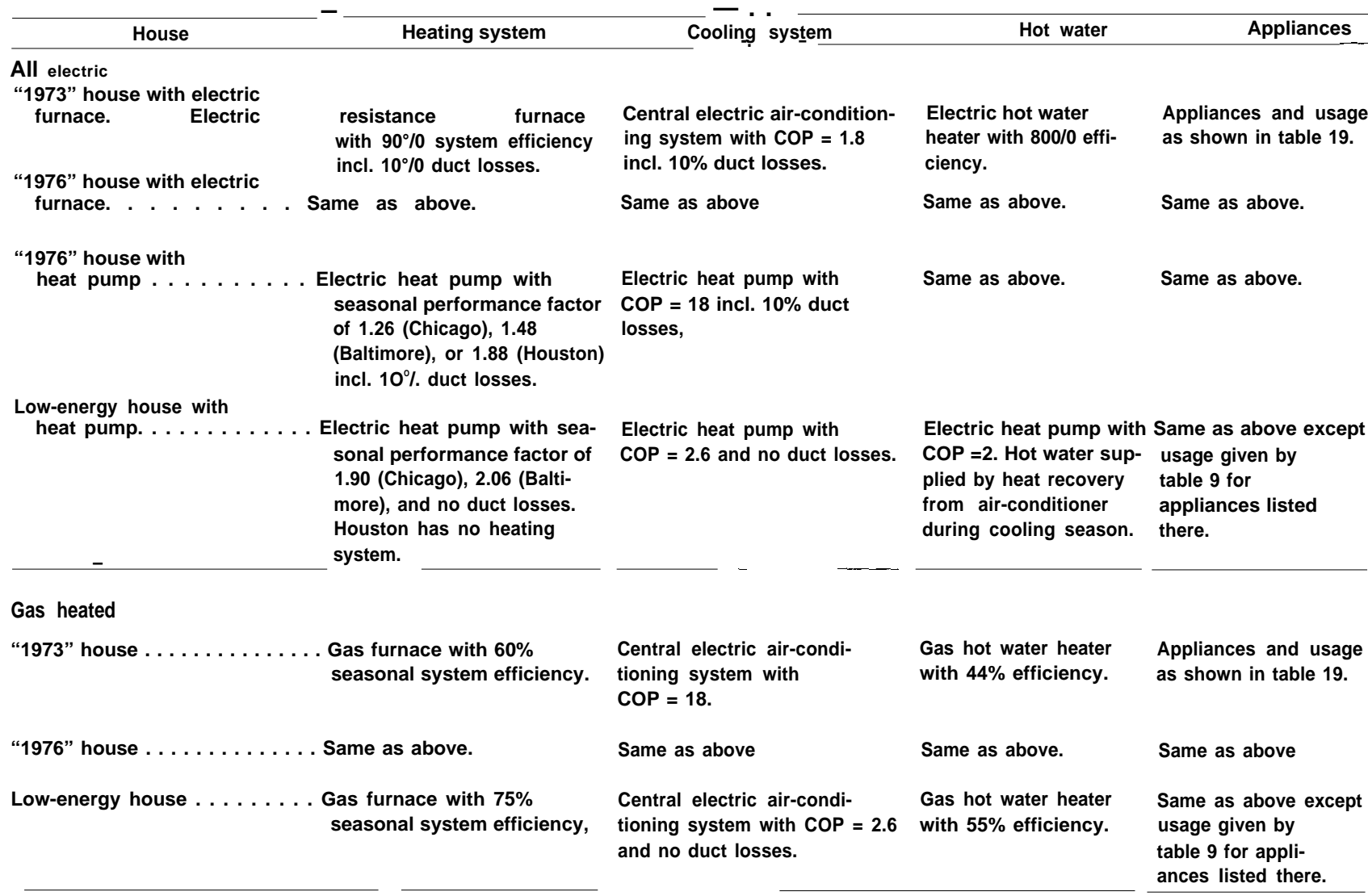

is also interesting to note that in all three cities, the primary energy requirement for the gas-heated low-energy house is almost the same as that of the one with the heat pump.

The changes that have been incorporated in the low-energy house vastly alter the fraction of total consumption that goes to each end use. Figure 13 shows that appliances and lighting now use 61 percent of the total (in Baltimore) while they used only 25 percent of the total for the 1973 house. Appliance use has been reduced slightly, but the total for other uses has been reduced by 80 percent. The disaggregate use for each house is shown in tables 23, 24, and 25.

Part of the reductions shown in table 15 are due to the use of improved heating and cooling equipment. The low-energy gas-heated house uses a furnace with a seasonal efficiency of 75 percent while the 1976 house has an efficiency of only 60 percent. The improved furnace is equivalent to thermal envelope im-
Figure 13.-Disaggregated Point, of Use Energy Consumption for the Low-Energy House With Heat Pump in Baltimore, Md.

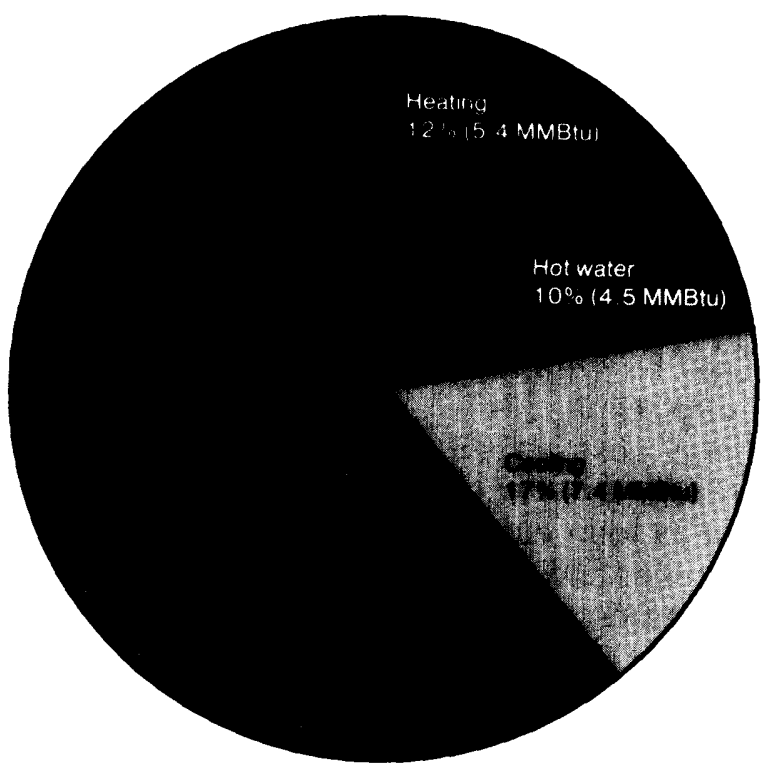

1 MMBtu = 105 gigajoule (GJ) Source Based on tables 19-25 
provements that reduce the heating load by 20 percent, which points out that the retrofit of equipment needs to be considered for existing housing. It may pay to consider an improved furnace before retrofitting wall insulation. Each case must be decided separately, but where insulation already exists in accessible places (attic, storm windows) the heating system offers considerable potential.

A number of additional steps- not considered in the computer simulation - could be taken to reduce consumption even further.
Cooling requirements could be reduced by using outside air whenever temperatures and humidity are low enough. South-facing windows could easily be increased to reduce the heating requirements and it might be possible to reduce the hot water requirements by lowering the water temperature or using water-conserving fixtures. Appliance usage could clearly be cut because no fluorescent lighting is used, and the "efficient" appliances used represent only the industry-weighted average performance, which can be achieved by 1980 .

\section{LIFECYCLE COSTING}

Dramatic savings in energy consumption have been shown to be readily achievable through existing technology. However, most consumers are more interested in saving money than saving energy. Comparison of two alternative purchases - buying additional equipment now and making smaller operating payments versus paying less now but assuming larger operating cost- is always difficult. Few homeowners resort to sophisticated financial analysis, but they may consider the "payback" time required for operating savings to return the initial capital investment. This figure is frequently calculated without considering future inflation in the operating costs- and hence in operating savings - or interest on the money invested.

A more sophisticated approach involves "lifecycle costing," which can be useful for policy purposes even if individual homeowners do not use it. Lifecycle costing, as used in this section, combines the initial capital investment with future fuel and operating expenditures by computing the present value of all future expenditures. The levelized monthly energy cost is then computed as the constant monthly payment that would amortize over 30 years a loan equal to the sum of the initial investment and the present value of al I future expenditures. The methodology and assumptions used are described in detail in volume 11, chapter I of the OTA solar study .35 The "inter-

\footnotetext{
${ }^{35}$ Application of Solar Technology to Today's Energy Needs (Washington, D. C.: U.S. Congress, Office of Technology Assessment, September 1978), vol. 11.
}

est rate" assumes that three-quarters of the investment is financed with a 9-percent mortgage and that the homeowner will receive a 10percent after tax return on the downpayment. It also considers payments for property taxes and insurance and the deductions from State and Federal taxes for interest payments. Future operating expenses include fuel costs, equipment replacement, and routine equipment operating and maintenance costs, all of which assume that inflation occurs at a rate of 5.5 percent. The present value of these expenses is calculated using a discount rate of 10 percent. It is generally agreed that future energy costs will not be lower than now (in constant dollars), but beyond that projections differ as a result of the different actions possible by the Government, foreign producers, and consumers. This study calculates levelized monthly costs for three different energy cost assumptions: 1) no increase in constant dollar prices; 2) oil and electricity prices increase by about 40 percent, while gas prices double (in constant dollars) by the year 2000 as projected by a Brook haven National Laboratory (BNL) study; and 3) a high projection where prices approximately triple by the year 2000 (see figure 4, chapter I). The detailed assumptions about the energy costs are given in volume 11, chapter I I of the OTA solar study above.

The levelized monthly costs for each of the houses described in table 15 are presented in tables 17 and 18 for each of the energy price increase trajectories described above. Two different starting prices are assumed, correspond- 
Table 17.-Levelized Monthly Energy Cost in Dollars for Energy Price Ranges Shown (All electric houses)

\begin{tabular}{|c|c|c|c|c|c|c|c|}
\hline \multirow[b]{2}{*}{ All-electric houses } & \multirow{2}{*}{$\begin{array}{l}\text { Primary energy } \\
\text { consumption } \\
\text { (MMBtu) }\end{array}$} & \multirow{2}{*}{$\begin{array}{ll} & \\
\text { Gas: } & 1.08 \\
\text { Electricity: } & 2.5 \\
\end{array}$} & \multicolumn{4}{|c|}{ Price range $1976-2000$ in 1976 dollars $^{b}$} & \multirow[b]{2}{*}{$\begin{array}{l}3.22-10.60 \\
4.4-14.4\end{array}$} \\
\hline & & & $\begin{array}{l}1.08-2.40 \\
2.5-3.6\end{array}$ & $\begin{array}{l}1.08-3.52 \\
2.5-8.2 \\
\end{array}$ & $\begin{array}{l}3.22 \\
4.4 \\
\end{array}$ & $\begin{array}{l}3.22-7.03 \\
4.4-6.4\end{array}$ & \\
\hline \multicolumn{8}{|l|}{ Chicago } \\
\hline $\begin{array}{l}\text { "1973" house with } \\
\text { electric furnace. . . . . } \\
\text { "1976" house with }\end{array}$ & 491 & 183 & 244 & 492 & 293 & 398 & 828 \\
\hline $\begin{array}{l}\text { electric furnace. . . . } \\
\text { "1976 house with }\end{array}$ & 424 & 170 & 224 & 442 & 268 & 362 & 743 \\
\hline $\begin{array}{l}\text { heat pump. . . . } \\
\text { Low-energy house }\end{array}$ & 353 & 175 & 221 & 408 & 260 & 341 & 668 \\
\hline with heat pump. . & 176 & 138 & 165 & 273 & 192 & 240 & 435 \\
\hline \multicolumn{8}{|l|}{ Baltimore } \\
\hline $\begin{array}{l}\text { "1973" house with } \\
\text { electric furnace. . . . . } \\
\text { "1976" house with }\end{array}$ & 400 & 158 & 209 & 416 & 252 & 341 & 703 \\
\hline $\begin{array}{l}\text { electric furnace. . . . . } \\
\text { "1976" house with }\end{array}$ & 351 & 150 & 195 & 381 & 235 & 315 & 641 \\
\hline $\begin{array}{l}\text { heat pump .......... } \\
\text { Low-energy house }\end{array}$ & 286 & 156 & 195 & 351 & 230 & 297 & 573 \\
\hline with heat pump. ..... & 154 & 136 & 160 & 257 & 185 & 229 & 407 \\
\hline \multicolumn{8}{|l|}{ Houston } \\
\hline $\begin{array}{l}\text { "1973" house with } \\
\text { electric furnace. . . . . } \\
\text { "1976" house with }\end{array}$ & 294 & 129 & 168 & 328 & 204 & 273 & 556 \\
\hline $\begin{array}{l}\text { electric furnace. } \ldots . . \\
\text { "1976" house with }\end{array}$ & 271 & 128 & 165 & 315 & 199 & 264 & 530 \\
\hline $\begin{array}{l}\text { heat pump ......... } \\
\text { Low-energy house . . . }\end{array}$ & $\begin{array}{l}261 \\
161\end{array}$ & $\begin{array}{l}150 \\
123\end{array}$ & $\begin{array}{l}185 \\
147\end{array}$ & $\begin{array}{l}331 \\
248\end{array}$ & $\begin{array}{l}218 \\
173\end{array}$ & $\begin{array}{l}282 \\
219\end{array}$ & $\begin{array}{l}541 \\
403\end{array}$ \\
\hline
\end{tabular}

aprimary eneray consumption is Computed assuming that overall conversion, transmission, and distribution efficiency fOr electricity is 0.29 and that processing transmission, and distribution of natural gas is perfor-med with an efficiency of 0.89

transmission, and distribution of natural gas is prices in $\$ / M M B$ tu and electricity in $₫ / \mathrm{kWh}$.
$\mathrm{b}$

Table 18.- Levelized Monthly Energy Cost in Dollars for Energy Price Ranges Shown (Gas heated houses)

\begin{tabular}{|c|c|c|c|c|c|c|c|}
\hline \multirow[b]{2}{*}{ Gas-heated houses } & \multirow{2}{*}{$\begin{array}{l}\text { Primary energy } \\
\text { consumption } \\
\text { (MMBtu) }\end{array}$} & \multirow{2}{*}{$\begin{array}{l}\text { Gas: } \\
\text { Electricity: }\end{array}$} & \multicolumn{5}{|c|}{ Price range $1976-2000$ in 1976 dollars $^{b}$} \\
\hline & & & $\begin{array}{l}1.08-2.40 \\
2.5-3.6\end{array}$ & $\begin{array}{l}1.08-3.52 \\
2.5-8.2\end{array}$ & $\begin{array}{l}3.22 \\
4.4 \\
\end{array}$ & $\begin{array}{l}\text { 3.22-7.03 } \\
4.4-6.4\end{array}$ & $\begin{array}{l}3.22-10.60 \\
4.4-14.4\end{array}$ \\
\hline \multicolumn{8}{|l|}{ Chicago } \\
\hline $\begin{array}{l}\text { “1973" house . . . . . . . . . } \\
\text { "1976" house . . . . . . . . } \\
\text { Low-energy house . . . . }\end{array}$ & $\begin{array}{l}311 \\
277 \\
168\end{array}$ & $\begin{array}{l}111 \\
111 \\
117\end{array}$ & $\begin{array}{l}160 \\
155 \\
144\end{array}$ & $\begin{array}{l}272 \\
261 \\
232\end{array}$ & $\begin{array}{l}204 \\
193 \\
168\end{array}$ & $\begin{array}{l}323 \\
298 \\
225\end{array}$ & $\begin{array}{l}553 \\
511 \\
387\end{array}$ \\
\hline \multicolumn{8}{|l|}{ Baltimore } \\
\hline $\begin{array}{l}\text { “1973" house . . . . . . . . . } \\
\text { "1976" house . . . . . . . . } \\
\text { Low-energy house . . . . }\end{array}$ & $\begin{array}{l}271 \\
244 \\
150\end{array}$ & $\begin{array}{l}106 \\
107 \\
110\end{array}$ & $\begin{array}{l}148 \\
145 \\
135\end{array}$ & $\begin{array}{l}257 \\
249 \\
221\end{array}$ & $\begin{array}{l}188 \\
181 \\
157\end{array}$ & $\begin{array}{l}288 \\
270 \\
206\end{array}$ & $\begin{array}{l}507 \\
475 \\
364\end{array}$ \\
\hline \multicolumn{8}{|l|}{ Houston } \\
\hline $\begin{array}{l}\text { "1973" house . . . . . . . . } \\
\text { "1976" 'house. . . . . . . . . } \\
\text { Low-energy house . . . . }\end{array}$ & $\begin{array}{l}252 \\
240 \\
160\end{array}$ & $\begin{array}{l}114 \\
115 \\
117\end{array}$ & $\begin{array}{l}151 \\
150 \\
142\end{array}$ & $\begin{array}{l}280 \\
274 \\
238\end{array}$ & $\begin{array}{l}186 \\
184 \\
169\end{array}$ & $\begin{array}{l}261 \\
254 \\
217\end{array}$ & $\begin{array}{l}501 \\
484 \\
397\end{array}$ \\
\hline
\end{tabular}

aprimary energy consumption is computed assuming that overall conversion, transmission, and distribution efficiency for electricity is 0.29 and that Processing, transmission and distribution of natural gas is performed with an efficiency of 0.89

$1 \mathrm{MMBtu}=1.05 \mathrm{GJ}$ 
ing to prices in different parts of the country. The price ranges shown at the top are those in 1976 and in 2000, both expressed in 1976 dollars. Only in the case of gas-heated homes and constant energy prices for low-priced gas (\$1.08/MMBtu) does it appear not to pay to go to the low-energy home. Thus, not only can investment in conservation provide substantial energy savings but also significant dollar savings as well. It is interesting that heating requirements for the 1976 house in Houston are so small that the added capital investment for a heat pump is not justified.

It is important that although the low-energy home reduces lifecycle costs it does not necessarily represent the combination of improvements that would have the lowest possible levelized monthly costs for a given set of economic assumptions. Although such a calculation has not been performed for this set of houses, one has been done for the houses modeled by ORNL discussed above. The ORNL calculations show only improvements to the building shell, rely on an uninsulated baseline house, and require a higher return on investment than the OTA calculations. Figure 14 shows the combined heating and cooling energy savings relative to the base case, and total costs (investment and fuel) over the life of the house plotted against the initial investment. While energy savings continue to increase as investments grow, the total dollar savings reach a maximum (corresponding to minimum lifecycle cost) at an investment of about $\$ 550$. After that the increase in investment to get more energy savings grows faster than the increase in fuel cost savings. This calculation was done for the BNL fuel cost projection, and if one used the higher price range, the investment for minimum lifecycle cost would be much greater than $\$ 500$ - meaning greater energy savings.

Figure 14.- Lifecycle Cost Savings vs. Conservation Investment for a Gas-Heated and Electrically Air-Conditioned House in Kansas City

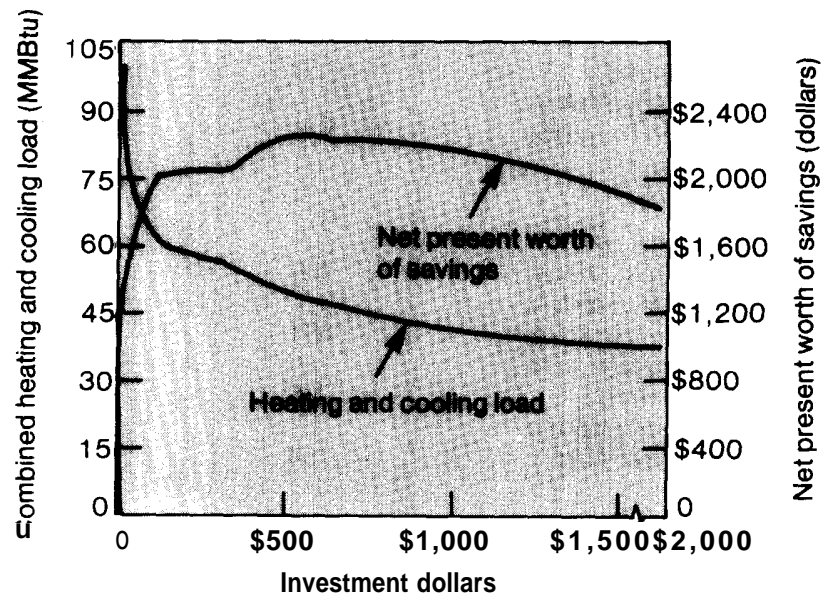

$1 \mathrm{MMBtu}=105$ glgajoule (GJ)

SOURCE Paul F Hutchins, Jr., and Eric Hlrst, "Engineering-Economic Analysis of Single-Family Dwelling Thermal Performance," Oak Ridge National Laboratory Report ORNL/CON-35, November 1978, tables 7 and 8.

Although one could not reasonably expect a person to go beyond the point that gives a minimum lifecycle cost (indeed, this is the point assumed in the projections discussed in chapter I), additional energy savings are possible. If these savings are desirable from society's point of view, then other economic incentives, such as tax credits, are called for to make the additional investments attractive.

\section{TECHNICAL NOTE ON DEFINITIONS OF PERFORMANCE EFFICIENCY}

At least eight different terms are used to describe the energy efficiency of furnaces, heat pumps, and air-conditioners, and the list could grow. Manufacturers have traditionally used efficiencies based on operation under specified steady-state conditions, but there has been growing interest in seasonal measures that would more nearly reflect performance of a home installation. The Energy Policy and Conservation Act (EPCA- Public Law 94-163) as amended by the National Energy Conservation Act (NEPCA — Public Law 95-619) required DOE to establish testing standards for the determination of estimated annual operating costs and "at least one other measure which the Secretary determines is likely to assist con- 
sumers in making purchasing decisions" for heating and cooling equipment and a number of appliances. Manufacturers are required to use these test procedures as the basis for any representations they make to consumers about the energy consumption of their equipment. The test procedures developed by DOE emphasize the use of seasonal efficiency measures. These should eventually be more useful to consumers but are likely to lead to increased confusion at first.

The performance of furnaces is customarily described in terms of efficiency. The "steady state efficiency" of a furnace refers to the fraction of the chemical energy available from the fuel (if burned under ideal conditions), which is actually delivered by the furnace when it is properly adjusted and all parts of the system have reached operating temperature. An actual home installation is seldom in perfect adjustment, heat is lost up the chimney while the furnace is not operating, and the duct systems that distribute heat always have some losses unless they are completely contained within the heated space. Thus, the "seasonal system efficiency" is typically much lower than the steady state efficiency. DOE has developed procedures for determining a seasonal efficiency, which is called the "annual fuel utilization efficiency."

Air-conditioners "pump" heat out of the house and are able to remove more than a Btu of heat for each Btu of electrical input. The usual measure of air-conditioner performance has been a somewhat arbitrary measure called the "energy efficiency ratio" or EER, which is defined to be the number of Btu of cooling provided for each watt-hour of electric input. The standard conditions for determining the EER have been $800 \mathrm{~F}$ dry bulb and $670 \mathrm{~F}$ wet bulb indoors and $950 \mathrm{~F}$ dry bulb and $750 \mathrm{~F}$ wet bulb outdoors. ${ }^{36}$ DOE has retained the use of the EER for room air-conditioners in its test

\footnotetext{
${ }^{36}$ Air-Conditioning and Refrigeration Institute, "Directory of Certified Unitary Air-Conditioners, Unitary Heat Pumps, Sound-Rated Outdoor Unitary Equipment, and Central System Humid ifiers," 1976 (Arlington, Va.), p. 85.
}

procedures $^{37}$ but has also adopted the use of a seasonal energy efficiency ratio (SE E R) for central air-conditioners. ${ }^{38}$ The seasonal energy consumption of an air-conditioner is increased by cycling the machine on and off since it does not operate at full efficiency for the first minute or so after it is turned on. An offsetting factor is provided by the increase in EER that occurs as the outdoor temperature drops. The seasonal energy efficiency ratio incorporates both of these effects and is defined on the basis of a typical summer use pattern involving 1,000 hours of operation, Use of the SEER became effective January 1,1979.

A final word should be added about heat pumps and their air-conditioning mode. The proposed DOE standards for heat pumps define tests for the heating seasonal performance factors (HSPF) in each of six different broadly defined climatic regions of the country. Cooling seasonal performance may be specified by a cooling seasonal performance factor (CSPF) or an SEER. In addition, an annual performance factor (APF) is defined as a weighted average of the HSPF and the CSPF based on the number of heating and cooling hours in different parts of the country. ${ }^{39}$

Since heat pumps, as their name implies, pump heat into the house from outdoors, they can provide more heat to the house than would be provided if the electricity were "burned" in an electric heater or furnace. The Coefficient of Performance (COP) is the ratio of the heat provided by the heat pump to that which would be provided by using the same amount of electricity $i \mathrm{n}$ an electric heating element. The COP of a heat pump decreases as the outdoor temperature drops, and the Air Conditioning and Refrigeration Institute has specified two standard rating conditions for

"',Test Procedures for Room Air Conditioners, " Federal Register, vol. 42, 227, Nov 25, 1977, pp. 60150-7 and federal Register, vol. 43, 108, June 5, 1978, pp. 24266-9.

$38 "$ Test Procedures for Central Air Conditioners," Federal Register, vol. 42,105, June 1, 1977, pp. 27896-7.

“"'Proposed Rulemaking and Public Hearing Regarding Test Procedures for Central Air Conditioners Including Heat Pumps," Federal Register, vol. 44, 77, Apr. 19, 1979, pp. 23468-23506. 
heat pump heating performance. '" Both specify indoor temperature of $700 \mathrm{~F}$ dry bulb and $600 \mathrm{~F}$ wet bulb with outdoor temperature for the "high temperature heating" condition being $470 \mathrm{~F}$ dry bulb and $430 \mathrm{~F}$ wet bulb, and specifications for "low temperature" being $170 \mathrm{~F}$ dry bulb and $150 \mathrm{~F}$ wet bulb. Heat pumps

${ }^{40}$ Air-Conditioning and Refrigeration Institute, op. cit., pp. 8,85 . are usually sized so that part of the heating load must be met by supplementary resistance heat at lower temperatures, lowering the overall COP still further. A useful measure of the total heating performance is the "seasonal performance factor," which is the average COP over the course of the winter for a typically sized unit in a particular climate. The seasonal performance factor includes the effects of supplementary resistance heating and cycling but does not include any duct losses.

Table 19.-Structural and Energy Consumption Parameters for the Base 1973 Single-Family Detached Residence

Structural parameters:

Basic house design

Foundation

Construction

Exterior walls:

Composition

Wall framing area, $\mathrm{ft}^{2}$
Total wall area, $\mathrm{ft}^{2}$
Roof:
Type
Composition

Roof framing area, $\mathrm{ft}^{2} \quad 78$ sq. $\mathrm{ft}$.

Total roof area, $\mathrm{ft}^{2} \quad 1,200$ Sq. ft.

Floor:

Total floor area, $\mathrm{ft}^{2} \quad 1,200$ Sq. ft.

Windows:

Type

Glazing

Area, $\mathrm{ft}^{2}$

Exterior doors:

Type

Number

Area, $\mathrm{ft}^{2}$
Double hung, wood

Single

105 Sq. ft.

3-bedroom rancher, one story, 8-ft stories.

Fasement, poured concrete.

$$
\begin{aligned}
& 1 / 2 \text { " insulation board } \\
& 31 / 2 \text {," fiberglass batts } \\
& 1 / 2 \text { " gypsum board }
\end{aligned}
$$

203 sq. ft.

Gable

Asphalt shingles, 3/8" plywood sheating, air space, 6 " fibreglass loose-fill insulation, $1 / 2$ " gypsum board

Wood frame

Two

$40 \mathrm{Sq}$. ft.
Patio door(s):

Type Aluminum, sliding

Glazing Double

Area, $\mathrm{ft}^{2} \quad 40$ Sq. ft.

Energy consumption parameters:

Energy consuming equipment:

Heating system

Cooling system

Gas, forced ai

Hot water heater

Cooking range/oven

Clothes dryer

Gas (270 therms/year)

Refrigerator/freezer

Electric (1 $200 \mathrm{kWh} /$ year)

Electric (990 kWh/year)

Lights

Electric (1 830 kWh/year)

Electric-incandescent

Color TV

Furnace fan

(21 40 kWh/year)

Dishwasher

Clothes washer

Iron

Coffee maker

Miscellaneous

Electric (500 kWh/year)

Electric (394 kWh/year)

Electric (363 kWh/year)

Electric (103 kWh/year)

Electric (144 kWh/year)

Electric (106 kWh/year)

Electric (900 kWh/year)

aFiaures shown $i_{\text {n }}$ parentheses represent energy input to Structure for each appliance.

Dependenton location.

SOURCE: Hittman Associates, Inc., "Development of Residential Buildings Energy Conservation Research, Development, and Demonstration," HIT-681, performed under ERDA Contract No. EX-76-C-01-21 13, August 1977, p. III-4.

Heating/cooling load parameters:

People per unit

Two adults, two children

Typical weather year

Monthly heating degree

5 yr. average (1 970-75)

days ${ }^{b}$

Monthly cooling degree

days $^{b}$

Monthly discomfort

cooling index ${ }^{\mathrm{b}}$ 
Ch.!!- Residential Energy Use and Efficiency Strategies • 57

Table 20.-Specifications and Disaggregate Loads for "1973" Single-Family Detached Residence

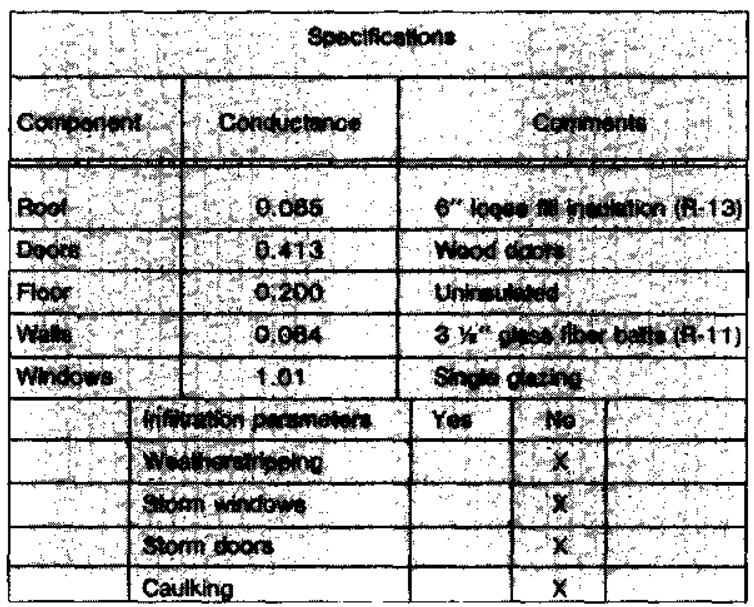

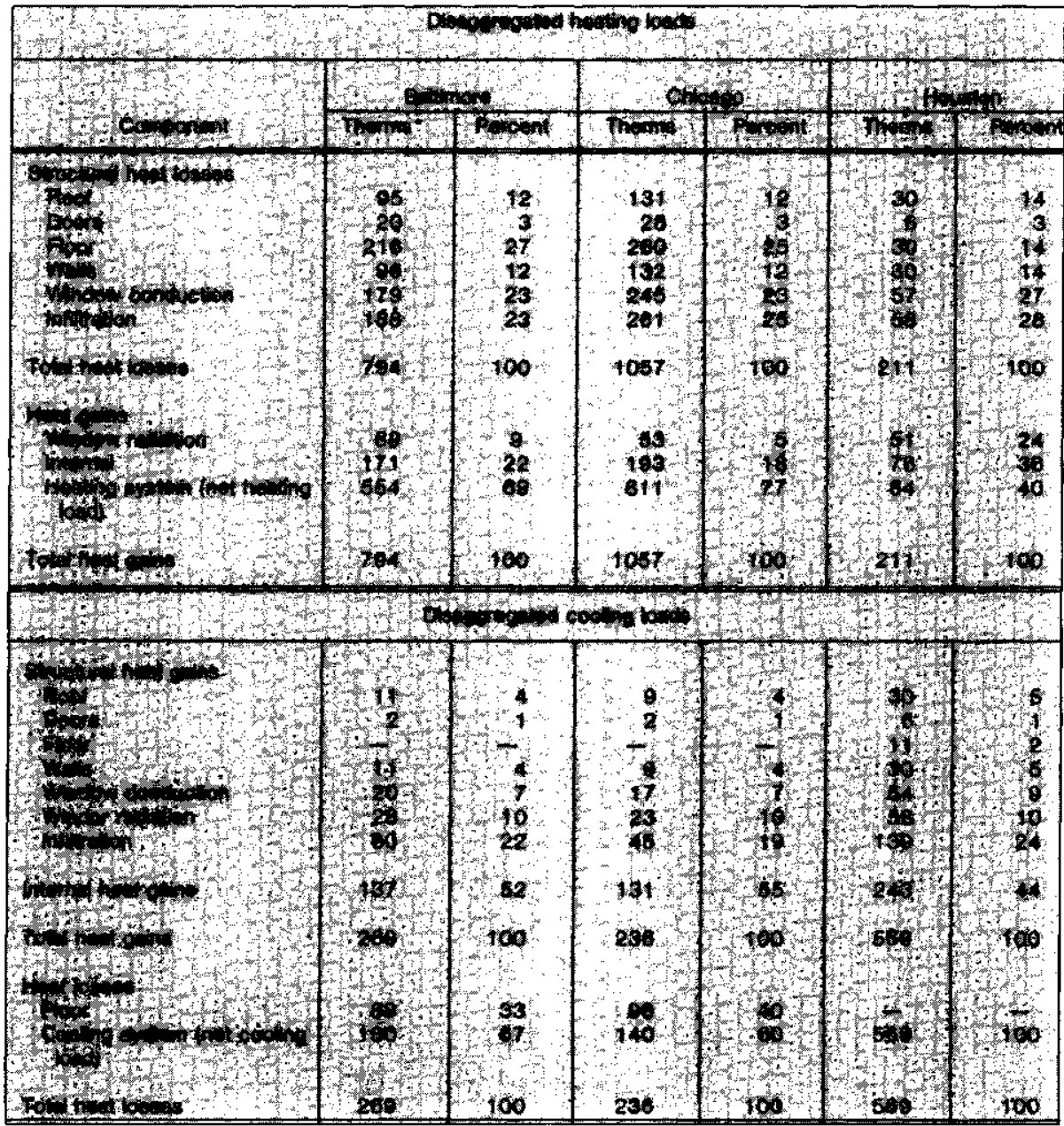

'Therm $=1 \times 10^{\mathrm{s}} \mathrm{Btu}=106$ megajoule $(\mathrm{MJ})$

SOURCE: HIttman Associates, Inc "Development of Residential Buildings Energy Conservin Research Development, and Demonstration Strategies, " HIT-681, performed under ERDA Contract No EX-76-C-01-21 13, August 1977 p IV 9 
Table 21 .-Specifications and Disaggregated Loads for "1976" Single-Family Detached Residence
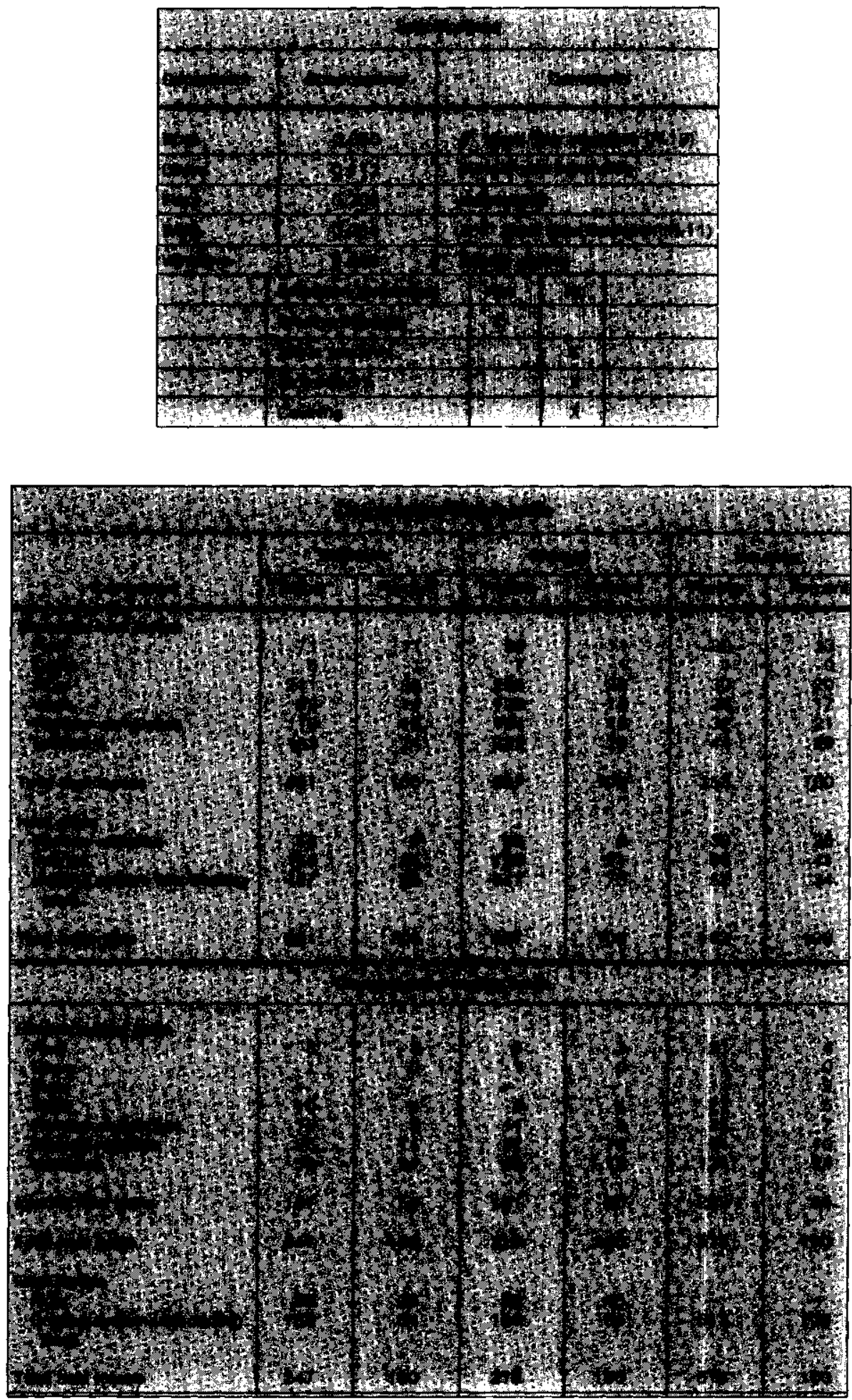

"Therm $=1 \times 10^{5} \mathrm{Btu}=106$ megajoule (MJ)

SOURCE: Hittman Associates, Inc., "Development of Residential Buildings Energy Conselvation Research, Development, and Demonstration Strategies," HIT-681, performed under ERDA Contract No EX-76-C-01-2113, August 1977, p IV-9 
Table 22.-Specific:ations and Disaggregated Loads for Low.Energy Single-Family Detached Residence

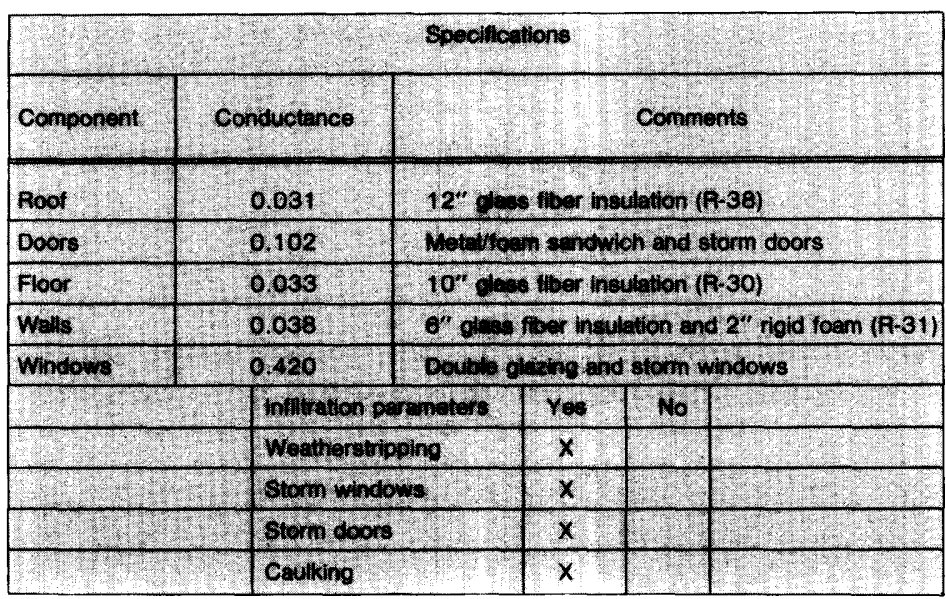

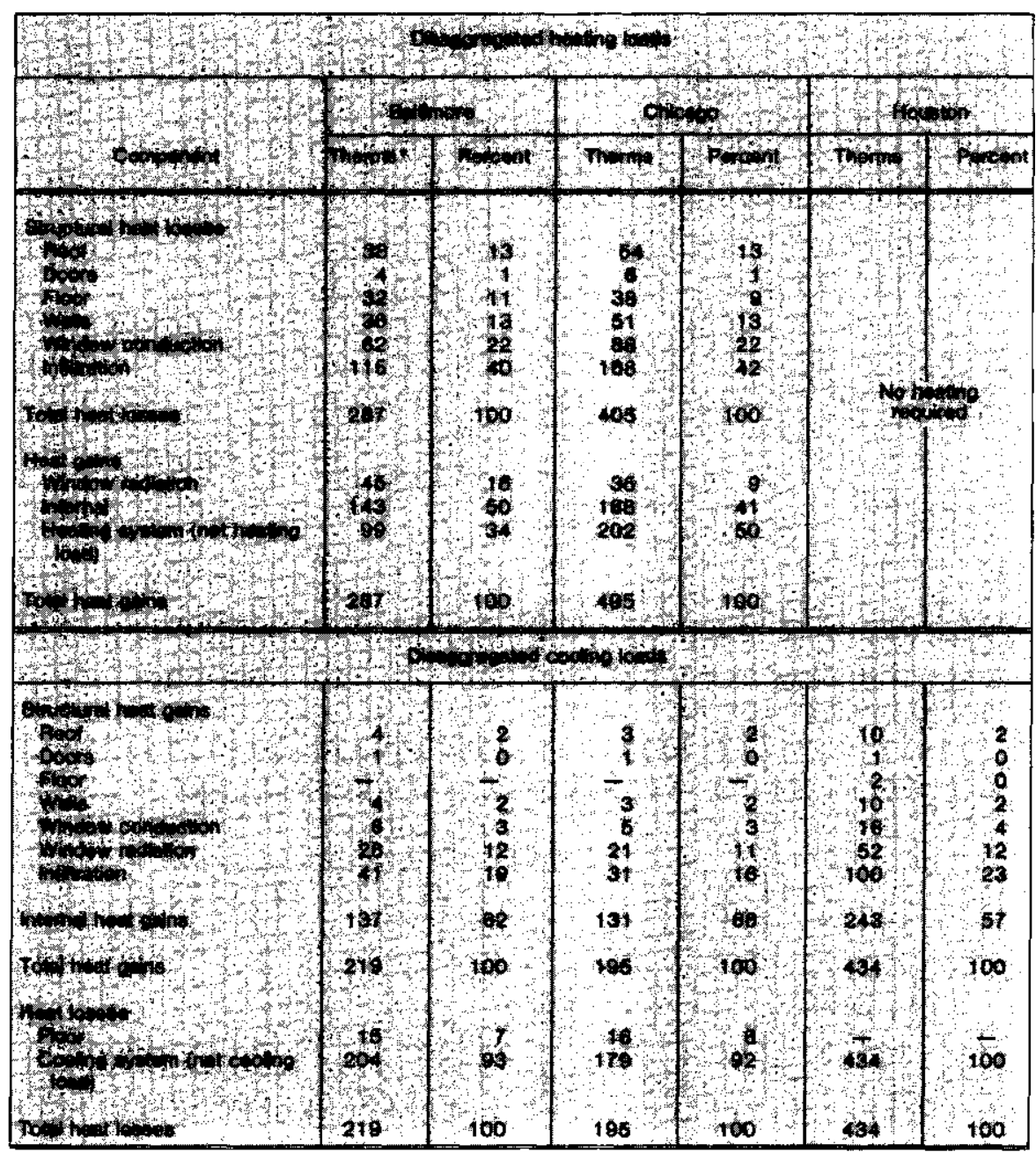

"Therm $=1 \times 10^{5} \mathrm{Btu}=106$ megajoule $(\mathrm{MJ})$

SOURCE Hittman Associates, Inc. "Development of Residential BuildingsEnerg Conser atron Research Development and Demonstration Strategies, "HIT-681 performed under ERDA Contrac'No EX 76-C-01 -2113, August $1977 \mathrm{p}$ ivo 
Table 23.-Disaggregated Energy Consumption for Different Combinations of Thermal Envelope and HVAC Equipment for Houses in Houston, Tex. (in MM Btu*)

\begin{tabular}{|c|c|c|c|c|c|c|c|}
\hline \multirow[b]{2}{*}{ Heves $\&$ equpmont } & \multicolumn{3}{|c|}{ Energy coneumption by source } & \multicolumn{4}{|c|}{ Energy consumption by end use } \\
\hline & Consumption & $\begin{array}{c}\text { Electric } \\
\text { consumption }\end{array}$ & consumption & Hoating & Cooling & Hot water & $\begin{array}{c}\text { Modowapous } \\
\text { Mectic }\end{array}$ \\
\hline All eloctic houses & & & & & & & \\
\hline $\begin{array}{l}1973 \text { " house with } \\
\text { blectric fumace }\end{array}$ & 294 & 85.3 & - & 9.3 & 31.6 & 14.8 & 29.6 \\
\hline $\begin{array}{l}1070 \text { " house with } \\
\text { etectric fumace }\end{array}$ & 271 & 78.7 & $\rightarrow$ & 5.8 & 28.6 & 14,8 & 29.6 \\
\hline $\begin{array}{l}\text { "1976" house with } \\
\text { heat pump }\end{array}$ & 261 & 75.7 & - & 2.8 & 28.5 & 148 & 29.6 \\
\hline $\begin{array}{l}\text { Lowengrgy house } \\
\text { with heat pump }\end{array}$ & 161 & 46.6 & - & 0 & 15.6 & 3.76 & 27.3 \\
\hline Cas heated houses & & & & & & & \\
\hline "1973" house & 252 & 61.2 & 41.0 & 14.0 & 31.6 & 270 & $29: 6$ \\
\hline "1976" house & 240 & 58.1 & 35.7 & 8.7 & 28.5 & 27.0 & 29.6 \\
\hline Low energy house & 160 & 42.9 & 10.8 & 0 & 16.6 & $10,8 c$ & 27.3 \\
\hline
\end{tabular}

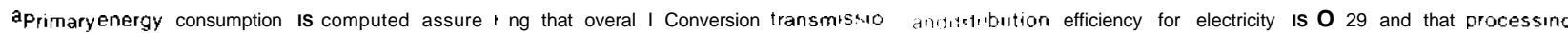
transmission, and distribution of natural gas has an r? fliciency of $\mathrm{O} 89$

bTh isfigure Includes on ly the electricity used bythf.hot water heat Pum P Some hot waleris riviyeyny heat recovery from the heat pump which heats and cools the

house

$C_{T h i}$ s figure includes only the gas used by the hot water heater Some hot water is provided $b$, heatrf $c$ very from the alr-conditioner

1 MMBtu $=105$ gigajoule (GJ) 
Table 24.-Disaggregated Energy Consumption for Different Combinations of Thermal Envelope and HVAC Equipment for Houses in Baltimore, Md. (in MM Btu*)

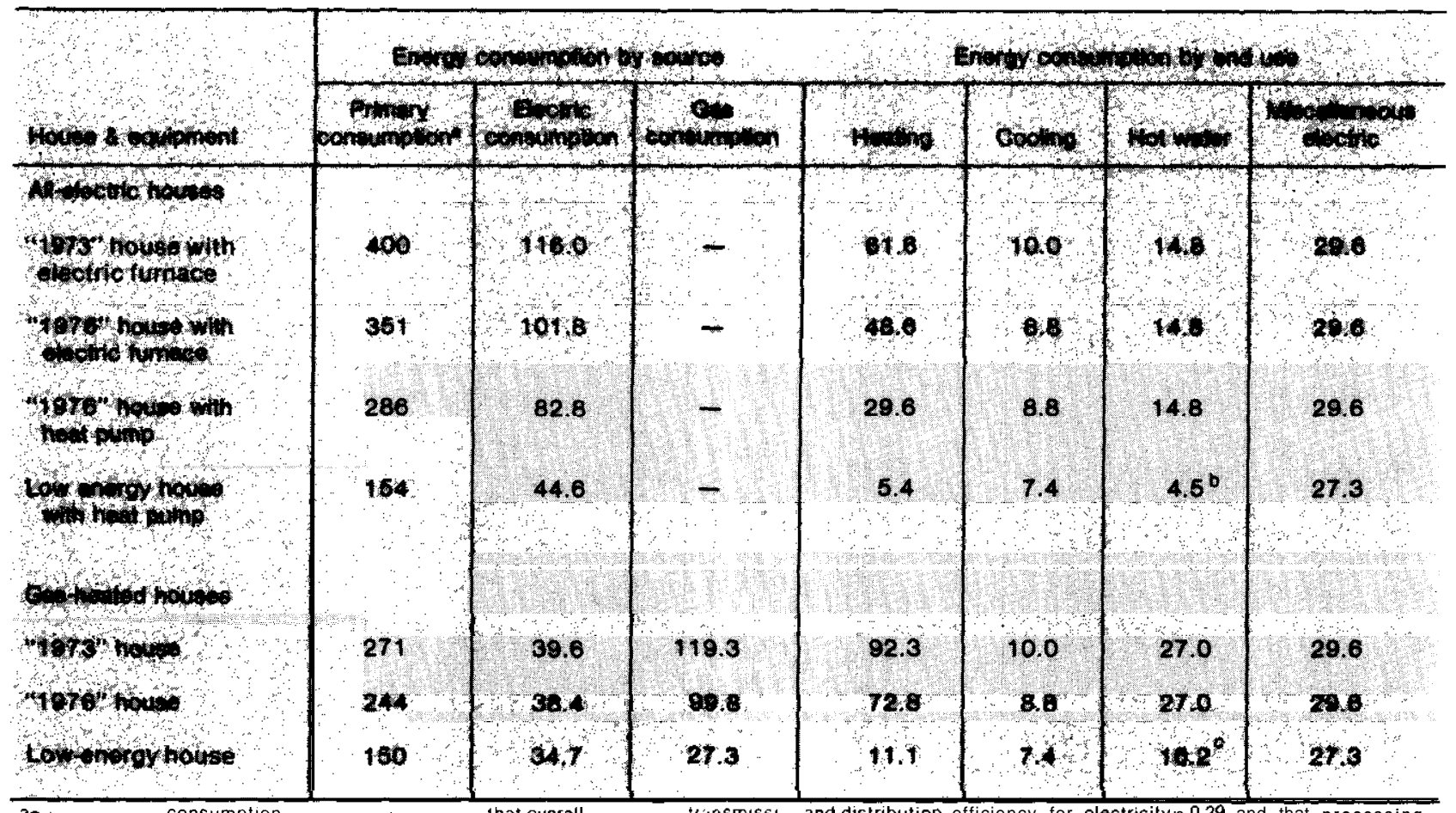

aPrimary energy consumption is computed assuming that overall conversion thensmissi in and distribution efficiency for electricity is 0.29 and that processing, transmission, and distribution of natural gas has an efficiency of 089

bThis figure includes only the electrilyusedbvihe hot water heat pumpsoner I waters provided by heat recovery from the heat pump which heats and cools the house

${ }^{C}$ This figure includes only the gas used by $t_{e}$ hot water heater Some hot water $1 s_{f}$ rovide $j$, $y$ heat recovery from the air-conditioner

-1MMBtu = 105 gigajoule $(\mathrm{GJ})$ 
Table 25.-Disaggregated Energy Consumption for Different Combinations of Thermal Envelope and HVAC Equipment for Houses in Chicago, III. (in MM Btu*)

\begin{tabular}{|c|c|c|c|c|c|c|c|}
\hline \multirow[b]{2}{*}{ House \& equipment } & \multicolumn{3}{|c|}{ Energy consumption by source } & \multicolumn{4}{|c|}{ Energy consumption by end use } \\
\hline & $\begin{array}{l}\text { Primary } \\
\text { consumption? }\end{array}$ & $\begin{array}{c}\text { Electric } \\
\text { consumption }\end{array}$ & $\begin{array}{c}\text { Gas } \\
\text { consumption }\end{array}$ & Heating & Cooling & Hot water & $\begin{array}{l}\text { Miecellaneous } \\
\text { electric }\end{array}$ \\
\hline \multicolumn{8}{|l|}{ All-electric houses } \\
\hline $\begin{array}{l}\text { "1973" houses with } \\
\text { electric fumace }\end{array}$ & 491 & 142 & - & 90.1 & 7.8 & 14.8 & 29.6 \\
\hline $\begin{array}{l}\text { "1976" house with } \\
\text { electric fumace }\end{array}$ & 424 & 123 & - & 71.0 & 6.8 & 14.8 & 29.6 \\
\hline $\begin{array}{l}\text { "1976" house with } \\
\text { heat pump }\end{array}$ & 353 & 103 & - & 51.3 & 6.8 & 14.8 & 29.6 \\
\hline $\begin{array}{l}\text { Low-energy house } \\
\text { with heat pump }\end{array}$ & 176 & 51.1 & - & 11.4 & 6.5 & $5.9^{\mathrm{b}}$ & 27.3 \\
\hline \multicolumn{8}{|l|}{ Gas heated houses } \\
\hline$" 1973 "$ house & 311 & 37.4 & 162 & 135 & 7.8 & 27.0 & 29.6 \\
\hline "1976" house & 277 & 36.4 & 135 & 108 & 6.8 & 27.0 & 29.6 \\
\hline Low-energy house & 168 & 33.8 & 45.9 & 28.8 & 6.5 & $17.1^{\circ}$ & 27.3 \\
\hline
\end{tabular}

aprimary energy consumption Is computed assum ingihat overal I Conversion transmissio and liributionefficiency for electricity is $O 29$ and that processı ng, transmission. and distribution of natural qashas a etfincy of $\mathrm{O} 89$

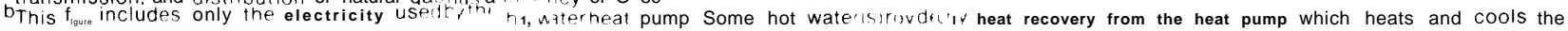

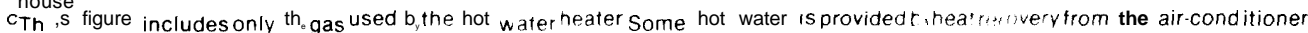

$1 \mathrm{MMBtu}=105$ gigajoule (GJ) 


\section{Unapter III}

THE CONSUMEK 


\section{Chapter III--CONSUMER}

Lack of Reinforcement ..........

Disparity of Effects and Opportunities by Income Groups . . . . . , . 68

Conflicts Between Conservation and Other Coals. . . . . .. . . . . . . 69

Distrust of Information Providers and Disbelief in Reality of Shortages 70

Lack of Specific Knowledge About How to Conserve . . . . . . . . 70

Faith in "American Technological Know-How" to Solve the

Energy Problem . . . . . . . . . . . . . . . . . . . . 71

Consumers and the Building Industry ........... . 71

Consumer Behavior and Energy Conservation in Home Operation . 73

Conclusions . . . . . . . . . . . . . . . . 74

\section{TABLES}

26. Percent of Potential Homebuyers Willing to Spend $\$ 600$ or More at Outset to Save $\$ \mathbf{1 0 0}$ or More Annually on Energy, by Family Income and House Price Range . . . . . . . . .

27. Percent of Homebuyers Desiring Energy-Saving Features in Five Major Housing Markets, 1978 
Americans want to own their homes. Few social phenomena have been more influential in shaping present-day American society than this strong and widespread desire for a home particularly for a detached single-family home- that has swept the country since World War 11. The result has been a profound impact on land use, transportation, community development, family life, and many other areas. Our present concern, however, is with the rapid growth in residential energy consumption that has accompanied the growth in household formation, population, and homeownership.

Energy use in the home accounts for approximately 20 percent of our total energy use, and of that amount, about 60 percent is used for heating and cooling. Residential energy use grew about twice as fast as the number of households between 1950 and 1970, reflecting the increase in use within each household. Household consumption of fossil fuels and electricity grew from 7 quadrillion $B^{*}$ in 1950 to 16 quadrillion Btu in 1974; with the number of households increasing from $\mathbf{4 3}$ million to $\mathbf{7 0}$ million, this represents an increase of $65 \mathrm{MMBtu}$ per household between 1950 and 1974.

The relationships between homeowners and other housing decisionmakers such as lenders, builders, architects, manufacturers of building supplies, and contractors for heating and cooling equipment installation, are very complex. No single group determines the ultimate energy consumption in a home. It is clear, however, that consumers are in control of a significant portion of the decisions that affect consumption directly or indirectly. Homeowners pay the utility and fuel bills and adjust their consuming behavior when prices rise. They maintain the heating and cooling equipment in their homes. They control thermostat settings and window and door openings, and they choose appliances. They make- or fail to make- investments to improve the energy efficiency of their homes, through structural or equipment changes. In short, within the very real limits of finances, technical capabilities, and comfort, they control the operational aspects of home energy consumption.

In a less well-recognized area, home consumers affect residential energy use levels through their influence on the homebuilding industry. There is evidence that builders ignore consumer preferences at their peril, for attempted innovations that have run counter to

${ }^{*}$ One Btu is equivalent to $1 \mathrm{~kW}$-per-second or 1 kilojoule. consumer tastes have generally failed to catch on and left builders with financial losses. Consumers appear to be conservative in their housing tastes, resisting radical changes in the design, comfort, or space of a home. The major trade associations and publications of the building industry spend considerable time and money surveying the attitudes and preferences of buyers, with the result that builders, too, are often conservative about major innovations that affect buyer perceptions. Efforts to lead, rather than follow, consumer tastes have not always succeeded. For example, the recent movement to build "no frills" housing in an attempt to bring families of modest means into the new home market is now considered a failure by the building industry. It appears that buyers would rather wait a year or two longer, if necessary, to buy the kind of house they really want-one with amenities such as a fireplace, a family room, a garage, and an extra bathroom.

In light of the rapid turnover of houses in the current-day real estate market, some of this buyer conservatism can be attributed to purchasers' concern with resale value. Homeownership represents the single largest financial investment made by most families, and its attendant risks can be minimized by investing in "safe" properties- those with the largest appeal. If the buyer decides to invest in extras, he 
wants to be sure that value will be easily acknowledged by potential future buyers.

This concern about resale values has implications for decisions about energy-conserving features. Until recently, homeowners would undoubtedly have been correct in deciding that extra insulation was not a feature likely to "turn on" later buyers. Now, however, with rising energy prices and occasional spot shortages of some fuels, prospective buyers have begun to demand information about utility costs, and to insist on more efficient houses.

It is important to bear in mind, however, that energy is only one of several items about which consumers are concerned. Efforts to conserve energy through design or construction methods often conflict with other values-for example, the desire to take advantage of a fine view by installing large amounts of north-facing glass. In determining which energy-conserving technologies will be attractive to consumers, builders and policy makers need to keep these conflicting values in mind.

Just as important as consumer attitudes toward housing are their attitudes toward the energy problem generally, and toward its causes, effects, and remedies as these relate to their own lives. Social scientists have carried out considerable research on consumer attitudes and behavior.

Many studies have been collected and analyzed by Sally Cook Lopreato and her colleagues at the University of Texas Center for Energy Studies.' Several of these studies indicate that many consumers have serious doubts about the severity of our energy problem, and are more concerned about issues like inflation, crime, and unemployment. Most people do not share the official views of either Government or business regarding the causes of the problem. In fact, it appears that most consumers

'Compilations and analyses by Lopreato et al. are found in Sally Cook Lopreato and Marian Wossum Meriwether, "Energy Attitudinal Surveys: Summary, Annotations, Research Recommendations" (unpublished: 1976), and in William H. Cunningham and Sally Cook Lopreato, Energy Use and Conservation Incentives: A Study of the Southwestern United States (New York: Praeger Publishers, 1977). mistrust both Government and industry-especially the oil industry-as sources of information about energy issues.

One major study by Jeffrey S. Milstein, of the Department of Energy's (DOE) Office of Conservation and Solar Applications, indicates that although a majority of Americans in 1977 did not believe that fuel shortages were real, an even larger majority did believe it was important to conserve energy. ${ }^{2}$ More than onehalf of the respondents in Milstein's national survey believed that fuel shortages were artificial, but 50 percent said the need to conserve energy was "very serious" and another 33 percent believed it was "somewhat serious." Perhaps consumers find it important to conserve because of high energy costs rather than because energy shortages require it.

Unfortunately, most consumer studies reveal that even when the energy crisis is perceived and accepted as real, this attitude does not necessarily lead to conservation behavior. Marvin E. Olsen of the Battelle Human Affairs Research Center concluded from his surveys that "with only a few minor exceptions, all the research conducted thus far has found little or no relationship between belief in the reality or seriousness of the energy problem and any actual conserving behavior." ${ }^{3}$ However, Olsen points out that consumers' belief in the seriousness of energy problems may make them more accepting of Government policies requiring conservation.

A number of factors appear to contribute to consumer inaction: a lack of practical knowledge about what to do; a lack of sense of personal involvement in the problem, a "them first" approach to potential sacrifices, and a conflict with other personal goals such as comfort and convenience. Not surprisingly, when queried about their willingness to undertake specific conservation measures, consumers indicate their highest levels of support for the

${ }^{2}$ Jeff rey Milstein, "How Consumers Feel About Energy: Attitudes and Behavior During the Winter and Spring of 1976-1977" (unpublished: 1977).

${ }^{3}$ Marvin E. Olsen, "Public Acceptance of Energy Conservation, " in Seymour Warkov, Energy Policy in the United States: Social and Behavioral Dimensions, pp. 91-109. 
easiest measures (like turning out lights), and lowest support for measures that call for major changes in lifestyles. Governmental and media-oriented public relations efforts, using catchy slogans such as "Don't Be Fuelish," appear to result in passive responses ("Something should be done ...") rather than active ones ("1 will do the following . . "). ${ }^{4}$

Studies also show that consumers often deceive themselves (and policy makers) about conservation steps they claim to be taking or be willing to take. For example, the Gallup Organization sampled households nationwide in February 1977 and found that the average temperature at which consumers said they set their home thermostats was $66^{\circ} \mathrm{F}$ during the day and $640 \mathrm{~F}$ at night. But pollsters for Gallup and for Louis Harris who actually measured temperatures of homes 1 month later found average temperatures were $700 \mathrm{~F}$ (plus or minus 20, during the day and $690 \mathrm{~F}$ (plus or minus 20, at night. Reflecting on this finding, Milstein concludes that the discrepancy "indicates a feeling on the part of people that they ought to have lower temperatures." He also notes that many thermostats may be miscalibrated. ${ }^{5}$

Many consumer studies indicate that the prospect of real cost savings is the most effective factor in moving people to conserve energy in their personal lives. Other motives, such as altruistic concerns about the Nation's future energy supply, independence from OPEC cartel manipulation, or the quality of the environment are less successful in generating conservation action. ${ }^{\text {b }}$

W. B. Doner, Inc., determined in a study done for the Michigan Department of Commerce that among Michigan consumers the single most powerful motivator for conservation is represented by the statement that

'Kenneth Novic and Peter Sandman, "How Use of Mass Media Affects Views on Solutions to Environmental Problems," journalism Quarterly, vol. 51, no. 3, pp. 448-452, cited in Cunningham and Lopreato, op. cit., p. 22 and p. 29.

${ }^{5} \mathrm{Mi}^{2}$ lstein, op. cit., p. 5.

'Cunningham and Lopreato, op. cit., p. 20. "conserving energy saves money."7 The Gal I up Organization, in conducting a series of group discussions on energy during 1976 for the Federal Energy Administration (FEA) (now part of DOE), found widespread agreement that monetary incentives are the critical conservation motivator. ${ }^{8}$ A Texas study reached the same conclusion after surveying about 800 households before and after the oil embargo.

Adding insulation is the most widely documented conservation action taken by cost-conscious consumers. About 80 percent of U.S. households were found to be insulated to some extent in Milstein's 1977 survey- up from 70 percent in 1976 and 62 percent in 1975. A Gallup survey conducted in January 1978 found that 17 percent of those surveyed had added some attic or crawl-space insulation and 11 percent had added wall insulation in the previous 12 months; less than one-third of the Gallup respondents had failed to take action to improve the energy efficiency of their houses in 1977. '0

Studies suggest a wide variety of reasons for some consumers' failure to take conservation actions, including: 1 ) lack of social pressure or reinforcement for conserving behavior; 2) disparity in effects of the energy problem, as well as in opportunities to conserve, among different income groups; 3) conflicts between conservation objectives and other goals such as comfort, convenience, and "fairness;" 4) distrust of information providers and disbelief that shortages are "real;" 5) lack of practical knowledge about how to conserve; 6) complacency caused by faith in a technical solution to future energy supply problems.

'W. B. Doner, Inc. and Market Opinion Research, "Consumer Study- Energy Crisis Attitudes and Awareness" (Lansing, Mich.: Michigan Department of Commerce, 1975), cited in Cunningham and Lopreato, op. cit., p. 130.

${ }^{8}$ Callup Organization, Inc., “Croup Discussions Regarding Consumer Energy Conservation" (Washington, D. C.: Federal Energy Administration, 1974), cited in Cunningham and Lopreato, pp. 131-132.

'David Cottlieb, Social Dimensions of the Energy Crisis (Austin, Tex.: State of Texas Governor's Energy Advisory Council, 1974), cited in Cunningham and Lopreato, pp. 134-135.

${ }^{10}$ Callup Organization, Inc., "A Survey of Homeowners Concerning Home Insulation" (Washington, D. C.: U.S. Department of Energy, 1978). 


\section{LACK OF REINFORCEMENT}

Robert Leik and Anita Kolman of the Minnesota Family Study Center maintain in a 1975 paper that social pressure could serve to reinforce conservation behavior. Without a strong national ethic to conserve energy, little or no social pressure for conservation exists. Consequently, consumers rely almost exclusively on economic reinforcement. However, Leik and Kolman maintain that much of the potential for economic reinforcement is lost because consumers pay for energy not as they use it but monthly or even less often. Also, because bills are usually paid by one member of a household, other members are not aware of economic savings or penalties unless informed by the person who pays the bill.

Field studies conducted at Twin Rivers, N. J., revealed that feedback about consumption

"Robert Leik and Anita Kolman, “Isn't It More Rational to be Wasteful ?," in Warkov, op. cit., pp. 148-163. and conservation can enhance people's efforts to conserve. Summertime electricity consumption among households studied was reduced by 10.5 percent when people were provided with almost daily feedback on their consumption performance and were exhorted to conserve. In a separate study, residents given a goal of a 20-percent reduction in electricity use actually cut back by 13 percent when provided with frequent feedback. In still a third experiment, use of a light that flashed whenever cooling could be achieved through open windows rather than air-conditioners led people to conserve 15.7 percent of their electricity. While these were relatively short-term experiments ( 3 to 4 weeks), they do suggest that frequent feedback to the consumer could provide substantial savings of energy.

${ }^{2}$ Clive Seligman, John M. Darley, and Lawrence J. Becker, "Behavioral Approaches to Residential Energy Conservation," Energy and Buildings, April 1978, pp. 325-337.

\section{DISPARITY OF EFFECTS AND OPPORTUNITIES BY INCOME GROUPS}

A 1975 Ford Foundation study, since confirmed by several other consumer surveys, found that household energy use (including transportation) rises with income and that the largest gaps in consumption between income groups are accounted for by elective or luxury uses. At the same time, the percentage of household income that is used for energy drops sharply as income rises. While the poor spent $\mathbf{1 5 . 2}$ percent of their household income on direct energy use in 1972-73, the more affluent spent only 4.1 percent. This means that while lower income households have the greatest need to conserve, they also suffer from a lack of opportunities to do so. There is very little fat in the poor family's energy budget. '3

An Austin, Tex., study found that short-term response to electricity price increases among

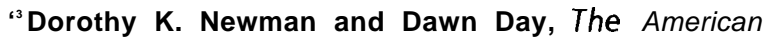
Energy Consumer: A Report to the Energy Policy Project of the Ford Foundation (Cambridge, Mass.: Ballinger Publishing Company, 1975), cited in Cunningham and Lopreato, pp. 145-146.
}

household energy users varied sharply by income group. Upper income households increased consumption despite rising prices; the small impact on total household budgets was not sufficient motivation for most to conserve. Lower income households showed very little change in consumption because, the researchers concluded, they are already at the minimum consumption level they can manage for reasonable comfort in homes that lack adequate insulation and efficient appliances. Only among middle-income families were consumption declines widespread in response to price increases. The authors conclude that the middle-income group offers the greatest potential for conservation, since this group has both a margin for conserving and economic incentive to do so. ${ }^{4}$

\footnotetext{
"Nolan E. Walker and E. Linn Draper, "The Effects of Electricity Price Increases on Residential Usage by Three Economic Groups: A Case Study," Texas Nuclear Power Policies 5 (Austin, Tex.: University of Texas Center for Energy Studies, 1975), cited in Cunningham and Lopreato, pp. 155-156.
} 


\section{CONFLICTS BETWEEN CONSERVATION AND OTHER GOALS}

A number of studies suggest that the energy crisis-at least at recent levels of severity- is not a sufficient incentive to deter consumers from their pursuit of comfortable lifestyles. Participants in the Gallup Organization's 1976 group discussions on energy represented a cross-section of consumers, varying by income, education, place and type of residence, age, and sex. Summarizing the attitudes Gallup discerned regarding lifestyles, values, and conservation, Cunningham and Lopreato wrote:

Participants hear 'Deny yourself' as the implicit theme in most conservation communications and are answering with ' 1 have earned the right to indulge' . . Convenience and immediate gratification are primary goals, limited only by financial pressure. Saving energy when it is 'convenient' provides a sense of contributing and helps relieve guilt.

This factor of "convenience" does appear to limit personal support for conservation measures and actual conservation behavior. An IIlinois survey found that consumers, both before and after the embargo and accompanying price increases, placed "high value emphasis on privacy, autonomy, and mobility." The researchers conclude that conservation campaigns affecting "deeper lifestyles" cannot succeed at present. 'b The fact that consumers value convenience and comfort, plus the fact that energy costs are still a small portion of the cost of operating a home, indicates that prices may need to rise much more dramatically before they will outweigh these competing values.

Family welfare was also mentioned often by consumers as a reason for not conserving. When Milstein asked certain consumers why they had not turned down their thermostats, many mentioned that their families would be uncomfortable or that there were babies or

'Cunningham and Lopreato, p. 132.

"Stanley E. Hyland, et al., The East Urbana Energy Study, 1972-1974: Instrument Development, Methodological Assessment, and Base Data (Champaign, III.: University of Illinois College of Engineering, 1975), cited in Cunningham and Lopreato, p. 141. sick or elderly people in the house. In the Twin Rivers study, concern with health and comfort correlated closely with levels of summer energy consumption; the stronger the respondent's perception that energy conservation led to discomfort and illness, the greater was his energy consumption. The Twin Rivers researchers also found that participants who believed that the effort involved in saving energy was too great for the cost savings achieved - for example, that it was too much trouble to turn off the air-conditioner and open the windows whenever it got cool enough outside- also had higher consumption levels. The third significant predictor of energy consumption found in the Twin Rivers research was the perception that the actions of individual homeowners could have only a negligible effect on national energy consumption.

Milstein's respondents believed strongly that conservation policies must be "fair" to be acceptable. Sometimes, this concern with equity appeared to lead to support for contradictory policies. For example, only $\mathbf{3 0}$ percent believed that "consumers have the right to use as much energy as they want to and can afford to, " and only 10 percent believed that "people should be allowed to drive their cars and heat their homes as much as they want to even if we all become dependent on foreign countries." While these attitudes might suggest support for a strong regulatory approach, the same respondents overwhelmingly believed that the best way to get people to save energy is by "encouraging voluntary conservation" (70 percent) rather than "passing and enforcing laws" (20 percent). Nor did Milstein's participants favor a free-market approach: 70 percent agreed with the statement that "raising [the] price of fuel is not fair, because rich people will use all they want anyway."' 8

\footnotetext{
${ }^{77}$ Milstein, op. cit., p. 5

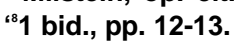




\section{DISTRUST OF INFORMATION PROVIDERS AND DISBELIEF IN REALITY OF SHORTAGES}

In February 1977, a month with widespread natural gas shortages, three-fifths of the consumers in Milstein's national sample believed that fuel shortages were "real." By March, however, fewer than half the sampled population thought so; this percentage has been consistent most of the time since the end of the Arab oil embargo. One-third of Milstein's respondents said they believed shortages are contrived by vested interests for economic or political gain. '9

The National Opinion Research Center at the University of Chicago found in a year-long series of weekly surveys that consumers held a widespread belief that the Federal Government and the oil industry-two major sources of advertising campaigns urging conservation -were actually responsible for the energy crisis through mismanagement and/or design. 20

\footnotetext{
${ }^{\prime}$ Ibid., p. 5.

“"James Murray, et al., "Evolution of Public Response to the Energy Crisis," Science 184:257-63, cited in Cunningham and Lopreato, pp. 144-145.
}

A number of other studies also found that consumers blame the energy problem on oil companies, utilities, "big business," and Government. In one public opinion survey, respondents blamed "oil company actions" and "Government favoritism to the companies" most for fuel shortages, but also placed some blame on "wasteful energy consumption." Very few believed the world was running out of fossil fuel. "'Nine out of ten in Milstein's 1977 survey agreed with the statement that the Government should investigate oil and natural gas companies to make sure they do not hold back production. ${ }^{22}$

\section{LACK OF SPECIFIC KNOWLEDGE ABOUT HOW TO CONSERVE}

Adding to this general mistrust of governmental and business advocates of conservation is the disincentive created by lack of consumer understanding about how to save energy. Milstein found that 36 percent of the respondents to a 1976 survey did not know that lower wattage light bulbs use less electricity, and 59 percent thought that leaving a light burning used less energy than switching it on and off as needed. Although water-heating is the second largest energy-consuming activity in the home (after heating and cooling), only 42 percent knew where to find their water heater controls or how to set them. Only 13 percent of respondents to the 1976 survey believed their houses needed additional insulation, ${ }^{23}$ al-

${ }^{23}$ Jeffrey S. Milstein, Attitudes, Knowledge and Behavior of American Consumers Regarding Energy conservation With Some Implications for Governmental Action (Washington, D. C.: Federal Energy Administration, October 1976), p. 6. though Milstein's 1977 survey found that 20 percent of all homes had no insulation at all and many more were inadequately insulated. Consumers do know that lowering thermostats saves energy and money, but Milstein found in 1977 that half the public believed that thermostats must be turned down $\mathbf{5 0}$ or more to save energy. ${ }^{24}$

Government efforts to help consumers determine savings potential and to provide practical "how to" information have either been too complex or not been made widely available, owing to funding problems. The information problem is particularly challenging because of regional variations in prices, heating requirements, and fuel mixes, as well as infinite variations in the thermal characteristics of the current housing stock.

\footnotetext{
${ }^{24}$ Milstein, How Consumers Feel (1977), P. 5.
} 


\section{FAITH IN "AMERICAN TECHNOLOGICAL KNOW-HOW" TO SOLVE THE ENERGY PROBLEM}

Americans are proud of the Nation's technological achievements, especially in producing "modern conveniences" and in glamorous accomplishments such as putting men on the moon. A 1975 study by Angell and Associates found respondents optimistic about prospects for solving the energy problem through American technological "know-how." ${ }^{25}$ Similarly,

\footnotetext{
${ }^{25}$ Angell and Associates, Inc., A Qualitative Study of Consumer Attitudes Toward Energy Conservation (Chicago, III.: Bee Angell and Associates, 1975), cited in Cunningham and Lopreato, pp. 121-122.
}

Bultena found consumers favoring "technological solutions" much more strongly than policies to reduce demand or promote efficiency. ${ }^{26}$ This optimistic view may dampen consumers' motivation to conserve, as it places the burden of a remedy on others, specifically the U.S. scientific community.

${ }^{26}$ Bultena, op. cit.

\section{CONSUMERS AND THE BUILDING INDUSTRY}

The preceding discussion focused on consumer attitudes and behavior relative to the overall energy problem and to conservation in particular. It is appropriate now to turn to the area of the consumer's role in the energy conservation aspects of decision making on housing.

As noted earlier in this chapter, families purchasing new homes typically make a series of judgments and comparisons, weighing such factors as attractiveness, size, location, convenience, comfort, and - not insignificantlyaffordability. Since very few homes are likely to be regarded as one's dream house, buyers must weigh the pluses and minuses of each potential choice.

What role does energy conservation play in these choices? Until recently, it would have been safe to say little or none. The presence of a fireplace, a family room, wall-to-wall carpeting, a picture window, a powder room - factors like these, along with external attractions such as convenience to schools, shopping, and transportation dominated the choice of a new home. Indeed, these factors remain very important in buyers' perceptions. But a 4-year series of surveys conducted by Professional Builder magazine suggests that families entering the market for new homes are increasingly aware of energy considerations as part of the choice process, and are expressing willingness to alter their buying habits somewhat to realize cost savings in energy .27

It has become commonplace to argue that builders and buyers alike tend to look only at first costs and ignore lifecycle costs when determining what features to include in a house. The Professional Builder survey suggests that this may no longer be the case when it comes to energy conservation.

In querying families currently in the market for newly constructed homes, Professional Builder asked this question in $1975,1976,1977$, and 1978:

Suppose you were interested in a new home and a builder told you that by spending $\$ 600$ more at the time of construction, he could cut your heating and cooling bills by $\$ 100$ per year. What would be your reaction?

In answering the question, respondents were given four choices:

\section{I would spend the additional $\$ 600$.}

"Data from the Profession/ Builder Annual Consumer/Builder Surveys of Housing can be found in the following issues of the magazine: 1975 data, January 1976; 1976 data, January 1977; 1977 data, December 1977; and 1978 data, December 1978. 
2. l'd be willing to spend even more to save more.

3. I would not spend the $\$ 600$ because the savings take too long to recover.

4. I would not spend the $\$ 600$ because the savings are not believable.

Results were tabulated according to type of home sought (detached single-family, attached single-family, or multifamily), economic status (measured by family income and by price range of home to be purchased), and geographic region. The results, described below, suggest that buyer attitudes are not an impediment to energy conservation, even when long-range conservation requires an increased initial investment.

Among 248 potential buyers of single-family homes in 1975, 80.5 percent expressed their willingness to spend $\$ 600$ to realize an annual saving of $\$ 100$ in energy costs, and another 8.8 percent said they would spend even more if the saving would be increased as well. In 1976, the percentage willing to spend $\$ 600$ or more remained nearly constant (89.1 percent), but of that fraction, a larger group than before (1 5.1 percent of the total sample of 596) expressed a willingness to pay even more than $\$ 600$ for a greater annual saving. In 1977, 93.2 percent of respondents were willing to spend $\$ 600$ or more to save $\$ 100$ or more in annual energy costs. In 1978, the fraction of willing energy savers returned to its $1975-76$ level of 89 percent.

It is particularly interesting to note that this willingness on the part of new-home consumers to increase their first costs to save money on energy over the long run can be found in similar percentage of every income group and every house price-range group. This is shown in table 26.

In its 1977 survey, Professional Builder asked potential buyers whether they would purchase, or consider purchasing either now or in the future, solar heating and water heating systems in order to reduce their fuel bills. The results indicate that solar is an idea whose time has not yet come, in terms of public acceptability, but that homebuyers are keeping an open mind and might well consider solar more
Table 26.-Percent of Potential Homebuyers Willing to Spend $\$ 600$ or More at Outset to Save $\$ 100$ or More Annually on Energy, by Family Income and House Price Range

\begin{tabular}{|c|c|c|}
\hline & 1975 data & 1976 data \\
\hline $\begin{array}{l}\text { By family income } \\
\text { Less than } \$ 15,000 \ldots \ldots \ldots \ldots \ldots \\
\$ 15,000-\$ 19,000 . ., \ldots \ldots \ldots \ldots \ldots \\
\$ 20,000 \text { or more. } \ldots \ldots \ldots \ldots \ldots\end{array}$ & $\begin{array}{l}89.2 \\
89.7 \\
89.1\end{array}$ & $\begin{array}{l}87.9 \\
89.2 \\
92.3\end{array}$ \\
\hline 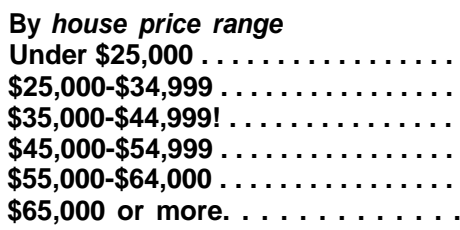 & $\begin{array}{l}90.2 \\
90.8 \\
88.9 \\
84.6 \\
90.6 \\
-\end{array}$ & $\begin{array}{l}88.8 \\
90.1 \\
85.5 \\
84.1 \\
94.7 \\
95.5\end{array}$ \\
\hline
\end{tabular}

seriously in the future. Told that solar space heating might cost them $\$ 7,000$ in additional first costs but could reduce fuel bills by 30 to 70 percent, only 8.4 percent of respondents said they would purchase the solar option; another 35.6 percent indicated they would consider purchasing it; 35.1 percent would not do so now but might in the future; and 20.4 percent said a flat no to solar heat. Consumers were also asked to consider a solar water heating system that would cost $\$ 1,200$ and save between 50 and 80 percent of water heating costs. Among those responding, 7.1 percent indicated they would purchase the system; 37.7 percent would consider the option; 39.5 percent might do so later; and $\mathbf{1 4 . 0}$ percent would not be interested, period.

Looking at six major housing markets in mid-1 978, l-lousing magazine surveyed buyers to learn what energy-saving options (among other housing choices) they wanted in the homes they would purchase. Costs for the options varied from city to city; in showing the results in table 27, cost ranges are provided.

Given the complex interplay between builders and buyers in determining what features and designs will be included in new homes, it is useful to look not only at buyers' opinions, but also at builders' perceptions of buyers' opinions. Builders remain the primary decisionmakers in new construction, but their decisions reflect what they find to be the dominant char- 
Table 27.-Percent of Homebuyers Desiring Energy-Saving Features in Five* Major Housing Markets, 1978

\begin{tabular}{|c|c|c|c|c|c|c|}
\hline \multirow[b]{2}{*}{ Energy-saving feature } & \multirow[b]{2}{*}{ Cost range } & \multicolumn{5}{|c|}{ Market area } \\
\hline & & Wash., D.C. & Miami & Chicago & San Fran. & San Diego \\
\hline $\begin{array}{l}\text { Upgraded insulation. . . . . . . . } \\
\text { Double-glazed windows. . . . } \\
\text { Solar water heater. . . . . . . . . } \\
\text { Solar space and water . . . . }\end{array}$ & $\begin{array}{r}\$ 500-1,500 \\
\$ 750-2,000 \\
\$ 1,800-2,000 \\
\$ 7,000-13,000\end{array}$ & $\begin{array}{l}97 \\
91 \\
34 \\
32\end{array}$ & $\begin{array}{l}88 \\
70 \\
58 \\
48\end{array}$ & $\begin{array}{l}95 \\
86 \\
25 \\
21\end{array}$ & $\begin{array}{l}95 \\
68 \\
41 \\
42\end{array}$ & $\begin{array}{l}83 \\
34 \\
36 \\
24\end{array}$ \\
\hline
\end{tabular}

"Phoenix, surveyed only with regard to upgraded insulation, is excluded from the table.

SOURCE: "What Home Shoppers Seek in Six Major Markets," Housing, October 1978.

acteristics of market demand. In early 1978, Professional Builder asked housing contractors, "How important is energy conservation to your customer?" Ninety-seven percent said it was either "somewhat important" (53 percent) or "very important, vital to buying decision" (44 percent). Given this overwhelming evidence, it is safe to say that purchasers of new housing are indeed energy-conscious, and that builders are sensitive to this concern.

\section{CONSUMER BEHAVIOR AND ENERGY CONSERVATION IN HOME OPERATION}

Does consumer behavior really make a significant difference in energy consumption? If not, consumers will have little incentive to cut back. But if so-and if the answer is measurable in dollars and cents - a residential energy conservation campaign will find a receptive audience.

Data on the direct impact of behavior on energy consumption have only recently become available-and the early returns, based on utility bills and other records, along with the experience of fuel suppliers - indicate that the way a home is used makes a substantial difference in how much energy is used. There are savings to be had - and while they will not, in the long run, compare with the vast savings derived from a house designed to save energy-the savings are real and can play a large role in reducing energy use in existing housing.

Thermostat and air-conditioner settings are an obvious example. The use of hot water can be a major energy drain. Opening or closing shades and curtains, using natural or mechanical ventilation, opening and closing doors, leaving windows open at night-all these and other choices combine to affect the total energy consumption for any given family.
Even more dramatic are certain observations about variable energy use levels in houses of similar or identical design. Wybe observed two houses, built by the same contractor, which were expected to have identical thermal characteristics. One used 2.2 times as much heat and 75 percent more total energy than the other..$^{28}$ Jay McGrew observed in a related analysis that the occupants' knowledge of proper energy management was generally more important in achieving low energy consumption than the quality of the construction. 29

Princeton University researchers found similar evidence in the Twin Rivers Project. In a sample of nine identically constructed townhouses, each with similar orientation, consumption of gas for heating varied by as much as a factor of 2 to 1 . When occupants changed, gas consumption also changed. In the nine townhouses where gas consumption was monitored from 1972-76, one house moved from the highest consumer (1975) to the lowest consum-

\footnotetext{
${ }^{28}$ Wybe J. van der Meer, "Energy Conservative Housing for New Mexico," report 76-163, prepared for the New Mexico Energy Resources Board, 1977, p. 19.

*'Jay McGrew, President, Applied Science and Engineering, Inc., private communication.
} 
er (1976) when occupancy changed, dropping almost 50 percent. When these nine houses were retrofitted, the gas consumption of each fell by an average of approximately 30 percent, but the ranking of the houses remained essentially the same. 30

${ }^{30}$ R.H.Socolow, "The Twin Rivers program on Energy Conservation in Housing: Highlights and Conclusions," Energy and Buildings, vol. 1, no. 3, April 1978, p. 225.
Although it is clear that the way people live is important in residential energy consumption, it is more difficult to determine how much energy could be saved by behavioral change, because the major determinants of use are the number and age of occupants, combined with living and working patterns, Also, large savings reflecting purely behavioral effects should drop as houses are better constructed and more energy sensitive from the beginning.

\section{CONCLUSIONS}

Using data from the large number of studies that have been completed in the area of consumer attitudes and behavior with respect to energy conservation, it is possible to state the following general conclusions with policy implications:

1. Consumer decisions on housing are complex, and it would be unrealistic to propose energy conservation options that fail to recognize this. Homebuyers look for many things besides energy efficiency in a home. They are conservative about drastic changes in house design or in home lifestyles. There is, however, great latitude for efficiency improvement in the structure and operation of the home within the confines of consumer tastes and needs.

2 Consumers are becoming more aware of the need for conservation, but this awareness does not necessarily lead to conservation behavior. Many consumers lack practical knowledge about how to accomplish conservation and harbor a degree of mistrust about Government and industry as information sources. Much of the available technical information appears to be too complicated or inaccessible for consumer use.
3. Consumers are most easily motivated by the prospect of monetary savings. Exhortations about the need to reduce imports or prevent energy-related environmental problems do not move most people to take conservation steps,

4. Consumers are undertaking minor adjustments (lights out, thermostats down) to their energy-consumin ${ }_{g}$ practices, but are displaying reluctance about major investments or lifestyle changes.

5. There are significant discrepancies in actual conservation opportunities (as well as incentives) among different income groups. Low-income consumers have little latitude to conserve, and upper income families lack the financial incentive, leaving conservation mostly in the hands of the middle-income householders.

6. Impediments to consumer conservation include inadequate information, conflicts with other goals, lack of perceived financial reward, doubts about others' motivations and commitments, and complacency about forthcoming technological solutions 
Chapter IV

\section{LOW-INCOME CONSUMERS}




\section{Chapter IV.-LOW-INCOME CONSUMERS}

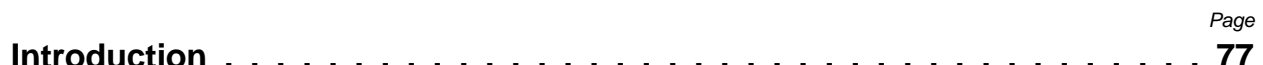

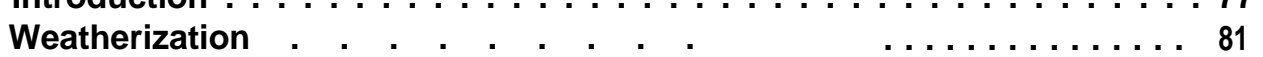

Low-Income Tenants. . . . . . . . . . . . . . . . . . . . . . . . 83

Emergency Financial Assistance for Utility Payments.. . . . . . . . . 83

Utility Policies for the Poor and Near-Poor . . . . . . . . . . . . . 85

I-lousing, Energy, and the Poor. . . . . . . . . . . . 87

\section{TABLES}

28. Consumption of Electricity and Natural Gas in U.S.

Households by Income Group, 1975. . . . . . . . . . . . . . 86 


\section{INTRODUCTION}

Energy problems hit hardest in low-income households. About 17 percent of the U.S. population - or 35 million Americans-have incomes below 125 percent of the official poverty line, ' and this group feels the most severe effects of inflation, unemployment, and high energy bills. ${ }^{2}$

Utility costs erode the meager budget of a low-income family. Utility costs account for 15 to 30 percent of the total available income for the low-income family, ${ }^{3}$ depending on the

1This 17-percent figure includes approximately 25 million people whose incomes are below, and approximately $\mathbf{1 0}$ million people with incomes no more than 25 percent above, the poverty level, as based on a poverty index developed by the Social Security Administration in 1964, modified by a Federal Interagency Committee in 1969 , and revised in 1974. For a nonfarm family of four in 1978 , the poverty line was set at an income level of $\$ 6,200$ per year.

${ }^{2} U$ sing Consumer price index (C PI) data as a measure of inflation, gas, electricity, fuel oil, and coal costs rose at rates 1.6 to 3.0 times the rate at which the CPI rose between 1972 and 1977. No other major CPI item had rates of increase as high.

Table A.-Consumer Prlce Index Increases, 1972-77

\begin{tabular}{|c|c|c|}
\hline & $\begin{array}{c}\text { Increase in CPI } \\
1972-77\end{array}$ & $\begin{array}{l}\text { Ratio of increase } \\
\text { of all items: } \\
\text { to each item }\end{array}$ \\
\hline All items $\ldots \ldots \ldots \ldots \ldots \ldots \ldots \ldots \ldots \ldots$ & 55.3 & - \\
\hline Food $\ldots \ldots \ldots \ldots \ldots \ldots$ & 68.2 & 1.2 \\
\hline Rent $\ldots \ldots \ldots \ldots \ldots \ldots \ldots$ & 33.0 & .6 \\
\hline Home ownership. $\ldots \ldots \ldots \ldots \ldots \ldots \ldots$ & 62.2 & 1.1 \\
\hline Fuel oil and coal $\ldots \ldots \ldots \ldots \ldots \ldots \ldots$ & 164.1 & 3.0 \\
\hline Gas and electricity $\ldots \ldots \ldots \ldots \ldots \ldots$ & 90.4 & 1.6 \\
\hline Apparel and upkeep $\ldots \ldots \ldots \ldots \ldots$ & 31.1 & .6 \\
\hline Transportation, public $\ldots \ldots \ldots \ldots \ldots$, & 38.1 & .7 \\
\hline Transportation, private. $\ldots \ldots \ldots \ldots$ & 60.3 & 1.1 \\
\hline Medical. $\ldots \ldots \ldots \ldots \ldots \ldots \ldots$ & 68.0 & 1.2 \\
\hline
\end{tabular}

The costs of food and medical care, for example, increased at rates only $\mathbf{1 . 2}$ times greater than did the overall CPI, while the costs of rent, apparel, and public transportation increased at rates less great than did the overall CPI. (Ratios of increases in gas, electricity, fuel oil, and coal costs from 1972-77 derived from table 770, p. 478. Statistical Abstract of the United States 1977.)

It is interesting to note the course of progress in the reduction of poverty since 1959 . I $n$ that year there were approximately 55 million persons below 125 percent of the poverty level, constituting about 31 percent of the total population. The greatest reduction occurred in the 1959-68 period, at the end of which 35.9 million persons or 18 percent of the population, were below 125 percent of the poverty level. There has been no significant reduc- tion in poverty since then. See Statistical Abstract of the United States 1977, U.S. Bureau of the Census, 98th edition, Washington, D. C., 1977, table 733, p. 453.

${ }^{3}$ These figures on average household expenditures for home fuels as a percentage of disposable income were submitted by the Federal Energy Administration (FEA) to the U.S. Senate's Special Committee on Aging. The figures were taken from FEA's Household Energy Expenditure Model (HE EM). The H E E M data shows:

Table B.-Average Annual Household Expenditures on Home Fuels as a Percent of Disposable Income by Age of Household Head, United States

\begin{tabular}{ccccc}
\hline & \multicolumn{3}{c}{$\begin{array}{c}\text { Household head } \\
\text { under } 65\end{array}$} & \multicolumn{2}{c}{65 and over } \\
\cline { 2 - 6 } Disposable income & 1973 & 1976 & 1973 & 1976 \\
\hline Less than $\$ 2,000 \ldots, \ldots \ldots \ldots \ldots \ldots$ & 34.1 & 50.1 & 34.5 & 50.7 \\
$\$ 2,000-\$ 5,000 \ldots \ldots \ldots \ldots \ldots \ldots \ldots \ldots$ & 10.1 & 15.9 & 10.3 & 15.1
\end{tabular}

According to U.S. Census figures, $\mathbf{1 7 . 9}$ percent of all households have total incomes of $\$ 5,000$ or under (1976). In other words, the first two brackets up to $\$ 5,000$ income correspond reasonably well to the 20 percent of the population at poverty line or below. Thus, a range of 15 to 50 percent would seem to be justified. However, the percentages in the above tables were calculated assuming the mean household incomes within each income bracket was equal to the midpoint of the bracket, i.e., that the mean household income within the less than $\$ 2,000$ bracket is $\$ 1,000$. Given that welfare payments for a single person are $\$ 177$ per month or $\$ 2,124$ per year, the number of households subsisting on $\$ 1,000$ per year is probably very small.

Thus, only a small percentage of households within that bracket are paying 50 percent of their incomes for energy. Twenty-five percent would be a more statistically meaningful figure, giving a range of 15 to 25 percent.

Middle-income families typically pay less for utility cost partly because most utility companies use some variation of the declining-block rate structure; the first block of energy consumed is charged the highest price, per unit price additional increments of energy consumed, the lower the average price that is paid.

(Continued) 
type of housing and the cost of different forms of energy in various parts of the country. Middle-income Americans, on the other hand, spend only about 5 percent of their total available income on utility bills. Further, increases in welfare payments and other assistance tied to the Consumer Price Index have not kept up with escalating energy costs. In 1972-79, fuel oil prices rose 197.3 percent, and gas and electricity prices rose 134 and 78 percent; meanwhile, the Consumer Price Index rose only 68.6 percent. ${ }^{4}$ Hence the substantial and growing proportion of a low-income family's budget that goes for utilities affects the family's ability to pay for other essentials such as food, rent, and clothing. Data from crisis intervention and weatherization programs sponsored by the Community Services Administration (CSA) have shown a large number of poor families spending $\mathbf{4 0}$ to $\mathbf{5 0}$ percent of their household budgets on fuel and utility costs during the heating season. ${ }^{5}$ Some of these families face a choice between paying for food and having their utilities shut off. Low-income families lack discretionary income that they could divert from other expenses to meet escalations in energy costs.

\section{(Continued)}

(See The Impact of Rising Energy Costs on Older Americans, Hearings before the Special Committee on Aging, U.S. Senate, 95th Cong., Apr. 7, 1977 (Washington, D. C.: U.S. Government Printing Office), stock \#052-070-042303), 1977, pt. 5, p. 259.

For corroborating information placing current U.S. low-income energy costs in the 15 to 25 percent of disposable income range, also see Hollenbeck, Platt \& Boulding, An Analysis of the Effects of Energy Cost on Low-Incorne Households, table 2 submitted to the Bureau of Applied Analysis, Regional Impact Division, Department of Energy, on Apr. 6, 1978, in response to a request by OTA; and Dorothy $\mathrm{K}$. Hewman and Dawn Day, The American Energy Consumer, ch. 5 and 7 (Cambridge, Mass.: Ballinger, 1975).

'See note 1. In 1973 (the last year for which data was available) before taxes, the poorest half of the U.S. lowincome population (those making less than $\$ 3,400$ yearly) spent an average of $\mathbf{5 2 . 1}$ percent for food: an estimated $\mathbf{2 0 . 0}$ percent for rent; 21.4 percent for gas, electricity, and other fuels; and had 6.5 percent left for apparel, medical care, and other expenditures.

Energy costs (see note 2) have risen at rates three times that of other costs. Projections of energy costs for people with disposable income below the poverty line indicate that energy costs, which represented 20.5 percent of a poor household's disposable income in 1974, may represent 31.8 percent by 1985 (Hollenbeck, Platt, Boulding, op. cit., tables 2 and 8 ). Any little discretionary income low-income people have will be eliminated and substitutions must be made from other cost categories, like food.

(Derived from table 9.26, p. 472, Social Indicators: 1976 (Washington, D. C.: U.S. Department of Commerce, 1977), and communication with Eva Jacobs, Bureau of Labor Statistics.)

${ }^{5}$ From testimony given by Mr. Tony Majori, Associate Director, Community Relations-Social Development Commission of Milwaukee County, Milwaukee, Wis., before the U.S. House Select Committee on Aging, Subcommittee on Housing and Consumer Interest, Sept. 26, 1978.
Nearly half (49 percent) of all low-income households live in the Northeast and NorthCentral regions, where winters are cold and prices for electricity and natural gas are high. More than half (54 percent) of all low-income families occupy single-family detached dwellings, which require more energy to heat than apartments or rowhouses. Fifty-five percent of the poor and near-poor rent their housing units; this tends to diminish their opportunities to control residential energy requirements or to make conservation-related home improvements. I $\mathrm{n}$ the colder Northeast, 59 percent of low-income families live in apartments, reducing their energy needs (relative to occupants of free-standing homes) but also reducing their control over energy consumption.

Forty-two percent of all low-income households live in rural areas or in small towns. For these 5.9 million families, home is often a small, old, substandard, uninsulated, and poorly heated single-family house. Only 51 percent have central heating, and 28 percent use supplementary room heaters. The large number of poor and near-poor families living outside metropolitan areas accounts for the fact that persons in this income group are five times as likely as those in the middle and upper groups to use wood, kerosene, coal, or coke to heat their homes instead of the more common oil, gas, or electricity.

\footnotetext{
'All statistics in this section describing energy-related characteristics of low-income households are from Eunice S. Crier, Colder. . . Darker: The Energy Crisis and Low-Income Americans (Washington, D. C.: Community Services Administration), \#B6B5522, June 1977.
} 


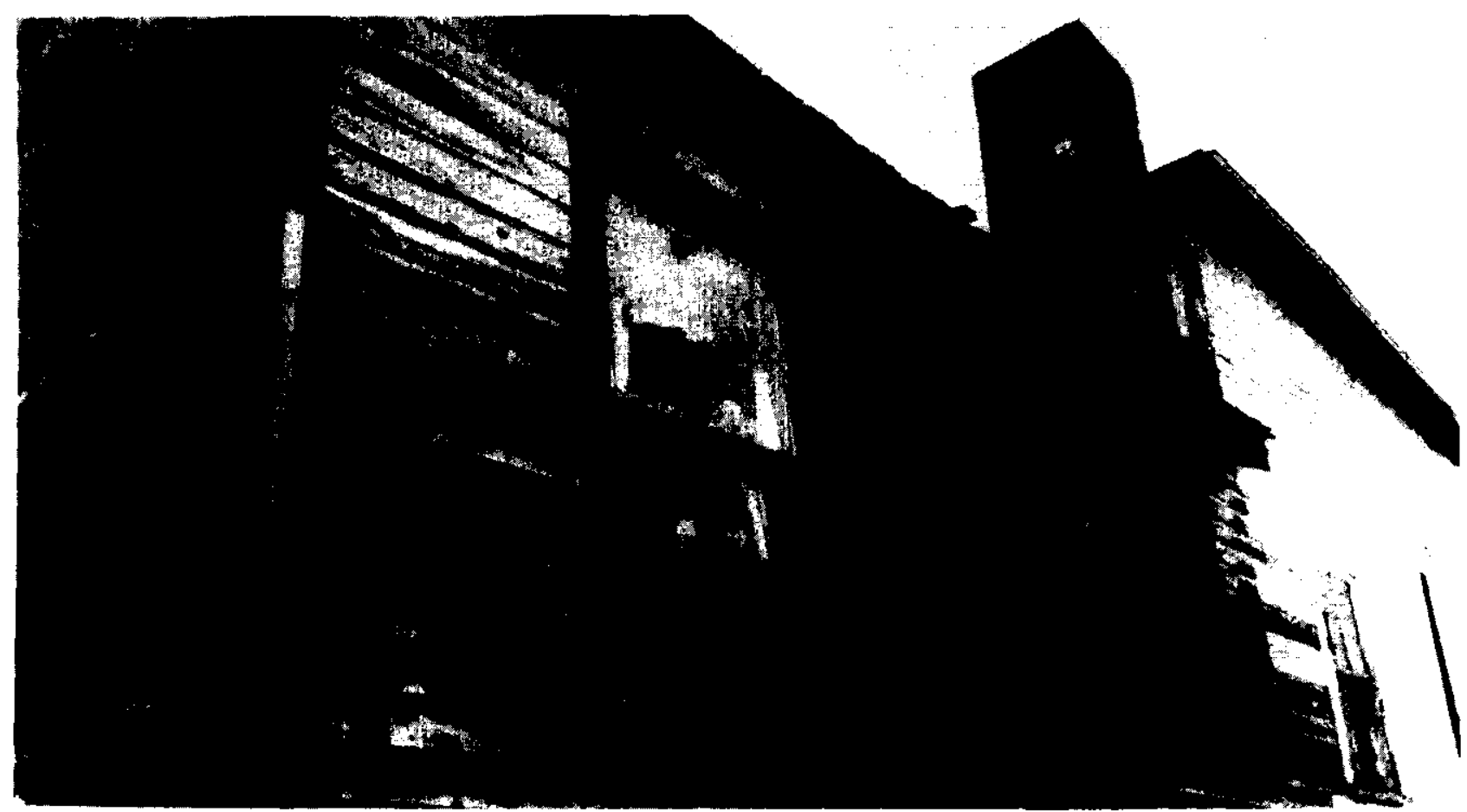

The poor-This photo is not an unusual sight in the rural poor areas throughout the United States. Note the homemade fuel rig and the patch-quilt siding to keep out the drafts and the elements

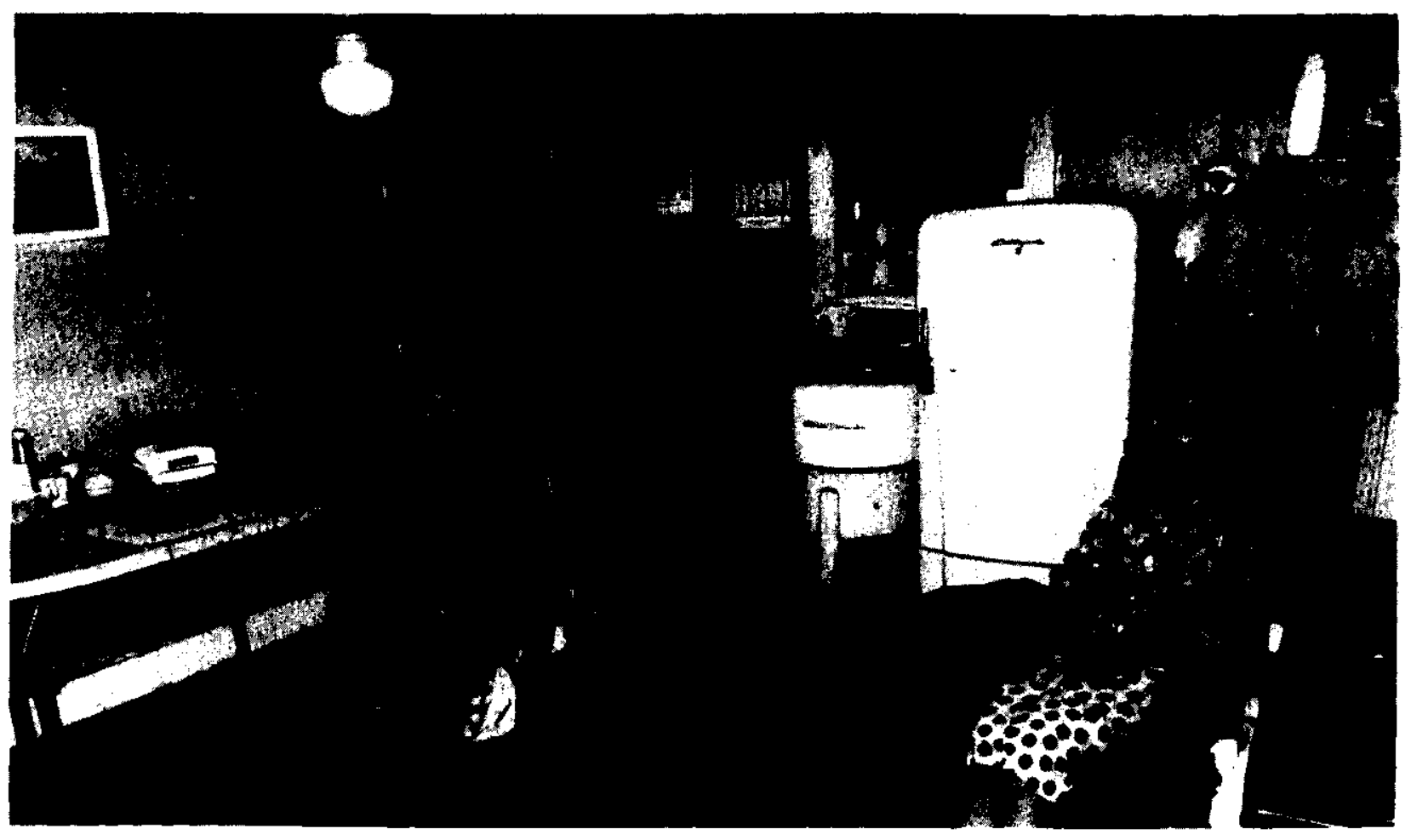

Photo credits: Department of Eneryy photos by Jack Schneider, 1975

The low-income elderly - Inadequate electrical wiring creates a hazardous situation for the older contructed homes that retired people must confront due to economic situations 
About 37 percent of all low-income households are headed by elderly persons; conversely, about 37 percent of all elderly households are classified as poor or near-poor. Just over half of these elderly low-income households live in the Northeast and North-Central regions. They tend to use more natural gas than other low-income households - and to pay a higher portion of their incomes for it-while consuming much less electricity. This means that a bigger share of the low-income elderly household's energy use can be attributed to space heating, the most essential use.

The poor and the elderly are usually not in a position to lower fuel bills by reducing consumption. Available data show that the average low-income household in 1975 used 55.4 percent less electricity and 24.1 percent less natural gas than the average middle-income U.S. household. In the aggregate, low-income households used only 11 percent of total U.S. residential energy, although they accounted for 17 percent of population. These figures are especially significant because at least 43 percent of low-income households have no insulation, and 58 percent have no storm doors or storm windows - factors that drive up the amount of home fuel use required to maintain minimum conditions of health and comfort. Moreover, 39 percent of low-income households have no thermostat or valve with which to control their heat, and among low-income renters 49 percent lack such control. Given these circumstances, recent increases in utility and fuel bills severely penalize poor people who cannot significantly cut consumption without enduring health hazards in their drafty, uninsulated homes. Similarly, lack of funds to pay for air-conditioning in hot climates has resulted in death from heat prostration for some low-income citizens. According to a newspaper account, the 20 persons who died from heat in Dallas, Tex., in July 1978 were elderly, poor, and without air-conditioning. ${ }^{7}$ The elderly, who comprise a substantial

'See Crier, ibid., p. 3; The Washington Post, "Life and Death in the Heat," July 22,1978, p. A8; and A. Henschel, et al., Heat Tolerance of Elderly Persons Living in a SubTropical Climate (Washington, D. C.: DHEW, Bureau of Disease Prevention and Environmental Control, National Center for Urban and Industrial Health, Occupational Health Program, February 1967). proportion of the poor and near-poor population, are more susceptible than the general population to health problems that are aggravated by cold (e. g., respiratory ailments, arthritis, or hypothermia) and by heat, because their bodies are less able to adapt to extreme temperatures. $^{8}$

\section{Three types of policy questions emerge:}

- How can it be ensured that the energy problems of the poor and the elderly are not overwhelming in either a financial or a health sense? Because low-income citizens are normally the last to move into newer and more energy-efficient housing, their proportion of residential energy consumption could actually increase over time.

- How can the financial hardships faced by the poor and elderly in purchasing adequate energy supplies be addressed without creating a dependency on long-term Federal financial subsidies or relief programs? How can a self-reliant approach be encouraged?

- How can low-income persons participate best in solving their energy problems, perhaps acquiring skills and preparing themselves for future jobs at the same time?

The questions are especially challenging because policy makers face difficult choices. Given limited Government financial resources, what criteria should be used to ensure that the neediest are reached first? How many Federal dollars should be directed toward helping poor households reduce energy consumption, and how many to help to pay utility and fuel bills? How should energy-related needs be coordinated with other social needs such as day care centers, job training, or medical care? How

\footnotetext{
${ }^{8}$ See K H Collins, et al., "Accidental Hypothermia and Impaired Temperature Homostasis in the Elderly," British Medical Journal, 1977, 1, 353-356; G. L. Mills, "Accidental Hypothermia in the Elderly," British Journal of Hospital Medicine, December 1973; Robert D. Rochelle, "Hypothermia in the Aged," Institute of Environmental Studies, University of California, Santa Barbara; Fred Thumin and Earl Wires, "The Perception of the Common Cold, and Other Ailments and Discomforts, as Related to Age, 'International Journal of Aging and Human Development, vol. 6(1), 1975.
} 
does a national goal of raising energy prices to levels that reflect true costs affect the poor? How could the Federal Government mitigate these adverse side-effects of an otherwise desirable policy?

Price mechanisms that encourage conservation through the marketplace do indeed exacerbate the financial problems of low-income persons. Tax incentives and penalties also discriminate against the poor. Direct subsidies, such as energy stamps patterned after food stamps, could address some of the problems the poor face in paying utility bills-at least temporarily. However, critics argue that such subsidies fail to get at the sources of the problem and tend to become self-perpetuating.

\section{WEATHERIZATION}

The most effective way to cope with higher prices is to reduce energy requirements by "weather i zing" homes. Federally sponsored weatherization grant programs have demonstrated the benefits of this approach. The Federal Government operates three separate but similar weatherization grant programs- in the Department of Energy (DOE), the Community Services Administration (CSA), and the Farmers' Home Administration (FmHA). Before passage of the National Energy Conservation Policy Act of 1978 (NECPA), these three programs operated under varying eligibility requirements and other administrative rules. The new law unifies the programs, all of which are designed to provide direct assistance to low-income homeowners and occupants by sending workers into the field to install insulation, storm windows, and other conservation devices. Recipients pay nothing for this service. Labor is provided primarily through the Department of Labor's Comprehensive Employment and Training Act (CETA) program.

The weatherization program of FmHA was limited, until passage of NECPA during the final days of the 95th Congress, to loans of up to $\$ 1,500$ at 8-percent interest to rural homeowners; no outright grants were available to those unable to afford to go into debt in order to save energy. The new energy law adds grants to FmHA programs on the same terms as those in the DOE and CSA programs, except that FmHA provides extra funds for labor when CETA workers are unavailable.

Unfortunately, low funding levels during the early years of the weatherization grant programs in DOE and CSA permitted only 3.5 per- cent of all low-income housing in need of weatherization to be retrofitted with conservation materials through October $1978 .^{\circ}$

Several other problems also emerged in the first 2 years of Federal weatherization efforts, particularly in the DOE program. Among them were overly restrictive limits on expenditures for weatherization materials and transportation of workers and equipment to the work site, a firm limit of $\$ 400$ in expenditures on each housing unit, and exclusion of all mechanical devices costing more than $\$ 50$ from the list of conservation materials to be installed. A labor shortage plagued the programs; without special funding for labor, both DOE and CSA relied almost exclusively on CETA workers, who were often unavailable. Finally, because families had to be at the poverty level or below to be eligible for DOE weatherization services, many near-poor households with substantial need for energysaving improvements were excluded from the program.

The recent National Energy Conservation Policy Act of 1978 and Comprehensive Employment and Training Act Amendments of 1978 have remedied some of these difficulties.

\footnotetext{
'This determination of the "total need," or the total number of poor and near-poor housing units that could be weatherized, is based on the fact that there are approximately 14 million households below 125 percent of the poverty level. Sixty percent are single-family dwellings and 22 percent are apartments of eight units or less, thus yielding approximately $11,480,000$ potentially weatherization units. According to the Community Services Administration, approximately 400,000 units had been weatherized by October 1978,
} 
The eligibility ceiling for DOE weatherization has been raised to 125 percent of the poverty line to include all those households generally considered to be low-income. The legal definition of weatherization materials has been expanded to include replacement burners for furnaces, flue dampers, ignition systems to replace pilot lights, clock thermostats, and other items that may be added by regulation. The new law also calls for development of procedures to determine the most cost-effective combination of conservation measures for each home, taking into account the cost of materials, the climate, and the value of the energy to be saved by the materials. The limit on allowed expenditures for each dwelling has been raised to $\$ 800$, an amount that includes materials, tools, and equipment; transportation; onsite supervision; and up to $\$ 100$ in repairs to the house that are needed to make the energy improvements worthwhile. Most important, the DOE program funding authorizations have been increased to $\$ 200$ million annually for FY 1979 and 1980. The new FmHA grant program is authorized at $\$ 25$ million for FY 1979.

Weatherization programs are especially appealing because they can help low-income persons not only to save energy, but in some cases also to obtain job training and improve their permanent employment prospects. Title VI of CETA authorizes county and local governments or private nonprofit "prime sponsors" to hire unskilled, underemployed, or hardcore unemployed labor for public service work, including weatherization. The primary objective of the program is to facilitate private employment for CETA workers after a 6-month or 1year training experience. Marriage between the weatherization and CETA programs, born of convenience and fraught with difficulties, nonetheless has the potential to make some headway against two of the Nation's most pressing problems -the energy crisis (including inflation in energy prices) and unemployment. More than 30,000 low-income unemployed persons had received training in weatherization skills - installation of home insulation, storm windows, and other conservation devices- by the end of 1978 .

\footnotetext{
“"Public Law 95-524, sec. 123 (c).
}

The chief difficulty in using CETA workers for weatherization has centered on community action agencies' inability to marshall the needed manpower when and where it was needed. Because CETA jobs have been statutorily limited to short periods of time, and because the CETA program as a whole has had to function with only 1-year lifespans (until extended by the new legislation), it has been virtually impossible to plan ahead for adequate labor supplies.

Along with the difficulty of training and scheduling CETAs, lack of authorization to use funds to hire supervisors as well as inadequate funds for training have resulted in limited skills. Program analyses at the local level have shown that little effective training has occurred, and that the more extensive skills that the trainee might have been able to learn and use in construction industry jobs (e. g., basic carpentry) have not been taught. Such factors have limited the trainee's effectiveness on the job and eventual desirability as an employee.

The 1978 CETA Amendments direct the Secretary of Labor to facilitate and extend projects for work on the weatherization of low-income housing, providing adequate technical assistance, encouragement, and supervision to meet the needs of the weatherization program and the CETA trainees. According to Gaylord Nelson, chairman of the Senate Subcommittee on Employment, Poverty, and Migratory Labor, the weatherization provisions of the CETA bill were needed to prevent three-quarters of the 1,000 active weatherization projects in the $\mathrm{Na}$ tion from shutting down for lack of workers.

In spite of the difficulties confronting CETA weatherization, some programs have been effective if not outstanding. For many others, however, continued effort by the Department of Labor, DOE, and CSA will be necessary if the program is to effectively meet its several goals.

Weatherization is not a panacea; this approach offers little help to those beyond the program's reach who face immediate hardship trying to pay high utility bills. Those least likely to receive weatherization assistance are the 55 percent of all low-income families who live 
in rental housing and those living in severely deteriorated housing for which bandaid improvements cannot be justified. For these persons, a number of additional policies may be required.

What additional policy options might be considered? The development of weatherized and rehabilitated public and private housing is one possibility. Or, if the rehabilitation of some housing is too costly, considering its useful life, the construction of new energyefficient housing for the poor might be a more cost-effective use of Federal funds. But given the emphasis that Federal assistance programs usually place on ownership as a precondition to any housing development activity, perhaps programs in individual or cooperative ownership might be developed. In any event, whether these, or other options for renters such as continuing emergency financial assistance are chosen, some action should be taken to address the problems of low-income renters in housing whose energy inefficiency is continually increasing.

\section{LOW-INCOME TENANTS}

The problems of low-income families living in rental housing are especially difficult to address. Those whose units are metered and billed individually have reason to seek ways to reduce energy consumption, but their opportunities to do so are limited. Even if they can afford to invest in conservation measureswhich most cannot-their investments bring them no personal benefits unless they continue living in the unit for a long time. Most tenants are understandably reluctant to improve properties they do not own. Many tenants cannot even control the thermostats or water heaters that serve their units. Individual tenants' relatively low levels of energy consumption mean that they pay the highest rates in the standard declining-block rate design. (See chapter VI.) Landlords who pay utility bills for their properties and pass the cost along to tenants through rent have little incentive to invest in weatherization improvements. When they do make such investments, they pass those costs along, too--so that tenants who move before the payback period is complete fail to receive the financial benefit of the lower utility bills.
Energy costs, along with property taxes and escalating maintenance costs, contribute in a major way to the tendency of slum landlords to abandon substandard buildings. Tenants are seldom well-enough organized to pressure municipal governments into enforcing building codes or retrofitting and renovating buildings that cities acquire through tax liens.

Federal weatherization programs have offered little help to low-income renters, particularly those living in apartments. CSA regulations prohibited use of the agency's funds for retrofitting multifamily housing until recently. The laws governing DOE and FmHA weatherization require that multifamily weatherization projects be designed to benefit tenants rather than landlords and direct the program managers to ensure that rents are not raised as a result of weatherization improvements and that no "undue or excessive enhancement" of the property results from weatherization activities. While these provisions are laudatory, implementing them is difficult.

\section{EMERGENCY FINANCIAL ASSISTANCE FOR UTILITY PAYMENTS}

Because of the slow pace of weatherization efforts and the severity of recent winters, many low-income families have faced the unpleas- ant choice of either sacrificing other necessities to meet utility and fuel costs or finding their gas, oil, or electricity cut off. To avoid 
these difficulties, three Federal programs have been used to help low-income consumers pay utility bills. They are the Department of Health, Education, and Welfare's (HEW) Emergency Assistance and Title XX programs, and the much larger CSA Special Crisis Intervention Program (SCIP).

HEW's Emergency Assistance (EA) Program is available to poor families with one or more children through the welfare system in 22 States. Emergency assistance payments are made to prevent imminent hardship, such as loss of fuel services. Close to 90 percent of the EA caseload is carried by only seven States, however. The Federal Government provides a matching share of 50 percent to States that offer the program. Some States find the required 50-percent non-Federal share too expensive.

Welfare officials often find it difficult to document the legitimacy of emergency needs claimed by applicants. 'Litigation in some States has resulted in court rulings that some State restrictions on the use of EA funds are illegal; State response has sometimes been to stop offering emergency assistance. ${ }^{2}$

Other factors have also limited this program's effectiveness. The program is available only to families with children, and only to public-assistance recipients. Further, a family may not receive EA payments for more than 1 month during any 12-month period.

Funds available through title $X X$ of the Social Security Act of 1975 may also be used to permit low-income consumers to pay fuel bills. Title $X X$ funds have traditionally been used for such social-service purposes as providing clothing and groceries for needy families, or for meeting the needs of handicapped, mentally ill, retarded, or other poor persons with special problems. HEW regulations were amended in January 1978 to permit the use of title XX funds for reimbursement of low-in-

'Consumer Federation of America, Low-Income Consumer Energy Problems and the Federal Government's Response, report to the Office of Technology Assessment, 1978, p. 135.

${ }^{12}$ See, for example, Kozinski v. Schmidt, D.C. Wis., 1975, 409 F. Supp. 215; Williams v. Wohlgemuth, D.C. Pa., 1975,400 F. Supp. 1309. come persons for payment of utility and fuel bills in emergencies. This provision has been controversial because HEW officials have expressed a concern that utility payments could consume such a great portion of title $X X$ funds that too little would remain for more traditional social services. ${ }^{3}$ Furthermore, at least one State- North Dakota-found title XX an impractical tool for utility payments because of the requirement that bills be paid in full before reimbursement funds are released." These problems, particularly the issue of competing needs for limited funds, may jeopardize the availability of title XX funds for energy-related financial assistance.

The Community Services Administration's SCIP was initially funded by a supplemental appropriation of \$200 million in March 1977. The program was intended to make available a variety of financial assistance mechanisms that included grants, loans, fuel vouchers, or stamps; payment guarantees, mediation with utility companies or fuel suppliers, and financial counseling; and maintenance of emergency fuel supplies, warm clothing, and blankets. In practice, assistance was limited to emergency grants in most cases.

Although funded for $\$ \mathbf{2 0 0}$ million, SCIP did not come close to helping all those in need. The maximum payment to individuals or families, limited to $\$ 250$ by Federal regulations, was often too low to cover the total bill, and some States set lower ceilings because the number of applications was too high for the available money. When consumers could not meet their entire bills with SCIP payments, utilities sometimes failed to establish deferredpayment plans and proceeded instead to shut off gas or power. Some utilities reportedly failed to reduce their customers' bills to reflect SC I P payments.

SCIP's major problems in the first year resulted from poor timing. Congress' action in appropriating funds in March was aimed at assisting with bills accumulated during the winter just ending, yet funds did not become available to community action agencies for

'3Consumer Federation of America, op. cit., p. 139

"ibid., p 138. 
distribution until late summer. By then, many poor families had already had their utilities shut off or had sacrificed other essential needs to pay their bills. When funds finally became available, they had to be distributed in the short time remaining in the fiscal year or else revert to the CSA weatherization program, a worthy program but one that could not meet the immediate and critical financial needs of many poor families. Of the amount appropriated in FY 1977, 82 percent was actually distributed to the needy population.

Community action agencies functioned with a frenzy of activity in order to handle SCIP funds in August and September 1977. With no funds provided for administration of the program, the agencies operated with staff hastily borrowed from other community action projects. They undertook efforts to communicate with eligible persons through newspaper, media, and poster advertising, but some failed to reach enough people to use all available funds, despite evidence of a large target population. Others succeeded in their public relations efforts but found potential recipients discouraged by long waiting lines for application processing and lack of transportation assistance, particularly in rural areas.

To be eligible for SCIP payments, utility and fuel customers were required to show written notice from their suppliers of intent to terminate service. Many small dealers in propane, butane, and wood were accustomed to oper- ating informally-for example, farmers who sold wood to their neighbors to earn extra wintertime income - and failed to provide such notice. Their customers were therefore ineligible for SC I P assistance.

Many local SCIP coordinators objected to the program because they felt it forced their agencies into an uncomfortable role: handing out money (like a social service agency) to try to alleviate the effects, rather than the causes, of a problem. They saw this as restraining them from focusing their efforts to do something about the causes of the local energy problem, and as providing local people with an erroneous perception of the agencies' role in their communities: that is, as surrogate welfare departments rather than as organizations which help people become more self-sufficient.

Some local antipoverty workers also took offense at the practice of making payments from Federal CSA funds to private utility companies and fuel oil distributors. They saw SCIP as a continuing subsidy to utilities, and not as a help to the poor."

CSA's second-year financial assistance program, also funded at $\$ \mathbf{2 0 0}$ million, was known as the Emergency Energy 'Assistance Program (EEAP). In FY 1978, funds were made available sooner and program administrators were able to benefit from many of the first year's experiences.

\section{UTILITY POLICIES FOR THE POOR AND NEAR-POOR}

Emergency payments to low-income persons, discussed in the previous section, are intended to forestall utility shutoffs and ensure enough energy to meet basic needs. A number of governmental jurisdictions have imposed additional policies, however, to protect lowincome consumers in their dealings with utilities.

In California, all utilities have been required by law since 1975 to design their electric and gas rate structures so that the first blocks of energy consumed - the amount needed to pro- vide necessary amounts of heat, light, refrigeration, cooking, and water heating - are sold

\footnotetext{
"Data derived from telephone interviews with 44 CAP weatherization, energy, and overall program directors, and interviews with community leaders at OTA. Telephone interviews discussed the structure and problems encountered with CSA energy education programs, which included extensive discussion of weatherization activities and problems with CSA/DOE and other programs, and SC I P, while additional interviews at OTA with local energy personnel visiting in Washington centered on the effect of and improvements that could be made in SCIP and other community energy conservation programs,
} 
at reduced rates. Utility revenues lost through the so-called "lifeline" subsidy are recovered by charging higher rates for energy consumed above the minimum allowance. This policy represents a reversal of the traditional utility "declining block" rate structure.

The California law is premised on a finding that "light and heat are basic human rights and must be made available to all people at low cost for minimum quantities. "Lifeline rates are discussed in the context of utility policy for energy conservation in chapter VI of this report. Here, they are discussed in terms of their purpose in meeting social welfare goals-that is, in preventing severe hardship caused by high energy prices or by termination of essential utility services as a result of inability to pay.

For lifeline rates to function as effective income-transfer devices, low-income households must hold their electricity and gas consumption at or near the low levels needed to meet only essential needs. Available data indicate that on the average, low-income households do indeed consume less energy than households in higher income brackets. A study by the Washington Center for Metropolitan Studies found that in 1975, the average low-income household consumed 60.6 million Btu* of electricity and $\mathbf{1 1 0 . 1}$ million Btu of natural gas, compared with an average of 94.2 million Btu of electricity and $\mathbf{1 3 6 . 3}$ million Btu of natural gas for all households. Table 28 indicates how gas and electricity consumption in low-income households compared with use of these energy sources in middle- and upper-income households. ${ }^{16}$

Table 28.-Consumption of Electricity and Natural Gas in U.S. Households by Income Group, 1975* (millions of Btu)

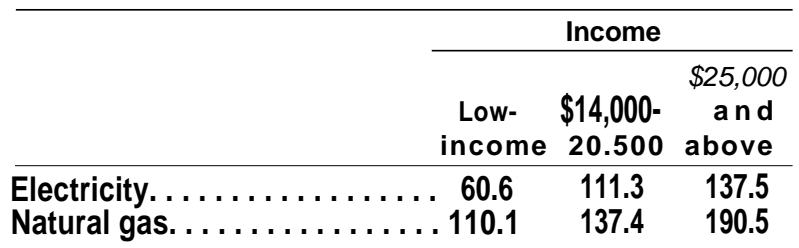

Average annual Btu per household. Average annual Btu per household.
SOURCE: Washington Center for Metropolitan Studies, National Survey of
Household Energy Use, 1975 .

*One Btu is equivalent to 1 kilojoule.

"Crier, op. cit., p. 11
Other studies of electricity and gas consumption among low-income users indicate, however, that looking at average household consumption patterns may not be the best way to evaluate the effectiveness of lifeline rates in meeting social welfare goals. Looking instead at the number of households in various income groups that exceeded lifeline allowance levels, the Pacific Gas \& Electric Company (PG\&E) found that significant numbers of low-income households exceed not only the lifeline consumption levels, but also the utility system's average consumption per household. For example, PG\&E determined that nearly 50 percent of its low-income customers in the San Francisco Bay area outside San Francisco consume more than the area's average monthly household level of $300 \mathrm{kWh} .{ }^{17} \mathrm{High}$ consumption levels among low-income customers were found to be very weather-sensitive and especially prevalent during winter peak-heating periods, probably because of the poor thermal integrity of many homes occupied by low-income consumers. PG\&E concluded that large numbers of low-income consumers were being penalized, rather than helped, by lifeline rates. $^{18}$

In a recent critique of the California lifeline policy, Albin J. Dahl expressed a doubt that landlords receiving lifeline allowances for units in master-metered buildings would in all cases pass on utility cost-savings to their tenants through lowered rents. He also pointed out that California residential gas consumers were paying for much of the gas they consumed at rates far below the costs borne by utilities in purchasing and delivering that gas. Dahl argued that the tax and welfare systems were more appropriate vehicles for solving the energy-based financial problems of low-income persons. ${ }^{19}$

Other utility-related policies that might assist low-income persons include prohibitions on wintertime utility shutoffs, legal aid to indigent utility customers, and requirements of third-party notification prior to shutoff.

\footnotetext{
${ }^{17}$ J. Dahl Albin, "California's Lifeline Policy," Public Utilities Fortnight/y, Aug. 31,1978, p. 20.

"81 bid., p 18.

“I bid., pp. 13-22.
} 


\section{HOUSING, ENERGY, AND THE POOR}

For low-income persons, problems of energy use in the home are a subset of the larger problems of poor housing quality in general. Opportunities to lower residential energy consumption - and reduce utility bills - are sharply limited for people who live in substandard housing, unless a way can be found to rehabilitate or replace such housing. Weatherization programs, financial assistance, and preferential utility rates cannot provide full remedies for either owners or renters of low-quality, energy-guzzling homes. A number of Federal programs address the housing needs of lowincome persons. Efforts are directed at both tenants and homeowners.

Programs affecting rental housing include:

- Federal assistance to local housing authorities for construction, maintenance, and subsidization of rents in public housing projects;

- Rent subsidies under section 8 of the National Housing Act which make up the difference between 25 percent of recipient families' incomes and the fair market rent for the private housing units they occupy;

- Mortgage insurance, interest and rent subsidies, and energy-related home improvement financing for rental housing under section 236 of the National Housing Act, as amended; and

- FmHA's Section 515 Rental and Cooperative Housing Loan Program, which finances housing for low- and moderateincome families developed by public, private, or nonprofit organizations.

Programs aimed at owner-occupied housing include:

- The Department of Housing and Urban Development's (HUD) section 312 program, providing loans at 3-percent interest to low-income homeowners in certain designated areas, for the purpose of rehabilitating their homes and bringing them into compliance with current local building codes;
- Mortgage insurance and interest subsidies made available under section 235 of the National Housing Act to permit low- and moderate-income persons to purchase new and existing housing under affordable financing terms;

- FmHA's Section 502 Homeownership Loan Program, offering either loan guarantees or direct loans for the purchase or rehabilitation of homes under financing terms that vary depending on the recipient's income; and

- FmHA's Section 504 Home Repair Program, which offers loans and grants to elderly rural low-income homeowners to remove certain dangers to health and safety.

Programs that can affect both rental and owner-occupied housing are:

- Community development block grants made available annually to local governments to meet broadly specified Federal objectives (which include the provision of adequate housing, a suitable living environment, and expanded economic opportunities for low-income groups) through projects designed at the local level; and

- HUD's urban development action grants designed to stimulate new construction and economic development in low-income areas.

All these programs have helped low-income persons to acquire "decent, safe, and sanitary housing" without the expenditure of an unreasonable portion of their incomes for housing. It is not clear, however, that the programs have helped in a noticeable way to make poor families' homes more energy-efficient. For most programs, energy conservation is a concern far from the minds of program administrators in Washington, D. C., and in the field; similarly, lenders, builders, owners, developers, nonprofit groups, and others on the receiving end of Federal housing funds have only rarely included energy efficiency in their planning or cost calculations. 
Public housing projects, for example, were constructed without effective thermal standards until 1963, and from 1963 to 1973, Federal guidelines for thermal standards were voluntary. In recent years, the emphasis within the public housing program has shifted from new construction to rehabilitation of existing projects, and energy efficiency has been designated as a "priority expenditure category" as part of rehabilitation. Since utility costs have been estimated by HUD to account for between 20 and 30 percent of project operating expenses, in many cases upgrading insulation, windows, and energy-consuming equipment in public housing units is a cost-effective use of public funds. Unfortunately, however, HUD cannot supply accurate estimates of the level of energy-related improvements being made in the public housing sector, or of the energy savings that are resulting.

The rental assistance program under section 8 of the National Housing Act assists over 350,000 low-income families by making up the difference between 25 percent of their family incomes and the fair market rent for the housing units they occupy. Tenants in both public and private housing are eligible for section 8 subsidies if their incomes do not exceed 80 percent of the median income in their geographic areas; nearly a third of all recipients earn less than half of the median income. As with the public housing program, section 8 guidelines pay little attention to energy efficiency. Only in the case of newly constructed apartments are section 8 subsidies tied even indirectly to requirements for thermal integrity in the buildings; newly built homes must meet HUD minimum property standards to be eligible for participation in the section 8 program. Older units are not subject to any energy standards for eligibility

Chapter VIII describes each of the Federal housing programs listed above, and evaluates their effectiveness (or lack thereof) in encouraging energy efficiency to keep utility costs down for low-income owners and tenants. 
Chapter V

HOUSING DECISIONMAKERS 
Page Introduction ................. 91

Characteristics of the Existing Housing Inventory . . . . . . . . . . . 91

Characteristics of New Housing . . . . . 93

Housing Processes and Participants . . . . 94 New Construction. . . . . . . . . . 95

Retrofit . . . . . . . . . . . . . . . . 97

Manufactured Housing. .,.. . . . 98

The Existing Housing Stock. . .... 99

Trends in Housing and Conservation .....101

Trends in Housing Costs .. ...101

Trends in Utility Costs ... .104

Findings and Opportunities for Energy

Conservation. . . . . . . . . . . . .112

Builders' Attitudes . . . . . ..113

Property Owners' Attitudes. . .......113

Is the Cost of Adding Energy Conservation

Features to New or Existing Housing

an impediment to Conservation? 114

Are Problems of Financing Impeding the

Pace of Residential Conservation?

What Are the Current and Potential Roles

of the Federal Government in

Encouraging Residential

Conservation?

Directions for the Future 115

\section{TABLES}

29 Structure Type: Year-Round Housing Units, 1976 . . . . . . . . . . . . . 91

30 Tenure and Number of Units by Type of Structure, $1976 \quad$. . . 91

31 Year-Round Housing Units by Location, 1976. . . . . . . . . . . . . . 92

32. Tenure by Location, 1976 . . . . 92

33. Income by Type of Occupancy, 1976 . 92

34. Age of Housing Units, 1976. . 92

35. Sales of Existing Single-Family Homes for the United States and Each Region by Price Class, 1977 . . . . . 93

36. Private Housing Starts by Type of Structure, $1977 \ldots . . . . . .93$

37. Private Housing Completions by Location, 1977. . . . . . . . . . 94

38. Sales Price of New One-Family Homes Sold, 1977 . . . . . . . . . . . 94
39 New Homes Sold, Sales Price by Type of Mortgage Financing, 1977.

40 The Original 1975 Annual Housing Survey Data Plus Tabulated Data for Years Prior to 1940 Expressed as a Percentage of the Total Housing Units in the United States

41 Thermal Characteristics of Houses: Regional Summary

42 Heating Equipment and Fuels for Gccupred Units, 1976

43 Selected Housing Series of the Consumer Price Index: Selected Years

44 Percentage Distribution by Income of Homebuvers Exceeding the 25-Percent Rule.

45 Percentage Distribution of Age of Homes Purchased by First-Time and Repeat Homebuyers

46 Median Home Purchase Price, 1977 . . 104

47 Median Utility Costs by Region. . . . . . 104

48 Percentage Distribution of Median Expenditures for Major Elements of Monthly Housing Expenses

49 Consumer Attitudes Toward Conservation Improvements in New Homes in Selected Iocalities

50 Comparison Between Average Insulation and Clazing Characteristics of New Single-Family Detached Houses Built in 1974 and in 1975-76.

51 Insulation Characteristics of 1975-76 Single Family Detached Housing Units. 109

52 Wincow and Door Characteristics of 1975-76 Single-Family Detached Housing I. nits

53 Single Family Detached Homes Wall and ( eiling Insulation by Housing Price

54 I stimates of Insulation and Storm loor Storm Window Activity in the ketrotit Market, 1977

FIGURES

15 Increases in Housing Costs, Income, and consumer Price Index, 1970-76

Page

16 Percent of Homebuyers Willing to Spend $\$ 600$ or More on Energy Conservation in New Construction Housing 106 


\section{INTRODUCTION}

This chapter assesses the efforts to improve the energy efficiency of new and existing housing. It identifies the opportunities for and impediments to more residential conservation. The characteristics of residential buildings, the factors that influence property owners' attitudes and behavior toward energy conservation, the participants and processes involved in new housing development and improvement of existing housing, and trends and institutional factors that encourage or discourage conservation are examined. Based on those judgments, some policy options and considerations that might further energy conservation are noted.

\section{CHARACTERISTICS OF THE EXISTING HOUSING INVENTORY}

To understand the context within which residential conservation actions occur, it is useful to review the general characteristics of existing housing. The types of units, tenure arrangements, the age of the housing stocks, and the income of property owners all influence the need, potential, and feasibility of energy conservation. In 1976 the inventory totaled nearly 81 million units, of which more than 79 million were all-year housing units and $\mathbf{7 4}$ million were occupied. The housing stock is diverse, varying by age, construction quality, size, design, and amenities. Most structures are single-unit buildings and most housing is occupied by owners. As shown by table 29, 53.6 million units or 67.6 percent are one-unit structures. Only $\mathbf{1 1 . 9}$ million units or $\mathbf{1 5 . 0}$ percent are in buildings with five or more units.

Table 29.-Structure Type:

Year-Round Housing Units, 1976

\begin{tabular}{|c|c|c|}
\hline Type & $\begin{array}{l}\text { Units in } \\
\text { thousands }\end{array}$ & Percent \\
\hline 1 unit. . . . . . . . . . . . . & 53,611 & 67.6 \\
\hline $2-4$ units $\ldots \ldots \ldots \ldots \ldots \ldots$ & 10,189 & 12.8 \\
\hline 5 or more units. . . . . . . . & 11,888 & 15.0 \\
\hline Mobile homes or trailers. . . . . . & 3,627 & 4.6 \\
\hline Total . . . . . . . . . . . . . . & 79,315 & 100 \\
\hline
\end{tabular}

SOURCE: U.S. Department of Commerce and U.S. Department of Housing and Urban Development, Annual Housing Survey, $7976 \mathrm{U} \mathrm{S}$ and Regions, Part A: General Housing Characteristics, p 1

Table 30 gives information on tenure and structure size. Nearly two-thirds of all Ameri-
Table 30.-Tenure and Number of Units

by Type of Structure, 1976 (units in thousands)

\begin{tabular}{lrrr}
\hline & $\begin{array}{c}\text { Owner } \\
\text { occupied }\end{array}$ & $\begin{array}{c}\text { Renter } \\
\text { occupied }\end{array}$ & \multicolumn{1}{c}{ Total } \\
\hline Occupied units $\ldots \ldots \ldots \ldots$ & 47,904 & 26,101 & 74,005 \\
l-unit structure $\ldots \ldots \ldots \ldots$ & 42,136 & 8,477 & 50,613 \\
2- 4-unit structure $\ldots \ldots \ldots$ & 2,143 & 7,116 & 9,259 \\
5 or more unit structures . & 638 & 9,867 & 10,505 \\
Mobile homes . . . . . . . . & 2,987 & 640 & 3,627
\end{tabular}

SOURCE' U.S. Department of Commerce and U.S. Department of Housing and Urban Development, Annual Housing Survey, 1976 U S. and Regions, Part A General Housing Characteristics, p 1

can families are owner-occupants; 47.9 million units or 64.7 percent are owner-occupied; and only $\mathbf{2 6 . 1}$ mill ion units or $\mathbf{3 5 . 3}$ percent are occupied by renters. The percentage of owneroccupied housing is increasing, with the biggest changes having occurred in the 1940's and 1950's. In 1940, owner-occupied units represented only 43.6 percent of all units; by 1960 , they accounted for 61.9 percent of all units.

Most one-unit structures and mobile homes are owner-occupied, but a significant number are rented. Only 14 percent of all units are in buildings with five or more dwellings.

Most housing is located in urban areas. More than two-thirds of all housing is in standard metropolitan statistical areas (SMSAs). But as shown in table 31 , only 31.0 percent of the housing stock is found in central cities, and 
most housing in SMSAs is not in central cities but in suburban areas.

Table 31 .-Year-Round Housing Units by Location, 1976

\begin{tabular}{|c|c|c|}
\hline Location & $\begin{array}{c}\text { Units in } \\
\text { thousands }\end{array}$ & Percent \\
\hline $\begin{array}{r}\text { Inside SMSAs } ., \ldots \ldots \ldots \\
\text { Within central cities } \ldots \ldots \ldots \\
\text { Not in central cities. } \ldots \ldots \ldots \\
\text { Outside SMSAs. } \ldots \ldots \ldots \ldots \ldots\end{array}$ & $\begin{array}{c}53,606 \\
(24,547) \\
(29,059) \\
25,710\end{array}$ & $\begin{array}{c}67.6 \\
(31.0) \\
(36.6) \\
32.4\end{array}$ \\
\hline$\ldots \ldots \ldots \ldots$ & 79,315 & 100.0 \\
\hline
\end{tabular}

SOURCE: U.S. Department of Commerce and U.S. Department of Housing and Urban Development, Annual Housing Survey, 1976 U.S. and Regions, Part A: General Housing Characteristics, p 3

Housing tenure varies by location. As shown by table 32, the incidence of rental housing is greater in SMSAs than outside SMSAs and more prevalent in central cities than in suburban areas. Nearly half the housing in central cities is rented, but in suburban areas of SMSAs rental housing makes up only 29 percent of all units. The Northeastern section of the country has the largest percentage of rental housing and the North-Central section the smallest.

Table 32.-Tenure by Location, 1976 (units in thousands)

\begin{tabular}{|c|c|c|c|}
\hline $\begin{array}{c}\text { Rental } \\
\text { units }\end{array}$ & $\begin{array}{l}\text { Percent } \\
\text { within } \\
\text { location }\end{array}$ & $\begin{array}{l}\text { Owner- } \\
\text { occupied } \\
\text { units }\end{array}$ & $\begin{array}{l}\text { Percent } \\
\text { within } \\
\text { location }\end{array}$ \\
\hline $\begin{array}{l}\text { Inside SMSAs } \ldots \ldots 19,557 \\
\text { Within central cities }(11,581) \\
\text { Not in central cities. }(7,976)\end{array}$ & 38.8 & $\begin{array}{l}30,895 \\
(11,349) \\
(19,546)\end{array}$ & 61.2 \\
\hline Outside SMSAs. . . . . 6, 6,544 & 27.8 & 17,009 & 72.2 \\
\hline Total . . . . . . . . . . 26,101 & & 47,904 & \\
\hline
\end{tabular}

SOURCE: U.S. Department of Commerce and U.S. Department of Housing and Urban Development, Annual Housing Survey, 1976 U S. and Regions, Part A: General Housing Characteristics, p 3

Owner-occupants earn more than renters, but a significant number of homeowners have low or moderate incomes. (See table 33.) Nearly 35 percent of homeowners had an income of less than $\$ 10,000$ in 1976 ; this group could be expected to be particularly affected by the increasing costs of homeownership.

More than one-third (34.3 percent) of the stock predates 1940, even with the high level of construction over the past three decades. As noted in table 34, a large fraction of the stock is new: 27.9 percent of the inventory has been built since 1965 .
Table 33.-income by Type of Occupancy, 1976 (numbers in thousands)

\begin{tabular}{|c|c|}
\hline $\begin{array}{c}\text { Number } \\
\text { of owner } \\
\text { occupants }\end{array}$ & $\begin{array}{c}\text { Number } \\
\text { of renter } \\
\text { occupants }\end{array}$ \\
\hline Total . . . . . . . . . . . . . . . . 47,904 & 26,099 \\
\hline 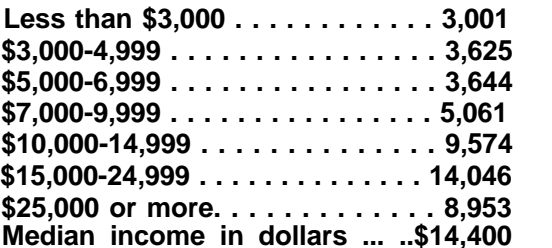 & $\begin{array}{r}3,938 \\
4,074 \\
3,301 \\
4,252 \\
5,318 \\
3,948 \\
1,268 \\
\$ 8,100\end{array}$ \\
\hline
\end{tabular}

SOURCE: U.S. Department of Commerce and U.S. Department of Housing and Urban Development, Annual Housing Survey, 1976 U.S. and Regions, Part A General Housing Characteristics, p. 10.

Table 34.-Age of Housing Units, 1976 (units in thousands)

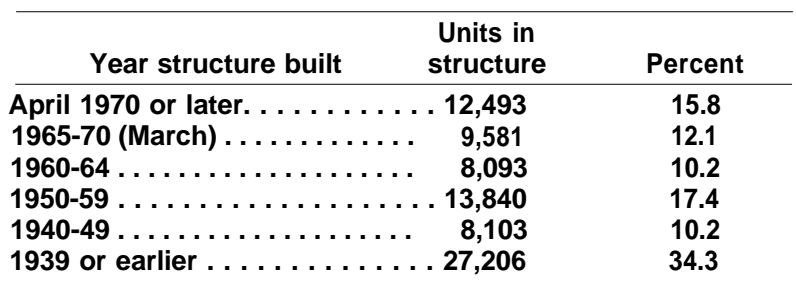

SOURCE: U.S. Department of Commerce and U.S. Department of Housing and Urban Development, Annual Housing Survey, 1976 U.S. and Regions, Part A General Housing Characteristics, p. 1.

A significant amount of the housing stock changes hands each year. In 1977, more than 3.5 million existing homes were bought and sold. The cost of existing housing has been rising rapidly. The median price in 1972 was $\$ 27,100$; in 1977 , it was $\$ 42,900$. The median sales price disguises a significant variety of home prices, generally and by region. Nearly 15 percent of all existing houses sold for less than $\$ 25,000$, but nearly 16 percent of all sales exceeded $\$ 70,000$. Table 35 provides a breakdown of sales by price class and region for 1977. Housing in the West is substantially more expensive than in other parts of the country. The incidence of lower cost housing is greatest in the North-Central and Southern sections of the country.

Based on this data it would appear that the focus of a residential conservation program should be on owner-occupants, most of whom occupy single-unit properties. Even though they own their own homes, many owner-occupants have limited incomes. Homes of many 
Table 35.-Sales of Existing Single-Family Homes for the United States and Each Region by Price Class, 1977 (percentage distribution)

\begin{tabular}{|c|c|c|c|c|c|}
\hline Price class & United States & Northeast & North-Central & South & West \\
\hline Under $\$ 14,999 \ldots \ldots \ldots \ldots$. . . . . . . . . . . . . . . & 2.9 & 2.3 & 4.3 & 3.2 & 0.5 \\
\hline$\$ 15,000-19,999 \ldots \ldots \ldots \ldots$ & 4.6 & 3.5 & 6.8 & 5.7 & 1.0 \\
\hline$\$ 20,000-24,999 \ldots \ldots \ldots \ldots . \ldots \ldots$ & 7.2 & 5.7 & 9.9 & 8.6 & 2.2 \\
\hline$\$ 25,000-29,999 \ldots \ldots \ldots \ldots \ldots \ldots$ & 10.0 & 9.4 & 12.8 & 11.5 & 4.6 \\
\hline$\$ 30,000-39,999 \ldots \ldots \ldots \ldots$ & 20.4 & 20.8 & 24.3 & 21.4 & 13.3 \\
\hline$\$ 40,000-49,999 \ldots \ldots \ldots \ldots \ldots$ & 17.3 & 19.1 & 18.2 & 16.4 & 16.3 \\
\hline 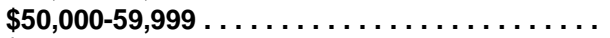 & 12.9 & 14.0 & 10.5 & 12.2 & 16.6 \\
\hline$\$ 60,000-69,999 \ldots \ldots \ldots \ldots \ldots \ldots$ & 9.0 & 9.1 & 6.1 & 8.2 & 14.2 \\
\hline$\$ 70,000-79,999 \ldots \ldots \ldots \ldots$ & 5.5 & 5.4 & 3.1 & 4.8 & 9.7 \\
\hline$\$ 80,000$ and over $\ldots \ldots \ldots \ldots \ldots$ & 10.2 & 10.7 & 4.0 & 8.0 & 21.6 \\
\hline Total . . . . . . . . . . . . . . . . . . & 100.0 & 100.0 & 100.0 & 100.0 & 100.0 \\
\hline Median price.... . . . . . . . . . . . . & $\$ 42,900$ & $\$ 44,400$ & $\$ 36,700$ & $\$ 39,800$ & $\$ 57,300$ \\
\hline
\end{tabular}

SOURCE: National Association of Realtors, Existing Home Sales, 1977, p. 32.

types and classes are available in spite of significant inflation in the cost of existing housing. Most housing is located in metropolitan areas, but most homeowners live outside central cities in suburbs. In central cities nearly half the occupants are renters. Differences in Location, tenure, price, and age of housing and in the resources and interests of occupants influence the incentives and barriers to energy conservation in residential buildings.

\section{CHARACTERISTICS OF NEW HOUSING}

The construction industry is a cyclical industry whose production varies widely year by year. In recent years, production has ranged from a low of $\mathbf{1 . 2}$ million units in 1975 to 2.4 million units in 1972. In 1977 nearly 2 million units were started, and 277,000 mobile homes were shipped to dealers. As might be expected, single-family construction predominated. Table 36 provides a breakdown of housing starts by type of structure. More than 73 percent were single-unit structures, only 21 percent were in structures of five or more units.

Table 36.-Private Housing Starts

by Type of Structure, 1977

(units in thousands)

\begin{tabular}{|c|c|c|}
\hline Type & $\begin{array}{l}\text { Number } \\
\text { of units }\end{array}$ & Percent \\
\hline $\begin{array}{l}1 \text { unit. } \ldots \ldots \ldots \ldots \ldots \ldots \ldots \ldots \\
2 \text { units. } \ldots \ldots \ldots \ldots \ldots \ldots \ldots \ldots \\
3-4 \text { units } \ldots \ldots \ldots \ldots \ldots \ldots \ldots \\
5 \text { or more units. } \ldots \ldots \ldots \ldots \ldots \ldots\end{array}$ & $\begin{array}{r}1,451 \\
61 \\
61 \\
413\end{array}$ & $\begin{array}{r}73.1 \\
3.1 \\
3.1 \\
20.8\end{array}$ \\
\hline $\begin{array}{r}\text { Total . . . . . . . . . . . . . . . . } \\
\text { Mobile homes or trailers. . . . . }\end{array}$ & $\begin{array}{r}1,986 \\
277\end{array}$ & 100 \\
\hline
\end{tabular}

NOTE: Totals may not add to 100 due to rounding.

SOURCE: Department of Housing and Urban Development's Office of Housing Statistics.
Nearly 70 percent (1 .377 million of the total 1.986 million housing starts) were located within SMSAs. Housing construction activity is greatest in the South and West, where the population is growing fastest. New construction is heavily concentrated in fast-growing metropolitan areas. Ten market areas are expected to account for 372,289 units or nearly 19 percent of all construction starts in 1978, with Houston and Dallas-Fort Worth alone accounting for nearly 109,000 units.

Table 37 shows the regional distribution of completed housing construction for singlefamily and multifamily housing. Over 38 percent of the completions occurred in the South. More than one-third of all multifamily completions were located in the West, an area with only 27 percent of total completions. The

\footnotetext{
' National Association of Home Builders' estimate. The top 10 markets are Houston, 62,706; Dallas-Fort Worth, 46,000; Chicago, 44,000; Phoenix, 40,000; Los AngelesLong Beach, 38,500; Riverside-San Bernardino, 35,000; Seattle-Everett, 31 ,320; San Diego, 28,000; DenverBoulder, 23,400; and Detroit, 23,360.
} 
Table 37.-Private Housing Completions by Location, 1977 (excluding mobile homes) (units in thousands)

\begin{tabular}{|c|c|c|c|}
\hline Location & Total & $\begin{array}{l}\text { Number of } \\
\text { single } \\
\text { family }\end{array}$ & $\begin{array}{l}\text { Number of } \\
\text { multifamily }\end{array}$ \\
\hline $\begin{array}{l}\text { Northeast } \ldots \ldots \\
\text { North Central . . . } \\
\text { South . . . . . . . } \\
\text { West. . . . . . }\end{array}$ & $\begin{array}{l}176 \\
399 \\
637 \\
444\end{array}$ & $\begin{array}{l}135 \\
300 \\
512 \\
311\end{array}$ & $\begin{array}{r}41 \\
99 \\
125 \\
133\end{array}$ \\
\hline Total. . . . . . . . & 1,656 & 1,258 & 398 \\
\hline
\end{tabular}

SOURCE: Department of Housing and Urban Development Office of Housing Statistics.

Northeast had a small fraction of activity relative to its population.

The cost of new housing has been rising rapidly and is significantly higher than the average cost of existing housing. In 1977, the average sales price of a new home was $\$ 54,200$, but the price of housing varied by region of the country. As is the case with existing housing, the highest average costs are in the West and East. In the Northeast, the average sales price was $\$ 54,800$; in the South $\$ 48,100$; and in the West $\$ 60,700$. $^{2}$

In 1978 prices have continued to escalate and to reflect a diversity in housing costs. Housing magazine reported that in the first half of 1978 new single-family detached houses sold and conventionally financed averaged $\$ 60,100$. San Francisco had the highest prices at $\$ 88,200$ per unit, followed by Los Angeles $(\$ 83,800)$, San Diego $(\$ 80,600)$, and New York City $(\$ 78,000)$.

Table 38 presents a breakdown by price class of housing sold in 1977. A majority of the housing sold was in the $\$ 30,000$ to $\$ 60,000$

'Characteristics of New Housing (Bureau of the Census and Department of Housing and Urban Development, 1977).

Table 38.-Sales Price of New One-Family Homes Sold, 1977

\begin{tabular}{|c|}
\hline Price class $\quad$ Perce \\
\hline 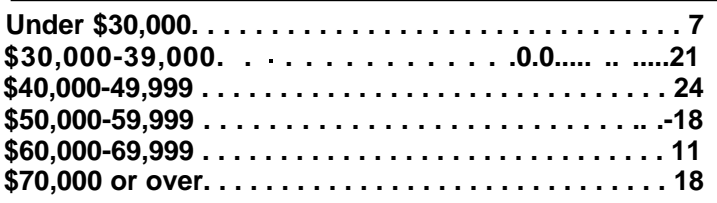 \\
\hline
\end{tabular}

range, but 18 percent sold for more than $\$ 79,000$.

New homes sold in 1977 totaled 819,000, of which 782,000 were financed. More than threefourths of these homes were financed by banks, savings and loans, and other mortgage lenders without the involvement of the Federal Government. The Federal Government's role in housing finance is relatively modest except in the case of lower income home purchasers, but Federal insurance programs and secondary financing mechanisms provide important leverage on the financing actions. Table 39 provides data on the role of Federal financing activities and shows that the average federally assisted loan is much smaller than the average conventional mortgage.

Table 39.-New Homes Sold, Sales Price by Type of Mortgage Financing, 1977

\begin{tabular}{|c|c|c|c|}
\hline $\begin{array}{l}\text { Type of mortgage } \\
\text { financing }\end{array}$ & $\begin{array}{l}\text { Number of } \\
\text { units in } \\
\text { thousands }\end{array}$ & Percent & $\begin{array}{c}\text { Median } \\
\text { sales price }\end{array}$ \\
\hline $\begin{array}{l}\text { FHA insured. . . . . . . . } \\
\text { VA guaranteed. . . . . } \\
\text { Conventional . . . . . . } \\
\text { Farmers Home. . . . }\end{array}$ & $\begin{array}{r}73 \\
93 \\
592 \\
24\end{array}$ & $\begin{array}{r}9 \\
12 \\
76 \\
3\end{array}$ & $\begin{array}{r}\$ 37,700 \\
41,600 \\
53,400 \\
25,800\end{array}$ \\
\hline Total . . . . . . . . & 782 & 100 & \\
\hline
\end{tabular}

\section{HOUSING PROCESSES AND PARTICIPANTS}

To assess the barriers to and opportunities for energy conservation in the housing sector, it is important to understand the attributes and institutional structure of the three general types of housing markets-new construction, retrofit, and manufactured housing - and the attitudes and interrelationships of the key decisionmakers in each market. The design, 
construction, financing, and operation of housing involve a multitude of participants. Each of these participants operates under different circumstances and conditions and each attempts to maximize profits and limit risks.

\section{New Construction}

The development of new housing is a complex entrepreneurial activity, involving many participants whose interactions and cooperation are necessary for its successful completion. The manner and extent of participation and interaction differ between single-family and multifamily construction and between housing constructed on behalf of an owner and that constructed on a speculative basis, which is more common. Participants in the process include the builder or developer' who plans, initiates, and carries out the development; lenders who provide construction and mortgage financing; specialized subcontractors who undertake construction activities; construction workers; architects and engineers who design the housing; local government officials who establish and administer local land use regulations, including zoning and building codes; realtors who assist in the sale or rental of the housing; and the homeowner, owneroccupant, or investor.

A new residential construction project, regardless of type, involves five basic steps: 1 ) determining whether the project is financially feasible and marketable; 2) detailed planning and securing the site and financial commitments; 3) detailed design and engineering and the organization and securing of labor and materials; 4) construction; and 5) sale or rental of the completed project or home. At each step the builder works closely with one or more of the participants.

The building industry is fragmented into many small producing units, none of which controls a significant percentage of the hous-

\footnotetext{
*The term builder is typically used in single-family construction. In multifamily construction the builder may be the developer or may only build the project for the developer. In this study the terms are used interchangeably.
}

ing market. There are more than 100,000 builders. The largest single-family builder in 1977 produced only 8,830 units and the largest multifamily builder 3,974 units. $^{3}$ In 1976 the top 419 builders built 21 percent of all new housing. The average builder operates a small business and builds fewer than 20 houses a year. ${ }^{4} A 1970$ survey of the building industry found that three-fourths of all builders who built only single-family housing built less than 25 houses, and 46 percent built less than 10 houses a year. Only 2.5 percent of these builders constructed more than $\mathbf{1 0 0}$ houses annually. Firms that built both multifamily and singlefamily housing tended to be larger. As a result only $\mathbf{5 7}$ percent of them built less than 25 units each year and 11.7 percent built more than 100 units. Firm's that handled only multifamily housing were the largest. Only 17.6 percent constructed less than 25 units a year and $\mathbf{5 2 . 6}$ percent built more than $\mathbf{1 0 0}$ units.

No builder dominates or controls a particular housing market, and the competition among builders is intense. Except in the largest housing development firms, the planning, design, construction management, and financing functions are carried out by different parties.

Most builders have few full-time employees. (An average builder employs 2.8 full-time executives, 3.4 office personnel, and 24.8 supervisors and tradesmen). ${ }^{5}$ The size of the firm and the precise role of the builder vary with the type of housing being constructed, as does the role of the builder and his relationship to other participants. Some builders only coordinate the developmental process; they rely fully on specialized subcontractors to construct the various building elements. Others carry out all or some part of the construction process. Some builders only build for clients on a custom basis. Most, however, build speculatively. A speculative project may involve a single lot or a large subdivision. Sixty-one per-

\footnotetext{
${ }^{3 / C}$ California Builders Still Going Strong," Housing, November 1978, p. 18.

"'Housing Giants on the Grow Again," Professional Builder, July 1977.

'Michael Sumichrast and Sara A. Frankel, Profile of the Builder and His Industry.
} 
cent of the single-family housing started in 1976 was built for sale or rent; the remainder was built by the owner or by a contractor for the use of the owner.

The builder is involved in a high-risk, highly leveraged situation, with his success or failure dependent on his ability to judge market demand and conditions accurately. Builders try to avoid situations that increase risk or that may hurt the marketability of the housing they produce. To be successful the builder must respond to local tastes and produce housing that is competitively priced. During the construction process decisions must be made quickly to deal with a constant stream of unforeseen events.

An analysis of the building industry commissioned by OTA noted:

Despite apparent outward similarities, the resulting product is quite heterogeneous in nature. It must be produced for al I types of unique building sites and in an incredible range of community types and climatic regions. Viewed in this light, the production of housing would seem to demand a significant combination of market sensitivity and managerial/organizational talent. This suggests that entrepreneurship is almost more important' than the other inputs because it is the entrepreneur who must organize, become at least practically responsible for, and eventually commit those resources.

As the entrepreneur, the builder or developer determines the character of the housing. If he is building on a speculative basis, the builder must decide what type of house is in demand and will sell at a profit within the local market and price class. The builder must not only weigh and evaluate the multitude of features that might be used but must gauge his market correctly in terms of price, style, and amenities, and compete with other builders serving the same market. Typically a builder keeps track of local market conditions and competitive projects. The National Association of Home Builders (NAHB)-to which most

\footnotetext{
'I bid.
}

homebuilders belong-and material suppliers alert builders to new trends and products.

Homebuilders tend to use stock plans, draft their own plans, or modify designs they or competitors have used previously; most homes are not directly designed by architects or engineers. Only 27 percent of homebuilders reported they used staff or consultant architects. ${ }^{7}$ Architects and engineers are more frequently used in multifamily projects because of their greater complexity.

Builders are adaptable and willing to change the characteristics of the housing they build, but only as a result of proven market demand. Most builders are reluctant to pioneer unproven changes that may adversely affect the marketability of housing and may meet consumer resistance. Builders must be concerned about the cost of their product and the cost of adding standard features will be carefully weighed against the advantages of those features in helping to sell the housing. First cost is given more consideration than lifecycle cost. Large builders are in a better financial position to take risks-but even they must carefully assess the risks and opportunities involved in deviating from established market practices.

The builder of custom homes is in a different position and need not make all the market judgments of the speculative builder. Many decisions will be made by the owner, perhaps on the builder's advice. The builder does have to manage the construction process so that costs fall within the budget of his client while the builder earns a profit.

The role of the builder and the financial management is different in the multifamily market. In the case of multifamily housing the builder may or may not be the owner/developer of the project. The owner/developer assumes the key decision making role and determines the character of the project. Project design is based on an estimate of the rents that

${ }_{71}$ 976HUDStatistical Yearbook (Washington, D. C.: Department of Housing and Urban Development), p. 284. 
can be charged for that location and type of unit. Rent projections determine an acceptable level of construction cost, which in turn serves to determine the features to be included in the project. The terms and conditions of available financing determine the ultimate feasibility of multifamily construction. Most developers build multifamily projects with only a token equity so that project characteristics and features are determined by the extent to which lenders believe they add to the value of the project and are willing to finance their inclusion. Multifamily property is an investment, and decisions are based on their impact on profit. The profit to be realized can be in the form of cash flow, depreciation, future appreciation, or amortization of debt. Additional cash investment to add a special feature may be avoided, in some cases, even if such an investment would be profitable over the long run. Developers seek to achieve maximum leverage; thus $f$ rent-end costs may be more important to them than lifecycle costs.

These concerns, combined with the requirements of local codes and regulations, provide the context within which the builder selects a site, determines what he can pay for the site, and makes decisions about the housing design and the specifications and quality of the different construction components.

Lenders are key participants in the housing construction process. Housing normally involves long-term debt financing. Lenders provide interim financial assistance to builders, developers, and subcontractors during the development process, and long-term mortgage loans to house purchasers or multifamily investors. Lenders seek to make profitable loans and protect themselves against default. Because they lend money, by nature and circumstance they tend to be conservative. Typically, lenders do not examine homebuilders' plans in detail. They rely instead on the experience and reputation of the builder in deciding whether to provide short-term financing. In terms of a level of mortgage debt, lenders base their willingness to finance particular homes on appraisers' estimates of value, on the perceived risk of the investment over the term of the loan, and on the credit-worthiness and ability of the borrower to afford the expense of homeownership. Appraisers play a key role in determining the availability of financing by estimating the value of the property to be financed. Appraisals are intended to reflect market values, so appraisers discount any housing features they believe are not accepted in the marketplace. Because multifamily loans are larger, plans and specifications for multifamily projects are scrutinized more carefully than for single-family homes, but typically lenders would not review indepth the specifications for the project. Lenders make financial judgments based on appraisers' estimates of value and, perhaps to some degree, on the demonstrated skills and experience of the developer/owner.

Funds for housing construction are made available by banks, savings and loan associations, life insurance companies, and federally related credit agencies such as the Federal $\mathrm{Na}$ tional Mortgage Association (FNMA) and the Federal Home Loan Mortgage Corporation (FHLMC). For multifamily lending, savings and loan associations and Federal credit agencies are the most active lenders; for single-family housing, savings and loan associations are the dominant lenders. There are more than 23,000 lending institutions throughout the country.

Other participants play less central roles in development. Subcontractors and workers working under the direction of the builder carry out specified construction tasks. Architects and engineers may be involved in the design of housing. Government agencies may be involved in a number of ways: the Federal Government for example, may provide subsidies, loans, or mortgage insurance to lenders to assist in the development or financing of housing. Such housing must be designed to Federal construction standards. These programs are discussed in detail in chapter IX. Local governments establish and administer local building codes to which most new housing must conform. Realtors may be employed to sell or rent completed housing.

\section{Retrofit}

The home-improvement or retrofit market, which involves upgrading or improving existing 
housing, functions differently from the new construction market. Typically, the property owner determines what improvements should be made to the property and how the work should be done.

Improvements can range from minor paintup/fix-up activities to substantial modifications to a building's structure or condition. Work can be accomplished by hiring a homeimprovement contractor or installer, or by the do-it-yourself approach. Home-improvement contractors are not normally involved in new construction projects. Property owners often look to hardware stores, lumber yards, or home supply centers for information on particular products or names of contractors. An estimated one-half of all property improvements are done on a do-it-yourself basis. The property owner usually specifies the work to be done, although some contractors promote and solicit business for particular types of work. This means that the homeowner must be knowledgeable about what improvements he or she wants or have access to reliable information or contractor advice. The most common types of retrofit energy-saving improvements are installation of insulation, storm windows, caulking and weatherstripping around doors and windows, and furnace replacement or improvements in furnace efficiency.

Qualified Remodeler magazine estimates that professional remodelers will be responsible for $\$ 21.5$ billion of remodeling in $1979,{ }^{8}$ including both residential and commercial activity. Nearly 31,000 firms do remodeling work. Firms vary from large and sophisticated enterprises capable of undertaking any type of renovation work, to one-person outfits specializing in a particular trade such as electrical work or storm window installation. Most firms are small; the average remodeler employs only nine full-time and two part-time employees. Most projects are also small, and contractor profits as a percentage of overall cost are higher than in new construction. More than half do less than $\$ 250,000$ worth of business a year, while only $\mathbf{1 1 . 6}$ percent have an annual volume in excess of $\$ 1$ million.

\footnotetext{
${ }^{8 \prime}$ Market Report: Five Year Forecast for Remodeling is Rosy," Qualified Remodeler, September 1978.
}

In terms of conservation improvements, the average firm installs $\$ 58,000$ worth of insulation annually, and on an average each firm installs 663 storm windows and 152 storm doors. As might be expected, contractors are predominantly involved in installing blown-in insulation. In 1978, contractors were expected to carry out 647,000 jobs involving blown insulation, 375,000 jobs using foam insulation, and 91,000 using batt insulation. Approximately three-fourths of all remodelers install storm windows and doors, and about 13,000 , or 43 percent, install insulation. '

Financing is less important in retrofit work than in new construction because most projects are small. The most common energy improvements represent relatively small sums of money, ranging from $\$ 100$ to $\$ 1,000$ for most homes. Improvements may be made all at once or over an extended time. In 1976, the average maintenance and improvement expenditure for owner-occupants of single units was $\$ \mathbf{4 5 0}$ per property. Expenditures varied widely by income group; those with incomes of less than $\$ 5,000$ averaged $\$ 203$; those whose income exceeded $\$ 25,000$ averaged $\$ 822$. As a result of the small sums involved, most improvements are paid for by cash on hand, short-term credit, or savings. It is estimated that only 17 percent of home improvements are financed by lending institution home-improvement loans. Small loans are not profitable to these institutions because of the high overhead costs in relation to the interest earned. Many lenders do not make home-improvement loans for less than $\$ 1,000$ or even $\$ 1,500$. As a result they are not involved in most home-improvement projects.

\section{Manufactured Housing}

Manufactured housing, including mobile homes and modular housing, is built in a factory Construction and sales processes for manufactured housing bear little resemblance to onsite construction. The housing is constructed by factory workers, rather than by

\footnotetext{
${ }^{9} \mathrm{BoOz}$, Allen, and Hamilton, Building l-lousing Outline: Energy Conservation Assessment Study for the Office of Technology Assessment, p. II l-10.

${ }^{10} \mathrm{M}$. Sumichrast, op. cit.
} 
subcontractors. As a result, the manufacturer maintains total control over the construction process.

About 276,000 mobile homes were shipped in 1977. Single-width homes range in price from $\$ 7,000$ to $\$ 25,000$; double-widths cost $\$ 13,000$ and up. All mobile homes built since June 1976 conform to the Federal Mobile Home Construction Standards, which preempt earlier and inconsistent State requirements. Homes are typically designed by company staff or consultants who might be draftsmen or engineers who have specialized in mobile home design.
Besides the manufacturer, the other key participants are the distributors or dealers who sell mobile homes and arrange financing, commercial banks who finance the manufacturing firms, and commercial banks, finance companies, and other lenders who finance the purchase of mobile homes. Manufacturers sometimes help distributors with financing. Mobile homes are considered personal property, although there is a growing trend to consider them real property. Mobile home loans, which are considered chattel mortgages, commonly run for 7 to 10 years at 12- to 13 -percent interest.

\section{THE EXISTING HOUSING STOCK}

How existing houses are built must be known before realistically assessing how much their thermal envelopes can be improved in a cost-effective manner. Very little information exists about the thermal characteristics of existing housing. A good deal of information about the general characteristics of the housing stock is contained in census data and in information collected by the Federal Housing Administration (FHA) for houses with FHA mortgages. But the only study of the thermal characteristics of existing houses seems to be that of Rowse and Harrje, ${ }^{11}$ which combines information from census data, FHA data, and historical trends in insulation use in the construction industry to estimate the potential for upgrading the thermal shells of existing housing. The situation is further complicated by the lack of information about the massive retrofits that have been underway for the last 3 or 4 years.

Nearly two-thirds of the houses existing in 1975 were built after 1940; almost a quarter were built in the 1960's. (See table 40.) Thus a majority of the housing stock has been constructed since insulation materials were gener-

'R. E. Rowse and D. T. Harrje, "Energy Conservation: An Analysis of Retrofit Potential in United States Housing" (unpublished) (Center for Environmental Studies, Princeton University). ally available. Tabulated information on the thermal characteristics of houses is shown in table 41. Nearly three-fourths of the homes have at least some attic insulation, with more than two-thirds of the houses in all parts of the country reporting attic insulation. Over half the homes have at least some storm windows or other double glazing, but these are largely concentrated in the Northeast and North-Central regions. Similar results hold for storm doors.

Rowse and Harrje ${ }^{12}$ point out that insulation was rare in homes built before 1940, and even for the 27 percent of the homes built between 1940 and 1960, the standard attic insulation was 2 inches of mineral wool. Thus all of these homes are potential candidates for retrofit. Additional savings are possible even for housing constructed in the 1970's, as illustrated by the experiments at Twin Rivers, N.J. Rowse and Harrje conclude that more than two-thirds of the existing housing stock is ripe for additional attic insulation.

From a practical viewpoint, it is likely that considerably less than the $\mathbf{9 0}$ percent of houses noted by Rowse and Harrje will actually be retrofitted, as the payback for the homes containing some insulation is not likely to appear

\footnotetext{
${ }^{12}$ |bid.
} 
Table 40.-The Original 1975 Annual Housing Survey Data Plus Tabulated Data for Years Prior to 1940 Expressed as a Percentage of the Total Housing Units in the United States

\begin{tabular}{|c|c|c|c|c|c|}
\hline Year built & United States & Northeast & North-Central & South & West \\
\hline 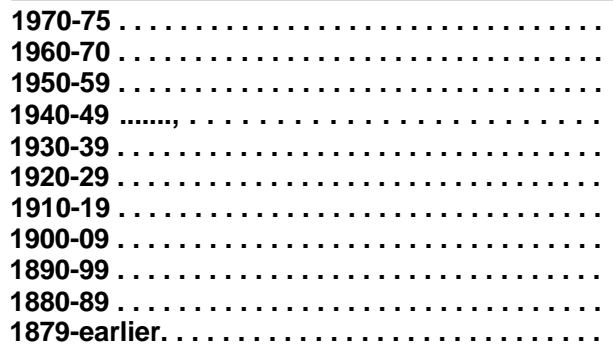 & $\begin{array}{r}14.5 \\
23.1 \\
17.5 \\
10.3 \\
6.5 \\
8.4 \\
5.8 \\
5.7 \\
3.5 \\
2.0 \\
2.7\end{array}$ & $\begin{array}{r}1.8 \\
3.8 \\
3.2 \\
2.0 \\
1.5 \\
2.6 \\
1.7 \\
2.0 \\
1.4 \\
.8 \\
1.6\end{array}$ & $\begin{array}{r}3.1 \\
5.5 \\
4.2 \\
2.3 \\
1.7 \\
2.5 \\
2.0 \\
2.1 \\
1.5 \\
.9 \\
.8\end{array}$ & $\begin{array}{c}6.1 \\
8.7 \\
6.1 \\
3.9 \\
2.1 \\
2.0 \\
1.3 \\
1.1 \\
.4 \\
.2 \\
.3\end{array}$ & $\begin{array}{r}3.4 \\
5.0 \\
4.0 \\
2.1 \\
1.2 \\
1.3 \\
.8 \\
.5 \\
.2 \\
.1 \\
.0\end{array}$ \\
\hline Total $\ldots \ldots \ldots \ldots \ldots \ldots \ldots \ldots \ldots$ & 100.0 & 22.5 & 26.6 & 32.3 & 18.6 \\
\hline
\end{tabular}

NOTE: Totals may not add to 100 due to rounding.

SOURCE: R. E. Rowse and D. T. Harrje, "Energy Conservation: An Analysis of Retrofit Potential in United States Housing" (unpublished), Center for Environmental Studies, Princeton University.

Table 41.-Thermal Characteristics of Houses: Regional Summary (percent)

a) Attic or Roof Insulation

\begin{tabular}{|c|c|c|c|c|c|}
\hline & United States & Northeast & North-Central & South & West \\
\hline $\begin{array}{l}\text { Yes } \ldots \ldots \ldots \ldots \\
\text { No } \ldots \ldots \ldots \ldots \ldots \\
\text { Don't know } \ldots \ldots \ldots \ldots \ldots \ldots \ldots \ldots \ldots \ldots \ldots \ldots \ldots \\
\text { Not reported. } \ldots \ldots \ldots \ldots \ldots \ldots \ldots \ldots \ldots \ldots \ldots \\
\end{array}$ & $\begin{array}{r}74.0 \\
16.5 \\
7.8 \\
1.7\end{array}$ & $\begin{array}{r}78.7 \\
13.8 \\
5.7 \\
1.8\end{array}$ & $\begin{array}{r}84.0 \\
9.0 \\
5.4 \\
1.6\end{array}$ & $\begin{array}{r}67.3 \\
22.5 \\
8.5 \\
1.7\end{array}$ & $\begin{array}{r}67.4 \\
18.8 \\
12.0 \\
1.8\end{array}$ \\
\hline
\end{tabular}

b) Storm Windows or Other Protective Coverings

All occupied units . . . . . . . . . . . . . . 100.0

All windows covered $\ldots \ldots \ldots \ldots \ldots \ldots \ldots \ldots \ldots$. $4 . \ldots \quad 46.0$

Some windows covered . . . . . . . . . . . . . . . . . . . . . . 10.0

No windows covered.. . . . . . . . . . . . . 42.9

Not reported.

1.1

$\begin{array}{rrrr}100.0 & 100.0 & 100.0 & 100.0 \\ 76.3 & 80.5 & 21.7 & 11.9 \\ 14.6 & 10.7 & 8.5 & 7.2 \\ 8.0 & 7.6 & 68.9 & 79.7 \\ 1.2 & 1.2 & 1.0 & 1.2\end{array}$

\section{c) Storm Doors}

All occupied units . . . . . . . . . . . . . . . . 100

All doors covered. . . . . . . . . . . . . .

100.0

Some doors covered $\ldots \ldots \ldots . \ldots . \ldots 1.7$

No doors covered. . . . . . . . . . . . . . . . . . 39.4

39.4
1.2

100.0
77.9
12.7
8.1
1.3

100.0
82.0
9.2
7.6
1.3

$\begin{array}{rr}100.0 & 100.0 \\ 25.0 & 11.1 \\ 14.6 & 8.9 \\ 59.4 & 78.8 \\ 1.1 & 1.3\end{array}$

\section{debasement}

With basement. . . . . . . . . . . . . .

$\begin{array}{rrrrr}00.0 & 100.0 & 100.0 & 100.0 & 100.0 \\ 47.9 & 85.2 & 70.5 & 18.3 & 21.7 \\ 52.1 & 14.8 & 29.5 & 81.7 & 78.3\end{array}$

attractive to many owners, and the 15.6 percent of homes that have masonry or concrete walls are considerably harder to retrofit.

Owens-Corning Fiberglas Corporation has developed estimates of the potential for energy conservation through reinsulating ex- isting housing. ${ }^{13}$ Its studies indicate that approximately three of every four owner-occupied dwellings had accessible attics and that the remainder had either no attic (15.1 percent)

${ }^{13}$ Owens-Corning data are taken from presentation to the Federal Energy Administration, Feb. 25,1977. 
or an inaccessible attic. In this part of the housing market only 10.9 percent of respondents reported their dwelling had no insulation, but the majority of homes appear underinsulated, with less than 4 inches of insulation in the attic. Only 15.3 percent of respondents had more than 6 inches of attic insulation.

A Gallup survey for the Department of Energy (DOE) in early 1978 is generally consistent with the Owens-Corning findings. Nearly three-fourths of all homeowners reported that they have attic insulation or some storm windows or storm doors.

In 1977, Construction Reports conducted a study of insulation requirements and estimated that the market for additional insulation totaled $\mathbf{2 5 . 5}$ million single-family and twoto four-family units. The report notes, however, that there is no agreement on the actual number of homes or properties that need insulation or on how many owners could cost-effectively reinsulate their homes.

Table 42 characterizes the types of heating equipment and fuel used in occupied units. The majority of housing units are heated by warm air furnaces. Gas is the dominant heating fuel, followed by fuel oil or kerosene. Gas and electricity are the predominant fuels used for cooking.

\section{Table 42.-Heating Equipment and Fuels for Occupied Units, 1976 \\ (in thousands)}

\begin{tabular}{|c|c|c|}
\hline & Number & Percent \\
\hline Total occupied units $\ldots \ldots \ldots \ldots$ & $.79,315$ & 100 \\
\hline $\begin{array}{l}\text { Warm air furnace. } \ldots \ldots \ldots \ldots \ldots \ldots \\
\text { Steam or hot water } \ldots \ldots \ldots \ldots \ldots \ldots \\
\text { Built-in electric units. .. } \ldots \ldots \ldots \ldots \ldots \\
\text { Floor, wall, or pipeless furnace } \ldots \ldots \ldots \\
\text { Room heaters with/without flu. } \ldots \ldots \ldots \\
\text { Fireplaces, stoves, portable heaters. } \\
\text { None. . . . . . . . . . } \ldots \ldots \ldots \ldots \ldots\end{array}$ & $\begin{array}{r}40,720 \\
14,554 \\
5,217 \\
6,849 \\
8,861 \\
2,398 \\
716\end{array}$ & $\begin{array}{r}51.3 \\
18.3 \\
6.6 \\
8.6 \\
11.2 \\
3.0 \\
.9\end{array}$ \\
\hline Total occupied housing units. . . . . . & $.74,005$ & 100 \\
\hline 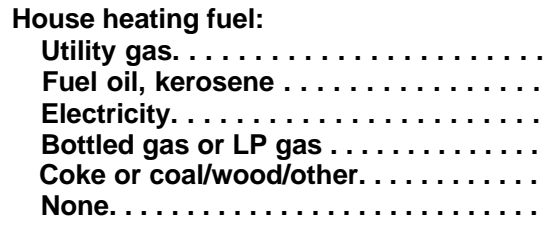 & $\begin{array}{r}41,219 \\
16,451 \\
10,151 \\
4,239 \\
1,482 \\
463\end{array}$ & $\begin{array}{r}55.7 \\
22.2 \\
13.7 \\
5.7 \\
2.0 \\
.6\end{array}$ \\
\hline 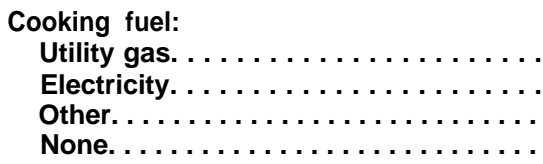 & $\begin{array}{r}32,299 \\
35,669 \\
5,748 \\
287\end{array}$ & $\begin{array}{r}43.6 \\
48.2 \\
7.8 \\
.4\end{array}$ \\
\hline
\end{tabular}

\section{TRENDS IN HOUSING AND CONSERVATION}

\section{Trends in Housing Costs}

It is clear that property owners and the building industry have become more aware of the importance of energy conservation and, as knowledge has improved and the cost of energy has risen, have taken steps to improve the energy efficiency of housing. This trend is apparent in both new construction and in the retrofit market.

\footnotetext{
"Gallup Organization, Inc., A Survey of Homeowners Concerning Home Insulation, conducted for the Department of Energy, April 1978.

${ }^{65}$ Bureau of Census, "Estimates of Insulation Requirements and Discussion of Regional Variation in Housing Inventory and Requirements," Construction Reports, August-September 1977.
}

Interest in conservation coincides with rapidly rising costs both for new and existing housing. Builders have been particularly concerned about the negative impact that rising costs may have on the ability of purchasers to afford housing. Table 43 provides a breakdown of changes in the Consumer Price Index during the period 1968-76, when the costs of homeownership nearly doubled. Fuel and utilities represent a rapidly rising element in housing costs over the past few years, although their total contribution to owning a home is still well below other factors.

Figure 15 portrays the relationships among the increases in median housing costs, ownership costs, income, and the Consumer Price Index between 1970-76. For the median-price 
Table 43.-Selected Housing Series of the Consumer Price Index: Selected Years $(1967=100)$

\begin{tabular}{|c|c|c|c|c|c|c|c|}
\hline \multirow[b]{2}{*}{ Year } & \multirow[b]{2}{*}{ Shelter $^{\mathrm{a}}$} & \multirow[b]{2}{*}{ Rent } & \multicolumn{4}{|c|}{ Home ownership } & \multirow[b]{2}{*}{$\begin{array}{c}\text { Fuel anc } \\
\text { utilities }\end{array}$} \\
\hline & & & Total $^{\mathrm{b}}$ & $\begin{array}{c}\text { First mortgage } \\
\text { interest rates }\end{array}$ & $\begin{array}{l}\text { Property } \\
\text { insurance rates }\end{array}$ & $\begin{array}{l}\text { Home } \\
\text { maintenance } \\
\text { and repairs }\end{array}$ & \\
\hline 1968........ & 104.8 & 102.4 & 105.7 & 106.7 & 104.7 & 106.1 & 101.3 \\
\hline $1969 \ldots \ldots \ldots$ & 113.3 & 105.7 & 116.0 & 120.0 & 109.3 & 115.0 & 103.6 \\
\hline $1970 . \ldots . .$. & 123.6 & 110.1 & 128.5 & 132.1 & 113.4 & 124.0 & 107.6 \\
\hline $1971 \ldots \ldots$ & 128.8 & 115.2 & 133.7 & 120.4 & 119.9 & 133.7 & 115.1 \\
\hline $1972 \ldots \ldots \ldots$ & 134.5 & 119.2 & 140.1 & 117.5 & 123.2 & 140.7 & 120.1 \\
\hline $1973 \ldots \ldots$ & 140.7 & 124.3 & 146.7 & 123.2 & 124.4 & 151.0 & 126.9 \\
\hline $1974 \ldots \ldots \ldots$ & 154.4 & 130.6 & 163.2 & 140.2 & 124.2 & 171.6 & 150.2 \\
\hline $1975 \ldots \ldots$ & 169.7 & 137.3 & 181.7 & 142.1 & 131.4 & 187.6 & 167.8 \\
\hline 1976. . . . . . & 179.0 & 144.7 & 191.7 & 140.9 & 144.3 & 199.6 & 182.7 \\
\hline
\end{tabular}

Includes rent, homeownership, and hotel and motel room rates.

Includes home purchase, mortgage interest, real estate taxes, property insurance, and home maintenance and repairs.

SOURCE: Department of Housing and Urban Development, 1976 HUD Statistical Yearbook, p 258

Figure 15.--Increases in Housing Costs, Income, and Consumer Price Index, 1970-76

Median sales price for new homes

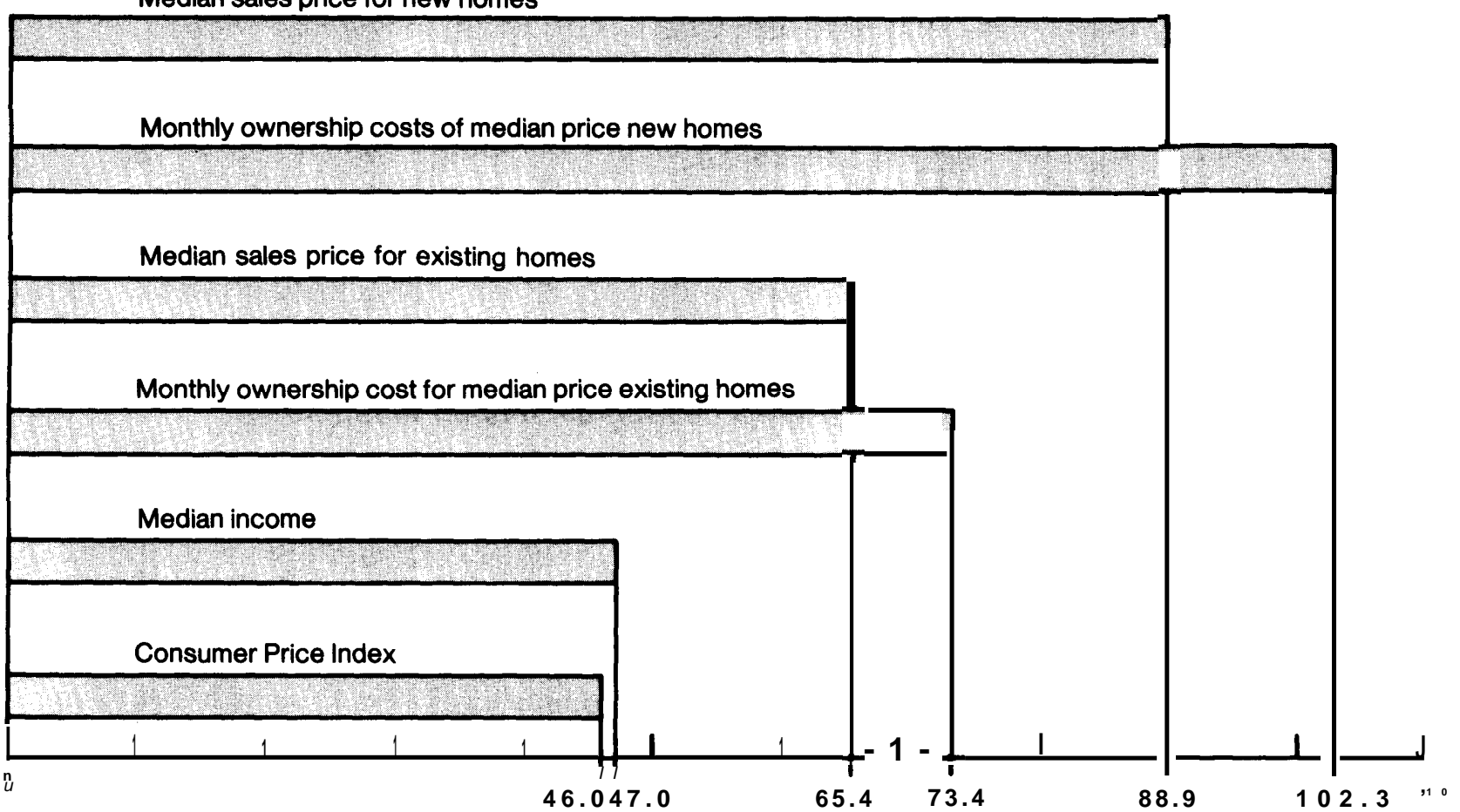

Percent increase, 1970-76

SOURCE: Joint Center for Urban Studies of MIT and Harvard University, The Nation's Housing, 1970-76, p. 119.

homebuyer, new housing operating costs have doubled (102.3 percent), and for the existing homebuyer they have increased 73.4 percent. During the same period median income in- creased only 47 percent. In 1970, 46 percent of all families could afford the median-price new home and 36 percent the median-price existing home. By 1976 only 26 percent of all families 
could afford the median-price new home and 36 percent the median-price existing home. 'G

A recent Department of Housing and Urban Development (HUD) study of housing costs also determined that housing costs outpaced family income in the period 1972-76. ' 7 During that period median family income increased at an average annual rate of 7.05 percent. During the same period the average annual rate of increase in the median sales price of new onefamily homes was $\mathbf{1 2 . 4 9}$ percent, and the median sales price of existing one-family homes increased 9.30 percent.

Even with the rapid escalation of housing costs demand for both new and existing homes has been strong. Several reasons explain why demand continues in the face of rapidly rising prices. Homeownership provides attractive tax advantages over rental housing. Buyers anticipate that owning a home is a sound and profitable investment and will cost more in the future. Many home purchasers buy existing housing rather than newly constructed housing. Americans are willing to devote more of their income to housing than would be expected based on traditional income/housing cost guidelines. As a result, the majority of Americans has been able to afford a house. In 1977, nearly 60 percent of all homebuyers had incomes of less than $\$ 25,000$ and nearly 40 percent less than $\$ 20,000.18$

Several factors have enabled families to continue to afford housing. A traditional industry rule of thumb has been that housing cost should not exceed 25 percent of gross income. In fact only 52 percent of all homeowners spend less than 25 percent, 24 percent spend 25 to 30 percent, and 14 percent spend more than 30 percent. Table 44 breaks down the percentage of buyers who exceed the 25percent income rule.

\footnotetext{
${ }^{16}$ The Nation's Housing: 1975-1985 (Joint Center for Urban Studies of the Massachusetts Institute of Technology and Harvard University, 1977), p. 103.

'7Fina/ Report of the Task Force on Housing Costs (Washington, D. C.: Department of Housing and Urban Development, May 1978), p. 3.

${ }^{18}$ Homeownership: Affording the Single Family Home (U.S. League of Savings Association, 1978), p. 27.
}

Table 44.-Percentage Distribution by Income of Homebuyers Exceeding the 25. Percent Rule

\begin{tabular}{|c|c|}
\hline Annual income & $\begin{array}{l}\text { Percentage of } \\
\text { all homebuyers }\end{array}$ \\
\hline Less than $\$ 15,000 \ldots \ldots \ldots \ldots$ & 30 \\
\hline 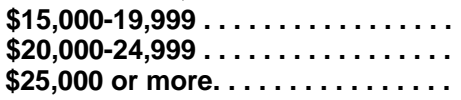 & $\begin{array}{l}30 \\
19 \\
21\end{array}$ \\
\hline Total. . . . . . . . . . . . . . & 100 \\
\hline
\end{tabular}

SOURCE: U.S. League of Savings Associations, Homeownership: Affording the Single Family Home, p. 32.

There are two general types of homebuyers-first-time homebuyers and repeat homebuyers. Repeat homebuyers tend to be older, have higher incomes, and have an equity from their old house to invest in the purchase of their new home. As a result they can afford to buy more expensive housing. The median price for first-time homebuyers is $\$ 37,500$ but for repeat buyers it is $\$ 48,500$. First-time homeowners are often able to afford a home because they are willing to buy existing housing.

About 43 percent of first-time homebuyers purchase housing constructed before 1955, compared with 25 percent of repeat buyers. By contrast, 29 percent of repeat buyers purchase new housing, versus 18 percent of the first-time buyers. Table 45 describes the difference between the two types of buyers.

Table 45.-Percentage Distribution of Age of Homes Purchased by First-Time and Repeat Homebuyers

\begin{tabular}{|c|c|c|c|}
\hline $\begin{array}{l}\text { Year of construction of } \\
\text { home purchased }\end{array}$ & $\begin{array}{l}\text { First-time } \\
\text { buyers }\end{array}$ & $\begin{array}{c}\text { Repeat } \\
\text { buyers }\end{array}$ & $\begin{array}{c}\text { All } \\
\text { buyers }\end{array}$ \\
\hline 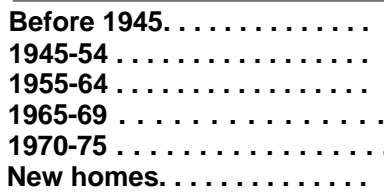 & $\begin{array}{r}26.5 \\
16.0 \\
17.8 \\
8.1 \\
8 \quad 13.3 \\
18.3\end{array}$ & $\begin{array}{r}16.2 \\
8.8 \\
16.0 \\
9.7 \\
19.9 \\
29.4\end{array}$ & $\begin{array}{r}19.9 \\
11.5 \\
16.7 \\
9.0 \\
17.5 \\
25.4\end{array}$ \\
\hline
\end{tabular}

First-time homebuyers are able to purchase housing partly because of the availability of liberal financing. Forty-five percent make downpayments of less than $\$ 5,000$, and 73 percent put down less than $\$ 10,000$. Forty-seven percent of first-time buyers make downpayments of less than 20 percent of the purchase price. By contrast, only 11 percent of repeat buyers make downpayments of less than 20 percent of the purchase price. 
It is also important to recognize that housing costs and markets vary significantly by region of the country and community size. Table 46 shows the substantial cost variation in new housing by metropolitan localities of different sizes.

Table 46.-Median Home Purchase Price, 1977

\begin{tabular}{|c|c|}
\hline Metropolitan area & $\begin{array}{l}\text { Median home } \\
\text { purchase price }\end{array}$ \\
\hline $\begin{array}{l}\text { All U.S. metropolitan areas with } \\
\text { population of } 1.5 \text { million or more } \ldots \\
\text { All U.S. metropolitan areas with } \\
\text { populations between } 250,000-1.5 \\
\text { million } \ldots \ldots \ldots \ldots \ldots \ldots \ldots \ldots \ldots \\
\text { All U.S. metropolitan areas with } \\
\text { populations of less than } 250,000 \ldots \\
\text { All of the United States } \ldots \ldots \ldots \ldots \ldots\end{array}$ & $\begin{array}{l}\$ 49,500 \\
\$ 42,900 \\
\$ 37,000 \\
\$ 44,000\end{array}$ \\
\hline
\end{tabular}

The increase in housing costs is pricing most lower middle-income families out of the new housing market; they must purchase existing housing or improve the dwellings they are currently living in. Only 3.7 percent of all house purchasers in 1975-76 earned less than $\$ 10,000$, although this income bracket represents 32 percent of the population. Families earning $\$ 10,000$ to $\$ 14,999$ represent more than 22 percent of the population but bought only 13.4 percent of the new housing. ' 9 While the pace of construction has remained high, much of the housing is being built for upper income groups. Families earning more than $\$ 25,000$ comprise 14.1 percent of the population, but they bought 32.4 percent of the new housing. ${ }^{20}$

Trends indicate that the new construction market is increasingly oriented to the upper income buyer. In 1965-66 the top quarter of the population, in terms of income, bought 58 percent of the new homes. By contrast the lower third of the population bought only 4 percent of the new housing in 1975-76, but bought 17 percent of the new housing in 1965-66.2'

\section{Trends in Utility Costs}

Historically, utility costs have been a small component of housing costs. As a result, build-

\footnotetext{
"Ibid.

${ }^{20} 1$ bid.

21 Ibid.
}

ers and consumers were not concerned, until recently, about the energy efficiency of housing. While utility costs have been rising substantially, so have other elements of homeownership, particularly in larger communities. As shown in table 47, utility costs are not uniform and also vary by region. They are highest in the South and lowest in the West, particularly California.

Table 47.-Median Utility Costs by Region

\begin{tabular}{|c|c|c|}
\hline \multirow[b]{2}{*}{ Region } & \multicolumn{2}{|c|}{ Median utility costs } \\
\hline & Monthly & Annual \\
\hline 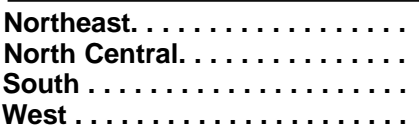 & $\begin{array}{r}\$ 60 \\
60 \\
70 \\
50\end{array}$ & $\begin{array}{r}\$ 720 \\
720 \\
840 \\
600\end{array}$ \\
\hline
\end{tabular}

SOURCE: U.S. League of Savings Associations, Homeownership: Affording the Single Family Home, p. 22.

Table 48 documents that utility costs still represent a relatively small fraction of monthly housing expenses. In metropolitan areas the mortgage payment is the largest element of monthly costs, followed by utilities and taxes. But in small communities, where taxes are low, utilities represent a much larger cost element than real estate taxes.

Buyers seem to be demanding reasonable levels of insulation and double-glazing or storm windows in most housing markets. Because of this demand, builders are including these features in their homes and appraisers and lenders are recognizing the added costs in their lending judgments. Although the larger downpayments and increased carrying costs may affect the ability of the marginal purchaser to buy a home, the overall marketability for housing has not been significantly affected by including such features, which builders view as adding to the appeal and salability of their homes.

Trade publications report strong buyer interest in energy-saving features. As noted in chapter 11, surveys by Professional Builder in 1974-77 indicate that the proportion of homebuyers willing to spend $\$ 600$ or more initially to save $\$ 100$ per year in energy costs increased from 78 to 93 percent. $^{22}$ As figure 16 shows,

*2" Consumers Tell What They Want in Housing," Professional Builder, December 1977. 
Table 48.-Percentage Distribution of Median Expenditures for Major Elements of Monthly Housing Expenses

\begin{tabular}{|c|c|c|c|c|c|}
\hline Metropolitan area & $\begin{array}{l}\text { Mortgage } \\
\text { payment }\end{array}$ & $\begin{array}{l}\text { Real estate } \\
\text { taxes }\end{array}$ & $\begin{array}{l}\text { Hazard } \\
\text { insurance }\end{array}$ & Utility costs & $\begin{array}{c}\text { Total } \\
\text { monthly } \\
\text { expenses }\end{array}$ \\
\hline All U.S. metropolitan areas with populations & & & & & \\
\hline $\begin{array}{l}\text { of } 1.5 \text { million or more } \ldots \ldots \ldots \ldots \ldots \ldots \ldots \\
\text { All U.S. metropolitan areas with populations }\end{array}$ & 67.6 & 15.8 & 2.9 & 13.6 & 100 \\
\hline $\begin{array}{l}\text { between } 250,000 \text { and } 1.5 \text { million } \ldots \ldots \ldots \ldots \ldots \ldots \ldots \\
\text { All U.S. metropolitan areas with populations }\end{array}$ & 69.1 & 11.8 & 3.4 & 15.7 & 100 \\
\hline $\begin{array}{l}\text { less than } 250,000 \ldots \ldots \ldots \ldots \ldots \ldots \ldots \ldots \ldots \ldots \ldots \ldots \ldots \ldots \ldots \ldots \\
\text { All of the United States } \ldots \ldots \ldots \ldots \ldots \ldots \ldots \ldots\end{array}$ & $\begin{array}{l}69.8 \\
68.3\end{array}$ & $\begin{array}{r}9.4 \\
13.5\end{array}$ & $\begin{array}{l}3.7 \\
3.3\end{array}$ & $\begin{array}{l}17.7 \\
15.0\end{array}$ & $\begin{array}{l}100 \\
100\end{array}$ \\
\hline
\end{tabular}

SOURCE: U.S. League of Savings Associations, Homeownership: Affording the Single Family Home, p. 25.

generally similar attitudes are apparent in all parts of the country.

A survey of builders reported by Professional Builder confirms this trend. It documents strong consumer interest in and builder response to energy conservation features in new homes. ${ }^{23}$ Builders report that buyers believe energy conservation is an important consideration in buying a home- and that for a majority of buyers in some regions it is a very important consideration. Such interest does not vary significantly by housing price.

The Professional Builder study reports that double-glazed windows are now a standard feature employed by almost 7 out of 10 builder respondents. Almost three of every four builders use some type of attic ventilation, and nearly two out of three use a zoned heating/cooling system with separate thermostats in different rooms. ${ }^{24}$ As a result, about half of the builders indicated they have been able to reduce the size of the heating and cooling systems used, thus mitigating the added costs of other energy-conserving features.

Simple conventional equipment and materials are most typically used by builders to upgrade the energy efficiency of their homes. The most common features used in the past 2 years are: increased attic (ceiling) insulation (83 percent), double/triple glazing (67 percent), improved weatherstripping/caulking (50 percent), roof overhangs (50 percent), heat pumps (39 percent), and attic fans (29 percent).$^{25}$

\footnotetext{
${ }^{23,}$ Energy and the Builder," op. cit.

${ }^{24} 1$ bid.

${ }^{25} 1$ bid.
}

Buyers are clearly concerned about energy costs and will invest in energy-saving improvements. Housing magazine recently conducted a survey of approximately $\mathbf{4 0 0}$ prospective new homebuyers in five market areas around the country to determine their attitude toward different features including energy-saving improvements. ${ }^{26}$ While the estimated costs of these improvements varied by region, the survey revealed some attitudinal similarities and some clear-cut differences among the market areas. The willingness to pay $\$ 500$ to $\$ 1,500$ for upgrading insulation was strongly evident in all five markets. Outside California, a large majority of respondents were willing to pay for double-glazed windows. Both types of improvements seem well accepted by consumers and would appear to be viewed as a worthwhile investment. Table 49 presents the data on the five markets.

The National Association of Home Builders Research Foundation conducted detailed surveys of members of NAHB in 1974, 1975, and 1976 to gain a comprehensive summary of the thermal characteristics of homes built in recent years. Table 50 compares the average levels of insulation and the glazing characteristics of more than 120,000 homes built in 1974 and more than 112,000 homes built in the last half of $\mathbf{1 9 7 5}$ and the first half of 1976.

The data show a rather remarkable jump in the levels of insulation and in the use of double- and triple-glazing. The levels of both ceiling and wall insulation increased in all nine census regions and now show surprisingly little

\footnotetext{
*b"'What Home Shoppers Seek in Six Major Market," Housing, October 1978.
} 


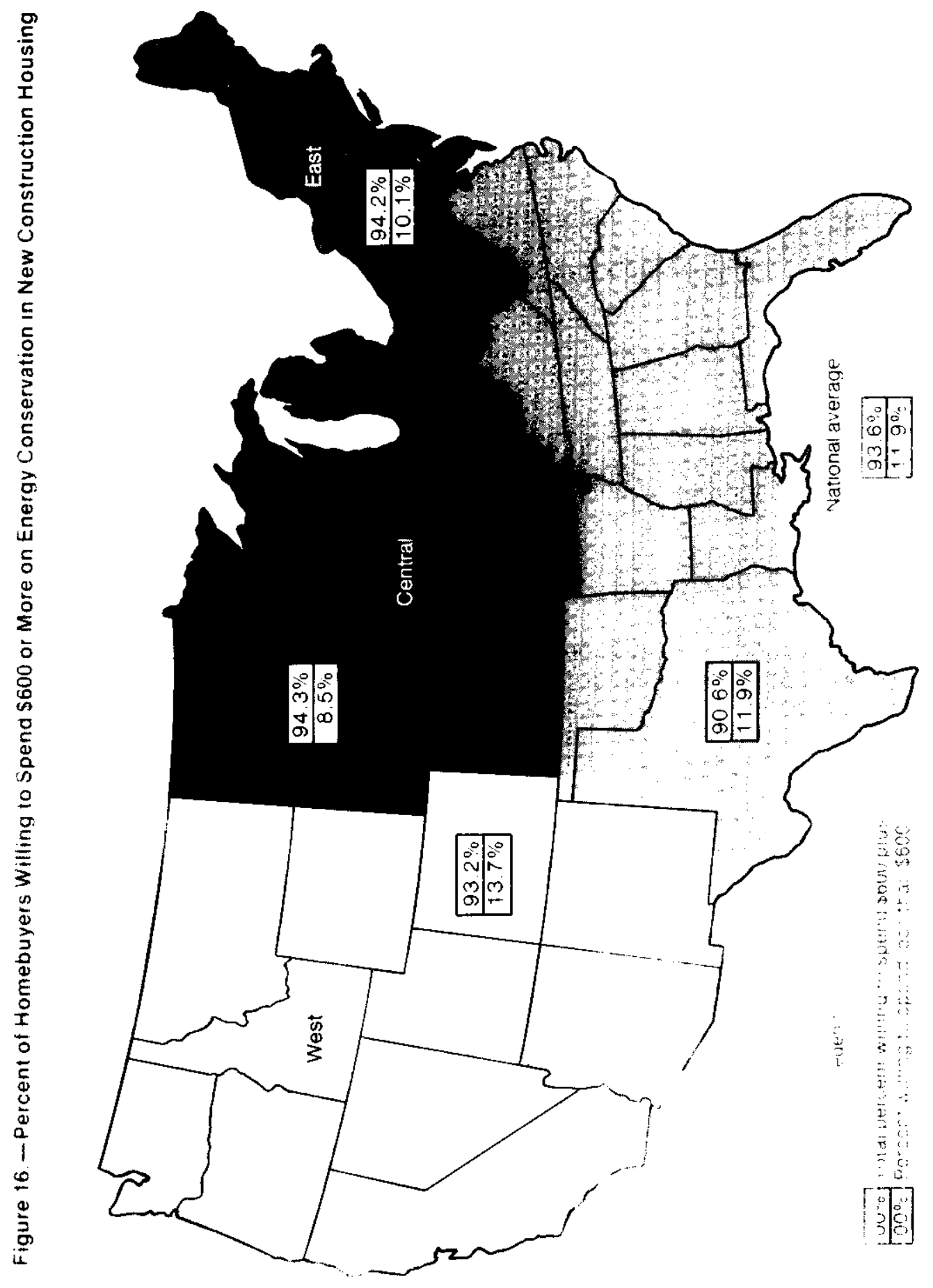


Table 49.-Consumer Attitudes Toward Conservation Improvements in New Homes in Selected Localities

\begin{tabular}{|c|c|c|c|c|c|}
\hline & Washington, D.C. & Miami & Chicago & San Francisco & San Diego \\
\hline \multicolumn{6}{|l|}{ Upgraded insulation } \\
\hline$\%$ want. . . . . . . . . . & 97 & 88 & 95 & 95 & 83 \\
\hline \% don't want. . . . . . . & 3 & 12 & 5 & 5 & 17 \\
\hline \multicolumn{6}{|l|}{ Double glazed windows } \\
\hline$\%$ want. $\ldots \ldots \ldots \ldots \ldots$ & 91 & 70 & 86 & 68 & 34 \\
\hline \% don't want. . . . $\ldots \ldots \ldots$ & 9 & 30 & 14 & 32 & 66 \\
\hline \multicolumn{6}{|l|}{ Solar water heater } \\
\hline$\%$ want. . . . . . . . . . & 34 & 58 & 25 & 41 & 36 \\
\hline$\%$ don't want. . . . . . . . . & 66 & 42 & 75 & 59 & 64 \\
\hline \multicolumn{6}{|l|}{$\begin{array}{c}\text { Solar water heater and } \\
\text { house heater }\end{array}$} \\
\hline \% want. $\ldots \ldots \ldots \ldots \ldots$ & 32 & 48 & 21 & 42 & 24 \\
\hline$\%$ don't want. . . . . . $\ldots$ & 68 & 52 & 79 & 58 & 76 \\
\hline \multicolumn{6}{|l|}{ Heat pump } \\
\hline$\%$ want. $\ldots \ldots \ldots \ldots \ldots$ & 92 & - & 44 & - & - \\
\hline$\%$ don't want. . . . . . . . . & 8 & - & 52 & - & - \\
\hline
\end{tabular}

variation by region, with the average $\mathrm{R}$-value of the wall ranging from 10.9 in the South Atlantic region to 12.2 in New England and the East North Central (States bordering on the Great Lakes) regions. Somewhat more variation is shown for attic insulation, with a low of 16.9 in the South Atlantic region and a high of 22.5 in the Mountain States. These data reflect the greater variety of materials used in attics and the ease of installing different amounts. The use of insulation between the floor joists actually showed a decrease, but this may reflect the fact that the 1976 survey separately tabulated basement wall insulation and insulation of the crawl space walls, rather than an actual decrease in the amount of floor insulation. A significant decline in the use of singleglazed windows is also evident, with only the East South-Central States (Kentucky, Tennessee, Mississippi, and Alabama) showing an appreciable increase in the use of single glazing. Triple glazing was not tabulated separately in the 1974 survey, but it is now being used in a small number of homes in the Midwest and East.

It should not be inferred that similar increases have occurred every year since the oil embargo of 1973, because the NAHB survey of houses built in 1973 showed insulation levels very similar to 1974 , with weighted average Rvalues for the walls of 10.0 (vs. 9.2 in 1974), 14.4 for the ceilings (vs. 15.8), and 4.0 for floors (vs. 4.3). ${ }^{27}$ The F. W. Dodge Co. surveyed 1,000 randomly selected homes built in 1961 and found that 65 percent contained exterior wall insulation, 92 percent had ceiling insulation, and 7 percent had perimeter insulation. ${ }^{26} \mathrm{By}$ contrast, 99 percent of the houses built in 1975-76 had both ceiling and wall insulation and 11 percent had perimeter insulation .29

The percentage of homes built in 1975-76 with various levels of insulation is shown in table 51. Almost 100 percent have ceiling insulation of some kind, with 83 percent having R-1 3, R-19, or R-22. Nearly 100 percent of the houses have wall insulation, with 93 percent having either R-11 or R-13 because of the almost universal use of $2 \times 4$ studs. It may seem surprising that only 20 percent of the houses have insulation between the floor joists, but this may be due to the fact that in many areas substantial cooling is provided through the floor in summer, offsetting the winter heating savings of floor insulation to a considerable degree. However, it is clear that a large number of houses with ventilated crawl spaces would benefit from insulation; increased in-

\footnotetext{
${ }^{27}$ Therma/ Characteristics of Sing/e Family Detached, Single Family Attached, Low Rise Multi-Family, and Mobile Homes for the Office of Technology Assessment (National Association of Home Builders, October 1977). (See appendix C.)

${ }^{28} \mathrm{lbid}$

"Ibid.
} 
Table 50.-Comparison Between Average Insulation and Glazing Characteristics of New Single-Family Detached Houses Built in 1974 and in 1975-76

\begin{tabular}{|c|c|c|c|c|c|c|c|c|c|c|}
\hline & $\begin{array}{l}\text { New } \\
\text { England }\end{array}$ & $\begin{array}{l}\text { Middle } \\
\text { Atlantic }\end{array}$ & $\begin{array}{c}\text { East } \\
\text { North } \\
\text { Central }\end{array}$ & $\begin{array}{l}\text { West } \\
\text { North } \\
\text { Central }\end{array}$ & $\begin{array}{l}\text { South } \\
\text { Atlantic }\end{array}$ & $\begin{array}{c}\text { East } \\
\text { South } \\
\text { Central }\end{array}$ & $\begin{array}{c}\text { West } \\
\text { South } \\
\text { Central }\end{array}$ & Mountain & Pacific & Total U.S. \\
\hline \multicolumn{11}{|l|}{ Average exterior wall insulation R-value } \\
\hline 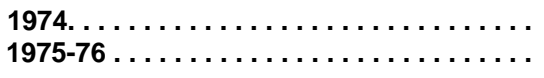 & $\begin{array}{l}10.3 \\
12.2\end{array}$ & $\begin{array}{r}9.3 \\
11.8\end{array}$ & $\begin{array}{l}10.6 \\
12.2\end{array}$ & $\begin{array}{l}11.3 \\
12.0\end{array}$ & $\begin{array}{r}7.2 \\
10.9\end{array}$ & $\begin{array}{l}10.3 \\
12.0\end{array}$ & $\begin{array}{l}10.3 \\
11.9\end{array}$ & $\begin{array}{r}6.7 \\
11.0\end{array}$ & $\begin{array}{r}8.8 \\
11.4\end{array}$ & $\begin{array}{r}9.2 \\
11.7\end{array}$ \\
\hline \multicolumn{11}{|l|}{ Average ceiling or roof insulation } \\
\hline 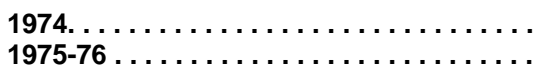 & $\begin{array}{l}17.9 \\
18.2\end{array}$ & $\begin{array}{l}17.9 \\
18.7\end{array}$ & $\begin{array}{l}15.7 \\
18.5\end{array}$ & $\begin{array}{l}16.6 \\
19.3\end{array}$ & $\begin{array}{l}14.8 \\
16.9\end{array}$ & $\begin{array}{l}15.1 \\
18.0\end{array}$ & $\begin{array}{l}15.1 \\
18.4\end{array}$ & $\begin{array}{l}18.1 \\
22.5\end{array}$ & $\begin{array}{l}14.6 \\
18.0\end{array}$ & $\begin{array}{l}15.8 \\
18.4\end{array}$ \\
\hline \multicolumn{11}{|l|}{$\begin{array}{l}\text { Average insulation R-value between } \\
\text { floor joists }\end{array}$} \\
\hline 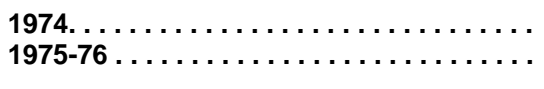 & $\begin{array}{l}4.8 \\
5.0\end{array}$ & $\begin{array}{l}4.8 \\
6.7\end{array}$ & $\begin{array}{l}2.8 \\
5.0\end{array}$ & $\begin{array}{l}5.2 \\
4.8\end{array}$ & $\begin{array}{l}5.4 \\
3.7\end{array}$ & $\begin{array}{l}5.2 \\
2.9\end{array}$ & $\begin{array}{l}6.6 \\
0.1\end{array}$ & $\begin{array}{l}1.8 \\
1.8\end{array}$ & $\begin{array}{l}1.8 \\
1.4\end{array}$ & $\begin{array}{l}4.3 \\
2.6\end{array}$ \\
\hline \multicolumn{11}{|l|}{$\begin{array}{l}\text { W in d o w s } \\
1974\end{array}$} \\
\hline Single glazing. . . . . . . . . . . . & 37.1 & 40.7 & 28.3 & 34.3 & 69.4 & 42.4 & 92.7 & 74.1 & 85.1 & 52.0 \\
\hline $\begin{array}{l}\text { Double glazing (insulation glass or } \\
\quad \text { single w/storm) } \ldots \ldots \ldots \ldots \ldots \ldots \ldots\end{array}$ & 62.9 & 59.3 & 71.7 & 65.7 & 30.6 & 57.6 & 7.3 & 25.9 & 14.9 & 48.0 \\
\hline \multicolumn{11}{|l|}{1975} \\
\hline Single glazing $\ldots \ldots \ldots \ldots \ldots \ldots \ldots$ & 37.6 & 26.6 & 5.8 & 14.3 & 58.8 & 49.6 & 80.2 & 22.6 & 76.0 & 44.0 \\
\hline $\begin{array}{l}\text { Double glazing (insulation glass or } \\
\text { single w/storm) } \ldots \ldots \ldots \ldots \ldots \ldots\end{array}$ & 62.2 & 71.6 & 89.5 & 82.8 & 41.1 & 49.4 & 19.8 & 76.6 & 23.5 & 55.0 \\
\hline Triple glazing (insulation w/storm. .,... & 0.2 & 1.7 & 4.8 & 2.9 & 0.1 & 0 & 0 & 0.8 & 0.5 & 1.0 \\
\hline
\end{tabular}

SOURCE: NAHB Research Foundation, inc. See appendix B of this volume for this and all other referenced NAHB data. 
Table 51.- Insulation Characteristics of 1975-76 Single= Family Detached Housing Units

\begin{tabular}{|c|c|c|c|c|c|c|c|c|c|c|}
\hline & $\begin{array}{l}\text { New } \\
\text { England }\end{array}$ & $\begin{array}{l}\text { Middle } \\
\text { Atlantic }\end{array}$ & $\begin{array}{c}\text { East } \\
\text { North } \\
\text { Central } \\
\end{array}$ & $\begin{array}{l}\text { West } \\
\text { North } \\
\text { Central }\end{array}$ & $\begin{array}{l}\text { South } \\
\text { Atlantic }\end{array}$ & $\begin{array}{c}\text { East } \\
\text { South } \\
\text { Central }\end{array}$ & $\begin{array}{l}\text { West } \\
\text { South } \\
\text { Central }\end{array}$ & Mountain & Pacific & Total U.S. \\
\hline \multicolumn{11}{|l|}{ Ceiling (\% of all houses) } \\
\hline \multicolumn{11}{|l|}{ Exterior wall (\% of all houses) } \\
\hline 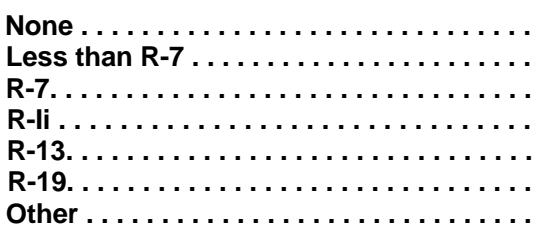 & $\begin{array}{r}0 \\
0 \\
0.4 \\
58.2 \\
35.6 \\
4.5 \\
1.3\end{array}$ & $\begin{array}{r}0 \\
0 \\
0.5 \\
73.0 \\
21.7 \\
4.0 \\
0.8\end{array}$ & $\begin{array}{c}0 \\
0 \\
0 \\
61.1 \\
33.7 \\
3.4 \\
1.8\end{array}$ & $\begin{array}{c}0 \\
0 \\
0 \\
63.8 \\
32.5 \\
3.4 \\
0.3\end{array}$ & $\begin{array}{r}0.6 \\
8.0 \\
0.9 \\
69.3 \\
18.6 \\
2.1 \\
0.5\end{array}$ & $\begin{array}{r}0 \\
0 \\
0.3 \\
64.5 \\
30.0 \\
4.6 \\
0.6\end{array}$ & $\begin{array}{r}0 \\
0 \\
0.2 \\
77.8 \\
15.5 \\
5.9 \\
0.6\end{array}$ & $\begin{array}{r}0.2 \\
2.0 \\
8.7 \\
62.8 \\
22.1 \\
2.6 \\
0\end{array}$ & $\begin{array}{l}0.2 \\
0 \\
0.4 \\
87.5 \\
8.9 \\
3.0 \\
0\end{array}$ & $\begin{array}{r}0.2 \\
1.4 \\
1.1 \\
71.0 \\
21.8 \\
3.5 \\
1.0\end{array}$ \\
\hline \multicolumn{11}{|l|}{ Between floor joists (\% of all houses) } \\
\hline 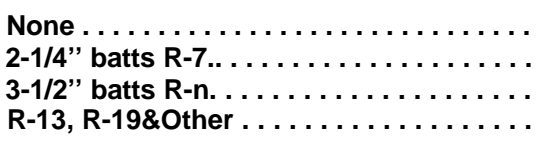 & $\begin{array}{r}63.0 \\
0.9 \\
16.5 \\
19.6\end{array}$ & $\begin{array}{r}51.0 \\
1.7 \\
32.9 \\
14.4\end{array}$ & $\begin{array}{r}63.1 \\
1.9 \\
18.5 \\
16.7\end{array}$ & $\begin{array}{r}65.7 \\
1.1 \\
14.3 \\
18.9\end{array}$ & $\begin{array}{r}75.0 \\
1.8 \\
16.8 \\
6.4\end{array}$ & $\begin{array}{r}75.7 \\
4.4 \\
11.5 \\
8.4\end{array}$ & $\begin{array}{r}99.1 \\
0.1 \\
0.4 \\
0.4\end{array}$ & $\begin{array}{r}88.3 \\
0.4 \\
4.1 \\
7.4\end{array}$ & $\begin{array}{r}88.9 \\
1.1 \\
7.3 \\
2.7\end{array}$ & $\begin{array}{r}80.1 \\
1.4 \\
11.2 \\
7.3\end{array}$ \\
\hline \multicolumn{11}{|l|}{ Crawl space walls(\% of all houses) } \\
\hline $\begin{array}{l}\text { None } \ldots \ldots \ldots \ldots \ldots \ldots \ldots \ldots \\
\text { Insulated }(R-7 \text { through } R-19) \ldots \ldots \ldots \ldots\end{array}$ & $\begin{array}{r}99.6 \\
0.4\end{array}$ & $\begin{array}{r}98.7 \\
1.3\end{array}$ & $\begin{array}{r}98.7 \\
1.3\end{array}$ & $\begin{array}{r}99.7 \\
0.3\end{array}$ & $\begin{array}{r}97.1 \\
2.9\end{array}$ & $\begin{array}{r}97.5 \\
2.5\end{array}$ & $\begin{array}{r}99.8 \\
0.2\end{array}$ & $\begin{array}{r}98.2 \\
1.2\end{array}$ & $\begin{array}{r}93.6 \\
6.4\end{array}$ & $\begin{array}{r}98.2 \\
1.8\end{array}$ \\
\hline \multicolumn{11}{|l|}{ Basement walls (\% of all houses) } \\
\hline $\begin{array}{l}\text { None } \ldots \ldots \ldots \ldots \ldots \ldots \ldots \\
\text { insulated (mostly } R-7,11,13, \& 19) \ldots \ldots\end{array}$ & $\begin{array}{l}87.0 \\
13.0\end{array}$ & $\begin{array}{r}93.5 \\
6.5\end{array}$ & $\begin{array}{r}93.0 \\
4.6\end{array}$ & $\begin{array}{l}81.8 \\
18.2\end{array}$ & $\begin{array}{r}97.4 \\
2.6\end{array}$ & $\begin{array}{r}95.1 \\
4.9\end{array}$ & $\begin{array}{r}99.8 \\
0.2\end{array}$ & $\begin{array}{r}93.9 \\
6.1\end{array}$ & $\begin{array}{r}97.7 \\
2.3\end{array}$ & $\begin{array}{r}96.0 \\
4.0\end{array}$ \\
\hline \multicolumn{11}{|l|}{$\begin{array}{l}\text { Slab-on-grade perimeter (\% of all } \\
\text { houses) }\end{array}$} \\
\hline 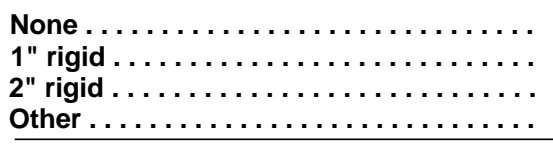 & $\begin{array}{r}99.3 \\
0.4 \\
0.2 \\
0.5 \\
\end{array}$ & $\begin{array}{l}96.7 \\
2.6 \\
0.7 \\
0\end{array}$ & $\begin{array}{r}92.6 \\
5.1 \\
2.2 \\
0.5 \\
\end{array}$ & $\begin{array}{c}99.3 \\
0.6 \\
0.1 \\
0 \\
\end{array}$ & $\begin{array}{r}86.3 \\
11.0 \\
2.3 \\
0.4 \\
\end{array}$ & $\begin{array}{r}88.8 \\
9.3 \\
1.3 \\
0.6 \\
\end{array}$ & $\begin{array}{r}89.0 \\
9.1 \\
0.9 \\
1.0 \\
\end{array}$ & $\begin{array}{r}93.3 \\
6.1 \\
0.1 \\
0.5 \\
\end{array}$ & $\begin{array}{c}91.9 \\
2.6 \\
0.8 \\
0\end{array}$ & $\begin{array}{r}89.3 \\
8.3 \\
2.1 \\
0.3 \\
\end{array}$ \\
\hline
\end{tabular}

SOURCE: NAHB Research Foundation, inc. 
sulation of basement walls and increased use of insulation between the floor joists are the most obvious areas where added insulation would be useful in new construction.

The window and door characteristics of the houses built in 1975-76 are shown in table 52. It shows that 42 percent of the entrance doors were insulated.

Table 53 shows the percentage of homes by price that have R-11 or greater levels of insulation in the exterior walls and R-13 or greater levels of insulation in the ceiling. More than 94 percent of all houses had exterior insulation levels of R-11 to R-19, and the incidence of less than R-11 levels does not seem to correlate with housing price. The data related to ceiling insulation are similar. Nearly 90 percent of all houses had ceiling insulation levels of R-13 or greater, and housing price does not seem to affect the levels of insulation.

There appears to be some buyer resistance to expensive conservation packages; many homeowners would prefer to invest in additional amenities rather than more conservation improvements. A Los Angeles Times ${ }^{30}$ article about Chicago builders indicated that while most builders provide R-11 exterior wall insulation and R-19 ceiling insulation, customers pass up beefed-up conservation packages for such luxury options as extra rooms or garages. One builder offered a $\$ 3,800$ optional energy package, but only 18 of 77 homebuyers bought it. Another reported a lack of interest in an optional feature to double the amount of insulation in the homes in one subdivision.

While builders have responded to consumer demand for energy-saving improvements, lenders have begun to promote saving in lending. Some lenders have promoted energy conservation through advertising the advantages of conservation - and providing special arrangements and rates for conservation loans. Many lenders have offered conservation home-improvement loans at interest rates below normal market rates. One California bank offers

\footnotetext{
${ }^{30}$ Don Debat, "Lending Institutions Say That Energy Expenses May Exceed Monthly Mortgage Payments," Los Angeles Times, Oct. 8,1978.
}

to rewrite homeowner loans and lend 100 percent of the cost of adding a solar system without raising the interest rate on the home mortgage and normally without increasing the total monthly payments. A bank in Washington State offers preferential terms for loans on homes that meet certain energy conservation requirements. ${ }^{31}$ A Minnesota bank promotes its conservation program as "the way lenders can help," while an Illinois bank group offers a home inspection at a $\$ 50$ cut-rate fee to detect heat-loss problems.$^{32}$ A survey by the Savings Institutions Marketing Society of America indicated that 20 percent of the 656 institutions surveyed featured energy-related homes in their 1977 advertising. 33 But while lenders have launched many types of programs, many have dropped them or lowered their expectations in the face of weak consumer response. Belowmarket interest rates appear to offer only a limited incentive to take conservation actions. Presumably, this reflects the general low-level of demand for small home-improvement loans (see Retrofit, page 97).

Data on retrofit are less precise, but many homeowners have been improving the energy efficiency of their homes. As noted in table 54, Building Supply News estimated that in 1977 4.2 million jobs involved insulation and $1.3 \mathrm{mil}-$ lion jobs involved storm windows and doors.

Extensive retrofit is confirmed by OwensCorning data. To monitor the extent of ceiling reinsulation activity by homeowners, OwensCorning conducted surveys in 1975 and 1976. During this period the average insulation installed increased from $4 \frac{1}{4}$ to $5 \frac{1}{2}$ inches. The extent to which reinsulation occurred did not vary widely across income groups: in fact, households with incomes under $\$ 10,000$ had a slightly higher rate of activity than their percentage of the population. Based on other studies Owens-Corning estimated that between 1974 and 1976, 8 million homeowners appeared to have reinsulated their ceilings, an additional 7 million did so in 1977. In 1978, 5

\footnotetext{
${ }^{31}$ Urban and Community Economic Development (American Bankers Association, May 1977).

32 I bid.

${ }^{33}$ Energy Savings Is Good (Savings Institutions Marketing Society of America).
} 
Table 52.-Window and Door Characteristics of 1975-76 Single-Family Detached Housing Units

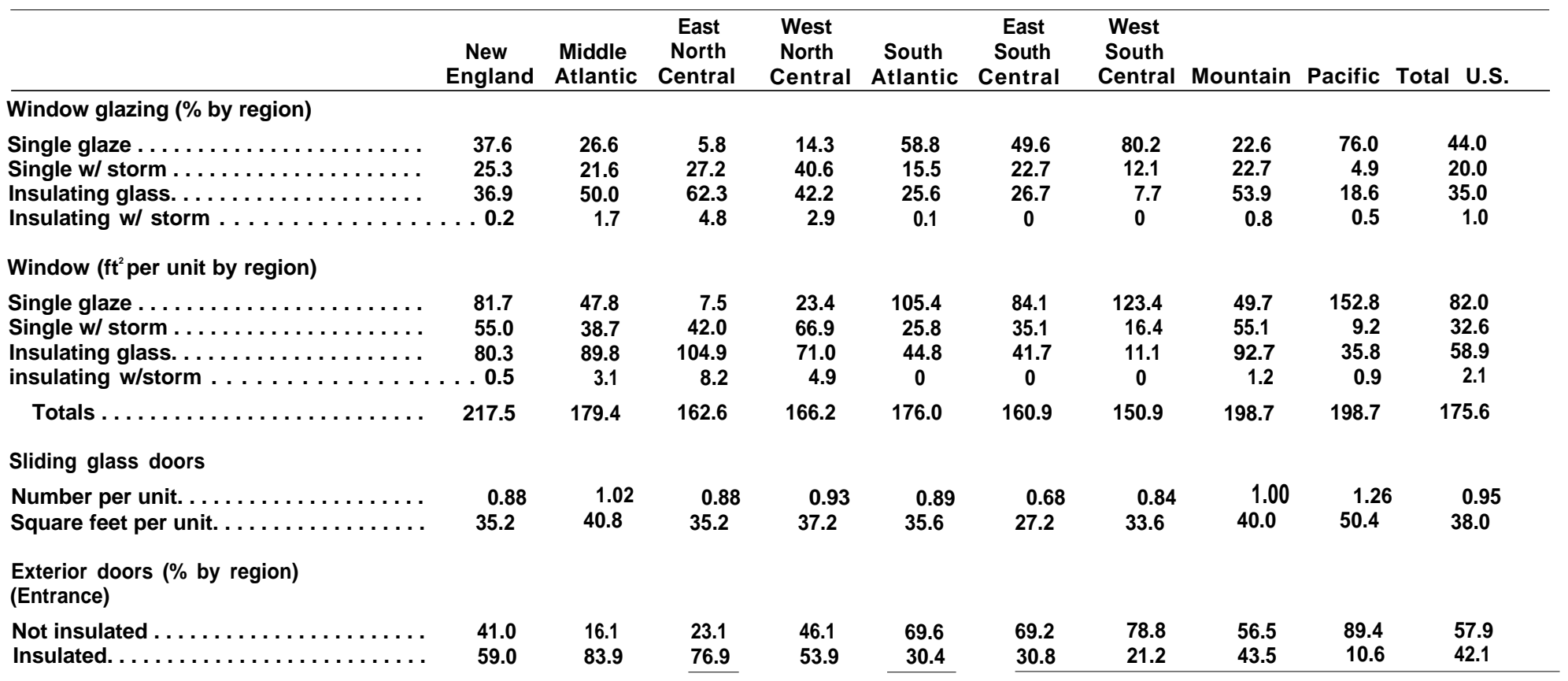

Table 53.-Single-Family Detached Homes Wall and Ceiling Insulation by Housing Price

\begin{tabular}{|c|c|c|c|c|c|c|}
\hline \multirow[b]{2}{*}{ Price range } & \multicolumn{3}{|c|}{ Exterior wall insulation } & \multicolumn{3}{|c|}{ Ceiling insulation } \\
\hline & Less than R-1 1 & R11-19 & Other & Less than $\mathbf{R}-13$ & R-13 or Greater & Other \\
\hline Less than $\$ 30,000$. & 2.7 & 96.7 & .6 & 3.7 & 95.8 & .5 \\
\hline$\$ 30,000-34,999 \ldots$ & 4.6 & 94.8 & .6 & 7.4 & 89.7 & 2.9 \\
\hline$\$ 35,000-39,999$. & 3.5 & 94.1 & 2.4 & 8.3 & 89.8 & 1.9 \\
\hline$\$ 40,000-44,999 \ldots \ldots \ldots \ldots$ & 2.6 & 96.5 & .9 & 6.4 & 93.4 & .2 \\
\hline$\$ 45,000-49,999 \ldots \ldots \ldots \ldots$ & 1.3 & 98.0 & .7 & 4.7 & 92.2 & 3.1 \\
\hline$\$ 50,000-54,999 \ldots \ldots \ldots \ldots$ & 4.2 & 94.8 & 1.0 & 6.7 & 91.3 & 2.0 \\
\hline$\$ 55,000-59,999 \ldots \ldots \ldots \ldots$ & 1.9 & 97.6 & .5 & 4.0 & 94.4 & 1.6 \\
\hline$\$ 60,000-64,999 \ldots \ldots \ldots \ldots$ & 1.7 & 97.6 & .7 & 4.9 & 95.0 & .1 \\
\hline$\$ 65,000$ and over. . . . . . . & 1.3 & 98.2 & .5 & 4.8 & 93.6 & 1.6 \\
\hline
\end{tabular}

SOURCE: NAHB Research Foundation, Inc. 
Table 54.-Estimates of Insulation and Storm Door/ Storm Window Activity in the Retrofit Market, 1977

\begin{tabular}{|c|c|c|c|}
\hline Type of activity & $\begin{array}{c}\text { Dollar } \\
\text { volume } \\
(\$ 000)\end{array}$ & $\begin{array}{l}\text { Number } \\
\text { of jobs }\end{array}$ & $\begin{array}{c}\text { Average } \\
\text { cost } \\
\text { per job }\end{array}$ \\
\hline $\begin{array}{l}\text { Additional insulation } \\
\text { Storm windows \& }\end{array}$ & $\$ 1,035,292$ & $4,243,000$ & $\$ 244$ \\
\hline doors . . . . . . . . . & $\$ 212,901$ & $1,339,000$ & $\$ 159$ \\
\hline
\end{tabular}

million to 5.5 million more homeowners were expected to invest in ceiling reinsulation.

The Gallup survey conducted for DOE in early 1978 found that 1 out of 6 respondents said that they had added insulation and 1 out of 10 installed storm doors or windows in the previous 12 months. Thirty-six percent of those with insulation believe more is needed..$^{34}$ Ninety-three percent believe their bills will be lower--(but only 44 percent know how large the savings will be). More than 80 percent of the homeowners said they know the type of insulation they want, where to buy it and how to install it. On the other hand, only 50 percent know what a fair price would be.
Energy conservation is a concern for the mobile home industry. The Federal standards under which all mobile homes are built include thermal performance standards. Three different thermal performance standards are used depending on the zone of the country. The NAHB study of 175,000 mobile homes built in 1976-77 shows that most homes had R-13 to R-18 levels of insulation in the ceilings, though sizable portions had R-19 to R-21. Walls and floors were typically insulated to an R-11 standard. Most units had single-glazed windows with storm windows, but in units to be sold in southern areas single-glazed storm windows were common. The Federal standards have had a positive effect in raising insulation standards in mobile homes. Most existing mobile homes have some insulation but its effectiveness is not known. Few mobile homes have storm windows or storm doors. Due to the nature of the industry, Federal regulation has been welcomed, and improved standards should not represent a major barrier.

\section{FINDINGS AND OPPORTUNITIES FOR ENERGY CONSERVATION}

Operating practices and market conditions largely determine the incentives for and obstacles to energy conservation. Opportunities for energy conservation differ among the three housing submarkets- new construction, manufactured housing, and existing housing. These differences must be considered in setting energy conservation goals and programs. Differences in practices, levels of knowledge, and attitudes toward conservation vary depending on whether the housing is investor-owned and rented or owner-occupied, and whether the housing is single-family or multifamily. These differences affect the economic circumstances, attitudes, and characteristics of the participants in the housing sector and the incentives needed to motivate property owners to take energy-saving actions.

\footnotetext{
${ }^{34}$ Gallup Organization, Inc., op. cit.
}

There is no single national housing market; each locality has its own characteristics and features. Practices, attitudes, and requirements vary by such factors as geography, supply and demand for housing, climate, tradition, cost and availability of fuel, patterns of tenure, community size, and type of construction. As a result, housing costs and characteristics differ widely depending on locality or region. These variations, true of both the existing housing stock and the new construction market, affect the attractiveness of investing in energy conservation improvements and determine in part the building industry response to conservation. The attitudes of property owners toward energy costs and energy conservation have changed significantly over the past 5 years. In response, many builders have raised their standards for energy efficiency in homes and are now actively promoting energy features in sales. Persons owning homes have 
begun to alter their homes to save energy; this effort is being augmented and supported by contractors, utilities, and some lenders.

Despite the growing response of the building industry and individuals, a great deal more can be accomplished. New construction offers more energy-saving potential per dwelling than existing housing, as many improvements possible during construction cannot be added, or can be added only at high cost, after the building is finished. Because most new construction must conform with local building codes, a system is in place to inspect plans and construction practices.

Because of the size of the existing housing stock - some 80 million units - retrofit will be most productive in saving energy in the short run. The level of thermal performance of the total housing stock will change only slowly as a result of new construction, with annual starts of 2 million units on the average.

\section{Builders' Attitudes}

The construction industry responds to wideranging changes in taste and demand. Since the new construction market is highly competitive, and most firms are relatively small, builders must compete in terms of price, design, and amenities as demanded by the public at a given time. Builders therefore add energy conservation improvements to their houses to the extent they expand or improve the marketability of the house.

In addition to watching buyer demand closely, builders also stay in close touch with building material suppliers, and some follow the research and publications of NAHB and similar groups. From such marketer's associations and other builders, they learn of new industry trends, practices, and products. Features like air-conditioning, once considered a luxury, became standard in a short time in response to buyer demand and technology transfer. Thus, education through building trade groups, combined with growing public concern over energy cost, should work to accelerate the use of conservation options by builders.
Although most builders now seem generally aware of opportunities for conserving fuel, their expertise is limited. Most building companies do not have design or engineering skills, but rely on architectural and engineering firms, utilities, design reviewers, and lending institutions to make decisions on energy-based changes. Designing energy-efficient housing requires consideration of climate, site, style, material costs, and specifications, financing costs, and taxes. Builders often cannot afford to hire experts in all these areas. Without proper engineering and design, housing can contain many "energy saving" features and yet fail to operate efficiently.

Builders appear willing to experiment with new materials, particularly if others in their area are also experimenting. I n 1978, a Professional Builder survey found that 25 percent of the builders had tried $2 \times 6$ framing with 6 inches of insulation to obtain an R-19 wall; this number was up from 20 percent of the builders surveyed in $\mathbf{1 9 7 7 . 3 5}$

The other factor that determines how builders build is the local building code, Inspections normally include both design review and onsite inspection. As code requirements relating to energy use become more stringent, builders will presumably comply. Most homes are constructed by builders who use prescriptive codes; i.e., acceptable materials and practices are clearly specified. These builders will easily cope with most new codes that can be translated into simple, easy to follow formats. (See the section in chapter VI 1 I on standards.)

\section{Property Owners' Attitudes}

The price of energy seems to be the most powerful incentive to conserve, and future conservation will depend on property owners realizing increased economic benefits. Where fuel costs are high and climatic conditions extreme, it appears that consumers are especially willing to invest in energy efficiency.

${ }^{35}$, Energy and the Builder," op. cit. 
A lifecycle costing analysis, while commonly used to make investment decisions of certain types, is not typically used by the homeowner. The commercial real estate investor may conduct a lifecycle cost analysis in an informal manner, balancing the analysis with judgments about the future of the property, the investment required, and other investment plans. Short ownership periods and investment horizons mitigate against adoption of lifecycle costing approaches.

The marketplace makes distinctions between conservation improvements that are clearly cost-effective and those which return the investment over a longer pried. This partially explains the greater interest in insulation and double-glazed windows than in, for example, solar energy systems. The difference in attitude may also reflect consumers' and building professionals' different levels of awareness and information about various conservation technologies.

Homeowners and investors assess energy conservation opportunities differently. Homeowners view conservation improvements in terms of their potential for reducing energy costs, effect on the downpayment and the monthly carrying costs, and the possibility of future maintenance difficulties. Investors in rental housing consider conservation improvements in terms of improved profitability, reduced risk, or additional income or profit. If increased energy costs can be directly passed on to tenants by increasing rents, conservation may not be an attractive investment. (See the section in chapter VI I I on tax policy.)

The principal opportunity for additional conservation activity in the retrofit market centers on ways to motivate the homeowner to improve the efficiency of his home. The homeowner can be made more aware of conservation opportunities through the media, utility advertising and energy audit programs, and publicity by manufacturers and suppliers of building materials. Realtors and lenders can also encourage homeowners and homebuyers to take conservation action.
Is the Cost of Adding Energy

Conservation Features to New or

Existing Housing an Impediment to Conservation?

The inclusion of conservation improvements in new housing is tempered by market conditions and considerations. The dramatic rise in the price of housing in recent years has made builders sensitive to increases in first costs or in carrying charges.

Including energy conservation features in a new home often increases downpayment requirements and fixed monthly charges. While it does not follow that if builders choose to upgrade the energy-saving characteristics of their housing and increase the price accordingly, households are priced out of the market altogether, marginal buyers might have to scale down their expectation. For example, assuming a 10-percent interest rate and 30-year term, a house cost of $\$ 50,000$ and $\$ 45,000$ loan, and a $\$ 5,000$ downpayment, a monthly mortgage payment of $\$ 394.91$ would be required. Extra improvements of $\$ 2,000$ financed on the same terms would increase the downpayment $\$ 200$ and the monthly payment would rise to $\$ 410.18$. The $\$ 15.27$ monthly increase would add $\$ 183.24$ a year to housing costs. Using the rule of thumb (which is no longer universally used) that a purchaser should spend 25 percent of his income for housing, a purchaser would have to earn an additional $\$ 733$ of annual income to afford the house. This additional cost might affect the marketability of the home; NAHB estimates that 39.8 percent of the public-22,771,000 households-could afford a $\$ 50,000$ home with the financing described above. Increasing the price to $\$ 52,000$ reduces the number of households who can afford the house to $21,283,000$ households or 37.2 percent of all households, according to NAHB. The builder therefore makes a decision to increase cost with great care.

Are Problems of Financing Impeding the Pace of Residential Conservation?

Lenders generally have been willing to finance the added cost of energy-efficient 
housing. Financing has not been a problem for the credit-worthy borrower. Lenders rely on appraisers to make judgments about the extent to which conservation improvements add to the value of a property; standard conservation improvements are not seen as valuation problems. Houses based on "solar passive" principles or other design approaches may not be acceptable to lenders if the houses have an unusual appearance or require no purchased energy; they are considered experimental. Lenders appear increasingly willing to make conservation-related home improvement loans, although most conservation improvements are inexpensive and not profitable for banks to finance. Most homeowners, however, pay for home improvements through cash on hand, savings, or short-term credit arrangements such as credit cards. Those who do need financing may not meet requirements for income and established credit. Low-income homeowners have more difficulty financing conservation improvements and may need some form of subsidy to make those improvements. The Community Services Administration (CSA) and DOE weatherization program partially meets the needs of low-income homeowners, but many may fail to qualify for or be reached by weatherization assistance. Newly authorized utility audit programs may also assist those who need financial help.

Lenders have limited interest in promoting energy conservation and do not consider it a significant factor in lending decisions. On the other hand, some financing institutions estimate utility costs in calculating the monthly housing expenses of a potential borrower. Some lenders may view energy-conserving improvements as potential means of reducing lending risks by reducing fuel costs, or as ways to improve resale value, but most do not evaluate the energy efficiency of housing they finance. Many lending institutions have initiated special, below-market interest-rate loan programs to promote conservation activity. These programs have not generated strong consumer response. Lenders therefore give these programs a low priority, treating them primarily as public relations endeavors.
Few lenders are concerned with the energy efficiency of the homes they finance. Since financing is essential to homeownership for most Americans, a change in the attitude of lenders could quickly facilitate a shift to much higher levels of conservation. If review of mortgage applications included a review of energy costs, much greater investments in saving energy could be expected.

\section{What Are the Current and Potential}

Roles of the Federal Government in Encouraging Residential Conservation?

The Federal Government currently affects the housing sector through programs that regulate lenders, through tax policy, programs that provide housing subsidies, insurance, and guarantees, and standards setting. The impact of Federal actions is much greater than the level of Federal insurance, guarantees, or subsidies would suggest. The role and impact of Federal programs are reviewed in chapter VIII.

The implementation of HUD's Building Efficiency Performance Standards (BEPS) and the adoption of federally sponsored "model code" standards should raise the energy efficiency of new housing. By using nationally developed energy standards and enforcement guidelines for all new construction, builders and local building code officials will be in a better position to understand and implement conservation actions. The process of reviewing and implementin ${ }_{g}$ standards should improve consumer awareness of energy conservation. (See chapter VII I.)

Other Federal initiatives that will affect energy efficiency in the residential sector have been mandated by the National Energy Policy and Conservation Act of $\mathbf{1 9 7 5}$ and the Housing and Community Development Amendments of 1978, which established programs to finance energy-conserving improvements and promote solar energy and energy conservation in HUDassisted housing. Tax credits for conservation improvements have been enacted. 


\section{DIRECTIONS FOR THE FUTURE}

Much remains to be done to upgrade residential structures and to encourage property owners to adopt energy-conserving practices. Tens of millions of homes require reinsulation and other energy-saving improvements. The design and features provided in new housing could be significantly upgraded even beyond current levels to improve their energy efficiency.

The key issue is whether the current pace of change is satisfactory, or whether additional Federal actions directed to property owners or the building industry are required to increase either the pace or the direction of current trends. Available information provides no conclusive answer, but signs indicate that increasing energy prices, greater awareness among property owners and industry participants, and previously enacted Federal legislation are encouraging property owners to invest in conservation. Legislation enacted in 1978, recent changes in Federal policies and practices, and the promised issuance and implementation of BEPS promise to bring about further improvement in the energy efficiency of residential buildings. Other new incentives for energy conservation in both the public and private housing sectors are described in detail in chapter VII I.

These new initiatives, plus those related to other aspects of residential energy conservation discussed elsewhere, should help to expand the awareness and knowledge of property owners and building industry participants about energy conservation, and stimulate further investments in conservation improvements. In the context of rising energy prices, further conservation can be expected.

Given the breadth of these recent Federal initiatives and the market dynamics of the housing industry, it seems appropriate to move cautiously in terms of proposing additional ac- tions. A cautious approach is warranted to avoid Federal actions that may be unnecessarily costly, provide windfalls, or have a negative impact on housing costs. Actions that increase housing costs must be weighed carefully in terms of costs and benefits.

Assuming that the availability and price of energy remain about as expected, it may be most efficient to focus on improving the quality or expanding the coverage of existing conservation programs, and to monitor the impact of the new initiatives, before mounting any major new efforts. Priority should also be given to modifying policies or practices that act as barriers to conservation.

Efforts to inform the building industry and property owners about the opportunities and techniques for saving energy need to be improved. Industry needs better technical information, and the average homeowner needs simpler, more useful information. The quality of information now available varies widely and is disseminated unevenly. The expanded energy audit program appears to be a promising educational approach. The Government should continue to work closely with trade groups to assure that building professionals are not only aware of the importance of considering energy costs in making housing decisions, but know how to design and construct more energy-efficient houses. Demonstration efforts promote the market for energy-saving improvements and should be continued.

More research should be directed to conservation. Promising technological approaches must be encouraged. More information is needed about the thermal efficiency of the housing stock and the extent and character of retrofit actions. A better understanding of real estate investors' attitudes and motivations, and the extent to which they are making conservation improvements, is needed. 
Chapter VI

\section{UTILITIES AND FUEL OIL DISTRIBUTORS}




\section{Chapter VI.- UTILITIES AND FUEL OIL DISTRIBUTORS}

Electric and Gas Utilities ......... 119

introduction . . . . . . . . . . . . 119

Electric Utility Industry Structure and Historical Development . . . .. ...119

The Regulatory Environment . . . .....120

The Problems of Recent Changes for the Electric Utility Industry.

Gas Utility Structure and Regulatory Environment . . . . . . . . 123

Recent Changes in the Gas Utility Industry. . . . . . . . . . . . . . 124

Utilities and Residential Consumers .. .125

Utility Activities in Residential Energy Conservation. . . . . . . . ... 126

Information Programs. . . . . . .126

Conservation Investment Assistance

Programs. . . . . . . . . . . . . .127

Rate Reform for Electric Utilities . . .. .130

Lifeline Rates . . . . . . . . . . . 131

Load Management . . . . . . . . . 132

Federal Programs and Opportunities in Utility-Based Issues. . . . . . . 133

New Legislation on Conservation Investment Assistance. . . . .134

New Legislation on Utility Ratemaking and Load Management . . .134

DOE Electric Utility Rate

Demonstration Program . . . . . . 135

DOE Load Management Activities . . 138

Conservation Programs of the Federally Owned Power Authorities . .. ...138

Conclusions for Utility Policy .. ..139

The Fuel Oil Distributors . . . . . . . .139

Industry Size. . . . . . . . . . . . . . 139

Fuel Oil Marketers . . . . . . . . . . . 140

Sales of Distillate Fuel Oils. . .........140

Service Activities . . . . . . . . . . . . . 140

New Construction . . . . . . . . . . 143

The Role of Oil Heat Distributors in

Energy Conservation Practices . . . 143

Introduction . . . . . . . . . . . . , 143

Marketing of Energy Conservation

Products . . . . . . . . . . ......143

Reduction in Annual Fuel

Consumption.
Factors That Influence and Limit Market Entry . . . . . . . . . . . . 144

Fuel Oil Customer Accounts . . . . . .144

Technical Notes-Computer Simulation: The

Effect of Conservation Measures on

Utility Load Factors and Costs . . ....145

The Question . . . . . . . . . . . . . 145

Background . . . . . . . . . . . . . . 145

OTA Analysis of Conservation Impact on

Utility Loads and Costs . . . . . . . 147

Results . . . . . . . . . . . . . . . . ...148

Discussion. . . . . . . . . . . . 149

TABLES

55. Residential Natural Gas and Electric

Prices . . . . . . . . . . . . . . . . .....125

56. Percentage Changes in Real Utility

Prices, Selected Periods, 1960-77......125

57. DOE Electric Rate Demonstration

Program kWh Consumption Effects . . .136

58. DOE Electric Rate Demonstration

Program kW Demand Effects . . . . . 137

59. Average Yearly Demand for Distillate

Fuel $011 \ldots \ldots \ldots \ldots \ldots . \ldots \ldots 141$

60. 1985 Projection of Heating Unit Mix and

Basic Loads . . . . . . . . . . . . . . ..148

61. 50-Percent Electric Resistance Heating

by $1985 \ldots \ldots$. . . . . . . . ......148

62 Simulated Utilities' Load Factors, Peaks,

Summer-Winter Ratio by 1985 ......148

FIGURES

17. Sales of Distillate Fuel Oil Use as

Percent of Total . . . . . . . . . . . ...142

18. Dispatching Generation to Meet a Cyclical Load , . ................146

19. Daily Load Curve . . . . . . . . . . . 146

20. Electrlc Energy Output and Annual Load Factors . . . . . . . . . . . 147 


\section{ELECTRIC AND GAS UTILITIES}

\section{Introduction}

The electric and natural gas utility industries serve as the conduit through which American households receive most-and sometimes all -of the energy used in their residences. Sharp increases in utility bills in recent years, along with such emergencies as blackouts and brownouts, have made American homeowners and renters increasingly aware of the critical role that utility companies play.

Probably no industry - not even the petroleum industry - has experienced the profound impact on its operations and policy decisions felt by the utility industry in the wake of the energy crisis of the 1970's. Other industries have experienced increased prices and or curtailed supplies; so have the utilities. But utility companies have also come up against societal demands for change in their fundamental purposes, plans, financial management, and delivery of service.

Thus, the entire relationship between utilities and their residential customers has shifted. After years of enjoying declining or stable real prices, promoting greater energy use, and responding to rapid growth in residential energy consumption, utilities are suddenly being asked to help their residential consumers use less gas and electricity.

To understand the role of electric utilities in the consumption and conservation of energy in the home, it is useful to review briefly the structure and historical development of the industry and the regulatory environment in which it operates. Following a discussion of these items, this chapter examines utility activities as they relate to residential energy conservation. Information programs, energy audits, conservation investment assistance, rate reform, and load management are examined.

\section{Electric Utility Industry Structure and Historical Development}

The electric utility industry is a diverse group of more than 3,500 companies, both publicly and privately owned, collectively comprising one of the Nation's largest industries. Some companies engage in all three of the industry's major functions - the generation, transmission, and distribution of electric power. Most, however, serve only as local distributors of power. Publicly owned municipal and cooperative companies, in particular, tend to purchase electricity from generating companies that may be investor-owned or federally operated entities such as the Tennessee Valley Authority (TVA). The term "electric utility," as used here, refers to a distributor of electricity, regardless of whether the company generates its own power. Electric utilities may also serve as distributors of natural gas.

Although publicly and cooperatively owned electric companies outnumber private investor-owned firms by almost 10 to 1 , the private companies dominate the industry in terms of generating capacity and quantity of electricity delivered. Furthermore, the largest 200 (out of a total of 400) investor-owned companies account for three-quarters of the Nation's total electric-generating capacity and serve 80 percent of all electric customers.

The electric utility industry is the Nation's most capital-intensive industry. In 1977, investor-owned electric power companies had aggregate plant investments of $\$ 190.4$ billion and annual revenues of $\$ 58.8$ billion, or a total investment of $\$ 3.24$ for each dollar of annual sales ${ }^{2}$ Attracting the capital needed for plant

Booz, Allen \& Hamilton, Inc., Utility Role in Residential Conservation, report to OTA, May 1978

${ }^{2}$ Energy Data Reports, Department of Energy, CRN 78032 3-9919, Mar. 22,1978 
expansion was not difficult for the utility sector until recently, as the industry's high, steady, and seemingly predictable growth, and its regulated return, were attractive to investors seeking secure earnings.

Before the oil embargo of 1973-74, personal incomes and retail prices paid for consumer goods in the United States grew much faster than retail electricity prices, so that "real" power prices - adjusted for inflation -fell. While the Consumer Price Index rose 31 percent and real family income rose 34 percent between 1960 and 1970, the price of electricity grew by only 12 percent. By contrast, medical care cost 52 percent more in 1970 than in 1960, while the increase for food was 31 percent and for homeownership 49 percent. ${ }^{3}$ The growth of electricity use in the United States, closely related to these economic trends, was also encouraged by the promotional activities of the electric utilities.

Low fuel costs for power generation have been one reason for traditionally low electricity prices. Another reason is that utilities have, until recently, enjoyed increases in productivity through economies of scale in generating equipment and improvements in thermal efficiency of boilers. The prospect of scale economies made the utilities' promotion of electricity beneficial to both shareholders and consumers during the pre-embargo period. As falling real prices and promotional activities encouraged growth, steady increases in consumption led to lower unit costs and, incidentally, made future planning a straightforward process of extrapolating from past trends.

As long as the electric utilities enjoyed rising productivity, they remained a declining marginal cost industry - that is, the incremental cost of electricity generated to meet new demand was lower than the average costs incurred by the power companies to meet existing demand. This situation facilitated the financing of new powerplants, the construc-

${ }^{3}$ Statistical Abstract of the United States (Washington, D. C.: 1977). tion of which could be planned, financed, and carried out in a few years.

The result of all these advantages, in the period before the mid-1970's, was long-term security in the electric power sector. Today, by contrast, utility companies find themselves facing high costs for new capacity and for fuel; new regulatory requirements for environmental protection, nuclear safety, and energy conservation; and uncertain future growth projections and capital availability prospects.

\section{The Regulatory Environment}

For investor-owned utilities, most regulation occurs at the State level. The Federal Energy Regulatory Commission (FERC), formerly the Federal Power Commission, regulates only the interstate transmission of power and the sale of power for resale (wholesale sales). State regulation is carried out by public utility commissions whose members are either elected or, more commonly, appointed by Governors (sometime with legislative consent) to serve fixed terms. The commissions function as quasi-judicial bodies and hand down decisions on rates and powerplant sitings after public hearings. Municipally owned utilities are usually regulated by local government officials, while cooperatively owned power systems are regulated by elected boards representing the consumer-owners. Regardless of ownership, all utilities are constrained from the arbitrary use of their monopoly power by the regulators, who require them to perform certain duties (such as providing a reliable power supply to all those who pay for it) in exchange for authorizing a "fair and reasonable" rate of return.

Electric utility rate regulation involves two major steps. The first step is to approve a level of revenues adequate to cover costs for operation and maintenance, debt service, depreciation, and taxes, plus a "fair and reasonable" rate of return on invested capital. The utility commission attempts to establish a rate of return that is high enough to attract capital for future expansion, yet not so high as to overcharge consumers or violate the "fair and reasonable" standard. 
The second step in utility regulation is to establish the rates at which electricity is to be sold in order to produce the allowed revenues. The ratemaking process is normally based on a "cost-of-service study," a tool used by utilities to break down their total costs over a specified time period among the different functions (generation, transmission, and distribution), customer classes (residential, commercial, and industrial), and cost classifications (customer, demand, and energy).

Cost classifications require some explanation. Customer costs include such expenses as meters, distribution lines connected to the customer's service address, billing, and marketing. As a general rule, customer costs vary hardly at all with consumption levels. Demand costs are fixed costs reflecting the company's investment in plant capacity and a portion of the transmission and distribution expenses; they represent the cost of providing the maximum (or peak) amount of power required by the system at any time. Energy costs are variable; they depend directly on the amount of power used by the system's customers. This cost category includes fuel costs, costs involved in running and maintaining the boilers, or in producing hydroelectric power (including pumped storage), and certain costs incurred in purchasing power from other generating companies.

Assigning customer costs and energy costs to different classes of customers is a fairly straightforward exercise, but allocating demand costs is more difficult. Here, a degree of judgment is required. Once the total contribution of each consuming class to the functional and classified costs is estimated, the totals are divided by the number of billing demand units in each class and translated into rates. In most cases - and in almost all situations involving residential customers - the customer, energy, and demand charges are not identified separately for the customer. Rather, they are lumped together in a single kilowatthour rate. For residential consumers, the customer charges are usually included in the rate charged for the first increments (or blocks) of power consumed each month (measured in kilowatthours), in order to ensure that they are recovered. Power companies usually charge a minimal fee even when no power at all is used, to cover these fixed customer costs. Consequently, the first blocks of power are more expensive than additional blocks consumed in the same month and the most common rate design is called a "declining block" rate. Until recently, most utility commissions have left the details of this second regulatory step, the design of rates, largely to the discretion of the utilities, with pro forma commission approval.

\section{The Problems of Recent Changes for the Electric Utility Industry}

In recent years, utilities have experienced changes - many of them traumatic - in every aspect of their operations. Like all fossil fuel consumers, utilities have faced drastic increases in the price of fuel, particularly oil. While utility fuel cost rose 24 percent between 1965 and 1970, they jumped a startling 248 percent between 1971 and $1976 .{ }^{4}$ In the face of such rapid cost increases, regulators have permitted the electric companies to pass on higher fuel costs to their electric customers through automatic "fuel adjustment clauses," without waiting for normally lengthy ratemaking proceedings before increasing rates. These clauses have reduced hardships that utilities would otherwise have experienced by shortening the regulatory lag and eliminating the need for constant repetition of hearings and findings in response to requests for rate increases. Whether fuel adjustment clauses have also served as disincentives to energetic utility searches for inexpensive fuels or alternative energy sources is a question currently under review in many State utility commissions. They have been major contributors to continuous increases in residential electric customers' bills, making the utilities the target of resentment and suspicion. Low-income customers and persons on fixed incomes have suffered particularly from large increases in their bills. DeIinquent accounts have increased, as have

'Electric Utility Rate Design Study, Rate Design and Load Control; Issues and Directions, A Report to the National Association of Regulatory Utility Commissioners, November 1977, p. 10. 
meter tampering and theft. In the two successive cold winters of 1976-77 and 1977-78, there were occasional news accounts of poor people freezing to death after utility shutoffs for nonpayment of bills. Some States enacted emergency relief programs that prohibited such shutoffs, and the Federal Government offered grants and loans to help pay the bills.

Utility managers have expressed surprise at their apparent fall into disfavor with many customers as rates have risen; typically, the electric (and gas) companies see themselves as analogous to the Greek messenger who was executed for bearing bad tidings. Public opinion surveys document a widespread public belief that the utilities are profiting from the energy crisis and are highly suspect as sources of information about the crisis and its remedies.' Many consumers appear not to understand the reasons behind their higher bills, and they attribute all rate increases to attempts to increase profits. $^{6}$

Fuel prices accounted for approximately 60 percent of all rate increases in 1974, but they are not the only reason for rising utility bills. Plant costs have also risen sharply, According to figures compiled by the Department of Energy (DOE), a single 1,000-MW nuclear plant begun in 1967 and brought online in 1972 cost an average of approximately $\$ 150$ million to build, while a similar plant begun in 1976 and expected to be ready in 1986 will have total projected costs of $\$ 1.15$ billion-10 times as high. A coal-fired plant begun in 1966 and placed in service in 1972 cost $\$ 100$ million, while a comparable plant constructed between 1976 and 1986 will cost $\$ 950$ million-again almost a tenfold increase.' A greatly lengthened period of planning and construction accounts for a significant portion of these higher plant costs. Caused in part by what John $\mathrm{H}$. Crowley calls an "exponential increase in regulatory requirements," these delays contribute in turn to massive increases in interest paid on borrowed capital during construction. Pro-

${ }^{5}$ Electric Utility Rate Design Study, op. cit., p. 83.

'Ibid.

'John H. Crowley, "Power Plant Cost Estimates Put to the Test," Nuclear Engineering International, July 1978, p. 41. tracted licensing procedures, inflation in labor costs, added hardware for safety and environmental protection, and higher interest rates all add to plant costs. I $n$ 1950, the average interest rate paid by utilities on newly issued bonds was 2.8 percent; in 1970, the rate was 8.8 percent, and by 1975 it had reached 10.0 percent. $^{8}$ Utilities must now look to external sources for most of their capital needs. As a result of all these factors, the electric utility sector is now an industry of increasing marginal costs-that is, the incremental cost of producing one more demand unit is higher than the average unit cost for meeting existing demand.

Regulatory changes have also caused some discomfort for the utilities. While the electric light and power industry could hardly be considered a textbook illustration of the free enterprise system at work - marked, as it is, by governmental regulation of profits and prices, as well as by its own monopoly control of markets and the power of eminent domain - utility managers have nonetheless tended to identify with business interests and to resent the expansion of Government power. They have, consequently, found themselves in an increasingly adversary relationship with regulators at both the State and Federal levels, as utility commissions and Federal agencies have reached ever deeper into their operations.

Utility regulators have responded to newly felt public needs to conserve energy, protect the environment, and deal with new consumer activism. Some State commissions began in the earl y 1970's to disallow the costs of promotional advertising as operational expenses. Some attempted to prohibit advertising altogether. A few have required experiments in new rate designs, such as peakload (time-ofday and seasonal) pricing and "lifeline" rates to subsidize poor and elderly consumers. Many commissions, most notably the California Public Utilities Commission, have begun to take a closer look at requests for new generating capacity, to see if energy conservation programs could delay or eliminate the need for proposed additional powerplants. Some have required utilities to initiate conservation pro-

${ }^{8}$ Electric Utility Rate Design Study, op. cit., p. 11. 
grams involving the sale, installation, or financing of insulation and other energy-conserving features for consumers. These new initiatives have come both from aggressive interpretations of existing mandates and from new State legislation.

Utilities are also being asked to meet new requirements imposed at the Federal level. Air and water quality standards mandated by Congress and enforced by the Environmental Protection Agency have accelerated the retirement of some older plants and required the installation of sophisticated control equipment on both existing and new plants. Many companies have altered their boiler fuels more than once to respond to Federal directives; after shifting from coal to oil or gas to meet air quality requirements, they have been asked by the Federal Energy Administration (and the more recent DOE) to convert back to coal to avert oil and gas shortages and cut imports. As nuclear power has begun to produce an important share of the Nation's total generating capacity, power companies have found it necessary to deal at great length and expense with the Nuclear Regulatory Commission (formerly the Atomic Energy Commission).

\section{Gas Utility Structure and Regulatory Environment}

Most gas utilities serve only as retail distributors, purchasing natural gas at wholesale rates from a relatively small number of 13 pipeline companies, which purchase in turn from producers. Among the 1,600 retail natural gas distributors, private companies predominate in terms of both their share of the industry (two-thirds of all gas companies) and the quantity of gas they sell, as a percentage of total sales (90 percent). Many of these companies are combination gas-and-electric companies; these account for $\mathbf{4 0}$ percent of all natural gas sales. $^{9}$

Almost two-thirds of the natural gas sold by utilities comes from the interstate market, where its price is regulated by FERC. Intrastate gas prices have been regulated by the public

${ }^{9}$ Booz, Allen \& Hamilton, op. cit. utility commissions of States in which the gas is produced and consumed. With passage of the Natural Gas Policy Act of 1978, intrastate prices have been slated to come under Federal regulation.

The separate regulatory systems for intrastate and interstate gas have contributed, over the years, to imbalances in both price and supply. Intrastate gas, which is not regulated at the wellhead, has generally been priced closer to competitive or substitute fuels such as distillate fuel oil. Interstate wellhead prices, on the other hand, which are subject to costbased Federal regulation, have been lower priced than substitute fuels. As a consequence, producers have kept as much gas as possible within the producing States which has helped bring about an imbalance in supply between the two systems. Even though wellhead prices are generally higher in producing States, the prices residential consumers pay is lower with some exceptions. This discrepancy in part is due to higher transmission costs for those living far from the producing regions and the need to supplement the flowing gas supply in the nonproducing regions in times of shortage.

The intrastate/interstate price discrepancies have increased during the last few years, as gas-short utilities in the nonproducing States have had to turn to high-priced supplemental gas sources such as imported liquefied natural gas (LNG) or synthetic natural gas (SNG) and propane just to meet their existing customers' needs. Expansion of their markets has been precluded in many areas by the supply shortages. Industrial customers in some consuming States have wearied of constant interruptions in their gas service and have permanently turned in large numbers to other fuels, particularly distillate fuel oil. Ironically, industrial fuel shifts have freed up enough gas in some places to cause pocket surpluses. But where utilities were prohibited from providing service to new customers, they had no market for this surplus gas and had to relinquish it to other distributors.

Historically, the gas utility industry has relied primarily on long-term debt to finance its capital needs. Its capital intensity has declined over the last 25 years, going from 
$\$ 3.00$ in total investment per $\$ 1.00$ of sales revenues in 1950 to $\$ 1.75$ in total investment per $\$ 1.00$ of sales in 1975 . ' 0

\section{Recent Changes in the Gas Utility Industry}

Like the electric utilities, gas companies have experienced a number of traumatic changes in recent years. In many regions, utilities have been totally unable to take on new customers and have had to curtail not only their large industrial customers whose contracts anticipated interruptions in service at times of peak demand, but also some customers whose contracts and rates were based on more expensive "firm" service. Allocations of scarce gas supplies by Federal and State agencies have caused some utilities to lose gas to other companies. While the need to conserve gas has been obvious from a national policy standpoint, the most immediate and direct benefits of such conservation have not always been available to the companies that were able to save supplies, only to see them allocated to others.

Recent passage of the National Gas Policy Act has brought a prospect of major changes for gas utilities and their customers. The new law paved the way for gradual deregulation of most gas prices and brought intrastate gas under Federal regulation for the first time, reducing the price gap between interstate and intrastate gas. High-cost gas is to be deregulated first, and the regulated price of other gas will be allowed to rise gradually from legislatively mandated ceiling prices, using annual inflation rates as guides for increases. Deregulation will be virtually complete by 1985 .

Utilities will pay much higher prices for gas under the new legislation. interstate pipeline companies will pass on to utilities the higher prices paid by pipelines for gas supplies, and the utilities will pass on the increases in turn to their own customers. Residential gas utility customers will be sheltered initially, however, from the increase in natural gas prices because of a provision for "incremental pricing" under

\footnotetext{
“"I bid.
}

which large industrial customers using gas as a boiler fuel will bear the full additional price burden -to a point. When incremental pricing causes industrial gas rates to exceed the cost of alternative fuels, the burden of higher gas prices in excess of alternative fuel costs will be shared by al I gas consumers.

Just how soon residential gas users feel the impact of the new legislation on their monthly utility bills is a matter of considerable debate. The number of industrial customers subject to the incremental pricing provisions is limited somewhat by the new law; only interstate customers, and only those who use gas as a boiler fuel (as opposed to a process feedstock), are affected. If rising industrial gas prices or requirements of the coal conversion legislation cause many industries to shift to alternative fuels (including, perhaps, imported fuel oil), then the fixed costs associated with gas pipeline transmission and storage must be shared by the remaining customers. The smaller the group of industrial customers subject to incremental pricing, the sooner the peak priceon a par with alternative fuels - is reached and the high-cost burden becomes dispersed among residential and commercial customers as well as industries.

As residential natural gas prices continue to rise steeply - and the Energy Information Administration estimates that they could reach $\$ 3.31$ per mcf in 1976 dollars by 1985-homeowners will have an even stronger incentive to conserve and overall consumption growth in the residential sector will continue to decline. On the other hand, the higher prices could cause special hardships for the poor and the elderly. Even without direct increases in gas prices, families will bear indirect costs through higher prices for products of industrial gas users subject to incremental pricing.

Also uncertain is the effect the new legislation will have on gas supplies for utilities and residential users. Experts in the producing industry believe that the new higher prices will stimulate exploration and production in fields previously inaccessible for economic reasons, and that ample supplies will tend to hold down prices to some extent. Consumer advocates, on 
the other hand, dispute the claim that deregulation will stimulate growth in production before 1985 and that a competitive market is at work which will restrain price increases.

\section{Utilities and Residential Consumers}

The 74 million U.S. households accounted for one-third of the electric utility industry's sales of 1.85 trillion kWh of electricity in 1976, and for just under 40 percent of the utility revenues of $\$ 53.5$ billion. The average American family consumed $8,400 \mathrm{kWh}$ of electricity in 1976 , spending $\$ 288$, or 3.45 cents per $\mathbf{k W h}$ (as compared with 2.89 cents per kWh for customers who heat electrically). Virtually all homes in the United States are served by electricity, with $\mathbf{1 2 . 6}$ percent of all occupied housing units heated electrically in $\mathbf{1 9 7 6 . 2}$

Forty-one million households with natural gas service accounted for one-third of the gas utility industry's sales of 14.8 quadrillion Btu (Quads) in 1976, bringing in revenues of $\$ 9.9$ billion, or 41.9 percent of the industry's total revenues of $\$ 23.6$ billion. Gas was the heating fuel for $\mathbf{5 6 . 4}$ percent of all occupied housing units in $\mathbf{1 9 7 6 . 3}$

Utility bills, like taxes, are a continuing source of particular unhappiness to consumers. I $\mathbf{n}$ fact, however, utility price statistics reveal just how great a bargain electric and gas consumers have enjoyed, at least until recently. Using constant 1976 dollars, which take account of inflation, table 55 indicates that real utility prices fell steadily during the 1960's. Although that trend has since been reversed, real gas prices in 1977 were still only $\mathbf{1 2 . 2}$ percent higher than their 1960 levels, while real electricity prices were still $\mathbf{1 7 . 7}$ percent lower in 1977 than in 1960. Table 56 shows the percentage change over certain indicated periods.

Table 55.-Residential Natural Gas and Electric Prices (1976 dollars, selected years, 1960-77)

\begin{tabular}{|c|c|c|c|c|}
\hline \multirow[b]{2}{*}{ Year } & \multicolumn{2}{|c|}{ Natural gas (\$/mcf) } & \multicolumn{2}{|c|}{ Electricity (c/kWh) } \\
\hline & 1976 dollars & Current dollars & 1976 dollars & Current dollars \\
\hline$\overline{1960 \ldots \ldots \ldots \ldots \ldots}$ & 1.97 & 1.03 & $\$ .043$ & $\$ .024$ \\
\hline $1965 \ldots \ldots \ldots \ldots$ & 1.76 & 1.05 & .035 & .022 \\
\hline $1970 \ldots \ldots \ldots \ldots$ & 1.58 & 1.90 & .028 & .021 \\
\hline $1971 \ldots \ldots \ldots \ldots$ & 1.58 & 1.15 & .028 & .021 \\
\hline $1972 \ldots \ldots$ & 1.64 & 1.21 & .031 & .022 \\
\hline $1973 \ldots \ldots \ldots$ & 1.64 & 1.29 & .031 & .023 \\
\hline $1974 \ldots \ldots \ldots \ldots$ & 1.69 & 1.43 & .031 & .028 \\
\hline $1975 \ldots \ldots \ldots$ & 1.77 & 1.70 & .032 & .032 \\
\hline $1976 \ldots \ldots \ldots \ldots$ & 1.98 & 1.98 & .034 & .034 \\
\hline $1977 \ldots \ldots \ldots \ldots$ & 2.21 & 2.34 & .035 & .037 \\
\hline
\end{tabular}

SOURCE: Adapted from Demand and Conservation Panel of the Committee on Nuclear and Alternative Energy Systems, "U.S. Energy Demand: Some Low Energy Futures," Science, Apr. 14, 1978, pp. 142-153.

Table 56.-Percentage Changes in Real Utility Prices, Selected Periods, 1960-77

\begin{tabular}{|c|c|c|}
\hline Period & Natural gas & Electricity \\
\hline $\begin{array}{l}1960-65 \ldots \ldots \ldots \\
1965-70 \ldots \ldots \\
1970-75 \ldots \ldots \ldots \\
1975-77 \ldots \ldots \ldots\end{array}$ & $\begin{array}{l}-10.7 \\
-10.2 \\
+12.0 \\
+24.8\end{array}$ & $\begin{array}{l}-17.6 \\
-21.1 \\
+14.3 \\
+10.6\end{array}$ \\
\hline
\end{tabular}

SOURCE: Adapted from Science, Apr. 14,1978, pp. 142-152.

IFactbook on the Proposed Natural Gas Bill, prepared by the Citizen Labor Energy Coalition, Energy Action, and the Energy Policy Task Force, Sept. 25, 1978, p. 21, supra.

${ }^{2}$ Statistical Abstract of the United States, 1977.
Consumer ire can best be accounted for by the suddenness of the increases and the degree to which they have contradicted long-term historical experience. For consumer activists who follow utility rate increase proceedings, the aggregate amounts requested in recent years also boggle the mind. Total annual rate increases granted to electric utilities across the country between 1961 and 1968 came to $\$ 16$ million. From 1969 to 1976 the annual total was \$1.4 billion, almost a tenfold increase."

\footnotetext{
'Ibid.

"Electric Utility Rate Design Study, op. cit., p, 13.
} 
The high prices consumers are paying (and to a lesser extent, the perceived threat of shortages) have created a new interest in the possibilities of conservation. Investment in insulation, weatherstripping and caulking, thermostats with automatic nighttime setbacks, and furnace efficiency improvements have all begun to look attractive to homeowners.

Many utility companies have tried to help their residential customers to conserve by initiating a variety of conservation programs, ranging from simple "bill-stuffers" providing information on how to conserve to extensive programs of insulation financing and installation, rate reform, and load management. The balance of this section describes these programs and analyzes the policy issues they raise for utilities and their consumers.

\section{Utility Activities in Residential Energy Conservation}

\section{Information Programs}

The simplest (and often the first) conservation activity undertaken by utility companies is to promote conservation by providing, in flyers sent to customers with their monthly bills, "how-to" information and reasons for cutting down on waste. These efforts, now common among gas and electric companies throughout the Nation, are natural substitutes for the "bill-stuffers" of earlier years. Only the products have changed: while the brochures of the 1950's and 1960's urged homeowners to invest in electric heating and air-conditioning, frost-free refrigerators, and other energy-consuming commodities, the current promotional literature extolls the merits of insulation and weatherstripping, along with practices such as lowering thermostats and cooking one-dish meals. This kind of information dissemination costs the utility little and can be useful to consumers. Attitudinal surveys provide evidence, however, that consumers generally regard utilities as suspect sources of information, ${ }^{5} \mathrm{Un}$ fortunately, there are no easy ways to measure the cause-and-effect relationship between

“I bid., p. 83. these information programs and consumers' actions in undertaking conservation measures.

More concrete information is provided to residential consumers by utilities that provide "energy audits" of individual homes. Making use of specially trained staff members and computer programs, utility audits include a survey of the home to determine the current level of insulation, the presence or absence of storm windows, and other structural details. The audits also include information about the historical energy consumption and costs associated with energy use in the home. They generally conclude with information about the cost of upgrading the thermal integrity of the structure through investments in insulation and other features, estimates of the energy and money that could be saved, and the amount of time needed to amortize the conservation investment through savings on utility bills.

Many utility companies conduct audits for all requesting homeowners in their service areas regardless of the fuel used for heating the home. Gas and electric companies, for example, audit homes that are heated by oil. In such cases they must rely on estimates or on customers' records (often incomplete) for historical heating cost data, and, inaccuracies in projected savings may be a problem. Even when relying on complete past billing records, auditors may either overestimate or underestimate both the potential savings and the lifecycle costs of insulation investments. Utility managers are concerned about the credibility and liability problems they may incur if customers are dissatisfied after relying on utility-conducted audits for promises of savings of energy or dollars that do not materialize. Despite the imperfections inherent in home energy audits, they are valuable tools for homeowners seeking practical guidance in improving the energy efficiency of their dwellings

Other conservation information programs carried out by utilities may include guidance for builders about energy-efficient construction and efficient appliances and heating systems. The Tennessee Valley Authority, for example, offers free seminars on heat pump design and installation for builders and contrac- 
tors. Some companies offer special awards to builders who construct energy-conserving houses. Seattle's Washington Natural Gas Company contacts all builders who obtain local building permits, urging them to use energy-efficient structural materials and heating, ventilating, and air-conditioning (HVAC) systems, A few utilities have constructed demonstration homes to display the latest in energy-conserving construction and systems and to improve their own conservation information through research and monitoring.

\section{Conservation Investment Assistance Programs}

A more direct involvement in conservation can be seen with utilities that offer customers installation and financing services for insulating their homes. Typically, loans offered by the utilities may be repaid through regular monthly bills. Michigan Consolidated Gas Company, an early entrant into the insulation business, offers its customers up to $\$ 700$ in loans to purchase ceiling insulation, with no downpayment requirement, at 12-percent annual interest, with 3 years to pay. Actual installation is done either by utility-approved contractors or by the homeowners themselves. The company estimates that approximately 140,000 homes within its service area have been insulated since its program began, but only $\mathbf{8 0 0}$ customers have taken advantage of the financing opportunity. Michigan Consolidated considers its insulation program a public service and the State's public service commission concurs; as such, its administrative costs are included among the company's allowable operating expenses. This means that all customers, whether or not they participate in the insulation program, share these costs in their utility bills. Some experts believe this situation constitutes unjust discrimination in ratesetting, while others find it justifiable since all customers presumably benefit from the utility's increased supply of gas acquired through conservation. One proponent of the Michigan Consolidated approach, the former chairman of the Michigan Public Service Commission, points to the similarity between the practice of including conservation program costs in the utility's revenue requirement and the nowdefunct policy-upheld in the courts-of sub- sidizing hookups for new customers in order to benefit all customers through economies of scale. $^{16}$

Washington Natural Gas Company has taken a different approach in its ambitious energy conservation program. It offers not only ceiling insulation, but also sidewall insulation, night setback thermostats, storm windows, furnace ignition devices (to eliminate pilot lights), and new furnaces and water heaters that meet certain efficiency standards. Because of the large total expense incurred by customers who buy several of these items, 45 percent of Washington Natural Gas's conservation customers take advantage of the company's financing arrangements. Even this number is lower than the company expected at the outset; it suggests a greater-than-anticipated consumer ability to pay for energy improvements. The utility's conservation business is carried out as a merchandising operation, which recoups its own costs and earns a modest profit. Hence, the gas company's normal operations and rates are not affected by its conservation activities. The company uses independent contractors to install the conservation devices, and the utility's management believes its program has benefited these small businessmen by stimulating a substantial volume of business.

A number of policy issues emerge from this new area of utility activity. The companies themselves have expressed concern about possibly adverse legal, financial, and management effects of conservation investment assistance programs, particularly if company participation were to be made mandatory by State or Federal legislation. Insulation manufacturers have worried about potential supply problems and consequent "demand pull" inflation stemming from utility-produced demand for their products. (See appendix A for a discussion of the insulation supply problem.) And some consumer advocates fear that utilities will use

\footnotetext{
"William G. Rosenberg, "Conservation Investments by Gas Utilities as a Gas Supply Option," Public Utilities Fortnight/y, Jan. 20,1977, p.19.

1 'Information provided to OTA by Don Navarre, Vice President for Marketing, Washington Natural Gas Company
} 
their conservation programs to realize windfall profits, extend their monopoly powers into a currently competitive market, justify unfair or unnecessary rate increases, or otherwise work in ways contrary to the public interest.

Little empirical information is available to substantiate or refute these concerns. The debate about utilities' roles in residential energy conservation is primarily theoretical. It is useful, however, to review the major points of concern and outline the limited available information about the corporate, societal, and consumer impacts of utility conservation assistance programs.

In recommending the installation of supplemental insulation and other conservation devices, utilities are often asked to estimate the amount of energy and money that could be saved by the proposed conservation investments. Utility spokesmen fear they will be held legally liable if customers later fail to achieve the promised savings. A discrepancy between projected and actual savings is not unlikely in some cases, given the difficulty of accounting for individual families' energy-consuming habits and keeping pace with the moving target of rising electric and gas rates. In fact, however, there is no record of any liability suits being filed or of judgments being made against utilities for failing to deliver promised savings, and the likelihood of such suits seems low. Utilities should be able to protect themselves through careful explanation of their methods of estimating savings and of the residual uncertainty that invariably remains.

A more serious liability threat may lie in the "implied warranty" offered by utilities who sell, finance, or even simply recommend specific insulation products or contractors. Managers have expressed concern about the quality control that customers may expect them to exercise over the efficacy and safety of insulation materials and the integrity of manufacturers and installation contractors. This matter has arisen with at least one utility's active conservation program. Some insulation

\footnotetext{
${ }^{18} \mathrm{Ken}$ Bossong, "The Case Against Private Utility Involvement in Solar/Insulation Program s," Solar Age, January 1978, pp. 23-27.
}

dealers used by the utility as installation contractors were found to be engaging in fraudulent activities, "puffing up" blown-in insulation to make it appear more substantial in volume (and, hence, in insulating value), and installing insulation that was a dangerous fire hazard. The problem appears especially acute in the cellulose insulation industry, which is characterized by large numbers of small manufacturers and installers who are outside any recognized regulatory authority. Cellulose insulation is normally mixed on the job site, making quality control virtually impossible. Recent recognition of the need for standards of quality and performance has produced voluntary certification programs developed by the insulation industry (and in a few cases by utilities or State government agencies) in some areas. Yet the impossibility of guaranteeing absolute quality control is likely to necessitate utility actions such as disclaimers and liability insurance to protect themselves from responsibility for contractors' fraud or safety failures.

Logically, if many of an electric utility's customers decide to take advantage of the company's conservation investment assistance program (hereafter referred to simply as an "insulation program"), they will use less electricity individually and reduce the utility rate of load growth collectively. A vigorous insulation program may reduce the utility's peakload temporarily, but the long-term effect will most likely be a reduction in the growth rate, not an absolute demand drop.

An important question remains: Will the utility's total costs be reduced by this change in demand patterns, allowing the savings to be passed on to consumers in the form of lower bills-or at least slower growing bills? The answer appears to depend on a number of factors, which vary from utility to utility. A consulting group commissioned by OTA to survey utilities' experiences with and attitudes toward insulation programs found this area of uncertainty to be a matter of major concern among the companies surveyed. ' 9

In planning for future capacity and capital needs, as well as for revenue and rate re-

‘9Booz, Allen \& Hamilton, op. cit. 
quirements, utilities must consider the variations they typically experience between average and peakloads. If insulation programs temporarily reduce their average (or base) loads, revenues will be reduced accordingly. However, if peakloads are not reduced as well, capacity requirements will remain as great as they would be without the insulation program. In such a case, the utility must still operate expensive peaking plants during peak periodsand with lower revenues, they must raise rates to meet the fixed costs. Such an occurrence could wipe out consumer savings.

A technical note at the end of this chapter contains a detailed discussion of this perceived problem and of an OTA computer simulation that tests the likelihood of insulation programs having an adverse effect on utility load factors and costs. Using a model developed for the recent OTA study, Application of Solar Energy to Today's Energy Needs, OTA had simulated the total loads of hypothetical utilities in four cities that represent a cross-section of climatic variations throughout the United States. The utilities were designed to be typical in their heating and cooling loads, with a mix of single-family homes, townhouses, low- and high-rise apartments, shopping centers, industry, and streetlighting. The model tested the effect of altering the insulation levels and heating and cooling equipment for certain fractions of each utility's 1985 residential load. The results suggest that insulation programs have only a small effect on a system's load factor-that is, on the ratio of its baseload to its peakload-and by extension, on total system costs. The effect is, in most cases, positive (a higher load factor). The impact of insulation in each case depends on such things as the utility's air-conditioning load, service area climate, and electric-heating load. Table 62 in the technical note illustrates the findings, which still need to be verified through actual experience. If they prove to be correct, they should reduce the fear that insulation programs will lead to higher costs and higher rates.

The long-term picture is clearer. By slowing demand growth, insulation programs should delay new capacity needs. As new powerplants are far more expensive than old ones, this, delay should also retard rate increases.

Another corporate concern about utility insulation programs is peculiar to the gas companies. This problem centers on whether the gas utilities will be permitted to add new customers to provide a market for any gas the company saves through existing customers' conservation efforts. As residential customers save natural gas through improved insulation and other conservation measures, they free up gas supplies for possible use by an expanded number of customers. Until recently, however, many gas companies were prohibited from adding new customers, and during periods of especially short supply companies often lost a portion of their available supplies to other companies through mandatory allocation programs. Without a promise of being able to keep and sell "conservation gas" at attractive prices - a so-called "finder-keepers" policygas companies correctly perceive their customers' gas-saving efforts as not necessarily beneficial to their operations. Indeed, conservation in the absence of a "finders-keepers" policy means the companies will have to spread fixed-distribution costs over reduced sales.

Although a large number of utilities have initiated insulation programs either voluntarily or in response to State requirements, the major trade associations representing both publicly and privately owned utilities have gone on record to oppose detailed uniform national directives for such programs. They fear that such requirements, which were included in different forms in the House and Senate versions of the National Energy Act before being modified substantially by the Conference Committee, fail to recognize each company's unique needs arid circumstances.

Some utilities are also reluctant to undertake the new roles of moneylenders and sellers of hardware, although in fact neither activity is totally new to the industry. (In former days, many utilities sold appliances to their customers and permitted them to make installment payments on their utility bills.) The electric and gas companies' strange bedfellows, in this viewpoint, are the consumer activists. 
Consumer groups are particularly fearful that small businessmen in the conservationdevice and insulation businesses would suffer from unfair competition at the hands of the utilities. ${ }^{20}$ The Washington Natural Gas experience suggests, however, that the opposite effect could also result. WNG made extensive use of small businessmen to install conservation materials.

\section{Rate Reform for Electric Utilities}

The area of electric utility rate design may eventually represent the most significant departure from past practices brought about by the changed circumstances of recent years. Declining-block rates, the rate structure usually applied to residential users, came into widespread use during the early days of electrification when lighting comprised most of the utilities' loads. Since the utilities had to maintain adequate capacity to meet a sharp peak in demand during evening hours, it made sense to promote other uses of power to fill the "valleys" of demand. Customers and utilities alike benefited from the economies of scale, and the load leveling that came with growth that was encouraged through declining-block rates. Now, however-as new capacity costs and fuel costs exceed average system costs, and as growth exacerbates peaking problems-promotional rates cease to be beneficial.

A number of State utility commissions have begun requiring utilities to experiment with departures from their traditional decliningblock rate structures, using "peakload pricing, " or "time-of-use rates" that rise at times of peak seasonal and/or daily demand, to encourage users to change their habits and reduce peak loads.

The area of innovative rate design - and particularly time-differentiated rate structure- is complex and controversial. This report can only touch briefly on the subject, yet its significance for residential electricity use is great enough to warrant a limited discussion of the issues surrounding peakload pricing.

\footnotetext{
${ }^{20}$ Bossong, op. cit
}

The basic argument for peakload pricing is clear: A utility's costs vary with the season and the time of day, due to the equipment and fuel mix that must be used to meet different levels of demand. These cost variations have increased in recent years, with the result that the highest operating costs are now incurred when reserve plants are pressed temporarily into service to provide peak power levels. Although these peaking plants require lower capital cost than baseload plants, they employ expensive fuels such as petroleum distillates, and they operate less efficiently than baseload plants. As a result, peak power costs run as much as four times higher than base power costs, therefore, the premise that rates should be related to costs in order to achieve objectives of equity and efficiency leads to the conclusion that rates should vary with time.

Each utility's peakload pricing system must be "custom made" to reflect the company's load characteristics, peak patterns, weather conditions, and generational equipment. The time-differentiated rate design recently offered by the Virginia Electric Power Company (VEPCO) to its residential customers is fairly typical: 2,000 VEPCO customers, chosen from among 17,000 who volunteered for the program, have had special meters (which cost the company $\$ 250$ apiece) installed at their homes to record their total kilowatthour usage and their consumption during peak hours 19:00 a.m. to 9:00 p.m. e.s.t., or 10:00 a.m. to 10:00 p.m. e.d.t., Monday through Friday). The meters also measure each customer's peak demand during any 30 -minute onpeak period of the billing period; the demand figure, in kilowatts, is not calculated during off peak hours. The customer's monthly bill is broken down into three separate parts:

1 , A basic customer charge of $\$ 11.50$ per billing month;

2. A kilowatt demand charge for onpeak demand, calculated at the following rates:

$-\$ .031$ per $\mathrm{kW}$ of onpeak demand during billing months of June through September;

$-\$ .022$ per $\mathrm{kW}$ of onpeak demand during billing months of October through May; 
3. An energy charge calculated on the basis of the following rates:

$-\$ .023$ per $k W h$ of on peak use.

$-\$ .015$ per $k W h$ of off peak use.

The kilowatthour charges may be adjusted for changes in fuel costs (i.e., fuel adjustment clause).

Because VEPCO's time-of-use experiment has only recently begun, the company does not yet have data on the effects of the experimental rates on participants' electricity consumption or bills, or on the VEPCO system's peaks, costs, or revenues. The Virginia utility is also experimenting with time-of-use rates that are applicable to water heaters only, and with voluntary time-differentiated rates for churches and other charitable organizations whose electricity demand tends to be greatest during evenings and weekends. VEPCO has also identified 9,000 residential customers with histories of substantial summer electricity consumption (at least $3,500 \mathrm{kWh}$ during at least one summer month of 1976 or 1977); these customers have been required to participate in a metering experiment in which they are not actually charged according to time-of-day rates, but are given monthly statements comparing their electricity bills under traditional pricing (which they actually pay) with costs under peak load pricing.

Because peakload pricing of electricity reflects the higher costs associated with generating and distributing power during the periods of highest demand on a utility system, such rate structures provide customers with "fair" and "appropriate" price signals. The actual level of demand elasticity-that is, customer response (through behavior changes) to price differences - is not well-understood at this time, but federally funded rate experiments are beginning to produce empirical data. (These experiments are discussed below.) The reasons for shifting to such innovative rates go beyond a desire of economists to perfect the workings of the marketplace. From the standpoint of national policy, such rates are desirable if they result in an energy savings, particularly of scarce and expensive fuels such as oil and gas.
Electricity savings at the point of end-use may or may not occur as a result of time-differentiated rates; however, energy savings at the "input" end of the utility could be substantial. This is because most utilities use their newest, most efficient and economical powerplants to generate their baseloads. Although these recently built plants typically represent large capital investments (and hence, high fixed costs) for the companies, their efficient thermal performance makes them the least expensive to run because they require fewer Btu of energy input per kilowatthour of output than do the usually older, smaller, less efficient peaking plants. Furthermore, baseload plants are more likely to use nuclear energy or coal, while peaking plants generally rely on imported oil or scarce natural gas.

To the extent that shifts in demand caused by peakload pricing can minimize use of the peaking plants and increase the proportional use of the efficient baseload plants, a net savings of energy and of operational costs should result. Over the long run, leveling peak demand could also save on fixed costs by reducing the need for construction of new plants. All these savings - of scarce fuel input, of fixed and operating costs, and perhaps of end-use electricity - represent conservation in the broad sense of the word.

\section{Lifeline Rates}

If the trend toward time-differentiated rates reflects a growing belief in the appropriateness of cost-based rates, a countervailing belief has affected some utility rates differently. "Light and heat are basic human rights and must be made available to all people at low cost for basic minimum quantities," says section 1 of the California Energy Lifeline Act of 1975. Based on this premise, the Act required California utilities to set rates below cost for certain minimum quantities of gas and electricity-the estimated amount needed by an average family of four living in a well-insulated $1,000 \mathrm{ft}^{2}$ single-family house to provide enough lighting, cooking, refrigeration, water, and space heating to maintain health and a reasonable level of comfort. 
So-called lifeline rates, which have also been implemented in Ohio, Georgia, and Colorado but were rejected on a national scale during the congressional debate over the Public Utilities Regulatory Policy Act of 1978, have two essential goals. First, they are intended to provide financial relief and avoid hardship for low-income families who consume only the minimum essential amount of energy in their homes. Second, they are intended to promote conservation by reversing the traditional declining-block rate structure and charging progressively higher rates for greater quantities of gas and electricity consumed. The California experience to date in striving to achieve the first purpose is discussed in chapter IV, "Low-Income Consumers." With regard to the second objective, that of promoting conservation, the California experience is not encouraging. The Pacific Gas and Electric Company found virtually no change in the average residential use of electricity during the first 2 years of the lifeline rate policy and determined that there was "little conclusive evidence as to the link between lifeline and conservation . . . customers respond more to their total bill than to any marginal price for the block in excess of lifeline (allowances)." ${ }^{21}$

\section{Load Management}

Load management is the deliberate manipulation of electricity demand at the point of end use, in order to maximize cost savings for the consumer, the utility system, or both. When a customer alters his energy-consuming habits to take advantage of time-differentiated rates, that customer is practicing a simple form of load management. His actions might include deferring dishwashing, clothes washing, and drying to off peak hours. On a slightly more sophisticated level, the homeowner might install a timer on the water heater to limit its operation to off peak hours. Forms of load

\footnotetext{
21"Lifeline Electric Rates in California: One Utility's Experience," presented by William M. Gallavan, vice president, rates and valuation, Pacific Gas and Electric Company, to the ninth annual Conference of the Institute of Public Utilities, Graduate School of Business Administration, Michigan State University, Dec. 14,1977, p. 9.
}

management that are under the consumer's (rather than the utility's) control are called indirect load management.

The term "direct load management" refers to actions under the direct control of the utility company. With the consumer's prior consent, the utility installs electromechanical means by which it can manipulate a certain portion of the customer's load. When the system approaches peak levels, preceded signals transmitted over high-voltage wires or radio waves can be used to disconnect certain appliances such as hot water heaters, air-conditioner compressors, and heat pumps. Customers are sometimes given compensation for any inconvenience caused by load management, in the form of credits against their utility bills. By carefully designing the patterns in which these appliances are cycled on and off throughout the utility system, the electric company can shave the sharp spikes in demand that require the expensive operation of peaking plants. In certain cases, it may also be possible to use load management as a means of deferring or eliminating the addition of new capacity; this prospect however, is considerably less certain than the probability of saving fuel costs associated with short-term operations.

Load management has been practiced widely in Europe for many years. There, mechanical cycling or timing devices have been combined with time-differentiated rates and energy storage systems to expand the use of load management practices to heating. At least one U.S. utility, the Central Vermont Public Service (CVPS) Company, has also experimented with a heat storage/load management combination. Twenty-five of CVPS's customers have installed electric heating systems that heat water during off peak hours (11 p.m. to 7 a.m.), cease heating during onpeak hours, and keep the customers' houses warm during the daytime by circulating the preheated water throughout the house. The company calculates that in 1974-75 each customer paid approximately the same amount for this system as he would have expended for oil heat, but that a customer who would have spent $\$ 724$ per year for electric resistance heat paid only $\$ 348$ under the heat storage option. For the utility, the important 
result of the experiment was the finding that each customer reduced his onpeak demand an average of $22 \mathrm{~kW}$, or a total of $565 \mathrm{~kW}$ for the system as a whole. ${ }^{22}$

One danger associated with the combination of load management and time-of-day rates is the possibility that their appeal to consumers will be so successful that they will simply "chase the peaks around the clock," as a Wisconsin utility regulator put it. I n Germany, preferential rates induced such a largescale shift to storage heating systems that higher nighttime peaks occurred and the rates had to be altered, thereby reducing the economic benefits enjoyed by consumers. ${ }^{23}$

Direct load management, keyed to mechanisms such as temperature readings, is being tried by a number of utilities. Compared with peakload pricing, direct load management has the advantage of assured response; the utility knows for certain that it can reduce a peakload by a specific amount through mechanical means, rather than hoping for an estimated price elasticity.

Residential consumers account for an estimated average of 30 percent of U.S. utility peakloads. ${ }^{24}$ Detroit Edison estimated that residential cooling accounts for 50 percent of summer temperature-sensitive load, the fraction of total system load that is most volatile. ${ }^{25}$ Only a fraction of this load can be eliminated through management. A typical arrangement shuts off air-conditioner compressors and outside fans for $\mathbf{1 0}$ to $\mathbf{1 5}$ minutes for each hour, in two periods, while leaving inside fans running to circulate air throughout the participating houses. The cycling signal is activated, typically, when outside temperatures are high enough to generate a substantial systemwide demand for air-conditioning. By shutting down air-conditioners in $\mathbf{5 0}$ homes for $\mathbf{1 5}$ minutes per hour between 2 and 5 p.m. on days when temper-

\footnotetext{
"2"'Storage Heat Shifts Load on Time at Central Vermont," Electric Light and Power, Mar. 15,1976, p. 3.

${ }^{23}$ Gordon C. Hurlbert, Improved Load ManagementNew Emphasis, Sept. 24,1975.

"',Survey Scrutinizes Load Management," Electrical World, July 15,1976.

*s" Cooling-Demand Controls Look Good," Electrical World, July 15,1976.
}

atures exceeded $750 \mathrm{~F}$, Detroit Edison was able to achieve a 25-percent reduction in these customers' air-conditioning demand. The utility's systemwide savings achieved through management of both air-conditioning and water heating were limited, however, by the fact that its summer peaks tend to be broad - that is, a high demand level is sustained for many hours during the day. While savings through water heater control amounted to $200 \mathrm{MW}$ in the winter, they were only 50 to $60 \mathrm{MW}$ in the summer.

A 1977 study by the Federal Energy Administration (FEA) indicated that a simulated coalburning utility's load management program could achieve a substantial shift from peaking plants to baseload plants, and could result in significant fuel cost savings. Furthermore, when adequacy of reserve margin is the criterion for planning new capacity additions, the hypothetical utility could justify the delay of some construction plans. FEA cautioned, however, that such delays probably could not be achieved in real-life situations because of the ever-growing problems of rising costs, financing problems, and delays in licensing and construction. ${ }^{26}$

Load management represents a significant departure from utilities' historical obligations to provide electrical service in any quantity customers desire and are willing to pay for. It represents a form of rationing, a practice that economists argue is unnecessary when a free marketplace employing cost-based prices allocates resources. Increasingly, however, utilities and their regulators are coming to view load management as one more tool in the diverse collection of policies that can aid in encouraging utility-based residential energy conservation.

\section{Federal Programs and Opportunities in Utility-Based Issues}

Because responsibility for utility regulation rests, for the most part, with States, Federal op-

\footnotetext{
${ }^{26}$ Federal Energy Administration, The Impact of Load Management Strategies UponElectric Utility Costs and Fuel Consumption, June 1977.
} 
portunities to encourage utility actions to stimulate residential energy conservation are limited. However, recent Federal legislation and programs do provide a framework of sorts for such utility activities.

\section{New Legislation on Conservation Investment Assistance}

The National Energy Policy Act of 1978, although not as ambitious as President Carter's original proposal to Congress, does require utilities to establish conservation programs for residential buildings of four units or less. Under the new law, utilities must inform their customers of suggested conservation measures and of available means of purchasing and financing investments in such measures. Utilities must offer onsite audits and services to assist homeowners in finding installation contractors and lenders. If the customer chooses, a utility must permit repayment for conservation investments on the regular monthly utility bill. Gas and electric companies may themselves lend customers up to $\$ 300$ each for conservation investments, but they are prohibited from direct involvement in the installation of conservation measures other than furnace efficiency modifications, clock thermostats, and load management devices. Utilities already engaged in installation of other conservation measures as of the date of enactment are exempt from this prohibition.

Utilities are also prohibited, under the new law, from incorporating the administrative costs of their residential conservation programs in their rates. Instead, they must charge those customers who use their conservation services.

\section{New Legislation on Utility Ratemaking and Load Management}

The Public Utilities Regulatory Policies Act, (P. L. 95-617), passed in October 1978 as part of the overall energy legislative package, increases the level of Federal involvement in electric utility ratemaking activities. The new law does not preempt State authority, but it requires State utility regulators to consider the adoption of certain federally proposed standards in their rate determinations, and either to adopt such standards or to state in writing the reasons for not doing so. The Federal standards applicable to residential buildings are:

1. rates that reflect the cost of service to various classes of electric consumers, to the maximum extent practicable;

2 prohibition of declining-block rates for the energy component of electric rates, except where such rates can be demonstrated to reflect costs that decline as consumption increases for a given customer class:

3 time-of-day rates reflecting costs of serving each customer class at different times of the day, except where such rates are not cost-effective with respect to a customer class;

4 seasonally variable rates, to the extent that costs vary seasonally for each customer class; and

5 load management techniques offered to consumers when they are determined by a utility to be practicable, cost-effective, reliable, and advantageous to the utility in terms of energy or capacity management.

A second set of standards under the Act deals with master metering of multifamily buildings, automatic adjustment clauses, information to be provided to consumers about rates applicable to them, procedures for termination of electric service, and limitations on the inclusion in rates of costs attributable to utility promotional and political advertising.

The new law's most significant opportunity for Federal participation in utility ratemaking may well be its provision for intervention in administrative proceedings. The Secretary of Energy (along with affected utilities and consumers) is allowed to "intervene and participate as a matter of right in any ratemaking proceeding or other appropriate regulatory proceeding relating to rates or rate design which is conducted by a State regulatory authority." (16 U.S.C. \$2601) According to the report of the conference committee on the legislation, such intervention is for the purpose of participating in the consideration of the Federal standards "or other concepts which contribute to the achievement of the purposes of the title. "The report also states a congressional intent that the phrase dealing with 
"other concepts" be construed broadly "so that no one will have to prove his case in advance before being allowed to intervene. "I $n$ effect, this provision for Federal intervention affords DOE a means of monitoring and encouraging effective state implementation of the Act through direct involvement in State regulatory proceedings.

\section{DOE Electric Utility Rate Demonstration Program}

Because empirical data on consumer response to alternative rate structures are scarce, the Federal Government's most helpful role may be in providing such data.

The electric utility rate demonstration program, initiated by FEA in 1975 and continued to the present by DOE seeks to analyze the results of 16 experiments with innovative rates undertaken by utilities across the country.

The rate demonstration program, on which $\$ 9.2$ million in Federal funds (supplemented by at least 10-percent State and local funding) were expended through FY 1978, has focused primarily on time-of-use rates applied to residential customers. Approximately 18,000 households have been studied, either as testing units or as control points. DOE, along with cooperating State utility commissions, utilities, and consulting analysts, has been watching customers' total electricity consumption, kilowatt demand peaks, and temporal use patterns to determine the degree of price elasticity among residential users over a period of 2 to 3 years. Although the analytical phase of the rate demonstration program is still underway, some results have become available and preliminary conclusions have been drafted by DOE.

Tables 57 and 58 list the projects in DOE's rate analyses and describe the innovations tried in each test. On the basis of complete test data from two States and partial data from four more, DOE has arrived at the following tentative general findings: ${ }^{27}$

\footnotetext{
“"'Electric Utility Rate Demonstration Program Fact Sheet," Economic Regulatory Administration, November 1977.
}

- customers have uniformly been found to respond significantly to changes in electricity prices at all hours of the day, including peak periods;

- peak period kilowatthour price elasticity (i.e., "responsiveness") appears to exceed off peak elasticity;

- t i me-of-use rates reduce residential customer peak demands even on the hot test days of the year; and

- customer attitudes toward time-of-use rates are decidedly positive.

More specifically, DOE has observed surprisingly uniform-and encouraging-results among the various time-of-use demonstration programs, even though the study designs varied considerably from test to test. Some studies metered consumption and demand during two different periods-onpeak and offpeak -while others employed at least one additional rating period, a "shoulder" or "intermediate" time of the day. The duration and the time used for each period varied according to different utilities' peakloads. While some time-of-day customers were compared with their own utility records from a year earlier, others were examined in comparison to groups of control customers with similar demographic, economic, and historical electricity consumption characteristics. The number of participating customers in each study ranged from fewer than 100 to several thousand. Some experiments lasted only a year, while others are continuing for up to 5 years. Finally, the ratios of onpeak to off peak rates differed substantially among the studies. Specific results of time-of-use tests in six States, dealing with kilowatthour consumption, kilowatt demand, and shifts among rating periods, are summarized in tables 57 and 58 .

In a few cases, utilities attempted to estimate actual or potential effects of time-of-use pricing on their system loads and fuel costs. Connecticut Light \& Power Company, for example, perceived an actual reduction in system peak of 8 to $13 \mathrm{MW}$ in its peak winter month, and 70 to $83 \mathrm{MW}$ in its peak summer month. Arkansas Power \& Light projected a fuel cost saving of $\$ 20$ million "over the short run" if the experimental rate design were to be implemented on a systemwide basis. 
Table 57.-DOE Electric Rate Demonstration Program kWh Consumption Effects

\begin{tabular}{|c|c|c|c|c|}
\hline State & $\begin{array}{l}\text { Onpeak } \\
\text { consumption }\end{array}$ & $\begin{array}{l}\text { "Shoulder" period } \\
\text { consumption }\end{array}$ & $\begin{array}{l}\text { Off peak } \\
\text { consumption }\end{array}$ & $\begin{array}{l}\text { Net change in } \\
\text { consumption }\end{array}$ \\
\hline Arizona & $\begin{array}{l}\text { T-O-D customers reduced, } \\
\text { compared with same } \\
\text { customers a year earlier }\end{array}$ & & $\begin{array}{l}\text { Increased slightly, compared } \\
\text { with year earlier, } \\
\text { according to inconclusive } \\
\text { evidence }\end{array}$ & $\begin{array}{l}\text { Inconclusive evidence } \\
\text { suggests slight decline }\end{array}$ \\
\hline Arkansas & $\begin{array}{l}\text { T-O-D customers reduced } \\
\text { to level } 18-26 \% \text { below } \\
\text { control customers on average } \\
\text { summer days, and } 15-59 \% \\
\text { below control customers } \\
\text { on system annual } \\
\text { peak day }\end{array}$ & & & $\begin{array}{l}\text { Slight decline on } \\
\text { average summer days, larger } \\
\text { larger decline on peak day }\end{array}$ \\
\hline California & $\begin{array}{l}\text { T-O-D customer reduced } \\
\text { compared with same } \\
\text { customers a year earlier }\end{array}$ & & $\begin{array}{l}\text { Increased, compared with } \\
\text { year earlier }\end{array}$ & \\
\hline Connecticut & $\begin{array}{l}\text { T-O-D customers reduced } \\
\text { "considerably" compared with } \\
\text { control customers i.e., con- } \\
\text { sumption } 23 \% \text { lower }\end{array}$ & $\begin{array}{l}\text { T-O-D reduced to "sign if i cant- } \\
\text { ly less" than control in } \\
\text { summer, but consumed at } \\
\text { same level in winter }\end{array}$ & $\begin{array}{l}\text { T-O-D consumed "significantly } \\
\text { more" than control in winter, } \\
\text { same level as control } \\
\text { in summer }\end{array}$ & $\begin{array}{l}\text { T-O-D consumed 9-13\% } \\
\text { less than control in } \\
\text { summer, was "not sig- } \\
\text { nificantly different" in } \\
\text { winter }\end{array}$ \\
\hline Ohio & $\begin{array}{l}\text { T-O-D customers reduced } \\
\text { "considerably" compared with } \\
\text { control customers }\end{array}$ & & $\begin{array}{l}\text { T-O-D consumption increased } T \\
\text { in winters; no noticeable } \\
\text { change in other months }\end{array}$ & $\begin{array}{l}\text { T-O-D customers consumed } \\
3.5 \% \text { less overall than control }\end{array}$ \\
\hline Vermont & $\begin{array}{l}\text { T-O-D customers reduced } \\
\text { some compared with year } \\
\text { earlier (amount not quantified) }\end{array}$ & (not quantified) & $\begin{array}{l}\text { T-O-D increased some from } \\
\text { year earlier }\end{array}$ & $\begin{array}{l}\text { T-O-D increased about } 3 \% \\
\text { compared with year earlier }\end{array}$ \\
\hline Six-State summary & $\begin{array}{l}\text { T-O-D customers reduced } \\
15-30 \% \text { compared with } \\
\text { control customers or year } \\
\text { earlier }\end{array}$ & & $\begin{array}{l}\text { T-O-D customers increased in } \\
\text { comparison with control } \\
\text { customers or year earlier }\end{array}$ & $\begin{array}{l}\text { T-O-D consumed } \\
5-8 \% \text { less overall than control } \\
\text { customers. Exception: Vermont, } \\
\text { Most reductions occur in } \\
\text { summer. Some increases occur } \\
\text { in winter }\end{array}$ \\
\hline
\end{tabular}




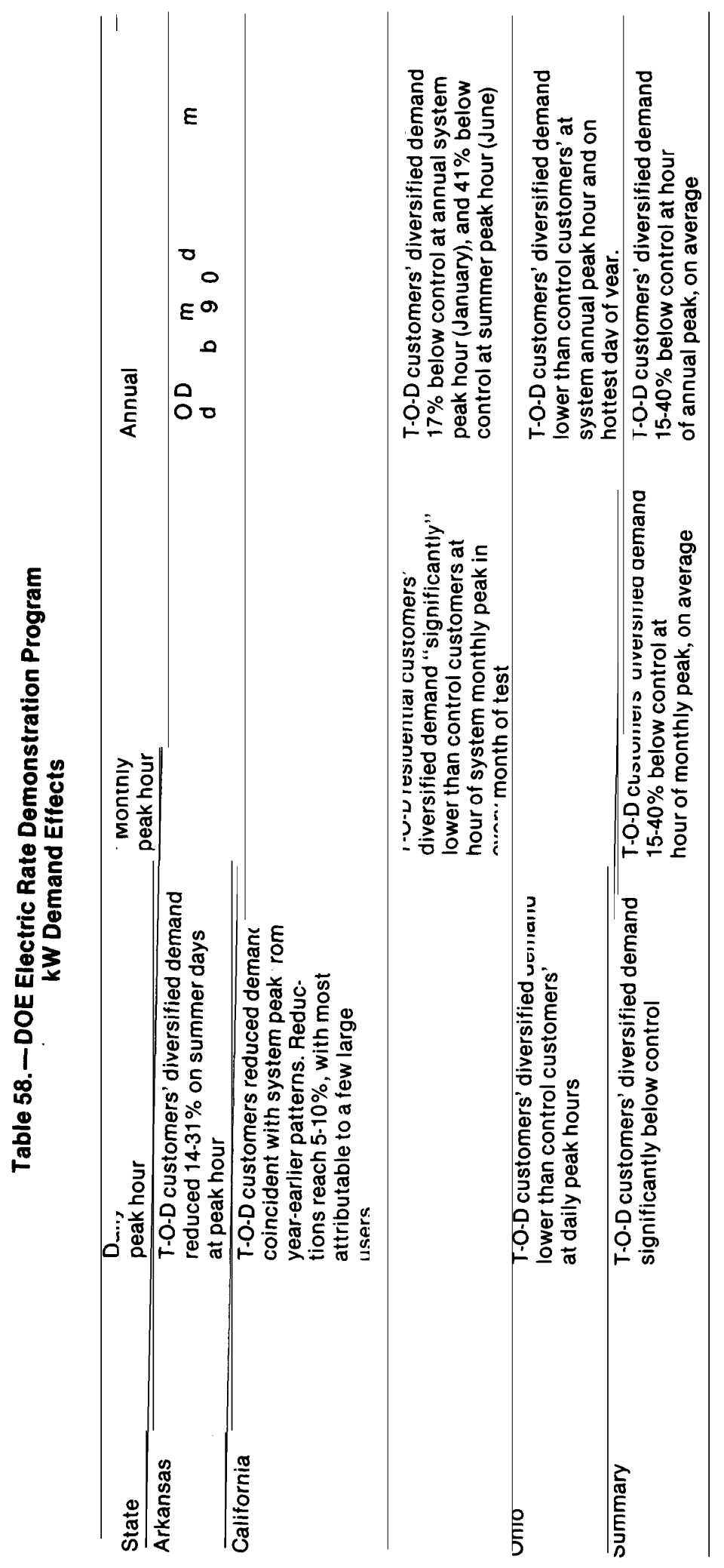


Much analysis of the rate demonstration program data remains to be done, but the initial findings appear to confirm the usefulness of time-differentiated rates as means of encouraging more efficient, cost-effective electricity delivery. Evidence of consumer acceptance of such rates may well be among the more important observations to date. It should be emphasized, too, that long-term implementation of time-differentiated rates can be expected to produce greater consumer response than the present experiments. This is because short-term response relies almost entirely on behavioral changes in the usage rate and time of use of presently owned appliances, while long-term response could include widespread changes in capital stock, such as purchases of water heaters with timing devices to limit their operation to off peak hours.

\section{DOE Load Management Activities}

The Department of Energy encourages load management through a small program in the Department's Economic Regulatory Administration (ERA). DOE provides States with funds and technical assistance to advance current knowledge and experimentation with load management programs, and will monitor the States' compliance with the new requirements for consideration of Federal standards (including load management) in future ratemaking proceedings. The Department's Electric Energy Systems Division and Energy Storage Division also carry out research and development activities to assist the development of new load management technologies.

\section{Conservation Programs of the Federally Owned Power Authorities}

The federally owned segment of the electric power industry, which accounts for about $\mathbf{1 0}$ percent of the Nation's installed generating capacity and 5 percent of total kilowatthour sales, has always served as a "yardstick" for certain national policies. For most of the history of the two largest Federal power authorities-the Tennessee Valley Authority (TVA) and the Bonneville Power Administration they have served as models for effective expansion of electricity service to rural areas at low cost. More recently, they have begun to function as models for programs in energy conservation.

The Tennessee Valley Authority encourages conservation among its customers in a number of ways. TVA offers consumers interest-free loans, payable over 3 years, for purchasing and installing insulation in their attics. The insulation program will soon expand to allow 7-year interest-free loans of up to $\$ 2,000$ for a number of conservation measures, including storm windows, floor insulation, caulking and weather-stripping, and insulation of duct work. TVA will determine which measures are costeffective for each customer and will inspect the installation before releasing funds. Additionally, TVA offers customers now using electric resistance heating systems a means of converting to heat pumps by providing 81/2-percent loans repayable over 10 years.

[n the area of rates, TVA asserts that its rate structure is based on cost of service and encourages conservation by applying automatic adjustment clauses only to that portion of a customer's electricity consumption that exceeds $500 \mathrm{kWh}$ in any billing period. TVA is also experimenting with four different rate structures designed to encourage conservation. In one study, time-of-use rates are being applied, with kilowatthour consumption billed at 9 cents per kWh during onpeak periods and 1.5 cents per kWh during off peak periods. Analysis of the results of the study is just beginning.

The Bonneville Power Administration has concentrated its conservation efforts on its own Internal operations and on information dissemination among its employees, its utility customers, and end-users. The Bonneville outreach effort has included workshops on insulation, energy audits, and training sessions for CETA workers employed in weatherization programs. Bonneville has also undertaken certain research programs aimed at conservation; these include experimental use of aerial and ground-based infrared sensors to detect heat loss from buildings, and the installation of wind data recording stations to determine where wind-driven electric generator systems could be installed to supplement hydroelectric energy in the Bonneville service area. Bonne- 
vine has not developed an insulation financing program or experimented with conservationoriented rates.

\section{Conclusions for Utility Policy}

In response to the dramatically different circumstances in which utilities have had to operate in recent years, electric and gas companies are undertaking a number of new activities to encourage residential users to reduce their consumption and aid in leveling system peakloads. Because many of these activities - including energy audits, insulation programs, rate reforms, and load management - are recent in origin and used by only a relatively small number of companies, important areas of uncertainty about their efficacy remain to be clarified. The opportunities for encouraging conservation through utility actions appear promising, but the adjustments to new methods of operation are proving difficult in some cases for both the utilities and their customers.

The great diversity among the Nation's 3,500 electric utility companies and 1,600 retail natural gas distributors precludes the development of a single national policy for conservation. Rather, there must be a flexible approach enabling each utility to design a residential conservation program around its unique system load, supply and cost situation, climate, and other variables. An examination of Federal programs and opportunities suggests that recently enacted legislation and programs offer a good start.

\section{THE FUEL OIL DISTRIBUTORS}

The distribution of home heating oil, as an industry, was developed by oil appliance manufacturers and their retail installers. Today, nearly 80 percent of heating oil demand in the United States is served by independent fuel oil marketers.

Although the heating oil industry operates nationwide, about 90 percent of the heating oils are sold in only 28 States, principally along the northern tier of the United States from the Pacific Northwest to New England and down the east coast to Florida. ${ }^{28}$ Over 16 million residential buildings depend on fuel oil for space heating. ${ }^{29}$

Historically, the fuel oil industry has not been regulated. In recent years, however, the industry has been subject to Federal regulations on pricing and allocation during periods of short supply. No such regulations are presently in effect.

\footnotetext{
'Sales of Fuel Oil and Kerosene in 1977 (Department of Energy, Energy Information Administration, 1978), p. 6.

${ }^{29}$ Annua Housing Survey, 7976 (Department of commerce, Bureau of the Census, 1978), p. 6.
}

Unlike the utilities with whom the industry competes for space-heating markets, most fuel oil marketers do not have captive customers, nor do they have a monopoly on product or service territory. The marketers are forced to compete within the oil industry for product supply, advantageous pricing, and customers. As marketers are in direct contact with the consumers, the success of their business depends entirely on customer satisfaction. One of the major concerns of fuel oil marketers is the need to maintain customer goodwill in light of national energy and conservation policies that could conceivably discriminate against fuel oil consumers and jeopardize the competitive position of the marketers.

\section{Industry Size}

In 1972, the Bureau of the Census of the Department of Commerce estimated that there were 7,276 fuel oil dealers with payrolls. This estimate, however; includes only those fuel oil dealers who list the sale of fuel as their principal business. However, in many markets, particularly nonurban markets, petroleum marketers may distribute both gasoline and heating 
oil, with gasoline predominant. According to industry estimates, the total number of fuel oil suppliers, including those who distribute more gasoline than fuel oil, falls between 10,000 and 12,000 marketers.

The predominant distillate oil consumed in residential space heating is No. 2 fuel oil. Heavier heating oils (No. 5 and No. 6 oil) are used primarily by industrial accounts, and are usually purchased directly from refineries or terminal facilities. Consumption of No. 2 fuel in 1977 amounted to 1.2 billion barrels. ${ }^{30}$ No. 1 fuel oil (kerosene) and No. 4 oil are also used for space heating. The demand for these distillate oils in 1973-77 appears in table 59.

\section{Fuel Oil Marketers}

About 85 percent of independent heating-oil marketers sell directly to consumers. Therefore, they are regarded as retailers rather than jobbers. However, a dual petroleum marketer will often have different suppliers or brands for its heating oil and its gasoline. It is not unusual for a distributor to be a jobber for one product and a retailer of the other.

A marketer may service from several hundred to 50,000 or more customer accounts. According to a 1978 survey, 16 percent of the marketers had more than 3,000 customers; their share represented 55 percent of the customers recorded .3' Forty-seven percent of the companies had between 1,000 and 3,000 accounts, representing 41 percent of the customers. Forty-two percent of the marketers had fewer than 1,000 customer accounts, accounting for approximately 14 percent of the customers. The survey also indicated that all fuel oil marketers sold No. 2 fuel oil, about half sold No. 1 fuel oil (kerosene), and less than 10 percent sold other fuel oils. The survey indicated that about 80 percent of marketers sold and serviced oil heat equipment, accounting for 62 percent of that end of the business. Seventy-eight percent of the heating oil marketers surveyed operate a bulk plant (large storage) facility.

\footnotetext{
${ }^{30}$ Sales of Fuel Oil, op cit., p. 1.

${ }_{3} 1$ Margaret Mantho, "Margins Improve to Offset Rising Costs," Fuel Oil and Oil Heat, September 1978, p. 35.
}

\section{Sales of Distillate Fuel Oils}

Figure 17 represents sales of distillate fuel oil by end use sector for the period 1973-77. As indicated by the table, nearly 50 percent of all sales of distillate fuel oil goes to heating. The data presented does not indicate what percentage of total sales is earmarked for the residential sector. However, according to one DOE official, approximately 85 to 90 percent of No. 2 heating oil is sold in the residential sector.

In general terms, fuel oil marketers deliver more than 2 million barrels of distillate oil daily from November through March to meet residential space-heating needs. The delivery schedules are temperature-sensitive and established according to the calculated "degree days." The average consumption per heating season for residential home heating varies from about 900 gallons in the South-Atlantic region to about 1,600 gallons per heating season in the New England region.

\section{Service Activities}

For the 1977-78 heating season, about 67 percent of all fuel oil consumers had their oil heat equipment checked and serviced as part of annual efficiency checkups. About $\mathbf{4 0}$ percent of fuel oil consumers have service contracts providing for annual efficiency checkups. These annual service calls are generally considered essential to maintain furnace efficiencies and promote fuel conservation.

In the same heating season, the average serviceman was responsible for 440 customers and managed to make six calls per day, exclusive of efficiency checkups. ${ }^{32}$ About 53 percent of the servicemen serviced burners exclusively. The remainder either installed burners only or serviced and installed them.

The lifetime of oil heat equipment is approximately $\mathbf{2 0}$ years while other equipment- such as gas furnaces - may be in place much longer. Improvements in oil burner efficiencies over the years have acted as an incentive for more rapid replacement of oil furnaces.

\footnotetext{
${ }^{32}$ Margaret Mantho, “Annual Service Management Analysis," Fuel Oil and Oil l-feat, May 1978, p. 36.
} 
Table 59.-Average Yearly Demand for Distillate Fuel Oil (in thousands of barrels)

\begin{tabular}{|c|c|c|c|c|c|}
\hline & & $\begin{array}{l}\text { Domestic } \\
\text { demand }\end{array}$ & Production & Imports & Stocks \\
\hline 1972 & Average...$\ldots \ldots \ldots \ldots$ & 2,913 & 2,629 & 181 & a154,284 \\
\hline 1973 & Average. ............ & 3,092 & 2,820 & 392 & a196,421 \\
\hline \multirow[t]{2}{*}{1974} & 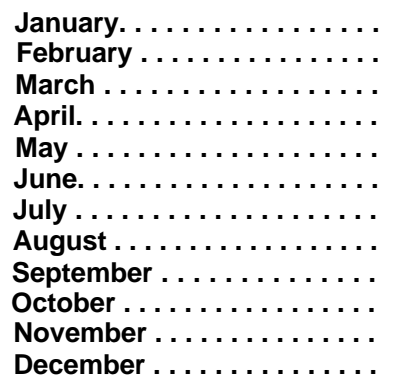 & $\begin{array}{l}3,835 \\
3,849 \\
3,164 \\
2,852 \\
2,450 \\
2,377 \\
2,309 \\
2,309 \\
2,385 \\
2,887 \\
3,157 \\
3,853\end{array}$ & $\begin{array}{l}2,880 \\
2,399 \\
2,226 \\
2,522 \\
2,704 \\
2,783 \\
2,792 \\
2,705 \\
2,552 \\
2,700 \\
2,801 \\
2,924\end{array}$ & $\begin{array}{l}464 \\
306 \\
287 \\
220 \\
268 \\
220 \\
221 \\
125 \\
152 \\
237 \\
454 \\
515\end{array}$ & $\begin{array}{l}181,179 \\
149,125 \\
128,822 \\
160,645 \\
141,806 \\
160,645 \\
182,458 \\
198,673 \\
208,269 \\
209,908 \\
212,875 \\
223,717\end{array}$ \\
\hline & Average $\ldots \ldots \ldots \ldots \ldots$ & 2,948 & 2,668 & 289 & \\
\hline \multirow[t]{2}{*}{1975} & 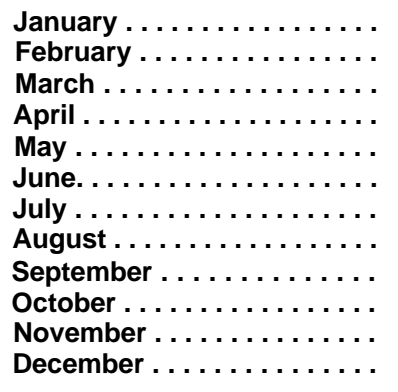 & $\begin{array}{l}3,953 \\
3,967 \\
3,293 \\
3,094 \\
2,382 \\
2,266 \\
2,112 \\
2,173 \\
2,163 \\
2,675 \\
2,544 \\
3,778\end{array}$ & $\begin{array}{l}2,852 \\
2,679 \\
2,531 \\
2,486 \\
2,431 \\
2,574 \\
2,589 \\
2,592 \\
2,812 \\
2,744 \\
2,767 \\
2,783\end{array}$ & $\begin{array}{r}324 \\
302 \\
256 \\
110 \\
136 \\
68 \\
106 \\
92 \\
129 \\
103 \\
96 \\
124\end{array}$ & $\begin{array}{l}199,715 \\
176,696 \\
161,111 \\
146,214 \\
152,027 \\
163,306 \\
181,472 \\
197,323 \\
220,732 \\
226,113 \\
235,749 \\
208,787\end{array}$ \\
\hline & Average $\ldots \ldots \ldots \ldots \ldots$ & 2,849 & 2,653 & 153 & \\
\hline \multirow[t]{2}{*}{1976} & 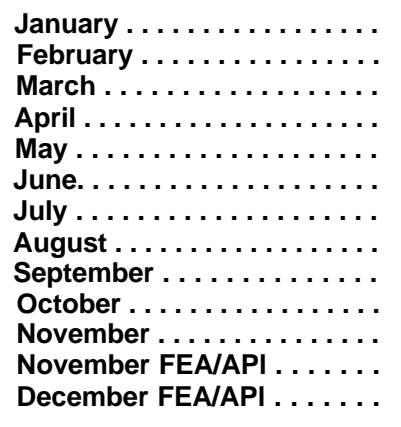 & $\begin{array}{r}4,298 \\
3,687 \\
3,336 \\
2,788 \\
2,519 \\
2,436 \\
2,255 \\
2,237 \\
2,618 \\
3,028 \\
3,714 \\
3,724 \\
4,654\end{array}$ & $\begin{array}{l}2,734 \\
2,961 \\
2,793 \\
2,655 \\
2,738 \\
2,885 \\
2,959 \\
2,982 \\
2,947 \\
2,995 \\
3,180 \\
3,199 \\
3,273\end{array}$ & $\begin{array}{r}164 \\
207 \\
151 \\
96 \\
97 \\
151 \\
126 \\
131 \\
147 \\
141 \\
135 \\
136 \\
166\end{array}$ & $\begin{array}{l}165,428 \\
150,439 \\
138,306 \\
137,249 \\
147,057 \\
165,064 \\
190,861 \\
217,930 \\
232,230 \\
235,599 \\
223,648 \\
221,178 \\
183,500\end{array}$ \\
\hline & Average $\mathrm{FEA} / \mathrm{API}^{\mathrm{c}} \ldots \ldots \ldots$ & 3,130 & 2,925 & 142 & \\
\hline 1977 & January $\mathrm{FEA} / \mathrm{API}^{\mathrm{c}} \ldots \ldots \ldots$ & 5.237 & 3,374 & 471 & 145.490 \\
\hline
\end{tabular}

a Total as of December 31.

b 1976 average is based on Bureau of Mines data for January through November and FEA data for December January 1977 data are from American Petroleum Institute (API).

SOURCES: Bureau of Mines, Federal Energy Administration, and American Petroleum Institute.

New burners installed today are expected to operate at seasonal efficiencies of 80 percent, and new promising technologies have produced burners with seasonal efficiencies up to
84 percent. To date, there has been little Federal support for development of high-efficiency oil heat equipment. Furthermore, most marketers cannot afford to establish R\&D programs 
Figure 17 -Sales of Distillate Fuel Oil Use as Percent of Total (millions of dollars]

\begin{tabular}{|c|c|c|c|}
\hline$\sqrt{2}$ & $\begin{array}{l}\text { off-highway } \\
\text { diesel }\end{array}$ & $\begin{array}{l}\text { Vessels and } \\
\text { railroads }\end{array}$ & $\begin{array}{l}\text { Industrial and } \\
\text { nil companies }\end{array}$ \\
\hline & $\begin{array}{l}\text { on-highway } \\
\text { diesel }\end{array}$ & $\begin{array}{l}\text { Electric } \\
\text { utilities }\end{array}$ & Heating \\
\hline
\end{tabular}

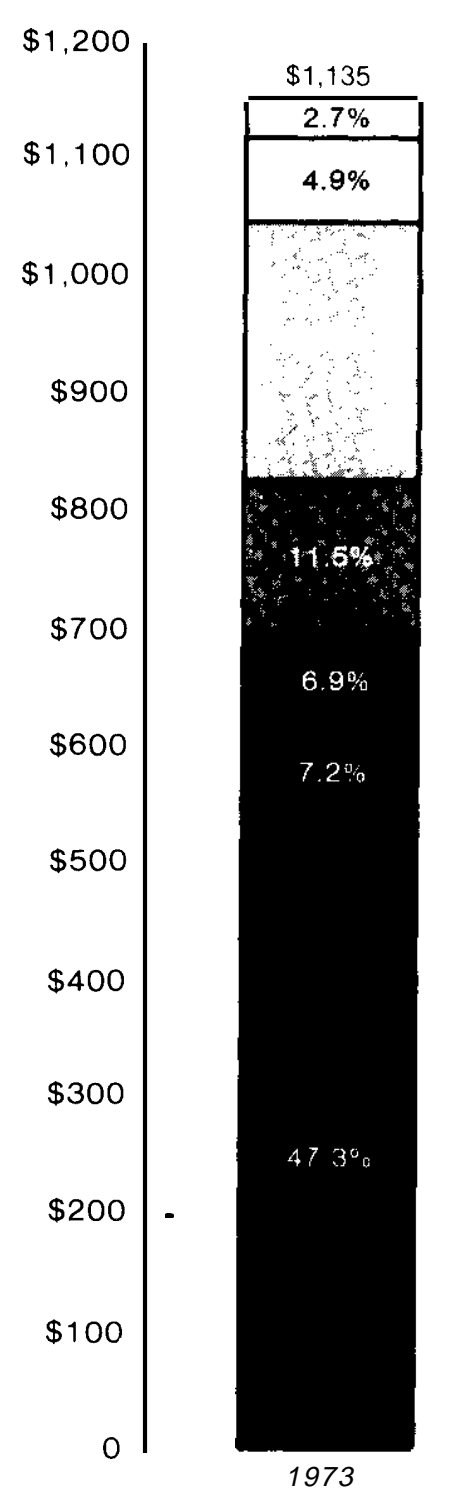

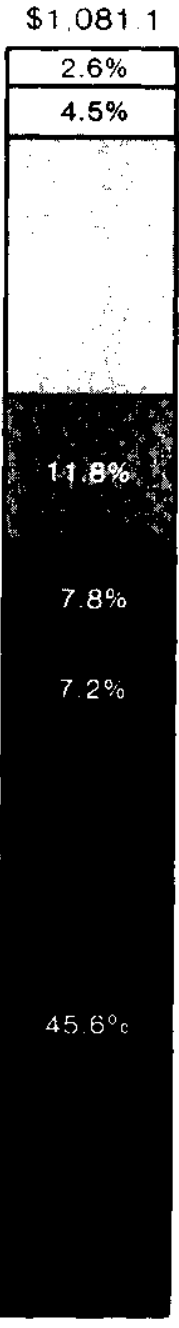

“ 974

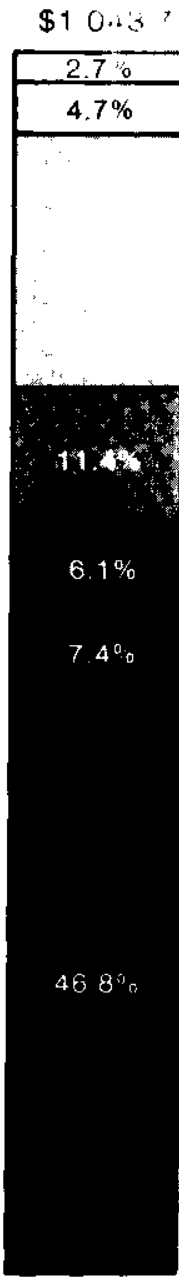

9

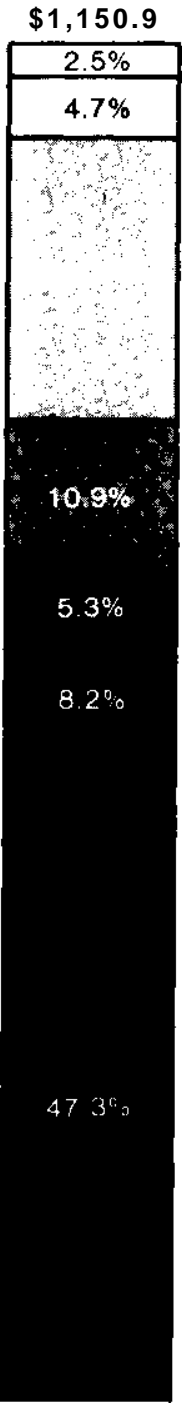

1976
$\$ 1,2310$
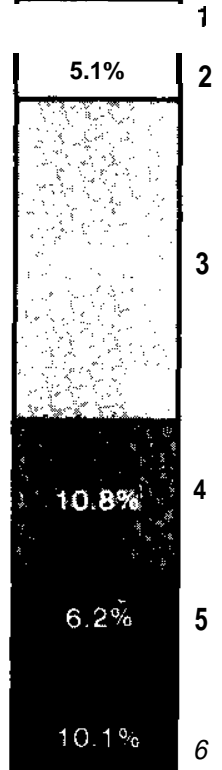

$437^{\circ}$ 
for high-efficiency equipment; research efforts are therefore centered in the furnace manufacturing industry.

\section{New Construction}

In 1971-77, from 8 to $\mathbf{1 1}$ percent of new homes were heated by oil. The following chart compares the relative position of oil, gas, and electricity in the new home market:

Percent of New Homes by Type of Heating Fuel ${ }^{33}$

\begin{tabular}{|c|c|c|c|}
\hline & Oil & Gas & Electricity \\
\hline $1971 \ldots \ldots \ldots \ldots$ & 8 & 60 & 31 \\
\hline $1972 \ldots \ldots \ldots \ldots$ & 8 & 54 & 36 \\
\hline 1973. . . . . . . & 10 & 47 & 42 \\
\hline 1974. . . . . . . . & 9 & 41 & 49 \\
\hline $1975 \ldots \ldots \ldots \ldots$ & 9 & 40 & 49 \\
\hline 1976. . . . . . & 11 & 39 & 48 \\
\hline 1977. . . . . . . . . & 9 & 38 & 50 \\
\hline
\end{tabular}

In the Northeast, however, the figures indicate an increase in the oil share of the new home market in 1971-76. The following chart shows the comparisons for the Northeast:

Percent of New Homes by Type of Heating Fuel ${ }^{34}$

\begin{tabular}{|c|c|c|}
\hline Oil & Gas & Electricity \\
\hline $971 \ldots \ldots \ldots \ldots$ & 42 & 26 \\
\hline $972 \ldots \ldots \ldots 33$ & 36 & 29 \\
\hline 973. . . . . . . . . 35 & 34 & 28 \\
\hline $974 \ldots \ldots 32$ & 29 & 38 \\
\hline $975 \ldots \ldots \ldots 4$ & 24 & 33 \\
\hline $976 \ldots \ldots \ldots 1$ & 15 & 31 \\
\hline $977 \ldots 49$ & 17 & 31 \\
\hline
\end{tabular}

Thus, while oil heat has grown slowly in the national new home market, still accounting for only slightly over a tenth of the units, oil heat in new homes in the Northeast has grown from just under a third of the market in 1971 to over half in 1976. The decline of the gas share in the early- to mid-1 970's, both nationwide and in the Northeast, can be attributed to prohibitions on new gas hookups by several State public utility commissions in response to supply shortages. Recent increases in gas supply and termination of moratoria on new hook-ups may reverse this trend.

\footnotetext{
${ }^{33}$ Characteristics of New Housing 7977 (Department of Commerce, Bureau of the Census, 1978), p. 28. ${ }^{34} \mathrm{I}$ bid.
}

\section{The Role of Oil Heat Distributors in Energy Conservation Practices}

\section{Introduction}

Given the relatively small and highly concentrated nature of the residential oil-heating market, a number of factors affect- and limit - the role of fuel oil distributors in residential energy conservation. This section outlines the industry's assessment of its current role in the energy conservation practices of its customers. The assessment is the product of a questionnaire that was mailed to 48 fuel oil distributors and 19 State, regional, and local trade associations in late November 1977. Twenty-one distributors and five trade associations responded from all regions of the country where fuel oil is consumed for space heating.

\section{Marketing of Energy Conservation Products}

Very few fuel oil distributors are actively selling residential insulation, storm windows and doors, and other conservation hardware. However, most fuel oil distributors are involved in helping their customers reduce the amount of fuel oil consumed. As mentioned earlier, about 69 percent of the residential consumers of fuel oil have their heating equipment checked and/or tuned at least once a year through a direct service offered by the distributors and many of the refiner markets.

More fuel oil distributors use independent contractors to provide insulation and other energy conservation products to their customers than sell these materials directly.

Besides the basic energy hardware (e.g., replacement burners, boilers, furnaces, insulation, etc.) that is being marketed by fuel oil distributors, some have attempted to market other energy conserving equipment such as automatic stack dampers, stack heat reclaimers, outdoor temperature controls, humidifiers, attic vents, fireplace heaters, and other related items.

\section{Reduction in Annual Fuel Consumption}

More than half of the respondents reported that 50 percent or more of their customers have reduced their annual consumption by 
more than 15 percent since the 1973 price rise. States in the colder climates reported the highest percentage of customers conserving fuel oil.

In the 1972-73 heating season (adjusted for actual rather than average degree days), residential oil consumption reflected predictable regional patterns, influenced by climate-for example, a low of 800 gallons in South Carolina to a high of 1,750 gallons in northern New England. It should be noted that homeowner consumption can vary widely even within a community. This divergence is largely attributed to variables such as living-space size, thermal characteristics of the housing unit, and consumer behavior patterns.

\section{Factors That Influence and Limit Market Entry}

Why have a few fuel oil distributors entered the business of marketing insulation and storm windows and doors, while most have not? The reasons most often cited include the expectations of increased profits, increased service of existing customers, and the prevention of customer switches to other fuels.

What prevents fuel oil distributors from marketing insulation and other related items? Reasons most frequently cited include the lack of available qualified independent contractors to service the distributor's customers, and the lack of capital to get into the conservation business. Furthermore, most competing distributors are simply not marketing this hardware. Other disincentives include the apparent shortage of insulation and other energy materials, the inability of homeowners to pay for or finance energy conservation measures, and the limited public interest in energy conservation.

Advertising is one of the major vehicles by which fuel oil distributors penetrate the market. Bill-stuffers are the most popular form, accounting for 5 to 30 percent of total advertising budgets. Direct mail to potential customers runs from a low of 10 percent to a high of 90 percent of advertising budgets. Radio is also used, but it accounts for a relatively low percentage of the total advertising budget.

A number of marketing choices that are exercised by fuel oil distributors are based on technical information about energy conservation. Some of the most frequently cited sources include State trade associations, magazines and other publications of general circulation, and local industry trade associations Suppliers and manufacturers of energy conservation materials, however, are considered the most reliable sources of technical information

\section{Fuel Oil Customer Accounts}

Since 1973, when costs of fuel oil began to rise, oil distributors' delinquent customer accounts (past due by more than $\mathbf{3 0}$ days) have increased significantly. Many distributors reported increases of about 15 percent or greater, and some distributors have reported an increase in delinquent accounts by 50 percent or more. Obviously, customers with delinquent accounts cannot normally finance additional expenditures, such as conservation improvements. A large number of delinquent accounts affects the ability of distributors to set aside capital or to acquire financing for the purpose of developing energy conservation guidelines.

One of the most significant problems facing fuel oil distributors in terms of their ability to carry delinquent accounts or to offer credit terms for financing conservation efforts is the elimination by wholesale suppliers of discount terms for payments. Another problem frequently cited is the increased interest charges associated with financing more expensive inventory. Furthermore, increases in insurance costs have also contributed to oil distributors' cash flow problem. 


\section{TECHNICAL NOTES-COMPUTER SIMULATION: THE EFFECT OF CONSERVATION MEASURES ON UTILITY LOAD FACTORS AND COSTS}

\section{The Question}

Will widespread adoption by residential electric customers of conservation measures, particularly insulation, result in utility load changes that are economically counterproductive to the utilities and/or their customers?

\section{Background}

Many residential consumers of electricity are investing in energy-saving materials and devices for their homes in hopes of reducing their utility bills, or at least stemming the rapid increases they have experienced recently. Adding insulation to existing homes is the action most commonly taken, but some homeowners - and builders of new homes- are also choosing HVAC systems with energy efficiency and cost savings in mind. Electric heat pumps are becoming widely used for this reason. Consumer attitudinal surveys indicate that electric customers investing in conservation measures are motivated primarily by the hope of saving money.

Whether or not consumers experience lower or even slower growing utility bills in the future depends ultimately on whether or not their utility companies can achieve cost savings that can be passed on, in turn, to ratepayers. Many factors affect utility costs, and consumer conservation actions will not be the only determinant of the direction in which rates will go in the next few years. But utility managers have raised questions about the possibility that conservation practices could have some adverse effect on load factors and systemwide costs, thereby contributing to a need for higher rates. From the consumer's standpoint, this would surely be the ultimate example of "Catch-22."

The fear of cost increases caused by conservation actions is based on the fact that utility costs are positively correlated to seasonal and daily variations in the demand for electricity, and on the possibility that insulation and other conservation measures could magnify these variations in uneconomic ways. Electric companies must have available to them at any given time enough generating capacity to meet the highest level of demand expected at that time, plus a reserve margin of capacity to use in the event that some powerplants are shutdown by emergencies or for routine maintenance. But since the peak demand level may be reached on only a few days each year, and for only a few hours even on those days, utilities are likely to have a considerable fraction of their total generating capacity idle much of the time.

Idle generating capacity is expensive, and certain kinds of powerplants are more expensive to keep idle than others. Although a company pays for fuel and other operating costs only when the plant is operating, many fixed costs ${ }^{-}$such as interest on the capital borrowed to build the plant- must be paid regardless of how much the plant is used. It follows, then, that newer, bigger, more capital-intensive plants (particularly nuclear plants) are the most expensive to shutdown, while older, smaller plants (like oil-fired turbines) are the least expensive to hold in reserve. Conversely, new plants are often the least expensive to operate, while the older ones (which usually use the most expensive fuels) are the most costly to run.

A utility's daily or yearly "load' '-the total amount of electricity it must generate during that time- is usually thought of as having three components. The baseload--that which is demanded nearly all the time- is the largest component and is usually generated with the company's newest, largest, and most technologically advanced plants. The intermediate load-an increment that is demanded less of the time - is typically derived from slightly older and smaller plants, fired with fossil fuels. 
The peakload - a sharply greater demand component that may be demanded only occasionally - is usually met with small oil- or gas- fired turbines, or with pumped-storage hydroelectric plants, or by purchasing power from other companies sharing the same distribution grid. Figures 18 and 19 illustrate a typical system load and the three major generating components.

Figure 18.-Dispatching Generation to Meet a Cyclical Load

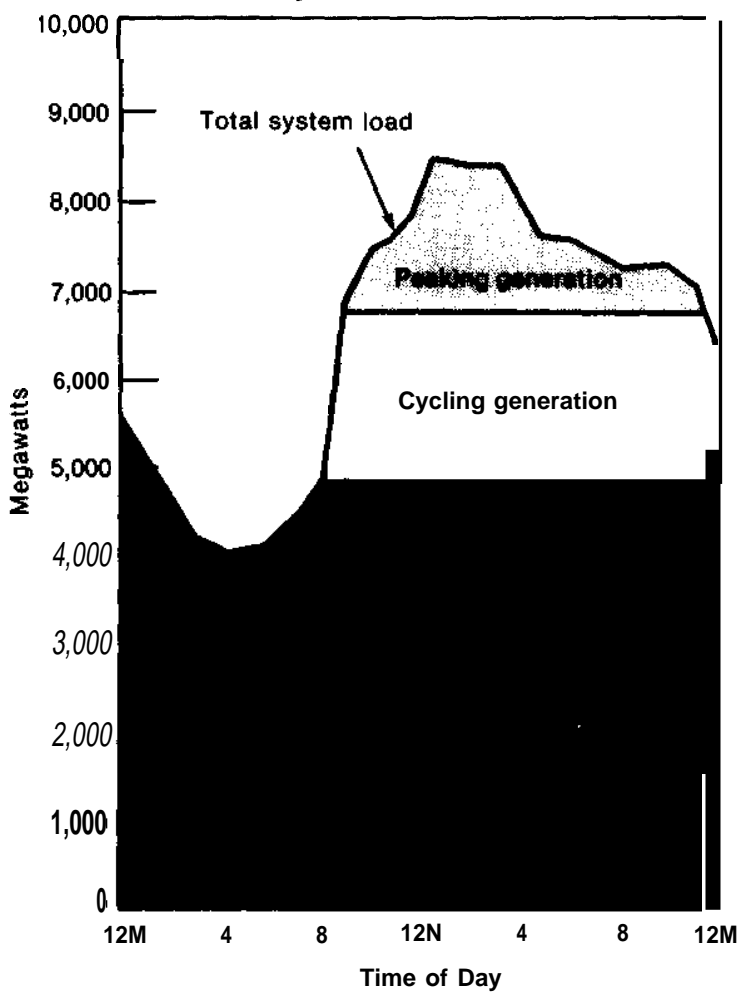

SOURCE: Electric Utility Rate Design Study, Rate Design and Load Control: Issues and Directions, a Report to the National Association of Regulatory Utility Commissioners, November 1977

The costs of keeping and operating these different kinds of plants vary, typically, as follows:

- Baseload plants-high fixed costs, low operating costs, resulting in the lowest overall costs when in operation.

- Intermediate-load plants- medium fixed costs, medium-to-high operating costs, resulting in medium overall costs when in operation.
- Peakload plants - low fixed costs, very high operating costs, resulting in the highest overall costs when in operation.

Figure 19.- Daily Load Curve

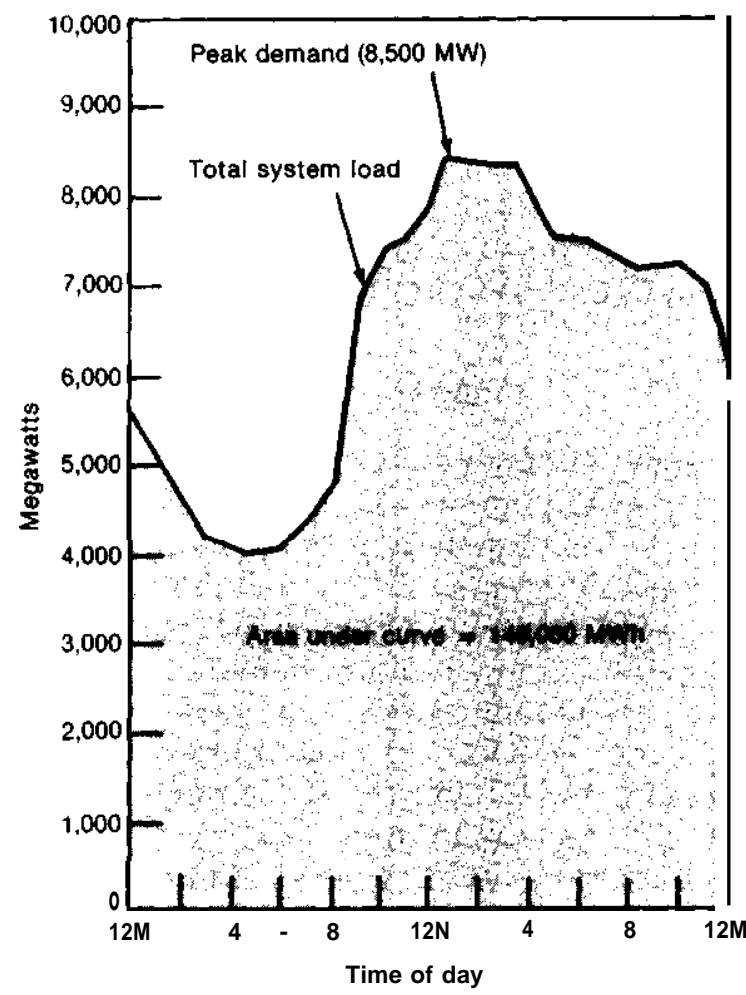

Jaily load factor $=\frac{\text { daily energy }}{24 \mathrm{hr} \text { X peakload }}=\frac{149,000 \mathrm{MWh}}{24 \mathrm{hr} \times 8,500 \mathrm{MW}}$

$$
=0.73=73 \%
$$

SOURCE. Electrlc Utility Rate Design Study, Rate Design and Load Control: Issues and Direct/ens, a Report to the National Association of Regulatory Utility Commissioners, November 1977.

A major determinant of total utility costs and generating capacity needs is a company's "annual load factor," which is the ratio of the average utility load over the year to the peakload during any time period (usually 15 minutes] during the year. The higher the load factor, the less total downtime the company experiences in its generating capacity. Up to a certain point, the utility benefits from keeping its plants running, generating sales revenues with which to cover both fixed costs and operating costs. Some idle capacity is needed, however, to allow normal maintenance operations to take place, to substitute for other plants in emergency outages, and to meet the peaks. When all plants are operating and additional 
power is being purchased, operating costs are very high. It is desirable, in other words, to balance the load factor properly so that base plants keep running, intermediate plants take up the gaps caused by planned and unplanned interruptions, and peaking plants are used as little as possible.
A typical load factor, and one which accomplishes this goal reasonably well, is in the neighborhood of 0.65 , or an average use of 65 percent of capacity. Figure 20 shows average annual load factors and total electricity output for U.S. utilities between 1948 and 1976.

Figure 20. - Electric Energy Output and Annual Load Factors

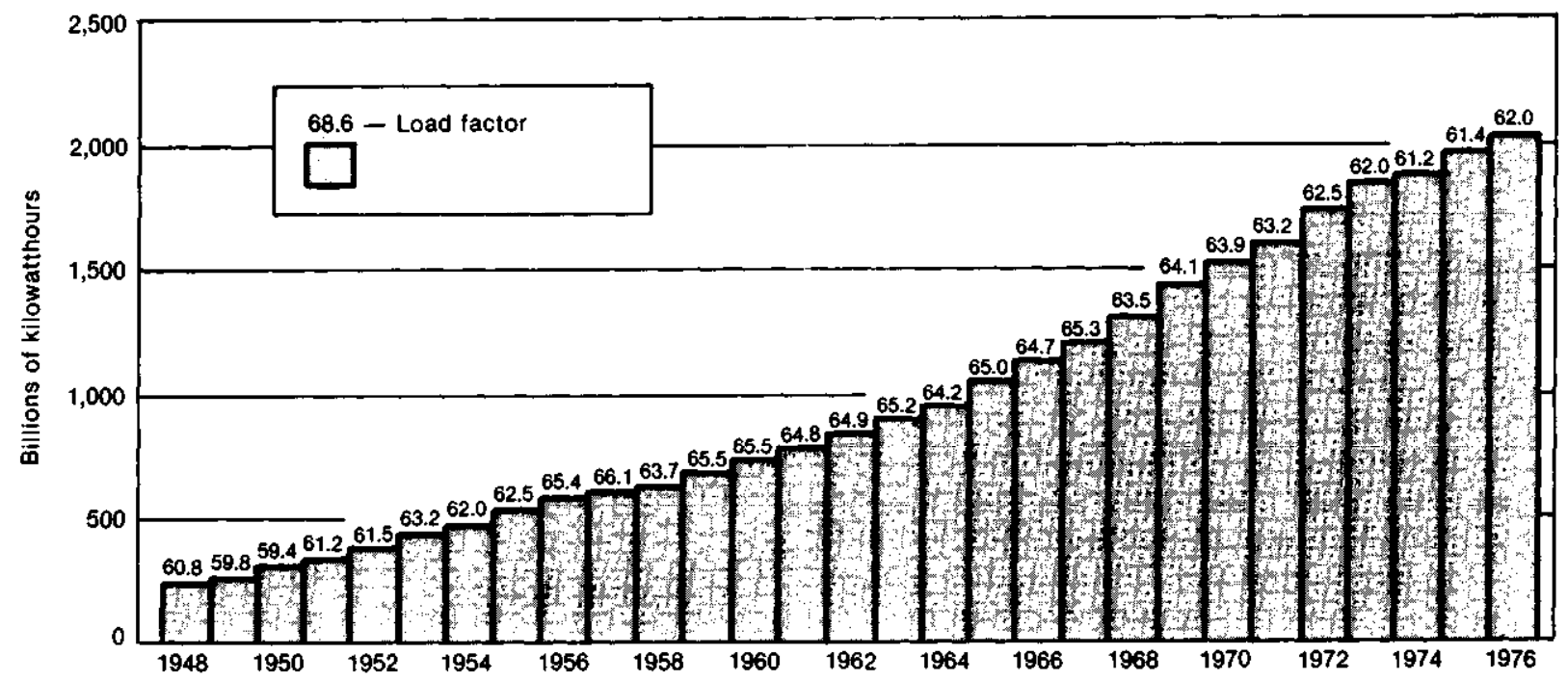

SOURCE: Electric Utility Rate Design Study.

Note: Figures shown are for the total electric utility industry of the contiguous United States.

\section{OTA Analysis of Conservation Impact on Utility Loads and Costs}

A model developed for OTA's recent study, Application of Solar Energy to Today's Energy Needs, analyzed the impact of conservation measures on utility operations.

OTA's model simulates utilities in four U.S. cities. The utility loads, shown in table 60 , consist of a mix of single-family homes, townhouses, low- and high-rise apartments, shopping centers, industry, and streetlighting. Each of the four cities has the same number of units although the heating and cooling loads are determined by the weather conditions, taken from 1962 data, of each city. The residential heating and cooling equipment mix is initially set to match conditions in $\mathbf{1 9 7 5}$ and then forecast. to 1985 using a residential energy use model developed by ORNL. All the single- family homes are initially set to the same level of Insulation, which the model can increase to a higher value. The insulation levels in the other buildings do not vary. The change for single-family homes corresponds to a heat load reduction of 31 to 49 percent, depending on the location. In addition to the insulation level, the type of heating equipment can be changed to allow the possibility of varying the percentage of homes that are electrically heated. Diversity is built into the model so that the peakloads of the individual homes do not all occur simultaneously. 35

To determine the effects on utility loads of increased insulation among resident $i$ al

\footnotetext{
3. Further details about the model and the hypothetical ut Ility loads can be found in Application of Solar Energy to Today's Energy Needs, vol. 1, chapter V, and vol. 11, chapter V 1.
} 
Table 60.-1985 Projection of Heating Unit Mix and Basic Loads (number of buildings)

\begin{tabular}{|c|c|c|c|c|}
\hline & $\begin{array}{c}\text { Albu- } \\
\text { querque }\end{array}$ & Boston & $\begin{array}{c}\text { Fort } \\
\text { Worth }\end{array}$ & Omaha \\
\hline \multirow{2}{*}{$\begin{array}{l}\text { Single family units } \\
\text { Electric heat. . . . . } \\
\text { Fossil heat. . . . . } \\
\text { Electric cooling. . . } \\
\text { Total . . . . . . . . }\end{array}$} & $\begin{array}{l}10,470 \\
45,450 \\
43,613\end{array}$ & $\begin{array}{r}8,080 \\
47,840 \\
34,863\end{array}$ & $\begin{array}{l}11,790 \\
44,130 \\
55,920\end{array}$ & $\begin{array}{r}7,720 \\
48,200 \\
55,920\end{array}$ \\
\hline & 55,920 & 55,920 & 55,920 & 55,920 \\
\hline $\begin{array}{l}\text { Townhouses . . . . . . } \\
\text { Low rise units . . . . . } \\
\text { High rise units. . . . . } \\
\text { Shopping centers . . . }\end{array}$ & $\begin{array}{r}6,960 \\
2,160 \\
600 \\
30\end{array}$ & $\begin{array}{r}6,960 \\
2,160 \\
600 \\
30\end{array}$ & $\begin{array}{r}6,960 \\
2,160 \\
600 \\
30\end{array}$ & $\begin{array}{r}6,960 \\
2,160 \\
600 \\
30\end{array}$ \\
\hline
\end{tabular}

Annual industrial loads (all cities) -2.54 billion kWh. Annual streetlight load (all cities) -98.78 million kWh.

customers, the model was run first with all single-family homes at the baseline insulation level and again at the high insulation level, using the forecast $1985 \mathrm{mix}$ of home heating systems initially, and then using an assumption that $\mathbf{5 0}$ percent of the homes were electrically heated. (The latter case was included to simulate utilities with winter peaks.) All other load characteristics remained constant throughout the analysis. The heating and cooling mix for single-family homes for the 1985 forecast is shown in table 60 . Table 61 shows the numbering of buildings assumed to have electric heat in the case when it was assumed that $\mathbf{5 0}$ percent of residences use electric heat.

\section{Results}

The load factor and seasonal peak demands are given in table 62 for the reference and the high insulation cases for both mixes of residential heating -1 985 projection and high electric resistance. The results show that an increase in insulation does not change the load factor significantly. In all but two situations, the load factor Increases as insulation is added, but the increase does not exceed 4 percent. The two exceptions are the utilities with 50-percent electric resistance heat that still experience their peak loads in the summer.

Table 61 -50-Percent Electric Resistance Heating by 1985 (number of buildings)

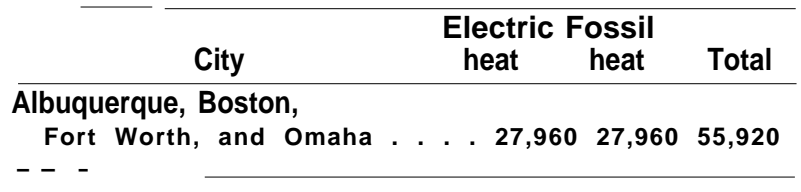

Table 62.-Simulated Utilities' Load Factors, Peaks, Summer-Winter Ratio by 1985

\begin{tabular}{|c|c|c|c|c|c|c|c|c|}
\hline & \multicolumn{2}{|c|}{ Albuquerque } & \multicolumn{2}{|c|}{ Boston } & \multicolumn{2}{|c|}{ Fort Worth } & \multicolumn{2}{|c|}{ Omaha } \\
\hline & $\begin{array}{c}\text { Reference } \\
\text { case }\end{array}$ & $\begin{array}{c}\text { High } \\
\text { insulation }\end{array}$ & $\begin{array}{c}\text { Reference } \\
\text { case }\end{array}$ & $\begin{array}{c}\text { High } \\
\text { insulation }\end{array}$ & $\begin{array}{c}\text { Reference } \\
\text { case }\end{array}$ & $\begin{array}{c}\text { High } \\
\text { insulation }\end{array}$ & $\begin{array}{c}\text { Reference } \\
\text { case }\end{array}$ & $\begin{array}{c}\text { High } \\
\text { insulation }\end{array}$ \\
\hline \multicolumn{9}{|c|}{ Base case } \\
\hline $\begin{array}{l}\text { Load factor. } \ldots \ldots \ldots \\
\text { Winter peak (MW, } \\
\text { month). . . . . . . . } \\
\text { Summer peak (MW, } \\
\text { month). . . . . . . . } \\
\text { Summer-winter ratio . }\end{array}$ & $\begin{array}{c}0.534 \\
1,359 \\
\text { Jan. } \\
1,386 \\
\text { Aug. } \\
1.02\end{array}$ & $\begin{array}{l}0.537 \\
1,315 \\
\text { Jan. } \\
1,352 \\
\text { Aug. } \\
1.03\end{array}$ & $\begin{array}{c}0.498 \\
1,316 \\
\text { Feb. } \\
1,354 \\
\text { Jul. } \\
1.03\end{array}$ & $\begin{array}{l}0.505 \\
1,263 \\
\text { Feb. } \\
1,320 \\
\text { Jul. } \\
1.05\end{array}$ & $\begin{array}{c}0.470 \\
1,562 \\
\text { Jan. } \\
1,942 \\
\text { Aug. } \\
1.24\end{array}$ & $\begin{array}{l}0.475 \\
1,472 \\
\text { Feb. } \\
1,873 \\
\text { Aug. } \\
1.27\end{array}$ & $\begin{array}{c}0.448 \\
1,453 \\
\text { Feb. } \\
1,823 \\
\text { Jul. } \\
1.25\end{array}$ & $\begin{array}{l}0.453 \\
1,397 \\
\text { Feb. } \\
1,768 \\
\text { Jul. } \\
1.26\end{array}$ \\
\hline \multicolumn{9}{|c|}{ 50-percent electric resistance heating case } \\
\hline $\begin{array}{l}\text { Load factor. } \ldots . . . \\
\text { Winter peak (MW, } \\
\text { month). . . . . . . . } \\
\text { Summer peak (MW, } \\
\text { month). . . . . . . . } \\
\text { Summer-winter ratio . . }\end{array}$ & $\begin{array}{c}0.472 \\
1,677 \\
\text { Jan. } \\
1,368 \\
\text { Aug. } \\
0.79\end{array}$ & $\begin{array}{l}0.485 \\
1,569 \\
\text { Jan. } \\
1,348 \\
\text { Aug. } \\
0.86\end{array}$ & $\begin{array}{c}0.466 \\
1,600 \\
\text { Feb. } \\
1,392 \\
\text { Jul. } \\
0.87\end{array}$ & $\begin{array}{l}0.492 \\
1,433 \\
\text { Feb. } \\
1,362 \\
\text { Jul. } \\
0.95\end{array}$ & $\begin{array}{c}0.483 \\
1,842 \\
\text { Jan. } \\
1,958 \\
\text { Aug. } \\
1.06\end{array}$ & $\begin{array}{l}0.481 \\
1,594 \\
\text { Jan. } \\
1893 \\
\text { Aug. } \\
1.19\end{array}$ & $\begin{array}{r}0.483 \\
1,787 \\
\text { Feb. } \\
1,847 \\
1.03\end{array}$ & $\begin{array}{c}0.467 \\
1,603 \\
\text { Feb } \\
1,805 \\
1.13\end{array}$ \\
\hline \multicolumn{9}{|c|}{ 50-percent heat pump case } \\
\hline $\begin{array}{l}\text { Load factor. } \ldots \ldots \ldots \\
\text { Winter peak (MW, } \\
\text { month). . . . . . . . } \\
\text { Summer peak (MW, } \\
\text { month). . . . . . . . } \\
\text { Summer-winter ratio . . }\end{array}$ & $\begin{array}{c}0.465 \\
1,632 \\
\text { Jan. } \\
1,373 \\
\text { Aug. } \\
0.85\end{array}$ & $\begin{array}{l}0.484 \\
1,528 \\
\text { Jan. } \\
1,351 \\
\text { Aug. } \\
0.88\end{array}$ & $\begin{array}{c}0.446 \\
1,587 \\
\text { Feb. } \\
1,400 \\
\text { Jul. } \\
0.88\end{array}$ & $\begin{array}{l}0.483 \\
1,426 \\
\text { Feb. } \\
1,368 \\
\text { Jul. } \\
0.96\end{array}$ & $\begin{array}{c}0.470 \\
1,778 \\
\text { Jan. } \\
1,976 \\
\text { Aug. } \\
1.11\end{array}$ & $\begin{array}{l}0.476 \\
1,569 \\
\text { Jan. } \\
1,906 \\
\text { Aug. } \\
1.21\end{array}$ & $\begin{array}{c}0.463 \\
1,787 \\
\text { Feb. } \\
1,861 \\
\text { Jul. } \\
1.04\end{array}$ & $\begin{array}{l}0.457 \\
1,599 \\
\text { Feb. } \\
1,815 \\
\text { Jul. } \\
1.14\end{array}$ \\
\hline
\end{tabular}


The effect on the summer-winter peak difference, shown in table 62, is more pronounced. For all summer peaking utilities, for either mix of heating systems, the ratio of the summer to winter peak increases as a result of increased insulation. These increases range from 1 to 12 percent and are greatest for the utilities with the highest percentage of electric heat. For the winter peaking utilities, the ratio decreases by about 8 percent when the residential insulation level is increased.

\section{Discussion}

These simulations indicate that the effect of extensive additions of insulation by residential customers depends greatly on the amount of residential electric heat in the utility's load, since adding insulation affects heating loads more than cooling loads. Utilities that have winter peaks or small electric heat loads (relative to their cooling loads) experienced increases in their load factors; this means that their peakloads were reduced more than their average loads by the addition of insulation. On the other hand, two of the simulated utilities those with summer peaks accompanied by large electric heating loads-experienced moderate drops in their load factors after insulation was added. Summer-winter peak ratios change very little - under 2 percent- in the cases for which the electric heating load is small, but as that load increases, the change in the ratio also grows until the winter peak begins to exceed the summer peak.

In sum, OTA's simulation indicates that most utilities will not be measurably affected by the widespread addition of insulation by residential customers, unless at least a third or so of their residential customers use electric heat If more than half use electric heat, the utility will still experience an improved load factor as long as its peak comes in the winter. In such cases, the increase in load factor and the leveling of differences between summer and winter peaks can assist in bringing about more efficient use of generating capacity. 
Chapter VII

\section{STATES AND LOCALITIES}




\section{Chapter VII._STATES AND LOCALITIES}

EPCA/ECPA: Legislative Foundation ... .

Federal Energy Policy Leadership and Federal Funds for State Energy

Conservation Programs Will Continue to be Necessary to Stimulate Many State Activities. . . . . . . . . . . . 160

Well-Defined State Energy Policy Has Not Emerged . . . .161

Energy Production Is the Predominant Concern of Energy-Rich States .161 New State Organizations Are Emerging to Grapple With Current

Energy Problems . . . . . . . . . . . . . 162

Information Flow From Federal to State and From State to State

Government Requires Attention . . . . . . . . . 162

State Legislatures Have Focused on Seven Major Issues in Energy

Conservation . . . . . . . . . . . . . 163

Four Residential Energy Conservation Programs Serve as the

Foundation of State Efforts ......... 164

\section{TABLES}

63. Residential Energy Conservation Legislation, 1974-77 Page

64. Residential Energy Conservation Programs . . . . . . . .157

65. State Issues in Residential Energy Conservation . . . . . .158 
The problems of federalism have a special bearing on residential energy conservation. States are the vehicles used to implement many of the federally defined programs aimed at reducing residential energy consumption, and States are the mechanism through which localities receive Federal dollars for many efforts. But the wide differences among States in attitudes, resources, climate, geography, population, size, governmental organization, and history combine to remind the policy maker of the diversity of the American political fabric. Policies that fail to recognize these differences face difficulty from the beginning.

It is not possible to examine a "representative sample" of States, but some information can be gleaned from viewing the States in the aggregate and a few States more carefully. This chapter reflects a close look at 10 States, with some information about all 50. Although conservation programs have been in place only a short time, it is possible to make some clear statements about areas of difficulty and areas of promise.

All States, plus the trust territories, have submitted plans for Federal approval under the Energy Policy and Conservation Act (EPCA) and the Energy Conservation and Production Act (ECPA). The eight mandatory areas defined in these laws form the core of State activities. Some States have launched broad and imaginative programs and seem to have achieved success. In these States, such as Minnesota, lowa, and California, State agencies, localities, interest groups, and others have joined to produce innovative and fruitful responses to the problem. On the other hand, many States have done very little.

Most States have simply responded to the Federal initiative and available Federal funding for the mandatory programs. Thus, the Federal Government tends to define State and local solutions. As the energy problems have been defined as a national problem and Congress has indicated that national policies will be forthcoming (and indeed are in effect), most States have been hesitant to initiate policy independently. Many States feel that the programs initiated and the organizations set in place, while responsive to the Federal view, are inappropriate to the particular State. Most States have substantial problems in program integration, technical assistance, and funding. Too few persons are trained to deal with the varied and overlapping aspects of energy conservation, and State agencies need more technical help than they are receiving. The usual problems-the pacing of Federal programs, uncertainties about guidelines and regulations, communications problems, late release of Federal funds, and changing players in national and regional Department of Energy (DOE) off ices - add to the confusion.
Beyond these complaints, which characterize the early stages of many Federal efforts, are problems relating to the States' energy viewpoint. States with substantial energy resources are less concerned with conservation than with obtaining a "fair shake" in the solution of the problems. States with large resources of fossil fuels place conservation in a secondary role compared to production issues. Legislative attention in these States tends to be directed toward resource extraction and development.

Of particular difficulty to the States has been the need to measure the energy savings the 'approved State plan" will produce. This problem is well stated by one of the leading State energy agency directors, John Millhone of Minnesota:

The requirement that the State plan save at least 5 percent of the 1980 energy consumption presumed a statistical sophistication that doesn't exist. Most rudimentary State energy data systems have an error of plus or minus 5 percent or more. The Act provided that part of 
a State's grant would be based upon its purported energy saving, stimulating exaggeration when accuracy about the real energy savings is sorely needed. The emphasis was placed on Btu savings alone, penalizing States that sought conversion from precious to more abundant fuels - natural gas to coal, for example-when conversions meant more Btu would be used.

Another problem with the 5-percent goal relates to the funding level. The State energy conservation program required energy savings equivalent to about $\mathbf{8 0 0}$ million barrels of oil by 1980 , and provided only $\$ 150$ million in funding authority. This meant that the Federal Government was trying to buy a barrel of oil through the program for 10 cents. ${ }^{2}$

A review of the findings from the 10-State study sample reveals a number of useful findings. More specific information appears in tables 63, 64, and 65.

\section{EPCA/ECPA: LEGISLATIVE FOUNDATION}

The Energy Policy and Conservation Act (Public Law 94-163) and the Energy Conservation and Production Act (Public Law 94-385) provide the foundation for Federal energy conservation policy. (The former Federal Energy Administration (FEA) weatherization program has been brought under these Acts.) These acts authorize funding to States that develop approved State energy conservation plans (SECP). The plans must address eight mandatory areas:

- mandatory lighting efficiency standards;

- programs promoting vanpools and public transportation;

- mandatory standards on energy efficiency that govern State and local procurement practices;

- mandatory thermal efficiency standards and insulation requirements;

- laws permitting a right-turn-on-red;

- public education;

- intergovernmental coordination in energy matters; and

- energy audits for buildings and industrial plants.

\footnotetext{
'John Millhone, Analysis of Energy Conservation Programs, paper prepared for the annual meeting of the American Association for the Advancement of Science, February 1978
}

A State may propose other activities to receive Federal funding. The proposed programs must cumulatively achieve a 5-percent reduction in energy demand by 1980 .

Every State, plus the trust territories, has submitted plans for Federal approval. Each State plan outlines many programs, but relatively few program elements have been started Some programs rely on State legislative action. In most cases the legislatures have not passed legislation specified in the plans. Most of the Federal funds for programs, moreover, were not dispersed until January 1, 1978. Planning activity predominated prior to that date

Seven major conclusions emerge from examination of these States. They include organizational or administrative difficulties as a result of funding characteristics, the emergence of new agencies in fields previously dominated by existing organizations, and problems in providing qualified technical expertise. None of these is trivial in the development of successful conservation programs.

\footnotetext{
'Ibid Much of the information in this chapter is based or State Residential Energy Conservation: Attitudes, Policiesand Programs, prepared for Office of Technology A sessment by Booz, Allen\& Hamilton, May 1978
} 
Table 63. -- Residential Energy Conservation Legislation, 1974.77

\begin{tabular}{|c|c|c|c|c|c|c|c|}
\hline Steto & $\begin{array}{l}\text { Building } \\
\text { standards }\end{array}$ & $\begin{array}{l}\text { Materials } \\
\text { standards }\end{array}$ & $\begin{array}{c}\text { Appliance efficiency } \\
\text { standards }\end{array}$ & $\begin{array}{l}\text { Insulation } \\
\text { programs }\end{array}$ & $\begin{array}{c}\text { Tax } \\
\text { incentives }\end{array}$ & $\begin{array}{l}\text { Uility rate } \\
\text { reform }\end{array}$ & Solar \\
\hline 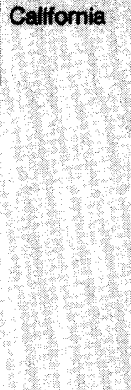 & $\begin{array}{l}\text { Establishment of } \\
\text { regulations for } \\
\text { the insulation of } \\
\text { attic spaces } \\
(1975) \\
\text { Adoption of res. } \\
\text { and nonres. } \\
\text { building stds. } \\
\text { by ERCDC } \\
\text { Adoption of energy } \\
\text { eliciency rating } \\
\text { systems for }\end{array}$ & $\begin{array}{l}\text { Prohibition of sale } \\
\text { of insulation mater- } \\
\text { lals not meeting } \\
\text { ERCDC standards }\end{array}$ & $\begin{array}{l}\text { Mandates com } \\
\text { pliance of appliances } \\
\text { With state- } \\
\text { determined } \\
\text { regulations }\end{array}$ & $\begin{array}{l}\text { Directive to PUC } \\
\text { to permit utilty } \\
\text { sponseored insula. } \\
\text { tion and financing } \\
\text { program }\end{array}$ & $\begin{array}{l}\text { Tax credits for } \\
\text { weatherization } \\
(1976)\end{array}$ & $\begin{array}{l}\text { Pue direc- } \\
\text { ective to } \\
\text { investigate } \\
\text { life line } \\
\text { rates } \\
(1974) \\
\text { Eill requir- } \\
\text { ing liteline } \\
\text { volume } \\
\text { and quan- } \\
\text { tity where } \\
\text { res. master } \\
\text { meter }\end{array}$ & $\begin{array}{l}\text { Standerds for } \\
\text { energy equip- } \\
\text { ment by } \\
711 / 77 \\
(1975) \\
\text { Income tex } \\
\text { deduction for } \\
\text { solar } \\
\text { Installation } \\
\text { State funded } \\
\text { solar loan } \\
\text { program }\end{array}$ \\
\hline (3) & $\begin{array}{l}\text { Development of } \\
\text { statewide thermal } \\
\text { efficiency stds. } \\
\text { (passed } 1977 \text { ) } \\
\text { Adoption of themal } \\
\text { efficiency stds. } \\
\text { (pending) }\end{array}$ & None: & None & $\begin{array}{l}\text { Loans for weather- } \\
\text { ization and conser- } \\
\text { vation improve } \\
\text { ments by financial } \\
\text { inst's at low } \\
\text { interest rates } \\
\text { (pending) } \\
\text { Financing of } \\
\text { conservation } \\
\text { improvements by } \\
\text { utilities (pending) }\end{array}$ & $\begin{array}{l}\text { Directive to } 3 \\
\text { state agencies } \\
\text { to develop a } \\
\text { tax incentive } \\
\text { to encourage } \\
\text { energy con- } \\
\text { servation } 8 \\
\text { use of alter- } \\
\text { nate energy } \\
\text { sources } \\
\text { (pending) }\end{array}$ & None & $\begin{array}{l}\text { Local property } \\
\text { tex exemp } \\
\text { tions for solar } \\
\text { installations } \\
(1975) \\
\text { Sales tax } \\
\text { exemption for } \\
\text { solar equip- } \\
\text { ment }(1975)\end{array}$ \\
\hline Ilinols & None & None & None & None & None & None & $\begin{array}{l}\text { Property tax } \\
\text { incentive for } \\
\text { solar heating } \\
8 \text { cooling } \\
\text { devices } \\
(1975)\end{array}$ \\
\hline lowa & $\begin{array}{l}\text { Establishment of } \\
\text { lowa building } \\
\text { code (1975) } \\
\text { Maximum energy } \\
\text { use in res., comm, } \\
\text { \& public buildings } \\
\text { Bill to set energy } \\
\text { efficiency stds. in } \\
\text { new buildings } \\
\text { (pending) }\end{array}$ & None & None & None & $\begin{array}{l}\text { Limited prop- } \\
\text { erty tax } \\
\text { exemption for } \\
\text { property used } \\
\text { to convert } \\
\text { solar energy, } \\
\text { wind, or water } \\
(1975)\end{array}$ & None & $\begin{array}{l}\text { Property tax } \\
\text { exemption for } \\
\text { solar heating } \\
8 \text { cooling } \\
\text { systems } \\
(1975)\end{array}$ \\
\hline Loulsiana & $\begin{array}{l}\text { Provide for estab- } \\
\text { lishment of bldg. } \\
\text { code council \& } \\
\text { state buliding } \\
\text { code (1975) } \\
\text { Bill to set state } \\
\text { wide building } \\
\text { performance } \\
\text { standards } \\
\text { (pending) }\end{array}$ & None & None & None & $\begin{array}{l}\text { Provides for a } \\
\text { rebate on } \\
\text { sales \& use } \\
\text { taxes for home } \\
\text { insulation \& } \\
\text { other improve- } \\
\text { ments (1975) } \\
\text { Exempts resi- } \\
\text { dential and } \\
\text { commercial } \\
\text { buildings from } \\
\text { advalorem } \\
\text { taxes on con- } \\
\text { servation im- } \\
\text { provements } \\
(1975) \\
\text { Income tax } \\
\text { credits for } \\
\text { expenses in. } \\
\text { curred in } \\
\text { installing res. } \\
\text { energy saving } \\
\text { devices } \\
(1975)\end{array}$ & None & $\begin{array}{l}\text { Income tax } \\
\text { credit for solar } \\
\text { heating and } \\
\text { cooling } \\
\text { systems } \\
(1975)\end{array}$ \\
\hline
\end{tabular}


Table 63.-Residential Energy Conservation Legislation, 1974-77-continued

\begin{tabular}{|c|c|c|c|c|c|c|c|}
\hline State & $\begin{array}{l}\text { Building } \\
\text { standards }\end{array}$ & $\begin{array}{l}\text { Materials } \\
\text { standards }\end{array}$ & $\begin{array}{c}\text { Appliance efficiency } \\
\text { standards }\end{array}$ & $\begin{array}{l}\text { Insulation } \\
\text { programs }\end{array}$ & $\begin{array}{c}\text { Tax } \\
\text { incentives } \\
\end{array}$ & $\begin{array}{l}\text { Uility rate } \\
\text { reform }\end{array}$ & Solar \\
\hline Maine & $\begin{array}{l}\text { Creation of a } \\
\text { commission to } \\
\text { prepare minimum } \\
\text { energy efficiency } \\
\text { bldg. performance } \\
\text { standards }(1977)\end{array}$ & None & None & $\begin{array}{l}\text { Jrovision of funds } \\
\text { or a winterization } \\
\text { rogram for low: } \\
\text { ncome elderly } \\
1977 \text { ) }\end{array}$ & None & $\begin{array}{l}\text { Jirective } \\
\text { o PuC to } \\
\text { imend its } \\
\text { ates o pive } \\
\text { irams to } \\
\text { incourage } \\
\text { inergy con- } \\
\text { rervation } \\
1977 \text { ) }\end{array}$ & None \\
\hline Montana & None & None & None & None & $\begin{array}{l}\text { Income tax } \\
\text { credit for } \\
\text { installation of } \\
\text { a non fossil } \\
\text { fuel energy } \\
\text { system } \\
(1977)\end{array}$ & None & None \\
\hline Pennsylvania & $\begin{array}{l}\text { Authority to regu- } \\
\text { late construction } \\
\text { of all blags, to } \\
\text { ensure energy con- } \\
\text { servation (pending) }\end{array}$ & None & $\begin{array}{l}\text { Requires listing of } \\
\text { energy consumption } \\
\text { information and } \\
\text { average operating } \\
\text { cost of appliances } \\
\text { before sale (1975) } \\
\end{array}$ & None & None & None & $\begin{array}{l}\text { Sales \& use } \\
\text { tax exemp- } \\
\text { tions for solar } \\
\text { materials \& } \\
\text { installation } \\
\text { costs (1975) } \\
\text { Real estate tax } \\
\text { exemptions } \\
\text { for solar } \\
\text { systems } \\
(1975)\end{array}$ \\
\hline $\begin{array}{l}\text { Tennessee } \\
\text { (Incomplete) }\end{array}$ & $\begin{array}{l}\text { Provide for more } \\
\text { efficient utilization } \\
\text { of energy in } \\
\text { buildings }(1976)\end{array}$ & None & $\begin{array}{l}\text { Requires disclosure } \\
\text { of energy consump- } \\
\text { tion \& efficiency } \\
\text { info. of appliances } \\
\{1975)\end{array}$ & $\begin{array}{l}\text { Authorization for } \\
\text { itlities to advertise } \\
\text { i promote res. } \\
\text { nsulation \& to } \\
\text { nstall insulation } \\
1976 \text { ) }\end{array}$ & $\begin{array}{l}\text { Exemption of } \\
\text { energy sav- } \\
\text { ings appli- } \\
\text { ances from } \\
\text { sales and use } \\
\text { tax }\end{array}$ & $\begin{array}{l}\text { Regulation } \\
\text { of utility } \\
\text { rates for } \\
\text { res. users } \\
\text { to provide } \\
\text { a certain } \\
\text { quantity at } \\
\text { low rates } \\
\text { to discour- } \\
\text { age waste } \\
(1976)\end{array}$ & $\begin{array}{l}\text { Property tax } \\
\text { exemption for } \\
\text { solar systems } \\
(1976)\end{array}$ \\
\hline Utah & None & None & None & None & Vone & None & None \\
\hline
\end{tabular}

SOURCE Booz. Allen \& Halm: Hesidential Energv

Office of Techm May 1978 
Table 64.-Residential Energy Conservation Programs'

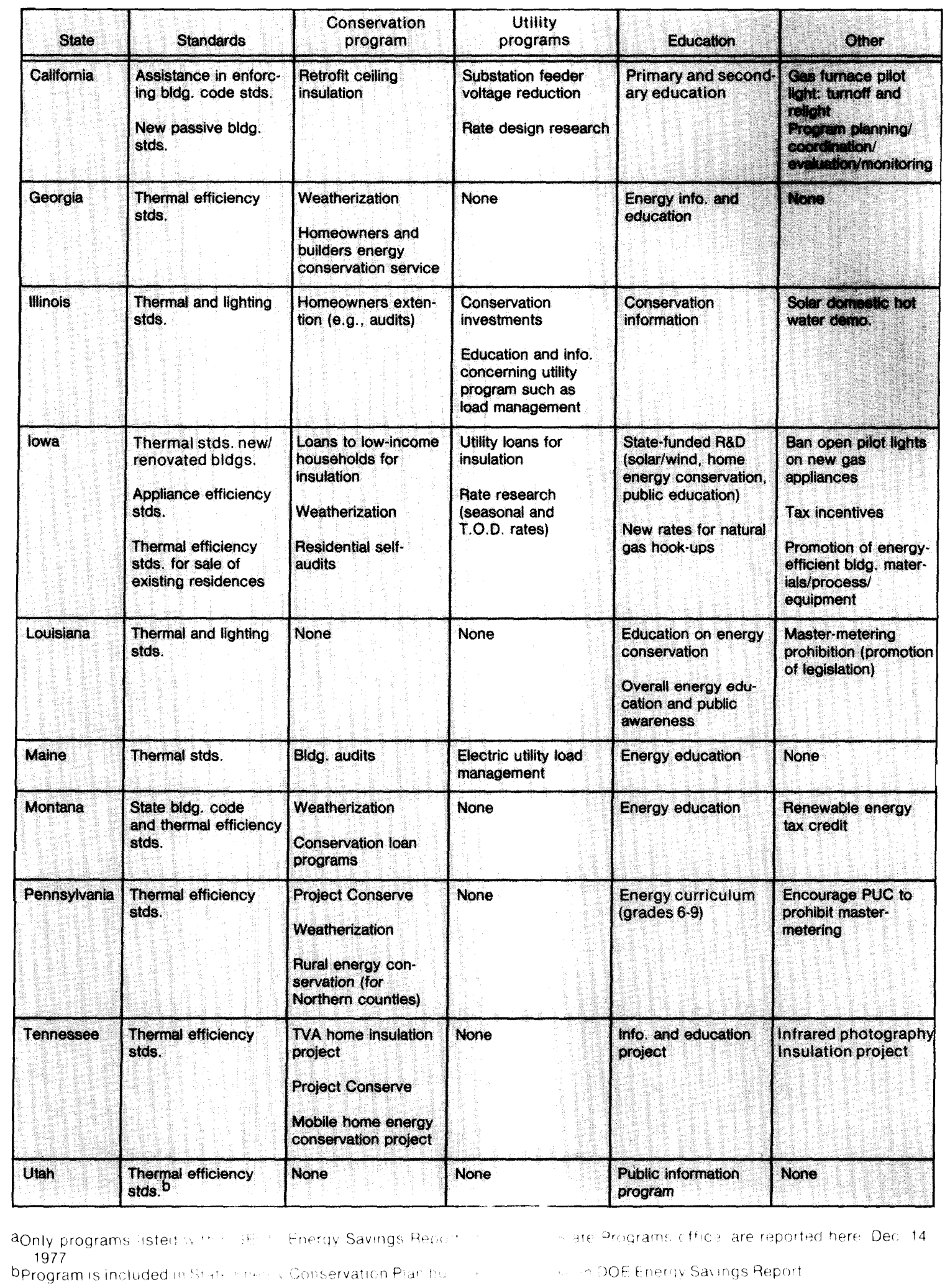


Table 65 -State Issues in Residential Energy Conservation

\begin{tabular}{|c|c|c|c|c|c|c|c|}
\hline State & $\begin{array}{l}\text { Conservation as an } \\
\text { issue (Residential }\end{array}$ & $\begin{array}{l}\text { Energy producer } \\
\text { vs. importer }\end{array}$ & $\begin{array}{c}\text { Intergovernmental } \\
\text { interaction } \\
\text { (\& local interaction }\end{array}$ & $\begin{array}{l}\text { Policymakfng } \\
\text { responsibility } \\
\text { in State gov't }\end{array}$ & $\begin{array}{c}\text { Attitude } \\
\text { toward } \\
\text { Federal program< }\end{array}$ & $\begin{array}{c}\text { Role \& } \\
\text { relationship of } \\
\text { utilities }\end{array}$ & $\begin{array}{l}\text { Programs and } \\
\text { dependence on } \\
\text { Federal }\end{array}$ \\
\hline California & $\begin{array}{l}\text { Conservation is of } \\
\text { primary concern to } \\
\text { Calif. as an energy } \\
\text { issue } \\
\text { - CPUC \& ERCDC } \\
\text { have stated a } \\
\text { policy that con- } \\
\text { servation is the } \\
\text { equiv. of an } \\
\text { alternative } \\
\text { source of supply } \\
\text { of energy } \\
\text { - Very concerned } \\
\text { about finders- } \\
\text { keepers issue } \\
\text { \& natural gas }\end{array}$ & $\begin{array}{l}\text { Energy importer } \\
\text { - Heavily depend- } \\
\text { ent on natural } \\
\text { gas } \\
\text { - Dependent on } \\
\text { supplemental gas } \\
\text { both foreign \& } \\
\text { domestic }\end{array}$ & $\begin{array}{l}\text { There appears to be } \\
\text { extensive cooperation } \\
\text { among the actors in } \\
\text { California although } \\
\text { CPUC \& ERCDC } \\
\text { appear critical of one } \\
\text { other's actions } \\
\text { All agencies appear } \\
\text { committed to the same } \\
\text { goal of achieving max. } \\
\text { conservation \& work } \\
\text { together toward this } \\
\text { goal }\end{array}$ & $\begin{array}{l}\text { Lack of comprehensive } \\
\text { energy policy has } \\
\text { slowed conservation } \\
\text { efforts } \\
\text { Seems that the energy } \\
\text { commission \& legisla- } \\
\text { ture play the key role! } \\
\text { in formation of energy } \\
\text { policy } \\
\text { - very strong energy } \\
\text { commission }\end{array}$ & $\begin{array}{l}\text { Strong belief } \\
\text { among all actors } \\
\text { that the Federal } \\
\text { Government has } \\
\text { not been the im- } \\
\text { petus for Calif. 's } \\
\text { aggressive con- } \\
\text { servation efforts } \\
\text { The State wants } \\
\text { the Fed's not to } \\
\text { preempt } \\
\text { Lack of under- } \\
\text { standing by Feds } \\
\text { of State problems } \\
\text {-lack of cooper- } \\
\text { ation with States } \\
\text { on Important Is- } \\
\text { sues In pursuing } \\
\text { conservation } \\
\text { Feds. can play a } \\
\text { role in setting } \\
\text { materials }\end{array}$ & $\begin{array}{l}\text { Utilities play a key } \\
\text { role in fostering } \\
\text { residential } \\
\text { conservation } \\
\text { PUC extremely } \\
\text { active in pushing } \\
\text { utilities into con- } \\
\text { servation activities } \\
\text { utilities find the } \\
\text { PUC's strong } \\
\text { stance to be bur- } \\
\text { densome at times } \\
\text { PuC has given } \\
\text { utilities incentives } \\
\text { to undertake con- } \\
\text { servation program } \\
\text { by basing rate } \\
\text { relief in part on } \\
\text { conserv. efforts }\end{array}$ & $\begin{array}{l}\text { There is very little } \\
\text { dependence on thi } \\
\text { Feds. for program } \\
\text { support or direc- } \\
\text { tion; Calif. devise } \\
\text { \& operates must } \\
\text { programs by itsel } \\
\text { thru leg. \& } \\
\text { ERCDC }\end{array}$ \\
\hline Georgia & $\begin{array}{l}\text { Energy conserva- } \\
\text { tion does not seem } \\
\text { to be a major issue. } \\
\text { Has been given } \\
\text { relatively little } \\
\text { attention }\end{array}$ & $\begin{array}{l}\text { Georgia is a very } \\
\text { strong energy import- } \\
\text { er; it imports } 97 \% \text { of } \\
\text { its energy. However } \\
\text { Historically low ener- } \\
\text { gy prices \& a mild } \\
\text { climate make it diffi- } \\
\text { cult to convince the } \\
\text { public that conserva- } \\
\text { tion is necessary }\end{array}$ & $\begin{array}{l}\text { There is relatively little } \\
\text { interaction among the } \\
\text { SEO, PSC, and LEG. } \\
\text { PSC focuses on rate } \\
\text { structure and the } \\
\text { legislature considers } \\
\text { energy to be of minor } \\
\text { Importance. Energy is } \\
\text { left, for the most part, } \\
\text { [o the SEO } \\
\text { The GMA (Ga. Munici- } \\
\text { pal Association is an } \\
\text { extremely powerful } \\
\text { body in Ga. \& GPC is } \\
\text { working w/govt. at the } \\
\text { local level to imple- } \\
\text { ment conservation } \\
\text { programs }\end{array}$ & $\begin{array}{l}\text { The Ga. SEO (Office c } \\
\text { Energy Resources) we } \\
\text { created by executive } \\
\text { order \& maintains a } \\
\text { close relationship w/ } \\
\text { the governor Policy } \\
\text { is formulated in the } \\
\text { Governor s office w/ } \\
\text { strong dependence } \\
\text { on the OER }\end{array}$ & $\begin{array}{l}\text { There exists a } \\
\text { positive attitude } \\
\text { w/in Ga. govt. to- } \\
\text { ward Fed, inter- } \\
\text { vention in State } \\
\text { programs. The } \\
\text { OER expressed } \\
\text { the view that the } \\
\text { Fed's are flexi- } \\
\text { ble w/respect to } \\
\text { their program re- } \\
\text { quirements, } \\
\text { even the' they } \\
\text { may not address } \\
\text { the most crucial } \\
\text { energy issues } \\
\text { Some of the sat. } \\
\text { isfaction w/Fed. } \\
\text { Jrograms may } \\
\text { zome from the } \\
\text { lact that many } \\
\text { zurrent Fed. } \\
\text { Jolicymakers } \\
\text { ormerly made } \\
\text { ja.'s State } \\
\text { Jolicy }\end{array}$ & $\begin{array}{l}\text { Utilities in Ga. } \\
\text { esp. GPC) are tak } \\
\text { ing an active role } \\
\text { in encouraging } \\
\text { residential consel } \\
\text { ration throughout } \\
\text { the State. They art } \\
\text { ecieving little } \\
\text { notivation from } \\
\text { he PSC, however. } \\
\text { PSC role is hin- } \\
\text { dered by fact tha } \\
\text { cornmissioners } \\
\text { are elected } \\
\text {-Utilities \& PSC } \\
\text { are more con- } \\
\text { cerned w/rate } \\
\text { reform } \\
\text {-PSC believes } \\
\text { utilities are al- } \\
\text { ready under too } \\
\text { much financial } \\
\text { pressure \& forc- } \\
\text { ing them to un- } \\
\text { dertake addi- } \\
\text { tional programs } \\
\text { would be unwise }\end{array}$ & $\begin{array}{l}\text { OER's annual con- } \\
\text { servation budget } \\
\text { ( } \$ 1.5 \text { million an- } \\
\text { nually) is entirely } \\
\text { federally funded } \\
\text { The State has not } \\
\text { implemented many, } \\
\text { if any, additional } \\
\text { programs } \\
\mathrm{Ga} \text { has a "wait \& } \\
\text { see" attitude con- } \\
\text { cerning Fed. leg. } \\
\text { before implement- } \\
\text { ing a State policy }\end{array}$ \\
\hline Illinois & $\begin{array}{l}\text { Coal conversion \& } \\
\text { exploration, nuclear } \\
\text { waste management } \\
\text { \& disposal are most } \\
\text { important: conser- } \\
\text { vation a secondary } \\
\text { issue }\end{array}$ & None & None & $\begin{array}{l}\text { Division of Energy } \\
\text { ICC in lead (according } \\
\text { to the ICC and Gov- } \\
\text { ernor's Office of } \\
\text { Manpower \& Human } \\
\text { Development) }\end{array}$ & $\begin{array}{l}\text { tate legislature is } \\
\text {; awaiting Fed. } \\
\text { action. State } \\
\text { funding sources } \\
\text { tied to Fed. }\end{array}$ & Vone & $\begin{array}{l}\text { Infrared flyovers } \\
\text { Community devel- } \\
\text { opment awards } \\
\text { Energy efficiency } \\
\text { index for } \\
\text { buildings } \\
\end{array}$ \\
\hline lowa & $\begin{array}{l}\text { Conservation con- } \\
\text { sidered an impor- } \\
\text { ant issue by } \\
\text { government } \\
\text { Other major issues } \\
\text { are: } \\
\text { nuclear facility } \\
\text { siting } \\
\text { Natural gas avail- } \\
\text { ability \& Curtailment } \\
\text { Jtility pricing } \\
\text { solicies } \\
\text { Joal availability } \\
\text { ind usage }\end{array}$ & $\begin{array}{l}\text { Imports } 80-90 \% \text { of } \\
\text { s energy }\end{array}$ & $\begin{array}{l}\text { All agree that } \\
\text { intergovernmental } \\
\text { relationships are } \\
\text { cooperative }\end{array}$ & $\begin{array}{l}\text { All agencies see the } \\
\text { Energy Policy Council } \\
\text { \& the lowa Commerce } \\
\text { Commisslon as major } \\
\text { actors } \\
\text { Secondarily. State } \\
\text { geological survey \& } \\
\text { council on } \\
\text { environmental } \\
\text { quality }\end{array}$ & $\begin{array}{l}\text { Almost all saw } \\
\text { Feds. as not } \\
\text { jaying important } \\
\text { ole in State's } \\
\text { jolicy. Fiercely } \\
\text { ndependent }\end{array}$ & $\begin{array}{l}\text { lelationship of } \\
\text { tilities seen as } \\
\text { lood. They're ex- } \\
\text { eerimenting with } \\
\text { Iternative pricing } \\
\text { tructures (time of } \\
\text { lay), provide insula- } \\
\text { on at } 9 \% \text {, do } \\
\text { 7ermography \& } \\
\text { 2oking into master } \\
\text { letering prohibition }\end{array}$ & $\begin{array}{l}\text { Utllity thermography } \\
\text { Rate structures } \\
\text { Bottle bill } \\
\text { Coal usage study }\end{array}$ \\
\hline
\end{tabular}


「able 65 - - State Issues in Residential f nera Conservation-continued

\begin{tabular}{|c|c|c|c|c|c|c|c|}
\hline State & $\begin{array}{l}\text { Conservation as an } \\
\text { Issue (residential) }\end{array}$ & $\begin{array}{l}\text { Energy producer } \\
\text { vs. Importer }\end{array}$ & $\begin{array}{l}\text { Intergovernmental } \\
\text { interaction } \\
\text { (\& local interaction) }\end{array}$ & $\begin{array}{l}\text { Policymaking } \\
\text { responsibility } \\
\text { in State Gov't }\end{array}$ & $\begin{array}{c}\text { Atutude towara } \\
\text { Federal } \\
\text { programs } \\
\end{array}$ & $\begin{array}{c}\text { Role \& } \\
\text { relationship of } \\
\text { utilities }\end{array}$ & $\begin{array}{l}\text { rivylains anu } \\
\text { lependence on } \\
\text { Federal }\end{array}$ \\
\hline Loulsiana & $\begin{array}{l}\text { Conservation is } \\
\text { Not an issue of } \\
\text { major concern to } \\
\text { La.; the governor } \\
\text { \& legislature are } \\
\text { much more con } \\
\text { cerned with } \\
\text { production } \\
\text { Of primary con } \\
\text { cern to La. is the } \\
\text { deregulation of } \\
\text { gas } \\
\text { Most conservation } \\
\text { efforts have been } \\
\text { directed toward } \\
\text { the industrial \& } \\
\text { governmental sec- } \\
\text { tors since it is } \\
\text { believed that more } \\
\text { energy con be } \\
\text { saved in this area } \\
\text { than in all other } \\
\text { sectors combined } \\
\end{array}$ & $\begin{array}{l}\text { Louisiana is an } \\
\text { energy producer: } \\
\text { La. produces \% of } \\
\text { all gas \& ol pro. } \\
\text { duced in the contig } \\
\text { usue } 4 . \mathrm{S} \text {. }\end{array}$ & $\begin{array}{l}\text { Most interactions } \\
\text { between State agen } \\
\text { cles take place on an } \\
\text { informal basis. The } \\
\text { PsC is more con. } \\
\text { cerned wregulation } \\
\text { than with promotion } \\
\text { of conservation } \\
\text { ocal auronomy in La. } \\
\text { zarishes is very strong } \\
\text { I makes it more } \\
\text { tiftcult to implement } \\
\text { state programs at the } \\
\text { ocal level (e.g. State } \\
\text { vide building code) }\end{array}$ & $\begin{array}{l}\text { nucn energy poicy } \\
\text { naking responsibility is } \\
\text { I result of interaction } \\
\text { retween the legisla- } \\
\text { ure \& Governor }\end{array}$ & $\begin{array}{l}\text { Strong negative } \\
\text { feelings toward } \\
\text { Fed. interven- } \\
\text { tion exist within } \\
\text { La.; Carter's } \\
\text { energy plan } \\
\text { focuses on the } \\
\text { conservation } \\
\text { energy, rather } \\
\text { than on produc. } \\
\text { tion; La believes } \\
\text { that the Fed. } \\
\text { Government } \\
\text { should keep pro. } \\
\text { ducing States in } \\
\text { mind when for. } \\
\text { mulating policy }\end{array}$ & $\begin{array}{l}\text { Utilties in La are } \\
\text { being forced to en- } \\
\text { courage energy } \\
\text { conservation as a } \\
\text { means of compen- } \\
\text { sating for the fact } \\
\text { that they are obtain- } \\
\text { ing almost no rate } \\
\text { reliet from the PSC } \\
\text { Juuves In La: are } \\
\text { seing forced to } \\
\text { iwitch to coal from } \\
\text { il \& gas. } \\
\text { juutes are uncer- } \\
\text { aking conservation } \\
\text { is a shortrun. } \\
\text { neasure to delay } \\
\text { he addition of new } \\
\text { sapacity }\end{array}$ & $\begin{array}{l}\text { pelule reuetai } \\
\text { inds were } \\
\text { tailable, La. } \\
\text { jerated several } \\
\text { tate programs } \\
\text { lat were State- } \\
\text { inded. } \\
\text { a.s conservation } \\
\text { torts are current- } \\
\text { dictated entirely } \\
\text { the Fed. funds } \\
\text { lallable. If Fed. } \\
\text { inds were cut, } \\
\text { 1. would cut its } \\
\text { tograms \& prob- } \\
\text { zly initiate a } \\
\text { naller State- } \\
\text { inded conserva. } \\
\text { on program }\end{array}$ \\
\hline Maine & $\begin{array}{l}\text { Conservation is } \\
\text { primary energy } \\
\text { issue } \\
\text { raunity siltiy abs, } \\
\text { big issue as is } \\
\text { small dam project } \\
\text { t. Dickeyflincoin } \\
\text { ydro facility } \\
\text { Utility rates are a } \\
\text { Jig political issue }\end{array}$ & $\begin{array}{l}\text { Imports much of } \\
\text { energy } \\
75 \% \text { dependent or } \\
\text { oil } \\
\text { Other } 25 \% \text { split } \\
\text { between nuclear } \\
8 \text { hydro }\end{array}$ & 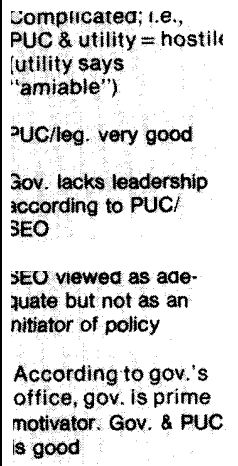 & $\begin{array}{l}\text { nutrracered seu, } \\
\text { JC/leg. active }\end{array}$ & $\begin{array}{l}\text { oen as inace } \\
\text { quate \& inappro- } \\
\text { prlate } \\
\text { No wood policy } \\
\text { tor Maine } \\
\text { Fed responsibil. } \\
\text { Ity in powerplant } \\
\text { siting } \\
\text { supercedes } \\
\text { State policy }\end{array}$ & 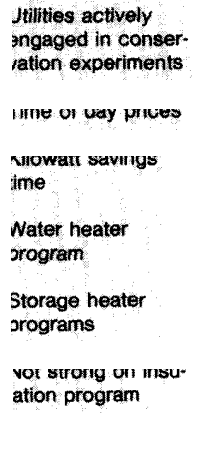 & 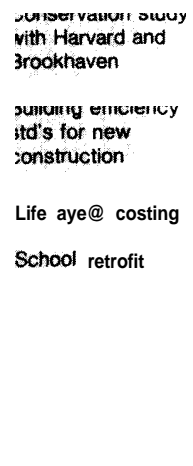 \\
\hline Montana & $\begin{array}{l}\text { Decidely conser } \\
\text { vation is an issue } \\
\text { but population gen- } \\
\text { erally not yet } \\
\text { geared toward } \\
\text { making effort } \\
\text { People more envi } \\
\text { ronmentally aware } \\
\text { than consevation } \\
\text { oriented }\end{array}$ & $\begin{array}{l}\text { Large issue-coal } \\
\text { shipped out of } \\
\text { State or power } \\
\text { generated in State } \\
8 \text { shipped out. Rap } \\
\text { the land or pollute } \\
\text { the air } \& \text { Montanan } \\
\text { get very fittle } \\
80 \% \text { of natural gas } \\
\text { shipped in from } \\
\text { Canada }\end{array}$ & $\begin{array}{l}\text { vot totaly clear, energy } \\
\text { expertise not devel. } \\
\text { jped. PUC does not } \\
\text { nandate }\end{array}$ & $\begin{array}{l}\text { siate energy Unice } \\
\text { \&. Lieutenant Gov's } \\
\text { sfice most active }\end{array}$ & $\begin{array}{l}\text { People want } \\
\text { more } \$ \text { to com- } \\
\text { plete programs } \\
\text { Dont want Fed's } \\
\text { imposing gen. } \\
\text { aral conservation } \\
\text { programs upon } \\
\text { Montana }\end{array}$ & $\begin{array}{l}\text { rou now peginning } \\
\text { to assess load } \\
\text { requirements \& } \\
\text { establish data } \\
\text { base } \\
\text { Utilities not involved } \\
\text { extensively in } \\
\text { conservation }\end{array}$ & $\begin{array}{l}\text { wal tax } \\
\text { creculcicy } \\
\text { jeneration and } \\
\text { snvironmental } \\
\text { safety }\end{array}$ \\
\hline Pennsylvania & $\begin{array}{l}\text { Coal conversion \& } \\
\text { protection of envi } \\
\text { ronment very im } \\
\text { portant } \\
\text { Price \& availability } \\
\text { of gas \& oil } \\
\text { Problem of environ- } \\
\text { mental spillover } \\
\text { from } N . Y . \& \text { Ohio } \\
\text { Price of natural gas } \\
\text { has forced reduced } \\
\text { consumption of } \\
10-12 \%\end{array}$ & $\begin{array}{l}\text { Energy producer - } \\
\text { coal primarily }\end{array}$ & $\begin{array}{l}\text { Seemingly good Statt } \\
\text { agency interaction. } \\
\text { Energy policy council } \\
\text { attached to Gover. } \\
\text { nor's office } \\
\text { PuC is independent } 8 \\
\text { its relations are de- } \\
\text { sent but adversary at } \\
\text { limes due to identify. } \\
\text { ing issues different } \\
\text { than energy council's } \\
\text { Little interaction be- } \\
\text { lween State and local } \\
\text { gov'ts }\end{array}$ & $\begin{array}{l}\text { jovernor } \\
\text { egislature (House } \\
\text { Snergy \& Environment } \\
\text { i Committee) } \\
\text { Energy council }\end{array}$ & $\begin{array}{l}\text { Fod. regulation of } \\
\text { natural gas pipe- } \\
\text { lines to allocate } \\
\text { curtailment most } \\
\text { significant issue }\end{array}$ & $\begin{array}{l}\text { ruU maanxans } \\
\text { utility sponsored } \\
\text { conservation pro- } \\
\text { grams. PUC man- } \\
\text { dates utilities' } \\
\text { conservation pro- } \\
\text { Jrams. PUC deter- } \\
\text { mined that } 80-90 \% \\
\text { customers need } \\
\text { some thermal } \\
\text { improvements }\end{array}$ & Jone \\
\hline
\end{tabular}


Table 65. - State Issues in Residential Ene gy Conservation-continued

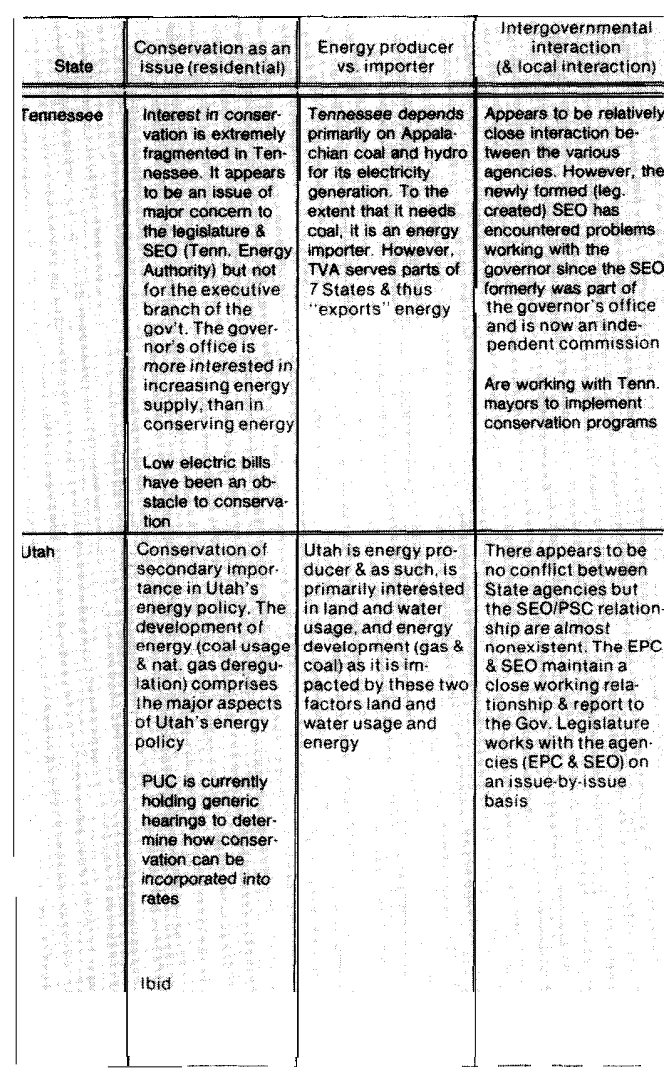

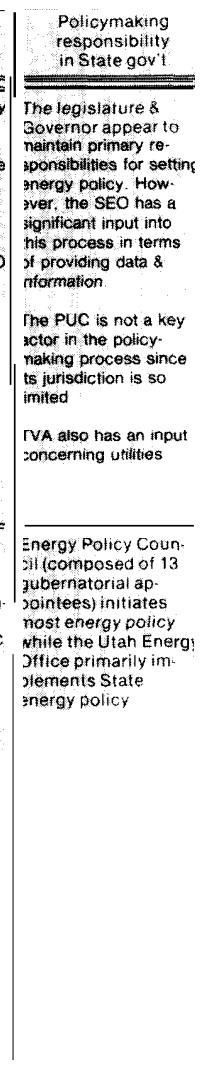

\begin{tabular}{|c|c|c|}
\hline $\begin{array}{c}\text { Attifucte toward } \\
\text { Federal } \\
\text { pfograms }\end{array}$ & $\begin{array}{l}\text { Role \& } \\
\text { relationship of } \\
\text { utilities }\end{array}$ & $\begin{array}{l}\text { Programs and } \\
\text { dependence on } \\
\text { Federal }\end{array}$ \\
\hline $\begin{array}{l}\text { Tennesse is } \\
\text { Unique in that TVA } \\
\text { supplies much of } \\
\text { its power needs } \\
\text { and TVA is Fed } \\
\text { operated. To this } \\
\text { extent. Fed. } \\
\text { actions heve a } \\
\text { major inpact on } \\
\text { Tenn.s energy } \\
\text { situation } \\
\text { With respect to } \\
\text { conservation. } \\
\text { Tenn would pre } \\
\text { fer to set its own } \\
\text { State programs } \\
\text { while stitifeceiv. } \\
\text { ing funding from } \\
\text { the Fed. Gov't. }\end{array}$ & $\begin{array}{l}\text { Most utilities in } \\
\text { Tesn are regulated } \\
\text { oy TVA. TVA has a } \\
\text { res. insulation pro- } \\
\text { gram in operation \& } \\
\text { thus impacts most } \\
\text { utilities in the State } \\
\text { TVA betieves it is } \\
\text { important to pro } \\
\text { mote conservation } \\
\text { and thus sets the } \\
\text { policy for all utilities } \\
\text { tnder its furisdic- } \\
\text { ton }\end{array}$ & $\begin{array}{l}\text { Tenn's. conserva- } \\
\text { tion programs are } \\
\text { almost exclusively } \\
\text { Fed tunded. The } \\
\text { SEO believes that } \\
\text { the } \$ 2 \text { million pro- } \\
\text { vided by the Feds } \\
\text { annually is sufti- } \\
\text { cient. These pro } \\
\text { grams include the } \\
\text { FEA mandated } \\
\text { plan \& EES }\end{array}$ \\
\hline $\begin{array}{l}\text { Utah feels that } \\
\text { the Fed Gov has } \\
\text { infringed upon } \\
\text { Utar's land usage } \\
\text { rights \& does no } \\
\text { allow Utah enough } \\
\text { voice in land use } \\
\text { \& thus energy de } \\
\text { velopment policy. } \\
\text { Land and water } \\
\text { use dominate } \\
\text { Utah's energy } \\
\text { policy. However. } \\
\text { the State has } \\
\text { adopted a wait \& } \\
\text { see' attitude } \\
\text { toward the devel } \\
\text { opment of Fed } \\
\text { legislation } 8 \\
\text { policy, before } \\
\text { pursuing its own } \\
\text { energy conser } \\
\text { vation policy }\end{array}$ & 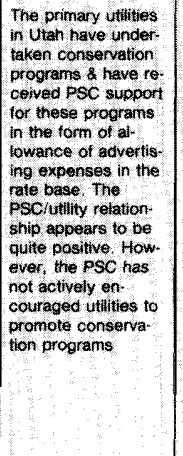 & $\begin{array}{l}\text { SEO has not in } \\
\text { plemented any } \\
\text { programs beyond } \\
\text { those mandated by } \\
\text { FEA These } \\
\text { programs were } \\
\text { termed sufticient } \\
\text { by the Energy } \\
\text { ottice to achieve } \\
\text { Utah's energy } \\
\text { goats } \\
\text { SEO has a } \\
\text { wait \& see } \\
\text { attitude toward } \\
\text { Fed, policymaking }\end{array}$ \\
\hline
\end{tabular}

\section{FEDERAL ENERGY POLICY LEADERSHIP AND FEDERAL FUNDS FOR STATE ENERGY CONSERVATION PROGRAMS WILL CONTINUE TO BE NECESSARY TO STIMULATE MANY STATE AC TIV TIES}

Most States look to the Federal jovernment for energy policy leadershi: the national character of the Nation's enersy problems and the strong indication that congres intends to act in this area are two subutantid: reasons for States to approach State enter moblems judiciously. State legislators ofte: hertate to an ticipate congressional action federal inaction in establishing a nationa onerge policy was often blamed by State offic $1 d$, fin decreasing consumer credence in the enerys insis, and for delaying the belief in a neet it state programs. Several officials indi dted their colleagues preferred to dew the mseleves to issues that would not be preen th. the Federal a. anetheless, State decisionmakers are 1. . rent to Federal policy. They seek. the wat gional and quasipolitical organiza$t i$ is Vational Conference of State $10,1.51$ to influence Federal decision$r$ the design of flexible policies that w w , specific needs of individual States

111. Hso lack sufficient human and fiscal rian * o perform detailed energy analyses an $4, t$ er hnical evaluations of such areas a die tandards. This too, causes most

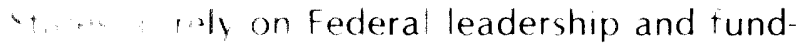
energi offices usually have small the other hand public service com- 
missions, which may have many employees, have generally not devoted themselves to questions beyond ratemaking. States appear to have trouble stimulating public support for increased State energy research funding. Most of the individuals interviewed suggested it would be imprudent for the State either to duplicate Federal analytical efforts or the ability of Federal laboratories to perform technical research. This viewpoint has its notable exceptions: California, for example, has established a large agency in addition to the existing Public Utilities Commission. The agency has been charged with conducting research and developing material, building, and appliance standards, as well as performing independent energy forecasting. One of the largest energyproducing States, Texas, has garnered sufficient revenue from energy expiration activities to be able to invest State money in seeking solutions to State energy problems.

Federal funding is a mainstay of State conservation programs. Without this support many States would be limited in their programs. Most States provide some contribution to conservation programs; some- like Colorado - rely on Federal funds. Federal legisia- tion has been the prime motivation for the development of conservation programs in most States.

Two other aspects of Federal action are of concern to States: program flexibility and technical assistance. States want Federal programs to provide sufficient flexibility to accommodate individual State needs. States view guidelines more favorably than strict standards, for example. States are also receptive to technical assistance from the Federal Government. Georgia officials suggested that the lack of technical staff to develop lighting standards could be accommodated by Federal technical support. Only in Minnesota was it determined that DOE had provided someone to assist with conservation program design. Although Federal assistance in both manpower and funding are desirable from the State viewpoint, most State officials interviewed were critical of the accountability requirements, which involve a significant amount of paperwork. These officials felt that Federal reporting procedures were an unreasonable burden given the number of persons and amount of time required to comply with Federal procedures.

\section{WELL-DEFINED STATE ENERGY POLICY HAS NOT EMERGED}

Many States can reach political consensus on nonenergy matters, such as education, and present that consensus to Federal decisionmakers. In such cases, it is quite clear what a State wants from Washington. But with energy, no State has developed well-defined, comprehensive programs and policies. In some in- stances, States have been able to coalesce their concerns on some (but not all) issues, such as California's position on the importance of liquefied natural gas, Texas' views on natural gas deregulation, or Pennsylvania's stand on coal extraction. But these are the exceptions.

\section{ENERGY PRODUCTION IS THE PREDOMINANT CONCERN OF ENERGY-RICH STATES}

States with large reserves of coal, oil, or gas are far more concerned with production than conservation. Moreover, States with plentiful resources desire to exploit and maintain State discretion over allocation. Thus, Louisiana disagrees with policies requiring it to distribute gas out of the State and convert some users to coal. I n contrast, States that must import energy perceive domestic energy resources as a national resource, rather than a State commodity. These States, such as Maine and Georgia, want to ensure that domestic energy products are equitably distributed. 


\section{NEW STATE ORGANIZATIONS ARE EMERGING TO GRAPPLE WITH CURRENT ENERGY PROBLEMS}

Many organizations play a role in State energy policymaking. These bodies may create new laws or rules to suit existing authority. The Governors, legislatures, and public service commissions are traditional participants in energy policy formulation. However, these organizations have accumulated new duties or new considerations for the conduct of their activities. Others have begun to consider issues previously left to administrative agencies, private enterprise, or the Federal Government. The functional relationships between these expanding and new organizations are not fully established. Uncertainty may disappear as Federal policy becomes established, State entities gather more experience, and as issues become more clearly defined for State, local, and Federal decisionmakers. Meanwhile, State decisionmakers may tend to defer difficult issues for study, or to shift highly sensitive issues to other decision makers (e. g., the Federal Government). Moreover, State energy policy will continue to be developed on a case-bycase basis.
State Energy Off ices (SEOs) and Public Service Commissions (PSCs) share responsibility for the conduct and implementation of conservation programs. The PSC utility regulatory responsibility and the SEO role in residential energy conservation programs provide a basis for interaction between these two State agencies. It is not uncommon, however, to find these agencies communicating very little with one another. PSCs are addressing the subject of rate reform and encouraging voluntary participation by utilities in energy conservation. SEOs, on the other hand, are primarily responsible for developing and implementing energy conservation programs. Many proposed SEO programs promote utility involvement in informing customers of conservation options, providing audits and, in some cases, financing. The lack of coordination between PSCs and SEOs can be a problem for utilities as well as consumers.

\section{INFORMATION FLOW FROM FEDERAL TO STATE AND FROM STATE TO STATE GOVERNMENT REQUIRES ATTENTION}

Though Federal agencies gather a lot of information, States have limited access to and benefit from this information. State officials reported their inability to secure information that they believed would be useful. No Federal effort was identified to discern State needs and uses for federally derived information.

The same informational problems exist among States. Thus, each State must address a problem from scratch, without significant benefit from previous similar efforts at the Federal level or in other States. Information must be disseminated. The Energy Extension Service and the Solar Heating and Cooling Information Center are examples of ways to do this. The Extension Service is designed to work with individuals and organizations to define problem areas and to provide informational and technical assistance. The Information Center is a federally funded repository for information on specific issues available to anyone who desires it. More trained individuals who can work directly with groups are needed. 


\section{STATE LEGISLATURES HAVE FOCUSED ON SEVEN MAJOR ISSUES IN ENERGY CONSERVATION}

- Thermal efficiency standards. States are required to develop thermal efficiency standards in order to receive funds for SECP. In some cases, this may be done administratively (as in Massachusetts); in others new legislation is required. Most of the State effort here has been to adopt directly or to model one of three model codes, American Society of Heating, Refrigeration, and Air Conditioning Engineers 90-75, National Conference of States on Building Codes and Standards, or the Department of Housing and Urban Development (HUD) minimum property standards. Twenty-six States have the legislative authority to establish energy conservation standards for new buildings. Twenty-one States have authority to establish standards for all new buildings, and one State, Washington, has authority to establish residential standards only. One more State, New York, has administrative authority to set standards for homes. Only six States have explicit legislative authority to enforce the standards when local jurisdictions do not. Enforcement has traditionally been a local, voluntary choice. State legislation has been introduced to adopt one of the approved codes, usually in a modified form as part of a State building code. I $\mathrm{n}$ many cases, proposed thermal efficiency code legislation refines existing law, such as in Tennessee and California.

- California has adopted insulation material standards; several other States have con- sidered similar legislation. States have not moved ahead strongly and appear to be waiting for Federal action.

- Minnesota and California have enacted appliance efficiency standards. Pennsylvania and Tennessee require disclosure information to assist consumers in selecting energy-efficient appliances. Here, too, most States are deferring to Federal action.

- Insulation programs have been enacted in 4 of the 10 States studied. Many other States have passed similar legislation. Most of the legislation authorizes State expenditures for weatherization for lowincome and elderly homeowners. In California, the legislature directed the Public Utilities Commission to authorize utility insulation and financing programs.

- Tax incentives to encourage homeowner conservation are being considered by lowa, Missouri, and Nevada. Alaska has made a \$200 tax credit available since 1977.

- Utility rate reform has been a major issue in most States. Maine, Tennessee, and California have enacted legislation requiring consideration of conservation rates by the State PSCs.

- Solar energy has been a popular legislative topic. Many States have passed or considered legislation on sun rights, tax credits, and solar system testing. Most States view the use of solar energy as an element of conservation policy. 


\section{FOUR RESIDENTIAL ENERGY CONSERVATION PROGRAMS SERVE AS THE FOUNDATION OF STATE EFFORTS}

States have emphasized four programs in residential energy conservation.

- Consumer education-The complexity of energy issues may be the most significant obstacle to motivating consumer action in conservation. States have placed much emphasis on the development of consumer education materials and programs.

- Weatherization programs-These programs were initially sponsored by FEA. State conservation plans have, in many instances, provided for the continuation of these programs. In some cases, State funds have been used to augment the Federal allocations. Weatherization programs have received the most Federal energy conservation dollars.
- Energy audits-Utility-sponsored audits have been one of the most successful and widely used programs. Audits have been instrumental in the encouragement of retrofit insulation activities by homeowners.

- Insulation retrofit- State energy office media presentations and utility bill-stuffers have provided strong motivation for consumer participation in retrofit programs. Many consumers are financing their retrofits through the utilities.

Besides these four programs, a few States have studied the need for State-determined heating, ventilating, and air-conditioning standards and for time-of-sale insulation requirements. Neither of these issues has received sufficient support to warrant State programs.

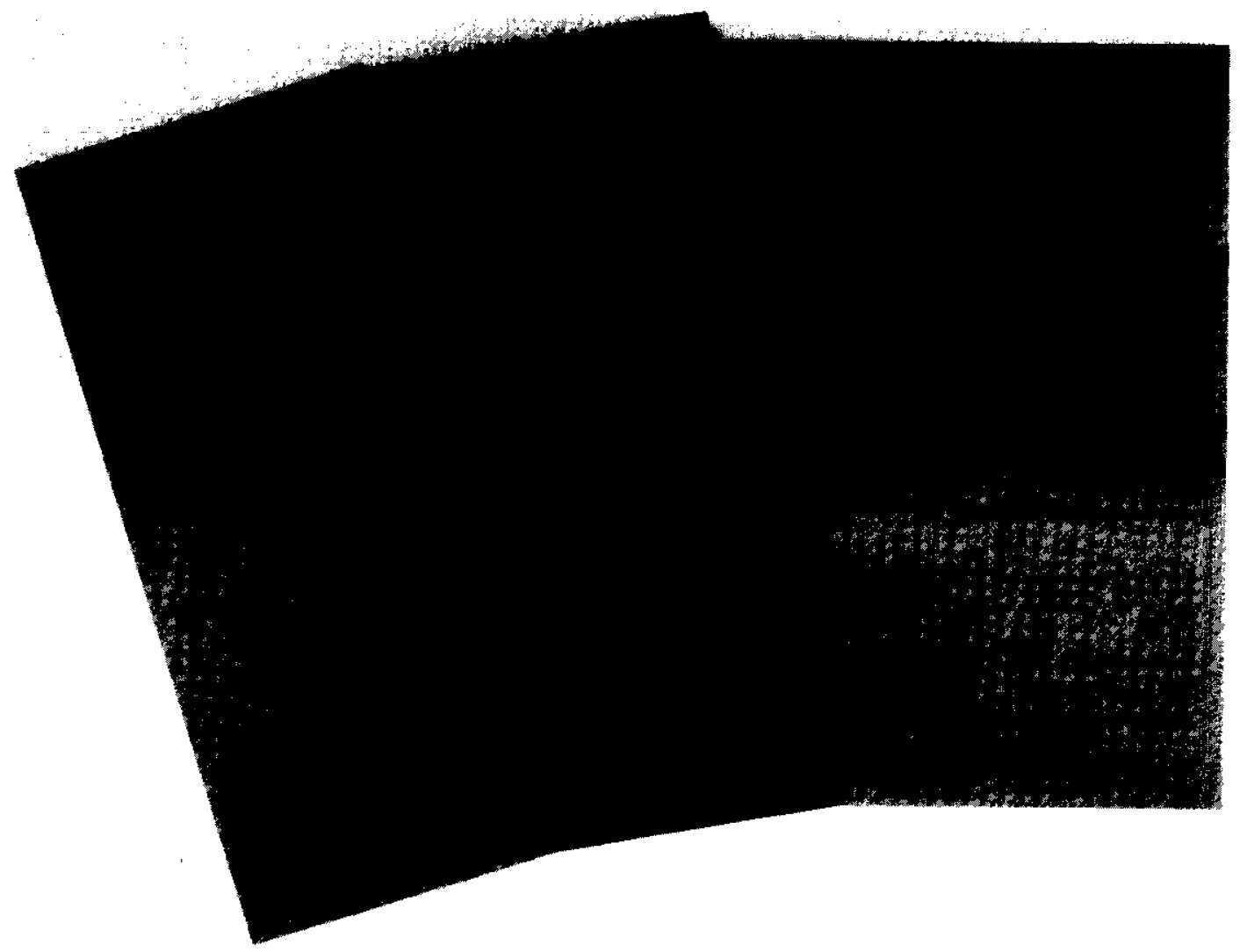

Educating the consumer on energy conservation through brochures and bill stuffers is being undertaken by States and utilities 


\section{Chapter VIII FEDERAL GOVERNMENT AND ENERGY CONSERVATION}

\section{Chapter VIII._FEDERAL GOVERNMENT AND ENERGY CONSERVATION}

Introduction $\ldots . . . . . . . . .167$

Department of Housing and Urban Development

Housing Programs Directed to Low-

and Moderate-Income Families . . . . 169

Low-Rent Public Housing . . . . . . . 169

Section 8 Low-Income Rental

Assistance . . . . . . . . . . , 170

Section 236 Rental and Cooperative Housing Assistance for Lower Income Families . . . . . . . . . 171

Section 202 Direct Loans for Elderly and Handicapped Housing . . . . 171

Section 312 Rehabilitation Loans .. 171

Section 235 Homeownership Assistance for Low- and Moderate-income Families.

Conservation Policies and opportunities . . . . . . .........172

Public Housing . . , . . . . . . . . .. 172

Section 8, Section 202, and Section 236 Projects. . . . . . . . . . ....173

Section 312 Rehabilitation Loans .. 174

Section 235 Homes . . . . . . . . . . 174

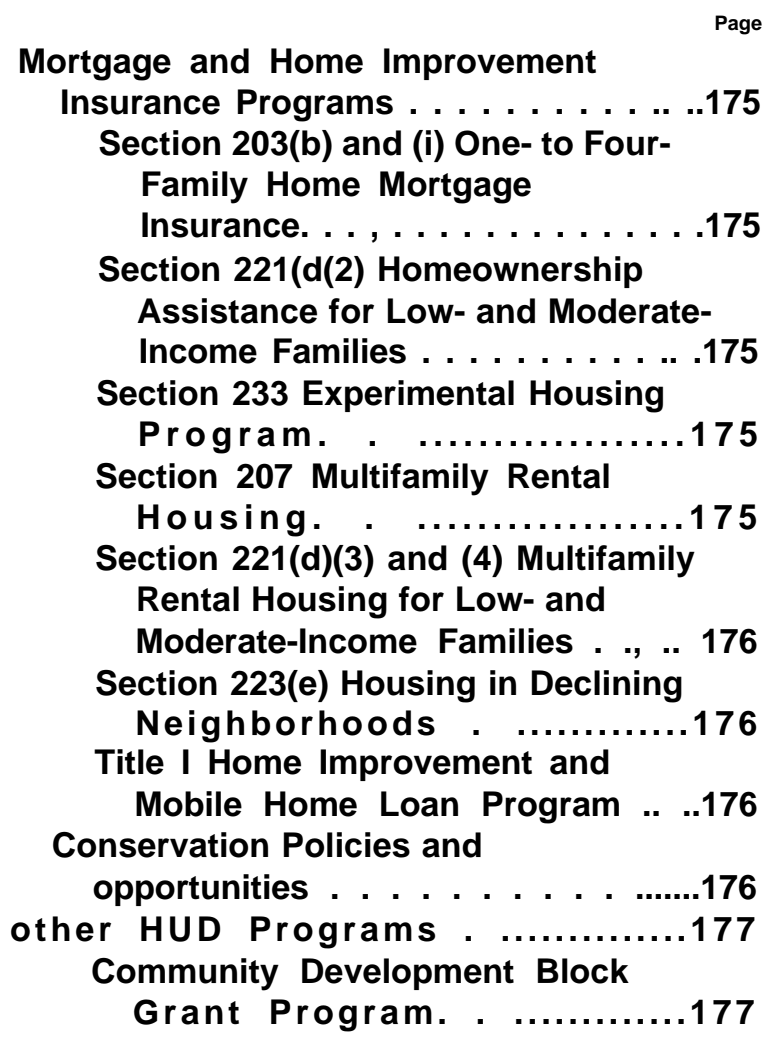

Mortgage and Home Improvement Insurance Programs . . . . . . . . . ...175

Section 203(b) and (i) One- to FourFamily Home Mortgage Insurance. . . . . . . . . . . . . . 175

Section 221(d(2) Homeownership Assistance for Low- and ModerateIncome Families . . . . . . . . . .175

Section 233 Experimental Housing Program.

Page

Section 207 Multifamily Rental Housing. . .175

Section 221(d)(3) and (4) Multifamily Rental Housing for Low- and Moderate-Income Families . ., .. 176

Section 223(e) Housing in Declining Neighborhoods . ............176

Title I Home Improvement and Mobile Home Loan Program .. ..176

Conservation Policies and opportunities . . . . . . . .......176

other HUD Programs . ............177

Community Development Block Grant Program. 
Acquired Property Management and Disposition . . . . . . . . .......178

GNMA Guaranteed Mortgage-Backed Securities and Special Assistance Mortgage Purchases . . . .. ....178

Research and Demonstration Projects . . . . . . . . . . . ....178

Minimum Property Housing Standards

Conservation Policies and Opportunities . . . . . . . . . . . 179

Community Development Block Grant Program.

Acquired Property Management and Disposition . ...............180 Government National Mortgage Corporation. . ..............181

Minimum Property Standards .. ...181

Farmers Home Administration . . . . . . .. .181

Section 502 Homeownership Loan

Program. . . . . . . . . . . . . 182

Section 504 Home Repair Loan and

Grant Programs. . ............182

Section 515 Rural Rent and Cooperative

Housing Loans. . . . . . . . . . . . 182

Conservation Policies and Opportunities 182

Veterans Administration. . . . . . . . . . . 184

VA Loan Guarantee and Direct Loan

Programs. . . . . . . . . . . . . . . . 184

Conservation Policies and Opportunities 184

Other Federal Departments and Programs .185

CSA Emergency Energy Conservation

Program. . . . . . . . . . . . . 185

DOE Weatherization Assistance

Program. . . . . . . . . . . . .185

DOE Division of Buildings and

Community Systems . . . . . .....186

DOE Obligations Guarantee Program. 186

Department of Defense. . . . . . . ...186

Treasury Department: Tax Policy . .. .187

Conservation Policies and

Opportunities . . . . . . . . ..........187

Housing Secondary Mortgage Market and

Regulatory Agencies . . . . . . . . . . 187

Regulatory Agencies. . . . . . . . . . . . . . . . . . . . .

Federal Home Loan Bank Board .. .188

Federal Deposit Insurance

Corporation. . . . . . . . ......188

Conservation Policy and

Opportunities . ..............188

Secondary Mortgage Market . ........188

Federal National Mortgage

Association . . . . . . . . . .. 189
Federal Home Loan Mortgage

Corporation . . . . . . . . . . . 89

Conservation Policies and

Opportunities ........... 189

Energy Conservation and Federal Tax

Policy . . . . . . . . . . . . . . . . . . 190

Present Law (Prior to the Energy Tax Act of 1978) . . . . . . . . . . . . . . . . 190

1 he Effect of Present Law on Energy

Conservation. . ...............191

1 he Energy Tax Act of $1978 \ldots \ldots \ldots .191$

Further Changes to Encourage Energy

Conservation Expenditures . . . . . . . 192

Investment Tax Credit. . . ., . .........193

Rapid Amortization . . . . . . . . . . . 193

Conservation R\&D Activities, Office of

Conservation and Solar Applications,

Department of Energy. . . . . . . . . . 194

Program Objective and Strategy. . . . . 194

Budget Allocation. . . . . . . . . . . . . . 194

Activities of the Buildings and

Community Systems Program . ......196

Program Evaluation . . . . . . . . . . . . . 197

Conclusion . . . . . . . . . . . . . . . . . . 199

Standards and Codes . .............200

Minimum Property Standards. . .......200

Farmers Home Administration Thermal

Performance Standards. . ........202

Model Code for Energy Conservation in

New Buildings . ................203

Building Energy Performance Standards. 204

\section{TABLES}

66. Federal Housing Programs Delivery Systems. . . . . . . . . . . . . . . . ...168

67. New Privately Owned and Publicly Owned Housing Units Started, Including Farm Housing, 1977. . . . . . . . . . . 169

68. New Privately Owned Housing Units Started by Type of Financing 1977 .. ..169

69. Originations of Long-Term Mortgage Loans 1977 . . . . . . . . . . . . . . . . . 187

70 Net Acquisitions of Long-Term Mortgage Loans on Residential Properties by Lender Groups. . . . . . . . . . . . . . . 188

71. FY 1979 Budget Estimates for Residential and Commercial Components of DOE's Conservation Mission . . . . . . . . . . . 196

72. FY 1979 Budget Estimates for DOE Energy R\&D. . . . . . . . . . . . . . .196 


\section{FEDERAL GOVERNMENT AND ENERGY CONSERVATION}

\section{INTRODUCTION}

The Federal Government exerts substantial influence on the character of the Nation's existing housing and on the location, type, and level of new construction activity. It would be logical to conclude that Washington is thus a leader in the drive for energy conservation in residential housing. But the Federal record is a mixed one. The Federal Government has not developed a coordinated or standardized policy to encourage residential energy conservation. The level of interest in promoting conservation varies by agency and program. Although there is evidence of greater concern and sensitivity about conservation by Federal agencies and important additional legislative authority was enacted in 1978, there are opportunities for accelerating conservation and for developing more systematic agencywide approaches.

This section of the report examines the major Federal agencies involved in housing and energy conservation and reviews what they are doing or could do to promote conservation. The important conservation-related programs are described in terms of their key features, authorization, and program activity. How these programs and activities affect lending institutions, the building industry, State and local governments, and property owners-and how they influence the knowledge and awareness of all of these sectors about energy conservation - is explained.

The Federal Government has been actively involved in promoting the objective of "a decent home and a suitable living environment" for all Americans through a variety of housing programs and regulatory activities. The Department of Housing and Urban Development (HUD), the Farmers Home Administration (FmHA) of the Department of Agriculture (USDA), the Veterans Administration (VA), and the agencies that regulate lending institutions are the major Federal agencies bearing on the housing industry. Federal activities are directed to lenders, property owners, developers, and lower income tenants and homeowners, Types of activity and assistance include:

- loan insurance for private lenders;

- subsidies to lower income families and owners of lower income housing projects;

- direct Government loans to property owners;

- establishment of construction standards;

- grants to local Government for housing infrastructure;
- demonstration projects to pioneer new approaches;

- research related to residential buildings;

- regulation of housing, financing, and market support activities; and

- direct construction and ownership of housing (by the Department of Defense (DOD)).

Federal assistance involves a number of Federal agencies and programs, private lenders, and State and local governments. Table 66 illustrates the fragmented nature of the delivery system. The types of lenders and agencies differ depending on the type of construction and the housing occupants.

For all of its regulations and standardswhich do affect general housing activities the direct Federal role in housing development is relatively small in relation to nonfederally assisted housing. (The exceptions are lowincome housing development and providing mortgage insurance or guarantees for the 
Table 66.-Federal Housing Programs Delivery Systems

\begin{tabular}{|c|c|}
\hline $\begin{array}{l}\text { Number of } f \\
\text { participating }\end{array}$ & $\begin{array}{l}\text { Id offices/ } \\
\text { estitution: }\end{array}$ \\
\hline 1. Federal agencies & \\
\hline $\begin{array}{l}\text { HUD } \\
\quad \text { Area/insuring offices } \ldots \ldots \ldots \ldots \ldots \ldots \ldots \\
\quad \text { Regional offices } \ldots \ldots \ldots \ldots \ldots \ldots\end{array}$ & $\begin{array}{l}76 \\
10\end{array}$ \\
\hline $\begin{array}{l}\text { FmHA } \\
\quad \text { County offices. } \ldots \ldots \ldots \ldots \ldots \ldots \ldots \\
\quad \text { FNMA regional offices. } \ldots \ldots \ldots \ldots \ldots\end{array}$ & $\begin{array}{r}1,760 \\
5\end{array}$ \\
\hline $\begin{array}{l}\text { VA } \\
\quad \text { Regional offices } \ldots \ldots \ldots \ldots \ldots \ldots \ldots \\
\text { Federal Home Loan Bank Board } \\
\quad \text { Regional banks } \ldots \ldots \ldots \ldots \ldots \ldots \ldots\end{array}$ & 49 \\
\hline $\begin{array}{l}\text { 2. State and local government agencies } \\
\text { States } \\
\text { State housing agencies } \ldots \ldots \ldots \ldots \ldots \text {. }\end{array}$ & \\
\hline $\begin{array}{l}\text { Local government agencies } \\
\text { CDBG recipients. } \ldots \ldots \ldots \ldots \ldots \ldots \\
\text { CDBG recipients proposing housing } / \\
\text { rehab type programs. } \ldots \ldots \ldots \ldots \ldots \ldots \\
\text { Section } 312 \text { agencies } \ldots \ldots \ldots \ldots \ldots \ldots\end{array}$ & $\begin{array}{r}3,200 \\
1,470 \\
200-250\end{array}$ \\
\hline 3. Private institutions (categories overlap) & \\
\hline 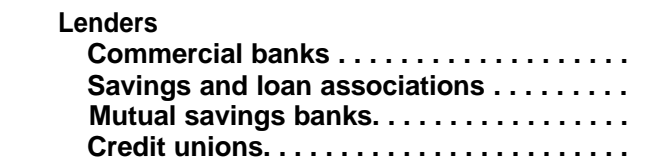 & $\begin{array}{r}14,697 \\
4,858 \\
473 \\
22,421\end{array}$ \\
\hline 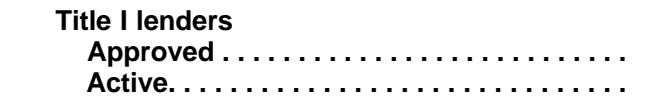 & $\begin{array}{r}10,000 \\
4,600\end{array}$ \\
\hline 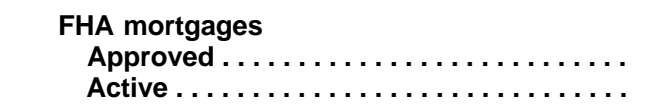 & $\begin{array}{r}11,700 \\
7,500\end{array}$ \\
\hline 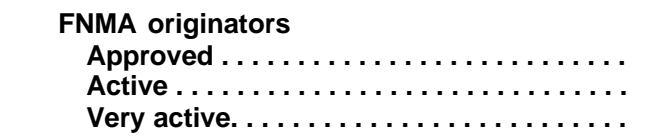 & $\begin{array}{r}3,000 \\
1,500 \\
400-500\end{array}$ \\
\hline $\begin{array}{l}\text { FHLMC originators } \\
\quad \text { Federally supervised savings } \& \text { loans.... } \\
\text { Active } \ldots \ldots \ldots \ldots \ldots \ldots \ldots \ldots \ldots \ldots \ldots\end{array}$ & $\begin{array}{l}2,048 \\
1,400\end{array}$ \\
\hline $\begin{array}{l}\text { GNMA originators } \\
\text { Approved (all are FNMA approved } \\
\quad \text { originators) } \ldots \ldots \ldots \ldots \ldots \ldots \ldots \ldots\end{array}$ & 1,000 \\
\hline $\begin{array}{l}\text { VA mortgages } \\
\quad \text { No approval system } \ldots \ldots \ldots \ldots \ldots \ldots\end{array}$ & NA \\
\hline
\end{tabular}

SOURCE: Rupi, Federal incentives for Solar Homes, 1977, table IV.7. National Association of Mutual Savings Banks, 1977 National Factbook of MutualSavings Banks, 1977, p. 12. lower end of the market.) Publicly owned housing is a small fraction of new construction starts as table 67 shows.

Most housing is built and financed without Federal assistance. [n 1977 only one in six privately owned housing starts were insured by HUD's Federal Housing Administration (FHA) or guaranteed by VA (table 68). FmHa financed an additional 126,000 units. Federally assisted housing totaled 435,000 units or 22 percent of all starts in 1977.

Even though most housing is conventionally financed and developed without direct Federal assistance, the Federal Government's influence on housing is significant and its role in promoting energy conservation can be important. Whether or not energy conservation is made a priority concern, Federal housing programs and policies affect residential energy conservation. In assisting in the development, maintenance, and financing of housing, the Federal Government is in a position to influence directly and indirectly the thermal characteristics of a significant portion of the existing housing inventory and plans for new construct ion.

In terms of reducing energy consumption, the Federal Government has an opportunity not only to promote energy conservation through requiring high thermal standards for newly constructed federally assisted housing or by retrofitting existing structures in which HUD has an interest, but it can also promote the adoption of energy conservation standards in State building codes and encourage mortgage lenders and secondary market mortgage purchasers to consider energy costs and the energy conservation characteristics of residential properties they finance. These latter activities could have a larger impact on the housing sector than many more direct Federal housing support activities. But as the following examination of agencies and programs indicates, conservation may be given inadequate priority in Federal programs and in funding decisions. 
Table 67.-New Privately Owned and Publicly Owned Housing Units Started, Including Farm Housing, 1977 (in thousands)

\begin{tabular}{|c|c|c|c|c|c|c|c|}
\hline & \multirow[b]{2}{*}{ Total } & \multicolumn{4}{|c|}{ Type of structure } & \multirow{2}{*}{$\begin{array}{l}\text { Inside } \\
\text { SMSAS }\end{array}$} & \multirow{2}{*}{$\begin{array}{c}\text { Outside } \\
\text { SMAS }\end{array}$} \\
\hline & & 1 unit & 2 units & 3 to 4 units & 5 units or more & & \\
\hline Total .......... & 1,990 & 1,452 & 61 & 61 & 415 & 1,378 & 612 \\
\hline Privately owned. & 1,987 & 1,451 & 61 & 61 & 414 & 1,377 & 610 \\
\hline Publicly owned. & 3 & 1 & - & -- & 1 & 1 & 2 \\
\hline
\end{tabular}

NOTE: Figures may not total due to rounding.

SOURCE: HUD Office of Housing Statistics.

Table 68.-New Privately Owned Housing Units Started by Type of Financing 1977 (in thousands)

\begin{tabular}{|c|c|}
\hline Number of housing units & Number \\
\hline 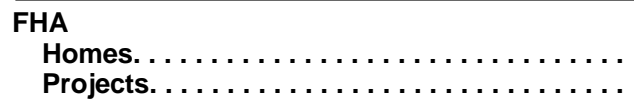 & $\begin{array}{r}100 \\
78\end{array}$ \\
\hline $\begin{array}{r}\text { VA } \ldots \ldots \ldots \ldots \ldots \ldots \ldots \ldots \ldots \ldots \\
\quad \text { Total FHA \& VA } \ldots \ldots \ldots \ldots \ldots \ldots \ldots \ldots \ldots\end{array}$ & $\begin{array}{l}131 \\
309\end{array}$ \\
\hline Other $\ldots \ldots \ldots \ldots \ldots \ldots \ldots \ldots \ldots \ldots \ldots$ & 1,678 \\
\hline
\end{tabular}

\begin{tabular}{|c|c|}
\hline Percent of total starts & Percent \\
\hline 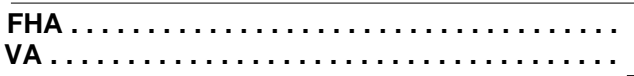 & $\begin{array}{l}9 \\
7\end{array}$ \\
\hline Total FHA \& VA. $\ldots \ldots \ldots \ldots \ldots \ldots$ & $\ldots 16$ \\
\hline Other $\ldots \ldots \ldots \ldots \ldots \ldots \ldots \ldots \ldots \ldots$ & $\ldots 84$ \\
\hline
\end{tabular}

SOURCE: HUD Office of Housing Statistics.

\section{DEPARTMENT OF HOUSING AND URBAN DEVELOPMENT}

The Housing and Urban Development Act of September 9, 1965, established HUD. It is the principal Federal agency responsible for programs concerned with housing needs and improving and developing the Nation's communities. It operates programs in all parts of the country except that for rural and small-town areas served by FmHA. HUD administers a variety of housing programs, including mortgage insurance programs for private lenders, rental and homeowners hip subsidy programs for lower income families, and programs to improve the availability of mortgage credit and policy research support programs. Local development activities are assisted by the community development block grant program. Through its promulgation of minimum property standards, HUD sets construction standards for all HUD-assisted, VA-guaranteed, and FmHAassisted housing.

HUD operates through a field structure of 10 regional offices and 82 field offices including 39 area offices.

The Assistant Secretary for Neighborhoods, Voluntary Associations, and Consumer Protection is the Department's principal energy conservation officer. An Office of Energy Conservation has been established. Energy conserva- tion does not appear to be a priority departmental concern and the role of the Energy Conservation Office is limited. Individual programs have established policies toward energy conservation but the Department has no overall policy or consistent priority for meeting conservation goals.

The Senate, Banking, Housing, and Urban Affairs Committee and the House Banking, Currency, and Housing Committee handle HUD's legislation.

The most important HUD programs are reviewed below. Housing programs designed to benefit low- and moderate-income families are discussed first. Subsequent sections discuss the principal mortgage insurance programs and other types of HUD programs with energy conservation potential. Each program's conservation policy is described, and its level of activity noted.

\section{Housing Programs Directed to Low- and Moderate-Income Families}

\section{LOW-RENT PUBLIC HOUSING}

This program provides financial and technical assistance to local public housing agencies 
(PHAs) to develop, own, and operate lowincome housing projects. Projects are financed through the sale of tax-exempt local obligations that are guaranteed by the Federal Government. HUD provides annual contributions to pay the debt service of PHA obligations so as to assure low rents and maintain adequate services and reserve funds. Rents, based on the residents' ability to pay (25 percent of adjusted gross income), contribute to the cost of managing and operating the housing.

Additional public housing can be developed by PHAs acting as the developer, by private developers under the "turn key" program, or through acquisition and rehabilitation of existing housing.

Two related programs-modernization and operating subsidies - provide financial support to the existing public housing inventory.

Under the modernization program, HUD finances capital improvements in public housing projects to upgrade living conditions, correct physical deficiencies, and achieve operating efficiencies and economies. The development cost is amortized through annual Federal contributions toward the debt service. I $\mathrm{n}$ addition, the National Energy Act authorized a special program to finance the cost of energyconserving improvements for public housing.

HUD also provides operating subsidies to help PHAs maintain and operate their projects, retain minimum operating reserves, and offset certain operating deficits. The operating subsidies are based on the Performance Funding System, a formula designed to calculate operating subsidies based on what it costs a wellmanaged PHA to operate its units.

Program Activity.-As of December 1977, more than 4,000 localities had public housing programs; $1,187,693$ units were available for occupancy, of which about 25 percent were designated for the elderly. In 1977, an additional 6,229 units were made available for occupancy, and 6,321 were placed under construction or rehabilitation.

In FY 1978, some 800 PHAs were expected to participate in the modernization program, $\$ 42.6$ million in contract authority was allocated to finance capital costs of $\$ 475$ million.
In FY 1978, \$685 million was appropriated for operating subsidies.

Authorization.- U.S. Housing Act of 1937 (Public Law 75-412) as amended.

\section{SECTION 8 LOW-INCOME RENTAL ASSISTANCE}

This program, which is HUD's main assistedhousing program, makes rental subsidies available to help lower income families rent standard privately owned housing. Eligible families must earn less than $\mathbf{8 0}$ percent of the median income for the area. Thirty percent of the families assisted must earn less than so percent of the median income for the area.

The program makes up the difference between what a lower income household can afford (no more than 25 percent of adjusted gross income) and the fair market rent for an adequate housing unit. Housing thus subsidized must meet certain standards of safety and sanitation, and rents for these units must fall within the range of fair market rents as determined by HUD. This form of rental assistance may be used in existing housing or newly constructed or substantially rehabilitated units Project sponsors may be private owners, profit-motivated, nonprofit or cooperative organizations, public housing agencies, and State housing finance agencies.

Local PHAs administer the existing housing program. They certify eligible tenants, inspect the units proposed for subsidy, and contract for payment with landlords whose units have been approved. Proposals for new construction or substantial rehabilitation are submitted for approval to HUD or State housing finance agencies.

Program Activity. -Through December 1977, reservations had been established for $\mathbf{9 8 2 , 4 3 9}$ units. As of that time, 25,636 new units, 4,341 rehabilitated units, and 327,797 existing units were occupied. A significant portion of program funds were being used to assist families living in HUD-financed projects that have been reacquired or assigned to HUD or are in financial difficulty.

Authorization.- Section 8 of the U.S. Housing Act of 1937 (Public Law 73-379) as amended 
by the Housing and Community Development Act of 1974 (Public Law 93-383).

\section{SECTION 236 RENTAL AND COOPERATIVE HOUSING ASSISTANCE FOR LOWER INCOME FAMILIES}

The section 236 program provides mortgage insurance and interest subsidies to lenders to reduce the rent that lower income households pay for housing. No additional commitments are now being made under the program. Under section 236, HUD insures mortgages and makes monthly payments to lenders on behalf of project owners to reduce mortgage interest costs to as low as 1 percent. The amount of subsidy provided is based on the income of the occupants. Projects are developed by nonprofit, limited-dividend, or cooperative organizations. In 1974 HUD began to pay additional subsidies to cover the differences between the tenants' contribution and the actual costs of operating the projects.

Program Activity. - In 1977, 561 units were insured. The program has financed more than 393,000 units since its inception.

Authorization. - Section 236 of the National Housing Act (1934) (Public Law 73-479) as amended by section 201 of the Housing and Urban Development Act of 1968 (Public Law 90-448).

\section{SECTION 202 DIRECT LOANS FOR ELDERLY} AND HANDICAPPED HOUSING

The section 202 program for the elderly and handicapped provides long-term direct loans to eligible, private, nonprofit sponsors to finance rental or cooperative housing facilities for elderly and handicapped persons. The interest rate is based on the average rate paid on Federal obligations during the preceding fiscal year. A minimum of 20 percent of the section 202 units must also be assisted by the section 8 program.

A household of one or more persons, the head of which is at least 62 years old or handicapped, is eligible to live in section 202 projects.

Program Activities.- In 1977, reservations for 32,801 units were made and projects involving 10,322 were started.
Authorization. - Section 202 of the Housing Act of 1959 (Public Law 86-372).

\section{SECTION 312 REHABILITATION LOANS}

The section 312 program provides rehabilitation loans in federally aided community development block grant, urban homesteading, and neighborhood strategy areas. The program makes available direct Federal loans to finance the rehabilitation of residential, mixed-use, and nonresidential properties. A loan may be used to insulate or weatherize properties. Loans may not exceed $\$ 27,000$ per dwelling unit or $\$ 50,000$ for nonresidential properties. The interest rate is 3 percent except for families whose income is above 80 percent of the median family income when the rate is tied to the Treasury borrowing rate. The loan term is for a period up to 20 years or threefourths of the property's remaining useful life. The applicant must evidence the capacity to repay the loan and be unable to secure necessary financing from other sources on comparable terms and conditions. Preference is given to low- and moderate-income applicants.

Program Activity.- Through December 1977, $\$ 430$ million of rehabilitation loans involving 80,327 units had been approved. In 1977 alone, 5,787 loans were made, involving 7,942 units with a total loan amount of $\$ 65.3$ million.

Authorization. - Section 312 of the Housing and Urban Development Act of 1964 (Public Law 88-560).

\section{SECTION 235 HOMEOWNERSHIP ASSISTANCE} FOR LOW- AND MODERATE-INCOME FAMILIES

The section 235 program provides mortgage insurance and interest subsidies to lenders. HUD insures mortgages and makes monthly payments to lenders on behalf of low- and moderate-income homebuyers to reduce their mortgage interest costs to as low as 4 percent. The program originally enacted in 1968 was significantly revised in 1975.

The homeowner must contribute 20 percent of his adjusted gross income to the monthly mortgage payments and must make a downpayment of 3 percent of the cost of acquisition. The income limit for initial occupancy is 95 percent of the area median income. Mort- 
gage limits are $\$ 32,000$ ( $\$ 38,000$ for homes for five or more persons) and in high-cost areas $\$ 38,000$ ( $\$ 44,000$ for homes for five or more persons).

Program Activity. - In 1977, 6,485 loans were insured for a total value of $\$ 174$ million. The program has financed nearly $\mathbf{4 8 5 , 0 0 0}$ units.

Authorization. - Section 235 of the National Housing Act (1934) (Public Law 73-479) as amended by section 101 of the Housing and Urban Development Act of 1968 (Public Law 90-448).

\section{Conservation Policies and Opportunities}

Legislation enacted in 1978 and changes in program policies have made energy conservation a more important policy concern in assisted housing programs than it had been previously. Recent legislative changes and the conservation policies of the different programs are discussed below.

The 1978 National Energy Conservation Policy Act and the Housing and Community Development Amendments of 1978 enacted important new energy conservation authorities and funding. I $\mathrm{n}$ the Housing and Community Development Amendments the Secretary of HUD is encouraged to promote cost-effective and economically feasible solar energy systems in housing assisted through sections 8 , 312 , and 202. The Secretary is also directed to promote cost-effective and economically feasible solar energy installations in residential housing in general, taking into account the interests of the low-income homeowners and renters. The Act requires that section $312 \mathrm{fi}-$ nanced improvements and section 8 substantial rehabilitation projects meet cost-effective energy conservation standards. The National Energy Conservation Policy Act included several provisions that affect assisted housing. A $\$ 10$ million authorization of contract authority specifically for the purchase and installation of energy conservation improvements was authorized. A $\$ 25$ million grant program was authorized to finance conservation improvements for sections 236, 221(d)(3), and 202 projects that are in financial difficulty as a result of energy costs. The law requires that the sav- ings resulting from the grants must either benefit tenants in the form of reduced rent or reduced Federal operating subsidies.

HUD has an opportunity to influence energy conservation in assisted housing in two general ways: as a part of the approval of the plans and specifications of new construction or substantial rehabilitation projects and, once the housing is built, in conjunction with the provision of annual subsidies that maintain the low- and moderate-income character of the housing. Because of the manner in which the program functions, the opportunities to promote conservation in the section 312 program are more limited and are explained below.

All assisted housing programs have similar policies governing the inclusion of energysavings improvements in new construction or substantially rehabilitated projects with the exception of the section 312 loan programs. All newly developed assisted housing must conform to HUD's minimum property standards (MPS) Improvements financed by section 312 loans must conform to local building code requirements. The conservation requirements of the MPS have been raised periodically and will be made more stringent as a result of the future adoption of the building energy performance standards. The upgrading of the MPS may increase the capital costs of new projects, which will over the short-run increase the amount of Federal subsidies required. Over the long run, however, the energy savings that will result from improved thermal performance will decrease Federal subsidy requirements.

The opportunities for improving conservation activities and saving energy in existing housing are significant. HUD policies related to conservation are in the process of being upgraded. Some of the specific policies and issues are reviewed on a program by program basis.

\section{PUBLIC HOUSING}

Concern for energy conservation in the management of public housing projects has been a distinct and often stated HUD policy. Conservation improvements for existing projects can be financed through the modernization program, and conservation has been identified as 
one of five areas for priority funding. The extent to which modernization funds are used for conservation is not known but it appears that significant numbers of projects involve some conservation activities. Some PHAs have funded conservation projects out of their own surplus funds without looking to HUD for special funding but few PHAs have significant surplus reserves and most must rely on HUD for funds to make conservation improvements. The energy efficiency of the public housing inventory is not known but because of historic construction cost limitations and the age of the housing stock it can be assumed that a large portion of public housing is not energy efficient. Recently HUD has encouraged PHAs to install individual utility meters in projects if it was judged cost effective.

HUD has proposed new regulations that would expand and extend energy conservation efforts in public housing and involve PHAs in systematic conservation programs. All PHAs would be required to conduct energy audits of their projects within 3 years. Based on the audits, PHAs would have to establish a list of conservation improvements ranked by their degree of cost effectiveness and to make improvement decisions based on the priority ranking. The scope of the audits would have to cover an assessment of certain specialized types of improvements. The regulations would require PHAs to buy appliances with the highest energy efficiency, thermostats would have to be set at no more than $750 \mathrm{~F}$, water heaters would have to be set at $1200 \mathrm{~F}$, and individual utility check meters would have to be installed unless other actions were considered more cost effective.

Adoption of these requirements could result in significant energy savings. PHAs currently spend $\$ 400$ million for utilities and the increase in the cost of utilities has been a major factor in the large operating losses sustained in public housing.

Prior to the development of these regulations, HUD and PHAs had not established energy conservation standards and goals. PHAs had been encouraged to include conservation projects in their modernization activities but there was no HUD review of conservation practices. Increased utility expenses were simply funded by the operating subsidies program. Operating subsidy funding decisions were not reviewed in order to determine how outlays could be reduced by making cost effective conservation improvements to projects.

The conservation potential in public housing is large for a number of reasons. Many projects are not now energy efficient. The information chain between HUD and PHAs is relatively short. Information can be easily distributed through established communication channels. Financing is a relatively modest problem. The modernization program could become primarily an energy conservation program through administrative action.

The operating subsidies program could be reoriented to give greater consideration to energy conservation. The performance funding system, the formula used to allocate operating subsidies, could be revised to provide incentives for conservation. Operating data could be reviewed to provide a clearer picture of the energy conservation potential of particular projects. Incentives could be created for PHAs to encourage them to give energy conservation more attention and priority.

\section{SECTION 8, SECTION 202, AND SECTION 236 PROJECTS}

These projects are largely owned by private nonprofit or limited dividend-for-profit corporations. Because of debt service payments and operating cost requirements owners have very limited cash flow or reserve funds available to finance energy conservation improvements. Most sponsors are unwilling to increase their equity in projects even if the investment will result in reducing operating costs. Although the relationship between HUD and these private housing owners is not as direct as with public housing agencies, owners should be sensitized and encouraged to make conservation improvements.

Motivating owners to retrofit their projects may be difficult. Project owners may not have an incentive to make conservation improvements because many have little investment or personal interest in the projects. Because util- 
ities in many projects are paid by the tenants, owners have no financial incentive to invest in conservation improvements.

HUD might use its authority to approve rent increases to get owners to make conservation improvements. The extent to which proposed increases in rent represent utility cost increases could be ascertained and, in situations where improvements would be cost effective, such improvements could be required as a condition of the rent increase. A similar requirement might be made as a condition of receiving section 236 operating subsidies. In granting operating subsidies HUD does not evaluate the energy efficiency of projects nor determine the impact of energy costs on operating costs. Prior to 1978 there was no funding available to finance such improvements but the National Energy Conservation Policy Act authorized a grant program to assist section 236 and section 202 projects, and loans for conservation improvements, solar energy systems, and installation of individual utility meters can be insured under section 241 of the National Housing Act.

Although HUD requires reserves for capital improvements in properties with HUD income mortgages, and those reserve funds might, in some cases, represent a source to cover conservation capital expenditures, that resource has limited potential. Many projects are in financial difficulty and many do not have adequate reserves. Applying stringent policies about making conservation improvements could increase the cash flow problems of projects and could bring about increased mortgage defaults and foreclosures.

In the section 8 existing housing program, HUD does not evaluate the energy efficiency of the units occupied by program beneficiaries, Assistance is calculated based on prototype utility costs and fair market rent determinations. As a result, actual energy costs are not considered in approving units and determining subsidy payments in the program. Although it would pose many administrative problems, the section 8 housing standard could be modified to require consideration of the energy characteristics of units eligible for assistance or consideration of the actual costs of utilities.
Recently proposed regulations would encourage PHAs to provide technical assistance, work writeups, and cost estimates to landlords participating in the section 8 existing program to help them determine what energy savings improvements would be cost effective.

Proposed regulations for the section 8 moderate rehabilitation program would allow owners to make conservation improvements such as installing storm windows and storm doors as long as the improvements are judged cost effective over the 15-year term of the subsidy contract.

Because virtually all section 202 elderly projects are on a sound financial footing and owned by experienced church and union sponsors, retrofitting existing projects offers an excel lent opportunity for saving energy. The area of prime potential for unrealized conservation measures in this program relates to projects built before 1973 when thermal standards were lower. Separate financing might be required to enable sponsors to make conservation improvements, but given the nature of the tenant group and the financial sources of these projects, such financing, especially if backed by a Government guarantee, should be readily available.

\section{SECTION 312 REHABILITATION LOANS}

Borrowers can make conservation improvements with proceeds from section 312 rehabilitation loans. The program has not specifically promoted conservation but consideration is being given to establishing energy conservation guidelines. Since properties assisted through section 312 must be brought up to local code standards, the effectiveness of the program in terms of saving energy could be improved by the upgrading of local energy conservation codes. Since most loans go to lowand moderate-income property owners there are tradeoffs that have to be made in establishing standards between additional energy saving and the ability of property owners to afford the extra costs.

\section{SECTION 235 HOMES}

No special conservation policies or opportunities have been identified for the section 235 
homeownership program beyond those relating to acquired property disposition and those which would result from changes to the MPS.

\section{Mortgage and Home Improvement Insurance Programs}

\section{SECTION 203(b) AND (i) ONE- TO FOUR-FAMILY HOME MORTGAGE INSURANCE}

The section 203(b) and (i) program provides mortgage insurance to lenders for loans to finance the purchase, construction, or rehabilitation of one- to four-family properties - up to 97 percent of the property value up to $\$ 25,000$ and 95 percent for the value in excess of $\$ 25,000$-for terms up to 30 years. The loans may finance homes in both urban and rural areas (except farms). The maximum mortgage loan on a single-family home is $\$ 60,000$.

Program Activity.- In 1977, 42,760 new construction and 241,504 existing home loans were insured for a total value of $\$ 7.7$ billion.

Authorization.- Section 203(b) and (i) of the National Housing Act (1934) (Public Law 73-479).

\section{SECTION 221(d)(2) HOMEOWNERSHIP ASSISTANCE FOR LOW- AND MODERATE- INCOME FAMILIES}

The section 221 (d)(2) program provides mortgage insurance to lenders for loans to finance the purchase, construction, or rehabilitation of low-cost, one- to four-family housing. The maximum insurable loan for an owner occupant is $\$ 31,000$ for a single-family home (up to $\$ 36,000$ in a high-cost area). For a large-family home $\$ 36,000$ (or up to $\$ 42,000$ in a high-cost area) is the maximum insurable loan. Higher mortgage limits apply to two- to four-family housing. A downpayment of 3 percent is required, and mortgage terms are for up to 30 years.

Program Activity. - In 1977, 1,039 new construction and 33,594 existing units were insured for a total value of $\$ 736.2$ million.

Authorization. - National Housing Act (1934) (Public Law 73-479) as amended by section 123 and section 221(d)(2) of the Housing Act of 1954 (Public Law 83-560).

\section{SECTION 233 EXPERIMENTAL HOUSING PROGRAM}

The section 233 program provides insurance for experimental single-family and multifamily projects involving unconventional housing systems or subsystems without the requirements that they adhere to normal HUD-FHA processing and MPS requirements. The program is intended to assist in lowering housing costs and improving housing standards, quality, livability, or durability of neighborhood design through the use of experimental technology or experimental property standards. The rationale for the program is to develop experience with a concept before the concept is written into the MPS. Occasionally, cases being considered by FmHA or VA that cannot be approved under their procedures are referred to the section 233 program for final action. No example of this procedure being used to facilitate processing of energy-conservation-oriented loans has been identified.

Program Activity. -Through September 1977, $\$ 8$ million in insurance on single-family housing had been issued, and $\$ 97$ million in insurance on multifamily projects had been issued. I n 1977, 14 single-family loans were insured at a total value of $\$ 399,300$. No multifamily projects were insured in 1977.

\section{SECTION 207 MULTIFAMILY RENTAL HOUSING}

The section 207 program provides mortgage insurance to lenders for loans to finance the construction or rehabilitation of multifamily rental housing (eight or more units) by private or public developers. The housing project must be located in an area approved by HUD for rental housing and in which market conditions show a need for such housing. The mortgage cannot exceed the lesser of 90 percent of value or unit-size cost limitations. The mortgage term is limited to $\mathbf{4 0}$ years.

Program Activity.- In 1977, 2,884 units were insured at a value of $\$ 49$ million.

Authorization. - Section 207 of the National Housing Act (1934) (Public Law 73-479). 


\section{SECTION 221(d)(3) AND (4) MULTIFAMILY \\ RENTAL HOUSING FOR LOW- AND MODERATE-INCOME FAMILIES}

This program provides mortgage insurance to lenders for loans to finance the construction or rehabilitation of multifamily (5 or more units) rental or cooperative housing for lowand moderate-income or displaced families. The insured mortgage amounts are controlled by statutory dollar limits per unit, which are intended to insure moderate construction costs. Section 221(d)(3) mortgages may be obtained by public agencies, nonprofit, limited-dividend, or cooperative organizations. Section 221(d)(4) mortgages are limited to profit-motivated sponsors. Under section 221(d)(3), HUD may insure 100 percent of total project cost for cooperative and nonprofit mortgages, but it may insure only 90 percent under section 22 I (d)(4) irrespective of the type of mortgage.

The National Energy Conservation Policy Act authorizes a grant program to finance the cost of energy-conserving improvements in section 22 I (d)(3) projects.

Program Activity. - In 1977, 70,809 units were insured for a total value of $\$ 1.57$ billion.

Authorization. - Section 221(d)(3) and (4) of the National Housing Act (1934) (Public Law 73-479) as amended by the Housing Act of 1954 (Public Law 83-560).

\section{SECTION 223(e) HOUSING IN DECLINING NEIGHBORHOODS}

The section 223(e) program provides mortgage insurance to lenders for loans to finance the purchase, construction, or rehabilitation of housing in older, declining, but still viable urban areas where conditions are such that normal requirements for mortgage insurance cannot be met. The terms of the loans vary according to the HUD/FHA program under which the mortgage is insured, but the loan must be an acceptable risk.

Program Activity.- In 1977, 8,511 loans were insured under this authority.

Authorization. -Section 223(e) of the $\mathrm{Na}$ tional Housing Act (1934) (Public Law 73-479) as amended by section 103(a) of the Housing and Urban Development Act of 1968 (Public Law 90-448).

\section{TITLE I HOME IMPROVEMENT AND MOBILE HOME LOAN PROGRAM}

The title I home improvement and mobile home loan program provides co-insurance to lenders for loans to finance major and minor improvements, alterations, and repairs of individual homes, nonresidential structures, and mobile homes.

Title I loans may be made in amounts up to $\$ 15,000$ for a term of up to15 years at an interest rate not to exceed 12 percent. Loans of less than $\$ 7,500$ are generally unsecured personal loans, Under the program HUD reimburses lenders for $\mathbf{9 0}$ percent of any loss under the program.

Under title 1, mobile home loans may be made in amounts up to $\$ 16,000$ and 12 years on single-module units and up to $\$ 24,000$ and 15 years for double-module units at any interest rate up to 12 percent.

Program Activity.- More than 32 million loans, of which more than 60,000 are mobile home loans, for a value of over $\$ 26$ billion, have been insured under the program since its inception. Program activity in 1977 was 345,579 loans with a value of $\$ 1,341$ million.

Authorization. - Section 2, title I of the National Housing Act (1934) (Public Law 73-479) as amended by the Housing Act of 1956 (Public Law 84-1020).

\section{Conservation Policies and Opportunities}

Conservation efforts in HUD mortgage insurance programs occur primarily through the requirements imposed by HUD's MPS (in the case of new construction) and standards of accepted practice (in the case of existing buildings). These standards are implemented through the relationships among area office staff, lenders, and applicants for mortgage insurance. Field staff are sensitized to conservation measures through formalized training of technical personnel (architects and engineers) who interact with the field representatives and applicants. An applicant who wants to incorporate a novel or first-cost intensive system in 
new construction can generally secure a full hearing for his case before local office personnel. If his costs are higher than those generally accepted for the kind of structure in that particular area, he will be persuaded to modify his approach to conform to accepted costs. [f his approach involves a system or a technique not provided for in the MPS, he may elect preferential processing under the experimental program (section 233 described above).

It is difficult to evaluate the impact the title I home improvement loan program has on energy conservation since this activity is administered primarily by lending institutions with HUD-FHA carrying out postaudits of insurance claims. Although the written instructions to the lending institutions are broad enough to allow practically any kind of conservation loan, no specific attempt is made to generate loans for conservation purposes. Further, there appears to be no effort to determine whether such loans are being made, and if so, what problems might exist. The 1974 Housing and Urban Development Act specifically authorized title I to insure loans for energy conservation improvements. The MPS do not apply to title I loans but HUD has specified standards for solar energy installations. The National Energy Conservation Policy Act authorizes Federal secondary market institutions to buy and sell title 1 loans that financed energy conservation improvements.

The National Energy Conservation Policy Act has increased the opportunity for insuring homes and multifamily projects with solar energy systems. Section 248 of the act authorizes HUD to increase the size of insured loans under sections 203 and 207 by up to 20 percent due to increased costs for the installation of solar energy systems.

The dissemination of conservation information by HUD to the portion of the housing market that relies on HUD mortgage insurance appears potentially effective, despite the number of participants involved, because of the large number of HUD area offices, the regular contacts that owners and the housing industry have with HUD staff and the variety of HUD publications going to the different parts of the housing industry. These channels, however, do not seem to be used as aggressively as they might be for transmitting information on conservation techniques and opportunities.

\section{Other HUD Programs}

\section{COMMUNITY DEVELOPMENT BLOCK GRANT PROGRAM}

The community development block grant program (CDBG) makes available block grants to local governments to fund a wide range of community development activities. Metropolitan areas-generally cities over 50,000 population - and qualified urban counties-those with populations in excess of $200,000-$ are guaranteed an annual grant or "entitlement" based on needs. Smaller communities compete for the remaining "discretionary" funds. Spending priorities are determined at the local level, but the law enumerates general objectives that the block grants are designed to fulfill, including the provision of adequate housing, a suitable living environment, and expanded economic opportunities for lower income groups. Grant recipients are required to estimate their lower income housing needs and address them in the overall community development plan they submit.

Funds may be used to finance or subsidize housing improvement and rehabilitation. CDBG rehabilitation assistance is provided in a variety of forms, including direct loans, loan guarantees to private lenders, interest subsidies, and loan writedowns to reduce the size of privately made loans.

Program Activity.- Under the program \$10.95 billion was authorized for FY 1978-80. The FY 1978 appropriation was $\$ 3.6$ billion, and some 3,200 local governments received grants, of which 1,300 received entitlement grants. The amount of funds earmarked for rehabilitation was estimated at $\mathbf{\$ 4 1 8}$ million in FY 1977, and about 1,500 communities expected to have rehabilitation programs.

Authorization. -Title 1 of the Housing and Urban Development Act of 1974 (Public Law 93-383) as amended by the Housing and Urban Development Act of 1977 (Public Law 95-128). 


\section{ACQUIRED PROPERTY MANAGEMENT AND DISPOSITION}

In the course of its activities, HUD acquires title to many properties it insured or assisted because of mortgage defaults by property owners. HUD's policy is to liquidate properties in such a manner as to assure the maximum return to the mortgage insurance funds existent with the need to preserve and maintain residential areas and communities.

Program Activities.- At the end of FY 1978 it is estimated that HUD will own 63,119 properties of which 25,701 would be houses and 37,418 multifamily units. Total acquisitions for 1978 are estimated at 50,575.

Authorization. - Not applicable.

\section{GNMA GUARANTEED MORTGAGE-BACKED SECURITIES AND SPECIAL ASSISTANCE MORTGAGE PURCHASES}

The Government National Mortgage Association (GNMA), a corporate entity within HUD, was originally established to provide a secondary market for federally insured residential mortgages not readily salable in the private market. These mortgages generally financed housing for special groups or in areas of special needs. Prior to September 1, 1968, GNMA's functions were carried out by the Federal National Mortgage Association (FNMA).

More recently GNMA was authorized to purchase both federally insured and conventional mortgages at below-market interest rates to stimulate lagging housing production. These mortgages are then resold at current market prices, with the Government absorbing the loss as a subsidy under the "tandem" plan. HUD-, FNMA-, or Federal Home Loan Mortgage Corporation (FHLMC)-approved lenders may apply to sell mortgages to GNMA.

Twenty-five special assistance programs have been implemented since 1954. Between January 1974 and September 1977 GNMA issued $\$ 20.5$ billion in commitments to purchase below-market interest rate mortgages.

GNMA also guarantees the timely payment of principal and interest to holders of securities issued by private lenders and backed by pools of HUD-insured and VA-guaranteed mortgages. The guarantee is backed by the full faith and credit of the U.S. Government. Applicants must be FHA-approved mortgagees in good standing and generally have a net worth in excess of $\$ 100,000$.

Program Activity.-GNMA guaranteed more than $\$ 152$ billion in mortgage-backed, passthrough securities in FY 1978. In FY 1978 it made tandem commitments of $\$ 2.1$ billion.

Authorization.- Tandem plan activities were authorized by the Housing and Urban Development Act of 1968 and 1969 (Public Law 90-488 and 91-1 52), the Housing and Community Development Act of 1974 (Public Law 93-838), the Emergency Home Purchase Act of 1974 (Public Law 93-449), the Emergency Housing Act of 1975 (Public Law 94-50), and the Housing Authorization Act of 1977 (Public Law 95-1 28). GNMA's guarantee authority is authorized by the Housing and Urban Development Act of 1968 (Public Law 90-44).

\section{RESEARCH AND DEMONSTRATION PROJECTS}

Solar Heating and Cooling Demonstration.As part of the national solar energy program administered by the Department of Energy (DOE), HUD is responsible for a demonstration of the practical application of solar energy in residential heating and cooling. The program includes 1) residential demonstrations in which solar equipment is installed in both new and existing dwellings, 2) development of performance criteria and certification procedures for solar heating and cooling demonstrations, 3) market development to encourage acceptance of solar technologies by the housing industry, and 4) data gathering and dissemination of demonstrations and market development efforts.

Program Activity. -As of December 1977 the first four of five funding cycles have been completed. A total of 325 grants valued at $\$ 13.5$ million, involving 6,924 dwelling units, had been made.

Authorization. - Solar Heating and Cooling Act of 1974 (Public Law 93-409).

Energy Performance Standards for New Buildings. -The purpose of this research, managed 
by HUD, is to develop energy performance standards for new buildings. It is divided into three phases: an assessment of how much energy buildings are designed to use; an assessment of how much less energy buildings could be designed to use; and the testing and evaluation of standards. For analysis purposes buildings were divided into two major groups - nonresidential buildings, including multifamily homes, and low-rise multifamily housing, and mobile homes.

The work is being carried out by the AIA Research Corporation and its subcontractors.

Data is being collected on 6,254 buildings, which were constructed in 1975 and 1976 in different metropolitan areas.

Program Activity. -The Phase I report has been completed. In November 1978, a draft set of standards and regulations and target numbers for different climatic regions were issued by DOE, and HUD issued draft implementation regulations for comment. After public review and comment, standards will be promulgated. Approximately $\$ 10$ million has been devoted to standards development.

Authorization. -Title I I I of the Energy Conservation Production Act of 1976 (EC PA) (Public Law 94-385).

\section{MINIMUM PROPERTY HOUSING STANDARDS}

HUD has established MPS for its programs, which prescribe minimum levels of design and construction. The preamble of the National Housing Act (1934), which established FHA, authorized the agency to promote the upgrading of housing standards. There are MPS for oneto two-family new construction, multifamily new construction, nursing homes, and rehabilitation. The rehabilitation standards are more in the form of guidelines than standards. The MPS are used not only by HUD but by VA and FmHA, except that the latter's standards for insulation differ somewhat from HUD's MPS. (See later section on Housing Standards.) The construction of all mobile homes is governed by HUD's Mobile Home Construction and Safety Standards.
Anyone may suggest modifications to the MPS; important changes are issued for comment through the Federal Register.

Program Activity. - Not applicable.

Authorization. - National Housing Act (1934) (Public Law 73-279).

\section{Conservation Policies and Opportunities}

\section{COMMUNITY DEVELOPMENT BLOCK GRANT PROGRAM}

Energy conservation activities are not specifically promoted nor precluded as one of the eligible activities under CDBG. Localities may choose to assist virtually any list of projects, provided there are community improvement activities and are primarily oriented toward helping low- and moderate-income families. Many approaches to energy conservation could be justified under these conditions; the most obvious would be an energy conservation CDBG-funded component tied into a housing rehabilitation or a public housing modernization program. Because individual communities select and design the projects they will undertake, HUD has no easy way of knowing to what extent energy conservation improvements are current] y encouraged.

The use of CDBG funds for conservation improvements in rehabilitation financing programs has been made explicit in draft regulations issued by HUD. The regulations would allow CDBG rehabilitation financing to be used for measures to increase the efficient use of energy in structures through such means as installation of storm windows and doors, siding, wall and attic insulation and conversion, modification or replacement of heating and cooling equipment, including the use of solar energy equipment. The regulations also propose that in considering discretionary grants for new communities, HUD will give some weight to proposals that demonstrate the potential of energy conservation.

The CDBG program could give greater attention to how its funds could be used to save energy. Better coordination of efforts between CDBG and the Community Services Administration's weatherization program could be an effective approach to promoting residential 
conservation. The weatherization program could be administered to dovetail with HUDfinanced rehabilitation projects, thus meeting particular needs.

Many jurisdictions, especially suburban and small communities, have had little involvement in HUD programs but may be eligible for discretionary CDBG grants. The situation surrounding the planning of an application or expenditure of CDBG funds in such communities may be fluid, and-with encouragementthey might find the promotion of energy conservation in housing worthwhile. I $\mathrm{n}$ this context, energy conservation would appear to be an ideal activity for the CDBG program to foster.

In larger cities CDBG funds can and frequently do go to agencies or organizations that may be particularly interested in energy conservation. These agencies are frequently neighborhood-oriented, close to citizens, and may be willing to launch energy conservation activities. Such groups could be encouraged to promote conservation. Urban planning activities, now supported by the block grant program, could be directed toward articulating the need for and scope of energy conservation programs.

There appear to be few procedural roadblocks to encouraging conservation in CDBG rehabilitation programs. HUD and local government personnel do not seem to be opposed to an energy efficiency emphasis but need encouragement and greater awareness of the magnitude of the opportunity and potential to use the CDBG program to achieve energy conservation objectives.

\section{ACQUIRED PROPERTY MANAGEMENT AND DISPOSITION}

Although three Federal agencies (HUD, FmHA, and VA) administer housing acquired due to default on Government-financed mortgages, HUD has the largest inventory consisting of both single- and multi-family units.

HUD and VA closely coordinate their activities in administering and disposing of reacquired properties. Field offices determine whether properties are sold "as is" or rehabili- tated and then marketed. For those properties that are fully repaired before resale, there are no statutory maximums placed on the dollar amount of improvements allowed per structure. A major goal of HUD, FmHA, and VA, insofar as their reacquired housing inventory is concerned, is to dispose of the units as quickly as possible with the highest dollar return.

In 1978, HUD modified its property disposition policies so that all single-family homes have to include certain energy conservation features, or the purchaser has to agree to add the features to the home as a condition of sale. The only exceptions to the policy are homes scheduled to be demolished, properties sold in conjunction with section 312 financing for rehabilitation by the purchaser, and properties transferred to local governments. Local governments, however, are required to agree that conservation measures will be included in their repair requirements for the homes. HUD required energy-savings features include weatherstripping and caulking as needed, replacement of warped or ill-fitting doors and windows, Insulation of the attic, air ducts, and hot water heating pipes, and installation of storm doors and windows in certain climatic zones. If heating or air-conditioning equipment is replaced, proper sized equipment must be selected.

Multifamily properties are not required to conform to a specific conservation standard. Field offices have discretion in determining what should be done or in the case of "as is" sales whether the making of conservation improvements should be a condition of sale.

An energy conservation emphasis by HUD may, in fact, have greater utility in helping prevent mortgage default and housing reacquisition by the Government than in rescuing properties once defaulted. The major area of concern for HUD (and FmHA) revolves around multifamily projects that are heading for but have not yet defaulted and been acquired. A possible first step might be for the agency to review its lists of publicly financed low- and moderate-income housing, using annual reports submitted for the projects as well as audit reports to identify those projects approaching default. Those projects where 
energy cost factors are the major financial problem could be identified and targeted for immediate action to improve the energy management situation. While it might or might not be possible to influence tenant attitudes toward saving energy, pinpointing such problem projects could encourage project managers to display a greater conservation consciousness. If escalating energy costs are the prime cause of the financial difficulty and major conservation expenditures are indicated, secondary financing could be made available and the financial problems that led to mortgage default might be lessened or eliminated. This approach may be particularly appropriate for projects using electric heat.

\section{GOVERNMENT NATIONAL MORTGAGE CORPORATION}

Because all its purchases are federally insured or guaranteed, HUD's MPS determine the energy efficiency of housing financed through GNMA. GNMA would presumably accept whatever increased standards and energysavings priorities were established by HUD.

The National Energy Conservation Policy Act provides authority to GNMA to purchase title I insured loans made to low- and moderate-income families to finance the installation of solar energy systems. Such loans cannot ex- ceed $\$ 8,000$ and total purchases and commitments cannot exceed $\$ 100$ million at any one time. The interest rate can range from a rate that is not less than the average yield on outstanding interest-bearing obligations of the U.S. Government of comparable maturities then forming a part of the public debt to the maximum rate authorized by title 1 . The Act also provides standby authority to buy and sell title I or section 241 loans made for the purpose of installing energy-conserving improvements.

\section{MINIMUM PROPERTY STANDARDS}

Section 526 of the Housing and Community Development Act of 1974 required that-to the maximum extent feasible- HUD promote energy conservation through the MPS. The National Energy Conservation Policy Act required under the Energy Conservation Standards for New Buildings Act of 1976 becomes effective." The MPS have been upgraded recently. (See section on standards.) HUD believes any upgrading of conservation standards requires a balancing of the need to keep down construction costs and the potential fuel savings that will result from energy conservation improvements, and tends to look with disfavor on additional requirements that might increase the net monthly housing costs of borrowers.

\section{FARMERS HOME ADMINISTRATION}

The Farmers Home Administration of USDA provides housing assistance in open country and rural communities with populations up to 10,000 . Its programs are also available in cities of 10,000 to 20,000 population that are outside standard metropolitan statistical area (SMSA) and have a serious lack of mortgage credit as determined by the Secretaries of HUD and USDA. The Federal Housing Act of 1949 gave FmHA authority to make housing loans to farmers; that authority has been broadened to serve other groups over the years.

The programs are administered by county agents through a system of 1,760 county of- fices in rural areas (usually county seats) nationwide. Unlike HUD, most of FmHA's programs are not dependent on banks or other approved lending institutions. FmHA makes loans directly to families or sponsors using funds secured by issuing Certificates of Beneficial Ownership placed with the Federal Financing Bank. FmHA also has the authority to insure loans made by commercial lenders.

Housing developed under FmHA programs must be modest in size, design, and cost and must meet HUD's MPS.

The Senate Banking, Housing, and Urban Affairs Committee and the House Banking, Cur- 
rency, and Housing Committee handle FmHA housing legislation.

\section{Section 502 Homeownership Loan Program}

The section 502 homeownership loan program provides loan guarantees to private lenders or direct loans to individuals to buy, build, or rehabilitate homes. FmHA guarantees $\mathbf{9 0}$ percent of the principal and interest on privately financed housing loans. The maximum repayment period is 33 years. New homes and homes older than 1 year may be financed with 100-percent loans. The interest rate depends on adjusted family income and can vary from 1 to 8 percent. Although there is no maximum amount that an applicant can borrow, the loan is limited by FmHA's requirement that the housing be modest in size, design, and cost and what an eligible family can afford for mortgage payments, taxes, and insurance within 20 percent of its adjusted income.

In addition to the use of "regular" section 502 loans for housing repair, families earning less than $\$ 7,000$ annually are eligible for another type of home improvement loan under section 502 . Under the 1:2:4 program a family can borrow up to $\$ 7,000$ over a period of 25 years at an interest rate of 1 to 4 percent depending on family income for improvements that would bring its home up to standard conditions.

Program Activity. - In 1977, 121,614 loans were made with a total value of $\$ 2,678 \mathrm{~m}$ i I I ion.

Authorization. -Title $V$ of the Housing Act of 1949 (Public Law 81-171) as amended.

\section{Section 504 Home Repair Loan and Grant Programs}

The section 504 home repair program provides loans and grants to low-income homeowners with grants restricted to the elderly to remove certain dangers to their health and safety. An applicant must lack the income necessary to repay a FmHA section 502 loan and must own and occupy a home that has conditions hazardous to health and safety. All loans are made at an interest rate of 1 percent. Loan terms vary from 10 to 20 years depending on the amount. Loans cannot exceed $\$ 5,000$. Loans of less than $\$ 2,500$ need only be evidenced by a promisory note. A combination loan grant is made to applicants if they can repay only part of the cost; if the applicant cannot repay any of the cost a 100-percent grant is made.

Program Activity.-During 1977, 3,843 loans were made at a value of $\$ 9$. I million.

Authorization. -Title $\mathbf{V}$ of the Housing Act of 1949 (Public Law 81-171) as amended.

\section{Section 515 Rural Rent and Cooperative Housing Loans}

The section 515 program provides loans to private, public, or nonprofit groups or individuals to provide rental or cooperative housing of economic design for low- and moderate-income families and the elderly. Funds may be used to construct new housing, purchase new or existing housing, or repair existing housing for rental purposes. The interest rate on loans varies from 1 percent to the FmHA market rate, depending on the housing sponsor and the incomes of the occupants. Loans up to 50 years are made to elderly projects; for all other projects the term is up to 40 years. Section 8 assistance provided by HUD can be used in conjunction with section 515 projects.

Program Activity.- In 1977, 1,509 loans were made with a value of $\$ 647 \mathrm{~m}$ i I I ion.

Authorization. --Title $\mathrm{V}$ of the Housing Act of 1949 (Public Law 81-171) as amended.

\section{Conservation Policies and Opportunities}

The FmHA loan programs have no specific energy conservation goals. They rely on conservation measures that may be integrated into HUD's MPS. Innovative approaches are discouraged in the new construction programs. As with solar applications, any measure requiring capital costs out of the ordinary must be separately financed and requires special review and approval from Washington. 
The National Energy Conservation Policy Act requires the Secretary of Agriculture to promote the use of energy saving techniques to the maximum extent feasible. Such standards should be consistent as far as practical with the HUD standards and be implemented as soon as possible.

The FmHA section 504 program (grants and low-interest loans for modifications to existing housing) has made an effort to promote the weatherizing of single-family homes generally wherever local community action agencies have been aware of FmHA's program.

Housing assistance of FmHA is very personalized. FmHA, unlike HUD, is decentralized down to the county level. Applicants always meet directly with the FmHA county agent and continue that relationship throughout the life of the loan. The county agent inspects construction in progress and manages the loan payment process. County agents have relatively complete authority, provided they deal with conventional building systems and techniques. On the other hand, the agents are not technically expert in housing, and agency resources are limited. FmHA usually has only one architect per State office. Several State offices, in fact, cover more than one State, further reducing the technical attention that can be given to individual projects.

Because of the rural nature of the program, there is heavy reliance on electric heat so that energy costs are an important concern. However, FmHA does not actively promote certain kinds of buildings or utility systems. FmHA reacts to what is proposed by builders, many of whom previously built single-family homes only.
Most FmHA financing is direct Government lending, sometimes at a subsidized interest rate. Conservation measures that exceed normal construction costs will therefore represent an additional cost to the Government in the latter case. FmHA rental projects typically have only one-third the number of units of a typical urban project, so larger apartment builders and architects are not attracted to the program and technical resources may be limited.

Several steps could be taken to make housing built through FmHA more energy-efficient. A much closer utility cost analysis could be required of every rental project applicant to assure that all feasible energy options are considered. Although FmHA has issued new insulation thermal efficiency standards, the Washington-level system for handling novel energy conservation questions and for simplified and sympathetic processing of such applications does not appear to have generally penetrated to the field level within the agency. Field staff could be encouraged to combine single-family loans and grants (section 504) with the weatherization grants administered by local poverty programs. The importance of energy conservation could be more actively promoted by FmHA. The county agents could be provided with more extensive information on conservation opportunities and given more extensive technical support.

The FmHA State and county personnel appear to be diligent and service-oriented and will respond to Government policy that encourages conservation if authority and direction are given. The message on energy conservation has so far been muted and very unclear, with the exception of the recently published thermal efficiency standards for insulation. 


\section{VETERANS ADMINISTRATION}

The Veterans Administration provides a variety of benefits to veterans and their dependents, including housing financing assistance on more liberal terms than is available to the nonveteran. The assistance is in the form of loan guarantees to private lenders. Where private capital is not available direct loans are made. The VA uses HUD's MPS in evaluating properties.

The VA operates through 49 regional offices.

In the Senate and House, the Veterans Affairs Committees handle VA housing legislation.

\section{VA Loan Guarantee and Direct Loan Programs}

The Veterans Administration provides loan guarantees to private lenders and direct loans to veterans to finance the purchase, construction, or rehabilitation of homes, mobile homes, or condominiums. One- to four-unit owneroccupied properties are eligible for assistance. The maximum guarantee is $\$ 17,500$ or 60 percent of appraised value, whichever is less. There are no limits on the value of properties that can be guaranteed. No downpayment is required and loans up to $\mathbf{3 0}$ years are eligible under the guarantee.

Program Activity. - In 1977, 392,557 guarantee commitments were issued with a total value of $\$ 13.9$ billion. In addition 2,566 direct loans were made for a total amount of $\$ 63.2$ million. Of the total program activity 369,024 involved home purchases, 12,206 refinancing, 2,638 condominiums, 3,459 mobile homes, and 5,230 direct loans sold and guaranteed.

Authorization. - Servicemen's Readjustment Act of 1944 as amended, title 30 U.S.C. 1, chapter 37.

\section{Conservation Policies and Opportunities}

The Veterans Administration has no formal system for promoting energy conservation in its home loan guarantee program. VA follows HUD's MPS in approving loans for new con- struction. Existing properties are approved on the basis of "value." There is no statutory limit on the value of structures the agency will guarantee, but energy-conserving improvements will not be recognized if those costs exceed the appraiser's notion of the "value" of the structure. As the VA operates its program through "approved lenders," (commercial banks and mortgage lending institutions), the first consideration is the "approved lender's" policies. If the lender is liberally inclined toward financing a house that includes extra costs due to energy conservation equipment or materials not fully recognized in the appraisal, the lender must then be willing to seek VA approval of the particular case. The VA may then review the appraiser's statement of "value," and the questionable costs may be included with in the mortgage. However, this is relatively difficult because the VA housing program is too thinly staffed for the case-by-case personalized attention this approach requires.

As far as new construction is concerned, VA follows HUD's MPS; therefore, any initiative or the raising of energy efficiency requirements in this area is up to HUD.

I $\mathbf{n}$ the existing home market, the determinations of value are largely made by fee appraisers - local real estate personnel who are not Government employees. Reaching such a large group concerning energy conservation and influencing their thinking may be best accomplished through the appraisal or professional organizations and through HUD channels, as these appraisers usually do FHA appraisal work, as well.

The Veterans Administration could also play an important role in educating VA lenders and originators about the importance of considering energy conservation in lending decisions. As VA does not guarantee the entire loan, but just a portion, many lenders may have a different and more conservative attitude toward VA loans than toward FHA loans. Moreover, VA is proud of its relatively low default rate and believes this is due to its conservative policies in analyzing risk and judging "value." 


\section{OTHER FEDERAL DEPARTMENTS AND PROGRAMS}

A number of other Federal departments play important roles in supporting residential energy conservation or housing production and can have a significant impact in promoting energy conservation. HEW's Community Services Administration (CSA) administers the emergency energy conservation program, which includes research and development activities and a program to weatherize the homes of low-income families. The DOE's Division of Buildings and Community Systems funds a wide variety of residential conservation research and demonstration activities. The Department also administers a weatherization assistance program for low-income families and is authorized to operate a loan guarantee program for energy conservation improvements. The Department of Defense is an important developer of residential housing for the military and is involved in energy conservation demonstrations. The Department of the Treasury affects energy conservation practices and housing production and maintenance through its formulation and administration of tax and fiscal policies.

\section{CSA Emergency Energy Conservation Program}

The emergency energy conservation program of CSA includes a weatherization component, which provides grants to low-income families (up to 125 percent of the Office of Management and Budget's (OMB) poverty income guidelines) for housing repair and energy-savings im prove merits that will minimize heat loss and improve thermal efficiency. Renters as well as homeowners are eligible. Funds are allocated to States, which in turn allocate funds to community action agencies (CAAs) or CSA can fund CAAs directly. Funds may be used for insulation, storm doors and windows, repairs of sources of heat loss, and repair of heating systems. Of the funds granted, 80 percent must be used for materials. Expenditure limits per unit vary from region to region and, since November 1977, can range up to $\$ 800$. CAAs are encouraged to attempt to secure labor, supervision, and transportation costs from other sources; most frequently man- power training funds provided under the Comprehensive Employment and Training Act (CETA) are used.

The emergency energy conservation program also funds a variety of research and demonstration activities related to energy conservation in various sectors of the economy.

Program Activity.-Approximately 800 CAAs participate in the weatherization program. About \$39 million was appropriated for weatherization grants in fiscal year 1978. As of December 31, 1977, 268,252 households had been assisted. The average grant was approximately $\$ 233$. The research and demonstration activities were funded at a level of $\$ 24$ million in FY 1978.

Authorization. -Section 222(a)(12) of the Economic Opportunity Act of 1964 (Public Law 88-452) as amended.

\section{DOE Weatherization Assistance Program}

The DOE weatherization assistance program is intended to supplement other Federal weatherization efforts. Grants are provided to the States, based on climate and the extent of poverty. The States contract with communitybased organizations, which in turn weatherize the homes of low-income families, particularly the homes of the elderly and handicapped. Priority is given to contracts with community action agencies. The income of recipients cannot exceed 125 percent of the OMB poverty income guideline. Normally, grants cannot exceed $\$ 400$ per household. Of the funds granted 90 percent must be used for program costs. Labor, supervision, and transportation are expected to come from other sources, particularly CAAs and manpower training funds provided under CETA.

Program Activity. -The program was initiated in the fall of 1977 and 501 homes were weatherized in 1977. About 1,000 organizations are participating. The FY 1978 appropriation was \$65 million; the FY 1979 appropriation $\$ 199$ million. 
Authorization. - Title IV, part A, of the Energy Conservation and Production Act of 1976 (Public Law 94-385). (See chapter III for current information.)

\section{DOE Division of Buildings and Community Systems}

The Division of Buildings and Community Systems supports a variety of research projects and demonstrations designed to: 1 ) encourage and support the installation of energy-efficient technologies, 2) develop and commercialize systems to reduce the dependence on petroleum and natural gas, 3) develop and disseminate information about energy-efficient technologies, 4) promote the use of energy-conserving technologies and practices, 5) develop and implement energy-efficient standards for new buildings and appliances, and 6) implement the weatherization assistance program. Activities include such projects as the testing of heat pumps, energy feedback meters, and insulation; a nine-city demonstration to improve the availability of energy conservation improvement financing; distribution of an energy retrofit manual to homeowners and home improvement contractors; and the encouragement of State adoption of the National Conference of States on Building Codes and Standards (NCSBCS) Model Code (Model Code for Energy Conservation in New Building Construction).

Program Activity. -The 1979 appropriation was $\$ \mathbf{7 9 . 5 5}$ million. In 1978 it was $\$ \mathbf{5 2 . 3}$ million.

Authorization. -The Department was established by the Department of Energy Organization Act of 1977 (Public Law 95-91) pursuant to Executive Order 12009 of September 13, 1977. (See p. 194 for discussion of program.)

\section{DOE Obligations Guarantee Program}

This program would provide loan guarantees for a wide range of conservation or renewable resource activities for existing commercial, industrial, and multifamily buildings. While multifamily housing is specifically included as one of the allowable uses of loan guarantees, the program appears to be only incidentally a housing program. To implement the housing portion a system to service the housing market would have to be established. Guarantees could be made if credit would not otherwise be available.

The program has never become operational. DOE has had second thoughts about whether it would be useful. Potential demand for the assistance is under study.

Program Activity. - None.

Authorization. - Section 451 of the Energy Conservation and Production Act of 1976 (Public Law 94-385).

\section{Department of Defense}

The Department of Defense owns and operates 385,000 units of family housing within the continental United States. DOD also leases some units off base, but these leases typically are short term to handle emergency situations.

Since 1976 DOD has operated a comprehensive energy conservation investment program (ECIP) designed to save energy in all types of DOD-owned buildings. Approximately $\$ 13$ million a year has been used for residential retrofit The ECIP requirements for FY 1976-84 are estimated to be $\$ 1.5$ billion.

Initially retrofit projects had to show a 5year payback period to be selected for implementation, but a Btu-saved formula is now being used. In FY 1979 al I projects must average 58 million Btu saved per $\$ 1,000$ of investment, but a project designed to save as low as 23 million Btu will be considered. Translated into a payback formula, this approach results in consideration of projects with payback periods as long as 15 years.

The DOD program is goal-oriented and implemented through the chain of command, and apparently the goals are being achieved. Information access is regular and there are no peculiar financing problems because all conservation is funded from line item appropria$t$ ions. 
Under a DOD solar demonstration project, DOD has retrofitted four houses.

Also, DOD appears to have a well-conceived and relatively thorough training program for upgrading housing managers and sensitizing tenants in day-to-day conservation measures.

Program Activity. - Retrofit activity has averaged approximately $\$ 13$ million a year during the FY 1977-79 period.

Authorization. - Not applicable.

\section{Treasury Department: Tax Policy}

The Treasury Department has a significant impact on the development and maintenance of the Nation's housing inventory and investment in conservation improvements through its administration and enforcement of internal revenue laws. These laws and their present and potential impact on energy conservation are discussed in detail at the end of this section.

\section{Conservation Policies and Opportunities}

Both the CSA and DOE programs directly support energy conservation. Tax policies are discussed in another part of the report.

To expand its conservation activities, DOD might consider using the annual appropriations for debt service dollars instead of direct expenditure dollars. In that way, it could accelerate the conservation program and realize the per unit savings of volume contracting at today's costs rather than future costs, thus accelerating all the energy cost savings into 1 year rather than realizing them incrementally. These earlier realized energy cost savings, plus avoidance of contracting cost increases due to inflation in future years, might be cost effective. Such an approach, which commits Congress to appropriations in advance, would require specific legislative approval but would not require additional appropriations.

\section{HOUSING SECONDARY MORTGAGE MARKET AND REGULATORY AGENCIES}

Nearly all of the capital for the housing industry is provided by a Variety of private lending institutions. Savings and loan associations, banks, and mortgage companies are the primary loan originators as shown by table 69 .
Lending practices are affected by the policies of lending regulatory agencies and the activities of secondary mortgage market institutions.

Table 69.-Originations of Long-Term Mortgage Loans 1977 (dollars in billions)

\begin{tabular}{|c|c|c|c|c|}
\hline Type & $\begin{array}{c}\text { New homes } \\
1-4 \text { family }\end{array}$ & $\begin{array}{c}\text { Existing homes } \\
1-4 \text { family }\end{array}$ & $\begin{array}{c}\text { New } \\
\text { multifamily }\end{array}$ & $\begin{array}{c}\text { Existing } \\
\text { multifamily }\end{array}$ \\
\hline Savings and loan associations $\ldots \ldots \ldots \ldots$ & 23.7 & 62.4 & 1.6 & 5.0 \\
\hline Mutual savings banks. . . . . . . . . . . . . . & 1.4 & 6.7 & .2 & 1.3 \\
\hline Commercial banks . . . . . . . . . . . . . . & 8.8 & 26.4 & .4 & 1.0 \\
\hline Life insurance companies . . . . . . . . . . . & .1 & .4 & .4 & .5 \\
\hline Noninsured pension funds $\ldots \ldots \ldots \ldots \ldots$ & (a) & (a) & .1 & (a) \\
\hline State \& local retirement funds . . . . . . . . . . & a & .2 & (a) & .1 \\
\hline State \& local credit agencies . . . . . . . . . . . & .1 & .6 & .3 & .6 \\
\hline Mortgage companies . . . . . . . . . . . . & 7.0 & 15.8 & .8 & 3 \\
\hline Federal credit agencies $\ldots \ldots \ldots \ldots \ldots$ & 1.7 & 1.3 & .9 & .1 \\
\hline State chartered credit unions . . . . . . . . . & .4 & .7 & - & - \\
\hline Mortgage investment trusts $\ldots \ldots \ldots \ldots \ldots \ldots$ & .1 & (a) & .1 & (a) \\
\hline Total ...................... & 43.3 & 114.5 & 4.8 & 9.0 \\
\hline
\end{tabular}

Under $\$ 50$ million

NOTE: Figures may not total due to rounding.

SOURCE: HUD Office of Housing Statistics. 


\section{Regulatory Agencies}

Most lenders are subject to Federal and/or State regulations. The two most important in terms of their impacts on the housing industry are the Federal Home Loan Bank Board (FHLBB) and the Federal Deposit Insurance Corporation (FDIC).

\section{FEDERAL HOME LOAN BANK BOARD}

The Federal Home Loan Bank Board is an independent executive agency that supervises and regulates savings and loan associations, which are the country's major private source of funds for financing housing. The Board governs the Federal Savings and Loan Insurance Corporation, which provides deposit insurance to savings and loan institutions. The Board directs the Federal Home Loan Bank System, which provides reserve credit and ancillary services to member saving and loans. There are 12 regional Federal Home Loan Banks in the system.

\section{FEDERAL DEPOSIT INSURANCE CORPORATION}

The Federal Deposit Insurance Corporation is an independent executive agency that supervises and regulates certain activities of $\mathrm{Na}$ tional and State banks that are members of the Federal Reserve System and State banks that apply for deposit insurance. FDIC provides deposit insurance to banks. The management of the corporation is invested in a three-person Board of Directors, one of whom is the Comptroller of the Currency. There are 14 regional FDIC offices in the system.

\section{Conservation Policy and Opportunities}

The Federal Home Loan Bank Board has no specific conservation policy. It is cooperating with DOE's attempt to sensitize all financial institutions to energy efficiency in their residential lending practices. These activities include structured group interviews, discussions about revision of loan appraisal procedures, and investigations of different financing incentives.

The Federal Deposit Insurance Corporation has no apparent energy conservation policy. It does not believe that it has the authority or leverage to encourage its members to adopt an energy conservation policy as it regulates but does not provide liquidity to banks as does FHLBB.

\section{Secondary Mortgage Market}

A number of Government-sponsored agencies have been established to provide liquidity to the mortgage market by purchasing loans originated by private lenders. As noted earlier, the Government National Mortgage Association (GNMA) purchases selected types of FHA and VA mortgages. The Federal Home Loan Mortgage Corporation provides a secondary market for conventional mortgages made by savings and loans and other lenders, and the Federal National Mortgage Association (FNMA) purchases mortgages originated by approved lenders. The important role of federally supported loan pools can be noted in table 70 , which breaks down net acquisitions of longterm mortgage loans on residential properties for 1977 . The pools acquired 15 percent of the one- to four-family loans made and 5.7 percent of the multifamily loans made. (Comparing this table to table 68 documents that mortgage companies particularly make use of the secondary market to sell off loans they originate. )

Table 70.-Net Acquisitions of Long-Term Mortgage Loans on Residential Properties by Lender Groups (dollars in billions)

\begin{tabular}{|c|c|c|}
\hline Type & $\begin{array}{c}\text { 1-to 4-family } \\
\text { homes }\end{array}$ & $\begin{array}{l}\text { Multifamily } \\
\text { projects }\end{array}$ \\
\hline \multicolumn{3}{|l|}{ Savings and loan } \\
\hline associations. $\ldots \ldots \ldots \ldots$ & 84.2 & 6.5 \\
\hline Mutual savings banks . . . . . & 10.3 & 1.7 \\
\hline Commercial banks. . . . . . . & 31.6 & 1.4 \\
\hline Life insurance companies. . & .6 & .9 \\
\hline Non insured pension funds. & .1 & .1 \\
\hline State \& local retirement & & \\
\hline funds. . . . . . . . . . . . & .3 & .2 \\
\hline \multicolumn{3}{|l|}{ State \& local government } \\
\hline credit agencies. . . . . . . & 2.6 & 1.0 \\
\hline Credit unions ............ & .7 & - \\
\hline \multicolumn{3}{|l|}{ Mortgage investment } \\
\hline trusts. . . . . . . $\ldots \ldots$ & (a) & .1 \\
\hline Federal credit agencies. ... & 4.5 & 1.1 \\
\hline Mortgage pools $\ldots \ldots \ldots$. & 22.5 & 1.2 \\
\hline \multicolumn{3}{|l|}{ State chartered credit } \\
\hline unions. . . . . . . . . . . & - & .3 \\
\hline Total $\ldots \ldots \ldots \ldots \ldots$ & 158.4 & 14.6 \\
\hline
\end{tabular}


These secondary market institutions are important to energy conservation not only in that they provide liquidity to lenders, but because they employ appraisal and mortgage credit standards, forms, and policies that are commonly used in the lending industry and have energy conservation implications. Generally, appraisal forms have not explicitly (with the exception of the HUD/FHA forms) required an estimate of energy costs. No forms require an appraisal of the energy efficiency of the property. Neither FNMA nor FHLMC requires energy costs to be considered to evaluating a borrower's credit.

\section{FEDERAL NATIONAL MORTGAGE ASSOCIATION}

The Federal National Mortgage Association is a Government-sponsored private corporation regulated by the Secretary of HUD. It provides supplementary assistance to the secondary market for home mortgages by supplying a degree of liquidity for mortgage investments, thereby improving the distribution of investment capital available for home mortgage financing. FNMA buys FHA-insured, VA-guaranteed, and conventional mortgages. FNMA makes mortgage funds available through periodic auctions of mortgage purchase commitments on home mortgages in which lending institutions, such as mortgage companies, banks, savings and loan associations, and insurance companies, make offers to FNMA, generally on a competitive basis. It also offers to issue standby commitments for both home and multifamily mortgages on proposed construction at approved prices based on its auction prices. The Secretary of HUD may require that a reasonable portion of the corporation's mortgage purchases support the national goal of providing adequate housing for low- and moderate-income families.

Program Activity.- In 1977, FNMA made commitments of $\$ 10.92$ billion and as of December 31,1977 , had a net mortgage and loan portfolio of $\$ 33.2$ billion.

Authorization. - Housing and Urban Development Act of 1954 (Public Law 83-560) as amended by the Housing and Urban Development Act of 1968 (Public Law 90-448).

\section{FEDERAL HOME LOAN MORTGAGE CORPORATION}

The Federal Home Loan Mortgage Corporation (the Mortgage Corporation) promotes the flow of capital into the housing market by establishing an active secondary market in mortgages for savings and loans and other lending institutions. It operates under the direction of FHLBB. The corporation's purchase programs cover conventional mortgage loans, participations in conventional mortgage loans, and FHA-insured and VA-guaranteed loans. Its sources of funds are borrowings from Federal Home Loan Banks, the issuance of GNMA mortgage-backed securities, the issuance of participation sale certificates, and direct sales from its mortgage portfolio.

Program Activity. -At the end of 1977, the Mortgage Corporation held $\$ 4.1$ billion in mortgages. Outstanding commitments totaled $\$ 5.5$ billion.

Authorization. - Emergency Home Finance Act of 1970.

\section{Conservation Policies and Opportunities}

The National Energy Conservation Policy Act authorized the Mortgage Corporation to purchase title I loans whose proceeds were used to finance energy conservation improvements and authorized FNMA to buy and sell conservation and solar energy-related home improvement loans.

FNMA and FHLMC have taken some actions to promote conservation. They have issued a new home mortgage appraisal form requiring appraisers after March 1, 1979, to determine whether insulation exists and is adequate, whether the home has storm windows, and to note any special energy features, their costs and contribution to the property's value. The FHLMC has announced that it will purchase refinance loans with loan-to-value ratio's of up to 90 percent rather than 80 percent if its proceeds will be used for rehabilitation, renovation, or energy conservation improvements.

FNMA and FHLMC are in a position to provide leadership to sensitize lenders to energy conservation considerations in lending. Their influence on lending practices is substantial 
because lenders commonly follow secondary market practices and requirements so that mortgages will be readily salable if the lender wants to dispose of them. Their forms are widely used in the industry. DOE has tried to encourage these institutions to induce lenders to require energy-efficiency information on mortgage applications, to consider energy costs in approving properties and judging the credit of borrowers, and to revise their guideforms and lending guidelines accordingly. A number of actions could be taken to promote conservation. Forms and procedures could require more explicit considerations of the energy efficiency of properties. Appraisals could take into account the actual energy costs of specific homes. Appraisers could identify and give greater consideration to the existence or absence of conservation improvements. Lenders could be required to use energy costs as a factor in determining the ability of the purchaser to afford a home. These actions would make homebuyers more aware of energy conservation issues and would provide financial incentives to purchasers of energyefficient properties.

The Mortgage Corporation is in a particularly strong position to change lender practices because it can require sellers to repurchase mortgages if it is determined that prescribed procedures and practices were not followed in originating the loan. On the other hand, appraisers and lenders are reluctant to to use information on the past energy consumption of a home because of the importance of lifestyle and family size in determining energy costs and because of potential issues of liability that might arise.

\section{ENERGY CONSERVATION AND FEDERAL TAX POLICY}

Federal tax policy can do much more than it has to stimulate energy conservation. Taxes have substantial impact on individual decisions about the construction, rehabilitation, improvement, and ownership of all kinds of residential property in the United States. Until very recently, existing law has not encouraged expenditures for energy conservation.

The tax laws may be used -as they have been in a number of similar situations-to affect certain investment decisions and to require certain behavior as a prerequisite to the availability of a financial benefit. If energy conservation is accepted as a valid national objective, long-term conservation goals may be assisted substantially by changes in the tax laws that affect the building and improvement of residential housing.

Some tax law changes have already been made to encourage energy conservation expenditures, and others could be made to strengthen the incentives. These changes fall into two categories: 1 ) limiting tax benefits to cases where energy conservation needs have been considered, and 2) providing new, spe- cific tax incentives for energy conservation expenditures.

\section{Present Law (Prior to the Energy Tax Act of 1978)}

Under present law, four types of tax law provisions principally affect the construction, rehabilitation, improvement, and ownership of residential property. They relate to the deductions available for the payment or incurrence of: 1 ) interest on indebtedness, 2) real property taxes, 3) depreciation, and 4) the costs of operating residential property. Section 163 of the Internal Revenue Code (the "Code") provides a specific deduction for all interest paid or incurred on indebtedness. Section 164 of the Code provides a specific deduction for real estate taxes paid or incurred. Section 167 of the Code is the basic depreciation provision providing various methods of depreciation for the owners of rented residential property, including a special 5-year amortization provision for the rehabilitation of low- and moderateincome residential property. For certain properties having historic significance, Congress 
added in 1976 a special 5-year amortization provision for rehabilitation expenditures (section 191 of the Code). With respect to the cost of operating rental residential property, sections 162 and 212 of the Code provide deductions for all of the ordinary and necessary expenses related to the operation of such property.

Single-family homeowners (whether the dwelling is a freestanding house, a condominium unit, or a unit in a cooperative) who occupy their own homes may take only the interest and real estate tax deductions. Owners of multifamily residential property (without regard to the number of rental units) are entitled, additionally, to the benefits available under the depreciation provisions and to deductions for the costs of operating the property.

\section{The Effect of Present Law on Energy Conservation}

The interest and real property tax deductions are both important factors in decisions made by individuals to build, rehabilitate, improve, or purchase a single-family home. The interest deduction reduces the real cost of the mortgage loan. The real estate tax deduction reduces the cost of providing shelter. The interest deduction indirectly encourages expenditures for capital equipment or structural changes that conserve energy. For example, to the extent that the cost of original construction or later rehabilitation or improvement is financed by a mortgage loan, the interest deduction reduces the real cost of the energy conservation expenditures. To the extent that such expenditures increase the appraised value of single-family homes - and thus, the applicable real property taxes -the real estate tax deduction reduces shelter costs.

While neither of these deductions is now available to renters, an effort is underway to make the real property tax deduction available. Under a recently enacted New York statute, a renter would become directly responsible for the real property tax allocable to his dwelling unit. The Internal Revenue Service is considering whether this new State law re- sults in the availability of the Federal tax deduction to renters.

The interest and real property tax deductions are available to the owners of multifamily residential property, with similar economic effects. I $\mathrm{n}$ addition, such owners have the opportunity to recover the cost of energy conservation expenditures through depreciation - ordinarily, over the useful life of the capital equipment or structural feature involved. While the depreciation deduction does afford cost recovery, it does not provide any greater incentive to make an energy conservation expenditure than to make any other capital equipment or structural expenditure. While the knowledge that energy operating costs will be reduced by such expenditures may affect certain decisions concerning newly constructed buildings, those costs have a much lower priority in rehabilitation and improvement decisions, particularly when utility costs are simply passed on to tenants.

Overall, therefore, it may be concluded that tax laws enacted before 1978 have provided very little encouragement to the owners of residential property considering decisions to make energy conservation expenditures.

\section{The Energy Tax Act of 1978}

To stimulate energy conservation expenditures by those homeowners who are not entitled to depreciation, the Energy Tax Act of 1978 provides certain new Federal income tax credits. The credits may be applied only against investments relating to a taxpayer's principal place of residence (whether owned or rented), which must be located in the United States and -to be eligible for the first category of credits - have been "substantially completed" before April 20,1977.

The new law permits tax credits amounting to 15 percent of the cost of energy conservation investments of up to $\$ 2,000$ (i. e., a maximum credit of $\$ 300$ ) made during a taxable year between 1977 and 1985. Eligible investments include insulation, furnace efficiency improvements, clock thermostats, storm windows and doors, caulking and weatherstrip- 
ping, utility meters that show the cost of service, and any other items "of the kind which the Secretary specifies by regulations as increasing the energy efficiency of the dwellings." Draft regulations specifically exclude heat pumps, according to Internal Revenue Service sources.

A second provision of the Energy Tax Act provides tax credits amounting to 30 percent of the cost of investments of up to $\$ 2,000$ in renewable energy sources, and 20 percent of up to $\$ 8,000$ in additional costs of such renewable energy sources (i. e., a maximum credit of $\$ 2,200)$. The renewable-energy tax credit, which may be used for newly constructed as well as pre-1 977 dwellings, may be applied against an investment in active or passive solar systems, geothermal energy, wind energy, or "any other form of renewable energy which the Secretary specifies by regulation, for the purpose of heating or cooling such dwelling or providing hot water for use within such dwelling." At this writing, the draft regulations are expected to prohibit application of the credit to wood-burning stoves. They are also expected to be restrictive with respect to passive solar features; they will exclude such things as greenhouses, draperies, special materials used in roofing, siding, or glazing, and any construction components that serve structural functions as well as passive solar functions.

The new credits may be used only to reduce tax liability, not to gain a refund. However, if the eligible expenditures exceeds a taxpayer's tax liability for the year in which the investment is made, the amount of the tax liability may be carried over to the next taxable year. This provision seeks to avoid discrimination against low-income persons with little or no tax liability.

\section{Further Changes to Encourage Energy Conservation Expenditures}

Further changes in tax policy would encourage additional energy conservation expenditures. Two broad categories of change deserve considerate ion:

1. Requiring that certain existing tax benefits be available only if energy conservation needs have been taken into account.
2. Providing new, specific tax incentives for energy conservation expenditures.

Two special provisions of present law allow owners of multifamily residential property to recover their costs of rehabilitation and improvement over a 5-year period (rather than the much longer useful life of the rehabilitated or improved property).

Under section $167(k)$ of the Code, owners of rehabilitated low- and moderate-income residential property may recover their rehabilitation expenditures - to the extent of $\$ 20,000$ per residential unit-over a 5-year period. The availability of this special provision should be conditioned upon making energy conservation expenditures that meet HUD standards. As the present $\$ 20,000$ limitation on rehabilitation expenditures to which this special provision now applies often does not cover the full cost of the actual rehabilitation, the present provision might be amended to provide similar treatment for up to an additional $\$ 2,000$ per unit of "certified energy conservation expenditures" made in connection with such a project. Such a requirement would produce a long-term budgetary benefit through its reduction of the long-range increase in section 8 housing assistance payment costs in section $167(k)$ housing projects. It would, thereby, offset the revenue losses in early years from such a change in tax policy.

Under sections 191 and 167(0) of the Code, the owners of substantially rehabilitated historic properties have been afforded the ability to deduct rehabilitation expenditures, without limit, over a 5-year period (under section 191) or to claim depreciation with respect to such costs in the same manner as would the owner of newly constructed residential property (section $167(0)$ ). The availability of these special provisions should also be conditioned upon making energy conservation expenditures that meet H U D standards. I $\mathrm{n}$ the case of owners who make an election under section 191, no new tax incentive is required, as all rehabilitation expenditures are deductible over a 5-year period. I $n$ the case of section 167(1) elections, a substantial tax incentive already exists and it seems improper to increase it at this time 
before any experience has been accumulated concerning its use.

Somewhat different considerations apply to owners of residential property who use it in a trade or business, or hold it for the production of income and are, therefore, entitled to claim depreciation deductions. In such cases, the tax laws have been utilized in two ways to encourage particular types of investments - either the provision of an investment tax credit or the provision of a form of rapid amortization of the costs of the investment. Either technique could be selected to encourage investments in energy conservation.

\section{Investment Tax Credit}

The existing investment tax credit provisions do not encourage energy conservation expenditures in that they do not now provide a credit for the cost of buildings (or the structural components of buildings) or for any tangible personal property used in connection with residential property (see section 43 of the Code). It would be necessary to amend the provisions of present law to provide for an exception for "certified energy conservation expenditures" to encourage such investments.

Indirectly, Congress has given such a provision active consideration for expenditures in connection with the rehabilitation of certain commercial and industrial buildings. Under section 314 of H.R. 13511 (which passed the House and reached the Senate Finance Committee in the 95th Congress), the investment tax credit would be available for qualifying energy conservation and al I other expenditures made in connection with a qualified rehabilitated building. These expenditures include investments in structural components of the building as well as capital equipment expenditures that constitute personal property.

Having recognized the importance of making available the investment credit in such circumstances to encourage the recycling of ex- isting commercial and industrial structures, it would seem equally important to extend such policy to "certified energy conservation expenses" - including structural components and capital equipment- in both newly constructed and rehabilitated residential structures. While the definition of "certified energy conservation expenditures" would require careful drafting to avoid abuse, the principle is the same as in the expansion of the investment credit.

\section{Rapid Amortization}

An altemative tax incentive to the expansion of the scope of the investment credit provisions is the enactment of a special rapid amortization provision for "certified energy conservation expenditures. " The technique of a 5year amortization provision has been used in the past to encourage investments in such areas as soil and water conservation (section 175), fertilizer (section 180), the clearing of land (section 182), the rehabilitation of lowand moderate-income housing (section 167(k)) and, most recently, the rehabilitation of historic structures (section 191 ). Such a technique seems particularly adaptable to encouraging investments in energy conservation.

Congress has, in more recent years, expressed the belief that incentive tax provisions should not become permanent parts of the Internal Revenue Code, but should be readily susceptible to review, change, and elimination as necessities and priorities change. Thus, for example, the 5-year amortization of expenditures for the rehabilitation of historic buildings applies only to expenditures made between J une 15,1976, and J une 15,1981. Such provision may be thereafter extended by Congress, as has the section $167(k)$ rehabilitation expense deduction for further periods (generally, of 2 years each in duration). A separate 5year amortization provision for energy conservation expenditures should be easily susceptible to such treatment. 


\section{CONSERVATION R\&D ACTIVITIES, OFFICE OF CONSERVATION AND SOLAR APPLICATIONS, DEPARTMENT OF ENERGY}

The buildings and community systems program of the Office of Conservation and Solar Applications is the major division within DOE that conducts $R \& D$ activities related to energy conservation in the residential sector. Under this program, there are a variety of subprograms which address specific areas of conservation $R \& D$. The purpose of this discussion is to provide a general description of the various subprograms and to address some of the problem areas in the $R \& D$ component of residential energy conservation.

\section{Program Objective and Strategy}

Specifically, the near-term objective of the buildings and community systems program, "is to produce total energy savings through the development and implementation of new technology equal to 2.4 million barrels of oil equivalent per day by 1985 by lowering unit energy consumption 20 percent in existing buildings and community systems; and 30 percent in new buildings, community systems, and consumer products."

The program is aimed at increasing energy utilization efficiency, providing options to substitute energy forms such as coal for natural gas, and providing technologies that decrease the need for energy to satisfy human needs. All activities are directed toward providing these new technologies within an economically and environmentally sound framework. Also, activities focus on preparing for transfer of energy-efficient technologies following demonstration to the residential and commercial sectors.

The strategy for attaining program objectives is to:

1. encourage and support the installation of energy-efficient technologies as soon as possible;

'Management Review and Control Document, Office of Conservation and Solar Applic ations, p. 1, Mar. 23, 1978
2 develop and commercialize systems that will reduce dependence on petroleum and natural gas;

3 develop and disseminate information about new and existing technologies conceming energy-efficiency utilization improvements;

4 promote the use of energy-conserving technologies and energy-conserving practices in the facilities and operations of the Federal Government;

5 develop and implement energy efficiency standards for new buildings and appliances; and

6 implement the weatherization program to meet certain energy needs of low-income citizens. $^{2}$

Another important objective of the buildings and community systems program is to involve nongovernmental groups in research, development, demonstration, and implementation activities to facilitate the transfer of technology and information to potential users as soon as the technology has been demonstrated to be economically and technic ally feasible. A majority of the funds that support these activities are spent with industry on a large number of cost-sharing projects. The program also works closely with various trade and non-Federal organizations to obtain comments from a variety of sources, including the $\mathrm{Na}$ tional Governors Conference, the National Conference of States on Building Codes and Standards, the League of Cities, Public Technology, Inc., the National Association of Home Builders, the American Institute of Architects, the American Society of Heating, Refrigerating and Air Conditioning Engineers, Inc., and the National Savings and Loan League.

\section{Budget Allocation}

Table 71 presents a summary of budget estimates (in thousands of dollars) by program ac-

2 $\mathrm{s}$ S Department of Energy, FY 1979 Congressional/ Budget Request, Jan. 23,1978, p. 1. 


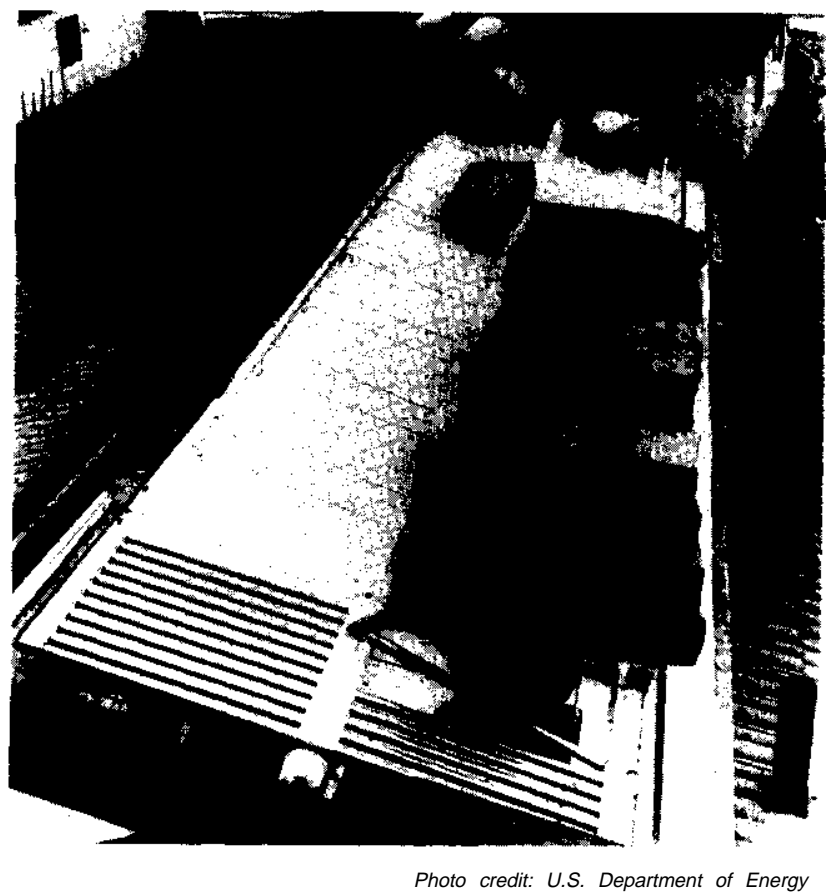

Energy-saving homes-Construction of homes in Mission Viejo, Calif., designed to use less than half the energy of surrounding conventional houses in a research project supported by DOE, Southern California Gas company, and the Mission Viego Company, a real estate firm

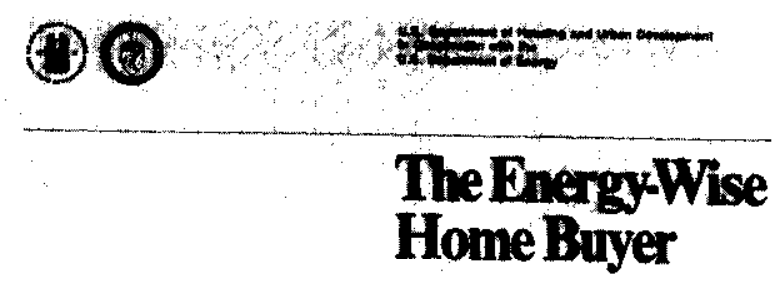

\section{AGuide to Selecting an Energy Eficient Home}

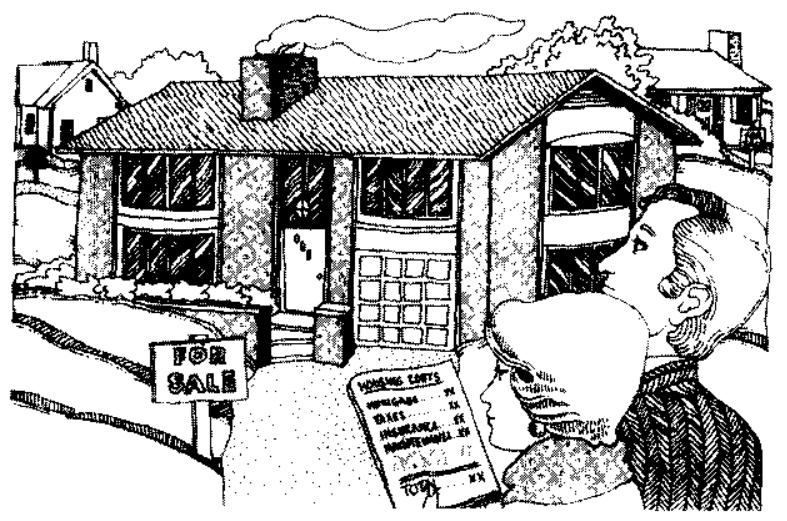

Disseminating information on residential energy efficiency involves cooperation within the executive branch. This publication was a joint effort of HUD and DOE

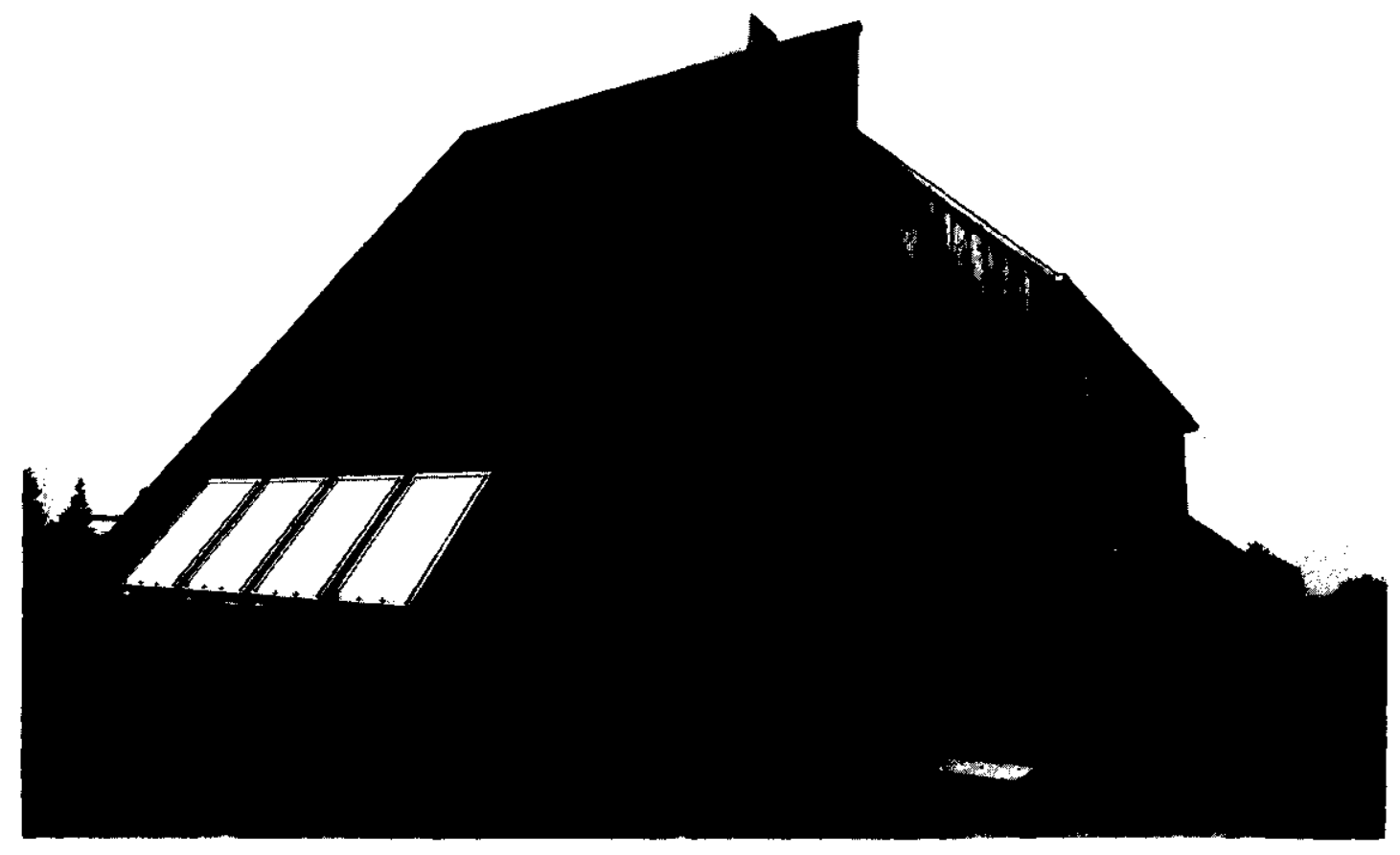

Photo credit: Department of Energy by Jack Schneider

Solar heating and cooling-This house in Baltimore County, Md., designed by architect Peter Powell, uses passive solar concepts to provide "natural" heating and cooling. DOE is studying passive solar heating concepts to determine how well they can work to save energy and money in buildings 


\section{Table 71._FY1979 Budget Estimates for Residential and Commercial Components of DOE'S \\ Conservation Mission}

(in thousands of dollars)

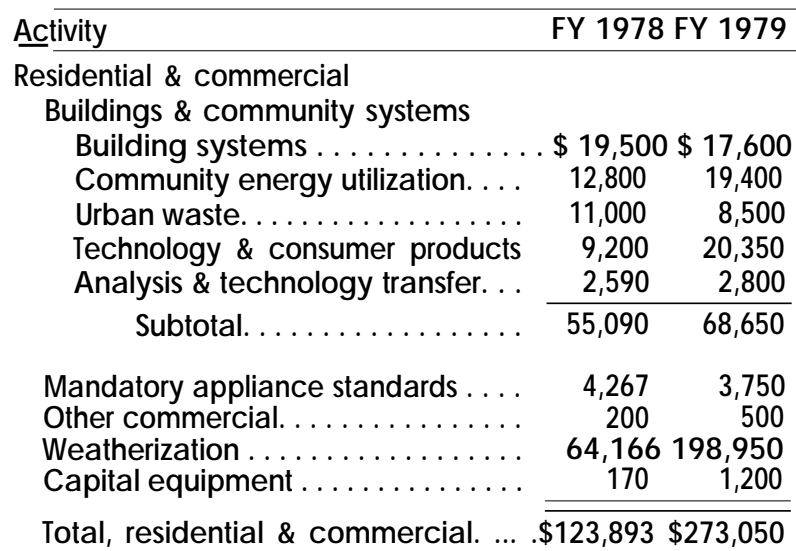

Estimate, residential \& commercial, FY 1979. . . . \$27,050

Estimate, residential \& commercial, FY 1978. . . . 123,893

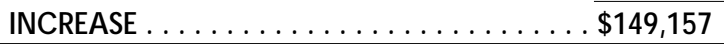

tivity for the residential and commercial component of DOE's conservation mission.

As the table indicates, the FY 1979 budget authority for $\$ 273,050,000$ represents an increase of $\$ 149,157,000$ from FY 1978. Part of this increase occurs in the community energy utilization program where projects are moving from the feasibility and design stages to demonstration. However, most of the increase occurs in the weatherization program to provide for weatherization of approximately 857,000 homes. The program essentially represents a balance between efforts which start to accumulate savings in the near-term (i. e., architectural and engineering systems, consumer products, weatherization, and utility retrofit programs) and the mid-term (i. e., community systems, urban waste, and technology development).

Table 72 represents a comparison of FY 1979 budget estimates for a variety of energy $R \& D$ activities within DOE.

\section{Table 72.-FY 1979 Budget Estimates for} DOE Energy R\&D

\begin{tabular}{|c|c|}
\hline ctivity & FY 1979 \\
\hline 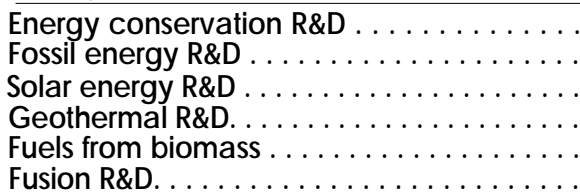 & $\begin{array}{r}\$ 707,101,000 \\
576,888,000 \\
441,900,000 \\
156,200,000 \\
42,400,000 \\
348,900,000\end{array}$ \\
\hline
\end{tabular}

As the figures suggest, conservation R\&D remains a high priority in the Federal energy agenda.

\section{Activities of the Buildings and Community Systems Program}

Building Systems. -The building systems objective is geared toward development and commercialization of energy-efficient design, methods of construction and operation, and the development of standards for new and existing residential and commercial buildings. For the residential sector, $R \& D$ attempts to provide cost-effective and acceptable technologies for retrofit of existing buildings (e. g., applications of revised mechanical ventilation and redesign of existing equipment to improve overall seasonal performance). Another major priority is the improvement of installation practices for mechanical equipment and the building envelope.

Community Systems.- There are three major thrusts to the community systems program: 1 ) integrated systems, 2) planning design and management, and 3) implementation mechanisms. All of these programs are moving from feasibility studies and initial design into demonstration activity, and the work is being performed cooperatively with other programs within other Federal agencies.

Some of the technological options of the integrated systems focus on energy sources (coal, solar), scaling (small to large), kinds of applications (new and retrofit), and targets of implementation (municipalities, utility companies, etc.).

The planning, design, and management activities focus on the development and testing of concepts, tools, and methodologies that identify and define relationships between urban forms and functions and energy utilization. For example, many case studies are being conducted on the tradeoffs between energy conservation measures and other community services, lifestyles, and economic activities.

The implementation activity is intended to provide data and develop strategies for implementation of the community energy systems 
and energy-conserving community design activities. Projects include market analysis for the integrated community energy systems, as well as development of financial strategies and management techniques for minimizing capital and operating costs and maintenance of community systems.

Technology and Consumer Products. -This activity strives to develop and encourage the commercialization of more energy-efficient new technologies in heating, cooling, and ventilating equipment and systems; lighting and windows; appliances; building controls; and diagnostic equipment for determining energy efficiency in buildings. Major activities are directed at the development and commercialization of advanced heat pumps and the development and testing of improved oil- and gasfired fumace components and systems. Other projects include the development and commercialization of high-efficiency gas- and oilfired space-conditioning systems and the development and testing of an integrated highefficiency space heating/domestic hot water heating system. Laboratory investigation and testing will continue to measure various properties of insulation materials.

Analysis and Technology Transfer.- The goal of this activity is to encourage early acceptance of new means for improving energy efficiency through the development of information and technology transfer methods, to conduct research that will encourage consumer purchase of more energy-efficient products, and to encourage more energy-efficient practices in the home. Major effects are the provision of information on savings for energy-efficient products, information on lifecycle costing and the cost effectiveness of energy-efficient products, and the provision of information on new technologies to the builder, homeowner, and manufacturer.

Appliances. -The major objectives of this program include the development of test procedures, minimum efficiency standards, and certification methods for a variety of appliances that include fumaces, central and room air-conditioning, water heaters, etc. I $\mathrm{n}$ addition, a consumer education program is underway to introduce the use of lifecycle costing concepts in comparative shopping for more efficient appliances.

Weatherization Assistance Programs, - This activity provides grants to the States for weatherizing the homes of low-income persons, particularly the eldenly and handicapped. At least 90 percent of the grant funds are expended on weatherization materials and related costs. In 1979 , approximately 857,000 homes will be weatherized.

Utility Insulation Service.- This effort is designed to guide the programs of insulation service that will be offered to the customers of large electric and gas utilities, and home heating suppliers, as directed by the National Energy Act of 1978. Implementation funding to State regulatory agencies, intervention in some hearings, and technical assistance to State agencies and utilities is involved.

Other Programs.- Other activities include the Energy Extension Service, designed to provide information and technical assistance to building owners and renters on reducing energy use; the State Energy Programs mandated under EPCA and EC PA; and the schools and hospitals program that assists these institutions in retrofitting buildings.

\section{Program Evaluation}

Activities in DOE represent a broad approach covering a number of technologies, institutional factors, and surveys of consumer attitudes. The R\&D program employs extensive analytical techniques to choose priorities, including cost/benefit calculations and projections of energy savings from proposed new technologies based on a sophisticated engineering-economic model. Despite this broad approach and strong analytical base, there are significant problems that are a result of both the general R\&D philosophy in the executive branch and program operation.

Problem Areas in Conservation R\&D.--This report has identified four areas with shortcomings in the current DOE conservation program. First, there is too much concentration on projects for the short term (5 to 15 years). Second, there is an insufficient connection be- 
tween supply $R \& D$ programs, particularly solar, and the goals of the conservation program. Third, there is an inadequate amount of basic $R \& D$ relevant to increasing energy productivity. Fourth, there is no clear relationship between the $R \& D$ activities and the policy and other program (weatherization, energy extension service, etc. ) portions of conservation.

1. Time Horizon. As stated earlier, the current buildings and community systems $R \& D$ program relies very heavily on sophisticated cost/benefit analyses and energy use projections to determine its direction. While this has merit in choosing between projects of neartem (5 to 15 years) application, it tends to bias against choice of anything that may have longterm ( 25 to 50 years) potential. The reason is that the only way to calculate the payoff of a project under this procedure is to estimate its likelihood of success, its use, and the amount of energy it will save. Such estimates became harder and harder the more speculative a project and therefore tend to be more readily dismissed when making funding decisions.

A certain portion of the research budget devoted strictly to more speculative proposals would help solve this problem, if it was based on a review process that did not have the shortterm bias built into the one just described. For example, the appropriate technology program not within the buildings and community systems division is designed to take some chances; the principal technical requirement is that the proposal not violate the laws of physics. Beyond that, the review process specifically goes after innovative and novel proposals. The procedure involves considerably more risk than the standard approach, and the frequency of failure will naturally be high. Change is needed because near-term technologies, such as the direct-fired heat pump, will be undertaken by private interests as energy prices continue to rise. The acceleration of technology development, which is supposedly the main reason for Government involvement with such R\&D, may be of marginal value in the residential sector, particularly when the inherent difficulties of commercialization are considered.
There is currently very little incentive to explore more efficient ways to use energy that will not be economical for decades. This could involve technologies requiring substantial modification of existing construction practices, extensive use of solar or other onsite generation, or new lighting, water heating, or space-conditioning methods. Work in these areas is not likely to gain support in the private sector, because the risk is so great and the potential payoff too far in the future.

2 Relation to Supply $R \& D$. One of the principal guidelines of an $R \& D$ program on demand technologies is that it should address the likely energy supply options. Currently, national research efforts are focused on synthetic fuel production from coal and biomass, solar thermal and electricity, geothermal, and electricity from nuclear and thermonuclear resources. All of these options will be expensive, and therefore it is important that new ways be found to use these sources efficiently. This coordination of goals is not apparent in the conservation $R \& D$ program. In particular, there is little work going on to explore appliance technologies, building construction techniques, and lighting schemes that would make use of solar energy in novel ways. Most of the work is directed toward conventional heating and cooling methods with solar replacing fossil combustion or electricity. Are there photochemical processes or passive solar designs that would dramatically reduce the amount of solar energy that needs to be collected, and therefore collector and storage costs? The OTA solar report indicated community solar energy systems could be economically attractive even using today's technologies if conventional energy prices continue to rise. Might not there be novel community designs and/or construction techniques that could reduce material costs for such systems? Although somewhat speculative, these proposals offer the potential for large economic benefits several decades from now. Similar arguments can be made about exploring ways to use expensive synthetic fuels, direct heat from geothermal steam, and electricity energy. To reiterate, the important points are that long-term, more speculative research should receive greater emphasis, and that it should be 
directed at the "inexhaustible" energy sources that will eventually be used.

3. Basic $R \& D$. Basic $R \& D$ in the conservation sector should be increased. Areas of importance include materials research for thermal insulation, optical coatings for windows, energy storage, air handling, and distribution to increase the overall efficiency of heating and cooling systems, and electro- and photochemical processes for more efficient use of electric and solar energy. Some work is underway in optical coatings and energy storage materials, but is only loosely connected to the residential conservation program, thus reducing the chances for application of results.

Other basic research areas concem nonhardware issues. For example, what constitutes comfort? A better understanding of the psychological mechanisms could suggest more efficient ways of delivering or removing heat. As suggested in the environmental section, indoor air quality may become very hazardous as buildings become tighter. Research on chemical pollutants that may be released in the home and ways to control them could be very useful in removing a potentially severe constraint to energy conservation.

More work needs to be done to learn how people actually use energy in their homes. A better understanding of use patterns is important for identifying areas for govemmental action in education and information. Technological decisions must be initiated not solely on the basis of technical feasibility, but on whether or not consumers will accept and use the technology.

The basic $R \& D$ efforts described here do not necessarily have to fall within one division of conservation for an effective program to exist. What is important is that basic conservation research be part of a comprehensive plan that is guided in part by the principals discussed above. Basic $R \& D$ is an essential part of any research effort that attempts to develop longterm, innovative technologies.

4. Relation to Conservation Policy and Programs. Under the Assistant Secretary for Conservation and Solar Applications in DOE there are several programs directed at increasing energy conservation in buildings. These include the weatherization and State energy management programs, and the energy extension service. I $\mathrm{n}$ addition, the Assistant Secretary for Policy of DOE is charged with Federal energy conservation policy. The issue here is the manner in which conservation $R \& D$ is used in carrying out the programs and developing policy. Currently there is no indication that this is done in a systematic fashion. The programs offer a unique opportunity to test new results coming from the near-term aspect of the $R \& D$ programs. If the latter had a specific goal for assisting Federal conservation programs, rapid commercialization of new technologies and more cost-effective conservation assistance could be possible.

The policy area is where the link between supply and demand $R \& D$ can be best made. By seeing to it that $R \& D$ on demand technologies associated with long-term supply options is given top priority, greater emphasis could be placed on long-term research in conservation. The policy could then be directed at encouraging the most economically efficient energy systems rather than just supply options. If $R \& D$ results identify technologies that use "inexhaustible" resources in novel and efficient ways, a national energy policy that better accounts for the contribution of conservation $R \& D$ can be outlined. The philosophy here is that there might be cases where development of new end use technologies could lower operating costs below that by improvement in energy production. For example, consider a home using solar energy to supply its needs. New construction techniques and materials might lower its energy requirements and improve the economics well below that resulting from any improvement in the energy production and conversion technologies. If policy is designed to encourage only the latter, however, the most economic solution would be missed. Therefore energy conservation $R \& D$ should be a major part of policy design with particular emphasis on looking for means to use the longterm energy source most effectively.

\section{Conclusion}

These problem areas appear to be more related to the general philosophy of conserva- 
tion apparently held by administration officials rather than to the management of the residential R\&D programs. An excessive concem for quick results has contributed to this posture. Part of the responsibility lies with $O M B$. It is in OMB that the decision to pursue near-term $R \& D$ is most prevalent. This rests in part on the need for OMB to maintain control over the Federal budget. As we have argued, however, if energy prices continue to rise, many of the DOE projects would become at- tractive enough to be undertaken by private interests.

As a result, there is probably a considerable amount of shifting that could take place within the program's current budget limits and still meet the objectives discussed above. This would seem to satisfy the OMB goals of budget restraint while simultaneously emphasizing the important long-term and basic research needs of residential energy conservation.

\section{STANDARDS AND CODES}

Building codes represent an obvious mechanism for improving the energy-use characteristics of new housing. In light of the growing awareness of concem over energy cost and a vailability, the Federal Government, both Congress and the executive branch, has taken an increased interest in codes. This section reviews the current level and extent of Federal activities that influence building codes with regard to energy. Because of congressional action, this is an area of much activity and controversy. The effort of the Federal Govemment to directly influence local building codes represents a new role in Federal-State-local relationships and raises many questions of equity, compliance, measurement, regulatory philosophy, and enforcement.

The energy-consciousness of the postembargo era triggered a number of congressional initiatives for encouraging greater energy efficiency in housing. Agencies with housing responsibility also tumed to standards and codes. Building codes are adopted by States and/or localities, normally in concert with codes endorsed by one of the three national code groups. Without exception, the principal responsibility for enforcement lies with localities. ( $1 \mathrm{n}$ some States, the State may act if localities do not.) Thus, the Federal Government does not write building codes. The Federal Govemment does, however, determine standards for participation in a number of federally funded housing programs. These standards have often influenced codes and practice.
Building codes have been used for nearly 4,000 years, to protect the safety and health of occupants. The earliest known example is the Code of Hammurabi, which dates from about 1750 B.C. Codes apply to new structures (or to very substantial alteration of a structure) and define acceptable materials and methods of construction. In this country, the emphasis of most codes has been to ensure a structurally sound building, reasonably resistant to deterioration over time, and reasonably protected against sanitation and fire hazards.

Two principal Federal programs have influenced building codes for a number of years: a) Minimum Property Standards and b) Building Energy Performance Standards.

\section{Minimum Property Standards}

The Department of Housing and Urban Development's MPS define and describe the minimum levels of acceptability of design and construction of housing built under HUD mortgage insurance and low-rent public housing programs. Although some of the requirements permit flexibility of design, the bulk of the standards are specified. In other words, they tell a builder what materials and methods are acceptable. This type of standard is known as a "prescriptive" standard, and is the type of standard of code in widest use today in the homebuilding industry. Designers, builders, and local code enforcement officials can refer to MPS and be certain that a given design or building is in compliance. 
Minimum Property Standards are mandatory national standards that cover one- and twofamily dwellings, multifamily housing, and certain care facilities insured or financed under HUD or FHA programs. MPS are also used to determine loan eligibility by VA and, until recently, FmHA.

Minimum Property Standards grew out of the National Housing Act of 1934. The purpose of that Act was to encourage improvement in housing construction and provide a base level of acceptability for mortgage insurance as the country began the great, federally supported housing expansion. Since that time, standards have been developed for a variety of housing types and a variety of factors. However, it is only recently that the use of MPS as a direct method to encourage energy efficiency has been perceived as a policy tool.

A decentralized network of HUD field offices (approximately 82 ) administers MPS in which architectural analysis and construction inspections are performed by architectural and engineering personnel. Working drawings and plans are reviewed and checked for compliance, and inspections are made during construction. If the construction does not meet the standard, Federal funding can be refused or withdrawn. This system of inspections has served to ensure a high level of compliance with MPS. It requires a substantial amount of time.

In 1977, about one in six private housing starts were insured by HUD's FHA or guaranteed by VA.

Over the past 2 years, HUD has been involved in upgrading MPS in response to new emphasis on energy conservation. The alterations to the standards have been controversial, and as of February 1979 final action was not complete.

The revised MPS reflect a decision to determine the acceptable level of certain measures in houses-those measures that reduce heating or cooling requirements -on the basis of costs over a 30-year period; the normal life of the mortgage. In addition to this time period, the DOE projected fuel costs are used. The use of these price projections means that MPS as altered will be a much more energy-efficient standard than those currently in use.

HUD employed a National Bureau of Standards computer model that uses a prototypical house with 15 different possible shell modifications to reduce heat transfer. The modifications include various levels of attic, wall, and floor insulation, double- and triple-glazing, and storm doors. The prototypical house has an unfinished attic and an unheated crawl space below the slab. The National Bureau of Standards load determination program (NBSLD) was used to calculate heating and cooling requirements of the house with various modifications for 14 cities with different climates. Cost data was detemined by present market levels and fuel prices were determined by DOE price data for 10 regions. (These prices assume increases until 1990 and a constant real price level thereafter. ) A 6-percent inflation rate is assumed throughout, and a 10 -percent discount rate. The computer program combines all the variables, and calculates a cost-benefit figure for each modification, in each location, based on a 30-year lifecycle cost. Separate calculations are made for electric resistance heat, gas heat, oil heat, and heat pumps. Results indicate whether each modification is cost-effective (savings over time exceed costs) or not.

The resulting new MPS thus attempts to balance costs, benefits, climates, and a vailable technology to reach an optimum level of reasonable energy conservation for new housing. There are three pathways for compliance with the standard.

The first method is the "component performance" approach, which defines the thermal transmission (U-value) through each of the components in the building. This approach sets a target for heat transmission through any component and allows flexibility in selecting materials. For example, a certain level of heat transfer for wall insulation, etc. Most homebuilders are expected to select this approach.

The second method is called an "overall envelope approach;" the overall thermal transmission of the dwelling must meet a stated value but components can be combined and 
manipulated within the structure. For instance, increased levels of insulation in the walls might be used to compensate for high heat losses through large window areas. This approach is the same conceptual method used in the ASH RAE 90-75 standard (see Model Code, below) but the standards as drafted appear to be more stringent. Some builders are expected to use this approach, particularly those building innovative housing and multifamily units. Masonry industry builders generally favor this approach, as it provides greater leeway for compliance and suits the particular needs of masonry structures.

The third avenue of compliance is "overall structural performance." Builders using this approach must demonstrate that they can meet or improve on the energy uses determined by either of the other two methods. Builders of manufactured housing and some masonry builders are expected to favor this approach.

The revised MPS are expressed in two forms; one for homes heated by electric resistance units and one for homes using heat pumps or fossil fuels. Approximately 49 percent of HUDfinanced buildings are estimated to use electric resistance heat, close to 50 percent are thought to use natural gas and only 0.5 percent use oil.

The new MPS will clearly mean an increase in first-costs as a result of increased amounts of insulation, more use of double- and tripleglazing, and possible increases in labor costs. They are designed, however, to effect a net savings in total costs through reduced energy bills, and to lower the consumption of fossil fuel.

A number of conservation groups, represented principally by the Natural Resources Defense Council, have objected to various aspects of the standards as not sufficiently effective in light of the necessity for lowering consumption of fossil fuel. The homebuilding industry has objected on the basis that the new MPS will be overly stringent, require levels of thermal protection that are not cost-effective, and will present technical difficulties for builders. (The National Association of Home- builders has argued that conservation investments should payback over a 7-year period, the time in which most homes are resold.)

Farmers Home Administration Thermal

Performance Standards

The Farmers Home Administration adopted MPS in 1971 as the minimum design and construction criteria for all residential structures constructed or purchased with FmHA loans or grant funds. At that time, FmHA found MPS provided adequate protection for its low- and moderate-income borrowers. However, escalating fuel costs and other economic pressures caused many FmHA borrowers to experience serious financial difficulties in the 1970's. There was an increase in the rate of foreclosures, abandonments, and voluntary transfers of FmHA housing units. Given what was then perceived to be HUD's lag in revising MPS, FmHA decided to act independently.

I n March 1978, FmHA issued its themal performance standards. The goal of the standards is to conserve energy and to control the heating and cooling costs for its borrowers. The economic rationale behind the thermal performance standards closely parallels that used by HUD for the revised MPS. However, FmHA elected to standardize its basic energy costs at 80 cents per 100,000 Btu delivered, and did not adopt a dual fuel standard, as most of their units ( 85 percent) are serviced by electric resistance heating.

The standards are more stringent than the proposed new MPS for fossil fuels, but are approximately the same for electric resistance. Higher levels of insulation are required in the ceilings, walls, and floors of dwellings. The choice of compliance paths is the same as for MPS - component perfomance, envelope performance, or overall structural performance.

Criticisms of the 1978 standards have been similar to the critic isms of MPS; conservation and some consumer groups have argued for strong standards to protect residents against rising costs; builders and some consumer groups have argued for keeping first costs low.

One of the major differences between the FmHA and the MPS programs is the approval 
process. FmHA activity occurs primarily at the county level; some 1,800 county offices serve the national constituency of the agency. Applicant interviews, review of plans, appraisals, and inspections are provided from the county off ice.

The Farmers Home Administration accounts for approximately 6 percent of the annual national housing starts. With the adoption of the new standards, FmHA estimates that the number of new housing starts for FY 1978 will decrease by up to 12 percent.

\section{Model Code for Energy Conservation in New Buildings}

In 1975, Congress enacted the Energy Policy and Conservation Act (Public Law 94-1 63). One of the numerous provisions of the measure is an authorization for funds to assist States in reducing the growth rate of energy consumption. States must initiate certain programs to receive the funding. (See chapter VII for discussion.) One of the requirements is the adoption of mandatory thermal efficiency standards and insulation requirements.

In implementing this legislative mandate, DOE had to determine a measurement of acceptability for the standards chosen by the States. This process led to creation of the Model Code, and launched a major Federal initiative affecting local building codes. The Department entered into a contractual agreement with NCSBCS. NCSBCS acts as a coordinator and an agent for uniformity and/or compatability between the major code groups. The major code groups are the Building Officials and Code Administration International, Inc. (BOCA), the International Conference of Building Officials, (ICBO), and the Southern Building Codes Congress Intemational (Southern). The Model Code reflects the technical provisions of ASH RAE 90-75, “Energy Conservation in New Building Design, " a document prepared by the American Society of Heating, Refrigeration and Air Conditioning Engineers. ASH RAE 90-75 as a consensus standard.

The provisions of the Model Code reflect its basis in standard engineering analysis. It is compatible with the language and approach of existing codes. Selection of this approach represented a major success for the engineering profession.

The provisions of the Code "regulate the design of building envelopes for adequate themal resistance and low air leakage, and the design and selection of mechanical, electrical, and illumination systems and equipment that will enable the effective use of energy in new building construction. " Three compliance paths are offered:

1. Specified Acceptable Practice Provisions A basic component approach, allowing the builder to check all materials and practices against guidelines.

2. Subsystem Approach. Various building elements can be combined to make a whole, i.e., the thermal performance and energy use of the envelope must be acceptable but there can be variation within the several parts of the structure [chapters IV through IX).

3. Systems Approach. Entire building and its energy using systems. This approach allows credit for the use of nondepletable resources (chapters $\mathrm{X}$ and $\mathrm{XI}$ ).

Once the Model Code was endorsed by DOE, it began to enter the State and local building code system through the various adoption processes. It is now estimated that by the end of 1979, 42 States will have adopted the Model Code or a similar methodology, either through direct adoption by the State or by reference.

The Department of Energy has provided funding for training programs for State and local officials on the Model Code. The code groups and NCSBCS have been the principal instruments for training and test efforts, along with engineering groups and other interested trade groups. Basic training documents have been prepared and tested in a few States. Much of the training material developed thus far is quite technical in nature. Early evaluation of training efforts conducted by some States on an informal basis has indicated that, due to the complexity of the provisions and the 
difference from existing practice, training will be needed for a long time.

It is not possible to conclude from the number of States that are in some stage of approving the Model Code the actual level of code enforcement. There is very little information available on code enforcement in general, in some jurisdictions a code is defined as enforced when it is adopted. This relieves the jurisdiction of the necessity for granting waivers. While local code inspectors have experience with traditional health and safety aspects of codes, the energy provisions are new and require leaming new calculations and practices. Building inspection as an activity is traditionally underfunded, and inspectors frequently have very large work burdens and slight technical preparation. I $n$ the past few years, budget trimming measures have often kept the number of officials at low levels despite increasing construction activity. (There are about 50,000 local code officials in the country. ) Building inspectors work for local governments and must be responsive to the desire of the locality and local builders to move quickly through the inspection process.

In addition to the normal range of objections to the Model Code (as being either too lenient or too demanding), the following principal technical objections are often raised:

1. The Code is not based on a clear measure of cost-effectiveness and therefore does not truly serve the interests of the consumer.

2. The Code is deficient in that the building envelope requirements are based entirely on heating degree days, with no consideration given to cooling loads.

3. The Code does not provide incentives for reducing the size of heating and cooling systems.

4. The Code allows the same building envelope requirements whether the fuel source is gas, oil, electric resistance, or heat pump.

5. The Code does not deal adequately with the important issues of siting, orientation, or dynamic effects.
6. The structural performance path, characterized as the most flexible compliance approach, is felt by some to be not sufficiently flexible to allow for real innovation in building design.

\section{Building Energy Performance Standards}

In 1976, Congress once again turned to building standards in enacting the Energy Conservation and Production Act (Public Law 94-385). This law requires that States and localities adopt building energy performance standards (BEPS). Such a standard is to consider the total energy performance of a building design and set energy use parameters without regard to specification of materials or type of construction. As normally defined, a performance-based standard specifies a goal without specifying the methods, processes, or materials used to reach the goal. The stated purpose of the Act is to:

(1) redirect Federal policies and practices to assure that reasonable energy conservation features will be incorporated into new commercial and residential buildings receiving Federal financial assistance;

(2) provide for the development and implementation, as soon as practicable, of performance standards for new residential and commercial buildings which are designed to achieve the maximum practicable improvements in energy efficiency and increases in the use of nondepletable sources of energy; and

(3) encourage States and local governments to adopt and enforce such standards through their existing building codes and other construction control mechanisms, or to apply them through a special approval process.

(Public Law 94-385, sec. 302(b))

The adoption of such a standard as a national target was understood to represent the most modern and far-sighted approach to energy conservation in buildings. Proponents of such standards, principally representatives of the architectural profession and certain environmental groups, expressed the conviction that performance standards would allow free reign to new, innovative design approaches, promote the use of nonrenewable resources, 
focus on energy consumption rather than materials or techniques, and in general raise the level of utility of standards. The adoption of performance standards was a victory for the architects, just as adoption of ASH RAE 90-75 as the basis for the Model Code had been a triumph for the engineering profession. It also marked a very new approach to measuring the energy use of building design. (No steps to require the building to actually meet the design energy level have been authorized.)

In November 1978, the "Advanced Notice of Proposed Rulemaking" (ANPR) containing the initial DOE statement on BEPS appeared in the Federal Register. Because of the legislative origin of BEPS, the new approach to standard setting BEPS represents, and the involvement of numerous interest groups in this issue, a great many important issues have emerged in the debate. Numerous studies and analyses have been prepared by the Govemment and private groups. This report does not attempt to restate the many complicated and thoughtful reports and analyses that are available on this topic. Six principal issues have been selected for specific discussion. These issues are likely to figure prominently in congressional debates.

1. The Unique and Complex Nature of the Standard. A perfomance standard approach to building design does offer the widest range of options to a designer. It appears to provide important freedom for innovation, particularly in the area of energy-conscious design ("passive solar"), where the structure itself acts as the heating and cooling mechanism. It also assures a focus on the energy consumption as a principal characteristic of the structure. It does not, automatically, ensure that a structure will use less energy than a comparable structure designed by standard code techniques. The practical side of the question, however, is that it has proven quite difficult to draw a performance standard that satisfies all the objectives and yet is correct for the majority of buildings and agreed on by all players. There are still many unanswered questions about the dynamic performance of buildings. An accurate figure is difficult to determine for likely actual infiltration rates. There is disagreement over the accuracy of various computer programs and calculations used to derive energy budgets. While initial calculations have been expressed in $\mathrm{Btu} / \mathrm{ft}^{2} / \mathrm{deg}$ ree day, some critics suggest that the function of various areas of the structure must be included (different budgets for homes with lots of bedrooms and little communal space, for example). Thus, a question exists as to whether the state-of-theart is adequate to determine a valid energy budget equation, (not whether housing can be improved).

I $\mathbf{n}$ addition to this issue, the draft statement released by the Department in the ANPR contains provision for RUFs - Resource Utilization Factors-and RIFs - Resource Impact Factors. The Resource Utilization Factor weighs the relative efficiency of total energy used in the various typical home fuels, and assigns a higher thermal integrity requirement to homes using electric heating. Traditional codes have measured energy from the input of the home rather than from the point of origin. While there are clearly different supply situations and different thermodynamic characteristics of various fuels, this issue has not been fully addressed by Congress. RI F, which has not been used as a meaningful factor as yet, represents an attempt to quantify the social, environmental, and similar "external" costs of using certain fuels. Reaching agreement on a quantitative value for RIF will be extremely difficult. Both RUFs and RIFs reflect an attempt to design a standard that measures impacts well beyond the simple heat use of buildings. Both RUFs and RIFs represent areas of great controversy and fuel the debate over BEPS.

2. Regulatory Philosophy. I n any standard-setting process, there will be varying opinions on the regulatory philosophy to be employed. Regarding BEPS, proponents of rapid energy conservation, including many environmental groups, wish to have the initial standard set at a level attainable by the construction industry but well above the current level of practice. Building industry representatives contend that the existing codes are adequate, that the industry is responding to consumer demand for energy conservation as quickly as possible, 
and that to require a higher level of performance would be injurious to the industry and cross the "reasonable" boundary.

Resolution of this controversy is related to many other problems in home energy conservation. No established and consistent strategy exists to reduce residential energy consumption over time. No schedule has been established for upgrading MPS, the Model Code, or BEPS regularly, and no second-or third-level targets have been created. An example of target setting exists in the automobile industry. Manufacturers were put on notice as to the acceptable levels of fleet average fuel consumption that would be expected over a number of years. Some similar set of goals might be useful for the housing industry. (The State of Wisconsin has adopted such an approach.) Goal setting is particularly necessary if some form of sanctions is to be invoked for noncompliance, either now or in the future. Similarly, incentives that could be added to the program could be tied to reaching certain energy use levels prior to the required date.

In any event, the first BEPS levels were based on 1974 construction data. Since 1974, there has been a considerable improvement in the level of insulation, use of double- and triple-glazing, and other factors influencing energy use. (See "Housing Decisionmakers," chapter $\mathrm{V}$ and appendix B.) To establish a standard based on 1974 data may well be drawing a standard below current industry level of practice.

3. BEPS Timetable. Many of the problems that now characterize the debate over BEPS appear to result from DOE's attempt to respond to an unrealistically accelerated timetable for preparation and publication of a standard. The first BEPS draft regulations were to appear at least 1 full year prior to rulemaking, to allow for full comment and review. This schedule was not met. ANPR appeared on November 21, 1978, and hearings began on December 1 , 1978. This timing has resulted in understandable cynicism from critics of ANPR regarding the openness of the process. Principal consultation during the drafting period for BEPS was with the construction industry, despite a legislative requirement for full public par- ticipation. A proprietary computer program was used for commercial building calculations. Since not only the specific formulas used in BEPS but the assumptions and premises of the supporting analysis are presumably open to review, the time allowed appears totally inadequate. Interestingly, the Federal experience seems to be paralleling the experience of the State of Califomia. California prepared an energy conservation code, including some energy budget standards. The standards were drawn quickly, and there was not enough time to fully consider comments or objections. The standard has met with resistance and litigation. While an agency cannot protect against litigation by taking a long time to act, the consequences of releasing a standard of such potential impact as BEPS without very thorough and sincere public review and involvement seem dire.

4. Implementation. Once agreement has been reached on the determination of the standard, very substantial problems will remain regarding Implementation. Implementation issues need to be faced from the beginning, in order that the standard as eventually promulgated can be as productive as possible. Federal standards that must be enforced by State and local officials face many problems of compliance There is no indication that the problems of implementation have been given the appropriate level of consideration. Implementation problems are critical because DOE, through the Model Code, has already launched States on a very different code course. Several factors stand out:

A) Preparation for the New Standard. Due to the existing DOE State grant program, States have put considerable effort and resources into adopting the Model Code or similar, engineering-based standards. The training that has been done by code and professional groups has concentrated on that approach. No training has been done to prepare States for BEPS. While some HUD and DOE research studies and contracts have been initiated to prepare for the new standards, OTA interviews with State officials and people working in code enforcement indicates that there is 
essentially no understanding of the performance standard, and almost no awareness that the standard is about to be adopted. The response of States contacted during the OTA study has been one of surprise that such a standard was in the pipeline, and skepticism about the seriousness of the Government in implementing it.

B) Equivalency. The enabling legislation states that States must adopt BEPS or a standard that will "meet or exceed the requirements" of the Federal standard. No determination has been made as to how the equivalency requirement will be defined. It could mean that all States and localities would have to adopt a performance standard using the same or similar methodology as BEPS. It could also mean that the localities must have in place, a standard that results in limiting energy consumption in buildings to approximately the same level. If this is the case, for example, changes in the Model Code to increase the level of effectiveness could meet the equivalency test. Without an indication of how the equivalency requirement will be interpreted, States have little guidance as to how to prepare. Will there be two separate, overlapping standards? If only a pure perfomance standard is acceptable, by whom will the design drawings be certified? Will computer analysis be made available by DOE, or will builders be required to obtain the imprimatur of an architectural and engineering firm for certification? Will local code officials be expected to interpret the BEPS criteria? Will special assistance or review be provided by DOE or HUD area offices? Who will monitor the progress of the industry? What sort of financial and technical assistance will be provided to localities for additional inspections? These problems are resolvable, but decisions must be made with the involvement of State and local officials if compliance is expected.

C) Transition. This issue relates once again to target setting, as well as to preparation. If a performance-based standard is designated as the only acceptable path of compliance, will the new approach be phased in over time? States and towns cannot modify building codes quickly. Traditional processes of review and approval must be followed. Many States are still moving through this process on the Model Code effort. Who will train the building inspectors, State energy office technicians, and others who will bear the brunt of the effort?

5. Sanctions and Incentives. The enabling legislation requires that the Secretary of DOE recommend to Congress whether or not to adopt the authorized sanction of the program. This sanction is the withdrawal of Federal funding mechanisms for housing, including FHA funding and Federal lending programs. If adopted, the sanction would be extremely strong. If the sanctions are not adopted, it is unclear what mechanism or leverage would be available to encourage compliance. The use of incentives for the early periods has been suggested; homes meeting low energy standards could receive favorable loan terms from Federal programs or other forms of assistance. The new standard could simply be adopted and localities encouraged to incorporate it into existing codes, so that those wishing to use this approach could take advantage of it. Data could be collected on houses designed by this approach and this data could be used to determine if broader application is desirable. Federal property, or property directly assisted by Federal programs, could be required to meet BEPS criteria. The Minimum Property Standards could be revised to incorporate BEPS. Special grants could be made available to localities to test BEPS and experiment with alternative methods for measuring compliance. Awards for design competitions might encourage BEPS usage. Congress could consider adding any one of a number of options to the existing legislation either in addition to or in lieu of the authorized sanctions.

6. Special Problems of Housing. The energy consumption in commercial-sized buildings is better understood than the consumption of most houses. The principal involvement of ar- 
chitects and engineers is with larger buildings rather than housing. Most housing in the United States is constructed by small builders who have little technical training or access to technical assistance and few resources (see chapter V). Most small builders use the simplest approach to meeting code approval; they follow accepted practice for their area and the prescriptive aspects of codes. Given the diffic ulties of determining an energy budget for a house, and the problems of training small builders to comply, it may be necessary to provide a simple methodology for the housing sector, such as previously approved designs that have been translated into specifications. In the
Advanced Notice of Proposed Rulemaking on BEPS, the residential sector was simply directed to follow the National Association of Home Builders Thermal Performance Guidelines. No rationale was given for this decision. A number of technical problems exist within the Thermal Performance Guidelines, although they do appear to be more responsive to climate and local conditions than the draft BEPS, which rely on seven climate zones.

If housing is to be included under BEPS, more thoughtful attention must be given to the special needs of the sector. 
Chapter IX

\section{ECONOMIC IMPACTS}




\section{Chapter IX.-ECONOMIC IMPACTS}

Unemployment, Inflation, and Real Economic Growth. . ..........211

The Total Number of Jobs . . . . . . . . . . . . . . . . . . . . 211

Labor Productivity and the Distribution of Jobs and Income

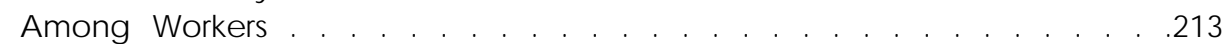

Inflation . . . . . . . . . . . . . . . . . . . . ...........214

Real Economic Development . . . . . . . . . . . . . . . . .....214

TA BLES

73. Full-Tme

73. Full-Time Employment Equivalents per $\$ 100,000$ Expenditure. . . . .212 


\section{UNEMPLOYMENT, INFLATION, AND REAL ECONOMIC GROWTH}

Home energy conservation may be evaluated for its impact on unemployment, inflation, and the general performance of the domestic economy in the long run. As throughout this report, this chapter assumes that real energy costs are rising and will continue to rise in the future, and that eventually energy consumers or society as a whole will pay prices that reflect these higher real costs. Given these assumptions, it is important to realize that this changing supply situation has a variety of economic impacts that cannot rightly be attributed to energy conservation in the home.

Higher real costs and prices have several effects. They mean that individual energy consumers and the United States as a Nation can buy fewer goods and services than otherwise. Money previously available for other purchases must now go to pay for energy. Higher energy prices also redistribute income from energy consumers to owners and producers of energy resources. Some of this redistributed income now goes abroad to pay for fuel imports and this further reduces domestic income. Higher energy prices also change the mix of job opportunities to reflect the buying pattems of those who benefit from energy sales, including fuel-exporting foreign countries. Finally, real domestic income may fall if energy prices jump too abruptly, causing short-term unemployment and other economic dislocations.

Home energy conservation, by the substitution of more energy-efficient devices and structures or by behavioral changes, is the economic response by the residential sector to higher energy prices and uncertain supplies. This chapter examines the broader economic effects of this response. Besides saving dollars, residential conservation has other economic implications because it redirects expenditures away from fuel to other goods and services.

Production of nonenergy goods and services generates income and it is important to see how this income is distributed compared to the distribution generated by energy production. This comparison will be made in terms of the proportion of national income going to workers, which is determined by the total number of jobs and by labor productivity. After the issue of who benefits, there are important questions about whether these benefits are proper economic incentives. Do they help or hinder the national economy in adjusting to the depletion of oil and gas supplies? Does this redistribution of income improve the utilization of labor and capital or does it aggravate inflation?

\section{THE TOTAL NUMBER OF JOBS}

Home energy conservation can increase the number of jobs in three ways:

1. by the substitution of domestic labor for imported fuels;

2. by the substitution of labor-intensive goods and services for capital-intensive, domestically produced energy;

3 by yielding a net retum or savings out of which families can increase personal con- sumption expenditures beyond what they could if old energy consumption patterns had been maintained.

Each of these three factors is discussed below and the order of discussion reflects the sequence in which they arise. When energyconserving investments are made, employment caused by this investment substitutes for employment in energy production (1 or 2 ). 
After energy-conserving improvements have been installed, consumers begin to accumulate net income from their profitable investments and this can be spent elsewhere (3).

1. Home energy conservation may reduce the demand for imported fuels directly as in New England where most home heating oil is imported. It may also reduce imports indirectly by freeing up domestically produced fuels that can substitute for imports elsewhere in the economy. In either case, jobs created by conservation are not offset by jobs lost anywhere else in the domestic economy, and total employment clearly increases, assuming there are unemployed people avail able.' Furthermore, keeping income within the country indirectly increases employment by an additional amount due to resending. One dollar of additional (real) domestic income generated by import substitution yields at least another in secondary expenditures, if unemployment is at a high level, and on the average $\mathbf{7 5}$ percent of this is spent on wages and salaries. ${ }^{2}$

2. Home energy conservation also reduces the need for more domestically produced energy. This would apply mainly to highcost supply altematives since any lower cost supplies saved from residential use would reduce the need for new higher cost alternatives elsewhere in the economy. High-cost energy supplies include electricity and new sources of oil, gas, and coal.

Labor intensities in terms of jobs are either indicated or can be inferred from the data presented in table 73. These are average data for existing enterprise, but it

${ }^{1}$ Of course payments abroad may be recycled in terms of U.S. exports but on the margin this is probably not important since there is a general dollar surplus among fuel exporting countries.

${ }^{2}$ For a recent discussion of multiplier effects, see Albert A. Hirsch, "Policy Multipliers in the BEA Quarterly Econometric Model," Survey of Current Business, June 1977 , pp. $\mathbf{6 0 - 7 1}$. The estimate that 75 percent of secondary expenditures goes to labor is based on the fact that the average labor share in national income is 75 percent. See Statistical Abstract of the United States, 1978, table 718, p. 444.
Table 73.-Full-Time Employment Equivalents per $\$ 100,000$ Expenditure" (1967 input/output data)

Sector

Manufacturing household appliances. . . . . . . 8.6

General maintenance and repair . . . . . . . . . . . . 8.8

All investment in fixed capital . . . . . . . . . . . 9.2

Residential construction . . . . . . . . . . . . 9.2

Personal consumption expenditure (average)

Natural gas. . . . . . . . . . . . . . . . . . . . . 2.7

Coal

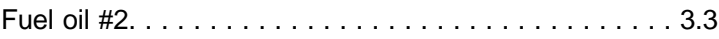

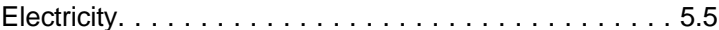

- See Donna Amado, "Creation of Labor Data for 1963, 1967, and 1972," Center for Advanced Computation, technical memo No. 77, University of Illinois at Urbana-Champaign, September 1976, pp. 66-72. Data includes both direct and indirect labor Inputs.

can be safely inferred that new fuel sources would not greatly increase labor utilization over conventional supplies since the former involve technically complex, capital-intensive stages of production added on to present fuel-producing a c tivities.

Compared to fuel production, home energy-conserving activities are relatively labor intensive. A comparison to home appliance manufacturing is pertinent when conservation is accomplished by more rapid turnover of the stock of heating, ventilating, and air-conditioning equipment as well as other home appliances. A comparison to residential construction is pertinent when conservation is accomplished by more rapid turnover or increased investment in housing stock. Finally, a comparison to general repair and maintenance is pertinent when conservation is accomplished by more rapid tumover or increased investment in housing stock. Finally, a comparison to general repair and maintenance is pertinent when conservation is accomplished by retrofitting homes. In all of these comparisons, based on the actual or inferred information contained in table 73, home energy conservation is relatively labor intensive.

3 After energy-conserving investments begin generating savings for families, private consumption expenditures for all goods and services can increase, offsetting to some extent the loss in real income caused by rising energy prices. These ex- 
penditures create more jobs per dollar than any other type shown in table 73 . The size of this third effect depends on the profitability of home energy-conserving investments, and OTA analysis above clearly suggests that these profits may be substantial. (See chapter I I.)

Despite these three positive conclusions about job creation, it should not be implied that home energy conservation will solve the national employment problem. Direct energy expenditures account for only about 5 percent of gross national product and residential consumption only for a fraction of that. However, we can say that some jobs will be created and this should make it easier to reduce the rate of unemployment.

\section{LABOR PRODUCTIVITY AND THE DISTRIBUTION OF JOBS AND INCOME AMONG WORKERS}

In analyzing labor productivity, it is important to reemphasize the distinction between rising real energy costs and prices and subsequent conservation efforts. The former clearly reduces average product per worker as it reduces real national production. Energy conservation on the other hand should increase both by moving to a more productive mix of energy, capital, and labor. This overall positive impact of home energy conservation is clear, based entirely on the fact that it is profitable. If prices of capital, labor, and energy all reflect real costs, then profitability is synonymous with getting more total product and larger average product per worker out of the same package of resources.

Not all workers, however, will benefit from reduced energy consumption in the home. In particular, workers in displaced energy supply activities may lose their jobs or be asked to accept lower incomes, and this prospect raises issues that must be resolved politically. However, in these political discussions, two points should be kept in mind.

First, a major advantage of home energy conservation, when compared to increasing energy consumption, is that jobs are less likely to be concentrated at centralized points of production such as at the wellhead, the mine mouth, or at the electric power station. Home energy conservation involves more extensive downstream operations (distribution, sales, construction, installation, and maintenance), which means that employment opportunities are spread out geographically in a pattem determined more by the location of the final consumer. This decentralization is beneficial because it spreads income from employment more evenly across the country and, in particular, it reduces the outflow of wealth from energy poor regions and districts that have suffered the most due to rising energy prices.

Second, the threat of job or income loss for presently employed people may not be significant if the national economy can reduce its energy consumption per dollar of product and still continue to grow apace with the size of the labor force. If it can, and energy conservation is one of the engines for such growth, then high-cost energy supply activities may not actually contract, but merely not grow as fast, and present workers can stay on the job. In other words, home energy conservation has more impact on the locus and kind of new jobs than on jobs that already exist. This situation obtains in part also because most of the energy-conserving options considered here will require a decade or more to accomplish. 
INFLATION

Home energy conservation, as defined here, is anti-inflationary because it costs less (for roughly the same convenience and comfort) to conserve or save a Btu of energy in the home than to produce it. This saving is partly due to the substitution of less expensive domestic goods and services for imported fuels. Since the United States has a serious balance of payments problem, this reduces downward pressure on the dollar and domestic inflation caused by currency devaluation.

Anti-inflationary savings also derive from the relatively broad geographical distribution of energy-conserving jobs, compared to jobs in energy supply, which makes them accessible to a larger number of potential workers. A large fraction of energy-conserving jobs can also be accomplished by people with skills in maintenance and repair. Such skills are fairly widespread and can be acquired without extensive training. Consequently, it is unnecessary to bid up wages very far before large numbers volunteer for work, including many from the large pool of chronically unemployed.

Finally, labor is substituted for energy without bidding up wages and salaries when families do a better job of housekeeping. The factor of two difference in energy use among people with the same basic energy services (see chapter III) suggests that this form of increased self-employment may be quite important in increasing real incomes while decreasing inflation and energy consumption.

In capital markets, home energy conservation has two distinct advantages when compared to alternative investments that would otherwise have to be made in energy supply. First, home energy-conserving investments are relatively profitable. There are exceptions of course, and new supply technologies might come along which are very profitable, but the current situation is illustrated by comparing investment payoff periods. New electric powergenerating stations are commonly amortized over 20 to 30 years because it takes that long to accumulate sufficient revenues above operating costs. Investments in home energy conservation typically pay off within 10 years and may yield revenues above debt senvice costs right from the very beginning. In other words, a given stock of real resources and finance capital can support a greater total amount of investment activity if home energy conservation reduces Investment in energy supply, and this means less pressure on interest rates to rise.

Second, for the approximately 65 percent of dwelling units that are owner occupied, home energy-conserving investments have many attractive aspects. A dollar of payoff in terms of reduced expenditures for energy is worth more than a dollar of income to buy energy because only the latter is subject to income tax. The home owner/investor, in other words, has a tax incentive to save rather than to buy energy. Also, energy-conserving investments, unlike savings accounts and other securities available to small investors, do not have fixed rates of retum that can be wiped out by inflation. Furthermore, rates of retum in terms of reduced energy expenditures are very likely to increase faster than inflation because price increments for energy are likely to be above average. Both of these factors are inducements to increase savings beyond what homeowners might otherwise and, again, this takes pressure off of interest rates.

\section{REAL ECONOMIC DEVELOPMENT}

As defined in this report, home energy conservation saves money and so it can occur largely as the result of private market behavior. In addition, this profitability also serves as an economic incentive toward reducing unemployment and inflation because it redirects spending toward relatively plentiful supplies of labor and capital, and results in a 
situation overall in which goods and services are delivered at a lower total cost. Home energy conservation, in other words, can be recommended both on the basis of its payoffs to the Nation as a whole as well as its profits for residential consumers.

Qualifications might be made based on short-run adjustment rates for labor and capi- tal markets (e. g., labor must be trained and interest rates may be temporarily very high), but in the long run the progressive economics of home energy conservation cannot be denied. The fundamental point is that energy supplies cannot be expanded without rapidly increasing real costs, while cost increments for the expansion of labor and capital, as substitutes for energy, are much smaller. 


\section{Chapter X INDOOR AIR QUALITY}




\section{Chapter X.-INDOOR AIR QUALITY}

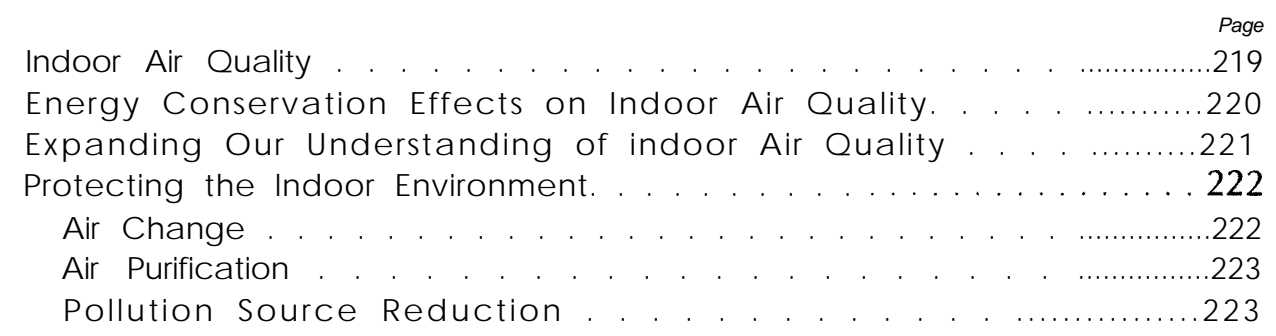

TA BLE

74. Characteristic s of Some Indoor Air Pollutants. ..............220

FIG URE

21. Nitrogen Dioxide Concentrations in a $27 \mathrm{~m}^{3}$ Experimental

Room at Various Air Exchange Rates . . . . . . . . . . . . . ...221 
Energy conservation measures that decrease air exchange rates in buildings may increase problems associated with indoor a ir quality. Without appropriate control measures, a "tighter" house may allow a significant buildup of air pollutants - carbon monoxide, nitrogen dioxide, hydrocarbons, respirable particulate, and others-that are generated within the structure. An increase in indoor concentrations of these pollutants may have a serious effect on the comfort and health of the occupants.

\section{INDOOR AIR QUALITY}

The air pollution control effort in the United States has generally considered the pollutant concentrations of outdoor air as the appropriate measure for population exposure. Exceptions to this emphasis have been the attention given the industrial workplace environment and building codes for office and public buildings, which require minimum ventilation rates. The indoor residential environment, to the extent that it has been considered, has generally been assumed to shelter the occupants from exposure to higher pollutant concentrations found outdoors.

It is now clear that indoor levels of several important air pollutants can be as high as or higher than outdoor levels. (See table 74.) Consider the results of a few recent research projects:

- Several studies have shown that household gas stoves can cause high indoor concentrations of carbon monoxide, nitrogen oxides, and fine particulates. Lawrence Berkeley Laboratory' and other sources have shown that nitrogen oxide emissions from such stoves are sufficiently high to cause kitchen concentrations to exceed the range of recommended 1-hour national ambient air quality standards (NAAQS). Some studies have also indicated that carbon monoxide levels may be raised to levels above the short-term ambient standards, but results have been extremely variable from study to study.

'Craig D. Hollowell and C. W Traynor, CombustionCenerated Indoor Air Pollution (Lawrence Berkeley Laboratory, April 1978) Report LBL-7832
- Danish scientists have found high levels (up to nearly twice the legal occupational exposure limit) of formaldehyde in homes that have substantial quantities of particle board in their structure. ${ }^{2}$ Similarly high levels of formaldehyde concentrations have been found in mobile homes in the United States.

- Several studies have shown that smoking seriously affects the indoor environment. The particulate from cigarette smoking are in the respirable size range; nicotine is the second largest component of the smoke. ${ }^{3}$ Moderate smoking (a pack a day) can cause particulate concentrations to exceed the 24-hour ambient air quality standard.

Internal sources of pollution include gas stoves, a variety of building construction materials including wallboard, paint, and insulation, cigarette smoking, aerosol spray, cleaning and cooking products, and products used for hobbies and crafts. Even the concrete and stone in the floors and walls of homes add quantities of radon "daughters" (a fission

${ }^{2}$ Andersen, "Formaldehyde in the Indoor Environmental-Health Implications and the Setting of Standards, "International Indoor Climate Symposium (Copenhagen, Aug. 30- Sept. 1, 1978).

${ }^{3}$ W C. Hinde and M. S. First, 1975, "Concentrations of Nicotine and Tobacco Smoke in Public places, "New England Journal of Medicine, 292:844-5.

'For example, see S. J. Peakale and G. De Oliverira, 1975, "The Simultaneous Analysis of Carbon Monoxide and Suspended Particulate Matter Produced by Cigarette Smoki rig," Environment/ Research, 9:99-114. 
product of radon)--potential causes of lung cancer-to the indoor environment. Table 74 provides a brief summary of the sources, ef- fects, and exposure levels of the important air pollutants found in significant quantities in indoor a ir.

Table 74.-Characteristics of Some Indoor Air Pollutants

\begin{tabular}{|c|c|c|c|}
\hline Pollutant & Major sources & Impacts & $\overline{\text { Exposure indoors }}$ \\
\hline Sulfur dioxide $\left(\mathrm{SO}_{2}\right) \ldots$ & . Outside air & $\begin{array}{l}\text { Risk' of 'acute and'long-term } \\
\text { respiratory problems in } \\
\text { conjunction with particulate }\end{array}$ & $\begin{array}{l}\text { Usually somewhat lower than } \\
\text { outdoors }\end{array}$ \\
\hline Carbon monoxide (CO). & $\begin{array}{l}\text { Outside air (autos), gas stoves, } \\
\text { smoking, infiltration from } \\
\text { garage }\end{array}$ & $\begin{array}{l}\text { Headache, dizziness at lower } \\
\text { concentrations; nausea, } \\
\text { vomiting, asphyxiation, } \\
\text { death at higher concen- } \\
\text { trations }\end{array}$ & $\begin{array}{l}\text { Can be high from indoor } \\
\text { sources; much outdoor } \\
\text { concentration is passed } \\
\text { indoors }\end{array}$ \\
\hline Nitrogen dioxide $\left(\mathrm{NO}_{2}\right)$. & $\begin{array}{l}\text { Outside air, gas stoves, oil } \\
\text { or gas furnaces (when } \\
\text { imperfectly vented) }\end{array}$ & $\begin{array}{l}\text { Risk of acute respiratory } \\
\text { problems, possible long-term } \\
\text { respiratory problems, possi- } \\
\text { ble increased mortality } \\
\text { from cardiovascular disease } \\
\text { and cancer }\end{array}$ & $\begin{array}{l}\text { Can be very high, especially } \\
\text { when gas stove is operating }\end{array}$ \\
\hline Photochemical oxidants & Outside air & $\begin{array}{l}\text { Eye irritation, respiratory } \\
\text { discomfort; long-term prob- } \\
\text { lems not well-understood }\end{array}$ & $\begin{array}{l}\text { Lower than outdoor concen- } \\
\text { tration }\end{array}$ \\
\hline $\begin{array}{l}\text { Total suspended } \\
\text { particulate (including } \\
\text { trace elements). . . . . . . }\end{array}$ & $\begin{array}{l}\text { Outside air and resuspension } \\
\text { from physical activity; } \\
\text { smoking, asbestos insulation, } \\
\text { gas stoves, etc. }\end{array}$ & $\begin{array}{l}\text { Risk of short-term pulmonary } \\
\text { effects; some toxic com- } \\
\text { ponents can have severe and } \\
\text { varied effects }\end{array}$ & $\begin{array}{l}\text { Can be very high, especially } \\
\text { from smoking; particles } \\
\text { in respirable size range } \\
\text { dominate }\end{array}$ \\
\hline Hydrocarbons. . . . . . . . & $\begin{array}{l}\text { Outside air, smoking, pesti- } \\
\text { cides, spray can propellants } \\
\text { (fluorocarbons), cleaning sol- } \\
\text { vents, building materials, } \\
\text { etc. }\end{array}$ & $\begin{array}{l}\text { Risk of a variety of severe } \\
\text { acute and long-term effects }\end{array}$ & $\begin{array}{l}\text { Can be high, also can have } \\
\text { continuous low-level concen- } \\
t \text { rations }\end{array}$ \\
\hline $\begin{array}{l}\text { Radon \& radon } \\
\text { daughters ... . }\end{array}$ & Cement, stone, bricks, etc. & $\begin{array}{l}\text { Enhanced risk of lung cancer, } \\
\text { other cancers }\end{array}$ & May be sign if i cant \\
\hline Bacteria \& spores. . . . & . Coughing, sneezing & Spread of respiratory illness & Higher than outdoors \\
\hline
\end{tabular}

\section{ENERGY CONSERVATION EFFECTS ON INDOOR AIR QUALITY}

A principal strategy for conserving energy in homes is to lower the rates of a ir exchange from infiltration and exfiltration, as this air exchange is a major heat loss mechanism (and a major source of cooling loss in hot weather) in buildings. Lowering air exchange rates is accomplished by sealing the structure, e.g., by weatherstripping, caulking, sealing cracks, and tight construction.

Lowering the air exchange rates in a structure also slows the diffusion of indoor-generated air pollutants to the outside. In other words, the pollutants tend to be trapped inside the structure. Many of the studies of indoor air quality show a clear and strong inverse relationship between pollutant levels and air exchange rates. For instance, figure 21 demonstrates a very strong inverse relationship between air exchange rates and nitrogen dioxide concentrations in the presence of an operating gas oven. ${ }^{5}$

Many of the indoor air quality problems were discovered only when air exchange rates were drastically reduced and the pollution effects became obvious to the building's inhabitants. These effects tend to be odor and mois-

\footnotetext{
${ }^{5}$ Hollowell and Traynor, op cit.
} 
Figure 21. - Nitrogen Dioxide Concentrations in a $27 \mathrm{~m}^{3}$ Experimental Room at Various Air Exchange Rates

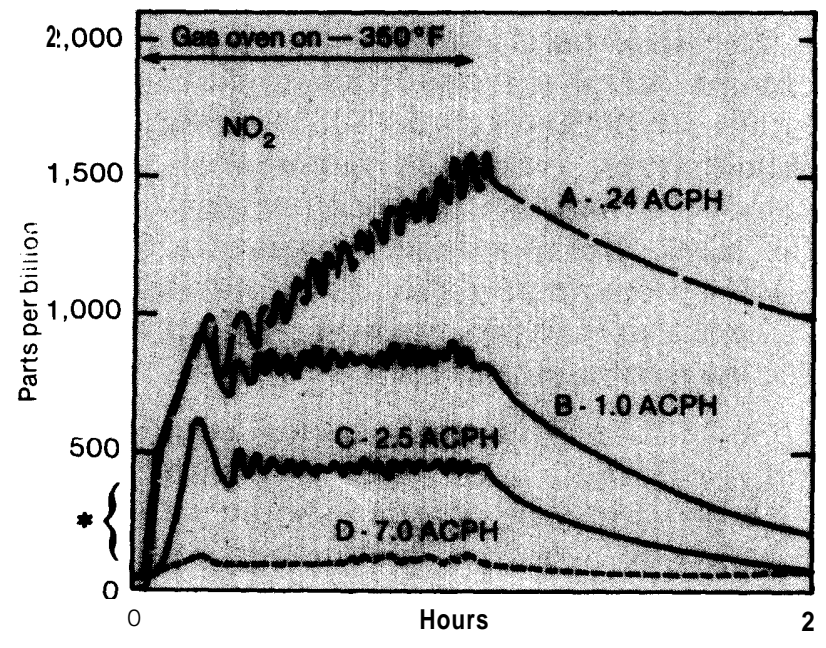

NOTE: Gas oven operated for 1 -hour at $350^{\circ} \mathrm{F}$. ture buildup rather than health problems, as the former are more commonly associated with the housing environment. Problems of this nature are not uncommon in Scandinavia, where recently built housing is far tighter than average new homes in the United States. Such difficulties could seriously impair the credibility of energy conservation programs in the same way that problems of flammable cellulose insulation have recently discouraged buyers,

Promotion of energy conservation measures for buildings may exacerbate an existing indoor air quality problem whose present dimensions are largely unknown. Thus, it is crucial that the conservation effort be closely coupled with a program to expand our understanding of indoor air quality as well as with measures to protect the indoor environment.

*Range of recommended $1 \mathrm{hr}$. air quality standard.

$\mathrm{ACPH}=$ air change per hour.

\section{EXPANDING OUR UNDERSTANDING OF INDOOR AIR QUALITY}

The Federal research effort on indoor air quality has been limited to a few small, piecemeal contracts. The total Federal effort appears to have been on the order of $\$ 1$ million yearly for the past several years. The Department of Energy (DOE) has funded most of its small effort through Lawrence Berkeley Laboratory in California; the Environmental Protection Agency's (EPA) major effort was with Geomet, Inc., in Gaithersburg, Md. Neither of these series of studies can be characterized as a comprehensive, systematic effort to increase our knowledge about the sources, characteristics, and effects of indoor air pollution.

This low level of effort is particularly difficult to understand because both DOE and EPA have ample evidence to demonstrate that the current system of air pollution monitoring based on central measurement stations is often not measuring true exposure. Besides the obvious problem of indoor air pollution, the exposure measurement problems that arise from nonuniform pollution distribution, commuting activities, and other factors severely limit the credibility of central-station-based exposure estimates.

As a result of these errors in measurement:

- The current enforcement of air quality standards based on central station pollution monitors may not be adequately protecting the public.

- The emission control strategies designed to support these standards may be either too lenient, too strict, or else simply badly skewed.

- Epidemiological studies of pollutant health effects suffer from severe errors in measurement of population exposure.

Thus the lack of understanding of indoor air quality is part of a larger problem of detemining total environmental exposure to air pollution. Any Govemment program designed to improve our understanding of the indoor environment should take care to integrate this research with research into the total exposure problem. 
In the past few years, a number of excellent personal air pollution monitoring instruments have been developed for selected air pollutants. If monitors were available for a wider range of indoor and outdoor air pollutants, field studies could use them to measure real exposures of a representative sample of the urban population. The relationship between existing air pollution monitors and actual exposures might be better understood, with the following benefits:

- A more accurate, uniform, and meaningful measure of air quality than is possible with today's data. This would provide a more realistic measure of the success of present control strategies.

- Identification of critical portions of the population -by occupation, location, or other factors - that require special attention, especially during episodes of extremely high pollution concentrations.

- Development and validation of models capable of predicting pollution exposure to other than ambient pollutant concentrations.
- Exposure data that is necessary to conduct credible statistical studies of the health effects of low levels of pollution.

Various experts estimate the cost of developing a personal monitor for a particular pollutant at $\$ 250,000$. ' A 1975 workshop' at Brookhaven National Laboratory recommended a national development program at the level of $\$ 1.5$ million per year for 5 years. Such a program probably would suffice to produce the prototype personal monitors needed for the most important pollutants.

Given the existence of personal monitors for industrial applications, the first step of any such development program should be a rigorous quality assurance testing and evaluation of the existing technology to determine its applicability to exposure assessment studies. As monitors for critical pollutants become available, they can be deployed to provide the assessments described above. These assessments, if conducted with careful attention to discovering the socioeconomic and physical characteristics that govem the variation of pollution exposure within an area, should provide the understanding of indoor air quality that is currently lacking.

\section{PROTECTING THE INDOOR ENVIRONMENT}

There are three basic approaches to protecting the indoor air environment:

1. maintenance of an adequate level of air change

2. air purification, and

3. reduction of indoor sources of air pollution.

\section{Air Change}

Because energy conservation involves deliberately reducing air infiltration and exfiltration - natural air exchange-the maintenance of a satisfactory level of indoor air quality involves artificially inducing an air exchange with some mechanism to recapture the heat in the exhaust air. In Europe, and particularly in Sweden, it is not uncommon to provide a heat- recovering system as part of the home ventilating system. An advantage of such controlled air change is that air removal points can be located near the major sources of moisture, odor, and pollutants. For example, the kitchen can be ventilated at a higher rate than the remainder of the home. Also, development of inexpensive monitoring equipment will allow the rate of air change to be varied according to the (air quality) need. However, the

\footnotetext{
'Lance Wallace, "Personal Monitors," in vol. IVa (Environmental Monitoring Supplement) of Analytical Studies for the U S Environmental Protection Agency, National Academy of Sciences, Washington, D. C., November 1977

'M. G. Morgan and S. Morris, "Individual Air Pollution Monitors An Assessment of National Research Needs," report of a workshop held at Brookhaven National Lab oratory, July 8-10, 1975, Energy Research and Development Administration, January 1976.
} 
critical factor in avoiding the loss of the conservation benefits of reducing natural infiltration is still the exhaust air heat recovery. A number of devices in varying stages of development are capable of extracting this heat and transferring it to the incoming air. These include heat pumps, heat pipes, interpenetrating ducting, heat wheels, and runaround systems (see volume 11, p. 548, for a description of how these systems work). The interpenetrating ducting systems, which are heat exchangers with the incoming and exhaust air streams in parallel but opposite directions, are presently available, can be extremely efficient, and are the simplest of the systems; they appear to be the most feasible systems for residential use.

\section{Air Purification}

Air purification is a $n$ altemative or a complement to air change as a method of assuring good indoor air quality. Ventilation with heat recovery may be inadequate to maintain adequate air quality if the outside air is polluted. Without air purification devices to screen the incoming air, the ventilation system can compromise the building's "sheltering" effect in protecting its occupants from outside pollution.

Indoor air pollutants vary sufficiently to require a variety of devices to ensure thorough control. The pollutant categories that require different methods of control are moisture, particulates, and airborne chemicals and odors. Moisture can be controlled by dehumidification equipment in the heating season and airconditioning in the cooling season. Particulate control is accomplished in most homes with forced-air heating and cooling by inserting a filter in the ducts. These filters are not efficient collectors of finer respirable particulate. Electrostatic precipitators can be added to allow control of a greater range of particle sizes; this equipment is available today.

Reduced infiltration rates will most affect the need for control of airbome chemicals and odors. Aside from ventilation, the control technology categories are:
1. Absorption by dissolving the pollutants in liquids. Spray washing, which can also capture particulate and provide a dehumidifying function, is often used in large buildings.

2 Adsorption of the odors and chemicals on a solid, usually activated carbon. This method should have the greatest residential application.

3 Chemical reaction by oxidation to an inert, odorless state. The oxidizing chemical can be added to the water in a spray washer or to the activated charcoal in an adsorption filter for a combined effect.

Much work remains to be done on all these technologies.

\section{Pollution Source Reduction}

Much indoor air pollution occurs because of (or is increased by) poor maintenance or improper manufacturing techniques. For example, levels of formaldehyde emissions from wallboard depend on proper curing of the material. Carbon monoxide emissions from gas stoves can be increased by several orders of magnitude by improper bumer adjustment or maintenance. Defects in the venting of gas and oil fumaces can and often do contribute to indoor air pollution. Many of the chemicals used in cleaning and in hobby work are extravagantly and/or improperly used, and their contribution to degrading of indoor air quality could be substantially reduced through increased awareness of their adverse effects. It seems likely that many chemicals in use in the home environment are inappropriate except under carefully controlled conditions and should be controlled; however, no analysis of the appropriateness of such controls was conducted during this study.

A strategy for pollution source reduction should clearly include an added emphasis on combustion equipment maintenance and design, as well as far greater Govemment attention to the composition of common household chemicals and their packaging and labeling, plus the pollution-causing properties of materials used inside the home. 


\section{Chapter XI \\ TECHNICAL OPTIONS}

\section{Chapter XI.--TECHNICAL OPTIONS}

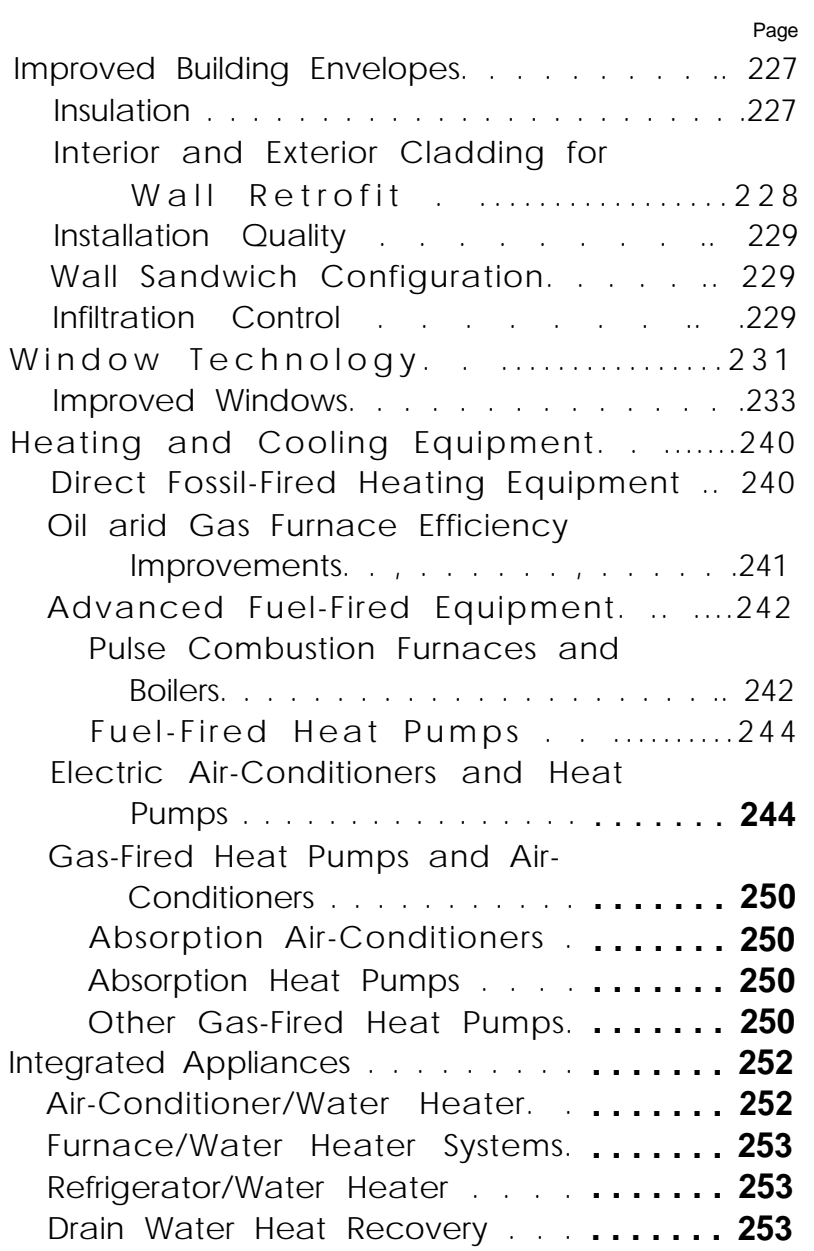

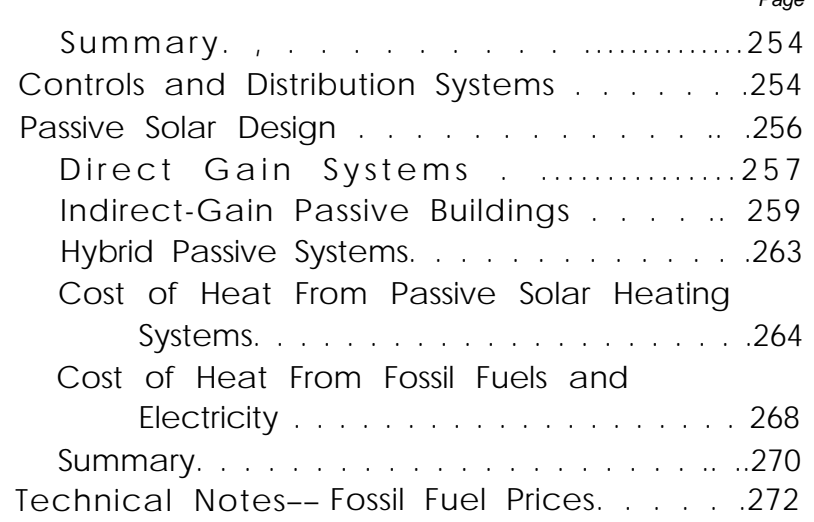


80. DOE Central Air-Conditioner EnergyEfficiency Improvement Target .. ...249

81. Estimated Performance of Camier Hot Shot ${ }^{\circledR}$ Heat Recovery Unit With a 3-Ton Air-Conditioner and a Family of Four. . . . . . . . . . . . . . ..........253

82. Cost of Heat From Passive Solar Heating Installations . . . . . . . . . . . . .268

83. Cost of Heat Supplied to Houses From Fossil Fuels and Electric ity 269

\section{FIG URES}

22. Air Leakage Test Results for Average Home of 1,780 sq. ft. . ...........230

23. The Double-Sided Blind . ...........234

24. Triple Blind, Winter Day Mode. .. ...234

25. Shades Between Glazing With Heat Recovery. . . . . . . . . . . . . . 235

26. Between Glazing Convection and Radiation Control . ..............235

27. Multilayer, Roll-Up Insulating Wind ow Shade . ...............235

28. Insulating Window Shade . ..........236

29. Window Quilt Insulating Window Shade . . . . . . . . . . . . . . .....236

30. Skylid . . . . . . . . . . . . . . . . . ....236

31. Beadwall. . . . . . . . . . . . . . . . . . . . .237

32. Beam Daylighting . ............237

33, Selective Solar Control . ..........237

34. Heat Mirror. . . . . . . . . . . . . . . . . .. 238

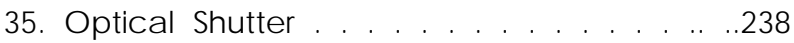

36. We a ther Panel ${ }^{\circledR}$. $\ldots \ldots \ldots \ldots \ldots \ldots \ldots \ldots \ldots 238$

37. Typical Energy Flow for a Gas

Furnace System. . . . . . . . .......241

38. Principles and Operation of the HydroPulse Boiler Which Uses the PulseCombustion Process . . . . . . . . . . . . . .243

39. A Typical "Split System" Heat Pump Installation . . . . . . . . . . . . . . . . . 245

40. Air-Conditioning COP of Heat Pumps and Central Air-Conditioning Units Shipped in $1977 \ldots . . . \ldots . . . . . . .246$

41. Performance of the Camier Split-System Heat Pump . . . . . . . . . . . . . . 247
42. The Seasonal Performance of Heat-Pump Units as a Function of Local Climate. .. 248

43. Estimated Cost of Increasing the Performance of Air-Conditioners From the Industry Average COP of 2.0 to the Performance Levels Indicated. . .249

44. Modified Saltbox Passive Solar Design Home . . . . . . . . . . . . . . . . . . . . 257

45. The Fitzgerald House Near Santa Fe, N. Mex., is 95-Percent Solar Heated by a Direct-Gain System at a 5,900 Degree Day Site . . . . . . . . . . . ...258

46. The Kelbaugh House in Princeton, N.J., Receives 75 to 80 Percent of Its Heat From the Trombe Wall and the Small Attached Greenhouse. . . . . . . . . . 260

47. The Crosley House in Royal Oak, Md., Comblnes a Trombe Wall System With Direct Gain and a Massive Floor, to Provide 50 to 60 Percent of Its Heating Needs . . 261

48. The Benedictine Monastery Off ice/ Warehouse Near Pecos, N. Mex, Uses Direct Gain From the Office Windows and Warehouse Clerestories Combined With the Drumwall Below the Office Windows to Provide About 95 Percent of Its Heating Needs. . . . . . . . . . . . . . .262

49 The PG\&E Solarium Passive Solar Home in (Califomia Uses the Large Skylight to Heat Water-Filled Tubes on Three Walls of the Solarium . . . . . . . . . . . . . . . . . 263

50 This Retrofit Sunspace is Manufactured by the Solar Room Co. of Taos, N. Mex.. . .264

51 This Retrofit Greenhouse is an Example of Those Built by the Solar Sustenance Project. . . . . . . . . . . . . . . . . .265

52. The Balcomb Home Near Santa Fe, N. Mex., Combines the Use of a Greenhouse With a Rock Storage Bed to Provide 95 Percent of Its Heating Needs . . . . . . . . . . . . . .266

53. This Home in Los Alamos, N. Mex., Combines a Large Trombe Wall With Small Direct Gain Windows and a Rock Storage Bed. . . . . . . . . . . ...267

54. Solar Feasibility for Trombe Wall With Night Insulation Alternative Fuel Natural Gas. . . . . . . . . . . . . . . . . ...271 
Technology is already available to at least double the energy efficiency of housing, but further improvements in technology promise a significant impact on savings. Conservation, possible with specific combinations of existing technology, is illustrated in chapter 11 . This chapter discusses a much broader set of technical options, including many still in the developmental stage.

Design of an energy-efficient house usually starts with a tightly built and well-insulated thermal envelope (exterior walls, windows, etc.) and adds efficient equipment for heating, cooling, hot water, and other energy needs. The thermal envelope and equipment technologies, which must be combined to build an efficient house, are considered individually in this chapter. Interactions between different types of energy-using equipment, which were treated earlier, are not repeated. Additional information about most of these topics appears in volume 11 of this report.

Many improved window systems and passively heated buildings represent marked departures from present building technology and practice; most of the other technical changes identified in this chapter are incremental improvements of existing materials or equipment. This does not mean that further research and development is unimportant. Figure 14 in chapter I I shows that the total cost of owning and operating a house with energy-saving improvements changes very little over a wide range of investment, so incremental improvements in technology would substantially increase the optimum investment level and energy savings. Improvements being developed would also greatly increase the options available for meeting a performance standard, such as the building energy performance standards (BEPS). These added options could greatly increase the willingness of the housing decisionmakers to invest in energy efficiency and hence lessen the institutional resistance to building energy- effic ient houses.

\section{IMPROVED BUILDING ENVELOPES}

\section{Insulation}

Minimizing the amount of heat lost from the interior is usually the first step toward constructing an energy-conserving house. This approach is almost always taken when the retrofit of a building is considered as well. It is frequently assumed that this merely means adding more insulation in the walls and over the ceilings, using storm windows and doors, and caulking and weatherstripping all of the cracks in the building. However, new ways of using these techniques are being implemented, and significant new products are being developed.

Thermal transmission through walls, ceilings, and floors is the single largest source of heat transfer in a typical house. While many older homes were built without insulation, vir- tually all new houses contain at least some insulation to reduce heat loss. Many different insulating materials are used including rock wool, fiberglass, cellulose, cellular plastic $s$ (such as polystyrene, urethane, and ureaformaldehyde), perlite, vermiculite, glass foam, and aluminum multifoil. The characteristics of these materials and insulation standards are discussed in appendix A. That discussion includes insulation properties, health and fire safety issues, and production capacity.

The choice of insulation depends on cost, application, availability, and personal preference. New wall cavities are generally filled with rock wool or fiberglass batts while plastic foam sheathing may be added to the exterior. Retrofit of walls built without insulation is generally accomplished by drilling holes be- 
tween each pair of studs and blowing in fiberglass, cellulose, or ureaformaldehyde. Insulation is occasionally added to the exterior if new siding is installed. Attics are insulated with batts or loose-fill insulation. Fiberglass, rock wool, and cellulose are widely used, but perlite and vermiculite are also used in attics. Floors are seldom insulated, but fiberglass batts are the most frequent choice for this application. Foams such as polystyrene or urethane are generally used when foundations or basements are insulated.

Cost-effective levels of insulation can substantially reduce heat losses as illustrated in chapter II.

Thus it might seem that new insulation material and techniques would represent a new technology area of substantial importance.

It appears, however, that this is not the case. Contacts with industry and with national laboratories indicate that new technology developments will not make a large contribution to insulation materials and practices. What advances do occur by 1985-90 will primarily augment existing techniques; not represent major new directions. A basic difficulty in assessing this area is that major companies carefully keep their new product developments to themselves. Nevertheless, the following points emerge:

1 Major breakthroughs in the cost per unit of insulating value of major insulating materials are not expected, and no fundamentally new materials of high cost-effectiveness are anticipated.

2. In frame wall cavity retrofit, incremental improvements may be expected in the handling and performance characteristics of the major materials, but no fundamental breakthroughs are anticipated.

3 New systems for reinsulating the exterior surfaces of walls are being developed, but, again, no fundamental change is expected.

4. Changes in wall sandwich configurations for new buildings are being developed that will result in more efficient wall performance.
5. The quality of installation is a major problem and may be the area in which insulation effectiveness can be most improved over the next decade.

Each of these areas provides a range of new opportunities, but institutional constra ints may limit implementation. The technical advances that are likely may be only incremental, but this could result in houses with substantially less energy consumption and lower lifecycle cost.

The price of insulation has increased sharply in the last 4 years, but this is largely due to a temporary lack of capacity in the industry, and future increases should be more directly related to cost increases. However, it does not appear that ways will be found to make significantly cheaper insulation, as the materials already used are quite inexpensive. It is expected that the price of insulating materials will generally keep pace with inflation.

Improved materials for retrofitting wall cavities would be useful since all of the materials now in use have at least one drawback. The labor cost is typically one to two times as great as the material cost for these retrofits. Thus, any dramatic drop in the installed price would require a less expensive material that also offered simplified installation.

\section{Interior and Exterior Cladding for Wall Retrofit}

In retrofitting exterior walls for improved thermal performance, an altemative to filling the wall cavity is the application of a layer of insulation over the exterior or interior wall surface, followed by re-covering of the wall. The advantage of this approach is that the insulation layer is monolithic (rather than broken by framing members) and that a wide range of durable and highly effective insulating materials is available for this application. This approach also has its disadvantages. If an interior insulating layer is used, the available interior space is reduced, the living space must be disrupted, and there are refinishing problems. If an exterior cladding is used, a sound weatherproof finish must be applied over it. Generally, 
exterior systems are more practical and have received more attention in the marketplace.

A number of complete insulation and siding systems are already on the market. None of these, however, is cost-effective purely as an energy-conserving measure; they are cost-effective only on the assumption that it is necessary to re-side the building anyway. There is no promising technical breakthrough on the horizon. Thus, it appears that wall cladding as a method of retrofit will not become a major energy strategy.

\section{Installation Quality}

It is well known that installation quality in both new and retrofit insulation application is a major and continuing problem.

In new construction, common defects include the failure to fill small or narrow cavities with insulation, the failure to pack insulation properly around and behind electrical and plumbing fixtures, and the incomplete coverage of cavities with insulation. The last problem is particularly serious if the defect extends vertically for a significant distance because convection currents are thereby set up that result in rapid heat transfer. I $n$ general, the percentage increase of heat loss is disproportionate to the area of the defect, because of the action of air infiltration and internal air currents.

In the retrofit of existing construction, serious problems exist in reinsulation of wall cavities. As the framing pattern is not easily apparent from the outside of the building, it is common to miss small cavities entirely. Even when a cavity is located, the filling may be incomplete or the insulation may be hung up on intemal obstructions. The fact that the extent of coverage of the completed installation cannot be seen results in a basic quality-control problem.

It is likely that increased understanding of these problems will result in corrective efforts by conscientious builders and inspectors. Infrared themography can be used to detect installation defects by taking a "heat-loss picture" of a house, but the cost of the equipment and other factors have limited its use to date.

\section{Wall Sandwich Configuration}

The typical exterior residential frame wall is insulated by glass or mineral fiber insulation with a themal resistance value of R-11 or R-13, fastened between $2 \times 4$ framing members. The interior and exterior wall surfaces and framing are composed of materials of low to moderate insulating value. Exclusive of openings, 15 to 20 percent of the area in such a wall is given over to framing. This portion of the wall area, insulated only by standard building materials, accounts for a disproportionate amount of the total wall heat loss; a framing area of 15 percent accounts for approximately 30 percent of the total heat loss through the wall.

A number of improved wall configurations and details have been developed and are finding increasing use. These, in general, involve increasing the total amount of insulation, usually from about R-1 3 to about R-20, and changing the wall sandwich to either reduce the size of framing areas or to insulate them. Several of these configurations are described on pp. 500505 of volume I 1.

\section{Infiltration Control}

Infiltration has traditionally been a major source of thermal inefficiency in homes. According to various estimates, it accounts for between 20 and 40 percent of all heat transfer through the building envelope, in both old and new construction. While the absolute magnitude of infiltration losses has declined with the advent of tighter building components and techniques, the decline has been comparable to the reduction in conductive losses. There is clear potential for large energy savings from further infiltration control.

Infiltration depends on how a house is built and used. It increases whenever the wind speed or indoor-outdoor temperature difference increases and may vary from near zero on a calm spring day to several air changes per hour (ACPH) on a windy winter day. These basic facts are well known, but overall infiltration behavior is rather poorly understood and documented. A review of the literature several years ago determined that the average infiltration rate for most houses in the United States 
was 0.5 to $1.5 \mathrm{ACPH}^{1}$ and no substantial changes have yet occurred.

The aggregate percentage breakdown of air leakage from different sources is illustrated in figure 22. This figure is based on measurements of 50 single-family homes by the Texas Power and Light Company. It shows that nearly half of the leakage occurs through electrical outlets and cracks between the foundation and the walls, with a surprisingly small contribution from windows and doors.

\section{Figure 22. - Air Leakage Test Results for Average Home of 1,780 Sq. Ft.}

(50 homes tested by Texas Power \& Light Co.)

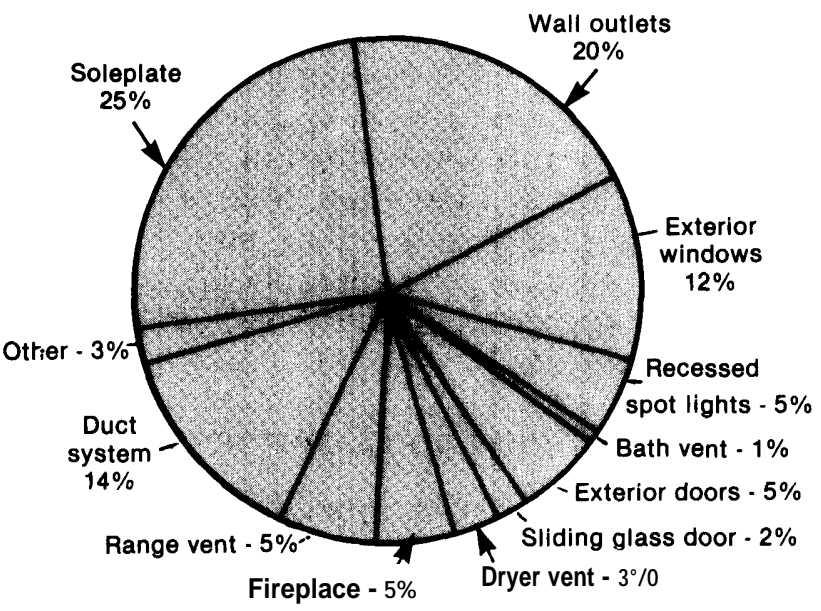

SOURCE: "Reprinted with permission from the American Society of Heating, Refrigerating, and Air-Conditioning Engineers

It is possible to build a house very tightly if the builder uses the right materials with sufficient care. The "Saskatchewan Conservation House" in Regina, Canada, has uncontrolled infiltration of only $0.05 \mathrm{ACPH} .{ }^{2}$ However, it is not known whether the average builder could build houses this tightly. The present Swedish building standard ${ }^{3}$ requires that a house have a

'T. H. Handley and C. J. Barton, "Home Ventilation Rates: A Literature Survey" (Oak Ridge National Laboratory, September 1973), ORNL-TM-4318.

${ }^{2}$ Robert W. Besant, Robert W. Dumont, and Greg Schoenau, "Saskatchewan House: 100 Percent Solar in a Severe Climate," Solar Age, May 1979, p. 18.

${ }^{3}$ Svensk Bygnorm 1975, Statens Planverks Forfattningssamling, Liber Tryck Publications (Stockholm, Sweden, 1978), PFS 1978:1, 3rd edition. maximum leakage rate that corresponds to about $0.3 \mathrm{AC} \mathrm{PH}$. It is enforced by measuring the leakage in a sample of the homes by each build er.

Insulation standards can be very specific and simple visual checks can determine whether the standard has been met. By contrast, infiltration reduction requires the use of materials and techniques in places that are inherently inaccessible and invisible. It appears that the only way to ensure compliance with an infiltration standard is to measure it as part of the inspection process.

There are two basic approaches to infiltration measurement. In the first, a small amount of sulfur hexafluoride $\left(\mathrm{SF}_{6}\right)$ or some other tracer gas is circulated through the house with the furnace blower and its concentration is measured several times during the next hour or two. Analysis of these measurements determines the infiltration rate for the specific wind and temperature conditions at the time of the measurement. The air samples can be taken in plastic bags and analyzed in a laboratory, so no elaborate equipment is required at the house. The other technique uses a large fan to suck air out of the house and measures the volume exhausted at different indoor-outdoor pressure differences (fan speeds). This provides a "leakage" measurement of the house that is relatively independent of the weather conditions and individual leaks can be located with the use of a smoke source such as incense. Several investigators ${ }^{4}$ have attempted to correlate these measurements with actual infiltration rates. The results have been highly variable so, in a strict sense, these measurements should only be considered leakage measurements. The leakage test is used for standards enforcement in Sweden where it requires about 2 hours to test a house. ' The equipment used in the test can be purchased for about $\$ 500$.

'Investigators who have worked with air infiltration and leakage measurements include Richard Grot, National Bureau of Standards; Robert Socolow, Princeton University; Robert Sonderegger, Lawrence Berkeley Laboratory; Maurice Gamze of Gamze, Korobkin, and Caloger, Chicago, III.; and Gary Caffey, Texas Power and Light Company

${ }^{5}$ Stig Hammarsten, National Swedish Institute for Building Research, private communication, May 1979. 
A house would use less energy if there were no infiltration, but the occupants would negate this strategy whenever they opened the windows. Alternatively, fresh air could be provided with very little loss of heat by a simple heat exchanger. The Saskatchewan Conservation House heats incoming air with outgoing air by running both through interpenetrating ducts made of plastic sheets separated by wooden spacers. This recovers over $\mathbf{8 0}$ percent of the heat. Many Swedish houses that meet the present building standard have experienced air quality problems (such as those discussed in chapter $X$ ) and excessive humidity levels. The standard is presently being reviewed and, according to one observer, it will likely be modified to require the installation of a heat exchanger. ${ }^{G}$ Minimum acceptable air change rates for homes are not well defined, but a number of people active in the field believe that heat exchangers or some other method of purification are needed if infiltration is below about $0.5 \mathrm{AC} \mathrm{PH}$.

The "technology" for infiltration control is and will remain primarily the plugging of holes

${ }^{6}$ lbid and cracks, weatherstripping, and attention to the tightness and quality of construction. Existing products are being used more extensively and others are being used in different ways; plastic sheeting is increasingly used to provide a vapor barrier instead of paper or foil insulation backing. Following the identification of electrical outlets as a major infiltration source, simple foam plastic gaskets that are placed under the outlet covers have come on the market.' Improved sealants and caulking materials that are easier to use have become available in recent years. A foam plastic sealant that can be squirted into a crack much like shaving cream is now available; it expands slightly as it cures to ensure a tight seal. ${ }^{8}$ Other devices and configurations used to reduce infiltration include outside combustion air intakes for furnaces, water heaters, and fireplaces, and tightly sealable exhaust vents. Each of these changes makes it easier to build a tight house or retrofit an existing house. Further improvements of this nature are likely.

'Three manufacturers of such gaskets are the Vision Co in Texas, KGS Associates in Greenville, Ohio, and the Armstrong Cork Co.

One manufacturer of such a foam is the Coplanar Corp, Oakland, Cal if.

\section{WINDOW TECHNOLOGY}

Windows serve multiple functions. They allow daylight to enter, provide a view of the outside with its changing weather patterns, can be opened to provide ventilation, and admit heat in the form of sunlight. They also allow heat to escape, both by infiltration around the frame and by the normal radiative/conductive/convective heat transfer processes.

From the standpoint of energy-efficient building operation, the ideal window would allow all the sunlight to enter the building whenever heating is needed, and would have very low thermal losses. During the summer when no heating is needed, it would admit only visible light, and only in the quantities needed for lighting and providing a view of the out- side. All of the invisible infrared rays (over half of normal sunlight) would be excluded.

The windows in most houses are quite efficient at admitting sunlight-80 to 90 percent of the light striking them passes through. In the summer, shade trees and shades and awnings on the windows limit the heat admitted. But windows have the poorest thermal loss behavior of any part of the building shell. Typically, windows have an R-value of 0.9 to 2, while insulated walls have an R-value of 10 to 15 and insulated attics have an R-value of 15 to 20 . There is clearly room for vast improvement.

Early windows were a simple hole in the wall to admit sunlight and allow the occupants to see out, or a translucent material that would admit some light and exclude cold air was 
used. Glass was a great advance, since it simultaneously let in sunlight and prevented drafts. Double-glazing and shutters have now been used for many years to reduce the heat loss from windows, and shades can prevent overheating in the summer. During the last few decades, most of the development of glass for architectural uses has concentrated on making windows that would admit less sunlight and heat while still providing an adequate view. The early solar control glasses simply absorbed part of the sunlight in the glass with the result that part of the heat entered the building, but much of it stayed outside. Then manufacturers began to put very thin reflective coatings on glass. These reflect most of the sunlight, and in some cases actually cut down on the winter heat loss through the glass because they also reflect the infrared heat waves back into a room. The vastly decreased amounts of sunlight admitted to the building are considered satisfactory because they still permit a good view and greatly reduce glare. These reflective glasses are marketed on the basis of their reduction of air-conditioning loads in the summer and their reduced heat loss in the winter, ignoring the fact that the additional sunlight kept out in the winter would in some cases be helpful. They are generally used on large buildings that have large air-conditioning loads in both summer and winter.

In the last 3 or 4 years, increasing attention has been devoted to new window products that will add to the flexibility of window use and substantially improve their overall effect on the energy requirements of houses. The successful commercialization of these products should make it possible for windows to generally lower the overall energy requirements of a house for space-conditioning.

Windows lose heat by all of the basic heat loss mechanisms discussed earlier: radiation, convection, and conduction. As the contribution of radiation and of convection/conduction is comparable in most windows, reduction of the losses attributable to either of these mechanisms can be important. One factor that has very little effect on heat loss is the thickness of the glass. Doubling the glass thickness has a barely perceptible effect, but the same amount of glass added as a stom window will cut the heat loss in half. The combination of an additional dead air space and layer of glass cuts both radiative and convective losses. It is generally true that the heat loss through a window will be divided by the number of panes (e. g., the heat loss through triple-glazing is onethird that through single-glazing).

In addition to multiple-glazing, the basic methods of conduction and convection control have been various forms of blinds, shutters, and curtains. Some sunscreen devices have the effect of baffling the outer air layer and reducing surface convection. Relatively little attention has been paid, in existing windows, to the control of convection between glazing layers. One technique that has been studied is that of filling the interglazing space with heavier molecular weight gases. Use of gases such as argon, sulfur hexafluoride, or carbon dioxide can result in a significant reduction of conduction. It is also possible to make "heat mirror" coatings that allow most of the sunlight to pass through but which reflect heat back into the room.

Room temperature radiation is a major contributor to heat loss, but sunlight has an even larger effect on the energy impact of many windows. Solar radiation at the Earth's surface is approximately 3 percent ultraviolet, 44 percent visible, and 53 percent infrared. The primary intent of glazing is to admit daylight and permit a view. Daylight is "free" lighting from a renewable source and has a more desirable "color" than most artificial light. As with artificial light sources, sunlight, both visible and invisible, is converted to heat energy when absorbed by materials. One property of sunlight, however, is that its lighting "efficiency" is higher than that of artificial light. In other words, for a given level of lighting, sunlight produces one-sixth the heat of incandescent light and slightly more than one-half the heat of fluorescent light.

The use of daylighting is particularly desirable in the summer because it can cut the use of electricity for both lighting and cooling. In winter, the heat from the lights is often useful, but daylighting is still beneficial since it reduces the use of nonrenewable sources. 
In the typical design approach to small residential buildings, little attention is paid to the use and rejection of solar radiation. Windows are treated simply as sources of conductive heat loss in winter and of cooling load in summer. in reality, summer heat gain can be greatly reduced and winter heat gain can be significantly increased by appropriately specified and properly oriented windows. It is likely that the sizing and orientation of windows will be more carefully specified in the future.

Shading to keep out heat from the Sun is accomplished most effectively by an exterior shade or reflector. An outer reflective surface is almost as effective, an interior reflector (e. g., a shade) is still quite effective, and absorbing glass is generally less effective.

At night, when sunlight and view are not factors, movable insulation that cuts the heat loss to that of an ordinary wall section can be extremely useful. A single-glass window combined with nighttime insulation can exceed the overall performance of even a triple-glazed window. ${ }^{9}$

Many variations on these ideas are being developed and some products are already on the market.

\section{Improved Windows}

Enormous improvements in the energy efficiency of windows could be achieved through the proper use of conventional materials and components. (Some of these approaches are presented in the discussion of Passive Solar Design at the end of this chapter.) In many cases "new" technologies are simply a revival of old ideas and practices. Several technologies and devices of recent origin that appear to provide significantly improved window efficiency are illustrated and described in figures 23 through 36 . These are:

- the double-sided blind,

- the triple blind,

- shades between glazing with heat recovery,

- between-glazing convection and radiation control,

'D. Claridge, "Window Management and Energy Savings," Energy and Buildings 1, p. 57 (1977).
. insulating shades and shutters,

- the Skylid ${ }^{\circledR}$,

. the Beadwall ${ }^{\circledR}$,

- beam daylighting,

- selective solar control reflective film, and

. the heat mirror (low-emissivity film),

- the optical shutter, and

- the Weather Panel®.

Some of these technologies have been developed by industry while others have been supported by the Department of the Energy (DOE) through its energy-efficient windows program managed by the Lawrence Berkeley Laboratory. This program has provided support for work on shades between glazing with heat recovery, between-glazing convection and radiation control, multi layer insulating shades, beam daylighting, selective solar control films, heat mirrors, and optical shutters. Testing and evaluation of other concepts and products has been performed.

Traditional blinds provide protection from glare and overheating near the window. The blinds illustrated in figures 23 through 26 all provide this protection but also allow the heat to be used elsewhere if desired, reduce the window heat losses, or both.

The devices shown in figures 27 through 37 all serve to reduce the heat losses from windows when the sun is not shining, and generally do it quite effectively. They can also be used as shades to exclude sunlight when it isn't wanted. The shades shown in figures 27 through 29 incorporate design features that attempt to eliminate air leakage a round the edges. The same convective processes that enable the double-sided and triple blinds to distribute heat into the room will effectively cancel the insulating value of a shade if the edges are not tightly sealed. Figure 32 illustrates one approach to increased utilization of daylighting, while figures 33 through 36 illustrate the use of some highly innovative materials. The materials in figures 33 and 34 share the property of transmitting some radiation and reflecting others, but their uses are very different. The heat mirror primarily reduces cool-

\footnotetext{
(3) Registered trademark of Suntek Research Associates, Inc., Coite, Madera, Cal if.
} 
Figure 23.-The Double-Sided Blind

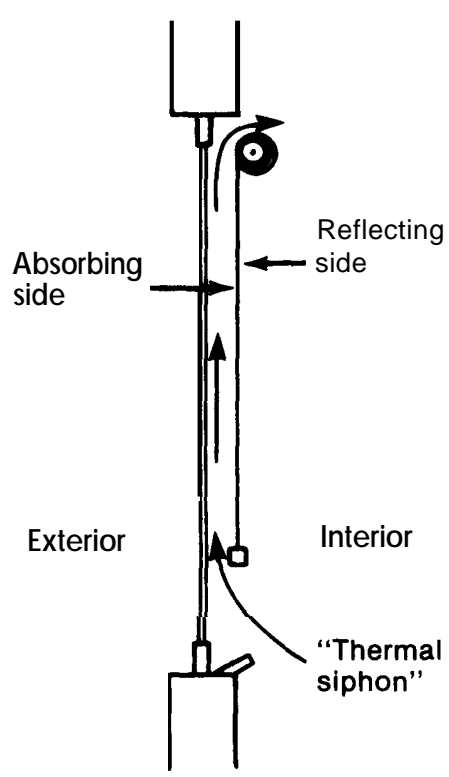

The double-sided blind is used on bright winter days when shading is needed to prevent overheating or glare from large windows. It absorbs and distributes to the room heat that would be reflected outside by an ordinary shade. It functions as an ordinary shade in the summer with the reflective side out.

ing loads while maintaining daylight availability for lighting. The heat mirror will be marketed by a subsidiary of Suntek Research Associates next year. The optical shutter is a passive shading material also under development by Suntek. It works well, but the economics are not considered promising if the shutter material is enclosed in glass. Some work has been done on developing a suitable method for encapsulating it in less expensive plastics. The Weather Panel ${ }^{\circledR}$ (figure 36 ) is a logical combination of heat mirror and optical shutter technology that could be a major advance in passive heating technology if it can be produced at low cost. A discussion of this system was presented at the Second National Passive Solar conference. '" Weather Panel ${ }^{\circledR}$ combines the advantages of high themal resistance and shading in a completely passive system. The

(1) Registered trademark of Suntek Research Associates, Inc., Coite, Madera, Calif.

"'Day Charoudi, "Buildings as Organisms," Proceedings of the Second National Passive Solar Conference, Mar. 16-18, 1978, p. 276 (Philadelphia, Pa.: Mid-Atlantic Solar Energy Association).
Figure 24.-Triple Blind, Winter Day Mode

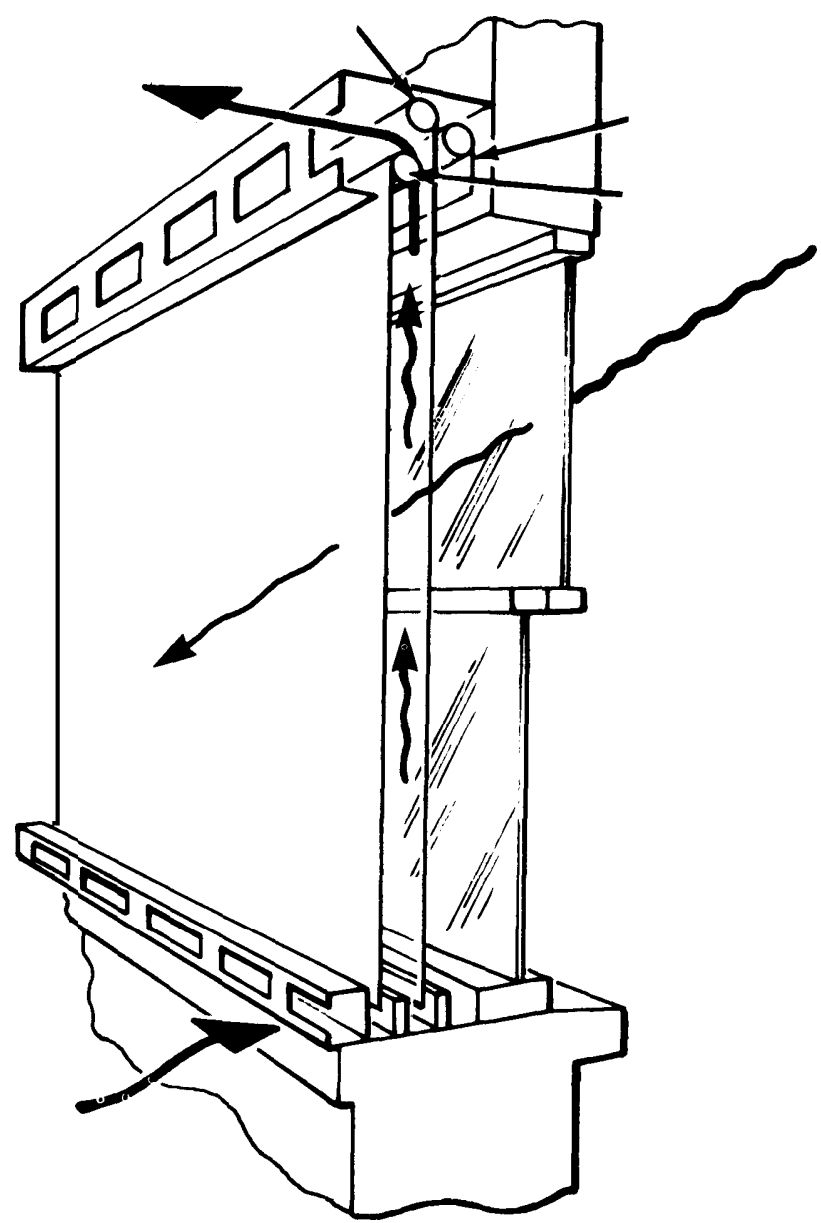

The triple blind is functionally similar to the double-sided blind, but the clear shade keeps more of the absorbed heat in the house. At night, thermal resistance of $R 5$ is achieved by pulling all three shades, according to the manufacturer,

Ark-tic-seal Systems, Inc., Butler, Wis.

Cloud $\mathrm{Gel} \circledast$ material can be made to tum reflective at any temperature in the range from 00 to $1000 \mathrm{C}$. (An essential requirement for systems like this is for all parts to last 15 years or more or be readily replaceable.)

None of these new technologies is the single "best" approach for all conditions. They differ radically from each other in cost, effectiveness, and range of applicability. Table 75 summarizes the salient features of these new technologies. This table presents the performance parameters, operating requirements, estimated cost-effectiveness, applicability to retrofit, and current status of each new technology. The estimates of the level of cost-effectiveness 
Figure 25. - Shades Between Glazing With Heat Recovery

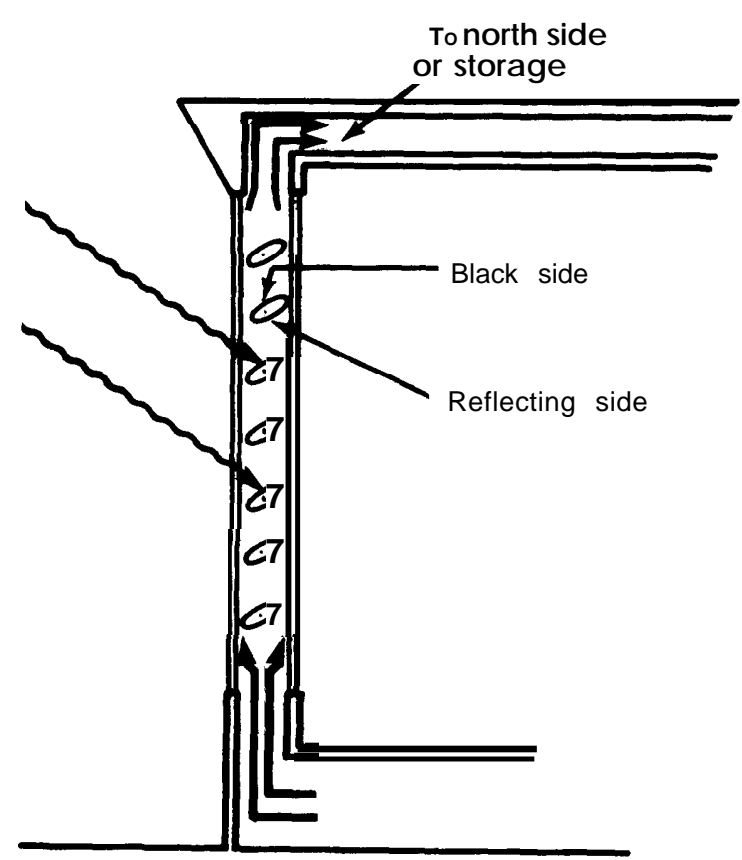

This is optically similar to the double-side blind except that heat is fed into conventional heating ducts and distributed with a blower.
Figure 27.-Multilayer, Roll-Up Insulating Window Shade

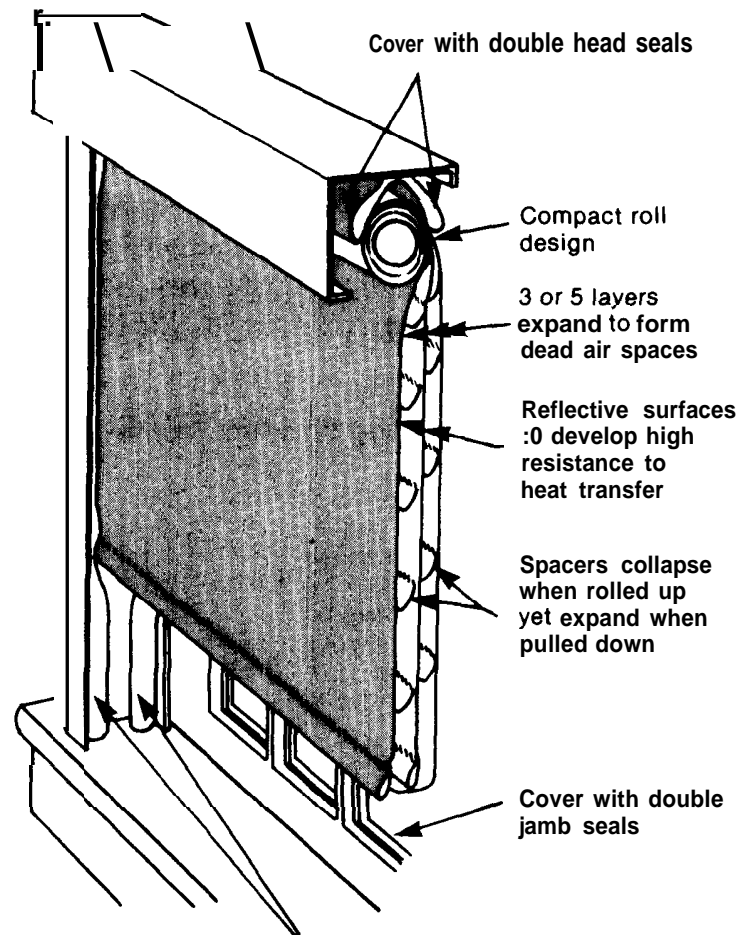

Thermally effective summer thru winter at windows and sliding doors

This multilayer shade stores in a compact roll and utilizes flexible spacers to separate the aluminized plastic layers and create a series of dead air spaces when in use. The five-layer shade used with double glazing offers thermal resistance of $\mathbf{R} 8$ according to the manufacturer, Insulating Shade Co., Guilford, Corm.

Figure 26.-Between Glazing Convection and Radiation Control
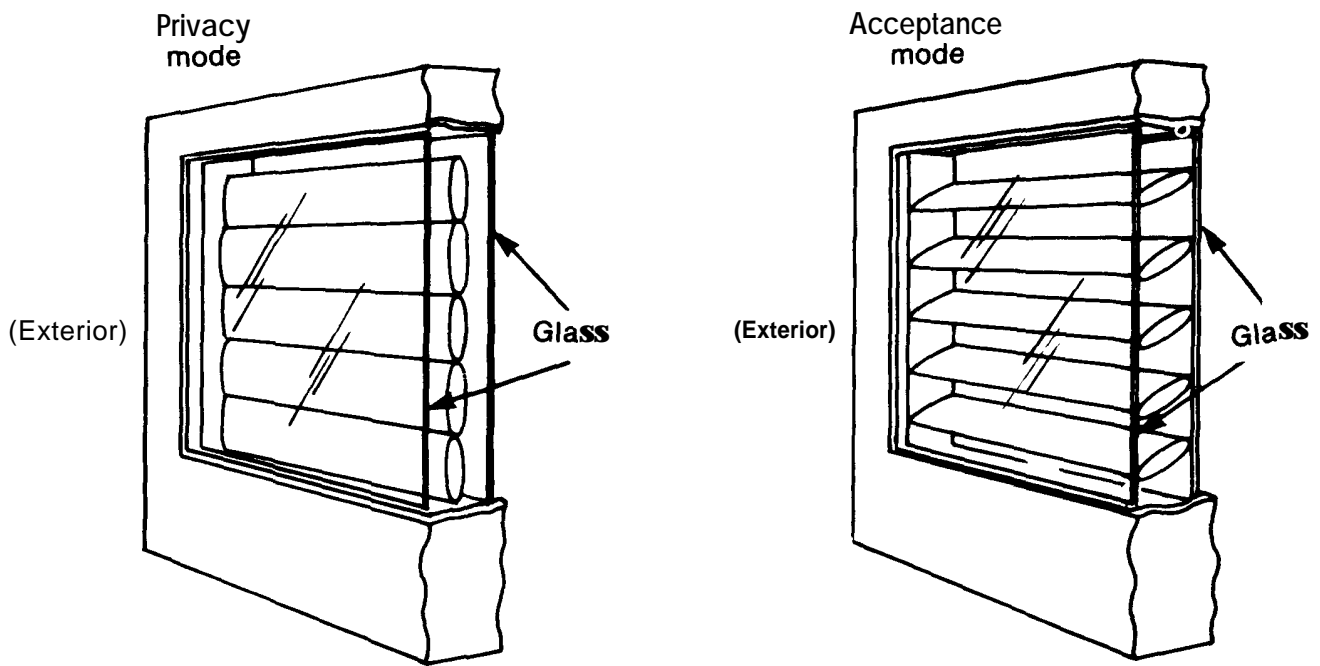

The horizontal slats between the glass suppress convective heat loss. In the "privacy mode," light is excluded and heat loss is reduced further. R3.5 has been achieved and R5 is believed possible with better design and construction. 
a re qualitative and approximate. They are based only on the length of payback period.

It must be remembered that windows are generally installed primarily for esthetic reasons. While there are a host of window acces sories and modifications, probably only storm windows and double-glazing have historically been marketed primarily on the basis of energy savings. Many of these accessories and improvement solve one "problem" and introduce

Figure 28.- Insulating Window Shade

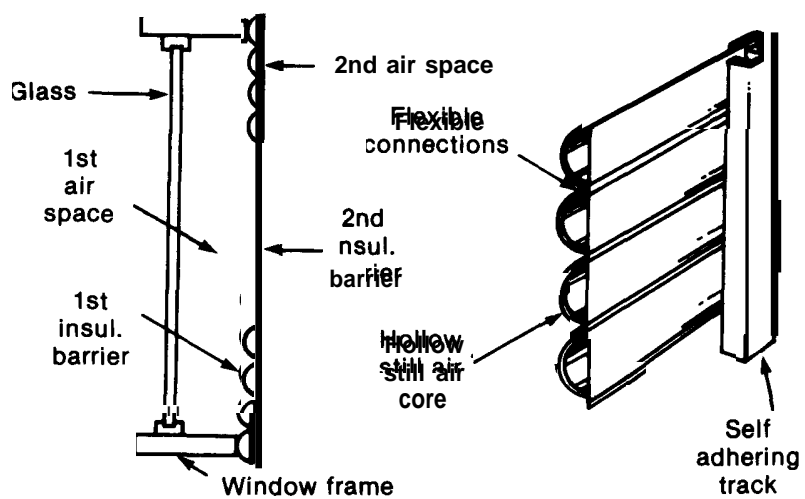

This roll-up shade is made of hollow, lens-shaped, rigid white PVC slats with minimal air leakage through connecting joints. It can be operated manually or automatically and is manufactured by Solar Energy Construction Co., Valley Forge, Pa. a nother. Important factors in their sale include:

- The desire for privacy. Shades, drapes, and blinds are sold primarily for the privacy they afford. Exterior shutters such as the Rolladen, which are widely used in Europe, offer both privacy and increased security.

Figure 29.-Window Quilt Insulating Window Shade

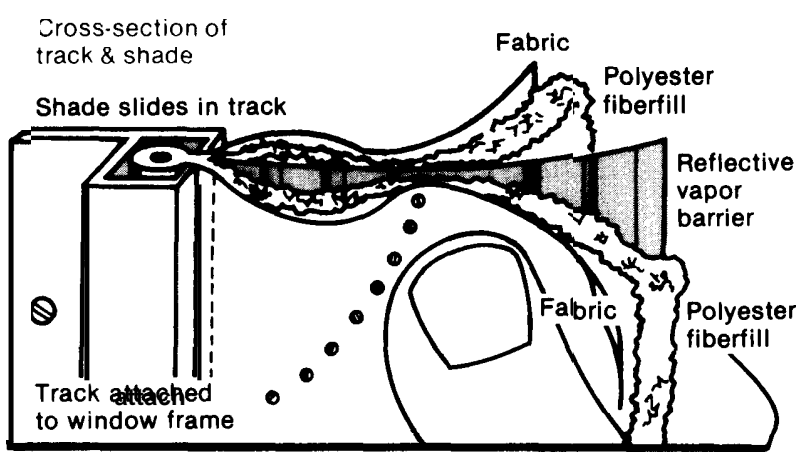

This roll-up shade is a fabric covered quilt whose edges slide in a track to reduce infiltration. It offers a thermal resistance of R5.5 when used with a double-glazed window according to the manufacturer, Appropriate Technology Corporation, Brattleboro, Vt.

Figure 30.-Skylid
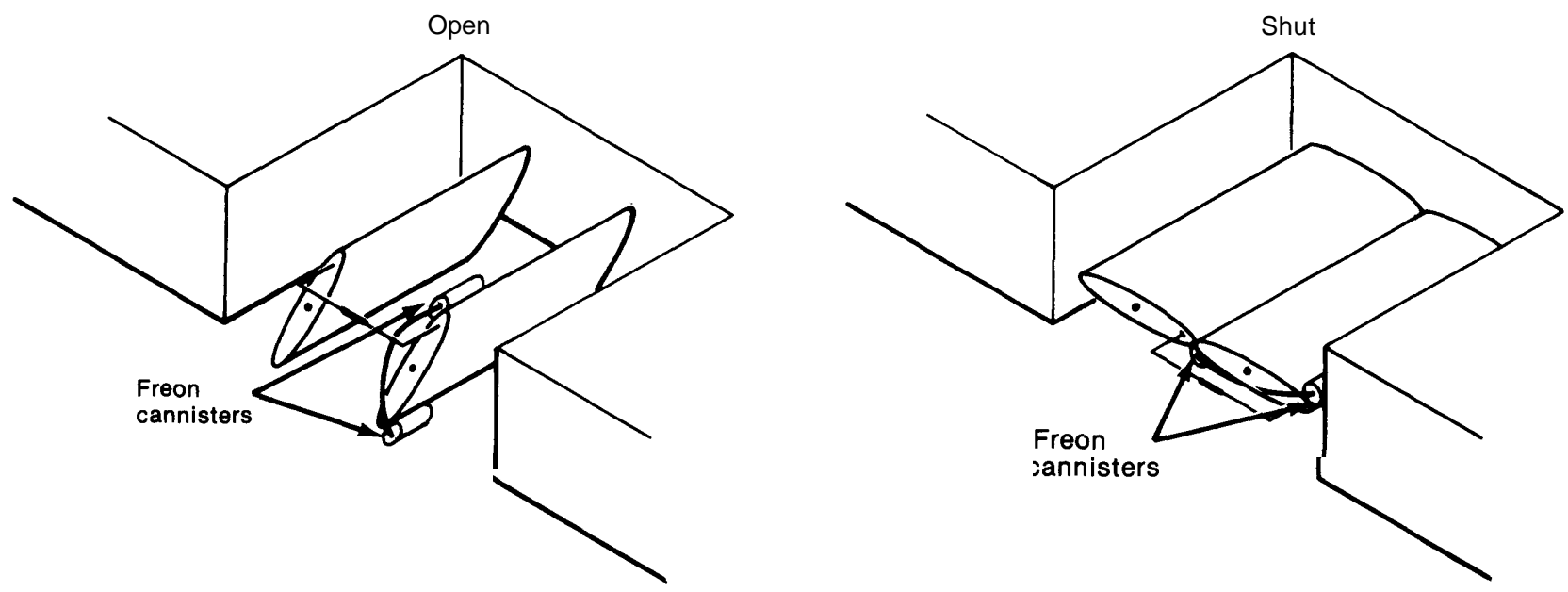

The sky lid is an insulating shutter that operates automatically. It opens when sunlight heats freon in the outer cannister causing it to flow to the inner cannister, and closes by the reverse process. It provides a thermal resistance of R3 when used with single-glazing according to the manufacturer, Zomeworks, Inc., Albuquerque, N. Mex. 
- The need for improved comfort is a major factor in the sale of "solar control" glasses. While they also reduce the need for a ir-conditioning, it is virtually impossible to provide comfort in the full glare of the summer Sun. This is another important consideration in the purchase of shades, drapes, and blinds. The "solar control" glasses also exclude useful winter sunlight.

- The ultraviolet rays in sunlight shorten the life of fabrics and home furnishings. The opaque window covers and some coatings reduce this problem.

Figure 31.-Beadwall

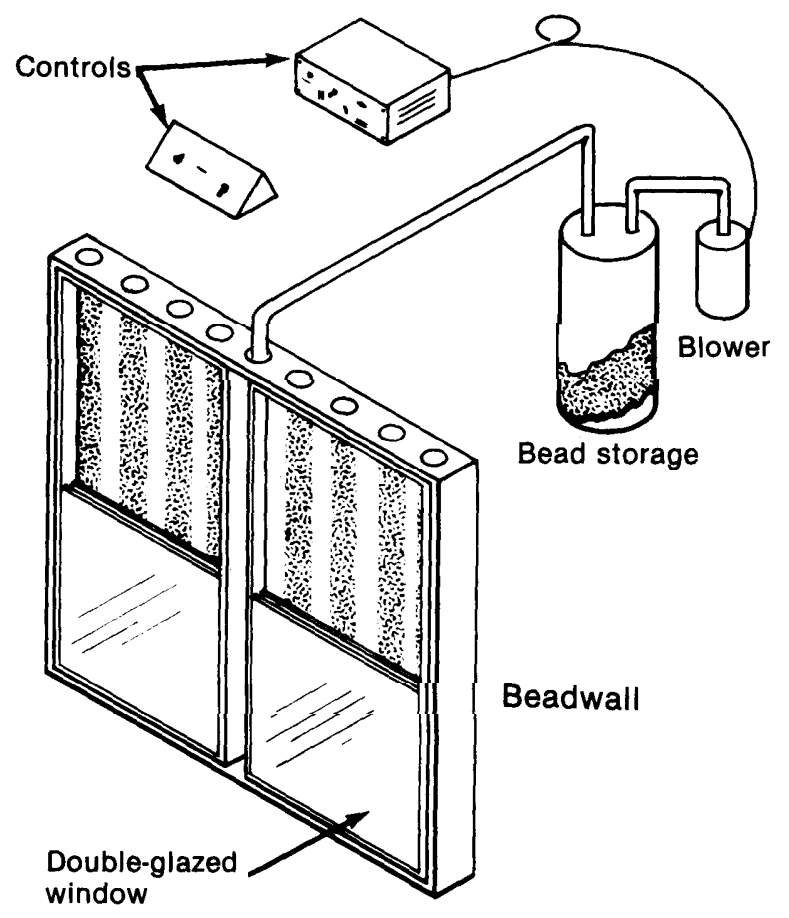

The beadwall uses automatic controls to pump small expanded polyurethane beads between the two layers of glass to provide a nighttime thermal resistance of R8. Beadwall is a registered trademark of Zomeworks, Inc.
- Drapes, shades, blinds, and shutters are opaque. By contrast, heat mirrors, selective solar control films, and between-glazing convection/radiation control devices provide both daylighting and outlook even when in operation.

Since reduced energy consumption is only one factor in the choice of window improvements, it is entirely possible, and perhaps likely, that some of the "less cost-effective" improvements that offer other advantages will ultimately become most widely used.

Figure 32.-Beam Daylighting

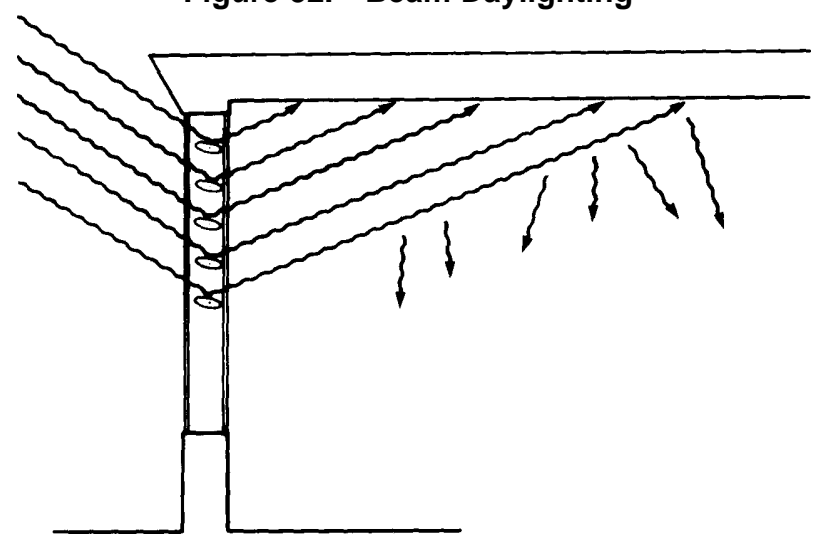

This beam daylighting approach uses adjustable reflective blinds to reflect light off the ceiling far into a room to extend the area where daylight levels are acceptably high.

Figure 33.-Selective Solar Control

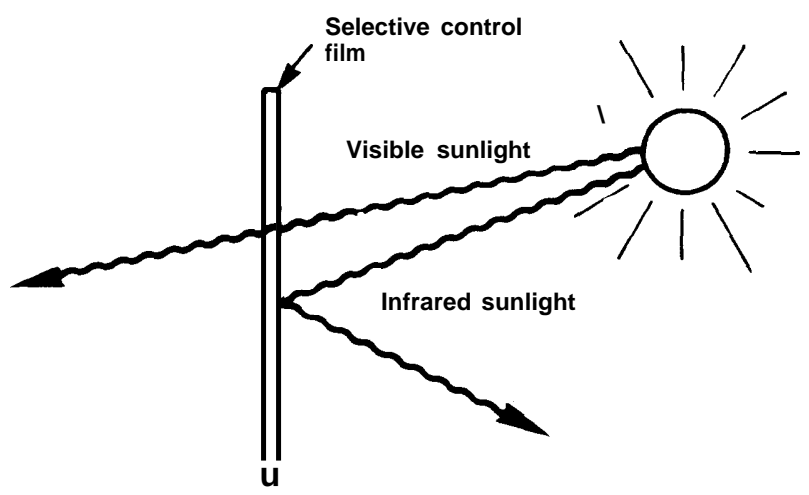

The selective solar control film transmits most of the visible sunlight while reflecting most of the infrared sunlight. This can reduce cooling loads while utilizing available daylight. 
Figure 34.-Heat Mirror

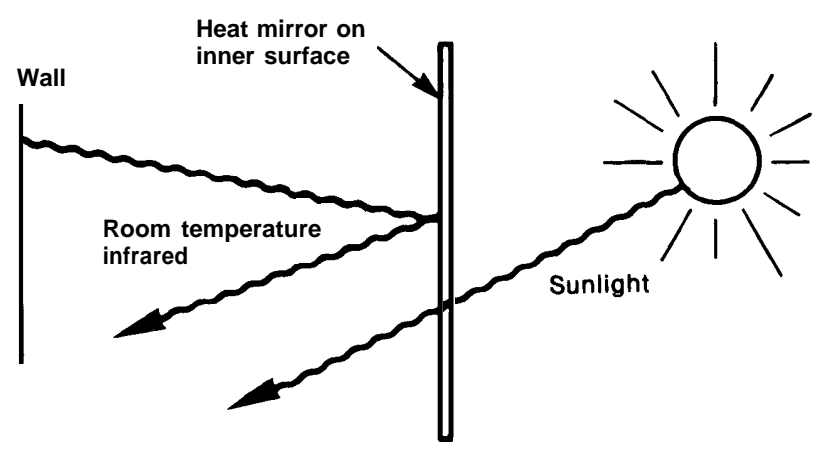

The heat mirror transmits almost all of the visible and invisible infrared sunlight but reflects almost all of the thermal infrared radiation back into the room. The overall effect can be similar to adding another pane of glass.
Figure 35.-Optical Shutter

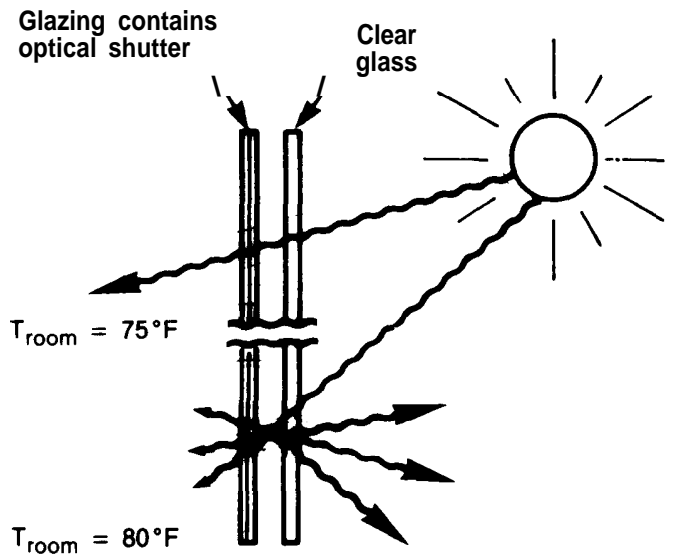

The optical shutter is a heat-activated sunshade made from a temperature sensitive polymer material which is transparent below a critical temperature $\left(76^{\circ} \mathrm{F}\right.$ in this example) and becomes a milky-looking diffuse reflector of $80 \%$ of the sunlight above that temperature.

Figure 36. -Weather Panel ${ }^{\circledR}$

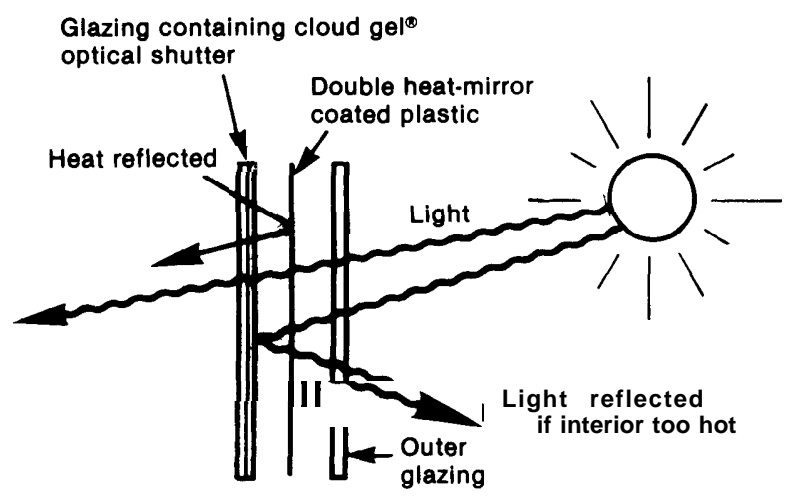

Weather PanelT.M. is a passive glazing system which combines good thermal resistance (R6 claimed) with passive shading capability. It is being developed by Suntek Research Associates. 
Table 75.-Summary of New Fenestration Technologies

\begin{tabular}{|c|c|c|c|c|c|c|c|c|c|}
\hline \multirow[b]{2}{*}{$\begin{array}{c}\text { Name of } \\
\text { technology }\end{array}$} & \multicolumn{2}{|c|}{ Winter } & \multicolumn{2}{|c|}{ Summer } & \multirow{2}{*}{$\begin{array}{c}\text { Effect on } \\
\text { lighting/ } \\
\text { outlook when } \\
\text { operating }\end{array}$} & \multirow{2}{*}{$\begin{array}{l}\text { Opera- } \\
\text { bility }\end{array}$} & \multirow{2}{*}{$\begin{array}{c}\text { Estimated } \\
\text { cost- } \\
\text { effectiveness }\end{array}$} & \multirow{2}{*}{$\begin{array}{l}\text { Applica- } \\
\text { bility to } \\
\text { retrofit }\end{array}$} & \multirow[b]{2}{*}{$\begin{array}{l}\text { Current } \\
\text { status }\end{array}$} \\
\hline & $\begin{array}{l}\text { Radiative } \\
\text { gain }\end{array}$ & $\begin{array}{l}\text { Heat loss } \\
\text { (all types) }\end{array}$ & $\begin{array}{l}\text { Radiative } \\
\text { gain }\end{array}$ & $\begin{array}{l}\text { Other } \\
\text { gains }\end{array}$ & & & & & \\
\hline $\begin{array}{l}\text { 1. Double-sided } \\
\text { blind }\end{array}$ & $\begin{array}{l}\cong 90 \% \text { of Un- } \\
\text { shaded; U.v. } \\
\text { is controlled }\end{array}$ & $\begin{array}{l}\text { moderate } \\
\text { reduction }\end{array}$ & $\begin{array}{l}\text { moderate } \\
\text { reduction }\end{array}$ & $\begin{array}{l}\text { moderate } \\
\text { reduction }\end{array}$ & $\begin{array}{l}\text { no outlook, } \\
\text { very low } \\
\text { light }\end{array}$ & $\begin{array}{l}\text { manual; } \\
\text { seasonal } \\
\text { reversal of } \\
\text { blind required }\end{array}$ & $\begin{array}{l}\text { very } \\
\text { high }\end{array}$ & $\begin{array}{l}\text { very } \\
\text { high }\end{array}$ & $\begin{array}{c}\text { ready for } \\
\text { commercial i- } \\
\text { zation }\end{array}$ \\
\hline 2. Triple blind & $\begin{array}{l}\cong 90 \% \text { of un- } \\
\text { shaded; U.v. } \\
\text { is controlled }\end{array}$ & $\begin{array}{l}\text { moderate- } \\
\text { high } \\
\text { reduction }\end{array}$ & $\begin{array}{l}\text { moderate } \\
\text { reduction }\end{array}$ & $\begin{array}{l}\text { moderate } \\
\text { reduction }\end{array}$ & $\begin{array}{l}\text { no outlook: } \\
\text { very low } \\
\text { light }\end{array}$ & $\begin{array}{l}\text { manual, } \\
\text { somewhat } \\
\text { complex }\end{array}$ & high & high & on market \\
\hline $\begin{array}{l}\text { 3. Shades } \\
\text { between } \\
\text { glazing with } \\
\text { heat recovery }\end{array}$ & $\begin{array}{l}\text { some loss } \\
\text { but distribu- } \\
\text { tion/storage } \\
\text { capability; U.v. } \\
\text { is controlled }\end{array}$ & $\begin{array}{l}\text { moderate } \\
\text { reduction }\end{array}$ & $\begin{array}{l}\text { moderate- } \\
\text { high } \\
\text { reduction }\end{array}$ & $\begin{array}{l}\text { moderate } \\
\text { reduction }\end{array}$ & $\begin{array}{l}\text { some outlook; } \\
\text { lighting pos- } \\
\text { sible when } \\
\text { I n operation }\end{array}$ & manual & high & low & $\begin{array}{c}\text { ready } \\
\text { commerciali- } \\
\text { zation }\end{array}$ \\
\hline $\begin{array}{l}\text { 4. Between } \\
\text { glazing con- } \\
\text { vection and } \\
\text { radiation } \\
\text { control }\end{array}$ & $\begin{array}{l}\cong 90 \% \text { of un- } \\
\text { shaded; slats } \\
\text { can direct } \\
\text { Sun away from } \\
\text { furnishings }\end{array}$ & $\begin{array}{l}\text { high } \\
\text { reduction }\end{array}$ & $\begin{array}{l}\text { moderate- } \\
\text { high } \\
\text { reduction }\end{array}$ & $\begin{array}{l}\text { high } \\
\text { reduction }\end{array}$ & $\begin{array}{l}\text { no outlook or } \\
\text { light: some } \\
\text { degradation } \\
\text { of outlook at } \\
\text { _ all times }\end{array}$ & none & $\begin{array}{l}\text { moderate- } \\
\text { high }\end{array}$ & low & $\begin{array}{l}\text { early } \\
R \& D\end{array}$ \\
\hline $\begin{array}{l}\text { 5. Insulating } \\
\text { shades and } \\
\text { shutters }\end{array}$ & $\mathrm{N} / \mathrm{A}$ & $\begin{array}{l}\text { very high } \\
\text { reduction }\end{array}$ & $\begin{array}{l}\text { high } \\
\text { reduction }\end{array}$ & $\begin{array}{l}\text { very high } \\
\text { reduction } \\
\text { if closed }\end{array}$ & $\begin{array}{c}\text { no outlook, } \\
\text { no light }\end{array}$ & $\begin{array}{c}\text { manual; } \\
\text { or } \\
\text { automatic }\end{array}$ & $\begin{array}{l}\text { low- } \\
\text { moderate }\end{array}$ & $\begin{array}{c}\text { low- } \\
\text { moderate }\end{array}$ & $\begin{array}{l}\text { products } \\
\text { marketed }\end{array}$ \\
\hline Skylid® & $N / A$ & $\begin{array}{l}\text { high } \\
\text { reduction }\end{array}$ & $\begin{array}{l}\text { high } \\
\text { reduction } \\
\text { if closed }\end{array}$ & $\begin{array}{l}\mathrm{high} \\
\text { reduction }\end{array}$ & $\begin{array}{l}\text { no outlook, } \\
\text { no light }\end{array}$ & automatic & $\begin{array}{l}\text { low- } \\
\text { moderate }\end{array}$ & low & on market \\
\hline 7. Beadwall@ & $\mathrm{N} / \mathrm{A}$ & $\begin{array}{l}\text { very high } \\
\text { reduction }\end{array}$ & $\begin{array}{l}\text { high } \\
\text { reduction } \\
\text { if filled }\end{array}$ & $\begin{array}{l}\text { very high } \\
\text { reduction } \\
\text { if filled }\end{array}$ & $\begin{array}{c}\text { no outlook, } \\
\text { no light }\end{array}$ & automatic & $\begin{array}{c}\text { low- } \\
\text { moderate }\end{array}$ & low & on market \\
\hline $\begin{array}{c}\text { 8. Beam } \\
\text { daylighting }\end{array}$ & $\begin{array}{l}\text { beneficial } \\
\text { distribution } \\
\text { effects and } \\
\text { u.v. control }\end{array}$ & $\mathrm{N} / \mathrm{A}$ & no effect & $\begin{array}{l}\text { reduced } \\
\text { lighting } \\
\text { load } \\
--\end{array}$ & $\begin{array}{l}\text { Increased } \\
\text { daylighting; } \\
\text { affects up- } \\
\text { per part of } \\
\text { window only }\end{array}$ & $\begin{array}{c}\text { manual; } \\
\text { only } \\
\text { seasonal } \\
\text { adjustment } \\
\text { is essential } \\
\end{array}$ & $\begin{array}{l}\text { low- } \\
\text { moderate }\end{array}$ & low & $\begin{array}{l}\text { advanced } \\
\text { R \& D }\end{array}$ \\
\hline $\begin{array}{l}\text { 9. Selective } \\
\text { solar control } \\
\text { reflective } \\
\text { film }\end{array}$ & $\begin{array}{l}\text { significantly } \\
\text { reduced }\end{array}$ & $\mathrm{N} / \mathrm{A}$ & $\begin{array}{l}\text { moderate- } \\
\text { high } \\
\text { reduction }\end{array}$ & $N / A$ & none & none & $\begin{array}{l}\text { high in pre- } \\
\text { dom, cooling } \\
\text { climates }\end{array}$ & $\begin{array}{l}\text { very } \\
\text { high }\end{array}$ & $R \& D$ \\
\hline 10. Heat mirror & $\begin{array}{l}\text { low } \\
\text { reduction }\end{array}$ & $\begin{array}{l}\text { low- } \\
\text { moderate } \\
\text { reduction }\end{array}$ & $\begin{array}{l}\text { low } \\
\text { reduction }\end{array}$ & $\begin{array}{l}\text { some } \\
\text { reduction }\end{array}$ & none & none & $\begin{array}{l}\text { moderate- } \\
\text { high }\end{array}$ & $\begin{array}{l}\text { very } \\
\text { high }\end{array}$ & $\begin{array}{l}\text { on market; } \\
\text { retrofit } \\
\text { package near } \\
\text { marketing }\end{array}$ \\
\hline $\begin{array}{l}\text { Optical } \\
\text { shutter }\end{array}$ & $\begin{array}{l}\text { low } \\
\text { reduction }\end{array}$ & $N / A$ & $\begin{array}{l}\text { high } \\
\text { reduction }\end{array}$ & $\mathrm{N} / \mathrm{A}$ & $\begin{array}{l}\text { no outlook } \\
\text { when } \\
\text { translucent }\end{array}$ & automatic & $\begin{array}{c}\text { probably } \\
\text { low }\end{array}$ & $\begin{array}{c}\text { probably } \\
\text { low }\end{array}$ & $R \& D$ \\
\hline $\begin{array}{l}\text { Weather } \\
\text { panel® }\end{array}$ & $\begin{array}{l}\text { low reduction } \\
\text { unless } \\
\text { overheating } \\
\text { occurs }\end{array}$ & $\begin{array}{l}\text { very high } \\
\text { reduction }\end{array}$ & $\begin{array}{l}\text { high } \\
\text { reduction }\end{array}$ & $\begin{array}{l}\text { very high } \\
\text { reduction }\end{array}$ & no outlook & $\begin{array}{l}\text { passive/ } \\
\text { automatic }\end{array}$ & & & R\&D \\
\hline $\begin{array}{l}\text { 13. Optimization } \\
\text { of fenestra- } \\
\text { tion design } \\
\text { (size, ori- } \\
\text { entation) }\end{array}$ & $\begin{array}{c}\text { significant } \\
\text { optimization } \\
\text { over } \\
\text { current } \\
\text { practice }\end{array}$ & $N / A$ & $\begin{array}{l}\text { high } \\
\text { reduction } \\
\text { through } \\
\text { proper shad- } \\
\text { ing, etc. }\end{array}$ & reduction & $\mathrm{N} / \mathrm{A}$ & $\mathrm{N} / \mathrm{A}$ & very high & $\begin{array}{l}\text { very } \\
\text { low }\end{array}$ & $\begin{array}{l}\text { early } \\
R \& D\end{array}$ \\
\hline
\end{tabular}




\section{HEATING AND COOLING EQUIPMENT}

\section{Direct Fossil-Fired Heating Equipment*}

Most residential and commercial buildings in the United States are heated with directfired gas and oil fumaces and boilers, as shown in table 76. Considerable controversy arises over the typical operating efficiencies of these

Table 76.-Heating Equipment and Fuels for Occupied Units in 1976 (in thousands)

\begin{tabular}{|c|c|c|}
\hline & Number & Percent \\
\hline Total occupied units. . . & 79,316 & 100.0 \\
\hline Warm air furnace. . . & 40,720 & 51.3 \\
\hline Steam or hot water. . & 14,554 & 18.3 \\
\hline Built-in electric units . & 5,217 & 6.6 \\
\hline Floor, wall, or pipeless furnace. . . & 6,849 & 8.6 \\
\hline Room heaters with/without flu . . . & 8,861 & 11.2 \\
\hline $\begin{array}{l}\text { Fireplaces, stoves, portable } \\
\text { heaters. } \ldots \ldots \ldots \ldots \ldots \ldots\end{array}$ & 2,398 & 3.0 \\
\hline None. ................... & 716 & .9 \\
\hline Total occupied housing unit . . . & 74,005 & 100.0 \\
\hline House heating fuel: & & \\
\hline Utility gas. $\ldots \ldots \ldots \ldots \ldots \ldots$ & 41,219 & 55.7 \\
\hline Fuel oil, kerosene. ............. & 16,451 & 22.2 \\
\hline Electricity .................. & 10,151 & 13.7 \\
\hline Bottled gas or 1 g gas. . . . . . . . . & 4,239 & 5.7 \\
\hline Coke or coal/wood/other. ...... & 1,482 & 2.0 \\
\hline None................. & 463 & .6 \\
\hline Cooking fuel: & & \\
\hline Utility gas. . & 32,299 & 43.6 \\
\hline Electricity . . & 35,669 & 48.2 \\
\hline 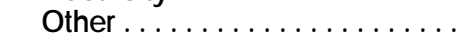 & 5,748 & 7.8 \\
\hline None................... & 287 & .4 \\
\hline
\end{tabular}

systems. One reason is that remarkably little is known about their performance in actual operating environments, and the literature in the area is replete with inconsistent information. (Figure 10 in chapter II illustrates the problem.) Performance undoubtedly varies with the type of unit, its age, size, installation, position in the building, and a number of other variables. Another reason for the controversy is the inconsistency in the definition of efficiency. Until recently, the most common value quoted was the steady-state or full-load combustion efficiency, which is defined as the ratio of useful heat delivered to the furnace bonnet

"Some parts of this section are taken from "Applications of Solar Technology to Today's Energy Needs," Office of Technology, June 1978. divided by the heating value of the fuel. " Typical values for direct-combustion fumaces are 70 to 80 percent; heat loss principally results from heated stack-gases lost during combustion. This definition does not give a complete measure of the fuel required to heat a living space over the heating season. A definition that does, and one that is increasingly being used, is the seasonal performance factor or seasonal efficiency. This measure is defined as the ratio of $(a)$ the useful heat delivered to the home to (b) the heating content of the fuel used by the fumace over the entire heating season. Typical gas fumaces have seasonal efficiencies in the range of 45 to 65 percent (see figure 37) Seasonal efficiency accounts for all factors affecting the heating system's performance in its actual operating environment. In addition to stack-gas losses these factors include loss of heated room air through the chimney while the fumace is off (infiltration), cycling losses, pilot light (gas furnaces only), and heat losses through the a ir distribution ducts when in unheated spaces. "Cycling losses are a result of operation at part loads, which causes heat to be lost in raising the temperature of the fumace before useful heat can be delivered to the living space. Most existing homes have fumaces oversized by at least 50 percent, so they are always operating at relatively inefficient part-load conditions. ' ${ }^{3}$ The oversizing is greater still in homes that have had insulation, storm windows, or other thermal envelope improvements added since the fumace was installed.

In addition to the fossil fuel required for the bumer, gas and oil fumaces and boilers require electric energy to operate fans and pumps.

${ }^{1}$ EE. C. Hise and A. S. Holmn, "Heat Balance and Efficiency Measurements of Central Forced Air Residential Gas Furnaces" (Oak Ridge National Laboratory).

${ }^{1 *}$ C. Samuels, et al., "MIUS Systems Analysis- Initial Comparisons of Modular-Sized Integrated Utility Systems and Conventional Systems, " ORNL/HUD/MIUS-5, June 1976, p. 24.

${ }^{13} \mathrm{H}$ ise and Holman, op. cit. 
Figure 37.-Typical Energy Flow for a Gas Furnace System

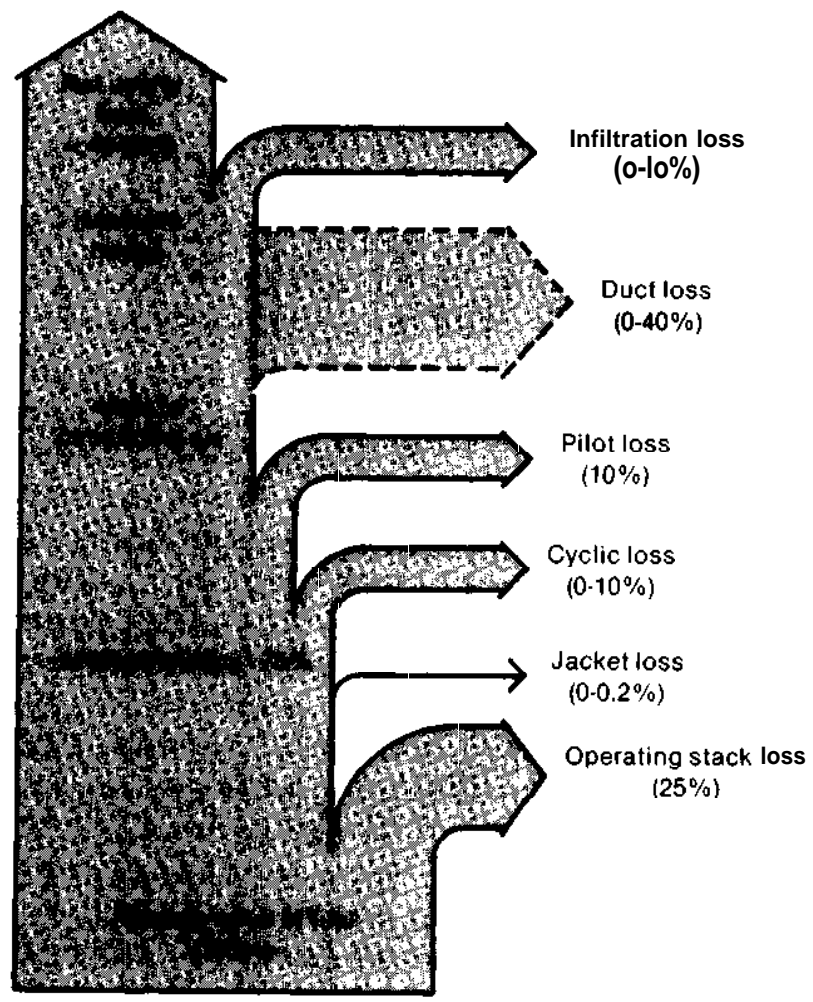

sUURLL: L. C. Hise et al., "Heat Balance and tticiency Measurements of Cen tral. Forced-Air. Residential Gas Furnaces," Oak Ridge National Lab oratory. ORNL-NSF-EP-88. October 1975. p. 4

\section{Oil and Gas Furnace Efficiency Improvements}

Fumaces with improved efficiency levels are now available and new devices are being developed. Table 77 summarizes the approximate energy savings and costs of a number of oil boiler improvements, most of which are now available. Corresponding tables of measured improvements for oil furnaces and gas furnaces and boilers are not available, but similar levels of improvement can be expected.

Several of these improvements reduce the heat lost when the fumace cycles on and off frequently. As most fumaces are now sized to supply at least one and one-half times the maximum anticipated heating load, reducing the furnace capacity, either by installing a smaller nozzle or a smaller fumace, will also substantially cut off-cycle losses.

Periodic adjustment of oil burners will improve their combustion efficiency and lower flue-gas temperatures. This service is available from heating oil distributors and furnace repair services.

Variable fining rate fumaces represent an attempt to provide reduced output for near continuous operation and thus cut off-cycle losses; development of a reliable and affordable technology for accomplishing this goal

Table 77.-Refit Modifications for Efficiency Improvement of Oil-Fired Boilers

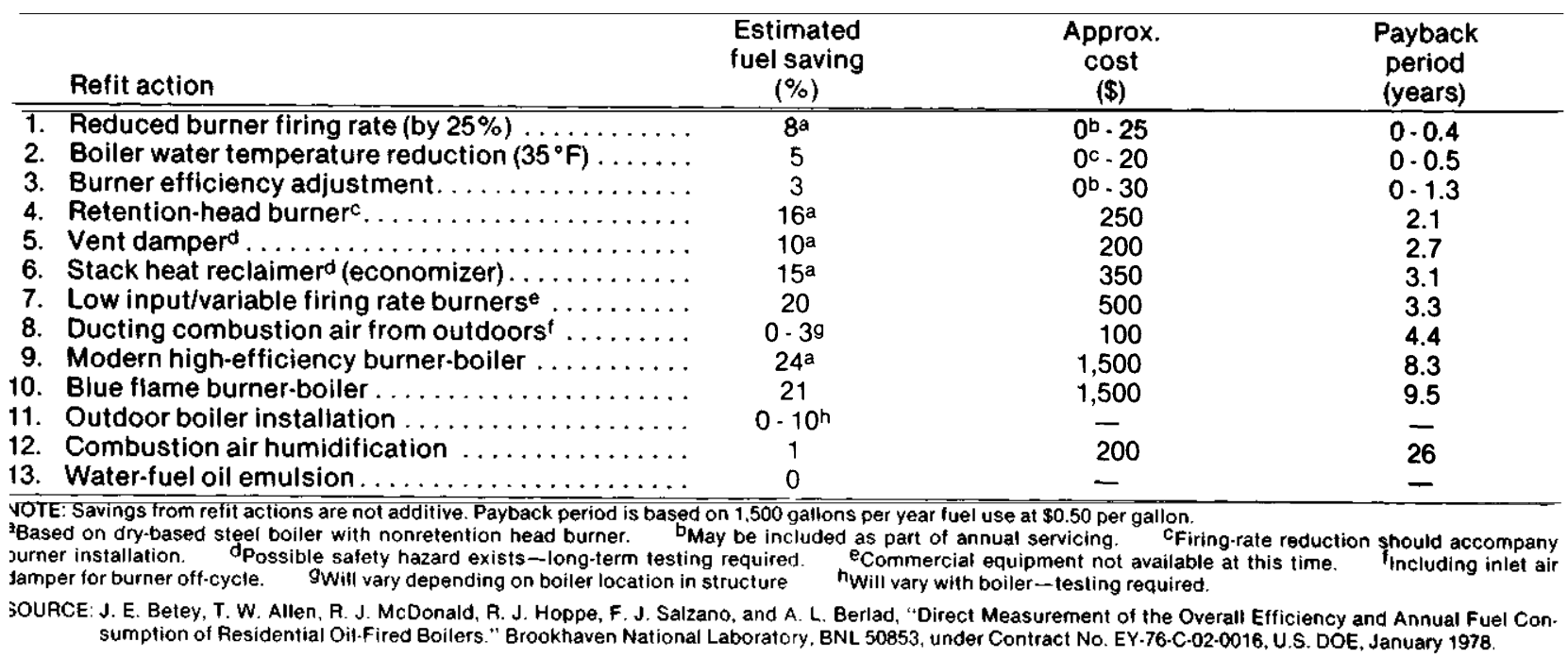


has proven difficult. Such fumaces are not expected to be commercially available until the late-I 980 's.

Automatic flue dampers close the flue after the fumace shuts off to drastically reduce the amount of heat that escapes up the chimney while the fumace is not operating. Flue dampers have been used in Europe for many years, but concern over safety questions delayed their acceptance in this country. They are now coming into use.

Flame-retention head burners improve combustion efficiency by causing turbulence in the combustion air, enhancing air-fuel mixing. These burners are on most oil fumaces sold now, but improved versions are being developed.

Sealed combustion units reduce flue-gas losses during both on and off cycles by using outside air for combustion. This means that the warm interior air is not exhausted up the flue. These improvements can result in furnaces with seasonal efficiencies of $\mathbf{7 5}$ to 81 percent. ${ }^{14} 15$

\section{Advanced Fuel-Fired Equipment}

Several types of equipment that should provide substantially higher seasonal efficiencies are under development. These include condensing flue-gas furnaces, pulse combustion bumers, and several different fuel-fired heat pumps.

Conventional furnaces maintain flue-gas temperatures of 4000 to $7000 \mathrm{~F}$ to avoid condensation and attendant corrosion and to maintain the nature draft.

The near-condensing flue-gas mechanism would reduce this temperature to nearly 3000 $\mathrm{F}$, and thus capture a great deal of the flue-gas heat; the condensing version would place the flue temperatures below $300^{\circ} \mathrm{F}$ and thus recapture the latent heat in the water vapor as well. Problems with this approach relate to

\footnotetext{
${ }^{14}$ J. E. Batey, et al., "Direct Measurement of the Overall Efficiency and Annual Fuel Consumption of Residential Oil-Fired Boilers" (Brookhaven National Laboratory, January 1978), BNL 50853.

"Department of Energy, "Final Energy Efficiency Improvement Targets for Water Heaters, Home Heating Equipment (Not Including Furnaces). Kitchen Ranges and Ovens, Clothes Washers and Furnaces," Federal Register.
}

corrosive flue-gas condensate and scaling on the heat exchanger. Neither version is expected to appear on the market for several years.

\section{Pulse Combustion Fumaces and Boilers}

The pulse combustion bumer is a unique approach that uses mechanical energy from an explosive combustion process to "power" the burner and permit condensation of the flue gases without the need for a fan-driven bumer.

The operation of the pulse combustion burner is illustrated in figure 38. Initially, a small fan drives air into the combustion chamber through flapper valves along with a small quantity of gas and the mixture is ignited by a spark plug. The explosive force of ignition closes the valves and drives the exhaust gases out the tailpipe. The combustion chamber and tailpipe are acoustically "tuned" so the exhaust process creates a partial vacuum that opens the intake valves and sucks air and gas into the combustion chamber without use of the fan. Residual heat from the previous combustion ignites this mixture without need for the spark plug. The exhaust gases are cooled to about $120^{\circ} \mathrm{F}$, recovering nearly all of their heat including the latent heat in the water vapor.

The pulse combustion principle has been known for many years and some development occurred in the 1950's and 1960's. The principal problems were related to muffling the intrinsically noisy combustion process and materials problems related to the extremely high heat releases in small volumes. "While these problems were not insolvable, the promise of higher efficiency was insufficient to offset higher production costs. Further development work has occurred and Hydrotherm, Inc., has started an initial production run of 300 residential boilers with full production to begin after mid-1979. ${ }^{17}$ Hydrotherm has measured efficiencies of 91 to 94 percent for this boiler and seasonal efficiencies are expected to be simi-

“J C. Griffiths, C. W. Thompson, and E. J. Weber, "New or Unusual Burners and Combustion Processes," American Gas Association Laboratories Research Bulletin 96, August 1963.

"Richard A. Prusha, Hydrotherm, Inc., Northvale, N. J., private communication, Mar. 30,1979. 
Figure 38.-Principies and Operation of the Hydro-Pulse ${ }^{\mathrm{TM}}$ Boiler That Uses the Pulse-Combustion Process.

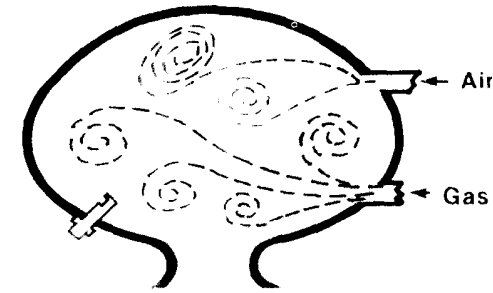

1. To start the boiler, a small blower forces outside air into a sealed chamber where it is mixed with gas.

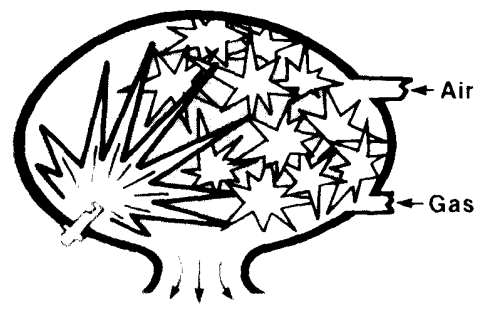

2. A spark plug is used on the first cycle only to ignite the mixture.

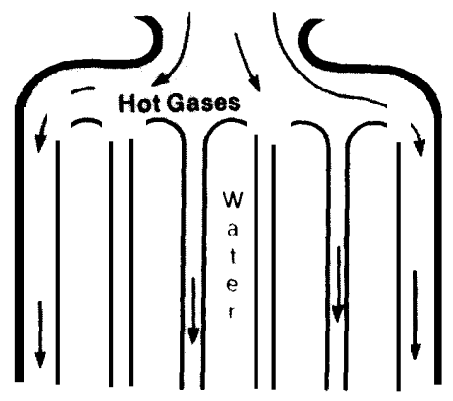

3. The pressure resulting from the combustion process forces the hot gases through tubes in the heat exchanger where surrounding water absorbs the heat.

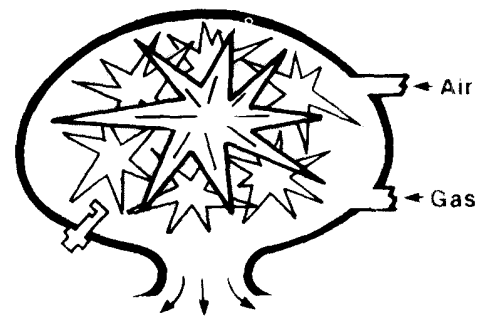

6. Residual heat from the initial combustion ignites the second and subsequent air/gas mixtures without the need for the spark plug or blower...at a ratein excess of 25 cycles per second.

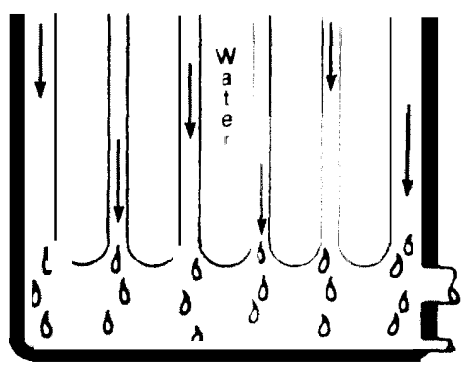

4. As the hot gases are cooled below the dew point, condensation of the water vapor in the flue gases takes place, releasing the latent heat of vaporization ....amounting to about $9 \%$ of the fuel input.

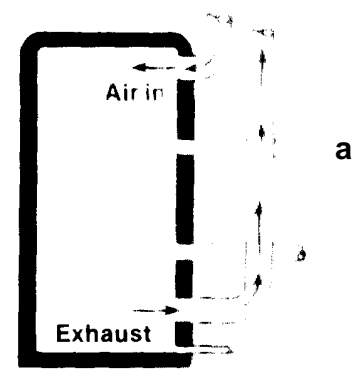

7. Air is drawn into the combustion chamber from outdoors by the vacuum caused by the velocity of the exiting exhaust gases...both through small diameter plastic pipe. No flue or chimney is needed

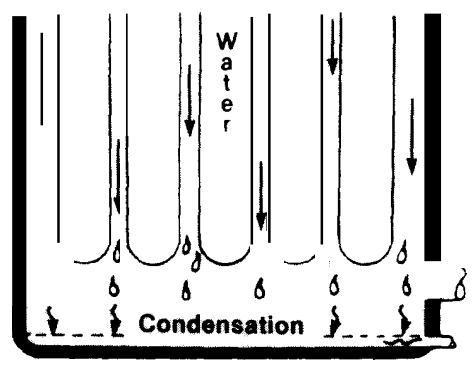

5. Condensation collects in the base of the boiler and is removed by a condensate drain.

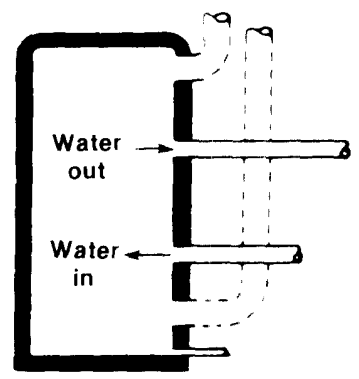

8. Water is circulated through HydroPulse $^{\mathrm{TM}}$ in much the same manner as in a conventional boiler. 
lar since outdoor combustion air is used and off-cycle flue losses are virtually eliminated. ${ }^{18}$ Due to the low flue temperatures, the flue gases are exhausted through a $1 \frac{1 / 2}{\text {-inch }}$ PVC plastic pipe and no chimney is needed to provide natural draft. The cost of this boiler will be about twice that of conventional gas boilers. An oil-fired pulse combustion boiler is now manufactured in Europe ("TurboPuls") and the manufacturer is apparently interested in marketing in the United States if certification can be obtained.

Both the noise problem and the materials problems are more severe for hot air fumaces, but Lennox Industries is developing a pulse combustion fumace in a joint project with the Gas Research Institute. Laboratory efficiencies above 95 percent have been achieved and a preproduction prototype has been installed in a home but additional work on noise reduction and controls development is needed. '9 Major field testing will be conducted before the furnace is marketed, perhaps in the mid-1 980's.

\section{Fuel-Fired Heat Pumps}

Heat pumps, as their name implies, pump heat from a cooler space to a wamer space. All refrigerators and air-conditioners are actually heat pumps, but the term "heat pump" is generally reserved for a device that is designed to provide heating by pumping heat from the outdoor air or a water supply. Most heat pumps can also be reversed and used as a ir-conditioners. The heat pumps now on the market are electrically driven but development of gas-fired heat pumps is underway. Most gas-fired designs could be modified and produced as oil-fired units as well. The designs being developed should provide seasonal performance factors of 1.1 to 1.5 for heating, or use about half the fuel consumed by present furnace installations. Three of these designs are discussed in the Heat Pump section.

\footnotetext{
Inc.

8Hydro-Pulse Boiler product literature, Hydro Therm, 191978 Annual Report (Chicago, I II.: Gas Research Institute).
}

\section{Electric Air-Conditioners and Heat Pumps*}

A typical residential air-conditioner/heatpump installation is illustrated in figure 39. These systems usually cool and dehumidify room air directly while the systems used in large apartments and commercial buildings typically produce chilled water, which is piped to fan-coil units in various parts of the building. Cooling systems have three basic components: 1 ) a unit that permits a refrigerant to expand, vaporize, and absorb heat from the room air (or water system); 2) a compressor that compresses the heated vapor (increasing its temperature); and 3) a condenser, located outside the building that rejects the heat $a b$ sorbed from the room air into the atmosphere (condensing the compressed vapor to a liquid). In "single-package" units, all three functions are provided in the same unit and can be connected directly to the ductwork (or chilled water system) of the building. In "split-system" devices, refrigerant is sent to an air-handling unit inside the building. Another distinction involves the technique used to compress the refrigerant vapor. Smaller units typically use a simple piston system for compression and are called "reciprocating" units. Larger units may use centrifugal pumps or screw compressors for this purpose.

Heat pumps use the same three basic components as the air-conditioners described above, but the cycle is reversed. In the heating cycle, the indoor air absorbs heat from the refrigerant and heat is acquired by the refrigerant from the outdoor fan unit (the "condenser" in the cooling model).

Heat pumps that can extract useful energy from outdoor a ir temperatures as low as $00 \mathrm{~F}$ are now on the market, although system performance is little better than electric fumaces at low temperatures. The electricity used by the system can be considerably reduced if a source of heat with a temperature higher than that of the outside air can be found. Lakes or

\footnotetext{
*Some parts of this section are taken from "Application of Solar Technology to Today's Energy Needs," Office of Technology Assessment, June 1978.
} 


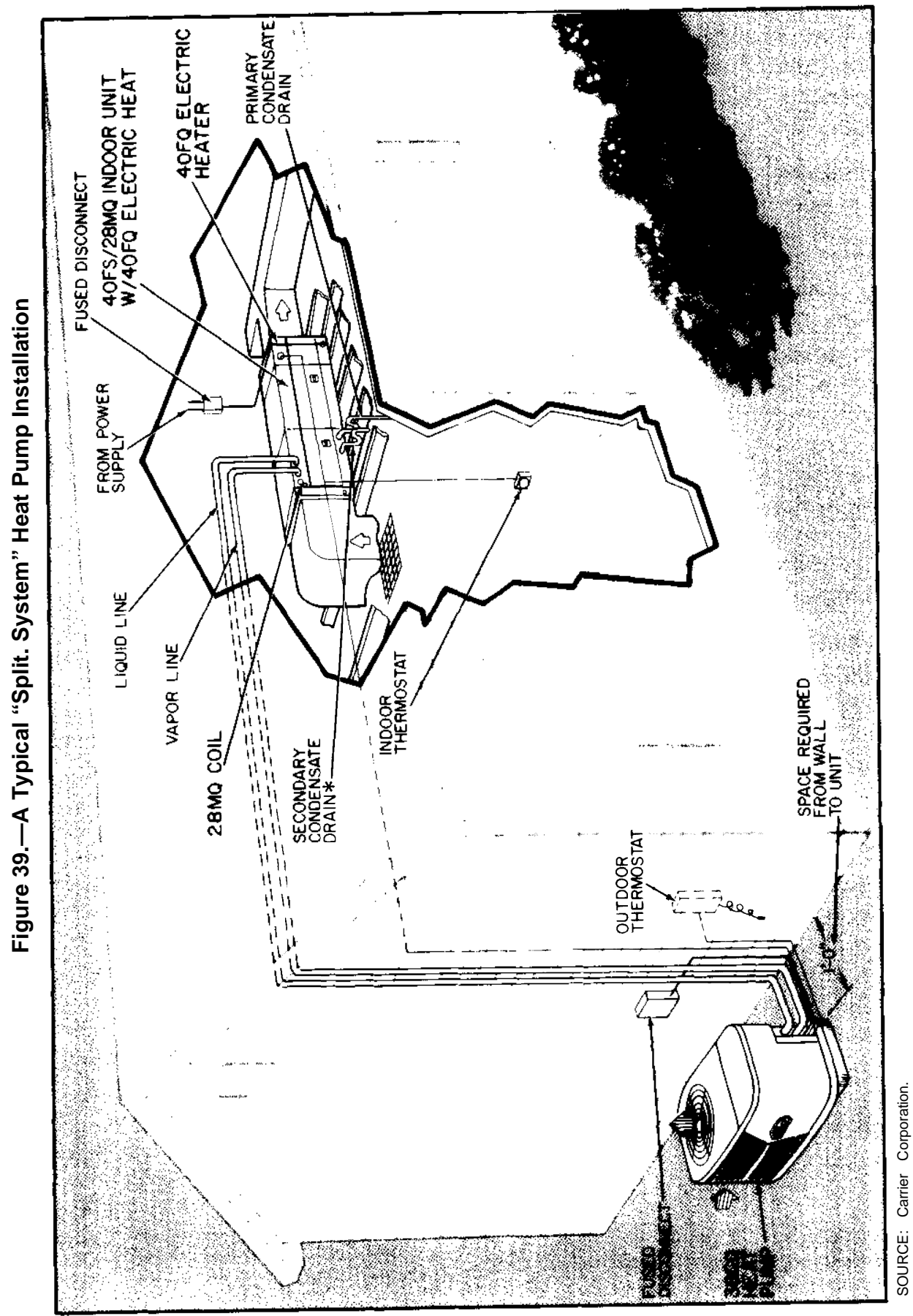


ground water, for example, are usually above ambient air temperatures during the winter and can be used to provide a source of input heat if they are available. Solar energy can also be used to provide a source of heated water. Systems that extract heat from water are called "water-to-a ir" heat-pump systems; units extracting energy from the air are called "air-to-a ir" systems. 20

In 1976, 51 percent of the housing in the United States was equipped with room air-conditioners or central air-conditioning, up from 47 percent in 1973. ${ }^{2 \prime}$ Housing units with central air-conditioning increased from 16.8 to 21.5 percent from 1973 to 1976 while the fraction with room air-conditioners showed very little change, going from 30.1 to 29.6 percent. From 1973-77, the fraction of new homes with central air-conditioning has ranged from 46 percent in 1975 to 54 percent in 1977.22 Thus, it is diffic ult to say whether growth in demand for central air-conditioning in new housing was merely slowed by the Arab embargo, or whether it is approaching saturation.

Less than 5 percent of U.S. homes currently have heat pumps, but 20 to 25 percent of new housing starts in 1978 used the system, The growth of the market has been slowed by the sensitivity of buyers and builders to the initial cost of the equipment (which is higher than conventional electric-resistance heat), and by the fact that regulated gas prices and promotional electric prices have made the cost of operating competitive heating systems artificially low. Concems about reliability have also been a problem. Some of the heat pumps marketed in the early 1960's were extremely unreliable, and sales of the units fell steadily between 1965 and 1970. While most of the reliability problems have been resolved, a recent study showed that the problem has not vanished.

\footnotetext{
${ }^{20}$ Cordial Associates, Inc., "Evaluation of the Air-toAir That Pump for Residential Space Condition ing," prepared for the Federal Energy Administration, Apr. 23, 1976, p. 114.

21 Breau of the Census, "1976 Annual Housing Survey. "

"Bureau of the Census, "Characteristics of New Housing: 1977, "Construction Reports, C25-77-13, 1978, p. 12.
}

The performance of heat pumps and air-conditioners now on the market varies greatly. Figure 40 indicates the performance of central air-conditioners smaller than $5 \mathrm{l} / \mathrm{z}$ tons now on the market. The difference in performance reflects both the quality of design and the cost of the unit. High-performance units may also result from a fortuitous combination of components. Manufacturers cannot afford to design condensers optimally suited for all compressors to which they may be attached, and some combinations of these units may therefore result in a high-efficiency system. As a result, while there are a few units on the market with very high efficiencies (figure 40, for example, indicates that 5 percent of the units on the market have a coefficient of performance (COP) greater than 2.5), this performance is not available in all size ranges. (The definition of COP, energy efficiency ratio, and other

Figure 40.- Air-Conditioning COP of Heat Pumps and Central Air-Conditioning Units Shipped in 1977

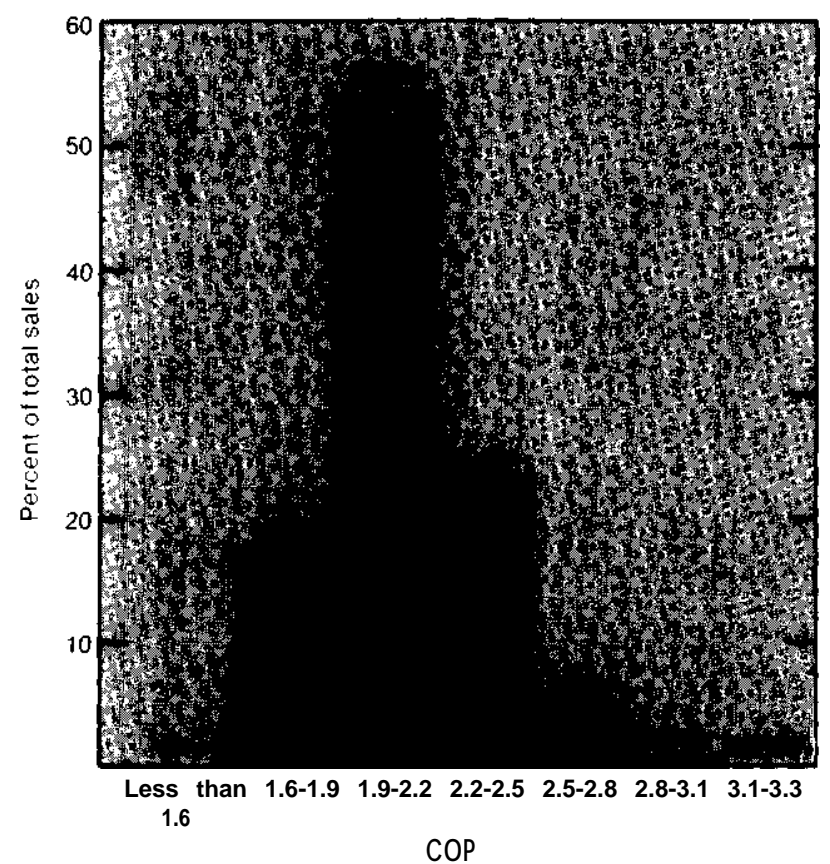

SOURCE Air Conditioning and Refrigeration Institute Includes only units of $\mathrm{u}$ rider 135,000 Btuh Data has been converted from EER to COP and values rounded to nearest tenth EER ranges were " 54 and under $55.6 .4657475 .8485 .94,95104$, and 105.114 
efficiency measures are discussed in a technical note to chapter 1 I.) The 1976 industry average COP was 2.00 .23

Heat pumps in the cooling mode were about 5 -percent less efficient than the average airconditioner, for a variety of reasons. Heat pumps cannot be optimized for maximum cooling performance as somewhat more complexity is required in the coolant piping, and the valve that switches the direction of the refrigerant when the system is changed from heating to cooling introduces some inefficiencies.

The performance of electric-cooling and heat-pump systems also varies as a function of the temperature and humidity of both the inside and outside air. This is because the theoretical capacity of a unit varies as a function of these parameters, and because most small units must be either fully on or fully off. The load control achieved by "cycling" the system from full capacity to zero output requires heating or cooling large parts of the system before useful space conditioning can be performed. Using energy to heat or cool the units decreases the system's efficiency, The dependence of a typical residential heat-pump unit COP on the outdoor temperature is shown in figure 41 . The fact that the heat pumps capacity to produce heat decreases as the outside temperature decreases results in a highly temperature-dependent heating mode. A system large enough to provide 100 percent of the heating load at the lowest anticipated temperature would be prohibitively expensive in most locations, and a common compromise is to assist the heat pump with electric-resistance heat whenever its capacity falls below the heating demand. The average COP of a heatpump system duning the winter season is called the seasonal performance factor (SPF). This parameter is shown in figure $\mathbf{4 2}$ as a function of local climate. As expected, the average COP of heat pumps is lower in northem parts of the

\footnotetext{
${ }^{23}$ George D. Hudelson (Vice President-Engineering, Carrier Corporation), testimony before the California State Energy Resources Conservation and Development Commission, Aug. 10,1976 (Docket No. 75; CON-3).
}

\section{Figure 41.-Performance of the Carrier Split- System Heat Pump}

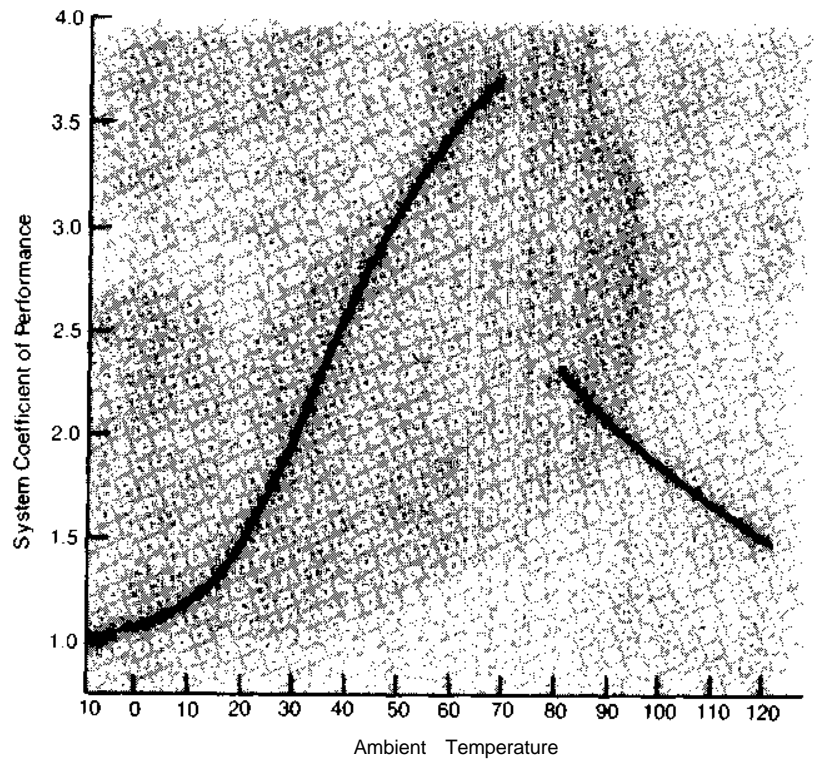

Model 38CQ020 ARI ratings: Heating mode nominal capacity 21,000 Btu/hour. COP at high temperature is 2.9, COP at low temperature is 1.7

Cooling mode nominal capacity is $19,000 \mathrm{Btu} /$ hour. COP is 2.1

Assumptions used in computing Heating mode entering indoor air system performance is $70^{\circ} \mathrm{F}(\mathrm{db})$ heating demand includes energy used for defrost balance point at $30^{\circ} \mathrm{F}$.

Cooling mode entering indoor air is $80^{\circ} \mathrm{F}(\mathrm{db})$ and $67^{\circ} \mathrm{F}(\mathrm{wb})$. Fan power is $0.2 \mathrm{~kW}$.

Energy use includes: compressor motor demands; resistance heat; the demands of indoor and outdoor fans, and the energy used in defrost cycles. The air-flow was assumed to be $700 \mathrm{cfm}$. Assumptions made about decrease in efficiency due to part load conditions were not explained in the literature.

SOURCE Career Sptil-System Heat Pump Outdoor Sections Carrier Corporation 1976 Form 38CQ-1P

country. As discussed in chapter 11, the performance of heat pump installations has generally been lower than predicted.

The performance of water-to-air heat-pump systems can be significantly higher than air-toair systems if heated water is available. When $600 \mathrm{~F}$ water is available, most commercial units have COPS in the range of 2.5 to 3.5 , but units with COPS as low as 2.0 and as high as 3.7 are on the market.

There are a number of straightforward changes that can improve the performance of air-conditioners without changing the basic design. Legislative actions and rising fuel costs have produced a number of higher perform- 
Figure 42.-The Seasonal Performance of Heat-Pump Units as a Function of Local Climate

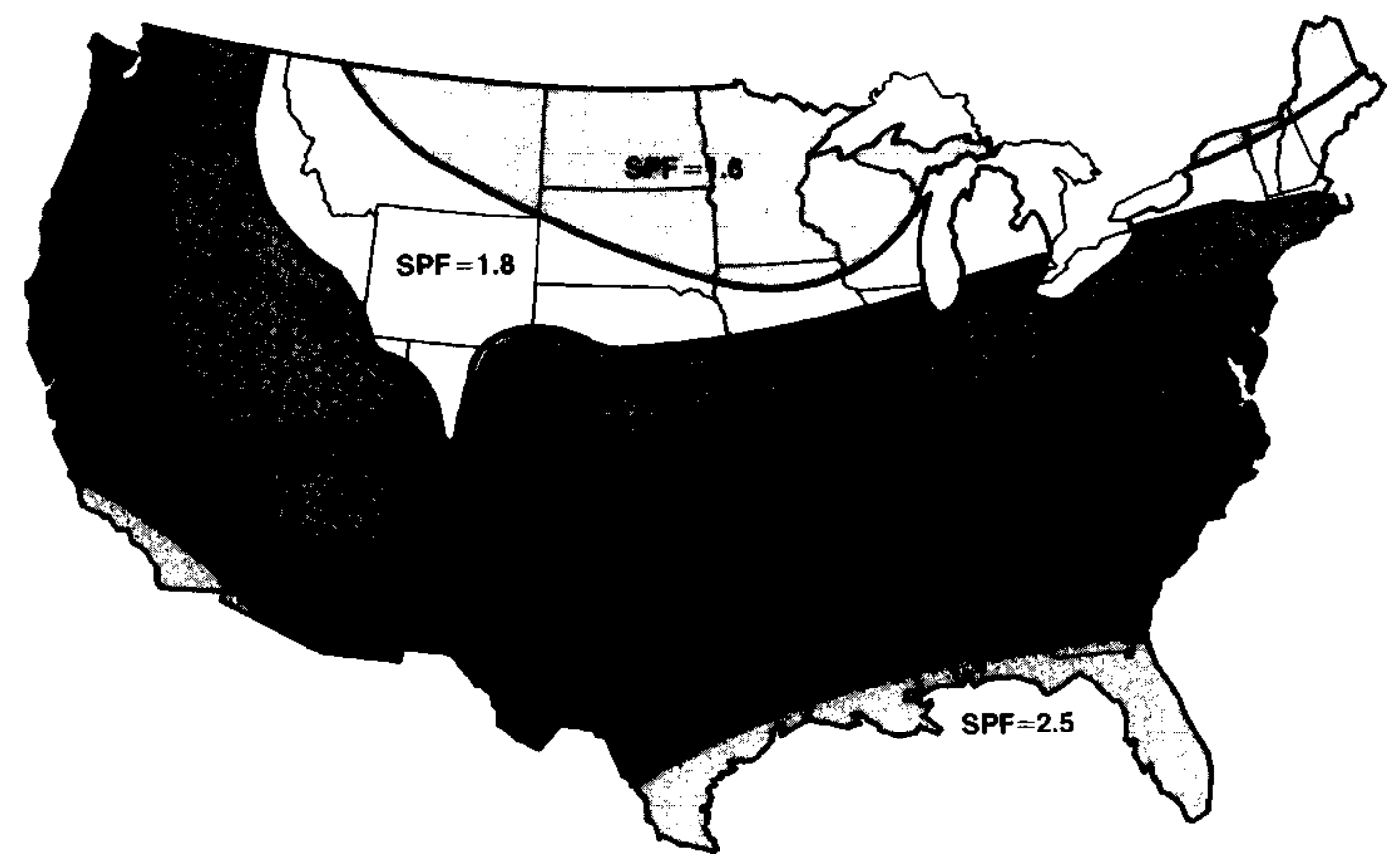

SOURCE: What is a Single-Packaged Heat Pump... and How Can it Save You Money?, Carrier Corporation, Catalog No. 650-069

ance units. Some of the steps being taken to improve performance include:

- use of more efficient compressors,

- use of two compressors or multiple-speed compressors to improve part-load efficiency,

- improved heat exchangers for both the condensor and evaporator,

- more efficient motors to drive the compressor and fan,

- automatic cycling of the fan with the compressor, and

- improved airflow.

One estimate for the cost of these incremental improvements is shown in figure 43. California has legislated performance standards in a two-step process; standards were first effective during 1977 and become more stringent in late-1979. These standards, which specify the minimum performance of any unit that can be sold in Califomia, are shown in table 78.

The Energy Policy and Conservation Act (EPCA-- Public Law 94-163) as amended by the National Energy Conservation Policy Act (NECPA-- Public Law 95-619) required DOE to establish energy-efficiency improvement targets for appliances. These targets for air-conditioners, shown in tables 79 and 80 , represent targets for the production-weighted average performance of all air-conditioners sold rather than a minimum standard. The National Energy Act has mandated the setting of efficiency standards that will be proposed in October 1979.

Looking further into the future, a number of systems have been proposed that could increase the COP of air-conditioning systems and heat pumps by as much as 50 percent. Researchers at General Electric believe that it would be possible to achieve an approximate 50 -percent increase in the average COP of both heating and cooling for an increase in the initial cost of the unit of about 20 to 30 percent. It should be noted that performance can be improved by increasing low-temperature performance, high-temperature performance, or both. The speed with which these new units appear on the market will depend strongly on the company's perception of whether the public is willing to invest in equipment that can reduce their annual operating expenses over the long 
Figure 43.- Estimated Cost of Increasing the Performance of Air-Conditioners From the Industry Average COP of 2.0 to the Performance Levels Indicated (estimates assume production rates equivalent to current production rates)

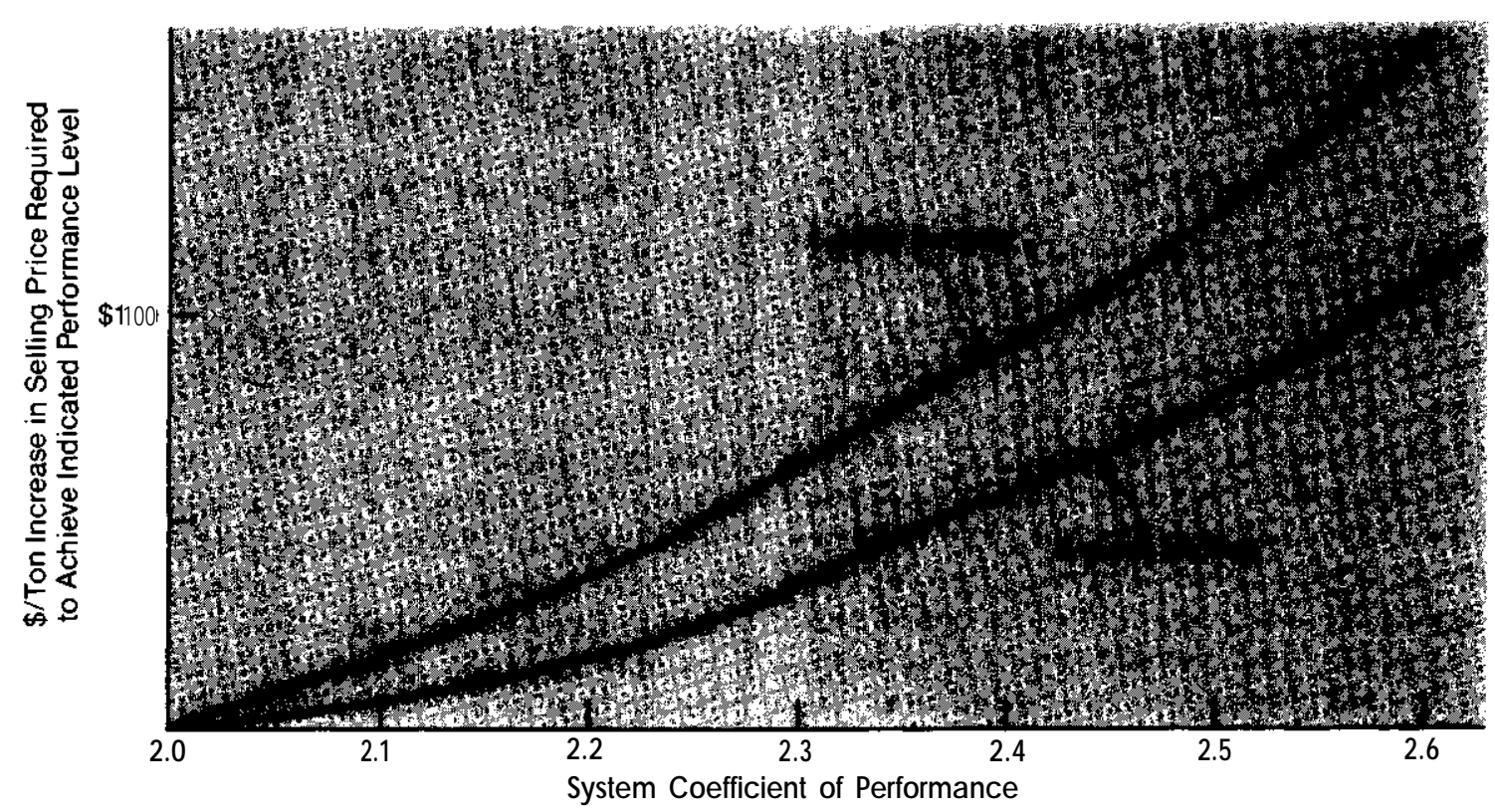

SOURCE George D Hudelson (Vice President-Englneerlng, Carrier Corp.) presentation to the Solar Energy Resources Conservation and Development Commission of California, Aug. 10, 1976, Docket No 75-CON-3

Table 78.-California Standards for Cooling Equipment

\begin{tabular}{|c|c|c|}
\hline System type & $\begin{array}{c}\text { Standard } \\
\text { aS of } \\
11 / 3 / 77^{\star}\end{array}$ & $\begin{array}{c}\text { Standard } \\
\text { after } \\
\mathbf{1 1 / 3 / 7 9}\end{array}$ \\
\hline \multicolumn{3}{|l|}{ Central Air-Conditioners } \\
\hline Heat pumps (cooling mode) & 1.96 & 2.2 \\
\hline Air-conditioners & 2.05 & 2.34 \\
\hline \multicolumn{3}{|l|}{ Room Air-Conditioners } \\
\hline $\begin{array}{l}\text { All systems with capacity greater } \\
\text { than } 20,000 \text { Btu's }\end{array}$ & 2.05 & - \\
\hline Other heat pumps & 2.08 & - \\
\hline Other air-conditioners & 2.20 & - \\
\hline $\begin{array}{l}\text { All systems using voltages } \\
\text { greater than } 200 \mathrm{v} .\end{array}$ & - & 2.40 \\
\hline Other heat-pump systems & - & 2.43 \\
\hline Other air-conditioners & - & 2.55 \\
\hline
\end{tabular}

'No system may be sold in the State after this date with a COP below the standard.
Table 79.-DOE Room Air. Conditioner EnergyEfficiency Improvement Target

\begin{tabular}{cccc}
\hline $\begin{array}{c}1972 \text { energy- } \\
\text { efficiency ratio } \\
\text { Btu/watt-hour }\end{array}$ & $\begin{array}{c}1972 \\
\text { COP }\end{array}$ & $\begin{array}{c}1980 \text { energy- } \\
\text { efficiency ratio } \\
\text { Btu/watt-hour }\end{array}$ & COP \\
\hline $\mathbf{6 . 2}$ & $\mathbf{1 . 8 2}$ & $\mathbf{7 . 9 4}$ & $\mathbf{2 . 3 3}$
\end{tabular}

SOURCE: Department of Energy, "Energy Efficiency Improvement Targets for Nine Types of Appliances," F.R. 43, No. 70, Apr. 11, 1978, p. 15143.

Table 80.-DOE Central Air-Conditioner Energy. Efficiency Improvement Target

\begin{tabular}{|c|c|c|c|c|}
\hline & $\begin{array}{c}1975 \\
\text { SEER } \\
\end{array}$ & $\begin{array}{c}1975 \\
\mathrm{COP}^{\mathrm{b}} \\
\end{array}$ & $\begin{array}{c}1980 \\
\text { SEER }^{\mathrm{a}}\end{array}$ & $\begin{array}{c}1980 \\
\text { COP }\end{array}$ \\
\hline \multicolumn{5}{|l|}{$\begin{array}{l}\text { Central air- } \\
\text { conditioners }\end{array}$} \\
\hline $\begin{array}{l}\text { (aggregate). } \\
\text { Single package }\end{array}$ & 6.5 & 1.90 & $\begin{array}{l}8.0 \\
7.2\end{array}$ & $\begin{array}{l}2.34 \\
2.11\end{array}$ \\
\hline Split system. . & 6.6 & 1.93 & 8.1 & 2.37 \\
\hline
\end{tabular}

a Seasonal energy efficiency ratio in Btu/watt-hour as defined in chapter II. bSeasonal coefficient of performance $=$ SEER/3.413.

SOURCE: Department of Energy, "Energy Efficiency Improvement Targets for Nine Types of Appliances," F.R. 43, No, 70, Apr. 11, 1978, p. 15145. 
term. These attitudes may be influenced by legislative initiatives, such as the National Energy Act.

\section{Gas-Fired Heat Pumps and Air-Conditioners}

\section{Absorption Air-Conditioners}

The only systems now available that use direct themal input to operate a heat pump or air-conditioner are the "absorption-cycle" airconditioners that have been used for decades. The refrigeration cycle is very similar to cycles used in other types of air-conditioning systems (vapor-compression). A chilled liquid (usually water instead of a refrigerant) is permitted to expand and cool air. This water is then recompressed and the absorbed heat is rejected into the atmosphere. The absorption cycle accomplishes this recompression by absorbing the low-pressure water vapor in a concentrated salt solution. This concentrated solution is continuously produced in a distilling unit driven by the heat from the fuel.

Absorption air-conditioners are inherently more expensive than electric systems because 1 ) of the larger number of heat exchangers required, and 2) the unit's cooling surface must be large enough to reflect both heat from the combustion process and heat removed from the space that was cooled. (In electric systems, the heat from generation is rejected at the electric generator site.) Absorption units had a lower operating cost than electric chillers in the era of cheap gas, and are still competitive in some areas, but their use was limited by first cost.

A typical single-effect absorption chiller has a COP of 0.52; double-effect units can have COPS of 0.88 . These COPS must, however, be carefully qualified, as they do not include the electricity used for fans and pumps. They cannot be directly compared with the COPS of electric chillers since fuel costs are different and the COP of electric units does not include powerplant losses. It is reasonable to expect that improvements in current designs could lead to significant improvements in performance.
The Iron-Firemen double-effect chiller, which was manufactured for a time, was able to achieve a COP of 1.2 (not including boiler losses and electric energy requirements). Some engineers believe it would be possible to increase this COP for double-effect absorption devices to the range of 1.35 .

\section{Absorption Heat Pumps}

An absomtion heat pump is being developed for residential use by Allied Chemical Corporation and Phillips Engineering under sponsorship of the Gas Research Institute. The current goals for operating COP of this unit are 1.2 for heating and 0.5 for cooling. ${ }^{24}$ Further improvement in heating COP could be obtained by recovering the waste heat from the generator section of the unit. It is believed that significant advances in fluids, fluid pumps, and heat exchangers have overcome problems that hindered earlier efforts to develop an absorption heat pump.

This unit has reached the preproduction prototype stage and negotiations are underway to accelerate commercialization by involving DOE and a major manufacturer in further development. After further development and extensive field testing, this system could be on the market in about 5 years. ${ }^{25}$ Similar units are being developed in Europe by the British Gas Corporation and others. ${ }^{26}$ This system is expected to cost about 15 percent more than a gas furnace/electric air-conditioner combination and will probably be most competitive in areas where heating is the major requirement.

\section{Other Gas-Fired Heat Pumps}

A different approach to the use of fossil fuels to operate a heat pump has been under investigation for some time. These designs bum fuel to operate a small onsite heat engine, which in tum drives the heat-pump compressor. A number of advanced, gas-fired, heat-

\footnotetext{
${ }^{24}$ James Drewry, "Gas-Fired Heat Pumps," GRI Digest, September 1978, pp. 1-5.

*'James Drewry, Gas Research Institute, private communication, May 1979.

*'Gerald Leach, et al., A Low Energy Strategy for the United Kingdom (London: Science Reviews, Ltd., 1979), p. 25
} 
pump systems are being examined by the industry with the support of DOE and the Gas Research Institute. These include:

- A concept that uses a subatmospheric gas turbine is being developed by the Garrett A i Research Corp.

- A free-piston Stirling engine is being developed by General Electric.

- Systems based on diesel engines and Rankine-cycle devices are also being examined.

An interesting feature of the heat-fired, heatpump systems is that their performance does not decrease with temperature as fast as the performance of conventional heat pumps.

The gas turbine heat pump development emphasizes commercial or multifamily applications. A "breadboard" system has been operated and development of a commercial prototype is underway. Commercial production is expected by the mid-1 980's, with units expected to range from 7.5 to 25 tons in capacity. The expected COP is 1.4 to 1.5 in the heating mode and about 1.0 in the cooling mode. ${ }^{27} 28$ The installed cost is expected to be 15 to 20 percent higher than existing systems with payback in fuel savings in about 2 years.

The free-piston Stirling engine heat pump seems to be at a similar stage of development, but is thought to be more applicable to the residential market. One prototype has been built and another will be completed during 1979. The design goal for the prototype is a heating COP of 1.4 to 1.5 and a cooling COP of 0.9 . This requires an engine efficiency of 30 percent and the present prototype operates at 22 to 25 percent. This design is potentially very reliable since there are only two moving parts in the engine and one in the compressor. It is expected to be on the market in the mid-1 980's

\footnotetext{
${ }_{27}$ rwinStambler, "Workin ${ }_{\mathrm{g}}$ on New Gas Turbine Cycle for HeatPump Drive," Gas Turbine World, March 1979, pp. 50-57.

${ }^{28}$ James Drewry, "Gas-Fired Heat Pumps," CR/ Digest, September 1978, pp. 1-5.
}

at a price that will allow payback from energy savings in less than 3 years. ${ }^{29}{ }^{30}$

Stirling and Ericsson cycle, free-piston devices may be able to achieve efficiencies on the order of 60 to 90 percent of ideal Camot efficiency. An engine operating between $1,400^{\circ}$ and $1000 \mathrm{~F}$ could therefore achieve a cycle efficiency of 40 to 63 percent.

ERG, Inc., has reported a measured indicated efficiency that represents 90 percent of Camot in a free-piston device operating in roughly this temperature region. The Garrett Corp. has reportedly achieved a cycle efficiency of 38 percent, using a small regenerated gas turbine. 31

If it is assumed that seasonal performance factors for heat pumps can be in the range of 2.5 to 3.0, the overall system COP (or ratio of heat energy delivered to the living space to the heating value of the fuel consumed) of a heat pump combined with a heat engine that is 38to 60-percent efficient can be in the range of 0.95 to 1.8. If waste heat from the engine is used, the effective COP can be as high as 2.2.

A 38- to 60-percent efficient engine combined with an air-conditioning cycle with COP of 2.5 could achieve system COPS of 0.95 to 1.5. These coefficients cannot be compared directly with COPS of electric heat pumps. In order to obtain comparable "system efficiency" for an electric system, the electric COPS must be reduced by the efficiency of converting primary fuels to electric ity and transmitting this energy to a heat-pump system. The average generating efficiency of U.S. utilities is approximately 29 percent; the average transmission losses, approximately 9 percent. Under these assumptions, an electric heat pump with a heating COP of 3.0 and a cooling COP of 2.5 would have an effective "system" COP of 0.79 for heating and 0.66 for cooling. A number of

\footnotetext{
${ }^{29}$ L. L. Dutram, J r., and L. A. Sarkes, "Natural Gas Heat Pump Implementation and Development," presented at Conference on Drives for Heat Pumps and Their Control, Haus der Technik. Essen, ynest Germany, Sept. 6-7,1978.
30 ames E. Drewry, Op. cit.

31 Patrick G. Stone (Garrett Corporation), private com munication, December 1976.
} 
questions remain about system performance as an integrated unit: reliability, safety, noise, ease of maintenance, etc.; these can be resolved only after more experience. The devices do offer the prospect of a much more efficient approach to converting fossil fuels to useful space-conditioning.
A major question concerning any onsite system requiring oil or gas is whether they will continue to be less costly than electricity. The heat-engine devices just discussed could, at least in principle, be used in connection with a coal-buming, fluidized-bed boiler or a solar heat source, and thus might present a promising long-term altemative.

\section{INTEGRATED APPLIANCES}

Heating and water heating are the major energy users in homes today. As discussed in chapter 11, the use of "waste" heat from other appliances already makes a significant contribution to heating and the relative contribution increases as the house is made tighter. Several sources of "waste" are not presently being used and others could be used more effectively by "integrated appliances." Most of these appliances would recover heat (that is now completely wasted) for either heating or water heating (e. g., air-conditioner/hot water heaters), while others would heat water with heat that now heats the house whether heating, cooling, or neither is needed (e. g., refrigerator/water heaters). While other applications of waste heat in the home can be imagined, cost of recovery and coincidence between availability and demand are expected to result in selected heating and hot water combinations.

Of the many possible combinations, this section discusses four systems identified in a stud $\mathrm{y}^{32}$ by Arthur D. Little, Inc., as particula rly promising, with brief mention of some other possibilities. The four promising systems identified are:

- air-conditioner/water heater,

- fumace/water heater,

- refrigerator/water heater, and

- drain water heat recovery.

${ }^{32} \mathrm{~W}$. David Lee, W. Thompson Lawrence, and Robert P. Wilson, "Design, Development, and Demonstration of a Promising Integrated Appliance, " Arthur D. Little, Inc., performed by the Energy Research and Development Administration under contract no. EY-76-C-03-1209, September 1977.
Costs and potential savings given in the following discussion are from the Arthur D. Little study unless another source is given.

\section{Air-Conditioner/Water Heater}

This system heats water with the superheated refrigerant vapor whenever the air-conditioner operates. It consists of a vapor-towater heat exchanger inserted in the refrigerant loop just ahead of the condensor (the finned radiator-like part of the air-conditioner located outside), The heat recovered is ordinarily rejected outdoors. This system can be retrofit rather easily by qualified personnel, and if added to an air-conditioner whose performance is limited by a small condensor, it can actually improve the COP by a few percent.

This system can also be used with a heat pump and when operated in the heating mode, the heat used is not waste heat, but is provided at the operating COP of the heat pump. This still offers substantial savings compared to a resistance heater.

This is the only integrated appliance that is commercially available. It is made by at least six manufacturers. The installed cost of these units ranges from $\$ 200$ to $\$ 500$, and several airconditioner manufacturers allow installation of one or more of these systems without voiding their warranty.

The estimated savings expected from use of the Carrier Hot Shot ${ }^{\circledR}$ unit (about $\$ 400$ ) with a

(1) Registered trademark of the Carrier Air Conditioning Corporation. 
3-ton air-conditioner in each of several cities is shown in table 81. Dollar savings would be greater for a larger family that used more hot water. Most sales of these units have been in a reas with high air-conditioning loads such as Florida and the deep South. Use of these units on heat pumps would probably double the savings shown for more temperate climates.

\section{Furnace/Water Heater Systems}

Combining the fumace and hot water heater offers several potential advantages. The most compelling is that it should be possible to build a high-efficiency unit that incorporates features like intermittent ignition, vent damper, and forced draft for less money than would be possible for two separate units incorporating comparable features. Some oil furnaces have been equipped with hot water heaters, but they have a reputation for high fuel use so many homes with oil heat use electric hot water. A high-efficiency combined system could provide significant savings over such systems. There is also the potential for reduced standby losses from use of a smaller storage tank (perhaps 10 to 20 gallons) since present furnaces often have 100,000 Btu per hour capacity or greater. This is more than twice the capacity of typical water heaters. This advantage could disappear as tighter houses reduce the necessary fumace sizes.

\section{Refrigerator/Water Heater}

The refrigerator generates heat that could be recovered and used to heat water. During the heating season, this helps heat the house but only part of it reduces consumption for space heating since it typically keeps the kitchen at a slightly higher temperature than the rest of the house. The Arthur D. Little study considered this fact and estimated that a hot water recovery unit on the refrigerator could save about 14 MMBtu of primary energy per year if an electric hot water heater is used with electric heat. The estimated cost of the heat recovery unit was $\$ 142$ with a payback of 3 to 4 years (8 years with gas). These savings could be reduced very substantially, perhaps by a factor of two or more, by more efficient refrigerator designs.

\section{Drain Water Heat Recovery}

Most of the heat added to hot water simply runs down the drain. Existing homes mix drains from showers, sinks, and washing machines (gray water) with toilet drains (black water). It appears that heat recovery will be more practical if the "gray" water is kept separate from the "black" water since there is less difficulty with sedimentation and the black water is always cold water. One proposed system that has been tried in a demonstration house in Europe would run the gray water into a drain tank (about 50 gallons) and use a water source heat pump to extract heat. Such a system could result in primary energy savings of 46 MMBtu per year for a first cost of $\$ 440$. This cost does not appear to include any additional cost for separate drain systems.

Table 81.-Estimated Performance of Carrier Hot Shot® Heat Recovery Unit With a 3-Ton Air-Conditioner and a Family of Four

\begin{tabular}{|c|c|c|c|c|c|}
\hline City & $\begin{array}{c}\text { Electric rate* } \\
(\$ / \mathrm{kWh})\end{array}$ & $\begin{array}{c}\text { Annual electric } \\
\text { water heating cost }\end{array}$ & $\begin{array}{l}\text { Water heating } \\
\text { cost with Hot } \\
\text { Shot } \AA\end{array}$ & Savings & Savings percent \\
\hline $\begin{array}{l}\text { Boston, Mass. . . . } \\
\text { Baltimore, Md. . . . } \\
\text { Atlanta, Ga.. . . . . . } \\
\text { Houston, Tex.. . . . } \\
\text { Chicago, Ill.. . . . . } \\
\text { Sacramento, Cal if. } \\
\text { Boise, Idaho . . . . . }\end{array}$ & $\begin{array}{l}5.0 \\
4.0 \\
3.0 \\
3.0 \\
4.0 \\
4.0 \\
2.0\end{array}$ & $\begin{array}{r}\$ 304 \\
\mathbf{2 2 9} \\
172 \\
161 \\
243 \\
214 \\
61\end{array}$ & $\begin{array}{r}\$ 264 \\
170 \\
115 \\
78 \\
199 \\
173 \\
48\end{array}$ & $\begin{array}{r}\$ 39 \\
\mathbf{5 9} \\
57 \\
82 \\
44 \\
41 \\
13\end{array}$ & $\begin{array}{l}13 \% \\
\mathbf{2 6} \\
33 \\
51 \\
15 \\
19 \\
21\end{array}$ \\
\hline
\end{tabular}

- Registered trademark of the Carrier Corporation.

"The electric rate is not necessarily the rate charged in each city but is representative of the region.

SOURCE: Carrier Corporation 


\section{Summary}

Many other systems are possible. One of the simplest would be a simple filter (for lint removal) and damper that would permit use of the clothes dryer output for heating during the winter months. Frequent filter changing would be required and considerable humidity would be added to the house. Freezer/hot water heat- ers should be similar to refrigerator systems and ingenuity may make other systems practical. All of these systems must compete with other improvements in hot water and heating as they reach the market, and it is unlikely that more than one system to augment hot water production would be practical in a single house.

\section{CONTROLS AND DISTRIBUTION SYSTEMS}

Controls and distribution systems can play a critical role in the efficiency and effectiveness with which fumaces, air-conditioners, active or passive solar systems, refrigerators, ranges, etc., function individually and as a complete system to maintain comfortable conditions and provide other amenities in a house. For purposes of this discussion, controls will be considered in two categories: 1 ) those that control individual equipment, and 2) those that control comfort conditions in the house.

Houses contain a surprising a rray of controls, some manual and some automatic. The most frequently used manual control is probably the light switch, but all of the major appliances in the home contain automatic controls and/or manual controls. Refrigerators, freezers, toasters, ovens, and water heaters all contain thermostats. Fumaces contain a thermostat (in addition to the room thermostat) that controls the blower shutoff. Fumaces and gas water heaters have flame sensors and valves to control the flow of fuel.

A number of the new or improved technologies being developed require additional control circuitry. Solar hot water heaters and active heating systems use controls of varied sophistication and several companies now manufacture these controls. Automatic flue dampers (considered under fumace improvements) are themselves a control and require additional controls and sensors for operation. The pulse combustion fumace is likely to require more sophisticated controls for safe operation since the combustion process is not continuous. Fuel-fired heat pumps can also be expected to have their own control requirements.
The discussion of indoor air quality in chapter $X$ indicated the need for several different sensors and controls. Powered ventilation that responds to odors and other indoor pollutants is needed. Other equipment that may be adapted for residential use provides particulate control, and removes airborne chemicals and odors by means of filters, precipitators, adsorption, absorption, and chemical reaction systems.

Instruments to provide rapid feedback on the cost of consumption and to show the effect of changes initiated by the occupants are not available now. They could significantly improve occupant behavior as discussed in chapter III.

A number of the losses associated with furnaces are related to nonoptimal controls. The fans (or pumps in hydronic systems) are shut off while the fumace is well above room temperature. It is necessary to shut off fans before the air reaches room temperature to avoid uncomfortable drafts, but this contribution to off-cycle losses could be reduced. The savings that could be realized without compromising comfort by lowering these set points are apparently not known.

The only systems control found in most homes is the thermostat, which controls the heating (and possibly the cooling) system. The registers in each room usually have a damper so that the air flow in individual rooms can be shut off manually if desired, but these dampers are generally designed for infrequent use. There are at least three potential changes in thermostats. Instruments that allow one or 
more temperature setbacks are increasingly available; at least one of these can be set for a different temperature each hour of the week. Most thermostats contain an "anticipator" that shuts the furnace off slightly before the set temperature is reached. The heat remaining in the furnace jacket then brings the house up to the set temperature. Houses often overshoot the set temperature when the thermostat setting is increased, resulting in added losses from the house. The extent of these losses is not really known, but improved "anticipators" could reduce them. One of the sources of furnace inefficiency is the loss associated with frequent cycling of the system on and off. The frequency of this cycling is related to the temperature band within which the thermostat keeps the house. The narrower this band, the more frequent the cycling and the greater the cycling losses. This is another problem that is very prevalent, but the extent of the losses and the practical potential for reduction by changing the themostat band-width is not known.

Heating unoccupied rooms obviously wastes energy. It may be possible to reduce this loss either through the use of timed controls or through active occupancy sensing. However, the widely varying use patterns of different rooms seem likely to limit the utility of this approach. As thermal envelopes are made tighter, the savings from such controls will also be reduced.

The rapid development of integrated circuit technology has led to sophisticated small computers that control energy use in some commercial buildings. Such systems could also be adapted for use in homes. Excess heat could be circulated from the kitchen when the range was in use, outside ventilation could be brought in through a heat exchanger as needed, an economizer unit could cool with outside air when practical, space conditioning could be provided only in occupied rooms, etc. However, the computer itself is only the "tip of

\footnotetext{
${ }^{33}$ Marvin L, Menka, "Controllers and Process App I ications," Proceedings of the Conference on Technical Opportunities for Energy Conservation inBuildings Through
}

the iceberg" in the cost of such systems. ${ }^{33}$ The purchase and installation of the sensors, additional valves, and dampers that such a system would require greatly exceeds the cost of the logical unit. It seems likely that other improvements in houses will obviate the need for some of these functions while making others more acute, so it is difficult to predict the savings that could be achieved or the potential for the use of such systems.

Distribution systems transfer hot or cold air from a central fumace or air-conditioner to the rooms where heating or cooling is needed. The principal losses from these systems occur when they are run through unconditioned space in the basement, attic, or exterior walls. These losses can best be eliminated in new construction by running ducts entirely within the conditioned space. The design of such systems is facilitated if smaller ducting, designed for use with high velocity air, is substituted for standard ducting. Such ducting has been used in large buildings for many years. Smaller ducting can be readily used in tight, highly insulated houses since heating requirements are greatly reduced.

Conflicting needs suggest larger distribution systems in some cases. The heating mode efficiency of heat pumps could be improved by lower distribution temperature. Similarly, the efficiency of simple solar collectors is much higher at low temperatures than at high temperatures. The same is true of passive solar systems, where very low-temperature heat must be circulated from the rooms receiving sunlight to other rooms. Some homes are being built with most of the rooms opening onto a common area so that heating can be accomplished much as it was in homes heated only with a central wood stove in the past. It is likely that several approaches to efficient distribution will evolve to satisfy the requirements of different housing designs.

\footnotetext{
Improved Controls, Boston, Mass., May 10, 1976, DOE publication CONF 7605138, p. 218.
} 


\section{PASSIVE SOLAR DESIGN}

The concept of using sunlight and winds to help heat and cool houses is rapidly being "rediscovered" in the wake of today's new consciousness about the use of energy. Features that were standard construction practices before the introduction of central heating and cooling systems are making a comeback. New refinements are being added so that some houses now being built without collectors on the roof get as much as 90 percent of their heat from the Sun. As these houses generally do not use the pumps, blowers, storage tanks, and associated controls typical of solar houses, they are generally referred to as "passive" solar houses, or houses with "energy-conscious design."

These houses use natural phenomena to minimize their use of conventional fuels for heating and cooling. Overhangs are used to admit sunlight in the winter and provide shade in the summer. Deciduous trees are another reliable method of ensuring summer shade and winter sunshine. Windbreaks can be used to temper the effect of winter winds. While these techniques reduce the need for heating and cooling, the key to the success of passive solar design lies in the fact that over the course of a winter, a good south-facing double-glazed window will admit more heat from the Sun than it will lose both day and night. Thus south-facing (or nearly south-facing) windows can be used to supplement the heating requirements of homes in virtually any climate in the continental United States. The most effective use of this solar heat requires that massive components such as concrete or masonry floors or walls be incorporated into the house. These components absorb heat and thus reduce temperature swings inside the dwelling.

The benefits of proper orientation toward the Sun have been recognized for centuries; the forum Baths in Ostia (near Rome) were built with large openings to capture winter sunlight nearly 2,000 years ago.

The classic examples of ancient passive solar design in North America are the cliff dwellings of the Indians of the Southwest.
They are typically situated on the south face of a rock cliff with an overhang to shade the summer sun. The dwellings, built into the wall of the cliff, use heavy adobe materials in conjunction with space hewn directly out of rock - thus providing tremendous capacity for moderating the huge swings in outdoor temperature occuming in this area.

In more recent times traditional southem architecture incorporated a variety of methods to enhance the summer cooling of homes, most prominently the use of huge porticoed porches.

With the advent of inexpensive gas and oil heating and electric cooling, these traditional regional practices were quickly discarded, as they limited design and were often less "effective" than the mechanical systems that replaced them. A few architects and engineers experimented with passive solar design in the 1940's and 1950's, but encountered problems with overheating on mild winter days. By the time OPEC tripled the price of oil in 1974, most engineers were not only unaware of passive design principles, but they believed that every window was an energy loser and that any energy-efficient building should limit the window area to the minimum level allowed by the esthetic demands of the occupants.

Following the OPEC embargo, new advocates of passive solar design appeared, many after independently rediscovering that windows really could reduce the fuel consumption of a house. These new advocates were largely people from outside the mainstream of engineers and architects-typically solar energy "nuts" with little formal training or scientists with no design experience. As in any change of technology, the early supporters received little attention or Government funding. Another complication was the "site specific" nature of these designs; as each dwelling must be defined by its site, the technology was not perceived as broadly applicable. Only very recently has passive solar design begun to receive significant research and demonstration money. 
There are just about as many approaches to design of a passive solar house as there are designers; it may be as simple as planting a shade tree or so complex that it stretches the concept of "passive" design. This description makes no attempt to provide exhaustive coverage of the ideas that have been proposed or even built; rather it attempts to provide some feel for the breadth of ideas which lend excitement to the field.

\section{Direct Gain Systems}

The simplest passive solar design simply adds larger south-facing windows to a house. The slightly modified saltbox design (figure 44) is a good example of the "direct gain" approach to passive solar heating. This house contains substantially larger windows on the south wall than is typical for this style of house in the New England area (Wiscasset, Maine, near Brunswick) and does not contain any fans, blowers, or heavy concrete walls to help store and distribute the heat. It does incorporate sliding insulating shutters that cover the windows at night to reduce the heat loss. The shutters also make the house more comfortable by reducing the window chill. The upstairs bedrooms have skylights angled with the roof to collect more winter sunlight than a similar area of vertical windows.

If most of the south wall were covered with windows, the typical frame house would often be too hot, even in cold weather, because of the limited capacity to absorb and store heat. As more windows are added it becomes necessary to add massive features to the construction of the house so more heat can be stored with small increases in the interior temperature The house shown in figure 45 has windows covering the entire south wall, but it also

Figure 44.-Modified Saltbox Passive Solar Design Home

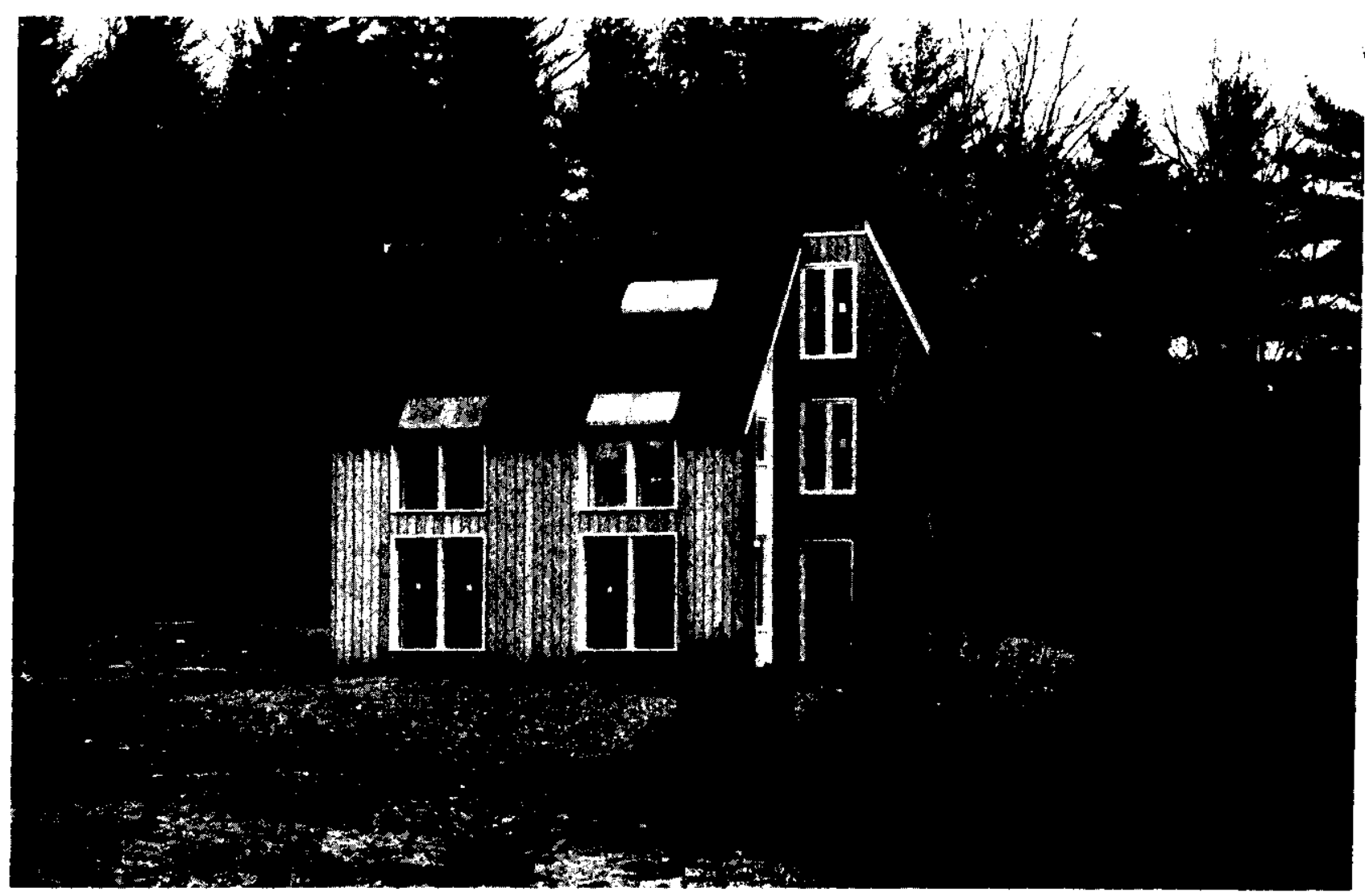

Photo credit Christopher Ayres, Pownal, Maine 


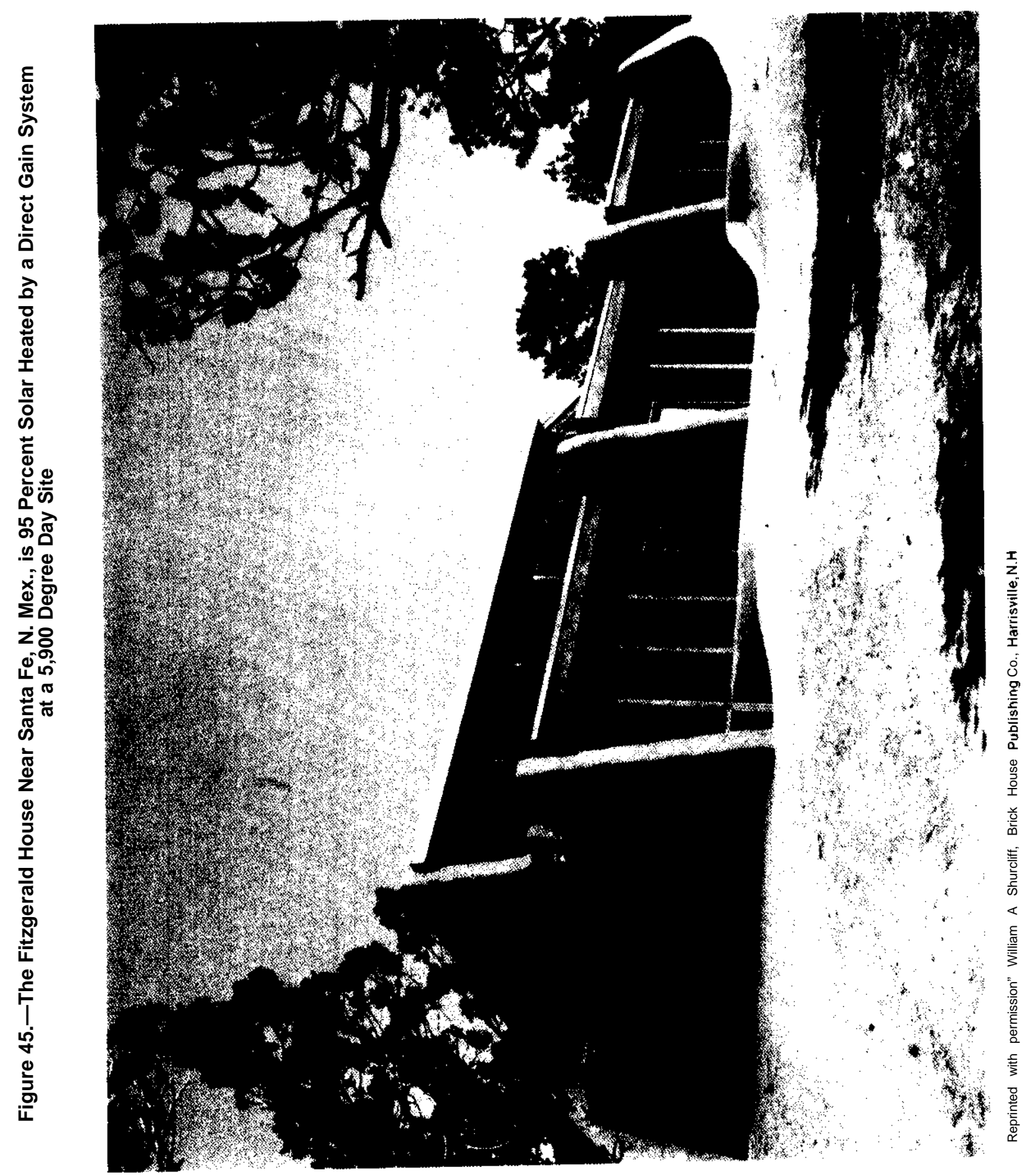


has lo-inch thick adobe walls with urethan insulation outside the adobe and a brick floor resting on 16 inches of sand. The sand has a 1inch layer of styrofoam insulation beneath it and the house has an overhang that limits the amount of summer Sun which enters. This house, in Santa Fe, N. Mex., receives about 95 percent of its heat from the Sun. This is not an area of mild winters-the location is at an elevation of 6,900 feet and the heating requirements are comparable to those of upstate New York. Supplementary heat is provided by two fireplaces and a small electric heater in the bathroom.

Such direct-gain systems are the ultimate in simplicity as they use no fans or dampers and the heat "stays on" when the electricity goes off. However, the large windows can produce uncomfortable glare, and if the floor is to be effectively used to store heat, it must not be carpeted. If the house does not effectively incorporate massive components, the temperature swings resulting can be uncomfortably large- as much as 200 to $250 \mathrm{~F}$ in a day.

\section{Indirect-Gain Passive Buildings}

The problems with glare and the wide temperature fluctuations experienced in many "direct-gain" buildings have led to the use of a variety of simple approaches where the Sun does not directly heat the living space.

One is illustrated in figure 46 where a massive concrete or masonry wall is placed directly behind a large glass surface. (This concept is called a thermal storage wall or a Trombe wall after its French inventor.) The sunlight is absorbed by the wall. Heat is transferred to air against the inside surface, this air becomes buoyant and sets up circulation loops that move hot air into the house through the vents. Part of the heat is stored in the wall; the interior surface of concrete walls will actually reach its highest temperature well after the Sun has set. The house in figure 47 illustrates the use of this approach in combination with direct gain. Behind the left awning is a brick wall 8 inches thick; the windows on the righthand portion of the house have a concrete/ brick floor 4 inches thick behind them. The house is 50- to 60-percent solar heated and on sunny winter days, the occupants open windows when the interior temperature reaches $86^{\circ}$ F. $^{34}$

Barrels of water may be substituted for the brick wall; computer calculations have shown that they will actually increase slightly the amount of heat that can be gained by a storage wall. The building shown in figure 48 is a combination off ice/warehouse used for editing and storing books by the Benedictine monastery near Pecos, N. Mex. This building combines direct gain with the use of a "water wall." The windows on the first floor and the clerestories on the second level provide direct gain. Below the windows on the first level is a window-wall with 55-gallon drums of water behind the windows. Reflective panels lying on the ground below the water wall serve to increase the amount of sunlight striking the wall. They can be closed at night to reduce the heat losses from the water barrels. This system has provided more than 90 percent of the heating needs of this large building.

A variation on the mass wall approach is the "greenhouse" or "attached sunspace" design. Sunlight provides all of the heat for the sunspace and part of the heat for the rest of the house. The sunspace is a large, live-in collector, and the storage wall is placed between the sunspace and the living quarters. The storage wall mass evens out the temperature variations for the living quarters, while the temperature in the sunspace undergoes wide swings. Such a sunspace can be used as a greenhouse, a sunny play area for children, an enclosed patio, or any use compatible with substantial temperature shifts.

Figure 49 illustrates the use of a solarium in a rather conventional appearing house specifically designed to be mass-produced in a standard Califomia tract development. The house incorporates direct gain through the windows on the south wall and water tubes near these windows to add storage. The skylight in the roof lights a square solarium in the center of

\footnotetext{
${ }^{34}$ Andrew M. Shapiro, "The Crosley's House-With Calculations and Results," Solar Age, November 1977, p. 31
} 
Figure 46.-The Kelbaugh House in Princeton, N. J., Receives 75 to 80 Percent of Its Heat From the Trombe Wall and the Small Attached Greenhouse

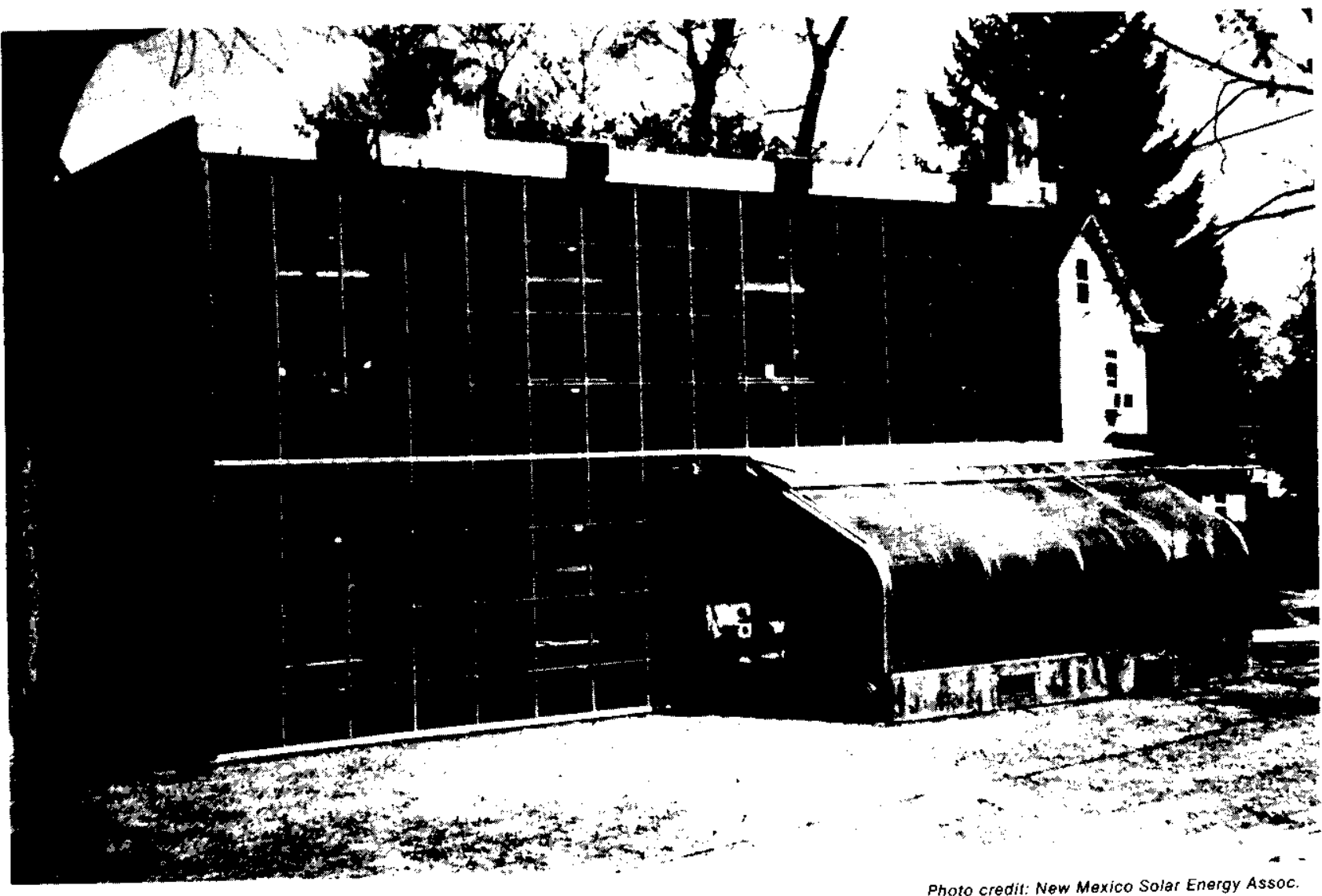

Note: Omitted from this diagram are: basement under greenhouse, footings of building and many other details

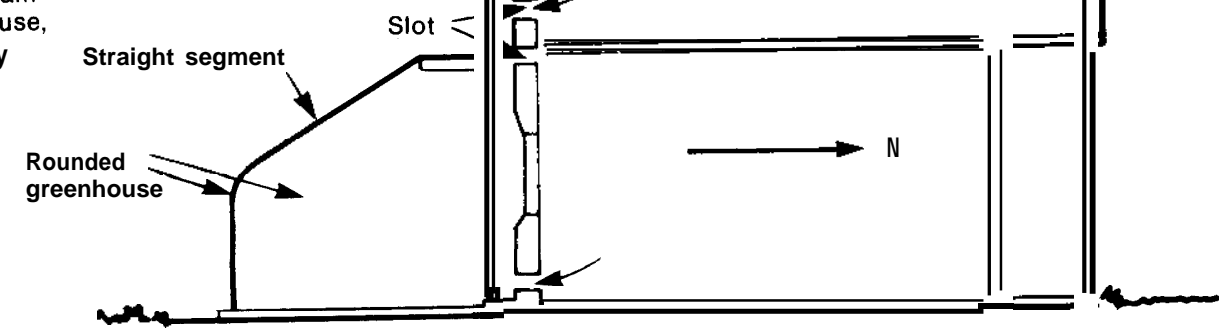


Figure 47. - The Crosley House in Royal Oak, Md., Combines a Trombe Wall System With Direct Gain and a Massive Floor, to Provide 50 to 60 Percent of Its Heating-Needs
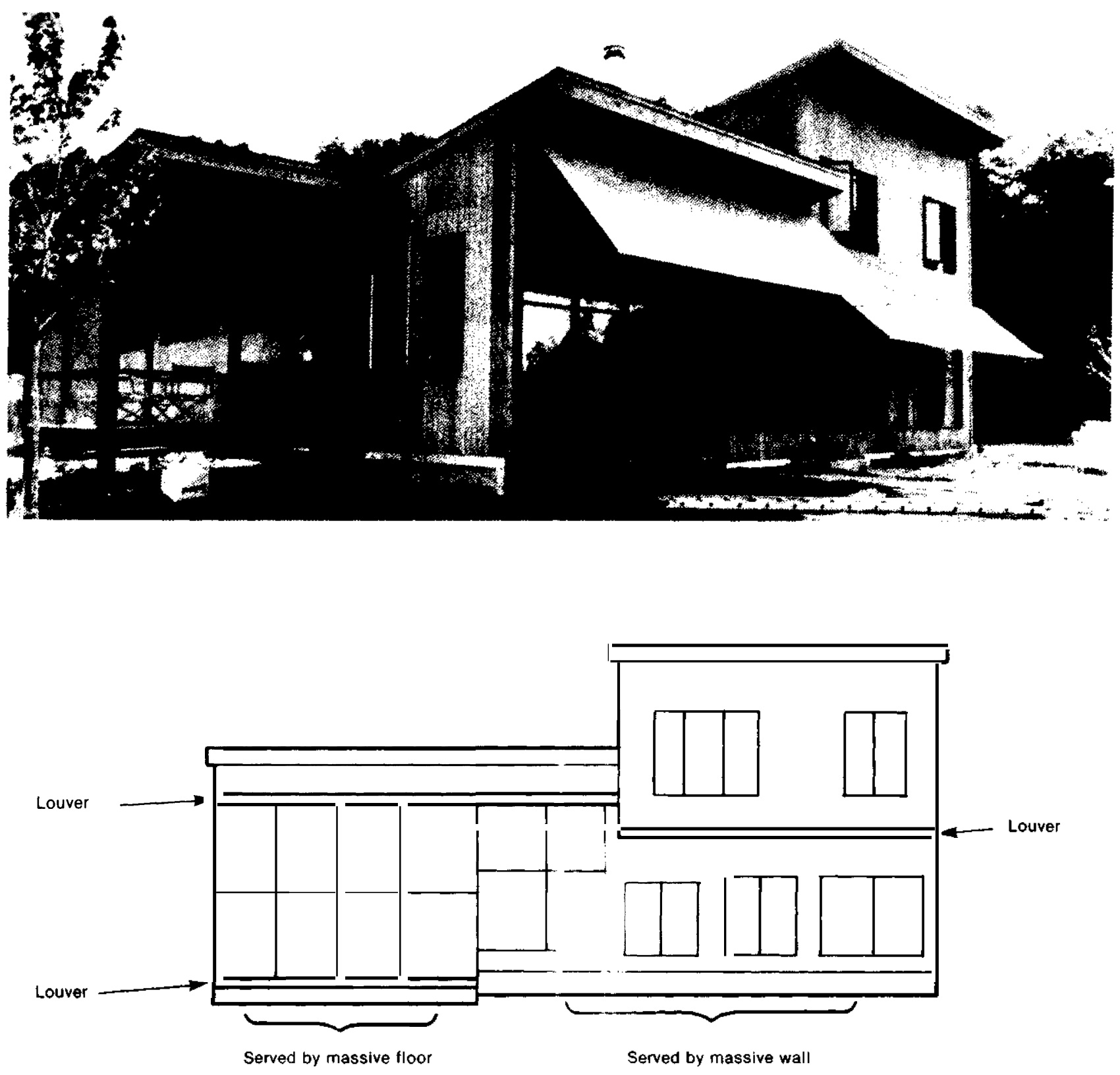

South elevation 
Figure 48.-The Benedictine Monastery Office/Warehouse Near Pecos, N. Mex., Uses Direct Gain From the Office Windows and Warehouse Clerestories Combined With the Drumwall Below the Office Windows to Provide About 95 Percent of Its Heating Needs

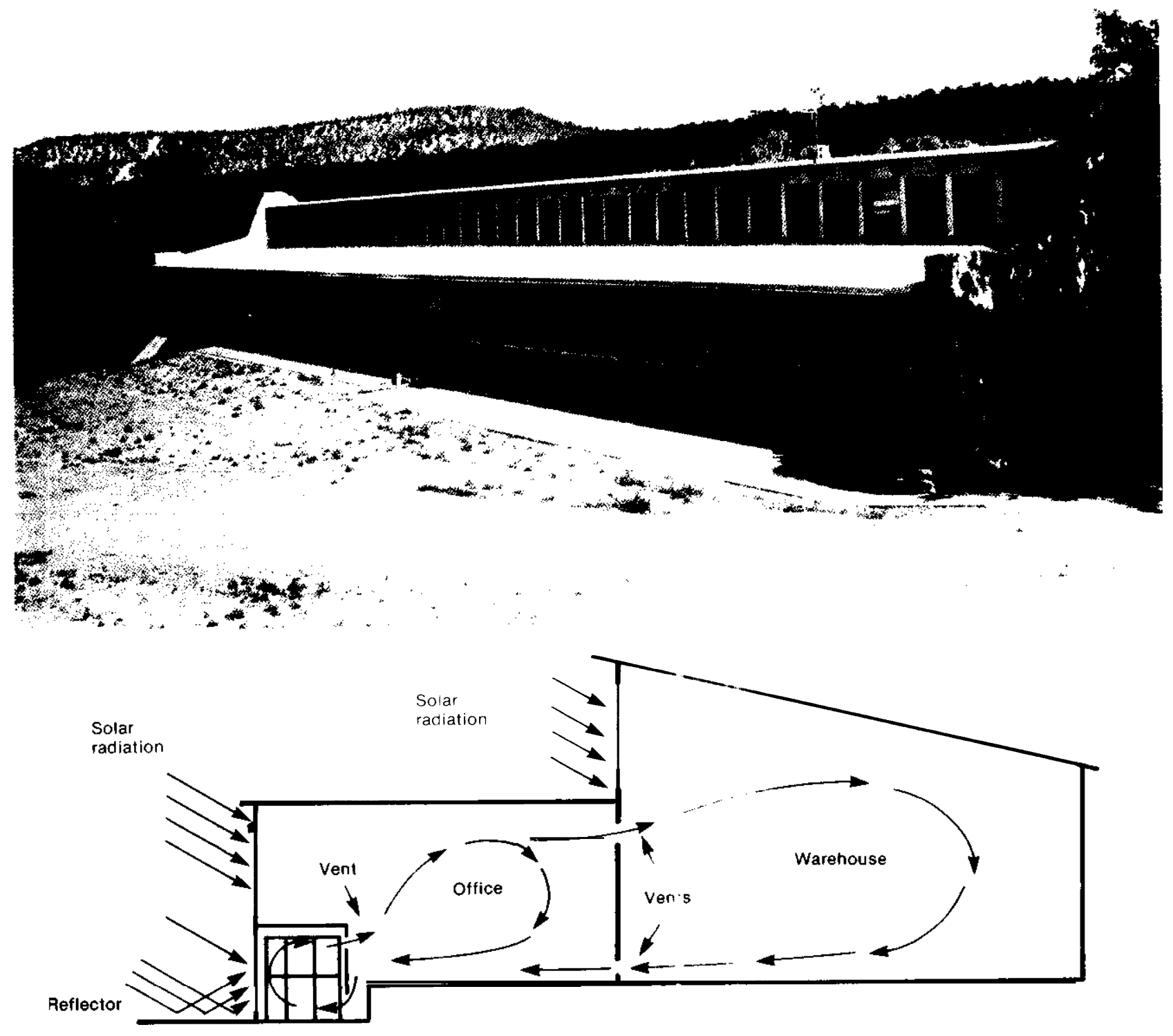

55 gallon

drums 
Figure 49.-The PG\&E Solarium Passive Solar Home in California Uses the Large Skylight to Heat Water-Filled Tubes on Three Walls of the Solarium. The Tubes Then Radiate the Solar Heat to the Surrounding Areas

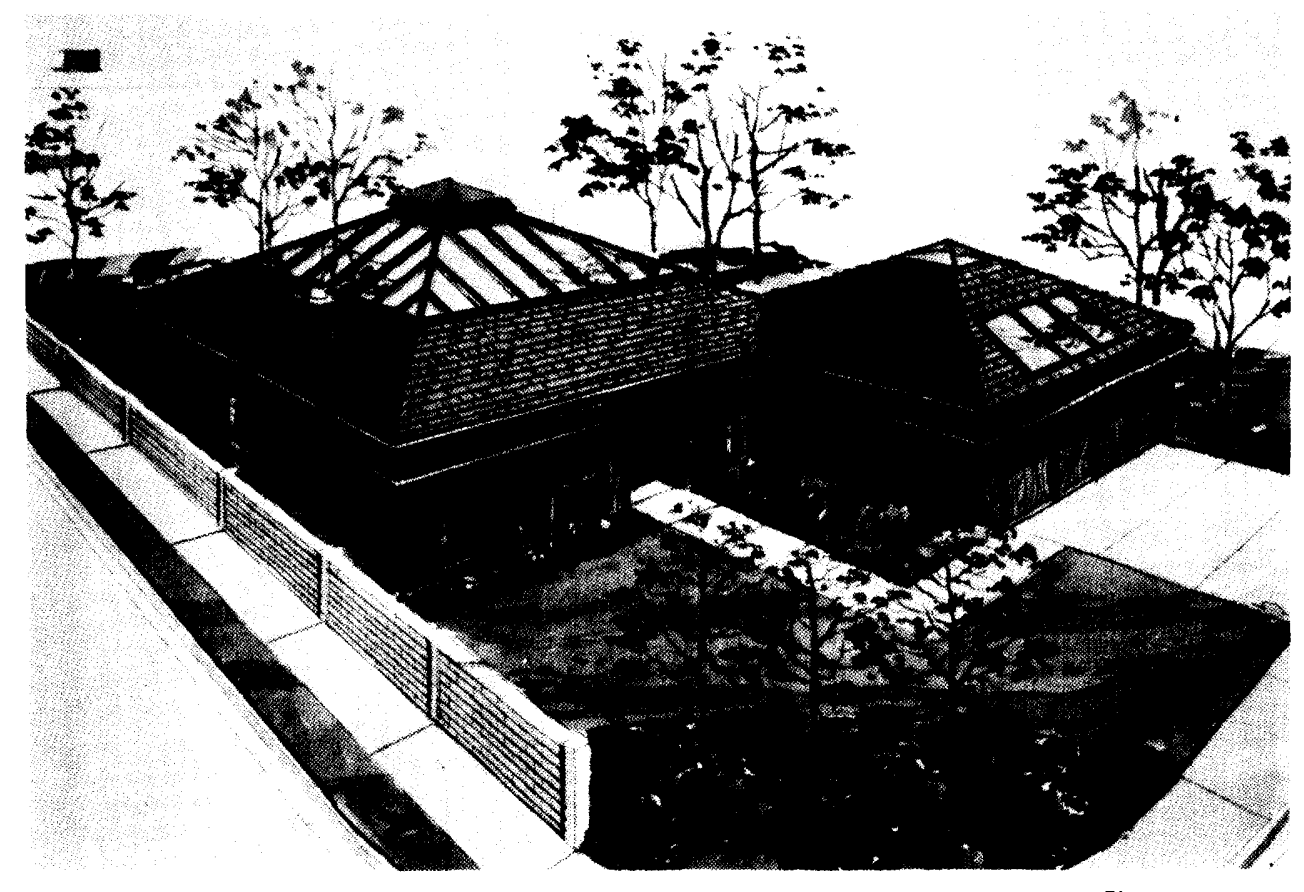

the house. Three walls of the solarium have water-filled tubes. As this house was built in Stockton, Calif., where summer day temperatures are frequently in the 90's but night temperatures regularly drop to the 50 's or low 60 's, it also incorporated a gravel bed 14 inches deep under the entire house The rock bed is cooled by the earth and by circulating cool night air through it. (The use of fans to circulate the air would cause some to regard this as a hybrid passive home ) Another feature of the skylight is the use of insulating panels, which are moved over the top of the solarium at night to reduce the heat loss.

An attached sunspace or greenhouse can be added to many existing homes. While most of the commercial lean-to greenhouses now available are single glazed, an increasing number of manufacturers offer double glazing. The Solar Room Co. emphasizes the heating benefits and multipurpose nature of their inexpensive double-glazed rooms (see figure 50) in their marketing. These units, which are designed for simple installation, use ultraviolet inhibited plastic coverings for extended life and can be easily taken down during the summer if de- sired. The Solar Sustenance Project has conducted workshops at numerous locations in the Southwest teaching simple greenhouse construction and promoting the benefits of both food and heat that can be derived from retrofit greenhouses such as the one shown in figure 51. The materials for the greenhouses built in these workshops cost from $\$ 395$ to $\$ 652$. Simple retrofits like those shown a re generally built over an existing door or window, which can be opened to circulate heat into the house. They use the mass of the house for any storage and can supply 10 to 20 MMBtu of useful heat annually in most U.S. locations.

\section{Hybrid Passive Systems}

The definition of passive systems is the object of some controversy; the term passive implies lack of machinery and controls, but some such houses also incorporate a storage bed to

William F Yanda, "Solar Sustenance Project Phase I I Final Report, "proceedings of the Conference on Energy Conserving Solar Heated Greenhouses (Marlboro, Vt.: Mallboro College, Nov. 19-20, 1977), p. 16. 
Figure 50.-This Retrofit Sunspace is Manufactured by the Solar Room Co. of Taos, N. Mex.

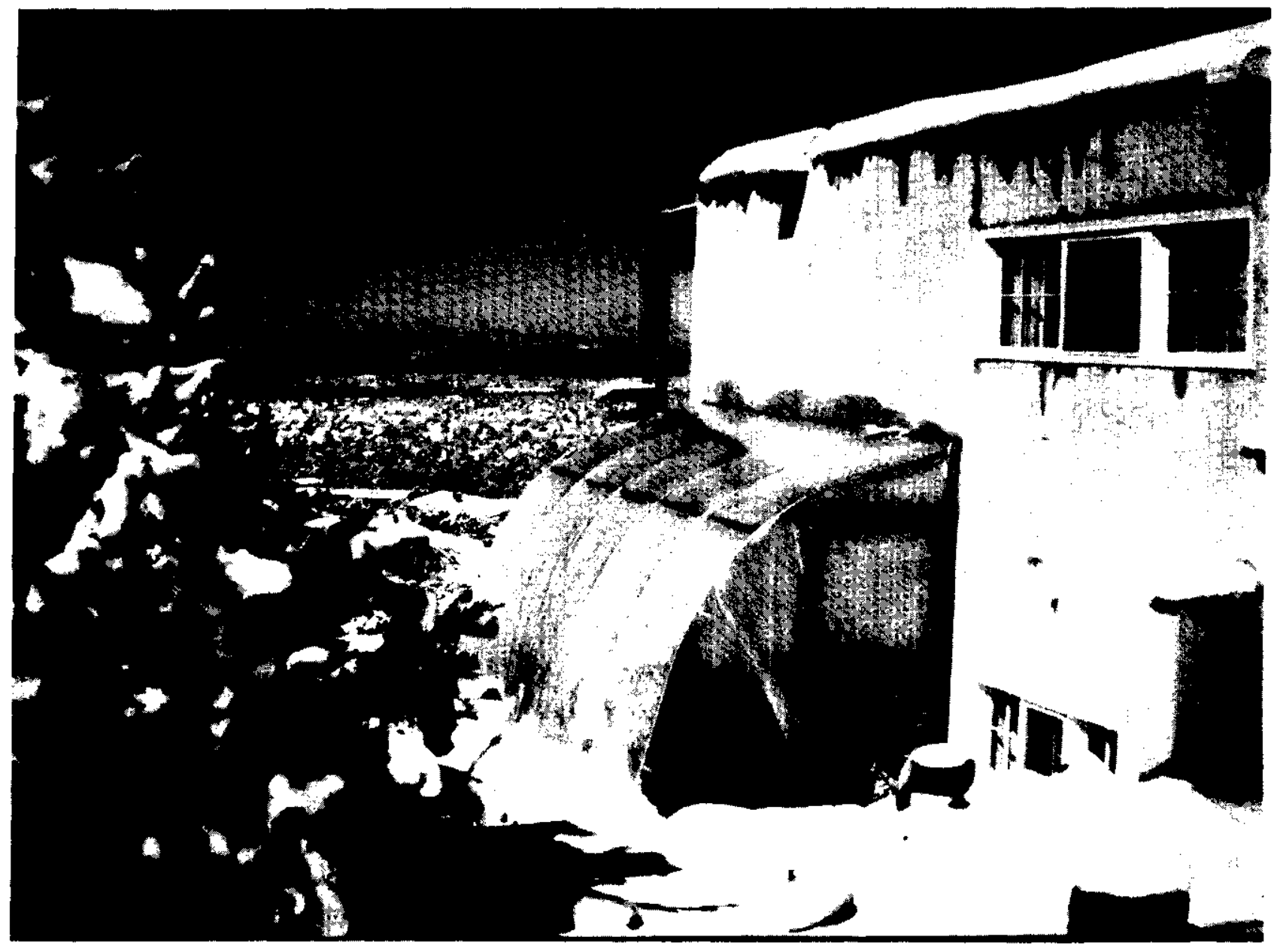

Photo credit: Solar Room Co.

improve the system's performance. Fans and controls circulate heat to and from the storage bed. Strictly speaking, the Pacific Gas and Electric house in Stockton could be considered hybrid, as it utilizes, some controls and motors.

The house shown in figure $\mathbf{5 2}$ successfully combines a greenhouse with a rock storage bed to provide additional heat storage. The wall between the greenhouse and the living quarters is a heavy adobe wall; blowers force air through the rock storage bed whenever the temperature in the greenhouse goes above a certa in point. This heat is used to warm the house after the adobe has exhausted its heat. This house is near Santa Fe, N. Mex., where subzero winter temperatures occur; it required less than $1,000 \mathrm{kWh}$ of electricity for supplementary heating (the equivalent of 30 to 40 gallons of heating oil) during a 6,400 degreeday winter). ${ }^{36}$

The house shown in figure 53 is an example of a dwelling with a storage wall and a rock storage bed.

\section{Cost of Heat From Passive Solar Heating Systems}

It is clear that a variety of passive heating systems are capable of providing substantial heat to buildings, that these systems are simple

${ }^{36}$ J Douglas Balcomb, "State of the Art in Passive Solar Heating and Cooling," proceeding of the Second National Passive Solar Conference, March 1978, p. 5-12. 
Figure 51 .-This Retrofit Greenhouse is an Example of Those Built by the Solar Sustenance Project

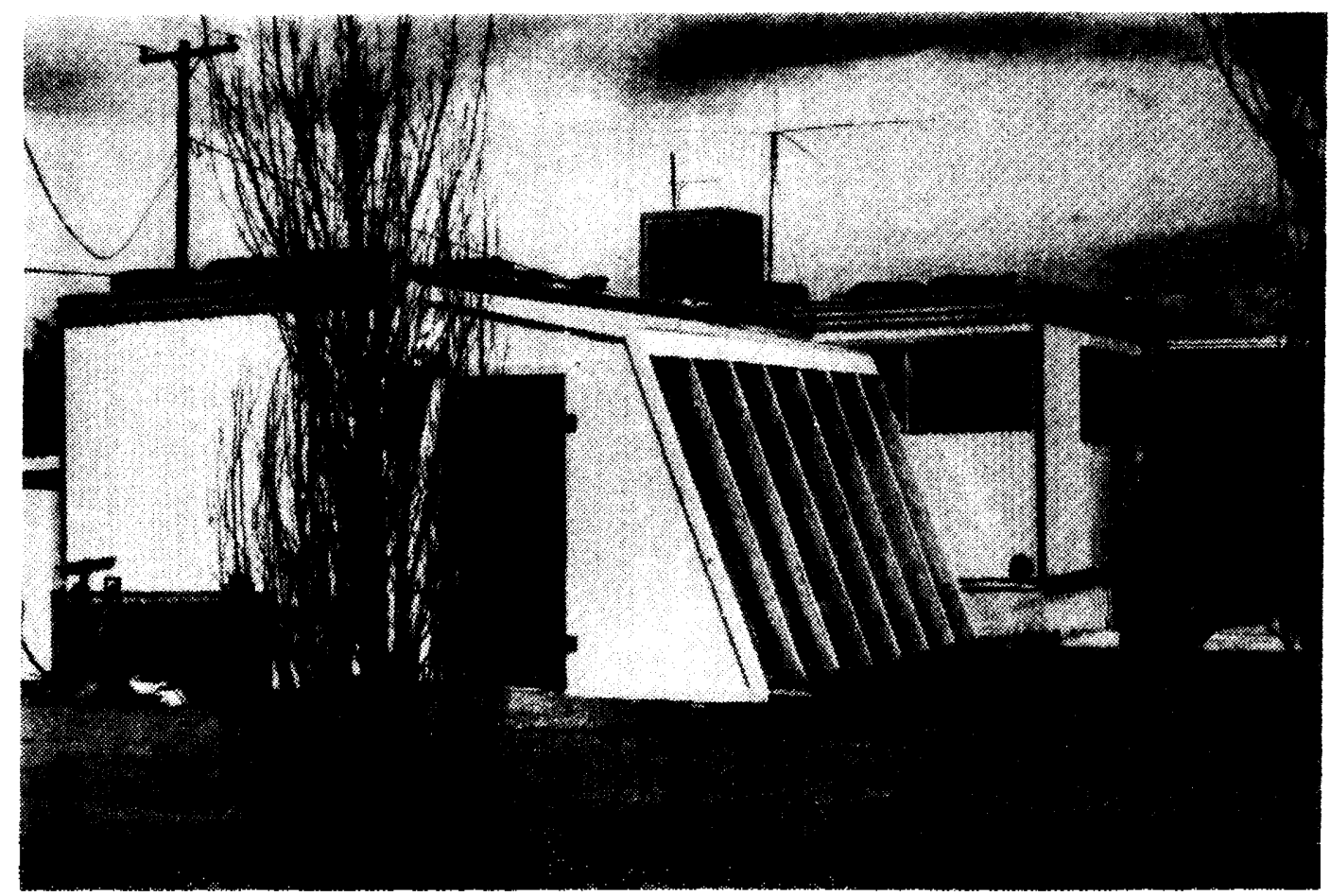

Photo credit: Sandia Laboratories

and that they can be built from rather ordinary construction materials. The experience of many people who have lived in passively heated homes suggests that consumer acceptance can be enthusiastic, although present owners are largely a self-selected group of innovators. As with any other new energy system, the installation cost and the value of the energy savings will be a major factor in general consumer acceptance.

The cost of heat from passive solar heating systems depends on the system and the costing methodology used. As an example, consider the role of windows in a residential building. Most free-standing houses have windows on their south wall that were installed purely for the light and view they provide. If they are unshaded they will also reduce the heating bill slightly, and it can be argued that this heat is free since the windows were installed for other reasons. Similarly, some of the windows that would ordinarily be placed on the north wall of a new house can be put in the south wall, reducing the heat needed, again at no additional cost. Altematively, the cost of this heat could be computed based on the difference between the cost of a blank wall and the cost of the wall containing windows. Attached sunspaces can be treated in the same manner in that the cost of heat they provide depends on how the intrinsic value of the sunspace is treated.

Passive systems may change the appearance of a house, and this further complic ates the costing. The addition of slightly larger windows to increase heat gain may be welcomed, but if they are too large then glare becomes a problem. Inclusion of a greenhouse in a home can be a distinct plus if the owners enjoy plants and indoor gardening, but would not be a strong selling point for others. The use of massive construction to provide heat storage in the winter and retention of coolness in the summer can be done in tasteful ways that should add to the value of the home, but floors that are used for themal storage lose efficiency if carpeted. Thus, a passive solar heating system may increase the value of a home as a heating system and for other reasons if it is 
Figure 52.-The Balcomb Home Near Sante Fe, N. Mex., Combines the Use of a Greenhouse With a Rock Storage Bed to Provide 95 Percent of Its Heating Needs

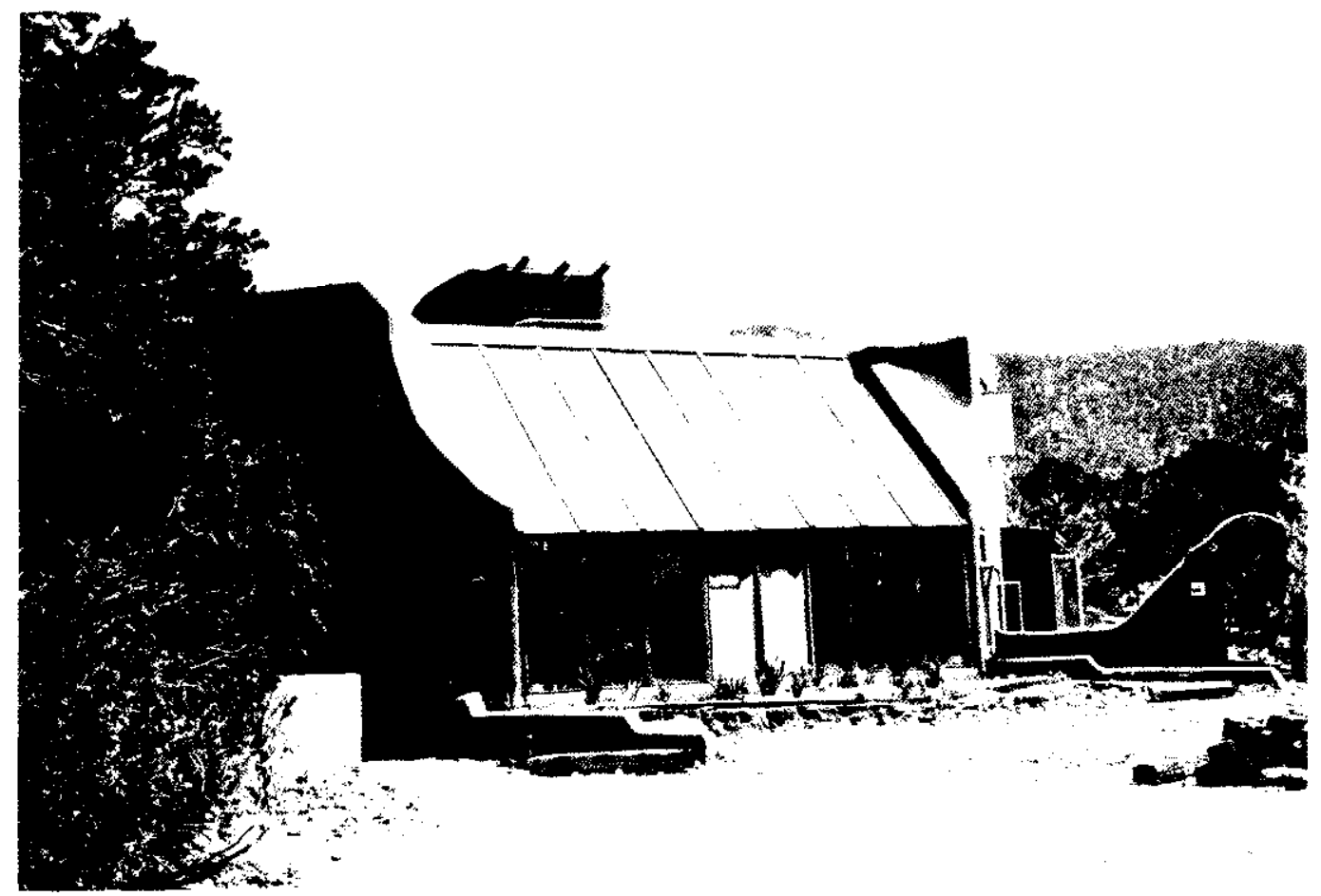

Photo credit Sanaia Laboratories

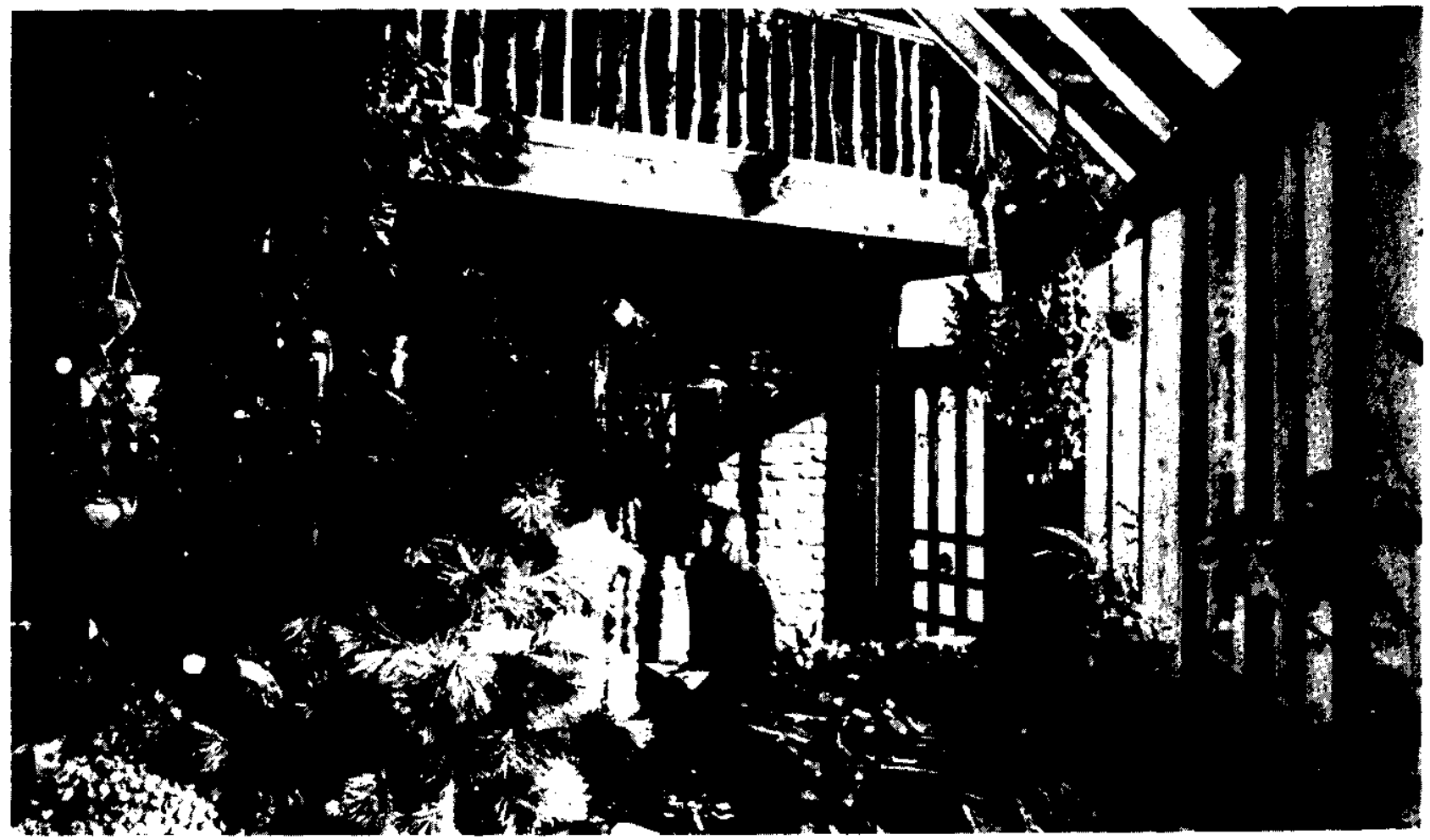

Photo Gredit New Mexico Solar Energy Assoc

The adobe wall separating the greenhouse from the interior of the house is clearly visible in this photo. 
This Home is Los Alamos, N. Mex., Combines a Large Trombe Wall With Small Direct Gain Figure 53. - This Home is Los Alamos, N. Mex., Com the Trombe Wall is a Distinctly Attractive Part Windows and a Rock Storage Bed. The of the Living Room
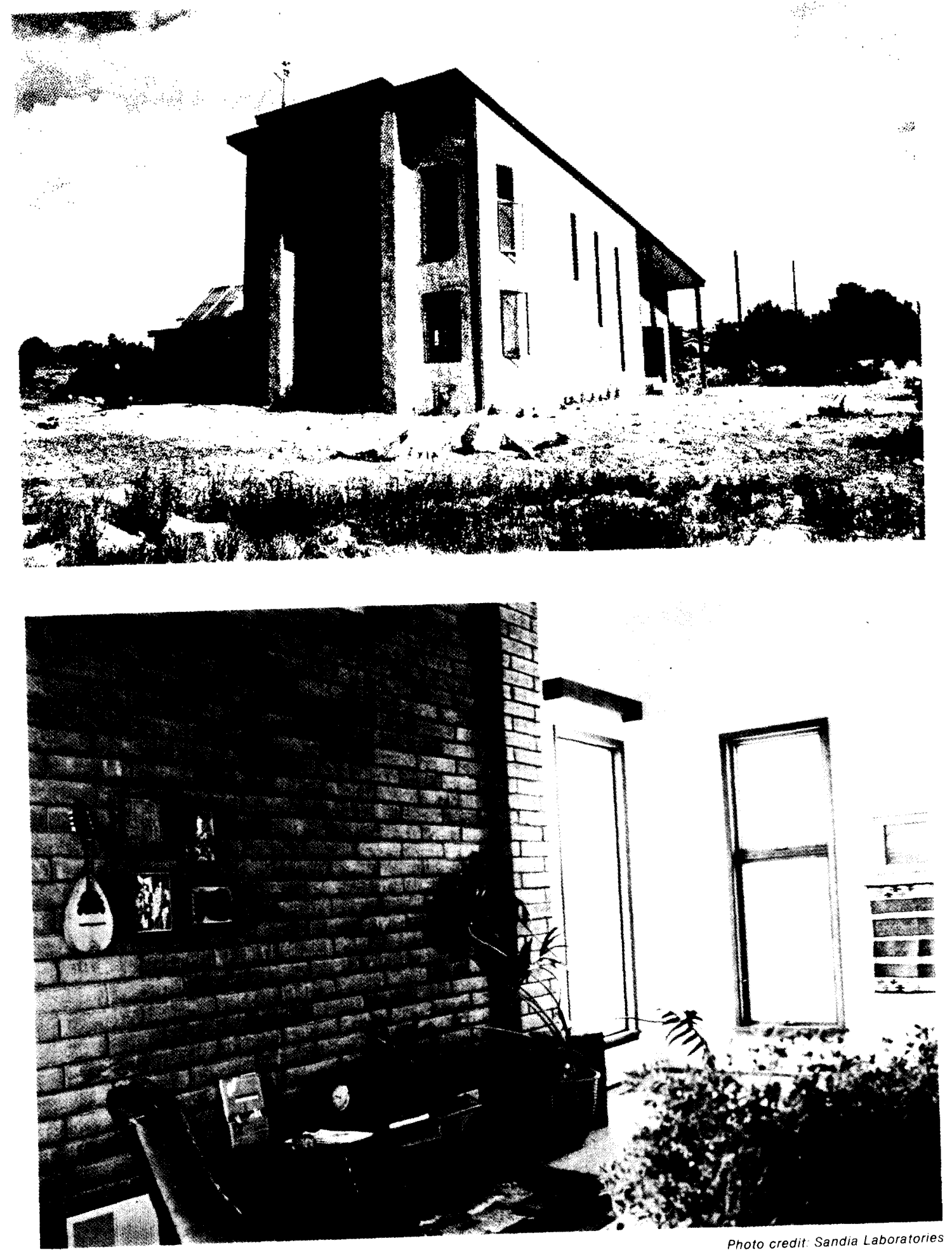
esthetically pleasing, but a poorly designed system could decrease a home's market value while reducing heating costs.

These subjective reasons make it difficult to estimate the total costs of the heat from passive solar heating systems.

The most comprehensive survey of the cost and performance of passive solar heating installations now available is that performed by Buchanon of the Solar Energy Research Institute).$^{37}$ It presents information on the installation cost and useful heat delivered by 32 actual systems and 18 simulated installations. The heat delivered by 20 of the systems was determined from monitoring of the building performance while engineering estimates have been made of the heat delivered to the other buildings. These estimates exclude heat that must be vented outdoors during the heating season because of insufficient thermal storage in the building.

Table 82 presents the cost of delivered heat for the systems surveyed. The cost of delivered heat was calculated using an annual capital charge rate of 0.094 and an annual maintenance estimate of 0.005 of the initial system cost, based on the average maintenance cost

Table 82.-C Cost of Heat From Passive Solar Heating Installations

\begin{tabular}{|c|c|}
\hline Installation type & $\begin{array}{l}\text { Cost of heat } \\
(\$ / \text { million Btu) }\end{array}$ \\
\hline \multicolumn{2}{|l|}{ Direct gain: } \\
\hline \multicolumn{2}{|l|}{ Monitored } \\
\hline \multicolumn{2}{|l|}{ Unmonitored . . . . . } \\
\hline \multicolumn{2}{|l|}{ Thermal storage wall: } \\
\hline \multicolumn{2}{|l|}{ Monitored . . . . . . . . } \\
\hline Unmonitored . . . . . . . & $\$ 8.80-15.40$ \\
\hline \multicolumn{2}{|l|}{ Thermal storage roof: } \\
\hline Monitored . . . . . . . . . . . . . . & $\$ 8.20$ \\
\hline \multirow{2}{*}{\multicolumn{2}{|c|}{ 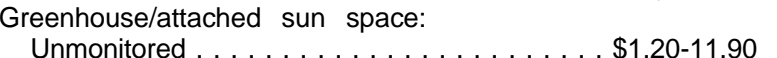 }} \\
\hline & $\$ 1.20-11.90$ \\
\hline \multicolumn{2}{|l|}{ Hybrid: } \\
\hline Monitored . . . . . . . . . . . . . . . . & $\$ 2.60-16.60$ \\
\hline Unmonitored ... , . . . . . . . . . . . . . . & $\$ 11.90$ \\
\hline \multicolumn{2}{|c|}{$\begin{array}{l}\text { SOURCE: Based on Deborah L. Buchanon, "A Review of the Economics of } \\
\text { Selected Passive and Hybrid Systems," Solar Energy Research In- } \\
\text { stitute publication SERI/TP-61-144, January 1979. The information on } \\
\text { combined cost and performance has been converted to a cost of } \\
\text { delivered heat using an annual capital charge rate of } 0.094 \text { and an an- } \\
\text { nual maintenance cost of } 0.005 \text { of the initial cost. }\end{array}$} \\
\hline
\end{tabular}

\footnotetext{
${ }^{37}$ Deborah L. Buchanon, "A Review of the Economics of Selected Passive and Hybrid System s," Solar Energy Research Institute, SERI/TP161-144, January 1979.
}

in the survey. It is assumed that the systems have no intrinsic value other than as heating systems. (This probably overcharges for the heat from attached sunspaces.) If a single entry is given instead of a range, only one system of that type was included in the survey. Results of monitored and unmonitored systems are shown separately and there do not appear to be major discrepancies. The ranges shown reflect variation in both quality of construction and climate. The systems pictured earlier in this section span most of the range of costs shown in the table.

\section{Cost of Heat From Fossil Fuels and Electricity}

The simplest comparison for the costs shown in table 82 is against the cost of gas, oil, and electricity to residential customers. However, it is also necessary to include the effects of equipment efficiencies such as fumaces and distribution systems to provide a meaningful comparison. The policy maker may also wish to compare the costs shown in table 79 with the marginal cost of new supply such as liquefied natural gas or electricity from new generating and transmission facilities.

Table 83 shows the cost of fuels and heat supplied to houses from a variety of present and future sources of fossil fuel and from electricity. The fuel prices shown were assembled from a variety of sources as described below and reflect ranges of present or expected costs for fuel delivered to a residential customer. The cost of heat delivered to the house is the cost of a million Btu of heat delivered to the interior of the house after considering the furnace losses and ownership costs. It is thus comparable to the cost shown in table 82. It is expected that for modest increases in initial cost, the efficiency of conventional furnaces and heat pumps will be improved in the future. The third column of this table shows cost estimates for this case. The fourth column shows cost with improved equipment levelized over 30 years; fuel costs are assumed to increase at a general inflation rate of 5.5 percent. The basis for the energy prices shown and the equipment efficiencies and costs used in preparing table 
Table 83.-Cost of Heat Supplied to Houses From Fossil Fuels and Electricity

\begin{tabular}{|c|c|c|c|c|}
\hline & $\begin{array}{l}1977 \text { residential } \\
\text { fuel prices } \\
(\$ / \mathrm{MMBtu})\end{array}$ & $\begin{array}{l}\text { cost of } \\
\text { heat to houses } \\
(\$ / \text { MMBtu })\end{array}$ & $\begin{array}{l}\text { cost of } \\
\text { heat to houses } \\
\text { using improved } \\
\text { equipment } \\
(\$ / M M B t u)\end{array}$ & $\begin{array}{l}\text { Levelized cost of heat } \\
\text { to houses using } \\
\text { improved equipment } \\
\text { (5.5\% inflation) } \\
\text { (\$/MMBtu) }\end{array}$ \\
\hline Natural gas. . . . . . . . . . . . . & $\$ 2.00-4.00$ & $\$ 4.80-8.10$ & $\$ 4.40-6.90$ & $\$ 6.60-11.30$ \\
\hline Intrastate gas. . . . . . . . . & $2.50-4.00$ & $5.60-8.10$ & $5.00-6.90$ & $7.80-11.30$ \\
\hline Synthetic gas. . . . . . . . . . . & $4.00-8.00$ & $8.10-14.80$ & $6.90-12.00$ & $11.30-21.00$ \\
\hline LNG. . . . . . . . . . . . . . & $3.00-6.10$ & $6.50-11.60$ & $5.70-9.50$ & $9.00-16.00$ \\
\hline Gas from "exotic" sources". . . & $3.25-7.50$ & $6.90-14.00$ & $6.00-11.00$ & $9.30-20.00$ \\
\hline $\begin{array}{l}\text { Oil at } 500 / \text { gallon. . . . . . . . . . . } \\
\text { Electrical resistance heat }\end{array}$ & 3.60 & 9.50 & 8.00 & 12.50 \\
\hline $\begin{array}{l}\text { electricity at } 3-5 \$ / k W h \ldots \\
\text { electricity at marginal }\end{array}$ & $8.80-14.60$ & $10.10-16.00$ & $10.00-16.00$ & $18.00-29.00$ \\
\hline cost of $7 థ / k W h \ldots \ldots \ldots$ & 20.50 & 21.80 & 21.80 & 40.00 \\
\hline Heat pumps & & & & \\
\hline $\begin{array}{l}\text { electricity at } 3-5 \$ / \mathrm{kWh} \ldots \ldots \\
\text { electricity at marginal }\end{array}$ & $8.80-14.60$ & $8.30-12.00$ & $7.00-9.90$ & $11.00-16.00$ \\
\hline cost of $7 \$ / k W h \ldots \ldots \ldots$ & 20.50 & 15.80 & 12.90 & 22.00 \\
\hline
\end{tabular}

83 are discussed in a technical note at the end of this chapter.

Comparison of tables 82 and 83 show similar cost ranges that suggest that passive solar heating is now competitive with conventional heating fuels in at least some cases. It is interesting to note that the low end of the cost ranges shown for passive solar heating are lower than present cost of heat from gas. This simple comparison of costs indicates that passive systems will often be competitive, but gives no indication of the geographic range of competitive behavior. Furthermore, the cost of heat from the passive solar systems will not increase with inflation, leading to a substantial cost advantage for the passive systems after the first few years of operation. Lifecycle costing can be used to provide a better measure of the competitive advantage or disadvantage of passive solar heating systems. Most of the work in this area has been performed at the Los Alamos Scientific Laboratory and the University of New Mexico. 38 Among the more in-

38 References on solar passive

(a) Scott A. Nell, "A Macroeconomic Approach to Passive Solar Design: Performance, Cost, Comfort, and Optimal Sizing," Systems Simulation and Economic Analysis Workshop/Symposium, San Diego, Cal if., June 1978.

(b) Scott A. Nell, "Testimony Prepared for the U.S. House of Representatives Subcommittee on Oversight and Investigations, Committee on Interstate and Foreign Commerce," Aug. 11, 1978. teresting of their results are those showing how a Trombe wall system will compete with gas and electricity in different parts of the country.

The group considered a double-glazed thermal storage wall with storage provided by 18 inches. of concrete. An engineering firm estimated that such a system would have an incremental installed cost of $\$ 12$ per square foot. For comparison, the thermal storage wall systems used in table 82 ranged from $\$ 5$ to $\$ 21$ per square foot with a single exception. A variation

(Continued)

(c) Fred Roach, Scott Nell, and Shaul Ben-David, "The Economic Performance of Passive Solar Heating: A Preliminary Analysis," AIAA/ASERC Conference, Phoenix, Ariz., November 1978.

(d) Fred Roach, Scott Nell, and Shaul Ben-David, "Passive and Active Residential Solar Heating: A Comparative Economic Analysis of Select Designs," submitted to Energy, the International Journal, January 1979.

(e) Scott A. Nell and Mark A. Thayer, "Trombe Wall vs. Direct Gain: A Macroeconomic Analysis for Albuquerque and Madison," The Third National Passive Solar Energy Conference, San Jose, Cal if., January 1979.

(f) Scott A. Nell, J. Fred Roach, and Shaul Ben-David, "Trombe Walls and Direct Gain: Patterns of Nationwide Applicability," The Third National Passive Solar Energy Conference, San Jose, Cal if., January 1979.

(g) Scott A. Nell, "Thermal Mass Storage and Glazings Show Effectiveness in New Modeling," Solar Engineering, January 1979, pp. 29-31. 
on this system was considered that assumed that the Trombe wall was equipped with movable insulation, which increases the R-value of the collector surface to R-10, between 4 p.m. and 9 a.m., at an added cost of $\$ 4$ per square foot. This insulation allows a smaller system to meet the same fraction of the heating load and is often found to be cost-effective.

Results of the State-by-State analysis a re shown in figure 54, maps 1 through 5 for five different combinations of system, backup fuel, and incentives. The first two maps show that Trombe wall systems with night insulation are now feasible in three States when natural gas is the backup and would be expected to be economic in one more within the next 10 years if no incentives are provided. The inclusion of Trombe wall systems in the solar energy tax credit contained in the National Energy Act of 1978 would make such systems economical in 29 of the 48 States shown by 1985, when natural gas is used for backup. It is interesting to note that the system is not economic in several Sun Belt States due to the relatively small heating requirements.

The feasibility of Trombe wall systems using electric-resistance heating as backup is examined in maps 3 through 5. Map 3 shows that Trombe wall systems are now feasible in every State except Washington, where electric rates are extremely low and there is relatively little sunshine. Systems that provide about half of the heating are feasible in Califomia, Arizona, and South Carolina. The addition of night insulation to the system makes it feasible to increase the fraction of the heat provided by the solar system as shown in map 4. (The night insulation is generally most effective in the colder States. ) The addition of the recent tax credit incentives would increase the fraction of solar heating that is feasible by 0.05 to 0.20 in about two-thirds of the States as shown in map 5.

The importance of this analysis lies not in the specific States and solar fractions shown to be feasible, but rather in the trends. Passive solar heating is shown to be marginally competitive on a lifecycle cost basis with gas heating in parts of the country. The large number of States where the addition of the tax credit incentives makes small systems com- petitive illustrates this. Systems that supply a significant fraction of the total heating needs are competitive with electric resistance heating in much of the country. Other passive designs such as attached sunspaces that offer other benefits in addition to heating may be more broadly applicable.

\section{Summary}

"Passive solar" buildings, which obtain 20 to 95 percent of required heat from the Sun without active solar collectors, have been built and are operating in many parts of the country. While data are sketchy, it appears that such housing is clearly competitive with electric-resistance heating in terms of cost, and is competitive with oil and gas in some parts of the country. In addition to the heat provided, many passive solar homes provide additional space, good natural light, and a pleasing view; these characteristics may be as important to homeowners as the savings in fuel costs. An additional benefit is that the systems are simply constructed and have few moving parts, so little maintenance is required. In some such homes, the daily swings in temperature are greater than commonly acceptable in houses using conventional heating/cooling systems.

Additional research and development is needed in this area, including the collection of field data on operation of homes now in place. It is likely, however, that the principal barriers to widespread use of these techniques (careful siting, construction, and landscaping) are institutional rather than technical. (This is generally true for home energy conservation issues. ) First costs of such a system will be higher than conventional systems. Code bariers may be a problem in some areas; for instance, some code changes implemented over the past 5 years in the name of energy conservation require extensive engineering justifications of such homes on a case-by-case basis.

Passive heating systems are largely conventional building materials in an unconventional combination rather than new products. Accordingly, industrial promotion of passive solar has been slow to materialize. Glass and plastics industries are potential proponents, 
Figure 54.-Solar Feasibility for Trombe Wall With Night Insulation Alternative Fuel-Natural Gas

Map I

No incentives

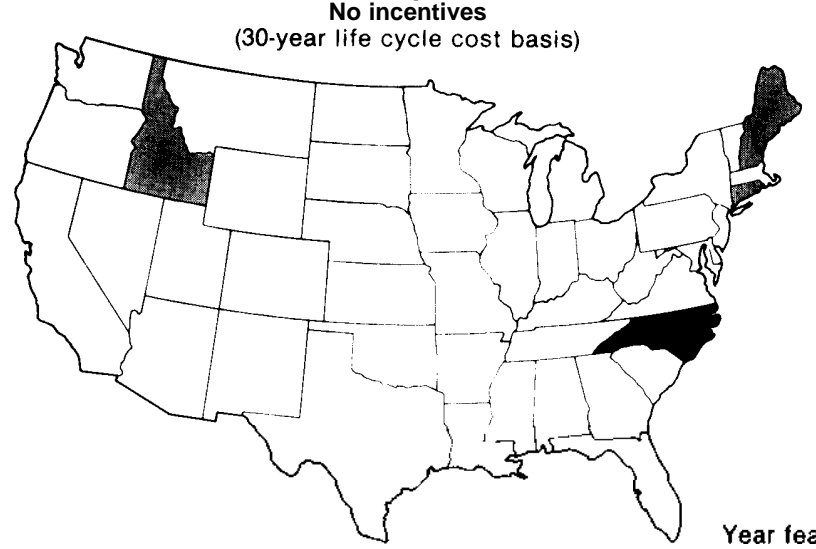

Year feas bility key

$1979-1980$
Map 2

NEP tax credit incentive (30-year life cycle cost basis)

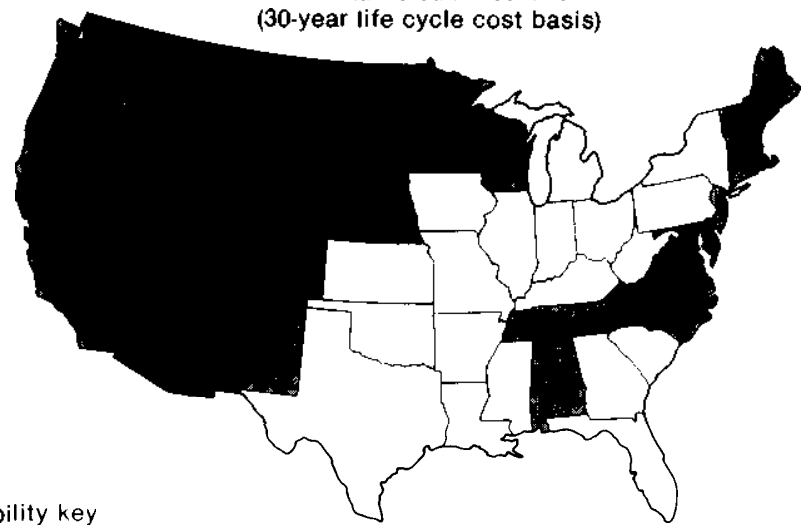

$1981 \cdot 1985$

$1986-1990$

Solar Feasibility for Trombe Wall wl/o Night Insulation

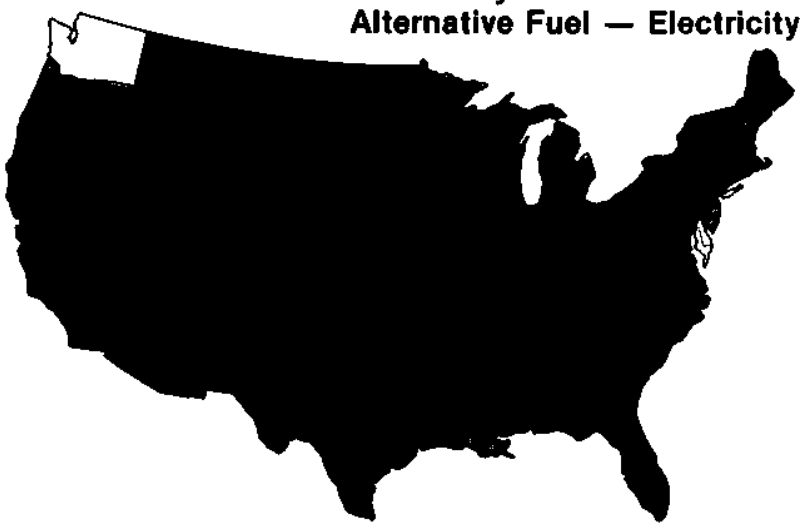

Map 3

No incentives

(30-year life cycle cost basis)

Solar fraction key

.10 .25

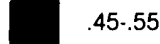

$30 \cdot .40$

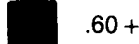

Feasibility achieved in 1978 for all stages except WA

Solar Feasibility for Trombe Wall with Night Insulation Alternative Fuel - Electricity (Resistance)
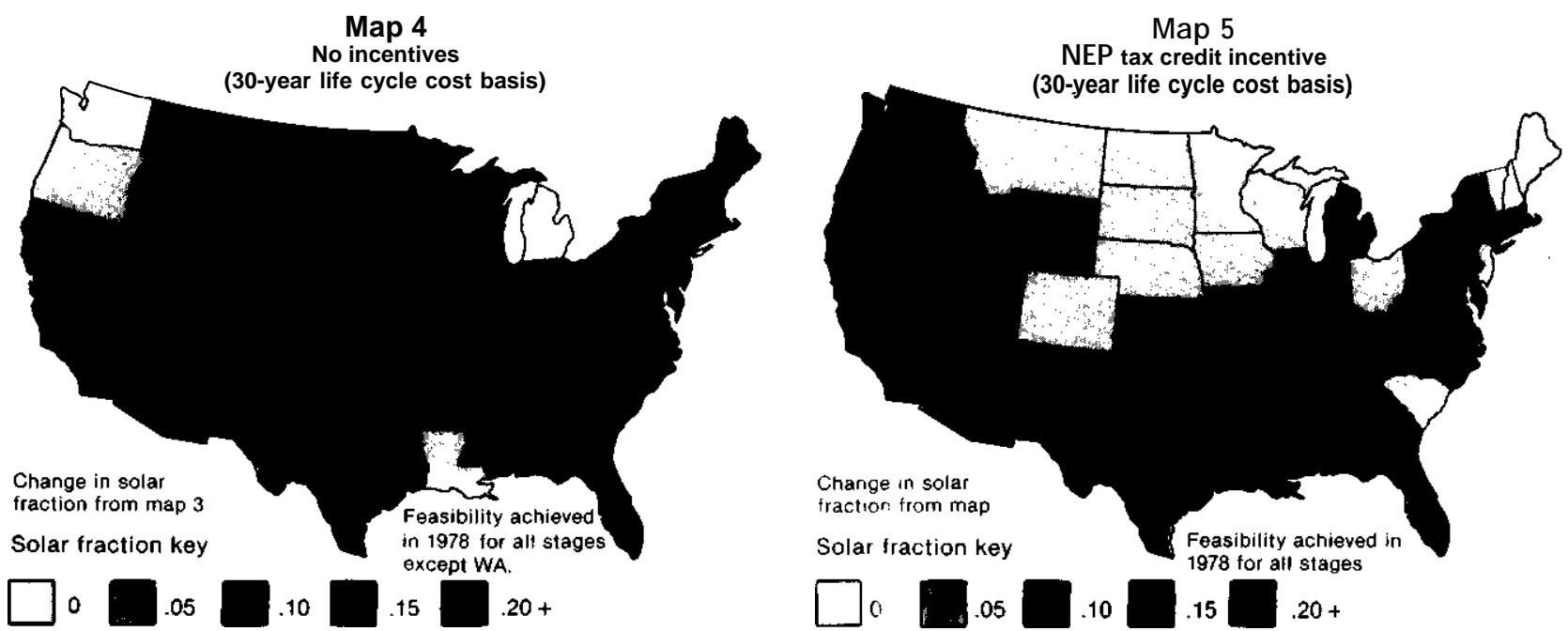

Source: Fred Roach, Scott Nell and Shaul Ben-David; The Economic Performance of Passive Solar Heating: a Preliminary Analysis, AIAA/ASERC Conference, November, 1978, Phoenix, Arizona 
but large industries such as these typically do not become active in a new market area until it has been established by small entrepreneurs.

Manufacturers of movable insulation are natural marketers for passive solar construction. This area is characterized by a number of small companies that have experienced difficulty in developing durable, reliable products and have not had extensive marketing experience.

The Internal Revenue Service interpretation of the solar energy tax credits (and conservation credits) recently authorized effectively excludes many passive systems. This places the passive approach, which can drastically reduce heating requirements, at a strong disadvantage to conventional supply technologies.

Accelerating the use of passive solar techniques calls for a vigorous information and demonstration effort, as the technology is not widely understood and does not have strong private sector support. Rapid and credible demonstration of a variety of systems in all regions of the country would help. These demonstrations could parallel the development and distribution of a design catalog, showing systems that have received adequate engineering analysis to meet local building code requirements. Such approaches could lead to the acceptance of "rules of thumb" for use by designers and builders in each part of the country. The recently concluded Passive Solar Design competition should provide a useful start on this task.

A number of homes could be built in varying climates and subjected to detailed and precise performance monitoring. This work could be coordinated with continued development and verification of computer programs designed to predict energy usage. Simple computer programs that are cheap and accessible are needed for field use by designers and builders; programs of greater precision and accuracy are needed for research.

Some applied research areas, such as improved glazing methods and infiltration monitoring, will be useful to passive solar. Passive cooling has received very limited attention and needs work. Possibilities for combining passive systems with active solar to further reduce dependence on conventional fuels have not been widely explored.

\section{TECHNICAL NOTES-FOSSIL FUEL PRICES}

These assumptions were used for comparing conventional fuel and solar passive heating costs in this chapter.

In 1977, natural gas prices for residential customers ranged from $\$ 2.00$ per MMBtu in the Southwest to $\$ 4.00$ per MMBtu in New England, ${ }^{39}$ where gas is piped over long distances or derived from supplemental sources, such as liquefied natural gas (LNG) or synthetic natural gas (SNG) from naphtha. In comparison, the average 1977 price for wellhead interstate gas was $\$ 0.93$ per MMBtu and $\$ 1.54$ per MMBtu to gas distributors. ${ }^{40}$ Although comparable average prices for wellhead intrastate gas are not known, typical new contracts ranged from

\footnotetext{
"American Gas Association, "Quarterly Report of Gas Industry Operations- Fourth Quarter 1977 “

“"Department of Energy, April 1978.
}

$\$ 1.50$ to $\$ 2.00$ per MMBtu. Synthetic gas prices were compiled from a variety of sources used in the OTA solar study, ${ }^{41}$ while LNG prices are based on current and pending LNG projects. ${ }^{42}$ Prices for "exotic sources" are based on the OTA Devonian shale study ${ }^{43}$ and a recent presentation by Henry Linden ${ }^{44}$ of the Gas Research institute.

A substantial quantity of fuel oil is imported and apparently is not affected by crude oil en-

\footnotetext{
"office of Technology Assessment, "Application of Solar Technology to Today's Energy Needs," June 1978. ${ }^{42}$ American Gas Association, "Gas Supply Review, , June 1978.

${ }^{43}$ Office of Technology Assessment, "Status Report on the Gas Potential From Devonian Shales of the Appalachian Basin," November 1977.

"Henry Linden, presentation at the Second Aspen Energy Conference, July 1978.
} 
titlements. Consequently, increasing the price of U.S. crude oil to world levels would not result in a large increase in fuel oil prices. Also, the delivered price of $\mathbf{\$ 0 . 5 0}$ per gallon equals $\$ 21.00$ per barrel delivered.

Typically, the price of electricity for residential customers ranged from 3 to 5 cents/kWh. Exceptions to this are the Northwest where electric ity costs are less than 3 cents/kWh and the Northeast where it costs more than 5 cents/ $\mathrm{kWh}$. The delivered price of electricity from new capacity was calculated within a few mills of 7 cents/kWh for each of the four cities treated in the OTA solar report.

Different efficiency values were used for gas and oil fumaces, baseboard heaters, and heat pumps. Seasonal efficiency for gas fumaces is 60 percent; for oil fumaces, 50 percent; and 100 percent for baseboard electric heaters. Gas fumace efficiency can be increased to 80 percent at a cost of about $\mathbf{\$ 4 0 0}$ per furnace, while oil fumace efficiency can be increased to 70 percent at a cost of about $\$ 500$ per furnace. Typical heat pumps have a seasonal performance factor of 1.55-an efficiency of 155 percent - in a 5,000 degree-day climate. ${ }^{45} \mathrm{~A}$ heat pump with "improved" installation was assumed to have a seasonal performance of 2.0 at no additional cost. The performance of the heat pump with "improved" installation corresponds to the performance of some heat pumps manufactured today and suggests that typical heat pump performance can be increased to the 2.0 level.

Conventional systems ownership costs, which include capital costs, annual maintenance costs, and a pro-rated replacement cost (for heat pumps that have a typical lifetime of only 10 years), are based on the OTA solar study.

\footnotetext{
${ }^{45}$ Westinghouse Electric Corporation, "Load and Use Characteristics of Electric Heat Pumps in Single-Family Residences," EPRI EA-793, Project 432-1, Final Report, June 1978.
} 
Appendixes 


\section{INTRODUCTION}

In his National Energy Plan presented to Congress on April 20, 1977, President Carter set as a national goal the insulation of 90 percent of existing homes in the United States by 1985. Given spiraling energy costs and a new tax credit, Americans have been insulating their homes in record numbers. According to the Department of Energy (DOE), 25 million to 47 million homes will be reinsulated by the end of 1985 .

Nationwide increases in thermal insulation have, however, resulted in a number of actual and potential problems. For example, the absence of uniform safety standards and testing methods among various levels of govemment and the absence of Federal and State laws on home insulation have contributed to the risks of consumer injury, illness, and death. Although some basic laws do exist with respect to the manufacture and installation of insulation materials, their effectiveness remains questionable.

This appendix outlines and discusses some of the major problems associated with the increased use of insulation.

\section{TYPES OF INSULATION MATERIALS}

The principal applications and market segments for insulation materials in the residential sector are shown in tables A-1 and A-2. A number of properties influence the thermal performance of insulating materials. Thermal performance is expressed in terms of thermal resistance (R-value), which describes the ability of a particular material to restrict heat flow. I $n$ addition to thermal performance, this section includes a brief overview of other important properties, such as corrosiveness and degradation. Tables A-3 through A-1 O provide a more extensive list of properties.

\section{Rock Wool and Slag Wool}

Rock wool and slag wool are terms used to denote glassy fibers that are produced by melting and fiberizing slags obtained from smelting metal ores ("slag wool") or by melting and fiberizing naturally occurring rock ("rock wool"). Rock and slag wool products appear in the form of batts and loose-fill for blown or poured application. The reported R-values for rock wool batts are 3.2 to 3.7 , and 2.9 per 1 inch thickness for blowing wool. The thermal performance of this product is reportedly

Table A-1. - Principal Residential Applications

\begin{tabular}{|c|c|c|c|c|c|c|c|}
\hline Locations & Fiberglass & $\begin{array}{l}\text { Rock } \\
\text { wool }\end{array}$ & Cellulose & $\begin{array}{l}\text { Cellular } \\
\text { plastics }\end{array}$ & Perlite & Vermiculite & $\begin{array}{c}\text { Reflective } \\
\text { surfaces }\end{array}$ \\
\hline \multicolumn{8}{|l|}{ New construction } \\
\hline Roof/ceiling. . . . . . . . & $\mathbf{x}$ & $\mathbf{x}$ & $\mathbf{x}$ & $\mathbf{x}$ & & & \\
\hline Walls ............ & $x$ & $x$ & & $x$ & & & $x$ \\
\hline Floors/foundation. . . . & $\mathbf{x}$ & $\mathbf{x}$ & & $\mathbf{x}$ & & & $\mathbf{x}$ \\
\hline \multicolumn{8}{|l|}{ Retrofit } \\
\hline Roof/ceiling. . . . . . . . & $\mathbf{x}$ & $\mathbf{x}$ & $\mathbf{x}$ & $\mathbf{x}$ & & $\mathbf{x}$ & \\
\hline Walls ............ & $x$ & $x$ & $x$ & $x$ & & & \\
\hline Floors/foundation. . . . & $\mathbf{x}$ & $\mathbf{x}$ & & $\mathbf{x}$ & & & $\mathbf{x}$ \\
\hline
\end{tabular}


Table A-2.-Market Segments and Product Usage

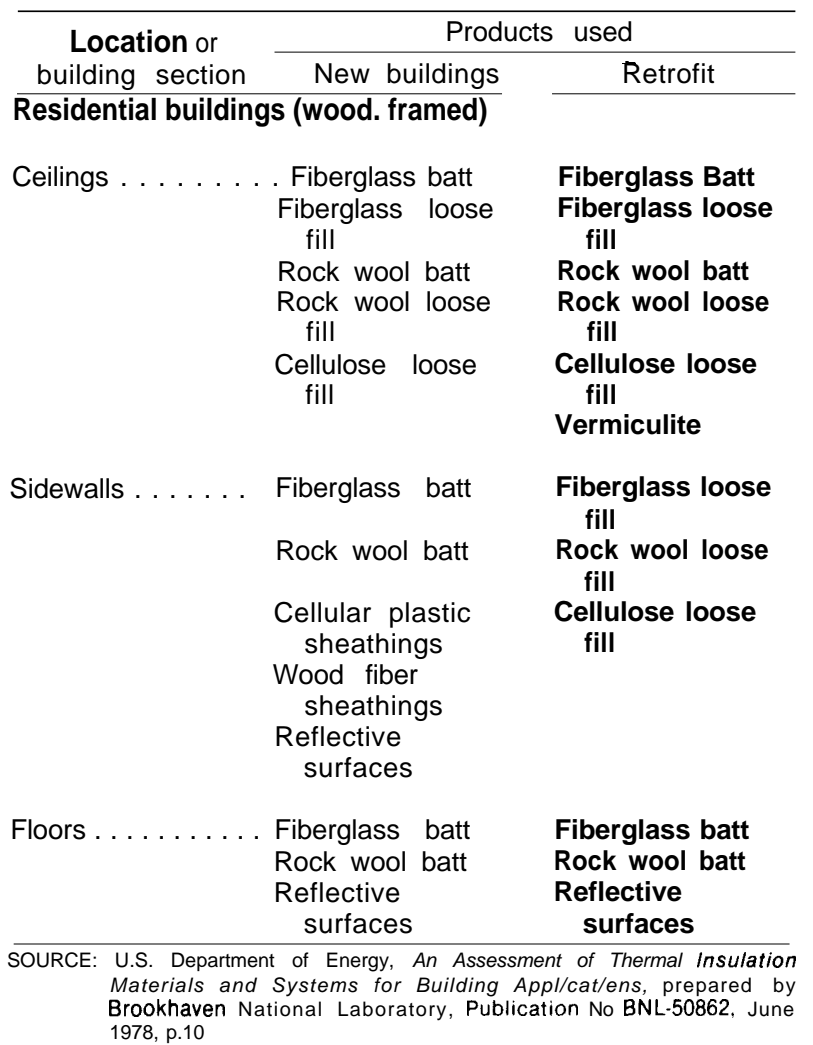

unaffected by age. Its thermal conductivity can be affected by moisture content, although the material, after drying, regains its original properties. When dry, rock wool does not support fungal growth, bacteria, or vermin; exudes no odor, and is noncomosive.

\section{Fiberglass}

Fiberglass is manufactured in a high-technology process in which glass raw materials are combined and melted in a fumace, then led out through a forehearth to the fiberization devices. Phenolic resin is a commonly used binder that is applied to the fiber as it flows through a collection chamber. The fiber with resin is collected on a moving belt and passed through an oven to cure or set the resin, and the finished product is removed from the end

\footnotetext{
'An Assessment of Thermallnsulation Materials and Systems for Building Applications, prepared by Brookhaven National Laboratory, Publication No. BNL-50862 (U.S. Department of Energy, June 1978), p. 82
}

Table A-3.-Rock and Slag wool

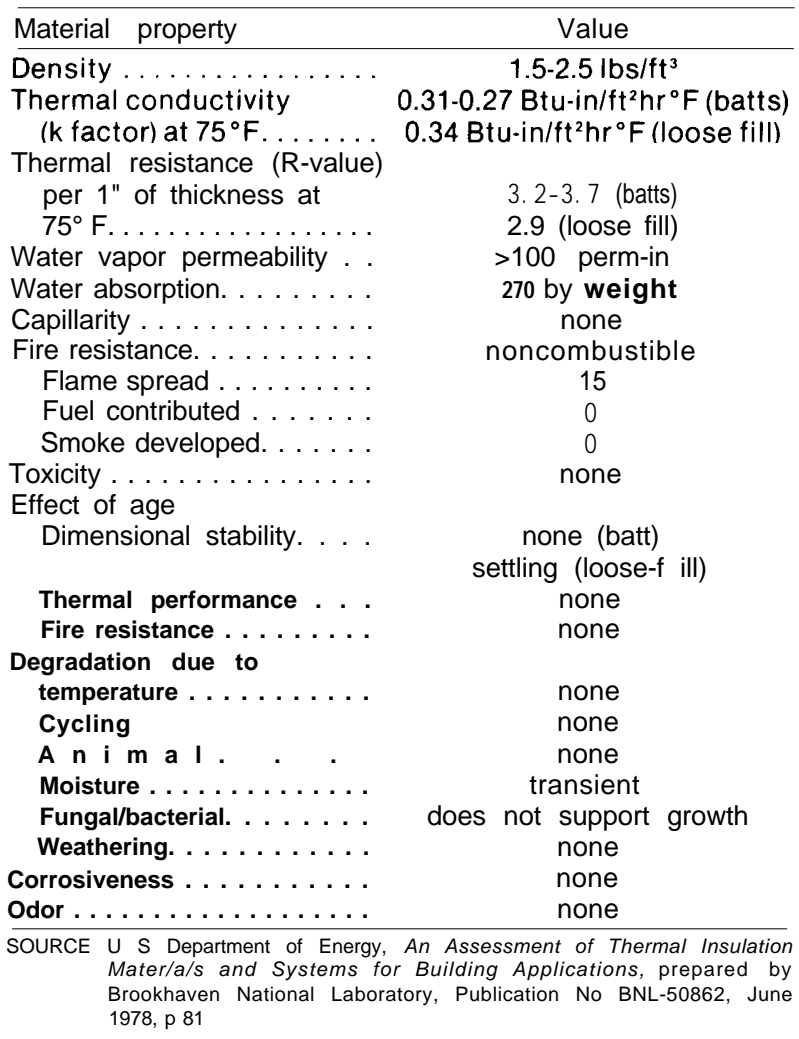

of the line and packaged. Fiberglass is usually sold in the form of batts and blankets (with or without a vapor barrier) or shredded, lubricated, and packaged as blowing wool. The Rvalue for fiberglass batts or blankets is about 3.2; the R-value for loose-fill is 2.2 per inch. It appears that fiberglass batt insulation does not settle or shrink with age, but loose fill may settle. The thermal performance of this material is reportedly unaffected by age. Fiberglass does not promote bacterial or fungal growth and provides no sustenance to vermin. Insulation materials made from fiberglass are noncomsive and have no objectionable odor. ${ }^{2}$

\section{Cellulose}

Cellulose insulation is manufactured by converting used newsprint, other paper feedstock, or virgin wood to fiber form with the incorporation of various chemicals (e. g., boric acid, borax, or aluminum sulfate) to provide flame

\footnotetext{
'Ibıd , p 79
} 
Table A-4.- Fiberglass

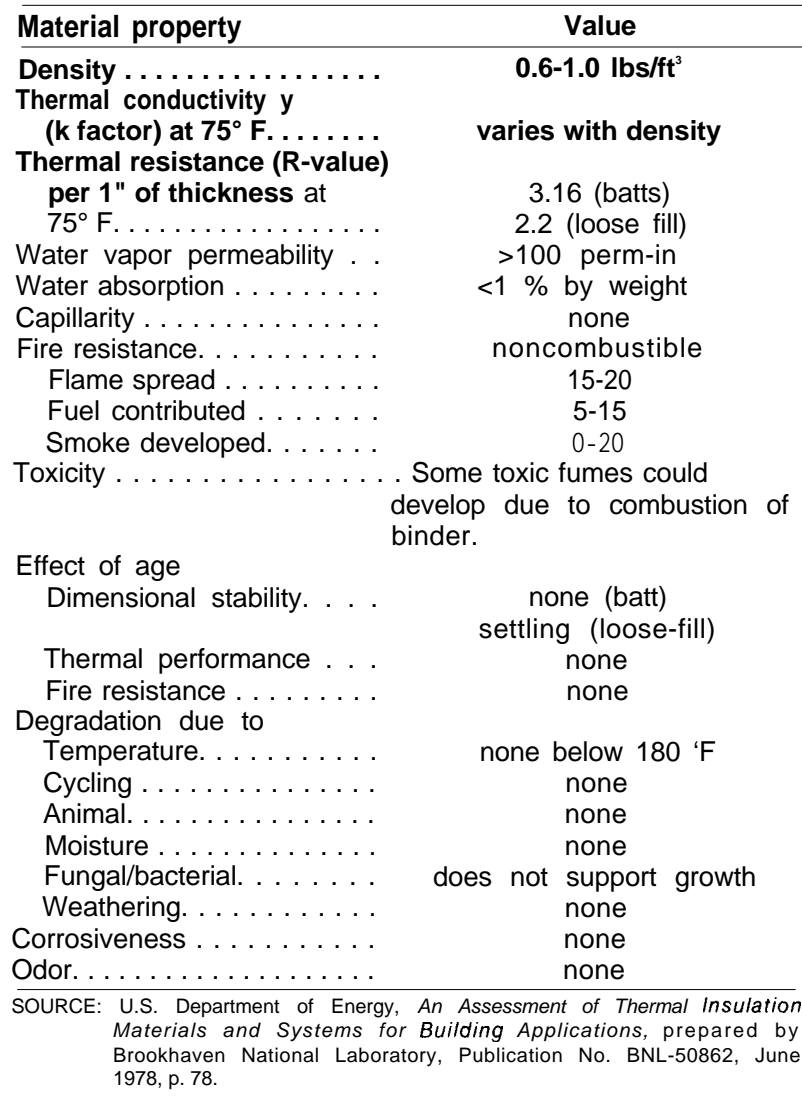

retardancy. Cellulose products a re usually available as loose-fill or spray-on. The thermal resistance values for cellulose insulation are in the range of 3.7 to 3.2. However, compaction (caused by vibration and settling under its own weight) can decrease its R-value in two ways: loss in thickness and an increase in conductivity due to the increase in density. If cellulosic material is properly treated, its weight gain from water absorption will not exceed 15 percent. However, poor quality control and improper selection of flame-retardant chemicals may increase the level of absorption. Some chemicals added to cellulose to provide flame retardancy are known to cause corrosion on metals such as steel, aluminum, and copper. Fungal and bacterial growth can be a problem, unless chemicals are added to inhibit such growth.

\section{Cellular Plastics}

A variety of different plastics, when produced as foams, are useful as insulation
Table A-5.-Cellulose

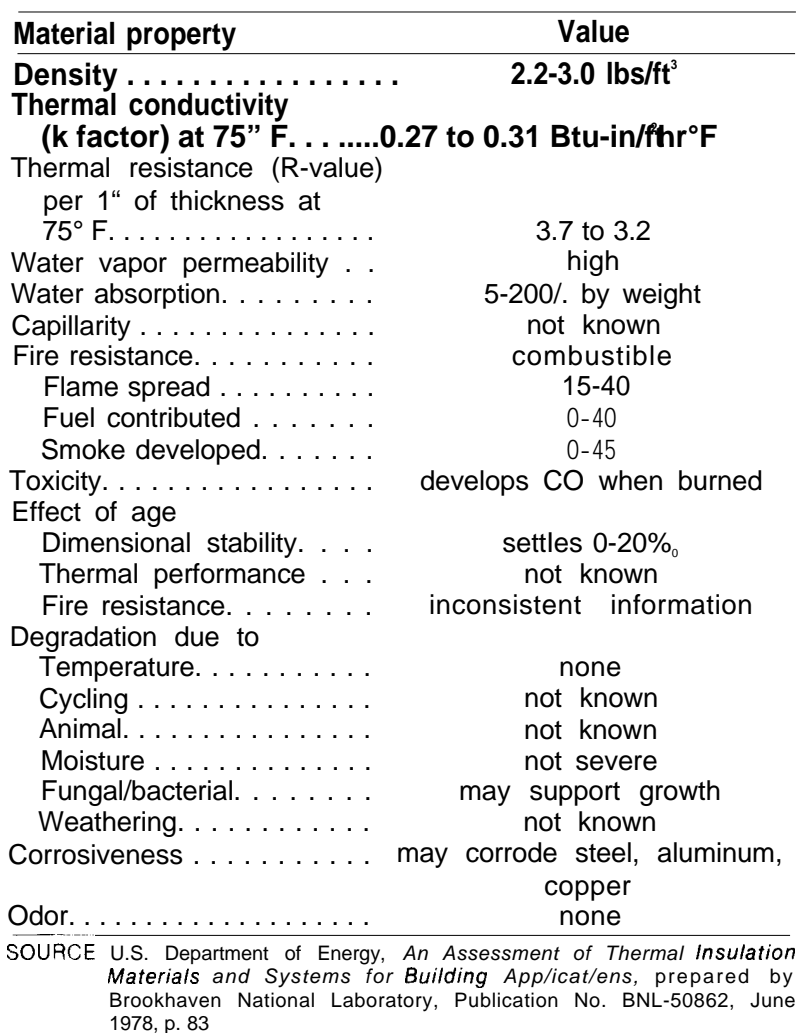

materials. Foamed-in-place and board stock foams exist. As differences exist in the chemical composition of these materials, a separate discussion is necessary for each cellular plastic insulation.

\section{Polystyrene Foam}

Polystyrene is a thermoplastic material produced by the polymerization of styrene in the presence of a catalyst. Polystyrene foam can be produced by either intrusion or extrusion. ${ }^{3}$ Foam produced by extrusion has a more consistent density than foam produced by the molding process, in which variations in density average about 10 percent. The R-value for molded polystyrene foam (3.85 to 4.35) is lower than the R-value for extruded polystyrene (5.0) as the former has air in the cells and the latter has a mixture of air and fluorocarbon.

Polystyrene foam must be protected from direct exposure to ultraviolet (UV) light, which can cause it to yellow and tum to dust. Its in-

'lbid , p 21 
Table A-6.- Expanded Polystyrene Foam

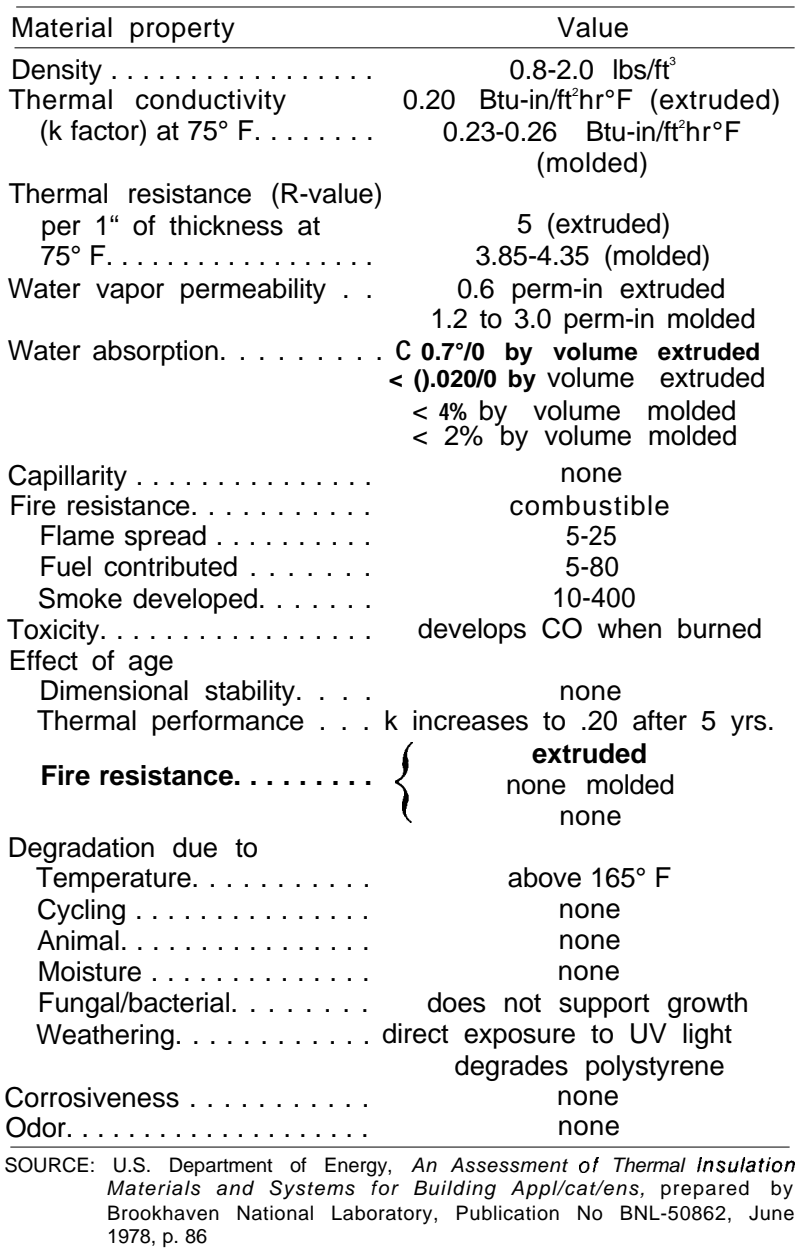

sulating properties, however, are not affected by short-term exposure to UV light. Polystyrene foam can tolerate temperatures up to 1650 F, but higher temperatures may cause it to soften. Polystyrene does not promote fungal or bacterial growth, and is odorless and noncorro sive. ${ }^{4}$

\section{Polyuretha ne}

Polyurethanes are plastics produced through the reaction of isocyanates and alcohols. Either rigid or flexible foam can be produced. For example, slab stock is produced by mixing the necessary components and metering the mixture onto a moving conveyor. The mixture forms a continuous foam that can be cut to predetermined lengths. Foamed-in-place

'I bid., p. 85
Table A-7.-Polyurethane/Polyisocyanurate Foams

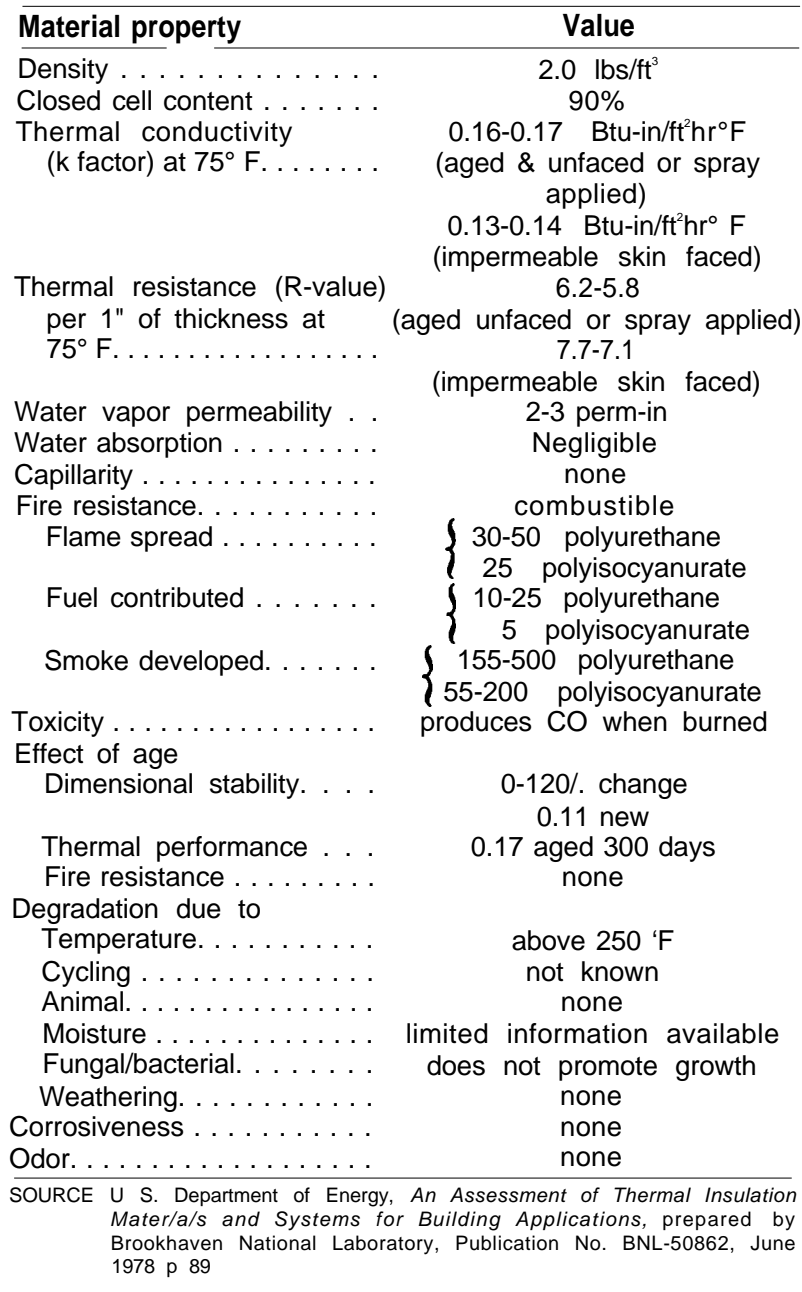

polyurethane are prepared by mixing or metering the components and manually or automatically dispensing them. Specially designed units are now available for spray-on applications.

The R-value for polyurethane is around 6 . Because of the closed cell structure of this material, water absorption and permeability are very low. I n curing and aging, polyurethane foam is reported to demonstrate a dimensional change. The degree to which this foam expands or shrinks is related to conditions of temperature and humidity and the duration of exposure to extreme conditions. ${ }^{5}$ One American Society for Testing of Materials (ASTM) test procedure indicated a change in volume

${ }^{5}$ / bid. 
Table A-8.-Urea-Formaldehyde and Urea-Based Foams

Material property
Density . . . . . . . . . .
Thermal conductivity
(k factor) at $75^{\circ} \mathrm{F} \ldots \ldots \ldots$
Thermal resistance (R-value)
per $1^{\text {" }}$ of thickness at
$75^{\circ} \mathrm{F} . \ldots \ldots \ldots \ldots$

Water vapor permeability.

Water absorption

Capillarity. . . . . . . . . . .

Fire resistance. . . . . . . . . . . . . . . . .

Flame spread . . . . . . . . .

Fuel contributed . . . . . . .

Smoke developed. . . . . . .

Toxicity. . . . . . . . . . . .

Effect of age

Dimensional stability. . . . 1 to $4 \%$ shrinkage in 28 days due to curing

4.6 to $10 \%$ shrinkage at $100 " \mathrm{~F}$ $100 \%$ rh for 1 week

30 to $45 \%$ shrinkage and $158^{\circ} \mathrm{F}$

90 to $100 \%$ rh-10 days
Thermal performance . . .

Fire resistance

Degradation due to

Temperature. . . . . . . . .

Cycling .............

Animal. . . . . . . . . . . .

Moisture . . . . . . . . . . .

Fungal/bacterial. . . . . . . . .

Weathering. . . . . . . . . .

Corrosiveness . . . . . . . . .

Odor. . . . . . . . . . . . .

$$
\text { No change }
$$

decomposes at $415^{\circ} \mathrm{F}$ no damage after 25

freeze-thaw cycles

not a feed for vermin not established

does not support growth none none

may exude formaldehyde until cured

SOURCE: U.S. Department of Energy, An Assessment of Thermal Insulation Materials and Systems for Building Applications, prepared by Brookhaven National Laboratory, Publication No. BNL-50862, June 1978, p. 91.

of up to 12 percent after 14 days. This material will begin to decompose at temperatures above $2500 \mathrm{~F}$. Polyurethane foam is resistant to fungal and bacterial growth, and is odorless and noncorrosive.

\section{Urea-Formaldehyde Foam}

Urea-formaldehyde foam is produced at the site of application "by the combination of an aqueous solution of a urea-formaldehyde based resin, an aqueous solution foaming agent which includes a surfactant and acid
Table A-9.-Perlite

\begin{tabular}{|c|c|c|}
\hline \multirow[b]{2}{*}{ Material property } & \multicolumn{2}{|c|}{ Value } \\
\hline & Loose fill & Perlite concrete \\
\hline $\begin{array}{l}\text { Density } \ldots \ldots \ldots \ldots \ldots \ldots \ldots \ldots \\
\text { K app at } 75^{\circ} \mathrm{F} \ldots \ldots \ldots \ldots \ldots \\
\text { Thermal resistance (R-value) }\end{array}$ & $\begin{array}{l}2-11 \mathrm{lb} / \mathrm{ft}^{3} \\
0.27-0.40\end{array}$ & $\begin{array}{c}20-40 \mathrm{lb} / \mathrm{ft}^{3} \\
0.50-0.93\end{array}$ \\
\hline per $1^{\text {" }}$ of thickness at $75^{\circ} \mathrm{F} . \ldots$ & 3.7-2.5 & $2.0-1.08$ \\
\hline Water vapor permeability . . . . . . & high & high \\
\hline Water absorption ............ & low & \\
\hline Capillarity. . . . . . . . . . . & none & none \\
\hline Fire resistance. . . . . . . . . & ioncombustible & noncombustible \\
\hline Flame spread $\ldots \ldots \ldots \ldots \ldots$ & 0 & 0 \\
\hline Fuel contributed . . . . . . . . & 0 & 0 \\
\hline Smoke developed . . . . . . . . . & 0 & 0 \\
\hline $\begin{array}{l}\text { Toxicity. . . . . . } \ldots \ldots \ldots \ldots \\
\text { Effect of age }\end{array}$ & not toxic & not toxic \\
\hline Dimensional stability . . . . . . . & none & none \\
\hline Thermal performance ........ & none & none \\
\hline Fire resistance $\ldots \ldots \ldots \ldots \ldots$ & none & none \\
\hline Degradation due to & & \\
\hline Temperature. . . . . . . . & $\begin{array}{l}\text { none under } \\
1,200 " F\end{array}$ & $\begin{array}{l}\text { none under } \\
500 " \mathrm{~F}\end{array}$ \\
\hline Cycling . & none & none \\
\hline Animal. ............... & none & none \\
\hline Moisture $\ldots \ldots \ldots \ldots \ldots \ldots$ & none & none \\
\hline Fungal/bacterial. . . . . . $\ldots \ldots$ & $\begin{array}{l}\text { does not pro- } \\
\text { mote growth }\end{array}$ & $\begin{array}{l}\text { does not pro- } \\
\text { mote growth }\end{array}$ \\
\hline Weathering. . . . . . . . . & none & none \\
\hline Corrosiveness . . . . . . . . . . . . & none & none \\
\hline Odor. . . . . . . . . . . . . . & none & none \\
\hline
\end{tabular}

SOURCE U.S. Department of Energy, An Assessment of Thermal Insulation Materials and Systems for Building Applications, prepared by Brookhaven National Laboratory, Publication No. BNL-50862, June 1978, p. 94.

catalyst (or hardening agent), and air. In the mixing or foaming gun, compressed air is mixed with the foaming agent to produce small bubbles which are expanded and coated with the urea-formaldehyde resin. The foam is delivered at about 75 percent water by weight and immediately begins to cure."

Urea-formaldehyde has an R-value of 4.2. According to a National Bureau of Standards (NBS) study, shrinkage and resistance to high temperature and humidity may be a problem. The magnitude of the shrinkage and the time period over which it occurs are subjects of debate. The study presented some data on material that had been installed in a wall of a test house. Periodic inspections were made of the insulated wall and in about 20 months the foam had undergone an average linear shrinkage of 7.3 percent. ${ }^{7}$ The NBS data are only preliminary; until more studies are concluded on the inservice performance of this material, the question of durability will remain unanswered.

\footnotetext{
I bid., p. 23,

'Urea-Based Foam Insulations: An Assessment of Their Thermal Properties and Performance, Technical Note 946
} (National Bureau of Standards, July 1977), p. 34. 
Table A-10.-Vermiculite

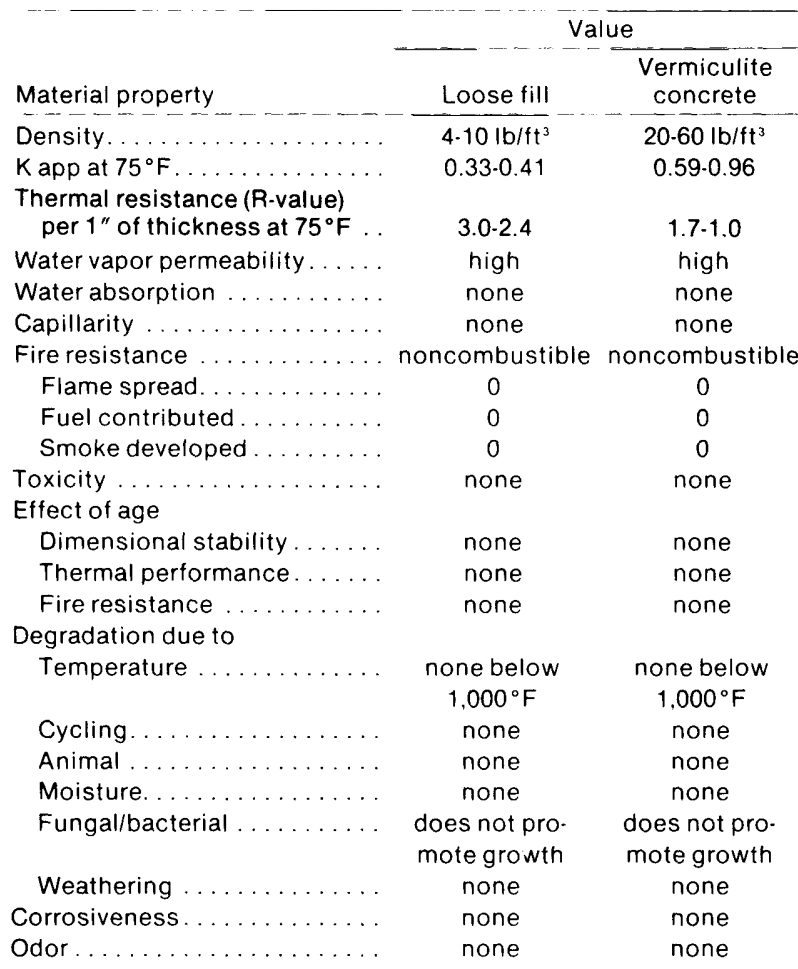

SOURCE: U.S. Department of Energy, An Assessment of Thermal Insulation Materials and Systems for Building Applications, prepared by Brookhaven National Laboratory. Publication No. BNL-50862, June 1978, p. 96.

An odor of formaldehyde may occur during the application of ureaformaldehyde-based foam insulation. Under normal circumstances, the odor should dissipate quickly and linger for only a few days. According to one major manufacturer, "formaldehyde gas is emitted from the foam, in the part per million range, during the drying and curing process, which will be over in 2 weeks." ${ }^{\prime \prime}$

\section{Perlite}

Perlite is a glossy volcanic rock mineral, indigenous to the westem United States. It contains between 2 and 5 percent water by weight. Perlite ore is composed primarily of aluminum silicate. When heated to a suitable point $\left(1,000{ }^{\circ} \mathrm{C}\right)$, the crushed ore particles expand to between 4 and 20 times their original volume and contain numerous cavities. It is then treated with nonflammable silicone to become

II bid., p. 58. highly resistant to water and to moisture. The R-value of perlite is between 3.7 and 2.5. As an inorganic material it resists rot, vermin, and termites. Perlite is noncorrosive and odorless. It is primarily used as loose-fill insulation, or as aggregate in insulating concrete.

\section{Vermiculite}

Vermic ulite is a generic name for micalike minerals. When subjected to high temperatures it expands to a corklike consistency. The R-value for this material is 3.0 to 2.4. Vermiculite is water repellant and noncombustible. As an inorganic material it is resistant to vermin, rot, and termites and is not affected by age, temperature, or humidity. Vermic ulite is noncomosive and does not exude an odor. Like perlite, it is primarily used as loose-fill insulation, or as aggregate in insulating concretes.

\section{Aluminum Multifoil}

Aluminum multifoil insulation consists of several sheets of aluminum foil separated by a ir spaces. The outer layers of the foil sandwich are usually backed with kraft paper for strength. The foil reflects infrared heat radiation, and the air spaces add to the insulation value. The R-value of this material depends on specific location. Three layers of foil with 4 air spaces can have an R-value of 29 under the floor, 14 in a wall, and 9.8 in the ceiling in winter. In summer, the same ceiling insulation can have an R-value of 29 for keeping the airconditioned house cool.9 Foil insulation weighs less and is less expensive than fiberglass

\section{Glass Foam}

Glass foam insulation is a rigid, closed-cell foam that is entirely resistant to water, fire, decay, vemin, and chemicals. [t can be made from recycled glass. Its R-value is 2.6 per inch. Present costs are about 20 times as high

'J R Schwartz, President, Foil Pleat Inc., personal communication, January 1979.

${ }^{10}$ Foamglassinsulation (Baltimore, Md.: Pittsburgh Corning Product Literature, Publication No F1-132 (rev.), April 1975) 
as the more common insulation materials. Therefore, it is limited to specialized applica- tions requiring its noncompressibility, moisture resistance, or chemical inertness.

\section{PRODUCTION CAPACITY OF THE U.S. INSULATION INDUSTRY}

This section attempts to summarize the present production capacity of the insulation industry, the leadtime for new insulation manufacturing facilities, and any roadblocks to large increases in production capacity. Table A-11 summarizes the data. Various projections of future insulation production capacity are not included here because they are so dependent on what manufacturers decide to do in the future. Decisions will depend on their perceptions of the market at a given time, and those perceptions will depend to a large extent on Govemment actions to encourage energy conservation and other future events. As an alternative to existing projections, this section gives leadtimes and constraints to capacity increases to illustrate just how flexible the future can be.

Table A-1 1.-Production Capacity of Insulation Industry and Leadtime for New Capacity

\begin{tabular}{|c|c|c|c|c|}
\hline Insulation type & $\begin{array}{c}\text { Number of } \\
\text { manufacturers }\end{array}$ & $\begin{array}{c}\text { R-value assumed } \\
\text { for calculation } \\
\text { of capacity }\end{array}$ & $\begin{array}{c}\text { Annual } \\
\text { production } \\
\text { capacity } \\
\text { (billion } \mathrm{Rxt}^{2} \text { ) }\end{array}$ & $\begin{array}{c}\text { Leadtime for } \\
\text { new capacity } \\
\text { (months) }\end{array}$ \\
\hline Rock \& slag wool . . . . . . . . . & $10^{a}$ & - & $19.4(1 / 77)^{\mathrm{a}}$ & $12-30^{e}$ \\
\hline Fiberglass . . . . . . . . . & $4^{a}$ & - & $98-160(1 / 77)^{a}$ & $12 \cdot 36^{c}$ \\
\hline $\begin{array}{l}\text { Cellulose . . . . . } \ldots \ldots \ldots \\
\text { Polyurethane \& }\end{array}$ & $>700(6 / 78)^{c}$ & 3.7 & $28(6 / 77)^{\mathrm{a}}$ & $1^{d}$ \\
\hline polyisocyanurate foams & $-35^{a}$ & 6.25 & $6.1(1 / 77)^{\mathrm{a}}$ & $6-12^{e}$ \\
\hline Polystyrene foam . . . . . . . & $100^{\mathrm{a}}$ & 4 & $4(1 / 77)^{a}$ & $6-12^{e}$ \\
\hline Urea-formaldehyde foam. . . & 4 Major $^{a}$ & 4.2 & $3.2(1 / 77)^{\mathrm{b}}$ & $10-20^{d}$ \\
\hline Perlite ............. & $>30^{\mathrm{b}}$ & 2.7 & $2.1(1 / 77)^{\mathrm{b}}$ & $6-12^{e}$ \\
\hline Vermiculite........... & $>16^{b}$ & 2.27 & $\begin{array}{c}3.2(1 / 77)^{\mathrm{b}} \\
\text { (loose fill only) }\end{array}$ & $6-12^{\mathrm{e}}$ \\
\hline Aluminum multifoil . . . . . . & $5^{\mathrm{b}}$ & 19 & $16(1 / 77)^{\mathrm{b}}$ & $6-12^{e}$ \\
\hline \multicolumn{5}{|c|}{$\begin{array}{l}\text { An Assessment of Thermal Insulation Materials and Systems for Building Applications, BNL-50862, prepared by Brookhaven National Laboratory for U.S. Depart- } \\
\text { ment of Energy, June 1978, pp. 31-37. } \\
\text { bW. Penoyar and F. E. Williams (U.S. Department of Commerce), "Survey of U.S. Residential Insulation Capacity and Projections for Retrofitting U.S. Housing Inven- } \\
\text { tory," Construction Review (U.S. Department of Commerce), August/September 1977, pp. 4-14. } \\
\text { CU.S. Interagency Task Force Report reviewing the supply and demand of insulation, preliminary draft, } 1978 . \\
\text { dSee text. } \\
\text { e }_{\text {H. Majors (Department of Energy, Conservation, and Solar Applications), personal communication, February } 1979 .}\end{array}$} \\
\hline
\end{tabular}

The "present capacity" figures presented here must be regarded with some caution since the references did not always distinguish between the amount of insulation produced in a year and the amount that could be produced if the factory were running at full capacity. Since insulation has been in short supply recently, factories have probably been operating close to full capacity, and any differences are probably not very great. Production capacities given include all the material produced, not just that sold for residential use. This gives a better idea of actual capacity for making the material. In several cases, the references did not make clear whether they were presenting total production or just residential insulation, so some figures in table A-11 may be less than full production capacity. Finally, most of these figures are for capacity in January 1977, and capacity has been growing steadily since that time

\section{Fiberglass}

Fiberglass insulation production is a hightechnology, capital-intensive industry. The four manufacturers are Owens-Corning Fiber-

“ Porter-Hayden Company, personal communication, January 1979. 
glas Corporation, Johns-Manville Corporation, Certain Teed Corporation, and Gebr. Knaut Westdeutsche Gipswerke. ${ }^{12}$ Owens-Corning has about half of the fiberglass insulation market, and Johns-Manville has about a quarter. Even for an established firm, an additional fiberglass plant can cost about $\$ 25$ million. '3 "Industry estimates of the time required for adding an additional line to an existing plant is about 12 to 18 months. A new plant would require 24 to 36 months to become fully operational once ground breaking has occurred.'" 4

\section{Cellulose}

It is fairly easy to get into the cellulose insulation manufacturing business, and many people are doing it. Between 70 and 100 new manufacturing companies were started in $1977^{15}$ and by mid-1978 there were over 700 companies in business. Most of these are very small businesses. ${ }^{16}$ It is possible to get into business for less than $\$ 10,000$ with a small machine on the back of a truck, but some larger manufacturers claim that it takes at least $\$ 300,000$ to set up a factory capable of producing cellulose that can meet safety standards consistently. ${ }^{17}$

Concern is frequently expressed that short supplies of borax and boric acid, used as fire retardants, could constrain rapid growth in the capacity of cellulose production. However, if shortfalls are met with imports, capacity could grow rapidly. Furthermore, "several chemical companies... are in the process of investigat-

\footnotetext{
${ }^{12}$ An Assessment of Thermal Insulation Materials, op. cit, p. 32.

${ }^{13}$ R. Kurtz, U.S. Consumer Product Safety Commission, memorandum to $\mathrm{H}$. Cohen, CPSC, on "Potential Effects of CPSC Regulations Upon Supply, Demand, and Utility of Home I nsulation: Initial Speculation, " Dec. 29, 1977, p. 4.

"Report on Insulation: Supply, Demand, and Related Issues, Office of Conservation and Solar Applications, preliminary draft, prepared by the Task Force on Insulation (U.S. Department of Energy, May 1978), ch. 6, p. 6.

"'Home Insulation Sales are Almost Too Hot," Business Week, September 1977, p. 88

"Report on Insulation, op. cit, p. 5

1 'R. Kurtz memo on "Potential Effects of CPSC Regulations," pp. 3-4.
}

ing different formulations requiring less boric acid." 8

\section{Urea-Formaldehyde Foam}

Urea-formaldehyde foam is produced at the house using a specially designed foam gun. Considerable skill is required to apply the foam properly. Poorly installed urea-formaldehyde foam can shrink and crack within a few months, and can release formaldehyde fumes for many months. The limited number of trained installers could limit rapid expansion of the near-term market. ${ }^{19}$

Most of the chemicals are produced by four companies, and one of them, Rapperswill Corporation, reportedly has 80 percent of the U.S. market for urea-formaldehyde insulation .20 The other major producers are Borden Chemical, Brekke Enterprises, and C. P. Chemical Company. ${ }^{21}$ Based on a projected tenfold increase in production within 2 years, ${ }^{22}$ it appears that the leadtime for new capacity "is rough y a year.

\section{Boric Acid and Borax}

Boric acid and borax are used in the manufacture of both cellulose and fiberglass insulation. In the manufacture of fiberglass, borax is used to reduce the drawing temperature of the fibers to less than $1,0000 \mathrm{C}$ as well as to strengthen the fibers. In the production of cellulose, borax improves the fire-retardant capabilities of boric acid and reduces its acidity. Both chemicals have recently been reported to be in short supply nationally. Therefore, prices may go up as more is imported.

Total U.S. boric acid production capacity in 1978 was around 180,000 metric tons, of which U.S. Borax and Chemical Corporation was responsible for about 65 percent. ${ }^{23} \mathrm{Kerr}-\mathrm{McGee}$ Chemical Corporation and Stauffer Chemical

\footnotetext{
${ }^{18} \mathrm{An}$ Assessment of Thermal Insulation Materials, op. cit., p 34

"Report on Insulation, op. cit., p. 6

${ }^{20}$ Energy Users Report, Aug. 18,1977, 210:16,

${ }^{21}$ An Assessment of Thermallnsulation Materials, op. cit., p 36

22 I bid

2، I bid , p 34.
} 
Corporation share the remainder of the production. The major foreign producers are France, U. S. S. R., Turkey, Chile, and Italy. In 1977, the United States exported 33,000 metric tons and imported 13,000 metric tons. ${ }^{24}$

Boric acid has been used as an important fire retardent chemical in cellulose insulation. Some cellulose manufacturers and chemical companies are investigating fire-retardant formu [as that use less boric acid and borax. ${ }^{25}$

During 1977, U.S. production of boron minerals and compounds was estimated to be 1.3 million metric tons. Exports were 241,000 tons and imports about 46,000 tons. The three U.S. producers of borax are U.S. Borax and Chemical Corporation, American Borate Corporation, and Kerr-McGee Chemical Corporation. ${ }^{26}$

Since 1975 there has been a growth in demand for borax and other berates attributable to increased demand for fiberglass, mineral wool, and cellulosic insulation. Current data is not available on how much borax is used in the manufacture of these products. However, the Bureau of Mines (BOM) estimates 35,000 tons of borax and other berates were used to manufacture cellulosic insulation n 1976.27 Current-
Iy, BOM is surveying the three borax producers to obtain specific end-use data on their sales to manufacturers, Domestic shortages of borax may occur in the future "if a producer alters its process to consume borax and produce additional boric acid by using the borax it otherwise would have produced." ${ }^{28}$

Concem over the possibility of a boric acid shortage led to the formation of an Interagency Task Force which pointed out four obvious options for increasing supply. The amount of minerals mined could be increased. This would not necessarily solve the problem as large amounts of berates are presently used for other products. A second option would be to increase refinery capacity and expand production of boric acid. This is seen as an unlikely response since long-term demand for berates is uncertain and boric acid refineries are not easily convertible to other uses. Some of the berates now going elsewhere in the market could be reallocated to boric acid production, or more boric acid could be imported .29 At present, market forces are responding adequately to meet boric acid demand, so Federal intervention does not appear nec essary.

\section{HEALTH HAZARDS}

The real and potential health hazards a sso c iated with various types of insulation materials have attracted much attention. This section addresses some of the major health-related problems.

\section{Fiberglass and Mineral Wool}

It has been known for a long time that fiberglass can produce eye and skin irritation. It is classified by the Occupational Health and Safety Administration (OSHA) as a nuisance dust. Furthermore, fiberglass workers sometimes experience respiratory tract irritation

\footnotetext{
${ }^{24}$ Report on Insulation, op. cit., ch. 5, p. 1

${ }^{25}$ Ibid., p. 3.

${ }^{26}$ Ibid., p. 1

${ }^{27}$ lbid., p. 4
}

characterized by bronchitis, rhinitis, sinusitis, pharyngitis, and/or laryngitis. These irritations are caused by mechanical injury to the skin and mucous membranes by small glass fibers and are "considered to be transitory since symptoms disappear without treatment when exposure to fiberglass is ended." ${ }^{30}$

As there is a failly well-established link between asbestos and several types of cancer, ${ }^{31} a$ number of researchers have been attempting

${ }^{28} /$ bid.

29 I bid., pp. 4-5.

“"Memorandum by Dr. Rita Orzel, Acting Director, Division of Human Toxicology and Pharmacology, Office of the Medical Director ${ }_{r}$ Consumer Product Safety Commission, Dec. 2,1976, p. 1.

1 Nat iona|Ca ricer Institute, Asbestos: $A n$ Information Resource, ed. by R. J. Levine, prepared by SRI International, Publication No. N I H 79-1681, May 1978, p, 1, 
to determine if other inorganic fibers act like a sbestos fibers in contributing to cancer. Studies of the relationship between fiberglass or rock wool and cancer have produced mixed results. Glass fibers surgically implanted in the lungs of rats have produced cancers, but the implantation process is artificial and does not allow the natural cleansing actions of the lung to remove the fibers. ${ }^{32}$ Several early studies found that workers in glass wool plants did not have any higher cancer rates than similar persons who did not work with fiberglass. ${ }^{33} \mathrm{To}$ date there is no evidence that fiberglass as normally manufactured and used is related to the occurrence of cancer in humans.

However, over the years, the average diameter of manufactured glass fibers has been decreasing. In the case of the implanted fibers, it is the small diameter fibers ( 0.5 to 5 microns) that have caused the most concern. ${ }^{34}$ In the 1930 's, the average fiber diameter of insulating rock and slag wool and fiberglass was $15 \mathrm{mi}-$ crons or more. Today, the average diameter is 6 microns with a fraction of the fibers falling below $3 .{ }^{35}$ Over the years, manufacturers have been changing the composition of the binders and lubricants coating the fibers, ${ }^{36}$ so the fiberglass handled by workers 30 years ago was not the same material that is manufactured today.

${ }^{32}$ M. F. Stanton, "Fiber Carcinogenesis: Is Asbestos the Only Hazard?" Journal of the National Cancer Institute, $51: 633-636$. Cited by J. Milne, "Are Glass Fibers Carcinogenic to Man? A Critical Appraisal, "British Journal of Industrial Medicine, 33:47.

${ }^{33}$ Criteria for a Recommended Standard. . Occupational Exposure to Fibrous Class, prepared by TabershawCooper Associates, Inc., Publication No. NIOSH-77-152 (National Institute for Occupational Safety and Health, April 1977), pp. 30-40.

${ }^{34} \mathrm{M}$. F. Stanton, "Some Etiological Considerations of Fiber Carcinogenesis," Biological Effects of Asbestos, Proceedings of a Working Conference, published by the International Agency for Research on Cancer, Lyon, France, IARC Scientific Publation No. 8, October 1972, ed. by P. Bogovski, et al., pp. 289-294 Cited by J. T.Maddock, et al., Small Fiber Inhalation, Publication No. AA I-238 3I2384-100-TR-2 (U.S. Consumer Product Safety Commission, December 1976), p. 9.

${ }^{35} \mathrm{~J}$. W. Hill, "Health Aspects of Man-Made Mineral Fibres, A Review," Ann. Occup.Hyg.,20:1 61-162 ${ }^{36}$ I bid., p. 162.
Because the latency period for cancer can be 20 to 50 years, there has been in sufficient time to assess fully the effects of exposure to small glass fibers and the newer resin systems. Several American studies are underway, but the results are not in. ${ }^{37}$

Until more studies and tests are completed, it seems prudent to minimize exposure to fiberglass, especially where small particles are prevalent. Areas calling for special care include:

- factories where fiberglass and fiberglass products are produced,

- handling during installation,

- a i $r$ ducts that could bring fiberglass particles into the house, and

- unwanted materials and debris from demolition or renovation of buildings.

\section{Cellulose}

Cellulose fiber appears to present no significant health problems. However, the borate salts that are used to impart flame retardancy to the shredded paper can be toxic if ingested. The estimated lethal dose is 15 to 20 grams for adults and 5 to 6 grams for infants; young infants are particularly susceptible. Acute borate exposure can affect the central nervous system and cause persistent vomiting and diarrhea, followed by profound shock and coma. Borate salts can be absorbed through the skin.

Investigators have so far determined cellulose dust to be a nuisance. That is, it does not have the potential to produce pathologic changes However, as the handling of cellulosic material can generate considerable amounts of dust, the user is advised to wear gloves, cover up, and wear a mask.

\footnotetext{
${ }^{37} \mathrm{M}$ Sloan, personal communication, January 1979.
} 


\section{Cellulose Plastics}

Polystyrene

According to the Consumer Product Safety Commission (CPSC), finished foam resins such as polystyrene generally do not produce adverse health effects. ${ }^{38}$ Although Sax classifies polystyrene as a "suspected carcinogen" when in the body, ${ }^{39}$ there appears to be no hazard from normal use.

\section{Polyurethane}

Polyurethane foam is an isocyanate-polyolresin blend to which flame-retardant chemicals are usually added. As the isocyanates are toxic, extreme caution must be exercised during application. Application must be performed by qualified persons using appropriate safety equipment such as goggles, gloves, head covers, and respirators.

It appears that the health hazards associated with polyurethane foam are in the handling, mixing, spraying, and other application procedures encountered in occupational situations. Sax classifies polyurethane as a "suspected carcinogen." ${ }^{\prime 40}$

\section{Urea-Formaldehyde}

Formaldehyde is a strong irritant. Exposure to its vapors can cause imitation of the mucous membranes of the eyes, nose, and upper respiratory tract. The level of initation is a function of the formaldeyhde concentration and of individual sensitivity. With increased concentrations, these irritations become more pronounced and tolerable for only a few minutes.

Repeated exposure may increase sensitivity to formaldehyde. Skin problems have also been reported after exposure to even small amounts in the air.

After the curing process, odor normally disappears, but it has been known to recur- in some cases persisting for 10 to 12 months. Some consumers have complained of formaldehyde released from wallboard, particle board, or fiberboard bonded with urea-formaldehyde resin. The continued odor has required that the wallboards be removed from the interiors of homes in some cases.

The safe application of this material requires a qualified person who knows how to handle, mix, and use the chemicals involved.

\section{Perlite and Vermiculite}

No potential health hazards have been associated with the use of perlite or vermiculite as an insulation material. A DOE study indicates that both are nontoxic and odorless."

\section{FIRE HAZARDS}

Data on the fire hazards associated with various insulation materials a re plentiful but sketchy. Most fire data identify only the first material ignited and do not indicate those instances where insulation may play a significant role in the growth of a fire started by another material.

\footnotetext{
${ }^{38}$ Memorandum by Dr. Rita Orzel, P. 3.

${ }^{39} \mathrm{~N} . \mathrm{I}$. Sax, Dangerous Properties of IndustrialMateri a/s, fourth cd., Van Nostrand Reinhold Co., 1975, pp. 1037-1038.

“"I bid., p. 1038.
}

\section{Fiberglass}

Fiberglass itself is considered nonflammable until subjected to very high temperatures. In flammability test procedures, however, flammable backing or vapor barrier materials are often not included. In the manufacturing of fiberglass, flammable oils and resins are introduced to reduce dust and solidify the insulation material. But often the flammability tests are performed on fiberglass that doesn't contain these organic materials. Additionally,

\footnotetext{
${ }^{4}$ An Assessment of Thermallnsulation Materials, o $\mathbf{p}$.
} cit., p 92. 
the absence of appropriate practices in the manufacture and installation of this material can increase the risk of fire and resulting smoke inhalation.

CPSC has discussed the potential flammability and organic burden of fiberglass insulation with representatives of Owens-Corning, Johns Manville, Certain Teed, and NBS and has concluded: ${ }^{42}$

1. Most paperbacking (foil and kraft) on the market today is flammable.

2. Most paperbacking is situated undemeath batts or blankets of fiberglass insulation and is unexposed to likely ignition sources. But NBS has indicated that if fiberglass is improperly installed (e.g., faceup in an attic space) or left exposed (e.g., in a garage beneath the second story of a house), it might be exposed to an ignition source.

3. There is currently no requirement to test fiberglass insulation with paperbacking intact. Some manufacturers do test fiberglass insulation with paperbacking intact and measure a higher flame spread than fiberglass insulation alone.

4. Phenolic binder, although combustible, does not promote flame spread in fiberglass insulation.

\section{Cellulose}

According to a petition filed by the Denver District Attorney's Consumer Office with CPSC, several fires have been observed and related to cellulosic insulation. Factors believed

\footnotetext{
“*Paul Lancer, U.S. Consumer Product Safety Commission, memorandum to Bernard Schwartz, CPSC, on "Home Insulation," Jan. 31,1977
}

by the petitioner to be related to the fires include: ${ }^{43}$

1. Poor quality control, which contributes to wide fluctuations in fire retardancy.

2. Inadequate knowledge about levels of fire retardancy necessary for proper protection.

3. Uncertainty about the permanency of the flame-retardant chemicals.

4. Certain fire retardants utilized and the extent to which sublimation and moisture affect the permanency of these fire retardants as the insulation ages.

5. Failure to add proper amounts of fire retardants at the manufacturing or installation stages, coupled with the absence of onsite testing.

6. Variance of flame spread requirements and, the lack of smoldering-resistance requirements.

7. Lack of uniform test methods, hence unsatisfactory flame spread and smoldering read ings.

This petition was rejected by CPSC on March 5,1979 .

Improper installation of cellulose insulation on or near electrical wiring, recessed lighting fixtures, attic furnaces, heating ducts, and other heat-bearing and heat-producing elements can cause fires. The absence of regulations by industry or Govemment is to be noted. There are no standard test methods used for determining the toxicity of combustible products.

\section{Other Materials}

Polystyrene and polyurethane foams are combustible; rock wool, vermiculite, and perlite are not.

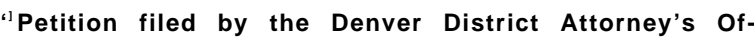
fice of Consumer Affairs with the U.S. Consumer Product Safety Commission, Oct. 8,1976, pp. 3-4
} 


\section{MATERIAL STANDARDS AND ENFORCEMENT}

Testimony before Congress, the Federal Trade Commission, and the CPSC has demonstrated a great need for new and improved materials standards and test procedures to ensure the efficacy, durability, and safety of residential insulation materials.

The General Services Administration (GSA) and the ASTM are the principal bodies responsible for the testing of insulation materials and the promulgation of materials standards. With one exception, however, these standards are not mandatory for residential insulation.

\section{GSA Standards and Specifications}

GSA sets standards and specifications for goods purchased directly by the Federal Govemment. This program encompasses 4,500 Federal specific ations and 1,500 standards. Included in this program are specifications for cellulosic or wood fiber loose-fill insulation $(\mathrm{HH}-\mathrm{I}-$ 515C), mineral fiber loose-fill insulation ( $\mathrm{H} \mathrm{H}-\mathrm{I}-1030)$, and mineral fiber blankets and batts ( $\mathrm{H} \mathrm{H}-\mathrm{I}-521$ ).

These specifications, however, do not have a direct application to thermal insulation purchased by consumers. They apply only to Federal procurement of thermal insulation for Government-owned buildings, etc. Nevertheless, it is the practice of many manufacturers of insulation for residential use to claim that their products meet current GSA specifications. There is no enforcement mechanism to discourage false claims.

GSA began in 1976 to upgrade its insulation specifications. In November 1977 it issued its proposed new standards for insulation purchased by the Federal Govemment.

Some of the most important changes proposed by GSA were contained in its proposed specifications for loose-fill cellulose insulation $(\mathrm{H} \mathrm{H}-\mathrm{I}-515 \mathrm{D})$. For example, the new specifications include a requirement conceming fungal growth, as it is now recognized "that this condition could cause the degrading of the thermal properties of the insulation by destroying the structure of the fibers. It could provide a source of fungal spores which might penetrate the living area and cause health problems. It could increase the corrosive action of the insulation material through the accumulation of metabolic products." ${ }^{\prime 4}$

Other changes include a requirement that all "cellulose tests be conducted at the product's settled density, i.e., the density of the product that would be expected to be found in the field sometime after installation." ${ }^{45}$ Th is would eliminate the current practice of some cellulose manufacturers of having their products tested at an arbitrary density to enhance their chances of passing the corrosion test or to obtain a better fire safety test result. The new standard for cellulose also includes a smoldering test that is not included in the $\mathrm{HH}$ 1-515C specifications. This test is to determine whether cellulose will continue to smolder beyond the area of an initial heat source, such as a hot electrical wire or a recessed lighting fixture.

Further revisions to the existing $\mathrm{HH}-\mathrm{I}-515 \mathrm{C}$ specifications for cellulose insulation include new tests for flammability. The GSA based its decision to switch to a radiant panel flammability test and to adopt a smoldering test on a number of factors:

1. The poor relationship between the Steinen tunnel flammability test and an actual attic situation.

2 Failure of the Steinen tunnel test to address a small open flame or a smoldering ignition source.

3 Unsuitability of the Steinen tunnel test for low-density materials such as cellulose.

4 NBS fire data that demonstrate that covered electrical or heating devices or wiring hot spots may cause ignition of exposed insulation, factors which are not simulated in the Steinen tunnel test.

\footnotetext{
${ }^{44}$ U.S. Congress, House Committee on Interstate and Foreign Commerce, Subcommittee on Oversight and Investigations, Home Insulation, 95th Cong., 2d sess., Apr. 26, 1978, p. 24.

"Ib Id,
} 
DOE estimates that while 80 percent of the manufacturers can pass the existing GSA C specifications, perhaps only 10 to 30 percent can pass the new version. The president of the Society for the Intemational Cellulose Insulation Manufacturers (SICIM) disagrees. It was reported that most of the SICIM member companies recently passed both the radiant panel and smoldering tests performed by Certified Laboratories of Dalton, Ga. However, these tests appear to be silent on the manufacturers' ability to meet the $D$ standard if the fire-retardant formulae were changed. ${ }^{46}$

In J une 1978, GSA issued the new HH-I-515D specifications for loose-fill cellulose insulation. They reflect only slight alterations to the originally proposed specifications. The proposed specifications for mineral wool, which include similar testing requirements, have been resubmitted for additional comments.

\section{Enforcement of GSA Standard $\mathrm{HH}-\mathrm{I}-515 \mathrm{C}$ for Residential Application}

As discussed earlier, there are almost no mandatory performance standards for residential insulation. One exception, however, applies to the most recent enforcement of the " $C$ " standard for cellulose insulation.

The Interim Consumer Product Safety Rule Act of 1978, which establishes an interim consumer product safety standard, went into effect September 8, 1978. Under this Act, CPSC will adopt the requirements for flame resistance and corrosiveness as set forth in GSA's $\mathrm{HH}-\mathrm{I}-515 \mathrm{C}$ specifications for cellulose insulation. The " $C$ " standard is to be enforced in the same manner as any other consumer product safety standard.

Accordingly, any cellulose insulation material that is produced or distributed for sale to the consumer is to have a flame spread rating of 1 to 25 , as such rating is set forth in GSA's specification HH-I-515C. Each manufacturer or private labeler of cellulose insulation is required to include on any container of cellulose insulation a statement indicating that

“Ibid., pp. 25-26 the material meets the applicable minimum Federal flammability standard. The statement must also indicate that the standard is based on laboratory tests that do not reflect actual conditions in the home.

Until a final consumer product safety standard takes effect, CPSC will incomorate into the interim safety standard for cellulose insulation each revision superseding the requirements for flame resistance and corrosiveness as promulgated by GSA.

The adoption of the " $\mathrm{C}$ " standard by CPSC thus marks the first federally supported initiative to protect the consumer against various hazards associated with cellulose insulation. At this writing, however, it is diffic ult to determine whether other thermal insulation materials will be covered by the Interim Consumer Safety Rule Act of 1978.

\section{Problem Areas in Materials Testing and Standards}

One of the major bodies responsible for the development of materials testing and standards is ASTM Committee C16 on Thermal and Cryogenic Insulation Materials. The committee was established by the American Manufacturing Industry about 40 years ago. The development of ASTM standards is based on "consensus" documents, which reflect the views of the "manufacturer," "user," and "general interest members. "After a standard is produced, it is usually reviewed every 5 years and revised as current technology and knowledge dictates. One criticism of this process is that the gestation period for a standard is at times too long.

Many testing methods are currently being revised or discarded in light of the critical problems now appearing. Given the number and variety of testing methods and standards, only general comments will be offered in this discussion.

Although a number of adequate testing methods do exist for determining the mechanical, thermal, and physical performance characteristics of a material under laboratory conditions, there is an immediate need for the extension of this knowledge to real life condi- 
tions and for complete systems. That is, the interrelationships between materials and overall system performance must be investigated.

The development of new test methods or technical revisions to existing methods is lengthy and expensive and until recently has been beyond the means of any organization outside of the major manufacturers and Govemment bodies. Given the existence of new testing needs, it is argued by some that increases in public funding will be necessary to support the level of effort that is needed in a short time ( 5 to 10 years), and to develop test methods that can be used in actual field conditions.

Another problem has been the absence of a general set of testing procedures that pertain to all materials. As is often the case, materials are compared with each other based on the results of different test methods used to evaluate their properties. It becomes important, therefore, that material standards contain the correct and relevant test methods and specific a tions.

Two of the immediate concems about materials testing are the adequacy of organizations currently available to undertake the volume of testing and evaluation that will be required in the future, and the reliability of the results that such organizations can obtain. There appears to be great dissatisfaction in the insulation field over these factors.

Widely divergent claims are made about material properties, such as thermal performance. In some cases, it has been found that such claims are made with no physical basis. In general, however, the common view is that the test methods are not at fault; rather, some organizations make unsubstantiated performance claims. Moreover, equipment or apparatus for testing has been designed that does not meet specified guidelines. I $\mathrm{n}$ other cases, the testing technique employed is often not the appropriate technique for the material. In view of these concems, the $\mathrm{Cl} 6$ Committee in mid-1 976 recommended to the Department of Commerce that a voluntary laboratory accreditation program be established in order to resolve some of the current problems of materials testing and standards. 
Appendix B

\section{Thermal Characteristics of Single-Family \\ Detached, Single-Family Attached, Low-Rise \\ Multifamily, and Mobile Homes-1975-76}

by the National Association of Home Builders

Research Foundation, Inc., October 1977

\section{INTRODUCTION}

This report contains information on thermal characteristics of single-family detached, attached, and multifamily homes built in the last half of 1975 and the first half of 1976 and of mobile home units built July 1976 through June 1977.

\section{Scope and Method}

In the last half of 1976, the National Association of Home Builders (NAHB) Research Foundation conducted a survey of the builder members of NAHB to determine construction practices for homes and apartments built in 1975 and 1976. Included in the survey were questions on general characteristics, thermal characteristics, and specific material use practices. Data were summarized by nine (9) census regions. Responses by building type was as follows:

\author{
Building Type \\ Single-family detached \\ Single-family attached \\ Low-rise multifamily
}

In addition, a survey of mobile home thermal and general characteristics was conducted in the summer of 1977. Response was received for almost 175,000 units, two-thirds of which were "single-wide" units and one-third "double-wide" units. This represented about 60 percent of all mobile home units built during that period.

\section{5-76 SINGLE-FAMILY DETACHED UNITS}

This section contains characteristics of almost 113,000 single-family detached homes built in 1975-76, summarized by nine census regions.
Included are tables which show national use of insulation by house price and size. 
Single-Farnily Detached Housing Units

\begin{tabular}{|c|c|c|c|c|c|c|c|c|c|}
\hline New & Mid- & $\begin{array}{l}\text { East } \\
\text { North }\end{array}$ & $\begin{array}{l}\text { West } \\
\text { North }\end{array}$ & Sol & $\begin{array}{c}\text { East } \\
\text { south }\end{array}$ & $\begin{array}{l}\text { West } \\
\text { South }\end{array}$ & & & U. S. \\
\hline land & Atlantic & Central & Central & Atlantic & Central & Central & Mountain & $P a c i f i c$ & Total \\
\hline
\end{tabular}

1. Number of Stories (\% by region)

$\begin{array}{lr}\text { One story } & 35 \\ \text { Two story } & 31 \\ \text { Bi-level } & 30 \\ \text { Split level } & 4\end{array}$

34
37
21

$\begin{array}{ll}41 & 46 \\ 29 & 12 \\ 14 & 28 \\ 16 & 14\end{array}$

$\begin{array}{rr}70 & 6 \\ 16 & 1 \\ 7 & 1 \\ 7 & \end{array}$

66
13
13
8

87
11
1
1

59
11
16
14

62
21
9
8

59.4

19.6

12.2
8.8

2. Foundation Type (\% by region)

\section{Basement}

Partial basement

Crawl space

67
29
2
2

68
16
8
8

$\begin{array}{lr}53 & 81 \\ 21 & 15 \\ 11 & 2 \\ 15 & 2\end{array}$

21
9
26
44

31
9
18
42

1
1
4
94

37
16
7
40

12
8
38
42

33.0

11.0

15.0

3. Floor Area By Type (averages by region)

$\begin{array}{lllllllllll}\text { One story } & 1,280 & 1,420 & \mathbf{1 , 5 0 0} & 1,490 & 1,515 & 1,510 & 1,510 & 1,510 & 1,500 & 1,499 \\ \text { Two story } & \mathbf{2 , 0 1 0} & \mathbf{2 , 1 0 0} & \mathbf{2 , 1 1 0} & 2,110 & 2,120 & 2,130 & 2,115 & 2,110 & 2,110 & 2,105 \\ \text { BI-level } & 1,710 & 1,685 & 1,660 & 1,680 & 1,690 & 1,710 & 1,695 & 1,708 & 1,720 & 1,691 \\ \text { Split level } & 1,860 & 1,820 & 1,860 & 1,850 & 1,840 & 1,860 & 1,840 & 1,840 & 1,870 & 1,850 \\ \text { Overall average } & 1,658 & 1,760 & 1,757 & 1,667 & 1,647 & 1,645 & 1,582 & 1,654 & 1,678 & 1,672\end{array}$

4. Average Selling Price (averages by region) (Including lot)

\begin{tabular}{|c|c|c|c|c|c|c|c|c|c|c|}
\hline $\begin{array}{l}\text { One story } \\
\text { Two story } \\
\text { Bi-level } \\
\text { Split level } \\
\text { Overall average }\end{array}$ & $\begin{array}{l}39,800 \\
58,300 \\
44,000 \\
49,400 \\
47,179\end{array}$ & $\begin{array}{l}41,500 \\
60,100 \\
44,900 \\
48,700\end{array}$ & $\begin{array}{l}41,200 \\
61,300 \\
45,100 \\
52,700\end{array}$ & $\begin{array}{l}41,300 \\
60,500 \\
45,500 \\
52,200\end{array}$ & $\begin{array}{l}40,600 \\
60,800 \\
45,800 \\
51,900\end{array}$ & $\begin{array}{l}40,900 \\
61,200 \\
45,700 \\
52,600\end{array}$ & $\begin{array}{l}40,900 \\
61,100 \\
45,400 \\
51,700\end{array}$ & $\begin{array}{l}40,600 \\
61,000 \\
45,300 \\
51,200\end{array}$ & $\begin{array}{l}40,300 \\
60,600 \\
45,300 \\
51,300\end{array}$ & $\begin{array}{l}40,803 \\
60,637 \\
45,139 \\
51,615\end{array}$ \\
\hline
\end{tabular}

5. Price Per Square Foot (averages by region)

\begin{tabular}{|c|c|c|c|c|c|c|c|c|c|c|}
\hline $\begin{array}{l}\text { One story } \\
\text { Two story } \\
\text { Bi-level } \\
\text { Split level } \\
\text { All houses }\end{array}$ & $\begin{array}{l}31.1 \\
29.0 \\
25.7 \\
26.6 \\
28.5\end{array}$ & $\begin{array}{l}29.2 \\
28.6 \\
26.6 \\
26.8 \\
28.2\end{array}$ & $\begin{array}{l}27,5 \\
29.1 \\
27,2 \\
28.3 \\
28.1\end{array}$ & $\begin{array}{l}27.7 \\
28.7 \\
27.1 \\
28.2 \\
27.8\end{array}$ & $\begin{array}{l}26.8 \\
28.7 \\
27.1 \\
28.2 \\
27.3\end{array}$ & $\begin{array}{l}27.1 \\
28.7 \\
26.7 \\
28.3 \\
27.4\end{array}$ & $\begin{array}{l}27.1 \\
28.9 \\
26.8 \\
28.1 \\
27.4\end{array}$ & $\begin{array}{l}26.9 \\
28.9 \\
26.5 \\
27.8 \\
27.3\end{array}$ & $\begin{array}{l}26.9 \\
28.7 \\
26.3 \\
27.4 \\
27.3\end{array}$ & $\begin{array}{l}27.2 \\
28.8 \\
26.7 \\
27.9 \\
27.6\end{array}$ \\
\hline
\end{tabular}


1975-76 HOUSING CHARACTERISTICS

Single-Family Detached Housing Units

\begin{tabular}{|c|c|c|c|c|c|c|c|c|c|}
\hline $\begin{array}{l}\text { New } \\
\text { ingland }\end{array}$ & $\begin{array}{c}\text { Mid- } \\
\text { Atlantic }\end{array}$ & $\begin{array}{c}\text { East } \\
\text { North } \\
\text { Central }\end{array}$ & $\begin{array}{c}\text { West } \\
\text { North } \\
\text { Central }\end{array}$ & $\begin{array}{c}\text { South } \\
\text { Atlantic }\end{array}$ & $\begin{array}{c}\text { East } \\
\text { South } \\
\text { Central }\end{array}$ & $\begin{array}{c}\text { West } \\
\text { South } \\
\text { Central }\end{array}$ & Mountain & Pacific & $\begin{array}{r}\text { U.S. } \\
\text { Total }\end{array}$ \\
\hline
\end{tabular}

6. Size In Increments of

200 SF-\% By Region

$$
\begin{aligned}
& \text { Less than } 800 \\
& 800-999 \\
& 1000-1199 \\
& 1200-1399 \\
& 1400-1599 \\
& 1600-1799 \\
& 1800-1999 \\
& 2000-2199 \\
& 2200-2399 \\
& 2400-2599 \\
& 2600-2799 \\
& 2800 \text { and more }
\end{aligned}
$$

$\begin{array}{rrrr}0.1 & 0 & 0.1 & 0 \\ 8.4 & 3.4 & 0.8 & 8.9 \\ 21.4 & 10.7 & 10.3 & 17.6 \\ 12.7 & 17.6 & 15.9 & 15.4 \\ 3.8 & 10.4 & 15.0 & 20.2 \\ 11.5 & 13.2 & 19.5 & 8.7 \\ 8.7 & 15.3 & 14.7 & 8.9 \\ 11.7 & 12.9 & 9.3 & 6.6 \\ 9.2 & 5.9 & 5.3 & 6.5 \\ 5.8 & 4.8 & 4.0 & 4.3 \\ 1.6 & 1.9 & 2.5 & 0.8 \\ 5.1 & 3.9 & 2.6 & 2.1\end{array}$

0
0.7
10.9
25.9
20.5
11.7
12.1
6.3
4.3
3.8
1.5
2.3

0
0
13.8
20.7
18.5
15.5
12.3
6.4
4.0
3.7
1.1
4.0

0.1

$0.1-0$

2.0

2.5
13.9

0
0.4 $\begin{array}{lll}13.4 & 21.0 \quad 12.3\end{array}$

12.3
22.6

$44.8 \quad 11.8 \quad 13.9$

10.3

9.2

13.9

15.0
10.9

9.0

$5.3 \quad 11.2$

5.1

$\begin{array}{ll}3.4 & 5.1 \\ 1.1 & 2.6\end{array}$

4.0

otal

7. Insulation ( $\%$ by region)

\section{Exterior Wall}

None
Less than $R-7$
R-7
R-n
R-13
R-19
Other

0
0
0.4
58.2
35.6
4.5
1.3

$\begin{array}{rrr}0 & 0 & 0 \\ 0 & 0 & 0 \\ 0.5 & 0 & 0 \\ 73.0 & 61.1 & 63.8 \\ 21.7 & 33.7 & 32.5 \\ 4.0 & 3.4 & 3.4 \\ 0.8 & 1.8 & 0.3\end{array}$

$\begin{array}{rrr}0.6 & 0 & 0 \\ 8.0 & 0 & 0 \\ 0.9 & 0.3 & 0.2 \\ 69.3 & 64.5 & 77.8 \\ 18.6 & 30.0 & 15.5 \\ 2.1 & 4.6 & 5.9 \\ 0.5 & 0.6 & 0.6\end{array}$

0.2
2.0
8.7
62.8
22.1
2.6
0

$\begin{array}{rr}0.2 & 0.2 \\ 0 & 1.4 \\ 0.4 & 1.1 \\ 87.5 & 71.0 \\ 8.9 & 21.8 \\ 3.0 & 3.5 \\ 0 & 1.0\end{array}$


1975-76 HOUSING CHARACTERISTICS

Single-Family Detached Housing Units

\begin{tabular}{|c|c|c|c|c|c|c|c|c|c|}
\hline $\begin{array}{l}\text { New } \\
\text { ngland }\end{array}$ & $\begin{array}{c}\text { Mid- } \\
\text { Atlantic }\end{array}$ & $\begin{array}{c}\text { East } \\
\text { North } \\
\text { Central }\end{array}$ & $\begin{array}{c}\text { West } \\
\text { North } \\
\text { Central }\end{array}$ & $\begin{array}{c}\text { South } \\
\text { Atlantic }\end{array}$ & $\begin{array}{c}\text { East } \\
\text { South } \\
\text { Central }\end{array}$ & $\begin{array}{l}\text { West } \\
\text { South } \\
\text { Central }\end{array}$ & Mountain & Pacific & $\begin{array}{l}\text { Us. } \\
\text { Total }\end{array}$ \\
\hline
\end{tabular}

7. (continued)

Ceiling

None
R-7
R-11
R-13
R-19
R-22
R-25
R-26
R-30
R-31
More than R-31
Other

$\begin{array}{rrr}0.1 & 0 & 0.6 \\ 0 & 0.7 & 0.4 \\ 7.0 & 11.6 & 4.1 \\ 24.1 & 7.8 & 30.6 \\ 52.7 & 46.7 & 28.4 \\ 8.1 & 14.2 & 25.3 \\ 0 & 1.3 & 2.5 \\ 2.5 & 0 & 0.3 \\ 0.1 & 5.6 & 2.0 \\ 0.2 & 1.1 & 0.9 \\ 4.4 & 4.4 & 3.5 \\ 0.2 & 6.6 & 1.4\end{array}$

$\begin{array}{rr}\mathbf{0 . 6} & 1.4 \\ \mathbf{0 . 4} & 3.8 \\ \mathbf{2 . 6} & 6.0 \\ 25.7 & 23.6 \\ 23.3 & 51.1 \\ 22.8 & 5.3 \\ 8.6 & 1.6 \\ 0 & 1.0 \\ 3.6 & 3.0 \\ 2.3 & 0 \\ 4.2 & 0.7 \\ 3.7 & 1.9\end{array}$

$\begin{array}{rr}1.3 & u \\ 0.6 & 0.3 \\ 3.6 & 2.7 \\ 25.6 & 20.7 \\ 42.6 & 59.5 \\ 17.0 & 6.8 \\ 4.5 & 1.3 \\ 0.4 & 0.3 \\ 0.4 & 3.8 \\ 1.3 & 0 \\ 1.5 & 2.4 \\ 1.1 & 1.2\end{array}$

$\begin{array}{rrr}5.6 & 0.7 & 1.0 \\ 0.4 & 0.3 & 1.0 \\ 0.3 & 2.5 & 4.4 \\ 13.4 & 12.6 & 20.4 \\ 42.8 & 80.9 & 50.0 \\ 22.9 & 0.9 & 12.3 \\ 1.0 & 0 & 2.0 \\ 0.2 & 0 & 0.5 \\ 20.3 & 0.8 & 4.0 \\ 1.1 & 0.3 & 0.6 \\ 1.9 & 0.4 & 2.2 \\ 0.1 & 0.4 & 1.8\end{array}$

Between Floor Joists (\% of all houses)

\begin{tabular}{|c|c|c|c|c|c|c|c|c|c|c|c|c|}
\hline $\begin{array}{l}\text { None } \\
2-1 / 4^{\prime \prime} \\
3-1 / 2^{\prime \prime} \\
3-5 / 8^{\prime \prime} \\
6^{\prime \prime} \\
0 \text { ther }\end{array}$ & $\begin{array}{l}\text { batts } \\
\text { "1 } \\
\text { " }\end{array}$ & $\begin{array}{l}R-7 \\
R-11 \\
R-13 \\
R-19\end{array}$ & $\begin{array}{r}63.0 \\
0.9 \\
16.5 \\
9.3 \\
10.3 \\
0\end{array}$ & $\begin{array}{r}51.0 \\
1.7 \\
32.9 \\
5.8 \\
6.7 \\
1.9\end{array}$ & $\begin{array}{r}63.1 \\
1.9 \\
18.5 \\
6.5 \\
8.9 \\
1.3\end{array}$ & $\begin{array}{r}65.7 \\
1.1 \\
14.3 \\
7.7 \\
11.2 \\
.0\end{array}$ & $\begin{array}{r}75.0 \\
1.8 \\
16.8 \\
2.5 \\
3.6 \\
0.3\end{array}$ & $\begin{array}{r}75.7 \\
4.4 \\
11.5 \\
4.3 \\
4.1 \\
0\end{array}$ & $\begin{array}{r}99.1 \\
0.1 \\
0.4 \\
0.1 \\
0.3 \\
0\end{array}$ & $\begin{array}{r}88.3 \\
0.4 \\
4.1 \\
0.9 \\
6.2 \\
0.1\end{array}$ & $\begin{array}{r}88.9 \\
1.1 \\
7.3 \\
0.3 \\
1.3 \\
1.1\end{array}$ & $\begin{array}{r}80.1 \\
1.4 \\
11.2 \\
2.6 \\
4.2 \\
0.5\end{array}$ \\
\hline
\end{tabular}


1975-76 HOUSING CHARACTERISTICS

Single-Family Detached Housing Units

\begin{tabular}{ccccc} 
New & Mast & West & Wast & West \\
England & North & North & South South South & U.S. \\
\hline
\end{tabular}

7. (continued)

Crawl Space Walls ( $\%$ of all houses)

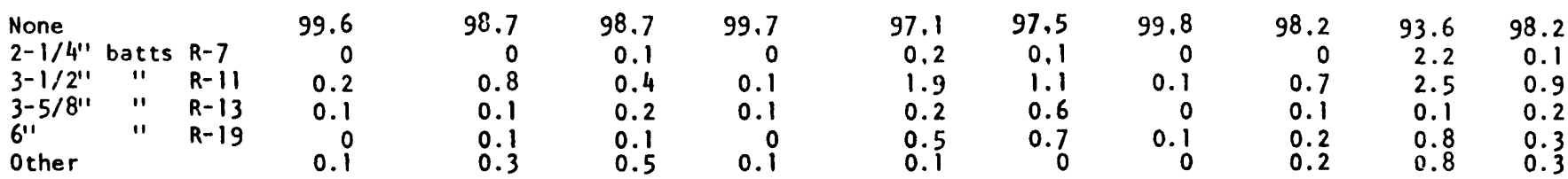

Basement Walls ( $\%$ of all houses)

\begin{tabular}{|c|c|c|c|c|c|c|c|c|c|c|c|}
\hline $\begin{array}{l}\text { None } \\
2-1 / 4^{\prime \prime} \text { batts } \\
3-1 / 2^{\prime \prime} \quad 11 \\
3-5 / 8^{\prime \prime} \quad 11 \\
6^{\prime \prime} \\
\text { Other }\end{array}$ & $\begin{array}{l}R-7 \\
R-11 \\
R-13 \\
R-19\end{array}$ & $\begin{array}{r}87.0 \\
0.1 \\
7.3 \\
4.7 \\
0.1 \\
0.8\end{array}$ & $\begin{array}{l}93.5 \\
1.7 \\
3.1 \\
0.6 \\
0.2 \\
0.9\end{array}$ & $\begin{array}{r}93.0 \\
0.7 \\
1.5 \\
0.6 \\
0 \\
1.8\end{array}$ & $\begin{array}{r}81.8 \\
4.4 \\
6.4 \\
1.3 \\
1.2 \\
4.9\end{array}$ & $\begin{array}{r}97.4 \\
0.2 \\
1.4 \\
0.2 \\
0.2 \\
0.6\end{array}$ & $\begin{array}{l}95.1 \\
1.7 \\
1.2 \\
1.2 \\
0.3 \\
0.5\end{array}$ & $\begin{array}{r}99.8 \\
0 \\
0.1 \\
0 \\
0.1 \\
0\end{array}$ & $\begin{array}{r}93.9 \\
0.8 \\
3.3 \\
0 \\
0.1 \\
1.9\end{array}$ & $\begin{array}{r}97.7 \\
0.1 \\
1.9 \\
0 \\
0.1 \\
0.2\end{array}$ & $\begin{array}{l}96.0 \\
0.6 \\
2.0 \\
0.4 \\
0.2 \\
0.8\end{array}$ \\
\hline $\begin{array}{l}\text { No change } \\
\text { Increased } \\
\text { Decreased }\end{array}$ & & $\begin{array}{r}58.5 \\
40.8 \\
0.7\end{array}$ & $\begin{array}{r}52.8 \\
47.1 \\
0.1\end{array}$ & $\begin{array}{r}48.6 \\
51.4 \\
0\end{array}$ & $\begin{array}{r}46.1 \\
53.9 \\
0\end{array}$ & $\begin{array}{r}53.5 \\
46.4 \\
0.1\end{array}$ & $\begin{array}{r}47.3 \\
52.7 \\
0\end{array}$ & $\begin{array}{r}62.1 \\
37.6 \\
0.3\end{array}$ & $\begin{array}{r}39.5 \\
60.5 \\
0\end{array}$ & $\begin{array}{r}62.0 \\
38.0 \\
0\end{array}$ & $\begin{array}{r}53.8 \\
46.0 \\
0.2\end{array}$ \\
\hline
\end{tabular}

Slab-on-grade Perimeter (\% of all houses)

\begin{tabular}{|c|c|c|c|c|c|c|c|c|c|c|}
\hline $\begin{array}{l}\text { None } \\
\text { l" rigid } \\
2^{\prime \prime} \text { rigld } \\
\text { Other }\end{array}$ & $\begin{array}{c}99.3 \\
0.4 \\
0.2 \\
0.1\end{array}$ & $\begin{array}{r}96.7 \\
2.6 \\
0.7 \\
0\end{array}$ & $\begin{array}{r}92.6 \\
5.1 \\
2.2 \\
0.1\end{array}$ & $\begin{array}{r}99.3 \\
0.6 \\
0.1 \\
0\end{array}$ & $\begin{array}{r}86.3 \\
11.0 \\
2.3 \\
0.4\end{array}$ & $\begin{array}{r}88.8 \\
9.3 \\
1.3 \\
0.6\end{array}$ & $\begin{array}{r}89.0 \\
9.1 \\
0.9 \\
1.0\end{array}$ & $\begin{array}{r}93.3 \\
6.1 \\
0.1 \\
0.5\end{array}$ & $\begin{array}{r}91.9 \\
2.6 \\
0.8 \\
0\end{array}$ & $\begin{array}{r}89.3 \\
8.3 \\
2.1 \\
0.3\end{array}$ \\
\hline
\end{tabular}


1975-76 HOUSING CHARACTERISTICS

Single-Family Detached Housing Units

\begin{tabular}{|c|c|c|c|c|c|c|c|c|c|}
\hline $\begin{array}{c}\text { New } \\
\text { England }\end{array}$ & $\begin{array}{c}\text { Mid- } \\
\text { Atlantic }\end{array}$ & $\begin{array}{c}\text { East } \\
\text { North } \\
\text { Central }\end{array}$ & $\begin{array}{c}\text { West } \\
\text { North } \\
\text { Central }\end{array}$ & $\begin{array}{c}\text { South } \\
\text { Atlantic }\end{array}$ & $\begin{array}{c}\text { East } \\
\text { South } \\
\text { Central }\end{array}$ & $\begin{array}{l}\text { West } \\
\text { South } \\
\text { Central }\end{array}$ & Mountain & Pacific & $\begin{array}{l}\text { US. } \\
\text { Total }\end{array}$ \\
\hline
\end{tabular}

8. Heating/Cooling

$\%$ by Type

by Region

Heating Equipment

Gas warm air
Electric warm air
Oil warm air
Gas hot water
Oil hot water
Heat pump
Elec.baseboard
or radiant
ceiling
Solar

$\begin{array}{rr}1 & 13 \\ 3 & 12 \\ 19 & 22 \\ 12 & 5 \\ 30 & 9 \\ 2 & 7\end{array}$

$\begin{array}{rrr}48 & 71 & 16 \\ 19 & 12 & 43 \\ 3 & 2 & 7 \\ 1 & 1 & 0 \\ 0 & 0 & 0 \\ 21 & 6 & 25\end{array}$

$\begin{array}{rr}29 & 34 \\ 0 & 57 \\ 0 & \\ 0 & \\ 29 & \end{array}$

$\begin{array}{rrrr}38 & 59 & 64 & 41 \\ 57 & 15 & 21 & 29 \\ 0 & 0 & 0 & 5 \\ 0 & 2 & 1 & 2 \\ 0 & 0 & 0 & 2 \\ 5 & 15 & 2 & 13\end{array}$

Heating Fuel

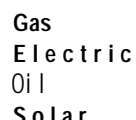

27
0

32
0

8

8
0

$$
\begin{aligned}
& 8 \\
& 0
\end{aligned}
$$

19
32
49
0

18
51
31
0

$\begin{array}{rr}49 & 72 \\ 48 & 26 \\ 3 & 2 \\ 0 & 0\end{array}$

$\begin{array}{rr}72 & 16 \\ 26 & 76 \\ 2 & 7 \\ 0 & 1\end{array}$

$\begin{array}{rr}29 & 38 \\ 71 & 62 \\ 0 & 0 \\ 0 & 0\end{array}$

$\begin{array}{rrr}61 & 65 & 43 \\ 39 & 35 & 50 \\ 0 & 0 & 7 \\ 0 & 0 & 0\end{array}$

Cooling Equipment

None
Central
Heat pump
Evaporative cooler
Window or wall

$\begin{array}{rrrrr}89.2 & 69.4 & 49.4 & 23.3 & 13.4 \\ 5.3 & 20.9 & 29.0 & 70.0 & 61.1 \\ 2.0 & 7.0 & 21.0 & 6.0 & 25.0 \\ 0 & 0 & 0 & 0.6 & 0.3 \\ 3.5 & 2.7 & 0.6 & 0.1 & 0.2\end{array}$

15.6
54.4
29.0
1.0

15.6
54.4
29.0
0
1.0

2.5
89.2
5.0
3.3
0

$\begin{array}{rrr}47.2 & 65.5 & 36.7 \\ 24.4 & 28.9 & 46.9 \\ 15.0 & 2.0 & 13.5 \\ 13.4 & 3.3 & 2.3 \\ 0 & 0.3 & 0.6\end{array}$


1975-76 HOUSING CHARACTERISTICS

Single-Family Detached Housing Units

$\begin{array}{cccccc}\text { New } & \text { Mid- } & \text { North } & \text { West } & \text { East } & \text { West } \\ \text { England } & \text { North } & \text { South } & \text { South } & \text { South } & \text { U.S. } \\ & \end{array}$

9. Window Glazing

$\%$ by Region

\begin{tabular}{|c|c|c|c|c|c|c|c|c|c|c|}
\hline Single & 37.6 & 26.6 & 5.8 & 14.3 & 58.8 & 49.6 & 80.2 & 22.6 & 76.0 & 44.0 \\
\hline Single w/storm & 25.3 & 21.6 & 27.2 & 40. 6 & 15.5 & 22.7 & 12.1 & 22.7 & 4.9 & 20.0 \\
\hline Insulating glass & 36.9 & 50.0 & 62.3 & 42. 2 & 25.6 & 26. 7 & 7. 7 & 53.9 & 18.6 & 35.0 \\
\hline Insul. w/storm & 0.2 & 1.7 & 4.8 & 2.9 & 0.1 & 0 & 0 & 0.8 & 0.5 & 1.0 \\
\hline
\end{tabular}

10. Vï ndow Square Feet

by Region

Single glaze
Si ngle W storm
Insul ating gl ass
Insul. W/ storm
Total s

$\begin{array}{rrr}81.7 & 47.8 & 7.5 \\ 55.0 & 38.7 & 42.0 \\ 80.3 & 89.8 & 104.9 \\ 0.5 & 3.1 & 8.2\end{array}$

23.4
66.9
71.0
4.9

105.4
25.8
44.8
0

$\begin{array}{rr}84.1 & 123.4 \\ 35.1 & 16.4 \\ 41.7 & 11.1 \\ 0 & 0\end{array}$

49. 7

152.8 $95.1 \quad 9.2$

217.5

179. 4

162.6

166. 2

176. 0

160.9

150. 9

1.2

11. Sl i di ng $\mathbf{G}$ ass Doors

SI i di ng glass doors

Number per uni $t$

0.88

1. 02

$\begin{array}{ll}0.88 & 0.93\end{array}$

0.89

0.68

0.84

1. 00

1.26

0.95

12. Exterior Doors (\% by region) (Entrance)

\begin{tabular}{|c|c|c|c|c|c|c|c|c|c|}
\hline $\begin{array}{l}\text { Not insulated } \\
\text { I nsul ated }\end{array}$ & $\begin{array}{l}41.0 \\
59.0\end{array}$ & $\begin{array}{l}16.1 \\
83.9\end{array}$ & $\begin{array}{l}23.1 \\
76.9\end{array}$ & $\begin{array}{l}46.1 \\
53.9\end{array}$ & $\begin{array}{l}69.6 \\
30.4\end{array}$ & $\begin{array}{l}69.2 \\
30.8\end{array}$ & $\begin{array}{l}78.8 \\
21.2\end{array}$ & $\begin{array}{l}56.5 \\
43.5\end{array}$ & $\begin{array}{l}89.4 \\
10.6\end{array}$ \\
\hline
\end{tabular}


13. I nsul ati on By Price and By Si ze

Exteri or WAI I Insul ation Pri ce Range

Less than $\$ 30,000$ $\$ 30,000-34,999$

35,000 - 399999

40,000 - 44, 999

45, 000- 49, 999

50,000 - 54, 999

55,000 - 59, 999

60,000 - 64, 999

$\$ 65,000$ and over

Single-Family Detached Housing Units

Ceiling Insulation

Price Range
Less than $\$ 30,000$
$\$ 30,000-34,999$
$35,000=39,999$
$40,000=44,999$
$45,000=49,999$
$50,000-54,999$
$55,000-59,999$
$60,000=64,999$
$\$ 65,000$ and over

\begin{tabular}{lll} 
None & $R 7$ & $R 11$ \\
& & \\
0.5 & 0.7 & 2.5 \\
1.1 & 0.3 & 6.0 \\
0.7 & 0.7 & 6.9 \\
1.6 & 0.5 & 4.3 \\
1.0 & 1.4 & 2.3 \\
1.1 & 3.4 & 2.2 \\
1.0 & 0.2 & 2.8 \\
1.0 & 0.3 & 3.6 \\
1.4 & 1.2 & 2.2 \\
\hline
\end{tabular}

\begin{tabular}{|c|c|c|}
\hline \multirow[b]{2}{*}{$\begin{array}{c}\text { Less } \\
\text { Than R7 }\end{array}$} & ion & \multirow[b]{2}{*}{ R11 } \\
\hline & R7 & \\
\hline 0.9 & 1.0 & 71.8 \\
\hline 0.9 & 3.6 & 76. 2 \\
\hline 3.3 & 0.2 & 67.0 \\
\hline 1.3 & 0.2 & 69.7 \\
\hline 1.0 & 0.3 & 70.0 \\
\hline 1.3 & 2.9 & 73. 3 \\
\hline 0.6 & 0.9 & 67.4 \\
\hline 0.9 & 0.6 & 72.4 \\
\hline 0.6 & 0.5 & 65.8 \\
\hline
\end{tabular}

\begin{tabular}{|c|c|c|}
\hline R13 & R19 & Other \\
\hline 22.6 & 2.3 & 0.6 \\
\hline 15.4 & 3.2 & 0.6 \\
\hline 24.0 & 3.1 & 2.4 \\
\hline 25.0 & 4.2 & 0.9 \\
\hline 23.5 & 3.7 & 0.7 \\
\hline 18.7 & 2.8 & 1.0 \\
\hline 28.1 & 2.1 & 0.5 \\
\hline 21.0 & 4.2 & 0.7 \\
\hline 27.0 & 5.4 & 0.5 \\
\hline
\end{tabular}

$\begin{array}{llrl}\text { R13 } & \text { R19 } & \text { R22 } & \text { R25 } \\ \text { 21.1 } & \mathbf{5 2 . 5} & 14.1 & 1.5 \\ \mathbf{1 8 . 8} & \mathbf{5 2 . 3} & 13.5 & 0.6 \\ 14.7 & \mathbf{4 7 . 9} & 17.1 & 1.9 \\ 20.1 & \mathbf{5 5 . 8} & \mathbf{8 . 8} & 1.7 \\ 16.1 & \mathbf{5 4 . 7} & 11.8 & 1.7 \\ 25.9 & 38.4 & 14.5 & 3.1 \\ 25.2 & 37.6 & 10.2 & 3.6 \\ 22.9 & 53.2 & 8.9 & 3.1 \\ 19.9 & 51.4 & 9.8 & 2.8\end{array}$

$R 26$
1.7
0.2
0.3
0.8
0.1
0
0.3
0.9
0.9

$\begin{array}{rr}\text { R30 } & \text { R31 } \\ 3.4 & 0 \\ 1.2 & 0.2 \\ 5.5 & 0.5 \\ 2.0 & 0.3 \\ 4.5 & 0.2 \\ 5.2 & 1.4 \\ 14.4 & 0.7 \\ 0.7 & 0.6 \\ 1.6 & 0.9\end{array}$

More Than

\begin{tabular}{lll} 
R31 & & Oher \\
\cline { 1 - 1 } 1.5 & & 0.5 \\
2.9 & & 2.9 \\
1.9 & & 1.9 \\
3.9 & & 0.2 \\
3.1 & & 3.1 \\
2.8 & & 2.0 \\
2.4 & & 1.6 \\
4.7 & & 0.1 \\
6.3 & & 1.6
\end{tabular}


Single-Family Detached Housing Units

13. ( cont i nued)

Exteri or Whl I Insul ation

$\begin{array}{lc}\text { Size Range (SF) } & \text { No: of Units } \\ \frac{1782}{11071} \\ \text { Less than } 1000 & 19082 \\ 1000-1199 & 17955 \\ 1200-1399 & 23559 \\ 1400-1599 & 13463 \\ 1600-1799 & 8490 \\ 1800-1999 & 6976 \\ 2000-2199 & 4478 \\ 2200-2399 & 1680 \\ 2400-2599 & 2986\end{array}$

$\begin{array}{ccc}\text { None } & & \begin{array}{c}\text { Less Inan } \\ R-7\end{array} \\ 0 & & 0.5 \\ 0.7 & & 1.0 \\ 0.1 & & 2.2 \\ 0.2 & 1.3 \\ 0 & 0.4 \\ 0 & 1.9 \\ 0.4 & 1.1 \\ 0 & 0.9 \\ 0.1 & 1.3 \\ 0 & 3.7 \\ 0.2 & 0.9\end{array}$

Insulation Percent

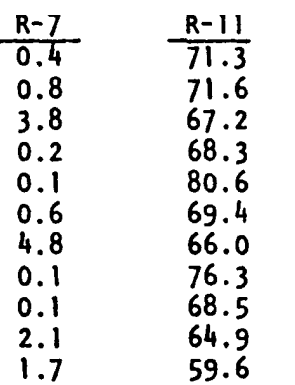

\begin{tabular}{l}
$R-13$ \\
\hline 25.1 \\
22.8 \\
22.0 \\
25.0 \\
15.1 \\
21.8 \\
24.1 \\
20.0 \\
24.9 \\
22.3 \\
31.7
\end{tabular}

\begin{tabular}{l} 
R- 19 \\
\hline 2.2 \\
2.2 \\
3.0 \\
4.0 \\
3.5 \\
4.7 \\
2.7 \\
2.0 \\
4.0 \\
4.0 \\
5.1
\end{tabular}

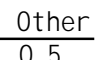

0.9

0.9
1.7

1.0

0.3

1.6

0.9

0.7

1.1

0.8

Ceiling insulation

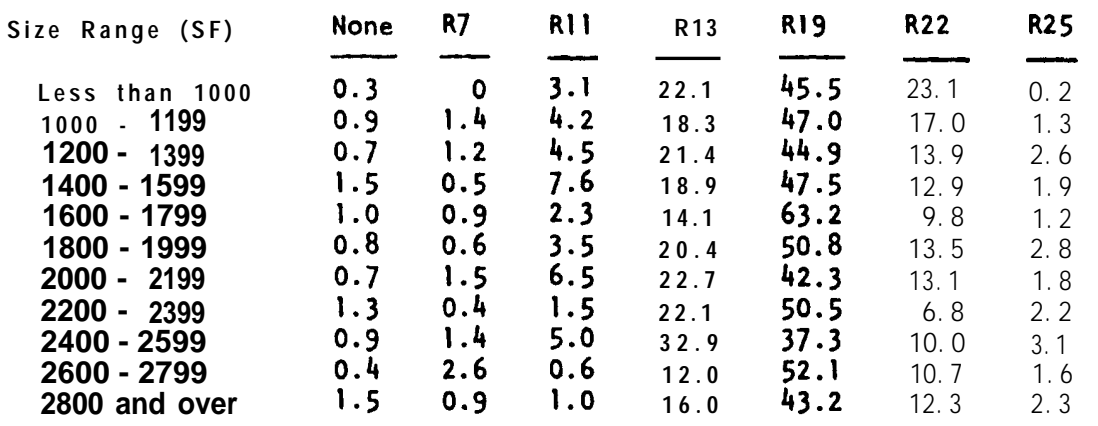

0.
0.
0.
0.
0.
0.1
0.2
0.3
0.9

\begin{tabular}{|c|c|c|c|}
\hline R30 & R31 & $\begin{array}{r}\text { More } \\
\text { Than } \\
\text { R31 }\end{array}$ & 0 ther \\
\hline 2.4 & 0.7 & 0.7 & 1.7 \\
\hline 3.8 & 0.8 & 2. 6 & 1.9 \\
\hline 6.0 & 0.5 & 2. 0 & 1.9 \\
\hline 2.3 & 0.6 & 3.6 & 2.1 \\
\hline 2.6 & 0.1 & 3.1 & 1.2 \\
\hline 2.9 & 0.7 & 2.9 & 1.9 \\
\hline 5.7 & 1. 2 & 1.8 & 2.5 \\
\hline 8.8 & 1.1 & 3.1 & 1.9 \\
\hline 2.7 & 0.9 & 4.0 & 0.9 \\
\hline 15.8 & 1.7 & 1.9 & 0.4 \\
\hline 13.8 & 0.1 & 6.4 & 0.1 \\
\hline
\end{tabular}


1975-76 SINGLE-FAMILY ATTACHED UNITS

This section contains data on al most 13,000 single-family attached housing units. 
1. Type of Unit - Percent

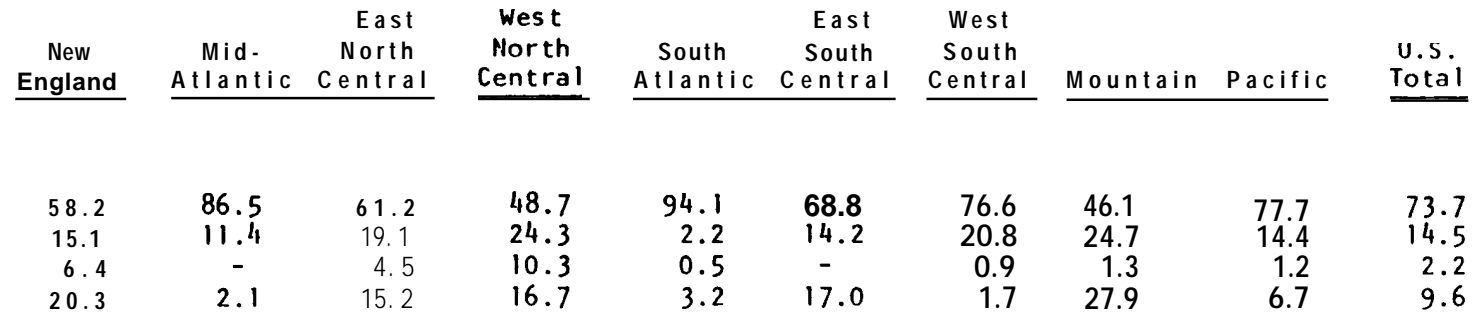

2. Foundation Types

$\%$ by Type by Region

Town Houses

Full Basement

Partial Basement

Crawl Space

Slab

0

57.0

0.7

61. 4

95.

$52.4 \quad 9.5$

23. 1

2.3
2.5
0

$\begin{array}{rr}32.6 & 12.0 \\ 1.1 & 0\end{array}$

Two Family Units

Full Basement

Partial Basement

Crawl Space

SIab

100.

$\begin{array}{lll}30.2 & 42.8 & 88.6\end{array}$

$\begin{array}{lll}1.3 & 6.7 & 2.2\end{array}$

36.9

2.2
6.7

$\begin{array}{rr}4.2 & 0.2 \\ 62.1 & 37.8\end{array}$

$\begin{array}{ll}0.9 & 34.5 \\ 4.4 & 4.3\end{array}$

4.3

$\begin{array}{ll}13.1 & 28.5\end{array}$

$6.7 \quad 29.9$

$0.7 \quad 1.6$

Three Family Units

Full Basement

Partial Basement

Crawl Space

Slab

11.1

88.;

35. 3

$\begin{array}{rr}0 & 0 \\ 0 & 0 \\ 11.1 & 13.6\end{array}$

0
0
13.6
36.4

0
0
0
100.0

26.4
6.4

55.4

Four Family Units

Basement

Partial Basement

Crawl Space

SIab

$\begin{array}{rrr}22.4 & 0 & 0 \\ 24.5 & 0 & 0 \\ 42.9 & 3.0 & 0 \\ 10.2 & 97.0 & 100.0\end{array}$

0
0
0
0

0
0
0
100.0

0
$76 . ;$
23.1

0
0
100.0
0

6.2

4.3

7.0

7.0
0
2.3

85.7

$\begin{array}{rr}1.8 & 95.1 \\ 7.2 & 0 \\ & 0 \\ 91 .: & 4.9\end{array}$

0
0
39.2
60.8

36.2

90.7

14.3

0
63.8

$\begin{array}{rr}0 & 23.0 \\ 0 & 0 \\ 0 & 71.7 \\ 100.0 & 5.3\end{array}$

0
0.5
13.7
85.8

24.5

1.1

21.7

52.6 


\begin{tabular}{|c|c|c|c|c|c|c|c|c|c|}
\hline $\begin{array}{c}\text { New } \\
\text { England }\end{array}$ & $\begin{array}{c}\text { Mid- } \\
\text { Atlantic }\end{array}$ & $\begin{array}{c}\text { East } \\
\text { North } \\
\text { Central }\end{array}$ & $\begin{array}{c}\text { West } \\
\text { North } \\
\text { Central }\end{array}$ & $\begin{array}{l}\text { South } \\
\text { Atlantic }\end{array}$ & $\begin{array}{c}\text { East } \\
\text { South } \\
\text { Central }\end{array}$ & $\begin{array}{l}\text { West } \\
\text { South } \\
\text { Central }\end{array}$ & Mountain & Pacific & $\begin{array}{c}\text { US. } \\
\text { Total }\end{array}$ \\
\hline
\end{tabular}

3. Number of Stories

$\%$ by Type by Region

Town Houses

One Story

Two Story

Three Story

More than 3

$\begin{array}{rrrr}10.8 & 15.6 & 11.5 & 32.5 \\ 59.5 & 83.2 & 86.1 & 38.6 \\ 29.7 & 1.2 & 2.4 & 26.8 \\ 0 & 0 & 0 & 2.1\end{array}$

32.5
38.6
26.8

64.

8.7
8.7

$21.4 \quad 17$.

6.4
9.2

$\begin{array}{lll}44.5 & 25.0 & 17.6\end{array}$

2.1

0.5

9.8
0

55.5

$\begin{array}{rr}7.8 & 7.6 \\ 0 & 7.6\end{array}$

Two Family Units

One Story

Two Story

Three Story

4. $7 \quad 6.0$

6.0
71.2
22.8

41. 0

51.5
22.4
26.1

18. 5
81. 5
0
0

36.1

36.1
10.7
53.2

$\begin{array}{rrrr}75.7 & 38.8 & 72.5 & 48.0 \\ 24.3 & 57.2 & 23.4 & 39.5 \\ 0 & 4.0 & 1.2 & 11.9 \\ 0 & 0 & 2.9 & 0.6\end{array}$

Three Family Units

One Story

Two Story

Three Story

More than 3

29.6
70.4
0

$\begin{array}{lll}49.0 & 47.5 & 100.0\end{array}$

0
0
0
0

0
0
0
0

85. 7

14. 3

$\begin{array}{rrr}76.9 & 27.3 & 47.5 \\ 23.1 & 72.7 & 52.5 \\ 0 & 0 & 0 \\ 0 & 0 & 0\end{array}$

Four Family Units

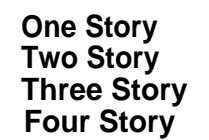

25.6
72.1
2.3
0

14.3
85.7
0
0

$\begin{array}{rr}4.8 & 92.7 \\ 95.2 & 7.3 \\ 0 & 0 \\ 0 & 0\end{array}$

$\begin{array}{rr}77.2 & 13.3 \\ 22.8 & 59.1 \\ 0 & 27.6 \\ 0 & 0\end{array}$

61. 5

$\begin{array}{rrr}36.0 & 34.2 & 38.4 \\ 59.0 & 65.8 & 57.7 \\ 5.0 & 0 & 3.9 \\ 0 & 0 & 0\end{array}$ 


\begin{tabular}{cccccc} 
New & Mid- & Nort & West & East & West \\
England & North & South & South & South \\
Atlantic Central & Central & Atlantic Central Central Mountain Pacific & Total \\
\hline
\end{tabular}

4. Finished Floor Area.

$\%$ by Region

Square Footage

Less than 800

800 - 999

$1000-1199$

$1200-1399$

1400- 1599

$1600-1799$

$1800-1999$

2000 - 2199

More than 2200

$\begin{array}{rr}1.9 & 7.9 \\ 10.8 & 3.4 \\ 2.7 & 2.5 \\ 54.2 & 30.1 \\ 19.9 & 45.7 \\ 2.8 & 9.0 \\ 7.1 & 0.9 \\ 0.6 & 0 \\ 0 & 0.4\end{array}$

$\begin{array}{rr}0.4 & 1.4 \\ 13.8 & 21.3 \\ 13.3 & 47.1 \\ 38.4 & 10.0 \\ 15.2 & 11.4 \\ 7.3 & 3.3 \\ 6.2 & 1.2 \\ 5.4 & 1.9 \\ 0 & 2.3\end{array}$

0
1.0
21.9
56.1
1.5
5.2
12.9
0.9
0.5

7.9

0
3.9
10.3
5.0
27.0
38.1
4.5
6.6
4.6

17.8
27.1
27.1
11.
5.8
4.8
6.4

$\begin{array}{rrr}0 & 2.0 & 2.0 \\ 17.8 & 7.2 & 8.3 \\ 27.1 & 5.9 & 14.3 \\ 27.1 & 36.2 & 33.8 \\ 11.0 & 19.2 & 18.8 \\ 5.8 & 17.1 & 11.8 \\ 4.8 & 9.6 & 7.2 \\ 6.4 & 2.0 & 2.6 \\ 0 & 0.8 & 1.2\end{array}$

5. Window Glazing

$$
\% \text { by Region }
$$

"Regular" Windows

single Glaze

Single w/Storm

Insulated Glass

Insul. w/Storm

$\begin{array}{ll}23.1 & 16.5 \\ 17.7 & 22.5\end{array}$

16.5
22.5
61.0

$\begin{array}{rr}0 & 22.1 \\ 46.4 & 27.8 \\ 53.0 & 48.4\end{array}$

22.1
27.8
48.4
1.7

$\begin{array}{rr}40.6 & 18.4 \\ \mathbf{4 5 . 9} & 79.5 \\ 13.5 & 2.1 \\ 0 & 0\end{array}$

70.1
0
29.9
0

28. 6

86

"Picture" Windows

Single Glaze

Single w/Storm

Insulated Glass

$28.9 \quad 30.4$

0.6

1. 7

30.4
30.2
39.4

0
34.1
65.9

25.3
30.6
44.1
0

$\begin{array}{rr}36.0 & 0 \\ 48.1 & 100.0 \\ 15.9 & 0 \\ 0 & 0\end{array}$

49.5
0
50.5
0

12.
51.
81.

$\begin{array}{rrr}12.8 & 81.6 & 43.2 \\ 5.6 & 3.2 & 21.8 \\ 81.6 & 15.2 & 35.0 \\ 0 & 0 & 0\end{array}$




\begin{tabular}{|c|c|c|c|c|c|c|c|c|c|}
\hline $\begin{array}{l}\text { New } \\
\text { England }\end{array}$ & $\begin{array}{c}\text { Mid- } \\
\text { Atlantic }\end{array}$ & $\begin{array}{c}\text { East } \\
\text { North } \\
\text { Central }\end{array}$ & $\begin{array}{c}\text { West } \\
\text { North } \\
\text { Central }\end{array}$ & $\begin{array}{l}\text { South } \\
\text { Atlantic }\end{array}$ & $\begin{array}{c}\text { East } \\
\text { South } \\
\text { Central }\end{array}$ & $\begin{array}{l}\text { West } \\
\text { South } \\
\text { Central }\end{array}$ & Mountain & Pacific & $\begin{array}{l}\text { U.s. } \\
\text { Total }\end{array}$ \\
\hline
\end{tabular}

6. V= ndow Square Feet

by Region

Single glaze
Single with storm
Insulated glass
Insul. with storm
Totals
Giding GIass Doors

$\begin{array}{rrrrrrrrrr}29.6 & 26.5 & 0 & 18.9 & 51.8 & 14.1 & 69.5 & 37.8 & 129.0 & 52.4 \\ 25.9 & 30.2 & 54.2 & 26.5 & 64.1 & 68.8 & 0 & 3.9 & 2.3 & 31.4 \\ 70.6 & 73.2 & 52.9 & 56.8 & 18.4 & 3.1 & 42.9 & 98.6 & 19.0 & 43.4 \\ 0 & 0 & 0.4 & 1.4 & 0 & 0 & 0 & 0 & 0 & 0.1 \\ 126.1 & 129.9 & 107.5 & 103.6 & 134.3 & 86.0 & 132.4 & 140.3 & 151.1 & 127.3 \\ & & & & & & & & & \\ 0.42 & 0.65 & 0.81 & 0.97 & 1.20 & 1.04 & 1.19 & 1.04 & 1.22 & 0.98 \\ 16.8 & 26.0 & 32.4 & 38.8 & 48.0 & 41.6 & 47.6 & 41.6 & 48.8 & 39.2\end{array}$

8. Exterior Doors

- Percent

by Type by Region

Not insulated

insulated

Storm doors

$\begin{array}{rr}13.2 & 21 \\ 86.8 & 79 \\ 8.1 & 12\end{array}$

21.0
79.0
12.7

10.8

89.2

37.8

37.8
62.2

33.1
66.9
24.1

98.4
1.6

75.3

$\begin{array}{lll}47.3 & 91.5 & 48.6\end{array}$

9. Exterior Wall

Structure

$\%$ by Region

First Floor

$2 \times 4,16$ "'o.c.

$2 \times 4,24$ 'o.c.

$2 \times 6,24$ '”.c.

Steel stud

Concrete block

Load-bearing

brick

$\begin{array}{rr}93.4 & 70.0 \\ 0 & 3.8 \\ 0 & 0 \\ 0 & 0 \\ 6.6 & 9.2 \\ & \\ 0 & 4.2 \\ 0 & 12.8\end{array}$

$$
\begin{array}{r}
90.4 \\
3.0 \\
1.1 \\
0 \\
4.6 \\
0.7
\end{array}
$$$$
80.2
$$$$
97 .
$$$$
2.9
$$$$
86.1
$$$$
\begin{array}{r}
0 \\
13.4 \\
0 \\
0
\end{array}
$$$$
84.8 \quad 93.0
$$$$
0
$$$$
2.6
$$$$
\begin{array}{r}
0.6 \\
1.1 \\
11.8
\end{array}
$$$$
\begin{array}{r}
0.4 \\
0
\end{array}
$$$$
\begin{array}{r}
6.1 \\
0
\end{array}
$$

86.4

0.7
0.2

0.4

12.2

$\begin{array}{rl}0.5 & 0 \\ 0 & 0\end{array}$

0

2.9

3.2

0.2

Other 


\begin{tabular}{|c|c|c|c|c|c|c|c|c|c|}
\hline $\begin{array}{c}\text { New } \\
\text { England }\end{array}$ & $\begin{array}{c}\text { Mid- } \\
\text { Atlantic }\end{array}$ & $\begin{array}{r}\text { East } \\
\text { North } \\
\text { Central }\end{array}$ & $\begin{array}{l}\text { West } \\
\text { North } \\
\text { Central }\end{array}$ & $\begin{array}{l}\text { South } \\
\text { Atlantic }\end{array}$ & $\begin{array}{l}\text { East } \\
\text { South } \\
\text { Central }\end{array}$ & $\begin{array}{c}\text { West } \\
\text { South } \\
\text { Central }\end{array}$ & Mountain & Pacific & $\begin{array}{l}\text { U.s. } \\
\text { Total }\end{array}$ \\
\hline
\end{tabular}

9. (Continued)

Upper Floors
$2 \times 4,16$ ',o.c.
$2 \times 4,24$ "'o.c.
$2 \times 6,24$ "'o.c.
Steel stud
Concrete block
Load bearing
brick
Other
Not applicable

$\begin{array}{rr}89.6 & 62.3 \\ 0 & 3.8 \\ 0 & 0 \\ 0 & 0 \\ 6.6 & 7.8 \\ & \\ 0 & 4.2 \\ 0 & 12.9 \\ 3.8 & 9.0\end{array}$

$\begin{array}{rrr}90.5 & 77.5 & 74.5 \\ 1.1 & 9.2 & 12.2 \\ 1.1 & 0 & 0.6 \\ 0 & 0 & 1.5 \\ 5.3 & 0 & 7.0 \\ & & \\ 0 & 0 & 0 \\ 0 & 0 & 1.6 \\ 2.0 & 13.3 & 2.6\end{array}$

74.5
12.2
0.6
1.5
7.0

0
1.6
2.6

76.3
17.6

$\begin{array}{rr}6.3 & 65.7 \\ 7.6 & 12.1 \\ 0 & 13.4 \\ 0 & \\ 0 & \\ 0 & \\ 0 & \\ 6.1 & 8.8\end{array}$

$\begin{array}{rr}65.7 & 80.7 \\ 12.1 & 2 \\ 13.4 & \\ 0 & \\ 0 & \\ & \\ 0 & \\ 0 & \\ 8.8 & 16.7\end{array}$

$\begin{array}{rr}y 2.1 & 79.3 \\ 5.9 & 7.4 \\ 0 & 1.8\end{array}$ $\begin{array}{rrr}2.6 & 5.9 & 7.4 \\ 0 & 0 & 1.8 \\ 0 & 0 & 0.3\end{array}$

0
0
16.7

0
0
2.0

0.4
1.7
6.0

10. Exterior Wall Sheathing

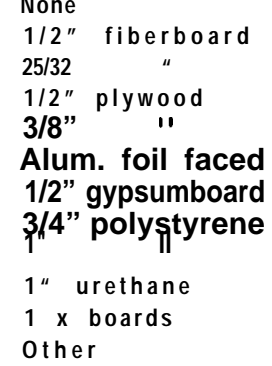

$\begin{array}{rrr}8.3 & 21.8 & 10.1 \\ 3.3 & 18.7 & 64.3 \\ 0 & 9.6 & 13.0 \\ 72.5 & 20.2 & 2.9 \\ 13.0 & 4.9 & 0 \\ 0 & 0 & 1.4 \\ 0 & 8.8 & 0.4 \\ 0 & 3.8 & 0 \\ 0 & 11.9 & 0 \\ 0 & 0.3 & 0 \\ 0 & 0 & 0 \\ 2.9 & 0 & 7.9\end{array}$

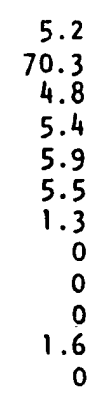

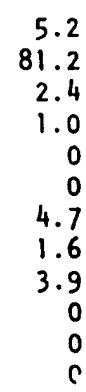

8.8
65.2
3.8
3.6
0
1.6
17.0
0
0
0
0
0

$\begin{array}{rr}54.6 & 21.1 \\ 0.3 & 42.5 \\ 0 & 4.0 \\ 14.6 & 13.3 \\ 14.8 & 6.3 \\ 0 & 1.4 \\ 8.5 & 6.6 \\ 0 & 0.5 \\ 0 & 1.5 \\ 0 & 0.1 \\ 0 & 0.3 \\ 7.2 & 2.5\end{array}$




\begin{tabular}{|c|c|c|c|c|c|c|c|c|c|}
\hline $\begin{array}{c}\text { New } \\
\text { Engl and }\end{array}$ & $\begin{array}{c}\text { mia- } \\
\text { Atlantic }\end{array}$ & $\begin{array}{c}\text { tast } \\
\text { North } \\
\text { Central } \\
\end{array}$ & $\begin{array}{c}\text { west } \\
\text { North } \\
\text { Central }\end{array}$ & $\begin{array}{l}\text { South } \\
\text { Atlantic }\end{array}$ & $\begin{array}{c}\text { tast } \\
\text { South } \\
\text { Central }\end{array}$ & $\begin{array}{l}\text { West } \\
\text { South } \\
\text { Central }\end{array}$ & Mountain & Pacific & $\begin{array}{l}\text { U.S. } \\
\text { Total }\end{array}$ \\
\hline
\end{tabular}

11. I nsul ati on- Percent by Locati on by Regi on

$$
\text { Ceiling }
$$

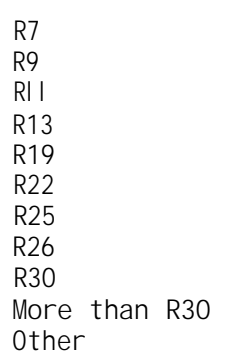

0
0
37.5
6.4
43.1
5.4
0
7.6
0
0
0

$\begin{array}{rr}0 & 0 \\ 0 & 0 \\ 14.8 & 33.5 \\ 9.1 & 9.3 \\ 71.0 & 43.6 \\ 4.5 & 10.2 \\ 0 & 3.4 \\ 0 & 0 \\ 0 & 0 \\ 0.6 & 0 \\ 0 & 0\end{array}$

0
0
38.1
22.3
36.4
0.2
1.8
0
0
0.6
0.6

0
0.7
35.0
36.4
13.4
3.8
2.4
0.5
0
2.1
5.7

$\begin{array}{rr}1.3 & 0 \\ 0 & 1.9 \\ 74.1 & 23.7 \\ 12.3 & 13.9 \\ 0 & 44.7 \\ 2.4 & 14.5 \\ 0 & 0 \\ 0 & 0.9 \\ 0 & 0 \\ 5.7 & 0.2 \\ 4.2 & 0\end{array}$

0
0
7.8
13.6
63.7
2.6
8.4
0
0
5.6
0.3

0
0
23.0
15.1
59.8
0
1.1
0
1.0
0
0

0.1 0.4

Exterior Walls

$\begin{array}{lrrrrrrrrrrrr}\text { None } & 0 & 0 & 0 & 0 & 0 & 4.7 & 0 & 0 & 0.2 \\ \text { R7 } & 5.7 & 6.8 & 0 & 1.2 & 1.1 & 11.1 & 1.9 & 0 & 2.5 & 2.7 \\ \text { R11 } & 58.6 & 72.7 & 57.6 & 67.9 & 87.3 & 73.1 & 44.6 & 72.5 & 72.8 & 69.6 \\ \text { R13 } & 35.7 & 20.5 & 42.4 & 30.8 & 8.6 & 11.1 & 39.5 & 21.7 & 22.6 & 24.3 \\ \text { R19 } & 0 & 0 & 0 & 0 & 3.0 & 0 & 14.0 & 5.9 & 2.1 & 3.2\end{array}$

Between Floor Joists

\begin{tabular}{|c|c|c|c|c|c|c|c|c|c|c|c|}
\hline None & & 44.1 & 65.5 & 52.1 & 50.4 & 71.0 & 81.9 & 96.8 & 84.8 & 32.4 & 72.6 \\
\hline $2-1 / 4$ "' batts & R-7 & 2.7 & 0.9 & 6.6 & 1.2 & 0.8 & 14.1 & 0 & 0 & 1.2 & 2.0 \\
\hline $3-1 / 2 " " 1$ & R-11 & 7.6 & 23.1 & 17.5 & 10.3 & 21.5 & 1.6 & 1.9 & 4.3 & 9.8 & 12.3 \\
\hline $3-5 / 811$ & $R-13$ & 31.8 & 4.7 & 17.0 & 12.1 & 6.2 & 2.4 & 0 & 8.3 & 0 & 7.0 \\
\hline 6" & R- 19 & 13.7 & $\begin{array}{r}5.8 \\
0\end{array}$ & $\begin{array}{r}6.8 \\
0\end{array}$ & $\begin{array}{r}26.0 \\
0\end{array}$ & $\begin{array}{r}0.5 \\
0\end{array}$ & $\begin{array}{l}0 \\
0\end{array}$ & $\begin{array}{r}1.3 \\
0\end{array}$ & $\begin{array}{r}2.6 \\
0\end{array}$ & $\begin{array}{l}5.9 \\
0.7\end{array}$ & $\begin{array}{l}5.9 \\
0.2\end{array}$ \\
\hline
\end{tabular}




\begin{tabular}{|c|c|c|c|c|c|c|c|c|c|}
\hline $\begin{array}{c}\text { New } \\
\text { England }\end{array}$ & $\begin{array}{c}\text { Mid- } \\
\text { Atlantic }\end{array}$ & $\begin{array}{c}\text { East } \\
\text { North } \\
\text { Central }\end{array}$ & $\begin{array}{c}\text { West } \\
\text { North } \\
\text { Central }\end{array}$ & $\begin{array}{l}\text { South } \\
\text { Atlantic }\end{array}$ & $\begin{array}{c}\text { East } \\
\text { South } \\
\text { Central }\end{array}$ & $\begin{array}{c}\text { West } \\
\text { South } \\
\text { Central }\end{array}$ & Mountain & Pacific & $\begin{array}{l}\text { U.S. } \\
\text { Total }\end{array}$ \\
\hline
\end{tabular}

11. (Continued)

Basement Walls

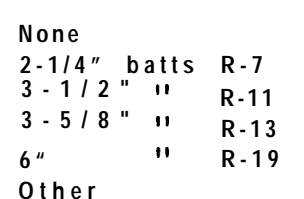$$
94 .
$$$$
5.7
$$

$\begin{array}{rr}83.5 & 91.0 \\ 4.4 & 3.4 \\ 2.9 & 0.2 \\ 0.5 & 0 \\ 0.7 & 0 \\ 8.0 & 5.4\end{array}$

92.2

9
0
2.2
2.4
0
0.2

83.2
7.1
9.7
0
0
0

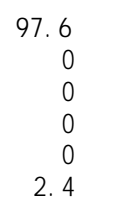

86.6
0
0
0
13.4
0

86.1
2.8
3.8
5.8
0
1.5

$\begin{array}{rr}97.2 & 89.8 \\ 2.3 & 3.2 \\ 0.2 & 3.0 \\ 0 & 0.7 \\ 0.3 & 1.7 \\ 0 & 1.6\end{array}$

Crawl space

Walls
None

None

$3-1 / 2$ " " $\mathrm{R}-11$

$3-5 / 8 " \| R=13$

6 “"

$\begin{array}{rrr}82.0 & 81.6 & 76.8 \\ 5.7 & 0 & 11.5 \\ 0 & 5.3 & 4.9 \\ 7.6 & 4.8 & 1.1 \\ 4.7 & 8.3 & 0 \\ 0 & 0 & 5.7\end{array}$

94.4
0
4.1
0
1.3
0.2

94.5
2.4
1.5
0
1.1
0.5

97.6

88.9
0
9.7
1.4
0
0

63.8
0
28.5
5.9
0
1.8

87.7

5.4

$\begin{array}{rr}0 & 9.7 \\ 2.4 & 1.4 \\ 0 & 0 \\ 0 & 0\end{array}$

0
0

85.7

3.2

1.8

1.3

Slab Perimeter

None
One-inch
Twc-inch

Other

Change From 1975

Increased

Decreased

$\begin{array}{rr}65.7 & 46.7 \\ 31.5 & 43.8 \\ 0 & 2.7 \\ 2.8 & 6.8\end{array}$

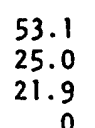

$66.7 \quad 14.3$

14.3
76.2
0.6

$\begin{array}{rr}96.9 & 82.9 \\ 3.1 & 16.8 \\ 0 & 0.3 \\ 0 & 0\end{array}$

62.594 .4

62.4

18.4
0.2

8.9

37.

2.9
2.7
0

30.6

4.3
2.7

84.

84.9
15.1

Bo.

19.8

$\begin{array}{rr}32.8 & 59.4 \\ 67.2 & 31.4 \\ 0 & 9.2\end{array}$

38.7
61.3

$\begin{array}{rr}89.8 & 70.2 \\ 10.2 & 29.8 \\ 0 & 0\end{array}$

40.
59.

63.8
.79

59.3
0

59.2

40.1
0.7 


\begin{tabular}{|c|c|c|c|c|c|c|c|c|c|}
\hline $\begin{array}{c}\text { New } \\
\text { England }\end{array}$ & $\begin{array}{c}\text { Mid- } \\
\text { Atlantic }\end{array}$ & $\begin{array}{c}\text { East } \\
\text { North } \\
\text { Central }\end{array}$ & $\begin{array}{l}\text { West } \\
\text { North } \\
\text { Central }\end{array}$ & $\begin{array}{c}\text { South } \\
\text { Atlantic }\end{array}$ & $\begin{array}{c}\text { East } \\
\text { South } \\
\text { Central }\end{array}$ & $\begin{array}{c}\text { West } \\
\text { South } \\
\text { Central }\end{array}$ & Mountain & Pacific & $\begin{array}{l}\text { U.S. } \\
\text { Total }\end{array}$ \\
\hline
\end{tabular}

12. Heating/Cooling

$\%$ by Type

Heating Equipment

None

Warm air furnace

Hot water system

Heat pump

Elec. baseboard

or radiant

ceiling

$24.1^{\circ}$

27.5

$\begin{array}{rr}0 & \text { i. } 2 \\ 27.1 & 74.5\end{array}$

$2.8 \quad 0.1$

94.8

0
.8
0
.8

0.1
64.5

82. 7

7

0
4.6

$\begin{array}{rrr}0.2 & 0 & 0.1 \\ 67.3 & 94.6 & 74.4\end{array}$

$\begin{array}{rrrrrr}0 & 0 & 0 & 0.8 & 1.1 & 2.4 \\ 31.8 & 11.5 & 15.4 & 15.5 & 1.2 & 13.4\end{array}$

eating Fuel

Gas

Electric

oil

43.2

$29.9 \quad 2.2$

4.4

3.6

5.2

0

16. 2

3.19 .5

Cooling Equipment

None
Port of heating
equipment

$35.9 \quad 43$.

43.0
56.7

78.6

78.6
21.4

10.4

$\begin{array}{ll}37.5 & 25.0 \\ 62.5 & 75.0\end{array}$

67.4

89.145 .8

27.7

17.7

0. 3

1.5

62.5
0

0

32.6
0

$\begin{array}{rr}10.9 & 50.2 \\ 0 & 4.0\end{array}$

heating

Heat pump

Evaporative

59.0

26.6

10. 4.

23.92.

2.9

1.0

$\begin{array}{ll}0 & 37.8\end{array}$

$56.9 \quad 25.8$

26.0

$50.5 \quad 66.7$

55.1

55.0

78. 1

65.8

i 4.9

$36.4 \quad 48.7$

$12.7 \quad 0.9$

$20.2 \quad 10$.

5.2

10.

22. 0

0.8

10.3
31.8

$\begin{array}{rrr}9.4 & 10.9 & 30.1\end{array}$

ooling Fuel

Gas

Electric

None

$41 .:$
59.0

3.6
69.8

8. 7

80. 9

0
76.1
23.9

0
97.1

99. 0

0
9.0
1.0

9.1
90.9

0.6
61.6

$\begin{array}{rr}4.5 & 2.8 \\ 38.6 & 71.4\end{array}$

$26.6 \quad 10.4$

2.9

0

37.8

$\begin{array}{ll}56.9 & 25.8\end{array}$ 


\section{5-76 LOW-RISE MULTIFAMILY UNITS}

This section contains data on almost 45,000 I ow $\mathbf{r i s e}$ mul tifami y duel I i ng uni ts. 


\begin{tabular}{|c|c|c|c|c|c|c|c|c|}
\hline $\begin{array}{c}\text { New } \\
\text { England }\end{array}$ & $\begin{array}{c}\text { Mid- } \\
\text { Atlantic }\end{array}$ & $\begin{array}{c}\text { East } \\
\text { North } \\
\text { Central }\end{array}$ & $\begin{array}{c}\text { West } \\
\text { North } \\
\text { Central }\end{array}$ & $\begin{array}{c}\text { South } \\
\text { Atlantic }\end{array}$ & $\begin{array}{r}\text { East } \\
\text { South } \\
\text { Central } \\
\end{array}$ & $\begin{array}{r}\text { West } \\
\text { South } \\
\text { Central } \\
\end{array}$ & pacific & $\begin{array}{c}\text { Us. } \\
\text { Total }\end{array}$ \\
\hline
\end{tabular}

1. Type Units - Percent

by Region

Efficiencies

Efficiencies

Two Bedroom

Three or more Bdrm.

$\begin{array}{rrr}21.2 & 3.7 & 4.6 \\ 35.4 & 54.1 & 38.2\end{array}$

54.1

50.5

5.4

24. 7

64.7

2.9
38.3

38.3
45.4

2.9
25.0
61.0
11.1

8.

44. $0 \quad 37$.

$39.0 \quad 50.1$

11.5

33.8

48.9
5.8

38.1

2. Foundation Types

\section{No Basement}

Live-in Basement

Live-in/Utility Bsmt

Utility Basement

$\begin{array}{rr}73.1 & 77.6 \\ 12.2 & 5.1 \\ 4.3 & 1.0 \\ 10.4 & 16.3\end{array}$

75.9
6.4
1.0
16.7

\begin{tabular}{r|}
52.7 \\
30.2 \\
0.4 \\
16.7
\end{tabular}

89.6

95. 0

10.5

37.0

47.0
8.9

3. Finished Floor Area. Percent by Region

\section{Square Footage}

Less than 400

$400-599$

$600 \cdot 799$

$800-999$

$1000 \quad-1199$

1200 and more

$\begin{array}{rrrr}0.9 & 0 & 0 & 2.5 \\ 21.9 & 15.5 & 7.6 & 4.6 \\ 23.1 & 26.8 & 39.2 & 48.1 \\ 32.7 & 30.4 & 34.4 & 33.2 \\ 14.9 & 19.6 & 16.9 & 7.1 \\ 6.5 & 7.7 & 1.9 & 4.5\end{array}$

1.0
1.8
25.5
34.8
20.2
16.7

0
3.3
31.2
29.1
29.7
6.7

$\begin{array}{rr}0 & 1.6 \\ 9.9 & 13.2 \\ 40.6 & 33.2 \\ 32.9 & 27.3 \\ 13.1 & 16.6 \\ 3.5 & 8.1\end{array}$

1.7
18.3
47.8
25.2
9.5
7.5

0.8
10.0
33.7
31.1
16.8
7.6 


\begin{tabular}{cccc} 
New & East \\
England & Morth \\
& Atlantic & Central \\
\hline
\end{tabular}

North

\begin{tabular}{ccc} 
South & South & South \\
Atlantic Central & Central \\
\hline
\end{tabular}

East West

Central

Mountain Pacific

U.S.

Total

4. Window Glazing -

Percent by Region

Single Glaze

Single w/Storm

Insulated Glass

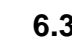

$\begin{array}{rr}4.2 & 0.3 \\ 50.6 & 13.9 \\ 45.2 & 85.6\end{array}$

0.3
13.9
85.6
0.2

19.5
35.0

43.
48.
8.

86. 5
0.6
12.9

98.9
0.6
0.5
0

$\begin{array}{rrr}79.3 & 91.2 & 51.6 \\ 0 & 1.9 & 20.6 \\ 20.7 & 6.9 & 26.9 \\ 0 & 0 & 0.9\end{array}$

5. V'Indow Square Feet by Regi on

Single Glaze
Single w/Storm
Insulated Glass
Insul. with Storms

6. Entrance Doors -

Total s $\overline{78.6}$

$4.3 \quad 4.9$

51. 1

0.3

12.1

44. 0

12.5

15.0

27.0

34.0

\begin{tabular}{rrr}
44.0 & 66.7 \\
0 & 0.2 \\
\hline 100.0 & & 79.7
\end{tabular}

27.3

$\frac{9.0}{85.3}$

$5.4 \quad 0.3$

51.2
0.3
7.7

81.3

0.3

$\begin{array}{r}0.2 \\ 0 \\ \hline 81.8\end{array}$

90.0

23.7

$98.4 \quad 45.2$

$\begin{array}{r}7.7 \\ \hline 59.2\end{array}$

0
13.7

1.9

Percent by Region

Unit Entrance

Not Insulated

50. 1

34.1

52.0

48. 0

53.7

30.8

89.4

97.2

50.8

31.4

57.4 


\begin{tabular}{|c|c|c|c|c|c|c|c|c|c|}
\hline $\begin{array}{c}\text { New } \\
\text { England }\end{array}$ & $\begin{array}{c}\text { Mid- } \\
\text { Atlantic }\end{array}$ & $\begin{array}{c}\text { East } \\
\text { North } \\
\text { Central }\end{array}$ & $\begin{array}{c}\text { West } \\
\text { North } \\
\text { Central }\end{array}$ & $\begin{array}{l}\text { South } \\
\text { Atlantic }\end{array}$ & $\begin{array}{c}\text { East } \\
\text { South } \\
\text { Central }\end{array}$ & $\begin{array}{c}\text { West } \\
\text { South } \\
\text { Central }\end{array}$ & Mounta in & Pacific & $\begin{array}{l}\text { U.S. } \\
\text { Total }\end{array}$ \\
\hline
\end{tabular}

\section{Exteri or Wal I Sheathi ng}

$\%$ by Type by Region

None

$1 / 2$ " fiberboard

25/32" fiberboard

$1 / 2$ " plywood

$3 / 8$ " plywood

Alum foil-faced board

$1 / 2$ " gypsumboard

$3 / 4$ " polystyrene

i " polystyrene

$3 / 4$ " urethane

I" urethane

Other

8. Insulation - Percent by

Location by Region

Ceiling Insulation

$2-1 / 4$ " batts R-7

$3-1 / 2$ " batts R-11

3-5/8" batts R-13

6" batts R 19

6-1/2" batts R-22

$8-1 / 2$ " batts R-26

9-1/2" batts R-30

5" loosefill R-11

$8-3 / 4^{\mathrm{H}}$ loosefill R-19

10" loosefill R-22

12" looseflll R-25

13-3/4" loosefill R-30

14" loosefill R-31

Other

3.6
3.5
3.3
35.3
4.4
0
41.8
8.1
0
0
0
0

$\begin{array}{rrrr}18.4 & 11.7 & 7.2 & 25.5 \\ 19.6 & 54.4 & 35.2 & 48.8 \\ 0 & 8.1 & 15.2 & 8.9 \\ 0.9 & 2.6 & 4.0 & 4.4 \\ 0.6 & 0 & 0.3 & 0 \\ 0 & 4.8 & 0 & 3.2 \\ 46.3 & 10.7 & 28.4 & 9.0 \\ 0 & 0 & 3.5 & 0 \\ 3.1 & 5.3 & 0 & 0 \\ 9.4 & 0.7 & 0 & 0 \\ 0 & 0.6 & 6.2 & 0 \\ 1.7 & 1.1 & 0 & 0.2\end{array}$

29.1
58.4
0.7
4.9
0
0
6.4
0.2
0.1
0
0
0.2

0.6

$69.7 \quad 39.2$

$39.2 \quad 18.9$

0.3

5.0

9.1

66.9

0

0
0

0
2.7

7.5

0
0

8.0

0
0

0
0
0

$\begin{array}{ll}0 & 3.8\end{array}$

$9.4 \quad 6.9$

$6.6 \quad 6.3$

$9.4 \quad 24.0$

0

0

2. 3

0.7
0.9

1.0

0.5

0
7.0
0
41.9
12.4
0
0
0
0
1.1
3.3
7.2
27.1
0
0

$\begin{array}{rr}0 & 0 \\ 0 & 0 \\ 1.4 & 0 \\ 62.9 & 7.7 \\ 0.5 & 0 \\ 0.5 & 0 \\ 0 & 1.3 \\ 1.7 & 0 \\ 0 & 0 \\ 20.4 & 31.1 \\ 4.2 & 29.7 \\ 1.4 & 13.4 \\ 0 & 8.0 \\ 1.6 & 1.2 \\ 0 & 3.6 \\ 5.4 & 4.0\end{array}$

0
10.3
0
7.7
0
0
1.2
0
3.6
18.2
0.5
14.5
2.2
0
3.8
38.0

10.8
1.3
0
39.0
0.2
0.8
0
0.9
0
28.1
11.4
0
0
5.8
0
1.7

3.4
15.7
0
14.5
0.7
0
0
0
0
35.3
5.6
4.5
0
0.4
0

0
0.7
0
20.2
0.9
0
0
0
0
46.9
24.6
2.7
0
0
0
4.0

0
16.1
0
38.4
0.5
0
0
2.9
0
11.0
8.1
13.5
0
0.2
4.4
4.9

$\begin{array}{rr}0 & 2.3 \\ 0.6 & 4.5 \\ 2.0 & 0.4 \\ 61.5 & 33.9 \\ 2.2 & 1.4 \\ 0 & 0.2 \\ 0 & 0.2 \\ 0 & 0.5 \\ 0 & 0.2 \\ 20.1 & 26.4 \\ 12.1 & 12.9 \\ 0 & 5.0 \\ 0.2 & 2.8 \\ 0 & 1.4 \\ 0 & 1.0 \\ 1.3 & 7.1\end{array}$

19.9 


\begin{tabular}{|c|c|c|c|c|c|c|c|c|c|}
\hline $\begin{array}{c}\text { New } \\
\text { England }\end{array}$ & $\begin{array}{c}\text { Mid- } \\
\text { A t I a n tic }\end{array}$ & $\begin{array}{c}\text { East } \\
\text { North } \\
\text { Centra I }\end{array}$ & $\begin{array}{c}\text { West } \\
\text { North } \\
\text { Central }\end{array}$ & $\begin{array}{c}\text { South } \\
\text { Atlantic }\end{array}$ & $\begin{array}{c}\text { East } \\
\text { South } \\
\text { Central }\end{array}$ & $\begin{array}{c}\text { West } \\
\text { South } \\
\text { Central }\end{array}$ & Mountain & Pacific & $\begin{array}{l}\text { U.s. } \\
\text { Total }\end{array}$ \\
\hline
\end{tabular}

8. Exteri or WhI I nsul ati on (cont i nued)

$\begin{array}{lr}\text { None } & 0 \\ 2-1 / 4 \text { " batts, R-7 } & 3.4 \\ 3-1 / 2 \text { " batts, R-11 } & 41.3 \\ 3-5 / 8 \text { " batts, R-13 } & 48.5 \\ 6 \text { " batts, R-19 } & 5.9 \\ \text { Pleated aluminum } & 0 \\ \text { Other } & 0.9\end{array}$

0
1.4
89.8
8.0
0
0
0.8

$\begin{array}{rrr}0 & 0 & 21.1 \\ 0 & 3.6 & 15.2 \\ \mathbf{4 0 . 9} & 62.5 & 32.3 \\ \mathbf{5 8 . 4} & 32.1 & 9.2 \\ 0 & 0.8 & 8.9 \\ 0 & 0 & 0 \\ 0.7 & 1.0 & 13.3\end{array}$

$\begin{array}{rr}0 & 0 \\ 4.7 & 2.7 \\ 85.7 & 93.3 \\ 4.3 & 1.2 \\ 0.2 & 2.4 \\ 4.2 & 0 \\ 0.9 & 0.4\end{array}$

0
0
95.0
1.8
3.2
0
0

$\begin{array}{rr}u & 3.7 \\ 0.5 & 4.2 \\ 82.6 & 68.6 \\ 16.2 & 17.4 \\ 0.7 & 2.4 \\ 0 & 0.7 \\ 0 & 2.8\end{array}$

Insulation Between Joists

\section{None}

$2-1 / 4$ " batts $R-7$

3-1/2" batts R-n

$3-5 / 8$ " batts R-13

6" batts R-19

Other

37.1
2.0
33.0
2.8
23.6
1.5

$\begin{array}{rrr}78.0 & 70.7 & 57.4 \\ 1.3 & 1.4 & 3.6 \\ 16.7 & 14.6 & 32.4 \\ 2.5 & 9.6 & 0 \\ 1.5 & 3.7 & 6.6 \\ 0 & 0 & 0\end{array}$

$\begin{array}{rr}66.5 & 63.4 \\ 2.6 & 3.5 \\ 30.7 & 19.8 \\ 0.2 & 1.9 \\ 0 & 11.4 \\ 0 & 0\end{array}$

59.6
0
29.5
1.4
9.5
0

69.7
6.3
8.9
0.9
0.3
13.9

$\begin{array}{rr}64.5 & 64.3 \\ 2.3 & 2.3 \\ 15.2 & 22.2 \\ 2.5 & 2.4 \\ 15.4 & 7.5 \\ 0.1 & 1.2\end{array}$

Crawl Space Walls

\section{None}

2-1/4" batts R-7

3-1/2" batts R-11

3-5/8" R-13

$6 "$ batts $R-19$

Other

$\begin{array}{rrrr}96.4 & 82.7 & 55.8 & 87.1 \\ 0 & 0 & 10.0 & 0 \\ 0.4 & 16.0 & 19.4 & 7.9 \\ 1.7 & 0 & 1.1 & 0 \\ 0 & 1.3 & 10.1 & 2.9 \\ 1.5 & 0 & 3.6 & 2.1\end{array}$

Insulation Basement Walls

\section{None}

$2-1 / 4$ " batts R-7

3-1/2" batts $R-n$

3-5/8" batts R-13

6 " batts R-19

Other

$\begin{array}{rrrr}93.2 & 80.3 & 96.5 & 76.3 \\ 0 & 0 & 0.5 & 0 \\ 3.6 & 18.2 & 1.8 & 10.3 \\ 1.7 & 0 & 0.9 & 3.2 \\ 0 & 0.2 & 0.3 & 0 \\ 1.5 & 1.3 & 0 & 10.2\end{array}$

$\begin{array}{rrr}94.5 & 95.2 & 96.6 \\ 0.9 & 0 & 0 \\ 4.4 & 1.2 & 2.5 \\ 0.2 & 1.9 & 0.9 \\ 0 & 0 & 0 \\ 0 & 1.7 & 0 \\ & & \\ & & \\ 87.9 & 94.5 & 94.2 \\ 1.2 & 1.9 & 0 \\ 10.2 & 1.2 & 5.8 \\ 0 & 0 & 0 \\ 0 & 0 & 0 \\ 0.7 & 2.4 & 0\end{array}$

83.7
0
5.1
0
0
11.2

$\begin{array}{rr}89.2 & 87.2 \\ 1.8 & 1.6 \\ 7.8 & 7.2 \\ 0.7 & 0.7 \\ 0 & 1.5 \\ 0.5 & 1.8\end{array}$

88.6
0
6.0
0
0
5.4

88.9
5.9
2.9
2.2
0
0.1

89.6 


\begin{tabular}{|c|c|c|c|c|c|c|c|c|c|}
\hline $\begin{array}{c}\text { New } \\
\text { England }\end{array}$ & $\begin{array}{c}\text { Md- } \\
\text { At I anti c }\end{array}$ & $\begin{array}{r}\text { East } \\
\text { North } \\
\text { Central }\end{array}$ & $\begin{array}{r}\text { West } \\
\text { North } \\
\text { Central } \\
\end{array}$ & $\begin{array}{c}\text { South } \\
\text { Atlantic }\end{array}$ & $\begin{array}{c}\text { East } \\
\text { South } \\
\text { Central }\end{array}$ & $\begin{array}{c}\text { West } \\
\text { South } \\
\text { Central }\end{array}$ & Mountain & Pacific & $\begin{array}{r}\text { U.S. } \\
\text { Total }\end{array}$ \\
\hline
\end{tabular}

8. (continued)

Practice Change

from '75

No change

$89.8 \quad 80.7$

Increased

10.2

80.7
19.3

35.2
64.8

73.0

60.3

95. 2

79.0

67.5
32.5

$64.8 \quad 69.9$

Perimeter Slab-ongrade

None

One I nch

Two Inch

Other

$\begin{array}{rrrr}18.6 & 25.2 & 21.9 & 30.3 \\ 13.9 & 57.2 & 35.3 & 32.8 \\ 67.5 & 17.6 & 34.2 & 33.1 \\ 0 & 0 & 8.6 & 3.8\end{array}$

$\begin{array}{rr}56.8 & 64.9 \\ 43.2 & 35.1 \\ 0 & 0 \\ 0 & 0\end{array}$

$\begin{array}{rr}91.4 & 69.6 \\ 8.6 & 24.8 \\ 0 & 5.6 \\ 0 & 0\end{array}$

$80.5 \quad 56.0$

$8.6 \quad 3.8$

. Heating/Coollng

$\%$ by Type by Region

Heating By Equipment

Central boiler
w/air handler
Central boiler
w/fan coils
Central boiler
w/hot water
baseboard
Ind. warm air
furnace
Ind. hot water
system
nd. heat pump
Ind. elec. base-
board or radiant
ceiling
Other

$\begin{array}{rrrrrrrrrr}0 & 10.8 & 0 & 8.3 & 11.0 & 0.2 & 0.8 & 7.4 & 13.2 & 6.2 \\ 0 & 0 & 0 & 0 & 0.7 & 0 & 0 & 13.9 & 1.8 & 1.5 \\ & & & & & & & & & \\ 4.5 & 4.7 & 12.4 & 5.1 & 0 & 2.6 & 0 & 19.1 & 1.4 & 7.1 \\ 7.3 & 52.3 & 64.3 & 45.5 & 54.7 & 78.8 & 93.5 & 42.0 & 40.4 & 57.2 \\ 0 & 0 & 0.3 & 0 & 0 & 0 & 0 & 0 & 0 & \\ 1.1 & 3.2 & 9.1 & 1.8 & 11.6 & 2.9 & 3.5 & 4.0 & 4.5 & 5.4 \\ & & & & & & & & & \\ 4.1 & 18.9 & 14.2 & 39.3 & 0.9 & 15.5 & 3.2 & 13.6 & 38.4 & 18.0 \\ 0 & 10.1 & 0 & 0 & 21.1 & 0 & 0 & 0 & 0.3 & 4.6\end{array}$




\begin{tabular}{|c|c|c|c|c|c|c|c|c|c|}
\hline $\begin{array}{c}\text { New } \\
\text { England }\end{array}$ & $\begin{array}{c}\text { Mld- } \\
\text { Atlantic }\end{array}$ & $\begin{array}{c}\text { East } \\
\text { North } \\
\text { Central }\end{array}$ & $\begin{array}{c}\text { West } \\
\text { North } \\
\text { Central }\end{array}$ & $\begin{array}{c}\text { South } \\
\text { Atlantic }\end{array}$ & $\begin{array}{c}\text { East } \\
\text { South } \\
\text { Central }\end{array}$ & $\begin{array}{l}\text { West } \\
\text { South } \\
\text { Central }\end{array}$ & Mountain & Pacific & $\begin{array}{l}\text { U.S. } \\
\text { Total }\end{array}$ \\
\hline
\end{tabular}

9. (continued)

Heating Fuel

Gas

Oil

Cooling Equipment

None
Central systems

chiller/alr handler

chiller/fan

coils

Ind.unit systems

Part of heating

equip.

Separate from

heat equip.

Heat pump

Evaporative

cooler

Room units

Cooling Fuel

None

Gas

Electric $\begin{array}{ll}16.1 & 22 \\ 49.8 & 58\end{array}$

49.8

22.4
58.5

58.5
19.1

41.5

58.5

43.7
54.6

54.6

11.2

15.0

13.

$\begin{array}{rrr}11.7 & 85.0 & 86.5 \\ 0.7 & 0 & 0\end{array}$

78.2

$38.5 \quad 28.2$

$61.5 \quad 67.6$

$\begin{array}{lllllllllll}5.0 & 4.0 & 4.4 & 0.8 & 1.8 & 15.5 & 0 & 16.9 & 52.1 & 12.6\end{array}$

3.4

19.1

$\begin{array}{ll}0 & 1.0\end{array}$

0.3

0

1.0

7.4

$1.8 \quad 3.1$

0.3

(

5.3

18.2

$46.4 \quad 37.1$

49.7

76.1

81.2

8

0

1.2

$\begin{array}{rr}16.4 & 6.6 \\ 1.1 & 3.2\end{array}$

$\begin{array}{ll}4.0 & 2.0 \\ 9.1 & 1.8\end{array}$

7.8
11.6

3.0
2.9

12.8
3.5

0.7

21.1

44.5

0
68.8

5.9
42.7

0
36.1

0
57.3

21.0
6.8

0
2.5

0
2.5

6.3

18.0

$\begin{array}{ll}6.9 & 7.2 \\ 4.5 & 5.4\end{array}$

$\begin{array}{rr}0 & 4.5 \\ 13.6 & 21.5\end{array}$

\begin{tabular}{|c|c|}
\hline $\begin{array}{r}5.0 \\
0\end{array}$ & $\begin{array}{l}4.0 \\
0.9\end{array}$ \\
\hline
\end{tabular}

95.0

95.1

86.3

0.3
98.9

1.8
0

15.5
0

9. 0

16.9

0.8
82.3

$52.0 \quad 12.6$

$\begin{array}{rr}5.0 & 3.3 \\ 43.0 & 84.1\end{array}$

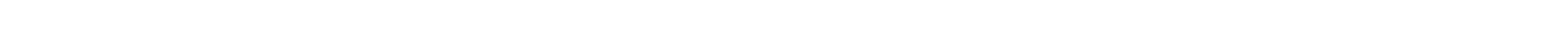


1976-77 MOBILE HOME UNITS

Thi s secti on contains data on about 175,000 mobi le hone units. 


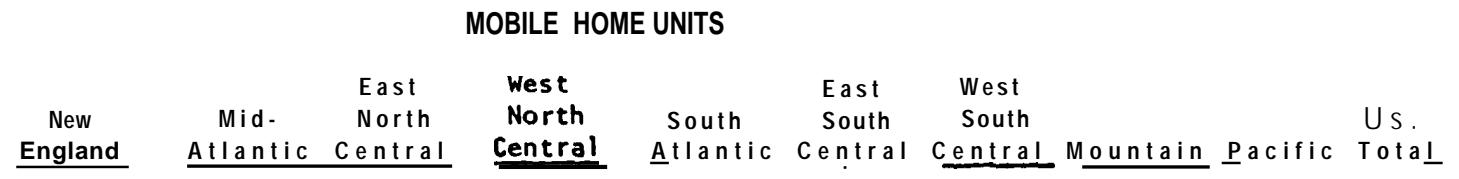

1. Average Size (SF)

$\begin{array}{lrrrrrrrrrrr}\text { Single wide } & 935 & 922 & 914 & 930 & 833 & 870 & 891 & 886 & 901 & 886 \\ \text { Double wide } & 1249 & 1248 & 1299 & 1326 & 1266 & 1265 & 1322 & 1320 & 1357 & 1311\end{array}$

2. Insulation

(Percent of units)

Single wide

Ceilings

\begin{tabular}{|c|c|c|c|c|c|c|c|c|c|c|}
\hline $\begin{array}{l}R 11 \text { to } R 12 \\
R 13 \text { to } R 18 \\
R 19 \text { to } R 21 \\
R 22 \text { or more }\end{array}$ & $\begin{array}{r}0 \\
39.5 \\
7.1 \\
53.4\end{array}$ & $\begin{array}{r}0 \\
81.5 \\
18.5 \\
0\end{array}$ & $\begin{array}{r}9.0 \\
64.8 \\
26.2 \\
0\end{array}$ & $\begin{array}{r}0 \\
86.2 \\
4.5 \\
9.3\end{array}$ & $\begin{array}{r}8.1 \\
78.5 \\
11.9 \\
1.5\end{array}$ & $\begin{array}{r}23.0 \\
63.7 \\
13.3 \\
0\end{array}$ & $\begin{array}{r}12.2 \\
76.6 \\
11.1 \\
0\end{array}$ & $\begin{array}{r}6.9 \\
76.2 \\
10.2 \\
6.7\end{array}$ & $\begin{array}{r}0 \\
54.3 \\
44.1 \\
1.6\end{array}$ & $\begin{array}{r}7.8 \\
72.5 \\
17.3 \\
2.4\end{array}$ \\
\hline \multicolumn{11}{|l|}{$\begin{array}{l}\text { Single wide } \\
\text { Walls }\end{array}$} \\
\hline $\begin{array}{l}\text { R7 } \\
\text { R11 } \\
\text { R12 } \\
\text { R13 } \\
\text { R19 }\end{array}$ & $\begin{array}{r}7.1 \\
92.9 \\
0 \\
0 \\
0\end{array}$ & $\begin{array}{r}15.5 \\
84.5 \\
0 \\
0 \\
0\end{array}$ & $\begin{array}{r}0 \\
100.0 \\
0 \\
0 \\
0\end{array}$ & $\begin{array}{r}0 \\
92.9 \\
0 \\
0 \\
7.1\end{array}$ & $\begin{array}{r}12.8 \\
85.7 \\
0 \\
1.5 \\
0\end{array}$ & $\begin{array}{r}13.2 \\
81.7 \\
0 \\
5.2 \\
0\end{array}$ & $\begin{array}{r}46.6 \\
51.8 \\
1.6 \\
0 \\
0\end{array}$ & $\begin{array}{r}2.6 \\
90.7 \\
0 \\
0 \\
6.7\end{array}$ & $\begin{array}{r}1.1 \\
98.2 \\
0 \\
0.7 \\
0\end{array}$ & $\begin{array}{r}13.4 \\
84.3 \\
0.3 \\
0.8 \\
1.2\end{array}$ \\
\hline \multicolumn{11}{|l|}{$\begin{array}{l}\text { Single wide } \\
\text { Floors }\end{array}$} \\
\hline $\begin{array}{l}\text { R7 } \\
\text { R9 } \\
\text { R11 } \\
\text { R13 } \\
\text { R14 } \\
\text { R15 } \\
\text { R19 }\end{array}$ & $\begin{array}{r}0 \\
100.0 \\
0 \\
0 \\
0 \\
0\end{array}$ & $\begin{array}{r}2.5 \\
0 \\
86.6 \\
4.4 \\
6.6 \\
0 \\
0\end{array}$ & $\begin{array}{r}0 \\
0 \\
82.7 \\
17.3 \\
0 \\
0 \\
0\end{array}$ & $\begin{array}{r}0 \\
0 \\
92.9 \\
0 \\
0 \\
0 \\
7.1\end{array}$ & $\begin{array}{r}8.0 \\
8.9 \\
79.3 \\
3.8 \\
0 \\
0 \\
0\end{array}$ & $\begin{array}{r}9.2 \\
0 \\
81.8 \\
0 \\
9.0 \\
0 \\
0\end{array}$ & $\begin{array}{r}5.9 \\
23.7 \\
68.8 \\
0 \\
0 \\
1.6 \\
0\end{array}$ & $\begin{array}{r}12.6 \\
0.5 \\
86.9 \\
0 \\
0 \\
0 \\
0\end{array}$ & $\begin{array}{r}4.5 \\
0 \\
90.5 \\
0 \\
4.3 \\
0 \\
0.7\end{array}$ & $\begin{array}{r}5.1 \\
6.0 \\
82.1 \\
4.1 \\
1.7 \\
0.3 \\
0.7\end{array}$ \\
\hline
\end{tabular}


1976- 77 HOUSI NG CHARACTER STI CS

MOBILE HOME UNITS

\begin{tabular}{|c|c|c|c|c|c|c|c|c|c|}
\hline $\begin{array}{l}\text { New } \\
\text { England }\end{array}$ & $\begin{array}{c}\text { Mid- } \\
\text { Atlantic }\end{array}$ & $\begin{array}{c}\text { East } \\
\text { North } \\
\text { Central }\end{array}$ & $\begin{array}{l}\text { West } \\
\text { North } \\
\text { Central }\end{array}$ & $\begin{array}{l}\text { South } \\
\text { At lantlc }\end{array}$ & $\begin{array}{c}\text { East } \\
\text { South } \\
\text { Central }\end{array}$ & $\begin{array}{l}\text { West } \\
\text { South } \\
\text { Central }\end{array}$ & Mountain & Pacific & $\begin{array}{l}\text { Us. } \\
\text { Total }\end{array}$ \\
\hline
\end{tabular}

Double Wide Ceilings

R11 to $R 12$
R13 to R18

R19 to R21

R22 or more

Double Wide W alls

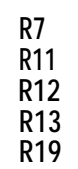

R13

Double Wide Floors

$\begin{array}{rrr}0 & 0 & 8.3 \\ 93.2 & 51.3 & 64.8 \\ 0 & 34.8 & 10.5 \\ 6.8 & 13.9 & 16.4 \\ & & \\ & & \\ 0 & & \\ 93.2 & 82.1 & 100.0 \\ 0 & 0 & 0 \\ 0 & 0 & 0 \\ 6.8 & 8.3 & 0\end{array}$

0
55.5
21.2

55.5
21.2

23.3

\section{7 \\ 67.8}

$19.1 \quad 16.6$

$11.4 \quad 12.4$

$\begin{array}{rr}3.1 & y .3 \\ 65.6 & 77.0\end{array}$

$y .3$
77.0
4.7

$\begin{array}{rr}0 & 3 . y \\ 26.5 & 52.5\end{array}$

$\begin{array}{llll}22.0 & 4.7 & 47.0 & 27.0\end{array}$

$\begin{array}{llll}8.7 & 8.8 & 26.5 & 16.6\end{array}$

0
86.0
0
0
14.0

27.9

10.

70.4

1.7
0

89.1

0.9

21.3
78.0
0.7
0
0

100.

$5.4 \quad 11.3$

14.0

0
0
86.0
0
0
0
14.0

$\begin{array}{rr}29.7 & 0 \\ 0.2 & 3.3 \\ 66.1 & 93.3 \\ 4.0 & 0 \\ 0 & 3.4 \\ 0 & 0 \\ 0 & 0\end{array}$

$\begin{array}{rr}11.5 & 13.7 \\ 0 & 0.9 \\ 85.8 & 81.7 \\ 0 & 1.8 \\ 2.7 & 1.2 \\ 0 & 0.1 \\ 0 & 0.6\end{array}$ 


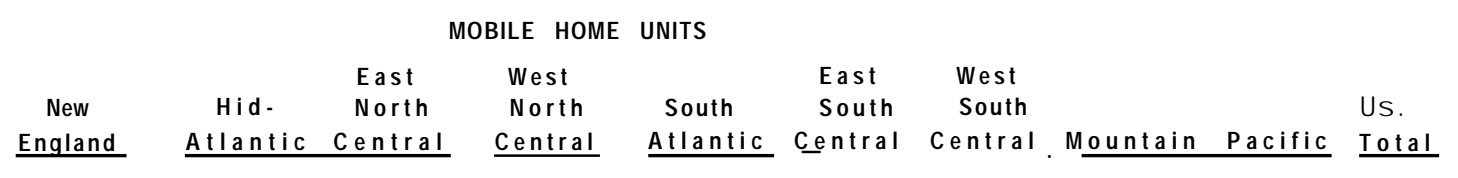

3. Vindows \& Doors

Si ngl e VIde

\begin{tabular}{|c|c|c|c|c|c|c|c|c|c|c|}
\hline $\begin{array}{l}\text { Average nunber } \\
\text { Average si ze (SF) }\end{array}$ & $\begin{array}{r}11.7 \\
102.0\end{array}$ & $\begin{array}{l}11.3 \\
115.8\end{array}$ & $\begin{array}{r}12.4 \\
118.7\end{array}$ & $\begin{array}{r}11.3 \\
115.9\end{array}$ & $\begin{array}{r}11.5 \\
113.5\end{array}$ & $\begin{array}{r}10.3 \\
109.0\end{array}$ & $\begin{array}{r}11.0 \\
107.1\end{array}$ & $\begin{array}{r}11.8 \\
119.7\end{array}$ & $\begin{array}{l}10.4 \\
111.1\end{array}$ & $\begin{array}{r}11.4 \\
113.4\end{array}$ \\
\hline azi ng ( percent) & & & & & & & & & & \\
\hline $\begin{array}{l}\text { ingle no storms } \\
\text { ingle with storms } \\
\text { nsul. no storms } \\
\text { nsul. with storms }\end{array}$ & $\begin{array}{r}14.8 \\
59.2 \\
0 \\
26.0\end{array}$ & $\begin{array}{r}9.8 \\
85.3 \\
0 \\
4.9\end{array}$ & $\begin{array}{r}30.8 \\
69.2 \\
0 \\
0\end{array}$ & $\begin{array}{r}21.3 \\
76.2 \\
2.5 \\
0\end{array}$ & $\begin{array}{r}41.5 \\
58.5 \\
0 \\
0\end{array}$ & $\begin{array}{r}38.5 \\
61.1 \\
0.2 \\
0.2\end{array}$ & $\begin{array}{r}60.6 \\
28.9 \\
10.2 \\
0.3\end{array}$ & $\begin{array}{r}25.5 \\
61.6 \\
0 \\
5.9\end{array}$ & $\begin{array}{r}44.0 \\
51.2 \\
3.4 \\
1.4\end{array}$ & $\begin{array}{r}37.8 \\
58.1 \\
2.3 \\
1.8\end{array}$ \\
\hline
\end{tabular}

Doors

(percent of units)

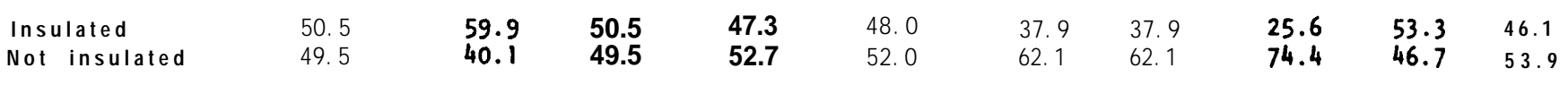




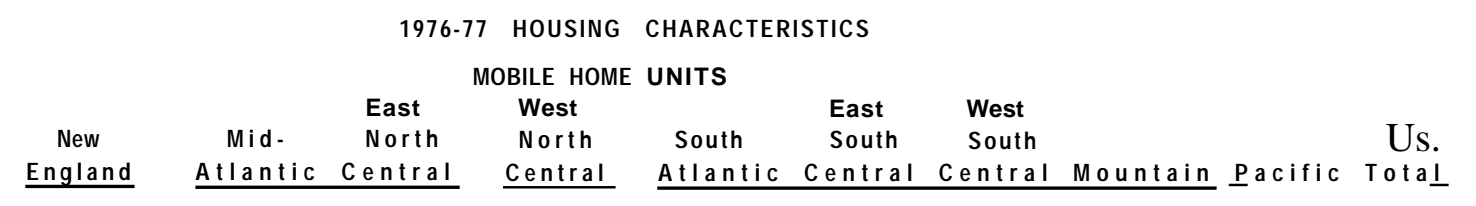

4. Heating/Cooling

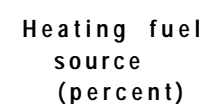

\begin{tabular}{|c|c|c|c|c|c|c|c|c|c|c|}
\hline $\begin{array}{l}\text { Gas } \\
\text { oi I } \\
\text { Electric }\end{array}$ & $\begin{array}{l}27.4 \\
53.9 \\
18.7\end{array}$ & $\begin{array}{l}31.7 \\
35.6 \\
32.7\end{array}$ & $\begin{array}{l}52.3 \\
10.4 \\
37.3\end{array}$ & $\begin{array}{r}57.3 \\
9.3 \\
33.4\end{array}$ & $\begin{array}{l}41.0 \\
11.4 \\
47.6\end{array}$ & $\begin{array}{r}41.9 \\
2.7 \\
55.4\end{array}$ & $\begin{array}{r}64.8 \\
2.2 \\
33.0\end{array}$ & $\begin{array}{r}41.1 \\
5.5 \\
53.4\end{array}$ & $\begin{array}{r}57.8 \\
2.4 \\
39.8\end{array}$ & $\begin{array}{r}49.7 \\
9.0 \\
41.3\end{array}$ \\
\hline \multicolumn{11}{|c|}{$\begin{array}{l}\text { ooling equipment } \\
\text { plant install- } \\
\text { ed (percent) }\end{array}$} \\
\hline $\begin{array}{l}\text { yes } \\
\text { no }\end{array}$ & $\begin{array}{r}2.9 \\
97.1\end{array}$ & $\begin{array}{r}3.2 \\
96.8\end{array}$ & $\begin{array}{r}9.6 \\
90.4\end{array}$ & $\begin{array}{r}5.2 \\
94.8\end{array}$ & $\begin{array}{r}7.4 \\
92.6\end{array}$ & $\begin{array}{r}2.8 \\
97.2\end{array}$ & $\begin{array}{l}16.7 \\
83.3\end{array}$ & $\begin{array}{r}4.9 \\
95.1\end{array}$ & $\begin{array}{l}23.4 \\
76.6\end{array}$ & $\begin{array}{l}10.9 \\
89.1\end{array}$ \\
\hline
\end{tabular}




\title{
Thermal Characteristics of Homes Built in 1974,1973 , and 1961
}

\author{
by the National Association of Home Builders \\ Research Foundation, Inc., July 1977
}

\section{INTRODUCTION}

This report contains information in thermal characteristics of homes built in 1973 and i $\mathbf{n}$ 1974, and thermal insulation data for 1961 homes. In addition, comments from 83 builders regarding levels of insulation being installed in 1976-77 a re included.

\section{Scope and Method}

In 1974, the Research Foundation conducted a national survey of builder practices for the National Association of Home Builders (NAHB). The study covered a wide range of home builder practices for homes built in 1973. Results represented a composite of about 84,000 homes built by over 1,600 builders selected at random from NAHB membership rolls. Data were summanized for four (4) census regi ons.

I n 1975, a survey of over 120,000 single family dwellings was completed for homes built in 1974. This survey was taken from the entire membership of NAHB and was summarized by nine (9) census regions. Housing characteristic data were collected in sufficient detail for thermal characteristics to be analyzed.
In 1961, F. W. Dodge Comoration conducted a detailed material inventory of 1,000 randomly selected dwellings. Data from this inventory are included in this report.

Another extensive survey is being conducted by the Research Foundation for homes built in 1975 and 1976. Data from this survey are not yet available but a review of several thousand questionnaires revealed many builders are installing more insulation than the average and some builders are installing less insulation than the average. Eighty-three of these untypical builders were surveyed in an attempt to discover what causes builders to make changes related to energy conservation. Results of that survey are included.

\section{HOUSING CHARACTERISTICS}

This section contains characteristics of about 120,000 single family detached homes built in 1974, summarized by nine census regions. Following are the regions and the percentage of the total number of homes with in each region.

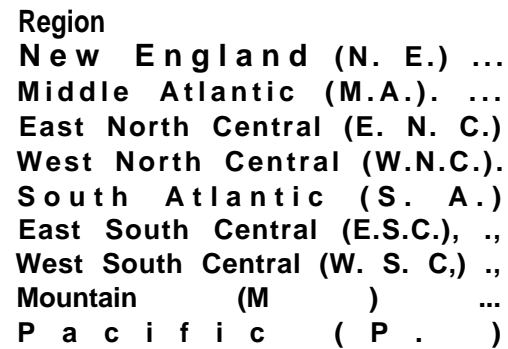

Percent

of homes

3

10

15

7

20

6

15

9 15 
1974 HOUSI NG CHARACTER STI CS

la. Finished Floor Area - Percent by Region

\begin{tabular}{|c|c|c|c|c|c|c|c|c|c|c|}
\hline Square Footage & N.E. & M.A. & E.N.C. & W.N.C. & S.A. & E.S.C. & W.S.C. & M. & P. & Total U.S. \\
\hline Under 800 & 7 & 4 & 3 & 5 & 1 & 3 & $\%$ & 2 & 1 & 2 \\
\hline $800-999$ & 8 & 9 & 5 & 7 & 2 & 2 & $*$ & 5 & 1 & 3 \\
\hline $1000-1199$ & 24 & 23 & 18 & 23 & 14 & 19 & 8 & 16 & 12 & 16 \\
\hline $1200-1399$ & 16 & 16 & 16 & 27 & 24 & 18 & 9 & 21 & 17 & 18 \\
\hline $1400-1599$ & 8 & 7 & 14 & 13 & 17 & 17 & 23 & 22 & 26 & 18 \\
\hline $1600-1799$ & 8 & 6 & 12 & 5 & 11 & 12 & 26 & 11 & 16 & 14 \\
\hline $1800-1999$ & 7 & 10 & 8 & 7 & 12 & 10 & 12 & 5 & 10 & 10 \\
\hline $2000-2199$ & 4 & 8 & 10 & 5 & 10 & 8 & 7 & 10 & 8 & 8 \\
\hline $2200-2399$ & 9 & 6 & 5 & 3 & 4 & 4 & 6 & 3 & 5 & 5 \\
\hline $2400-2799$ & 6 & 8 & 6 & 3 & 3 & 4 & 6 & 3 & 3 & 4 \\
\hline Over 2800 & 3 & 3 & 3 & 2 & $\underline{2}$ & 3 & 3 & 2 & I & 2 \\
\hline Total & 100 & 100 & 100 & 100 & 100 & 100 & 100 & 100 & 100 & 100 \\
\hline Average SF & 1,518 & 1,570 & 1,507 & 1,429 & 1,584 & 1,610 & 1,746 & 1,535 & 1,604 & 1,585 \\
\hline
\end{tabular}

1b. Finished First Floor Area - Percent by Region (Estimated)

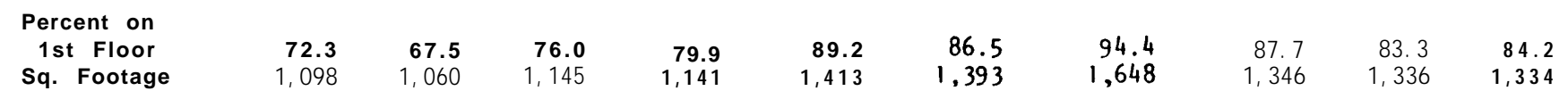

1c. Wood Frame vs. Concrete Slab 1st Floor, by Region

\begin{tabular}{|c|c|c|c|c|c|c|c|c|c|c|c|}
\hline $\begin{array}{l}\text { Wooc } \\
\text { Wooc }\end{array}$ & $\begin{array}{l}\text { Frame } \% \\
\text { Frame SF }\end{array}$ & $\begin{array}{r}96 \\
1.054\end{array}$ & $\begin{array}{r}88 \\
933\end{array}$ & $\begin{array}{r}87 \\
996\end{array}$ & $\begin{array}{r}99 \\
1,130\end{array}$ & $\begin{array}{r}47 \\
664\end{array}$ & $\begin{array}{r}54 \\
752\end{array}$ & 3 & $\begin{array}{r}49 \\
660\end{array}$ & $\begin{array}{r}44 \\
589\end{array}$ & $\begin{array}{r}52 \\
694\end{array}$ \\
\hline Slat & $\%$ & 4 & 12 & 13 & 1 & 53 & 46 & 97 & 51 & 56 & 48 \\
\hline Slat & SF & 44 & 127 & 149 & 11 & 749 & 641 & 1,599 & 686 & 748 & 640 \\
\hline
\end{tabular}

*Less than $1 \%$ 
2. Number of Stories - Percent by Region

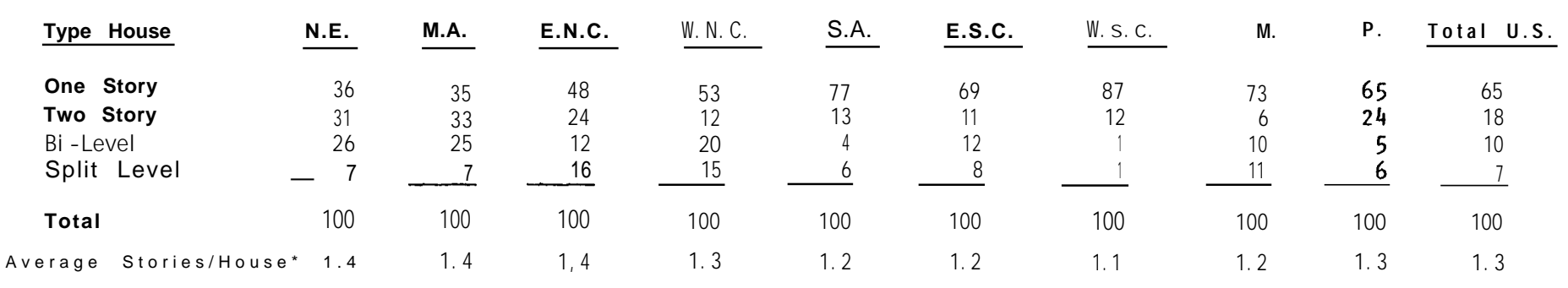

3. Square Footage of Exterior Wall - by Region

\begin{tabular}{|c|c|c|c|c|c|c|c|c|c|c|}
\hline $\begin{array}{l}\text { Opaque Wall } \\
\text { Windows \& Doors }\end{array}$ & $\begin{array}{r}1,190 \\
-287\end{array}$ & $\begin{array}{r}1,221 \\
296 \\
\end{array}$ & $\begin{array}{r}1,188 \\
282 \\
\end{array}$ & $\begin{array}{r}1,087 \\
282\end{array}$ & $\begin{array}{r}1,134 \\
-\quad 297\end{array}$ & $\begin{array}{r}1,201 \\
294\end{array}$ & $\begin{array}{r}1,193 \\
324\end{array}$ & $\begin{array}{r}1,091 \\
297 \\
\end{array}$ & $\begin{array}{r}1,194 \\
298 \\
\end{array}$ & $\begin{array}{r}1,162 \\
295 \\
\end{array}$ \\
\hline Total SF & 1,477 & 1,517 & 1,470 & 1,369 & 1,431 & 1,495 & 1,517 & 1,388 & 1,1192 & 1,457 \\
\hline
\end{tabular}


4. Heating and Cool ing Equi pnent - Percent by Type

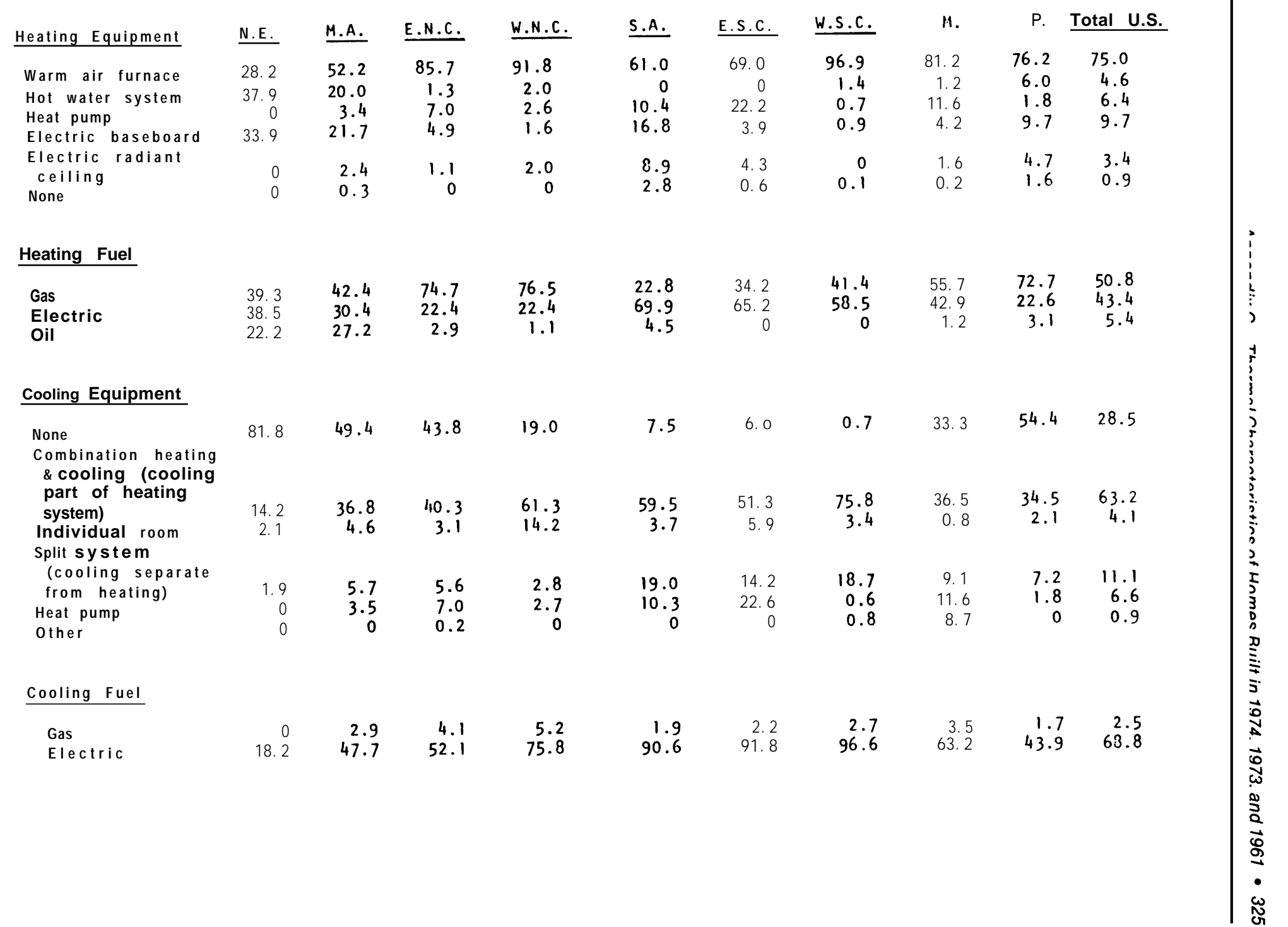


5. Thermal Resistance (R) Values of Insulation - Percent

\begin{tabular}{|c|c|c|c|c|c|c|c|c|c|c|}
\hline W & & M.A. & E.N.C. & $W \mathrm{~N} C$ & S.A. & E.S.C. & w.s.c. & M. & P. & Total U.S. \\
\hline
\end{tabular}

None

R-7

Re $\mid 1$

R- 19
Other

Ceiling/Roof

None

R-9

R-11

R-1 3

R-1 18

R-19

R-22

R- 26

Other

Floor Joists

None

R-7

R-11
R-19

Other

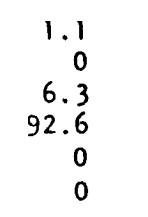

1.2
0
6.6
91.9
0
0.3

$\begin{array}{rr}1.9 & 29.5 \\ 0 & 2.6 \\ 0 & 8.5 \\ 90.5 & 59.2 \\ 5.7 & 0 \\ 1.9 & 0.2\end{array}$

2.2
0.8
9.7
86.4
0
0.9

4.1
0.3
5.9
89.7
0
0

0.8
40.8
2.9
55.5
0
0

$6.0 \quad 8.3$

$9.6 \quad 5.9$

$\begin{array}{ll}15,1 & 7.3\end{array}$

$\begin{array}{rr}69.2 & 77.8 \\ 0 & 0.4\end{array}$

0. 1

0.3

0
2.8
0
20.7
6.9
32.7
29.1
4.8
3.0

1.6
0.7
11.4
9.3
3.6
46.0
27.2
0.2
0

$\begin{array}{rr}3.3 & 2.3 \\ 7.5 & 8.9 \\ 0 & 0 \\ 35.9 & 32.7 \\ 23.7 & 24.5 \\ 12.5 & 1.1 \\ 13.2 & 9.1 \\ 3.6 & 19.6 \\ 0.3 & 1.8\end{array}$

1.3
8.5
0.7
54.3
5.6
22.2
1.9
5.1
0.4

4.2
4.7
2.0
45.6
15.1
13.9
11.5
2.1
0.9

5.4
3.3
1.6
45.6
5.2
26.9
11.3
0.7
0

0.8
1.2
11.6
7.1
9.4
47.8
20.8
1.6
0

$\begin{array}{rr}4.8 & 2.9 \\ 4.5 & 5.2 \\ 16.3 & 5.1 \\ 28.2 & 34.7 \\ 4.4 & 10.2 \\ 41.6 & 27.3 \\ 0.1 & 10.7 \\ 0 & 3.5 \\ 0.1 & 0.4\end{array}$

$\begin{array}{rrrr}62.2 & 53.4 & 79.9 & 69.8 \\ 0 & 7.7 & 1.4 & 0 \\ 28.6 & 38.9 & 10.7 & 0 \\ 8.1 & 0 & 7.9 & 29.6 \\ 1.1 & 0 & 0.1 & 0.6\end{array}$

50.8
0
49.1
0
0.1

52.4
0
47.1
0
0.5

39.6
0
60.4
0
0

15.6

$\begin{array}{rr}83.6 & 63.4 \\ 0 & 1.0 \\ 16.4 & 32.1 \\ 0 & 3.4 \\ 0 & 0.1\end{array}$ 
6. Average Number of Windows and Sliding Glass Doors Per House

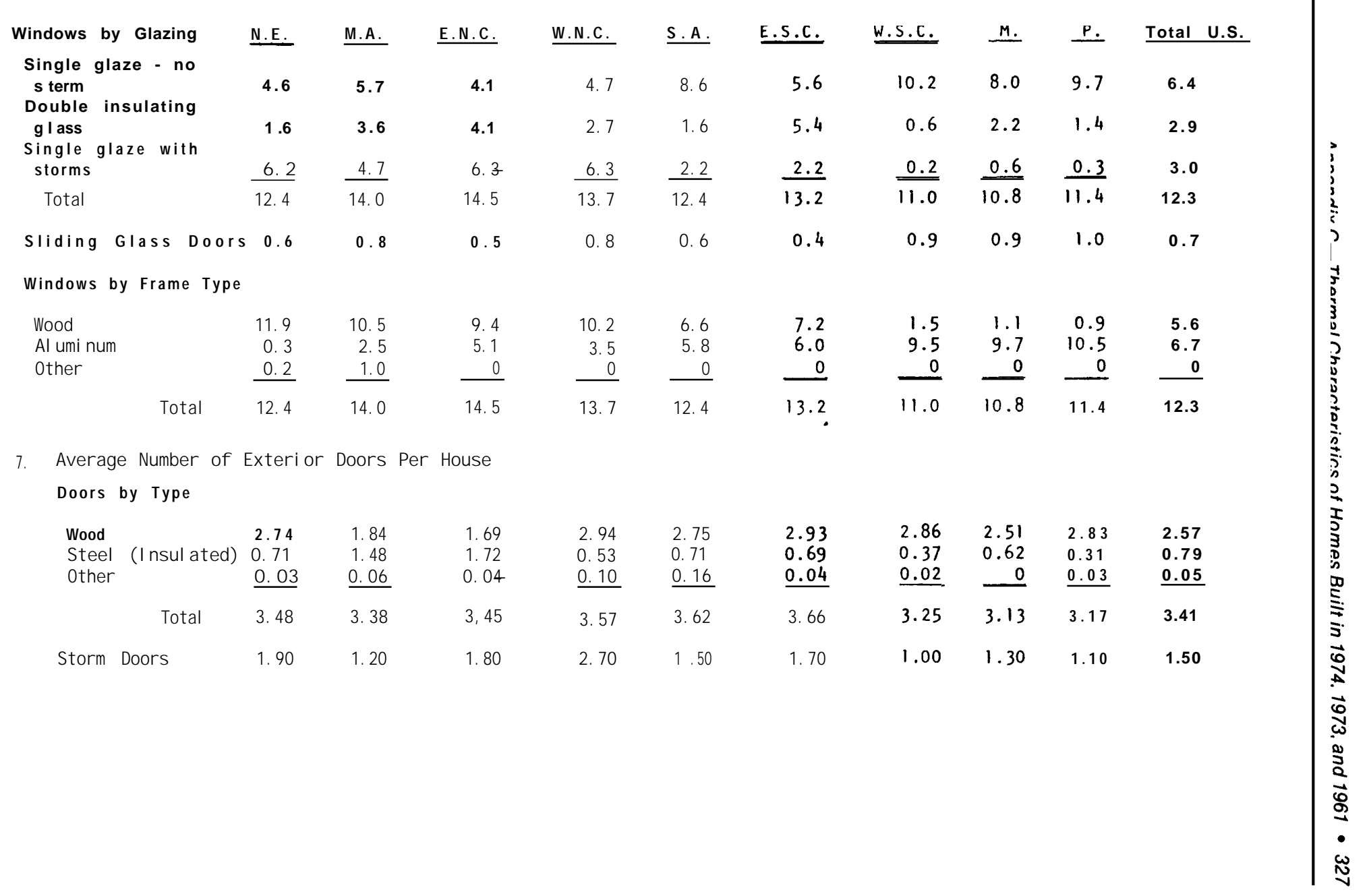


8. Weighted Average Thermal Resistance (R) Values of All Other Materials in Walls, Ceilings and Floors

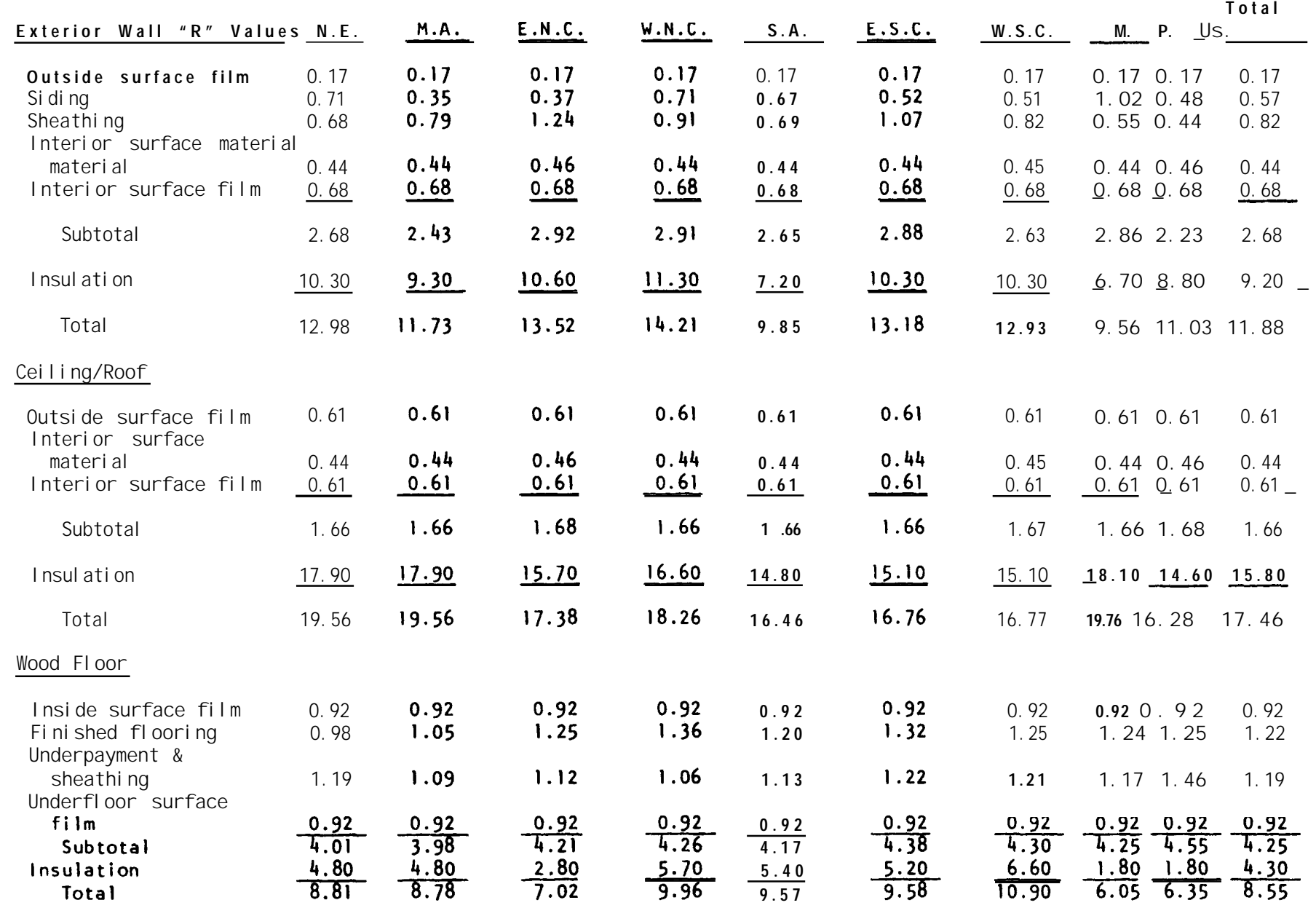




\section{Housi ng Characteri sti cs}

This section contains characteristics of about 84,000 homes built

in 1973, a pre oil embargo year. Data are summarized by four

census districts: Northeast, North Central, South and West. 
1973 HOUSI NG CHARACTERI STI CS

la. Finished Floor Area By Region

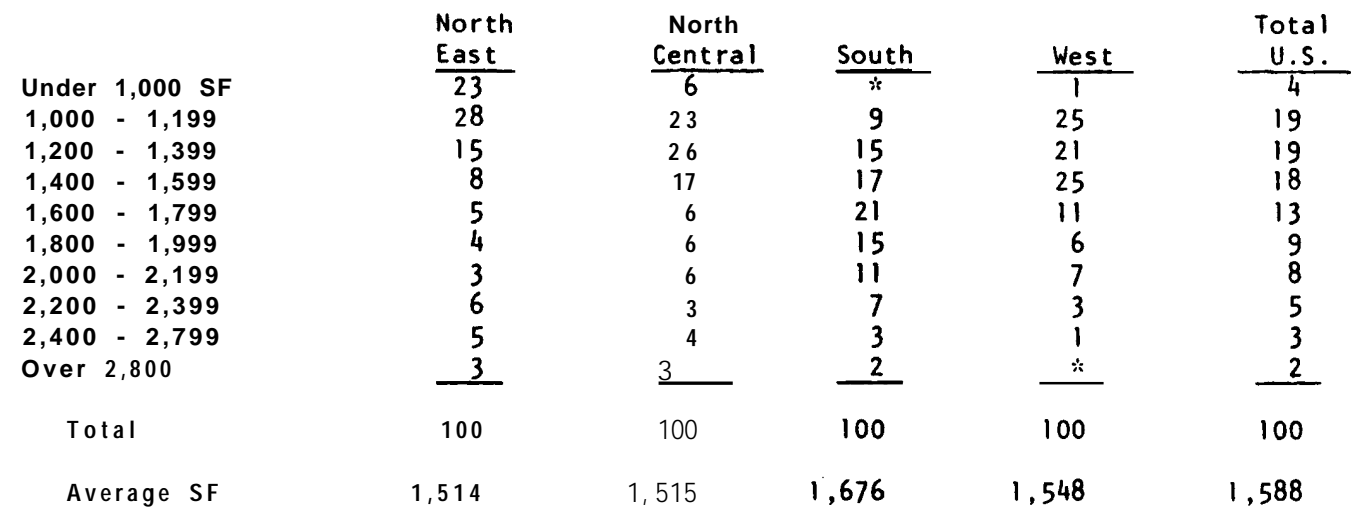

1b. Finished First Floor Area - Percent By Region (Estimated)

$\begin{array}{lrrrrr}\text { Percent on Ist Floor } & 71.4 & 76.6 & 89.3 & 84.4 & 81.2 \\ \text { Square footage } & 1,081 & 1,160 & 1,497 & 1,306 & 1,289\end{array}$

Ic. Wood Frame vs. Concrete Slab First Floor, By Region (Estimated)

$\begin{array}{lrrrrr}\text { Wood frame \% } & 92 & 92 & 26 & 48 & 64 \\ \text { Wood frame SF } & 995 & 1,067 & 299 & 627 & 825 \\ \text { Slab \% } & 8 & 8 & 80 & 52 & 36 \\ \text { Slab SF } & 86 & 93 & 1,198 & 679 & 536\end{array}$

$"$ Less than $1 \%$ 


\begin{tabular}{lr} 
Type House & $\begin{array}{c}\text { North } \\
\text { East }\end{array}$ \\
\cline { 2 - 2 } One Story & \\
Two Story & 34.3 \\
B i - Level & 32.7 \\
Split Level & 25.7 \\
Total & 7.3 \\
\cline { 2 - 2 } Average Stories/House & 100.0 \\
&
\end{tabular}

3. Square Footage of Exterior Wall, by Region

$\begin{array}{cr}\begin{array}{l}\text { Opaque Wall } \\ \mathbf{W}^{*} \text { ndows and Doors }\end{array} & \mathbf{1 , 1 8 7} \\ \mathbf{2 8 6} \\ \text { Total SF } & \mathbf{1 , 4 7 3}\end{array}$

South

$$
\text { North }
$$

20.4

15.4

16. 3

100.0

1. 4

76.5

12.2

$\frac{5.5}{100.0}$

1.2

1,186

1,178

1,465

$\frac{312}{1,498}$
West

66.2

17.6

7.8
8.8

8.4

100.0

1.3

171 
4. Heating and Cooling Equipment - Percent by Type

\begin{tabular}{|c|c|c|c|c|c|}
\hline Heating Equipment & $\begin{array}{l}\text { North } \\
\text { East }\end{array}$ & $\begin{array}{c}\text { North } \\
\text { Central }\end{array}$ & South & west & $\begin{array}{l}\text { Total } \\
\text { U.S. } \\
\end{array}$ \\
\hline $\begin{array}{l}\text { Warm air furnace } \\
\text { Hot water system } \\
\text { Heat pump } \\
\text { Electric baseboard } \\
\text { Electric radiant ceiling } \\
\text { Other }\end{array}$ & $\begin{array}{r}43.3 \\
21.4 \\
0.1 \\
30.3 \\
\text { C. } 4 \\
4.5\end{array}$ & $\begin{array}{r}93 . ? \\
2.0 \\
0.4 \\
2.0 \\
1.2 \\
1.3\end{array}$ & $\begin{array}{r}83.3 \\
0.4 \\
6.0 \\
4.0 \\
0.3 \\
6.0\end{array}$ & $\begin{array}{r}80.2 \\
0.5 \\
4.3 \\
1.2 \\
8.7 \\
5.1\end{array}$ & $\begin{array}{r}80.8 \\
3.4 \\
3.3 \\
5.7 \\
2.4 \\
4.4\end{array}$ \\
\hline \multicolumn{6}{|l|}{ Heating Fuel } \\
\hline $\begin{array}{l}\text { Gas } \\
\text { Electric } \\
\text { Oil }\end{array}$ & $\begin{array}{l}38.7 \\
42.2 \\
19.1\end{array}$ & $\begin{array}{r}70.4 \\
28.9 \\
0.7\end{array}$ & $\begin{array}{r}31.6 \\
67.2 \\
1.2\end{array}$ & $\begin{array}{c}80.9 \\
19.0 \\
0.1\end{array}$ & $\begin{array}{r}51.9 \\
45.1 \\
3.0\end{array}$ \\
\hline \multicolumn{6}{|l|}{ Cooling Equipment } \\
\hline $\begin{array}{l}\text { None } \\
\text { Central system } \\
\text { Individual room } \\
\text { Heat pump }\end{array}$ & $\begin{array}{r}59.2 \\
36.2 \\
4.5 \\
0.1\end{array}$ & $\begin{array}{r}37.9 \\
61.4 \\
0.3 \\
0.4\end{array}$ & $\begin{array}{r}5.2 \\
88.8 \\
0 \\
6.0\end{array}$ & $\begin{array}{r}47.5 \\
46.4 \\
1.8 \\
4.3\end{array}$ & $\begin{array}{r}29.2 \\
66.7 \\
0.8 \\
3.3\end{array}$ \\
\hline Cooling Fuel & & & & & \\
\hline $\begin{array}{l}\text { Gas } \\
\text { Electric }\end{array}$ & $\begin{array}{r}0.5 \\
40.3\end{array}$ & $\begin{array}{r}1.2 \\
60.9\end{array}$ & $\begin{array}{r}0.9 \\
93.9\end{array}$ & $\begin{array}{r}1.0 \\
51.5\end{array}$ & $\begin{array}{r}1.7 \\
69.1\end{array}$ \\
\hline
\end{tabular}


5a . Thermal Resistance (R) Values of Insulation - Percent

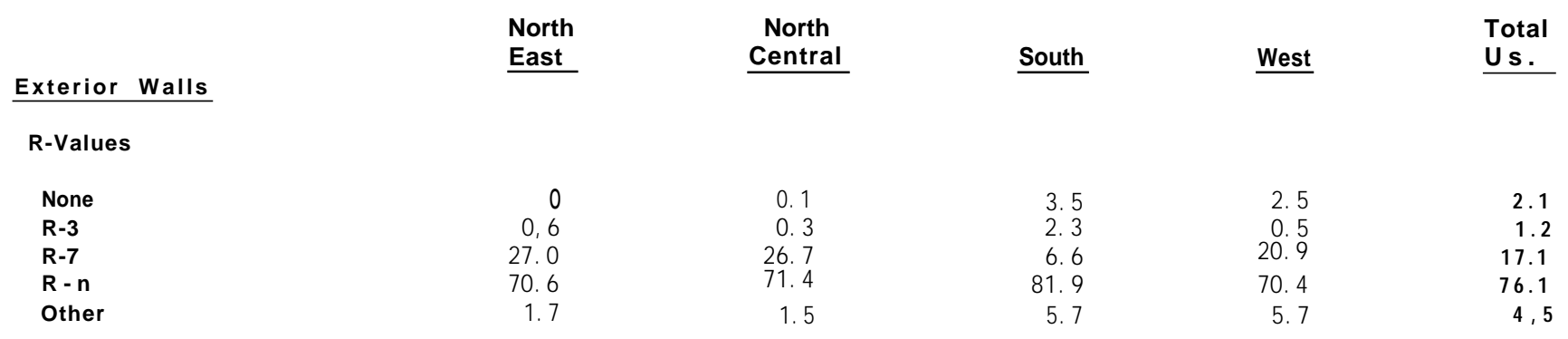

Ceiling/Roof

None
R-7
R-9
R- 11
R- 13
R- 18
R- 19
Other

$\begin{array}{rr}0.5 & 0.2 \\ 1.8 & 0.8 \\ 2.6 & 5.6 \\ 30.0 & 16.8 \\ 11.7 & 39.4 \\ 4.6 & 15.4 \\ 46.7 & 16.1 \\ 2.1 & 5.7\end{array}$

Wood Floor

None

Rone

R - $n$

R-19

53.9
6.2

35. 1

Other

1. 2

70.5
3.6
18.5
6.3
1.1

5b. Weighted Average "R" Values

WhIIs

Ceiling
Floor

9. 8

15.2
5.0

9. 9

14.2
3.5

0.4

0.1

4.5
5.0

46.5

11.4

31.9

3. 0

3.0
0.2

17. 0

11,5
38.5

1. 2

16. 8

11.8

44, 9

28. 2

16. 0

6. 5
4.4

82.0
10.2
6.9

0.2

0.7

1.0
0.5
7.5
12.4
38.6
9.3
26.4
4.3

61. 4

14. 1

17.6

4.8
2.1

10.0
14.4

10.1
15.2

9.6

12.7
1.5

4. 0 
b. Average llumber of Windows Per House (Estimate)

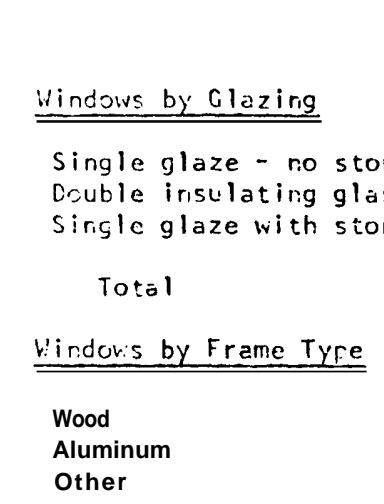

Tota1

\section{North}

East

5.9
4.0

$\underline{3.8}$

13.7

10. 7

\begin{tabular}{l}
2.0 \\
1.0 \\
\hline
\end{tabular}

13. 7
North

Central

4.0
7.8

2.4

14.2

$\begin{array}{r}9.6 \\ 4.6 \\ 0 \\ \hline\end{array}$

14.2
Solth

8. 7

1.8

12.2

3.9

12.2
West

9.2

0.5

11.2

0.1
$\mathbf{1 0 .} 8$

$\begin{array}{r}10.8 \\ 0.3 \\ \hline\end{array}$

11.2

7. Average Number of Exterior Doors Per House Doors by Type

Wood

Steel (insulated)

Other

1.8

$$
\text { Total }
$$

0.1

3. 5

Storm Doors

0.4

1. 9

1.6
0.1

3. 6

1.2
2.5
0.7

0

3. 2

0.5

\section{5}

0.5
0.1

3.1

0.3
2. 3

"1. 0

0.1

3. 4

0.6 
8. Weighted Average Thermal Resistance (R) Values of All Materials in Walls, Ceilings and Floors

Exterior Wall Materials
Insulation
Total
Ceiling/Roof Materials
Insulation
Total
Wood Floor Materials
Insulation
Total

\begin{tabular}{|c|c|}
\hline $\begin{array}{l}\text { North } \\
\text { East }\end{array}$ & $\begin{array}{l}\text { North } \\
\text { Central }\end{array}$ \\
\hline $\begin{array}{l}2.5 \\
9.8\end{array}$ & $\begin{array}{l}2.9 \\
9.9\end{array}$ \\
\hline 12.3 & 12.8 \\
\hline
\end{tabular}

\begin{tabular}{|c|}
\hline South \\
\hline 2.7 \\
\hline 10.1 \\
\hline 12.8 \\
\hline
\end{tabular}

\begin{tabular}{rr}
1.7 & 1.7 \\
\hline 15.2 & 14.2 \\
\hline 16.9 & 15.9 \\
4.0 & \\
5.0 & 4.2 \\
9.0 & 3.5 \\
& 7.7
\end{tabular}

1.7
15.2
16.9
4.3
$\underline{5 .:}$
9.5

west
2.5
9.8
12.3


1961 Housi ng Characteri sti cs

This section contains a summary of housing characteristic data for 1,000 randomly selected homes built in 1961. Data were col l ected

by F.W. Dodge and are summarized by four census districts. 
1. Average Size By Region

$\begin{array}{ll}\text { Northeast } & 1,442 \mathrm{SF} \\ \text { North Central } & 1,358 \mathrm{SF} \\ \text { South } & 1,506 \mathrm{SF} \\ \text { West } & 1,497 \mathrm{SF} \\ \text { Total U.S. } & 1,448 \mathrm{SF}\end{array}$

2. Number of Stories Percent By Region

\begin{tabular}{ll} 
Region & One \\
\cline { 2 - 2 } Northeast & 60 \\
North Central & 92 \\
South & 90 \\
West & 92 \\
Total U.S. & 85
\end{tabular}

\begin{tabular}{c} 
Two or More \\
\hline 15 \\
4 \\
7 \\
8 \\
8
\end{tabular}

Split-Level

3. Foundations Percent By Region

\section{Region}

Nor theast

North Central

South

West

Total U.S.

\section{Basement}

80
75
10
16
45

4.

Region

Nor theast

North Central

South

West

Total U.S.

\section{Exterior Walls}

87

75

50

49
Crawl Space

12
18

35
46

28

Ceiling/Roof

92

100

85

70
92

25
4
3
1
7

Concrete Slab

8
7
55
38
27

Perimeter

9
8
6
4
7


5. Heating Fuel Percent By Region

$\underline{\text { Region }}$

Northeast

North Central

South

West

Total U.S.

\begin{tabular}{c} 
Gas \\
\hline 50 \\
81 \\
70 \\
89 \\
73
\end{tabular}

\begin{tabular}{c} 
Electric \\
\hline 1 \\
2 \\
1 \\
6 \\
5
\end{tabular}

Oil

49

17

14

22 


\section{Builder Survey}

This section contains the results of a survey of eighty-three single

family home builders. An in-depth survey of all homes built in 1975

and 1976 reveal ed the nanes and I ocati ons of many bui I ders who are

i nstal I ing nore i nsul ati on than average and sone bui I ders who are

i nstal I ing l ess i nsul ati on than average. Fol l owing are comments from ei ghty-three of these bui I ders. 
BUILDER SURVEY RESULTS

1. Sharon, MA builder of ten $\$ 87,000$ homes.

Uses R-19 in walls and R-30 in ceiling with insulating glass windows. May consider more insulation if fuel costs continue to increase.

2. Warwick, RI builder of fifteen $\$ 37,000$ homes.

Uses R-13 in walls, R-22 in ceiling and storm windows. Recently improved insulation values in ceiling because of energy costs.

3. West Haven, CT builder of forty to fifty $\$ 50,000$ homes.

Uses $R-n$ in walls, $R-n$ in ceiling and single pane windows, all low values for New England. Builder does shade southerly facing windows with roof overhang. He offers R-19 insulation in ceiling as an option because he "offers the buyer the choice, not simply dictate what I or anyone else thinks best!"

Builder believes fuel costs in a free economy will require maximum insulation levels without more regulations. "We have enough regulations al ready," he said.

4. Warwick, RI builder of twelve $\$ 68,000$ homes.

Uses R-13 in walls and R-19 in ceiling. Does not plan on changing levels of insulation in the next year. Provides storm windows. Energy costs may lead him to increase levels of insulation.

5. Montpelier, VT builder of $\$ 38,000$ homes.

Uses R-19 in walls, R-38 in ceilings and insulated glass windows with storm windows. Plants deciduous trees to provide shade in summer for south facing windows. Plans on retaining these levels in the next year. If climate turns colder and energy costs get higher, he will consider increased insulation levels.

6. Boston, MA builder of $50 \$ 37,000$ homes.

Uses R-13 in walls and ceilings and single glazed windows. Plans on increasing to R-22 in ceilings next year because of energy savings.

7. Burlington, VT builder of thirty $\$ 28,000$ homes.

Uses R-13 in walls, R-30 in ceilings and storm windows in his homes which are low cost. He plans to improve levels by insulating basement walls, using insulated doors, polystyrene behind electrical outlet boxes and more liberal use of caulking. He will do these things because of customer demand and awareness.

He may increase insulation levels because of economic factors and because of a sense of national and local responsibility. 
8. Nashua, $\mathrm{NH}$ builder of sixty $\$ 43,000$ homes.

Uses R-19 i n ual I s , R- 30 i $\mathbf{n}$ cei I ing and storm wi ndows. Does not $\mathrm{pl}$ an on making any changes in fut ure because, "We feel we have reached the cost/benefit ratio.

9. Pittsburgh, PA builder of ei ght $\$ 67,000$ hones.

Uses R- 19 i n val I S, R- 30 i n cei I i ngs and i nsul ati ng glass windows. Plans on changing to R-38 in ceilings next year. Believes conservation features to be a marketing point and has built to these high insulation standards for past ten years.

10. Southern New Jersey builder of thirty $\$ 40,000$ homes.

Uses R-16 in walls, R-30 in ceilings and storm windows. Achieves R-16 with R-11 fiberglass batts and Dow R-5 Styrofoam sheathing. Does not plan on making any changes because, "We are currently building houses which exceed all insulation standards now in effect." Rising fuel costs might cause him to increase insulation levels.

11. Pittsford, NY builder of twelve $\$ 74,000$ homes.

Uses R-15 walls, R-30 ceilings and storm windows. Polystyrene sheathing is used to obtain R-15. Has been using this method for over a year. Plans on insulating basement walls next year because of Public Service Commission regulations. Public demand could cause him to increase insulation levels and public refusal to pay for increased levels might cause him to lower insulation levels.

12. Rochester, NY builder of twenty $\$ 45,000$ homes.

Uses R-11 in walls and either R-30 or R-38 in ceilings. Also uses storm windows. Plans on increasing ceiling levels and insulating basement next year because of increased heating costs.

13. Fai rport, NY bui I der of ei ght $\$ 58,000$ hones.

Uses R-n walls, R-19 ceilings and storm windows. Plants trees to shade southern windows from summer sun. Plans on increasing ceiling to R-30 and insulating basement. Also plans to caulk around all doors and windows.

14. Readi ng, PA builder of fifteen $\$ 64,000$ homes.

Uses R-n walls, R-19 ceilings and insulating glass windows. May increase levels in future if fuel costs increase or availability becomes a problem. Also may increase levels because of "sales appeal."

15. Lancaster, PA buil der of $\mathrm{f}$ i fteen $\$ 75,000$ hones.

R-19 in walls, R-30 in ceilings and insulating glass with storm 
wIndows. Does not 'plan on 'making ' changes' because '" '"I' feel present levels are adequate.

16. Rochester, NY builder of thirty $\$ 55,000$ homes .

Uses R-n in walls, R-30 in ceilings and insulating glass windows.

Does not plan on changing levels in the future.

17. Syracuse, NY builder of twenty $\$ 50,000$ homes.

Uses R-13 in walls, R-30 in ceilings and storm windows. Plans on reducing air infiltration and improving wall sheathing for better R values.

18. Philadelphia, PA builder of twenty $\$ 40,000$ homes.

Uses R-12 in walls, R-22 in ceilings and single glazed windows. Doesn't plan on making any changes next year.

19. Grand Rapids, MI builder of 75- $100 \$ 49,000$ homes.

Uses R-13 in wal I s, R-36 i n ceilings and storm wi ndows. May go to tri ple gl azed windows and sliding glass door in near future. Michigan energy code (effective $7 / \mathbf{1} / 77$ ) may i nf I uence bui I der to make changes. Publ i c awareness of i nsul ati on l evel s may cause sone i ncrease i n R-val ues.

Bui I der said "We wi I conti nue to I ook for new and better ways to achi eve best standards possi bl e using the cost/benefit approach."

20. Quincy, IL builder of eight $\$ 74,000$ homes.

Uses R- 19 in walls, R-40 in ceiling and storm windows. Does not plan on changing insulation levels but does plan on improving installation procedures. Builder says his customers are very satisfied at present. Higher utility bills might make him increase insulation levels.

21. Canton, $\mathrm{OH}$ builder of twenty $\$ 51,000$ homes.

Uses R-13 in walls, R-37 in ceilings and triple glazed windows. Does not plan on changing next year. Will retain present levels because of fuel savings and because home buyers are requesting these levels.

22. Deerfield, IL builder of thirty $\$ 105,000$ homes.

Uses R-11 in walls and R-13 in ceiling. Some single glazed, some insulating glass and some storms are installed as options. Low level of ceiling insulation is "standard" w ith higher levels offered as options to buyers. Believes in providing what customer requests and can afford to spend. 
Energy crisis , government credits and customer, requests will influence builder to increase insulation levels.

23. Lindenhurst, ILL builder of twenty-five $\$ 58,000$ homes.

Uses R-n in walls, $\mathbf{R - 1 9}$ in ceilings and storm windows or insulating glass windows. May increase insulation levels next year because of public awareness, conservation and utility costs.

24. Flint, MI builder of $\$ 70,000$ to $\$ 140,000$ homes.

Uses R-13 in walls, $R-24$ in ceiling and insulating glass windows. Does not plan on making changes next year. Believes he is at optimum now.

25. Green Bay, WI builder of twenty $\$ 50,000$ homes.

Uses R-19 in walls, $R-30$ in ceiling and insulating glass windows. Builder believes that people are quite conscious of the value of insulation in saving heating dollars and are willing to pay initially for increased insulation. He also believes buyers tend to associate better insulating practices with better all around building practices.

Would decrease levels only if competitive building tends to reduce price of homes to a point where minimum levels of insulation would be acceptable.

26. Milwaukee, WI builder of 125 single family detached dwellings and 75 si ngle family attached duel I ings with \$53,000 average sel I ing pri ce.

Uses R- 13 wal I and R- 22 cei I ing i nsul at $i$ on and st orm wi ndows.

24" overhang shades windows from summer sun. Plans on retaining present insulation levels because of fuel conservation. Lower cost insulation would prompt him to use more.

27. Fargo, ND builder of fifteen $\$ 70,000$ homes.

Uses R-19 in walls and R-52 in ceilings. Windows are all insulating glass. Uses a 36" overhang to shade south facing windows from summer sun. Believes he has already attained maximum insulating levels.

28. Independence, MO builder of $100 \$ 41,000$ homes.

Uses $R-n$ in walls, $R-13$ in ceiling and storm windows. Will increase levels only if codes or competition require it.

29. Hutchinson, KS builder of $\$ 55,000$ homes.

Uses R-19 in walls, R-38 in ceilings and insulating glass windows. 2'-6" overhangs shade south facing windows from summer sun. Plans on using 5/8" foil-faced foam plastic sheathing in the future. 
30. St. Louis, MO builder of $120 \$ 45,000$ homes.

Uses R-11 in walls, R-19 in ceilings and insulating glass windows. Plans on increasing insulation levels next year because buyers are asking for it. Will definitely increase levels if required by governmental regulations.

31. Shakopee, MN builder of fifteen $\$ 55,000$ homes.

Uses R-18 in walls, R- 38 i n cei I ing and tri pl e gl azed wi ndows. Does not pl an to add to present levels. Added polystyrene sheathing last year.

32. Sioux Falls, SD builder of twenty-five $\$ 79,000$ homes.

Uses R-19 in walls, R-38 in ceiling and triple glazed windows in some homes. Next year will use more triple glazing.

33. Wichita, KS builder of twenty $\$ 44,000$ homes.

Uses R-18 in walls and R-19 in ceiling. Also uses storm windows. Does not plan on making any changes unless utility costs force him to increase insulation.

34. Lincoln, NE builder of eighteen $\$ 47,000$ homes.

Uses R-n in walls, R-19 in ceiling and storm windows. Plans on increasing insulation amounts and improving installation methods next year because home buyers are requesting it and because of energy savings.

35. Topeka, KS builder of five $\$ 56,000$ homes.

Uses R-17 in walls, R-30 in ceiling and double glazed windows. He keeps glass area to a minimum and provides 24 " overhan $t 0$ shade windows from summer sun. Is considering $2 \times 6$ walls for electrically heated houses because of natural gas shortage. Builder believes added insulation is a selling feature and considers workmanship of insulation installation more important than high "R" values. Would prefer properly installed R-n to poorly installed R-19 with gaps, etc.

He believes we must encourage insulation of attached garage walls and ceilings, insulated basements or crawl spaces versus concrete slabs, open living areas for better air circulation, natural or artificial shade around A.C. compressor, attic power ventilators, etc.

He believes we must discourage high vaulted ceilings, ducted range hoods, excessive glass, fireplace chimneys on outside walls, etc.

36. Cedar Rapids, 1 A builder of $\$ 51,000$ homes.

Uses R-12 in walls and R-19 in ceiling. Plans on using more 
insulation in ceiling to save fuel. Installs storm windows.

37. Winter Haven, FL builder of fifty $\$ 21,000$ homes.

Uses no insulation in concrete block walls and R-g in ceiling in these very low cost homes. Uses single glazed windows. Plans on making no changes in the future.

38. Myrtle Beach, SC builder of from three to six $\$ 112,000$ homes.

Varies insulation from R-16 to R-19 in walls and from R-30 to R-38 in ceilings. Uses insulating glass windows. Some of his homes have large overhangs to shade windows from summer sun.

He offers good insulation package and sales pitch on what the low energy home should save in the long run. The final decision is the buyer's and his ability to pay.

Builder believes his customers are interested in low energy homes and takes pride in his homes and in giving the buyers what they want.

He normally uses l-inch thick polystyrene sheathing to obtain an R-16 wall but is considering another sheathing product which is more expensive but will increase the wall to R-19.

Builder uses heat pumps and would like to use more water to air heat pumps. Attics are ventilated by fan. Concrete slabs are insulated with rigid foam plastic around the perimeter. In crawl space hems, 6" batt insulation is installed between joists. He talks customers into using light shades of roofing.

39. Wilkesboro, NC builder of $120 \$ 39,000$ homes.

Uses R-17 in walls, R-30 in ceiling, R-19 in wood floors and insulating glass windows. Builder believes he has done all that is possible but will conform to any code requirement in the future.

The change to higher levels of insulation were made to help the customer. Will decrease level only if power company rates are lowered.

40. Ft. Lauderdale, FL builder of sixty $\$ 35,000$ townhouses.

Uses R-19 in walls and R-19 in ceilings. Will increase insulation levels if consumers require it. Builder believes a developing market shortage is causing material cost increases to the point where inexpensive alternatives for low to moderate housing are not available.

41 Seminole, FL builder of fifteen $\$ 46,000$ homes.

Uses R-5 in walls and R-19 in ceilings. Single glazed windows are used. Does not plan on making any changes next year. 
42. Pinellas County, Fl builder of fiffy $\$ 62 ; 000$ homes.

Uses R-8 in walls, R-22 in ceiling and single glazed windows. Uses overhangs and/or tinted glass to shade against summer sun on south facing windows. Does not plan on making changes because he believes his levels are adequate for Florida.

43. Warrenton, VA builder of twelve $\$ 77,000$ homes.

Uses R-28 in walls, R-40 in ceilings and insulating glass windows. Builder believes he is at maximum insulation levels and therefore plans no changes. Uses $2 \times 6$ walls and 1 " polystyrene sheathing.

44. Louisville, $K Y$ builder of twenty $\$ 40,000$ homes.

Uses $\mathrm{R}-\mathrm{n}$ in walls, $\mathrm{R}-19$ in ceiling and storm windows. Plans on reducing air infiltration by using poly film vapor barrier in future. Plans on building $2 \times 6$ walls on a presold basis only. Believes pay back will be in from 5 to 7 years.

45. Lexington, KY builder of twenty $\$ 52,000$ homes.

Uses R-13 in walls and R-25 in ceiling. Installs insulating glass windows.

46. Louisville, KY builder of twenty $\$ 60,000$ homes.

Uses R-11 in walls, R-22 in ceiling and insulating glass windows. Does not plan on changing insulation level. "Consumer paranoia" would be the only reason he would increase levels.

47. Louisville, KY builder of thirty-five $\$ 77,000$ homes.

Uses R-16 in walls and R-22 in ceiling. Installs insulating glass windows with storm windows. May change to polystyrene sheathing to conserve energy and satisfy buyers.

48. Louisville, KY builder of ten $\$ 54,000$ homes.

Uses $R-n$ in walls, $R-30$ in ceiling and storm windows. Does not plan on making changes in next year because "W e feel that presently we have the best insulation for the area and dollar spent." Might increase in future if the cost of fuel increases.

49. Louisville, KY builder of twenty-three $\$ 65,000$ homes.

Uses R-13 in walls and R-30 in ceiling. Will not increase because he believes levels are adequate for the climate.

50. Fort Thomas, KY builder of twelve $\$ 48,000$ homes.

Uses R-19 in wall, R-30 in ceiling and storm windows. Plans on increasing walls to R-24 next year because he believes it will be cost-effective. Other increases may be made due to sales appeal.

51. Lexington, KY builder of seventy single family detached and 206 


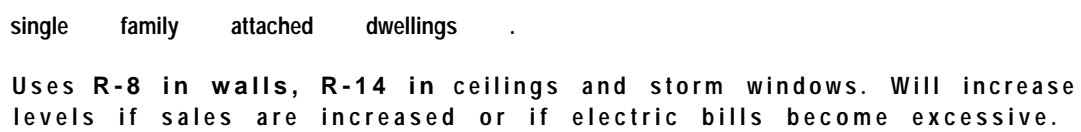

52. Birmingham, $A L$ builder of twelve $\$ 66,000$ homes.

Uses R-8 in walls, $R-13$ in ceiling and single glazed windows. Plans on increasing ceiling to R-19 because of increased fuel costs. Customer concern may also lead to increased insulation levels.

53. Lexi ngt on, KY bui I der of si $x \$ 65,000$ homes.

Uses R-19 in walls, R-38 in ceiling and storm windows. Plans on making no changes.

54. Lubbock, TX bui I der of $120 \$ 28,000$ hones.

Uses R-22 in walls, R-30 in ceiling and triple glazed windows.

Uses roof overhang to shade south facing windows from summer sun. Builder upped insulation program this past year and will continue to update as new and better products come on the market. Is presently testing how various plans sold over 12 month period and is monitoring energy costs. Depending on results, insulation levels may be changed.

55. Tul sa, OK bui I der of forty $\$ 36,000$ hones.

Uses R-23 in walls, R-39 in ceiling and insulating glass windows. Does not plan on making changes next year because he believes his homes are insulated well enough. He would increase levels of insulation if buyers showed enough interest.

56. Lewi sville, TX buil der of thi rty $\$ 60,000$ hones.

Uses R-16 walls, R-26 in ceiling and single glazed windows with storm windows as an option. Builder claims his homes meet utility company recommended levels so does not plan on making changes.

Builder will increase amounts when public demands it or when energy costs require it.

57. Arl i ngt on, TX bui I der of twel ve $\$ 54,000$ homes.

Uses R-19 in walls, R-30 in ceiling and insulating glass windows. Builder says he is dedicated to building energy efficient homes.

58. Tyl er, TX builder of forty $\$ 28,000$ hones,

Uses R-13 in walls, R-20 in ceiling and single glazed windows. Will increase insulation levels if market demands and if utility costs increase. 
59. Dallas, TX builder of one thousand $\$ 34,000$ homes.

Uses R-11 in walls, R-22 in ceiling and insulating glass windows. Builder does not $p$ lan on increasing levels because he believes the present levels are optimum for the climate.

60. Marion, AK builder of twenty-five $\$ 36,000$ homes

Uses R-19 in walls, R- 38 in ceiling and triple glazed windows.

Uses overhang to shade windows from summer sun. Builder does not plan on changing levels in the near future. This is the builder who developed the "Arkansas Story" method of building energy efficient homes.

61. Fort Worth, TX builder of three hundred $\$ 34,000$ homes.

Uses R-11 in walls, R-22 in ceiling and storm windows. plans on retaining present levels because of buyer interest and energy conservation.

62. Boulder, CO builder of thirty $\$ 44,000$ homes.

Uses R-19 in walls, R-30 in ceiling and insulating glass windows. Roof overhang shades south windows against summer sun. Plans on increasing roof insulation to $R-40$ and changing to wood windows. Builder believes it is very important to build much smaller homes, say 1,000 square feet. He says "We are totally going to run out of fuel. We have to reduce the size of homes! !"

63. Salt Lake City, UT builder of seventy-two $\$ 41,000$ homes.

Uses R-19 in walls, R-38 in ceiling and insulating glass windows. Plans on no changes because present levels are considered sufficient.

64. Salt Lake City, UT builder of sixty $\$ 40,000$ homes.

Uses R-n in walls, R-19 in ceiling and insulating glass windows.

Plans on increasing ceiling insulation in the next year to help

relieve the energy crisis and help sales.

65. Boise, ID builder of twenty $\$ 72,000$ homes.

Uses R-13 in walls, R-30 in ceiling and insulating glass windows. Builder is unsure if he will make changes next year. If so, he will increase levels for energy savings.

66. Denver, CO builder of seventy five \$77.000 homes.

Uses R- 13 i n wal I s, R- 30 i n cei I ing and i nsul ati ng gl ass wi ndows. PI ans no changes in fut ure. Comments, "We i nsul ate from frost I i ne up."

67. Denver, co builder of forty $\$ 57,000$ homes.

Uses $R-n$ in wall, $R-19$ in ceiling and insulating glass windows. 
May possibly change insulation levels next year depending on market conditions and cost.

68. Colorado springs, co builder of seventy $\$ 58,000$ homes.

Uses R-13 in walls, R-38 in ceilings and insulating glass windows. Plans overhangs to reduce summer sun effect on south windows. Plans no changes next year.

69. Mesa, AZ builder of twenty-five $\$ 35,000$ homes.

Uses R-6 to R-13 in walls and R-30 in ceiling. Installs insulating glass windows. Overhang shades south facing windows from summer sun. Does not plan on any changes for next year. Will make changes based on customer demand.

70. Phoenix, AZ builder of fifteen $\$ 125,000$ homes.

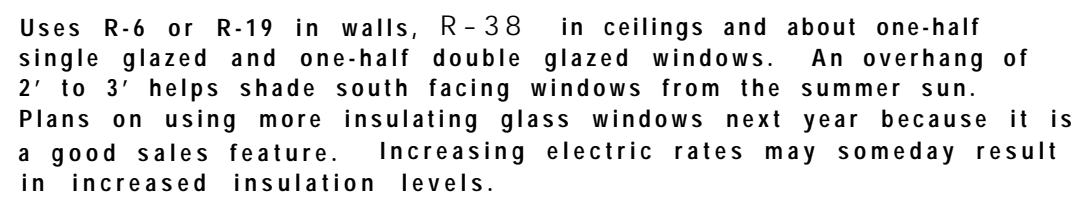

71. Mountain Home, ID builder of one hundred $\$ 35,000$ homes.

Uses R-19 in walls, R-38 in ceiling and insulating glass windows.

Uses trees to shade south facing windows. Builder does not

presently plan on any changes, but says, "If a better product becomes available, we will make use of it. We have a very strong energy conservation program and will continue to use new energy saving concepts. It is our intent to give our customers the best deal possible for his housing dollar."

72. Denver, co builder of two hundred $\$ 73,000$ homes.

Uses R-13 in walls, R-22 in ceilings and insulating glass windows. Shades south facing windows with overhangs, and porch and patio roofs. Does not plan on making any changes soon. "As long as natural gas is available at current rates, which are still low, there is no need to go further on insulation," he said.

Will increase when there is a demand from buyers or an awareness of future energy problems.

73. Phoenix, AZ builder of two hundred \$36, 000 homes.

Uses R- 22 in walls, R- 33 in ceiling and single glazed windows. Uses overhang to shade south windows. Plans no changes because, "We have the highest in town." 
74. Denver, co bui I der of one thousand, four hundred $\$ 45,000$ hones.

Uses R-n in walls, R-30 in ceilings and insulating glass windows. Does not plan any changes because he believes it is not economical for homeowner or builder to increase R-values over above amounts. Might consider increase from $R-n$ to $R-13$ wall insulation because of the minor cost increase. Builder believes it would be impossible for homeowner to recapture any additional costs passed on by the builder because of increased cost of insulation.

75. Fort Collins, CO builder of fourteen $\$ 69,000$ homes.

Uses R-13 to R-21 in walls, R-35 in ceiling and insulating glass windows. Has 2' overhang to shade south facing windows. Plans on $2 \times 6$ exterior walls or use of styrofoam sheathing on $2 \times 4$ walls because customers are becoming more aware. Energy costs and public awareness of the value of well insulated homes will cause builder to consider increase in insulation.

76. Maui , HI builder of twenty $\$ 95,000$ homes.

Uses no insulation in walls, no insulation in ceilings and single glazed windows because, according to the builder, "They are not needed in Hawaii."

77. Walnut Creek, CA builder of $\$ 110,000$ homes.

Uses R-n in walls, R-19 in ceilings and single glazed windows.

Not planning on changes because considers present levels adequate for climate.

78. Fresno, CA builder of forty $\$ 55,000$ homes.

Uses R-19 in walls and R-30 in ceilings. Attempts to get 48 " overhang to shade south windows in summer. Is considering using I-inch styrofoam sheathing. Increased levels of insulation good sales point. 
79. Seattle, WA builder of twenty-five $\$ 65,000$ homes.

Uses R-19 in walls, R-30 in ceiling and insulating glass windows.

Does not plan on changes in future. Says, "We have always insulated this way".

80. Tampa, FLA builder of $150 \$ 59,000$ homes.

Uses R-3 masonry walls, R-13 in wood frame walls, $R-26$ in ceilings

and single glazed windows. Plans on no changes next year because,

"We feel that, with our present levels, we are giving our buyers

the best insulating envelope for their dollar. Increasing $R$ values

would spend our customer's dollar without adequate return".

81. Minneapolis, MN builder of twenty-four $\$ 97,500$ homes.

Uses R-20 in walls, $\mathbf{R - 3 0}$ in ceilings and insulating glass windows.

Plans on increasing wall and ceiling insulation and triple glazing

more windows to reduce energy costs and to upgrade homes.

82. Hutchinson, Kans. builder of thirty $\$ 47,000$ homes.

Uses $R-n$ in walls, $R-19$ in ceilings and storm windows. Shades south facing windows with wide overhangs and porches. Plans on increasing insulation amounts next year because of consumer demand and better sales. He also believes it to be in the public interest. He said, "We think the industry needs to establish (insulation) standards. All we are getting is slanted information from manufacturers".

83. Indianapolis, Ind. builder of thirty $\$ 63,000$ homes.

Uses R-19 in walls, R-30 in ceiling and double glazing in windows. Does not know whether he will change insulation levels but may "To satisfy the buyer and conserve energy". Is concerned about increasing costs and buyer's ability to afford new homes. 
The following three tables represent the homes built by the eighty-three survey builders. The data have little, if any, statistical validity because the sample was not chosen at random and the response distribution does not resemble the total population distribution.

The tables are presented only to give an indication of how the eighty-three respondents collectively insulate their homes and how much those homes cost. 
Weighted Average Insulation and Price By Region

\section{Region}

New England

Middle Atlantic

East North Central

West North Central

South Atlantic

East South Central

West South Central

Mountain

Pacific (1)

Pacific (2)

Total U.S. (1)

$\begin{array}{ccc}\begin{array}{cc}\text { Houses } \\ 222\end{array} & & \text { Ceiling } \\ 184 & & 21.2 \\ 523 & & 27.8 \\ 372 & & 25.4 \\ 461 & & 21.6 \\ 434 & & 17.7 \\ 1567 & & 23.4 \\ 2321 & & 30.0 \\ 85 & & 22.9 \\ 65 & & 30.0 \\ & & \end{array}$

25. 6

Weighted Averages

\begin{tabular}{|c|c|c|}
\hline Wall $\mathbf{R}$ & Glazing & Price \\
\hline 14.9 & 1.6 & $\$ 43,946$ \\
\hline 13.9 & 2.0 & 53,223 \\
\hline 13.5 & 2.0 & 56,237 \\
\hline 13.2 & 2.1 & 51,393 \\
\hline 13.0 & 1.3 & 47,380 \\
\hline 13.1 & 2.0 & 53,115 \\
\hline 12.5 & 2.0 & 34,121 \\
\hline 13.1 & 1.9 & 44,655 \\
\hline 14.5 & 1.3 & 66,882 \\
\hline 19.0 & 1.4 & 58,231 \\
\hline
\end{tabular}

13. 1

1. 8

$\$ 44,532$

(1) including Hawaii

(2) Excluding Hawaii 
Weighted Average Insulation By Price Range

\begin{tabular}{|c|c|c|c|c|}
\hline P $r$ ice Range & Houses & $\begin{array}{l}\text { Average } \\
\text { Ceiling R }\end{array}$ & $\begin{array}{l}\text { Average } \\
\text { Wall } R\end{array}$ & $\begin{array}{l}\text { Average } \\
\text { Glazing }\end{array}$ \\
\hline$\$ 25-35,000$ & 1675 & 23.6 & 12.7 & 2.0 \\
\hline $36-45,000$ & 1008 & 26.5 & 12.6 & 1.7 \\
\hline $46,55,000$ & 2373 & 26.8 & 12.2 & 2.0 \\
\hline $56-65,000$ & 497 & 26.7 & 13.0 & 1.5 \\
\hline $66-75,000$ & 316 & 25.4 & 14.0 & 2.0 \\
\hline $76-125,000$ & 230 & 28.5 & 16.1 & 2.3 \\
\hline Totals & 6099 & 25.9 & 12.7 & 1.9 \\
\hline
\end{tabular}

Note: Not included in above were (50) $\$ 21,000$ Florida homes with $R-9$ in ceiling and $O$ in walls with single glazed windows and $(20) \$ 95,000$ Hawail homes with 0 in ceiling and 0 in walls with single glazed windows. 


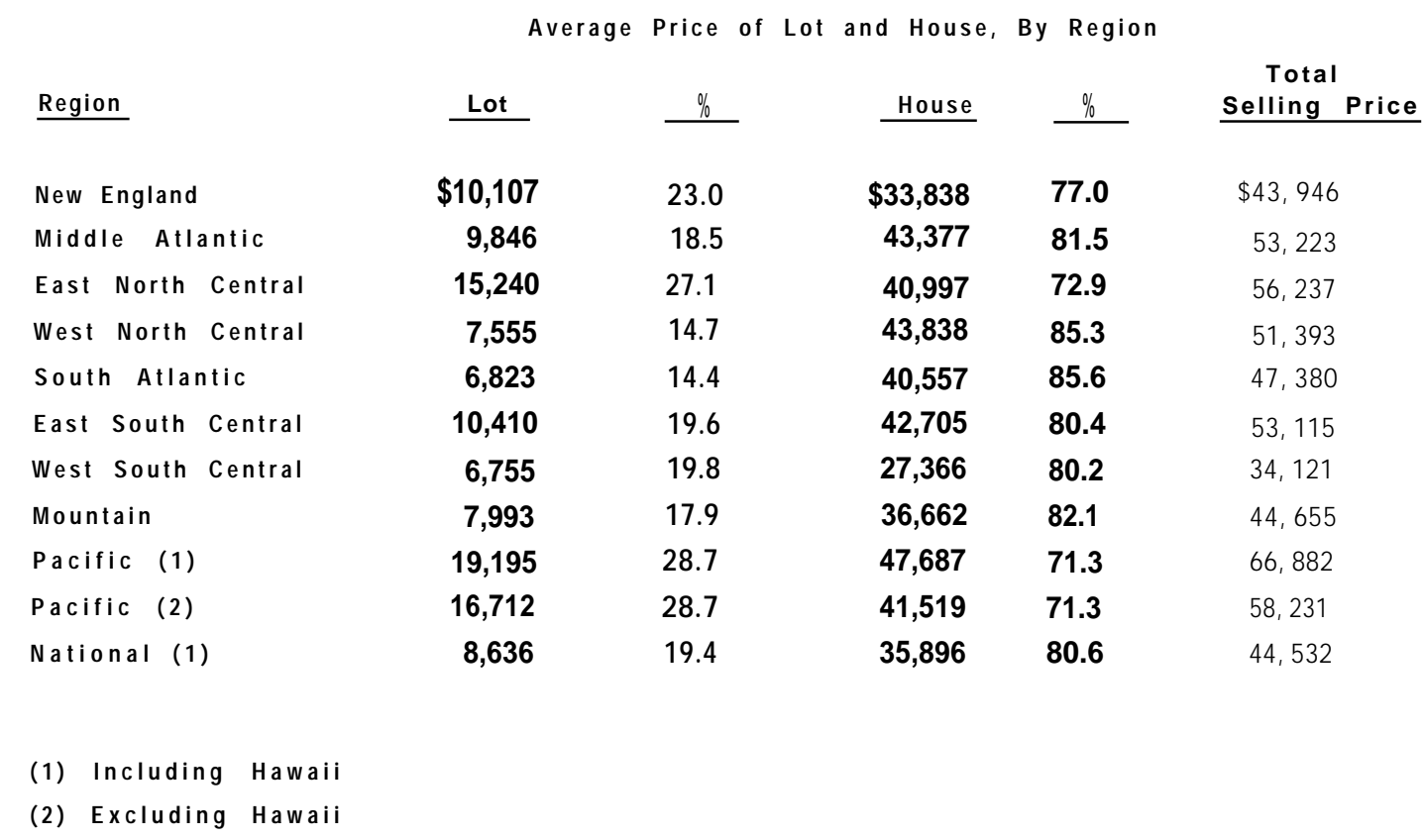

